\title{
Arc Melter Demonstration Baseline Test Results
}

N. R. Soelberg

A. G. Chambers

G. L. Anderson

L. L. Oden

W. K. O'Connor

P. C. Turner

Published July 1994

\section{Idaho National Engineering Laboratory EG\&G Idaho, Inc. Idaho Falls, Idaho 83415}

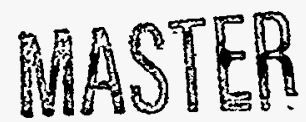

DISTRIBUTION OF THIS DOCUMENT IS UNLIMITED

Prepared for the

$6^{r}$

U.S. Department of Energy

Office of Environmental Restoration and Waste Management

Under DOE Idaho Operations Office

Contract DE-AC07-76ID01570 


\section{DISCLAIMER}

Portions of this document may be illegible in electronic image products. Images are produced from the best available original document. 


\section{ARC MELTER DEMONSTRATION BASELINE TEST RESULTS}

EGG-WTD-11138

Prepared by:

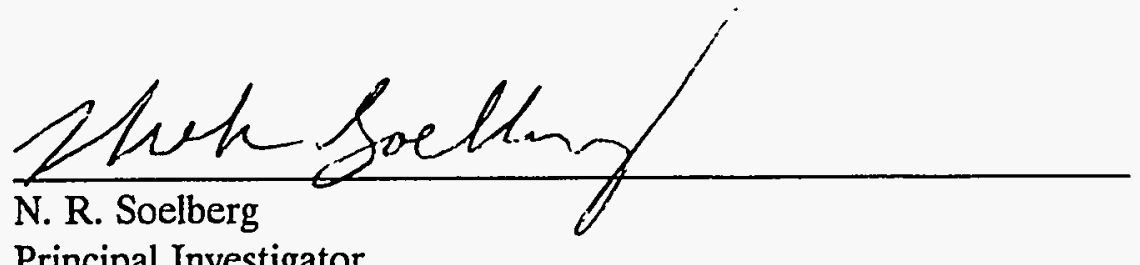

Principal Investigator

Reviewed by:

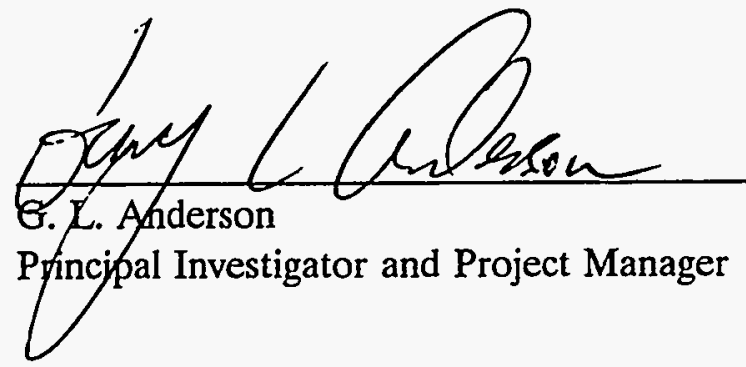

Approved by:

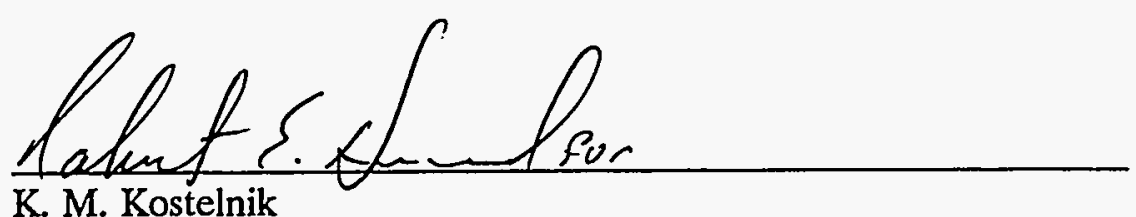

K. M. Kostelnik

Coordinator, Buried Waste Integrated Demonstration 


\section{ABSTRACT}

An initial series of pilot-scale electric arc melter baseline tests were conducted on five mixtures of surrogate buried mixed wastes and soil that simulate those present at the Idaho National Engineering Laboratory (INEL). This test series was the first of several planned on behalf of Buried Waste Integrated Demonstration Program (BWID) for the U.S. Department of Energy (DOE) in cooperation with the U.S. Bureau of Mines (USBM) in Albany, Oregon for evaluating and demonstrating commercially available electric arc furnace technology for potential waste treatment applications. The test system at the USBM Albany Research Center included a small, industrial scale, three phase ac electric arc furnace. Additional waste application and system modification tests are planned for later phases.

Surrogate waste mixtures that simulated "as incinerated" buried wastes and soil located at the INEL were melted in this baseline test series. $\mathrm{TiO}_{2}$ and $\mathrm{ZrO}_{2}$ were added to two mixtures in order to investigate leachability in higher durability, tailored glass-ceramic final waste forms. All mixtures contained cerium oxide added as a surrogate for transuranic (TRU) oxides to investigate partitioning of TRU elements in the furnace. Structural and toxic metals and metallic cerium were added to one of the feed mixtures.

The results show the feasibility of using existing industrial arc melter technology for treating "previously incinerated" buried mixed wastes and soils on a production basis. Furnace operating parameters were generally within expected values and typical of reliable industrial arc furnace practice norms. Over $52,000 \mathrm{lb}$ of surrogate materials were processed at rates representative of those anticipated as needed for full scale production processing of buried mixed wastes and soils $(1,000$ to $2,000 \mathrm{lb} / \mathrm{hr}$ ) during a semi-continuous 80 -hour test period essentially without failure. Extensive additional design, testing, and evaluation is required to optimize the arc furnace system and improve operations. Modifications such as an enhanced the feed system, overall system containment, and a remote tapping operation will enable application at the existing technology represented by the USBM system for radioactive waste treatment.

\section{DISCLAIMER}

This report was prepared as an account of work sponsored by an agency of the United States Government. Neither the United States Government nor any agency thereof, nor any of their employees, makes any warranty, express or implied, or assumes any legal liability or responsibility for the accuracy, completeness, or usefulness of any information, apparatus, product, or process disclosed, or represents that its use would not infringe privately owned rights. Reference herein to any specific commercial product, process, or service by trade name, trademark, manufacturer, or otherwise does not necessarily constitute or imply its endorsement, recommendation, or favoring by the United States Government or any agency thereof. The views and opinions of authors expressed herein do not necessarily state or reflect those of the United States Government or any agency thereof. 


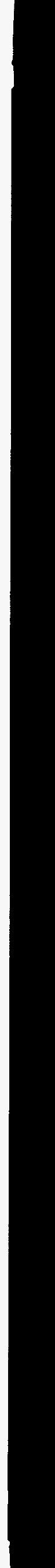




\section{CONTENTS}

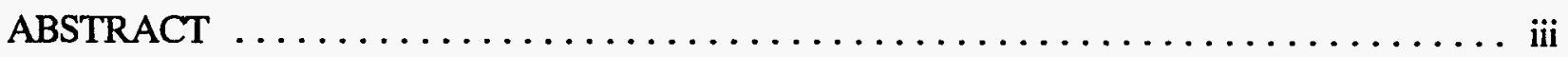

ACRONYMS $\ldots \ldots \ldots \ldots \ldots \ldots \ldots \ldots \ldots \ldots \ldots \ldots \ldots \ldots \ldots \ldots \ldots \ldots \ldots \ldots \ldots \ldots$

1. EXECUTIVE SUMMARY $\ldots \ldots \ldots \ldots \ldots \ldots \ldots \ldots \ldots \ldots \ldots \ldots \ldots$

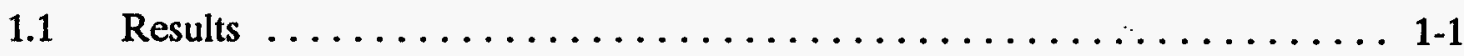

1.2 Conclusions and Recommendations $\ldots \ldots \ldots \ldots \ldots \ldots \ldots \ldots \ldots \ldots \ldots \ldots$

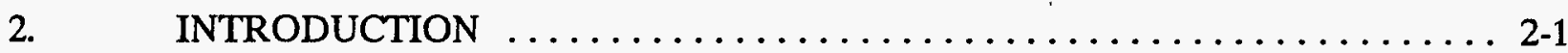

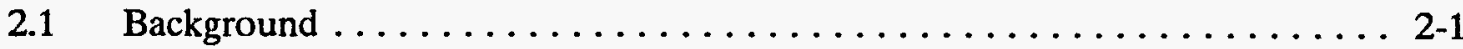

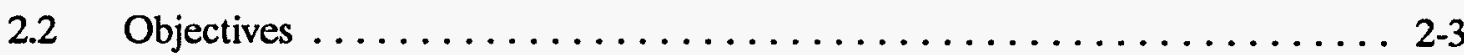

2.2.1 Project Objectives $\ldots \ldots \ldots \ldots \ldots \ldots \ldots \ldots \ldots \ldots \ldots \ldots \ldots \ldots \ldots, 2-3$

2.2.2 Baseline Test Objectives $\ldots \ldots \ldots \ldots \ldots \ldots \ldots \ldots \ldots \ldots \ldots, 2-3$

2.3 Arc Furnace Waste Treatment Test System $\ldots \ldots \ldots \ldots \ldots \ldots \ldots \ldots .42-4$

2.4 Measurements, Sample Collection, and Analyses $\ldots \ldots \ldots \ldots \ldots \ldots$ 2-7

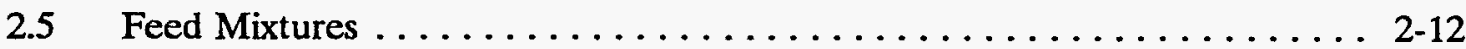

3. TEST OBSERVATIONS AND MELTER SYSTEM PERFORMANCE ...... 3-1

3.1 Operating Conditions and Results Summary $\ldots \ldots \ldots \ldots \ldots \ldots \ldots \ldots \ldots$

3.1.1 Shakedown Test $\ldots \ldots \ldots \ldots \ldots \ldots \ldots \ldots \ldots \ldots \ldots \ldots \ldots \ldots \ldots \ldots, 1$

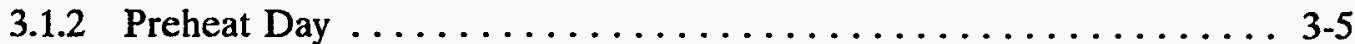

3.1.3 Baseline Tests .......................... 3-6

3.2 Arc Melter System Performance $\ldots \ldots \ldots \ldots \ldots \ldots \ldots \ldots \ldots . . \ldots \ldots$

3.2.1 Feed System Performance $\ldots \ldots \ldots \ldots \ldots \ldots \ldots \ldots \ldots \ldots \ldots . . \ldots \ldots$

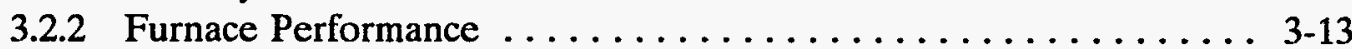

3.2.3 APCS Performance .......................... 3-20

4. FATE OF FEED MATERIALS, METALS, AND TRU SURROGATE ...... 4-1

4.1 Input and Output Mass Balances and Feed Material Partitioning . . . . . . 4-1

4.1.1 Entrained and Volatilized Particulate $\ldots \ldots \ldots \ldots \ldots \ldots \ldots .4 .8$

4.1.2 Volatilization (Gas Evolution) from the Feed Materials . . . . . . 4-9 
4.2 Elemental Mass Balances and Partitioning

4.2.1 Elemental Partitioning to the Glass/Ceramic Slag Product . . . . . . 4-13

4.2.2 Elemental Partitioning to the APCS .............. 4-15

4.2.3 Partitioning of the M60 Feed Mixture ... . . . . . . . . . 4-29

4.2.4 Elemental Mass Balances ................... 4-32

5. PROPERTIES OF FURNACE PRODUCTS $\ldots \ldots \ldots \ldots \ldots \ldots \ldots \ldots$

5.1 Slag Density and Waste Volume Reduction $\ldots \ldots \ldots \ldots \ldots \ldots \ldots \ldots$

5.2 Mineralogy of the Furnace Products $\ldots \ldots \ldots \ldots \ldots \ldots \ldots \ldots \ldots \ldots \ldots$

5.3 Elemental Composition of Furnace Product Slag, Metal, and APCS

Solids ......................... 5-4

5.4 Slag and APCS Solids Leachability $\ldots \ldots \ldots \ldots \ldots \ldots \ldots \ldots \ldots$

5.4 .1 Slag Leachability . . . . . . . . . . . . . . . . . 5-6

5.4 .2 Leachability of APCS Residues .............. 5-7

6. OFFGAS EMISSIONS $\ldots \ldots \ldots \ldots \ldots \ldots \ldots \ldots \ldots \ldots \ldots \ldots \ldots \ldots$

6.1 Operating Conditions and Emissive Summary $\ldots \ldots \ldots \ldots \ldots \ldots$

6.2 Offgas Compositions $\ldots \ldots \ldots \ldots \ldots \ldots \ldots \ldots \ldots \ldots \ldots \ldots \ldots \ldots$

6.3 Particulate and Metals Emissions ................... 6-5

6.4 Offgas Composition Trends $\ldots \ldots \ldots \ldots \ldots \ldots \ldots \ldots \ldots \ldots \ldots \ldots$

7. CONCLUSIONS AND RECOMMENDATIONS $\ldots \ldots \ldots \ldots \ldots \ldots \ldots \ldots \ldots$

8. REFERENCES $\ldots \ldots \ldots \ldots \ldots \ldots \ldots \ldots \ldots \ldots \ldots \ldots \ldots \ldots \ldots \ldots \ldots$

Appendix A-Operating Conditions During Shakedown Test of RWMC Soil and Mill

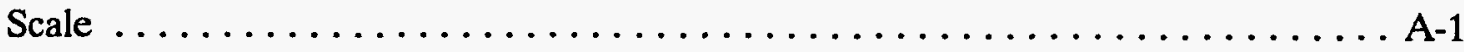

Appendix B-Operating Conditions During Melting of S60 $\ldots \ldots \ldots \ldots \ldots \ldots \ldots \ldots$

Appendix C-Operating Conditions During Melting of S60-IV $\ldots \ldots \ldots \ldots \ldots \ldots \ldots \ldots$

Appendix D-Operating Conditions During Melting of N80 and N80-Mod ......... D-1

Appendix E-Operating Conditions During Melting of N80-IV and N80-IV-Mod ....... E-1

Appendix F-Operating Conditions During Melting of M60 and M60-Mod ........ F-1 
Appendix G-Additive and Feed Mixture Compositions $\ldots \ldots \ldots \ldots \ldots \ldots \ldots$ G-1

Appendix G-1-Compositions of Feed Mixture Additives $\ldots \ldots \ldots \ldots \ldots \ldots \ldots \ldots$ G-1-1

Appendix G-2-Feed Mixture Additives and Compositions $\ldots \ldots \ldots \ldots \ldots \ldots \ldots$ G-2-1

Appendix $\mathrm{H}-$ Chemical Composition of Individual Slag Molds $\ldots \ldots \ldots \ldots \ldots \ldots \ldots$ H-1

Appendix I-Variation of Slag Composition During Melting Tests $\ldots \ldots \ldots \ldots \ldots \ldots$ I-1

Appendix J-X-Ray Diffraction Analysis of Furnace Products $\ldots \ldots \ldots \ldots \ldots \ldots \ldots$ J-1

Appendix $\mathrm{K}-$ Chemical Composition of Furnace Products $\ldots \ldots \ldots \ldots \ldots \ldots \ldots \ldots \ldots \ldots$

Appendix L-Distribution of Components Among Furnace Products $\ldots \ldots \ldots \ldots \ldots \ldots$ L-1

Appendix M-Distribution of $\mathrm{Ce}$ and Toxic Metals Among Furnace Products ......... M-1

Appendix N-Toxic Characteristic Leaching Procedure (TCLP) Analysis of

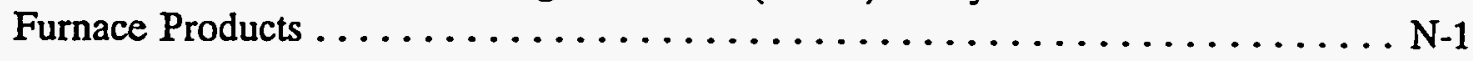

Appendix O-Offgas CEMS Reduced Data $\ldots \ldots \ldots \ldots \ldots \ldots \ldots \ldots \ldots \ldots \ldots \ldots \ldots \ldots \ldots$

Appendix P-Particulate/Metals Reduced Data $\ldots \ldots \ldots \ldots \ldots \ldots \ldots \ldots \ldots \ldots$ P-1

Appendix P-1-MMT Analysis for the S60 Feed Mixture $\ldots \ldots \ldots \ldots \ldots \ldots \ldots \ldots$ P-1-1

Appendix P-2-MMT Analysis for the S60-IV Feed Mixture $\ldots \ldots \ldots \ldots \ldots \ldots \ldots$ P-2-1

Appendix P-3-MMT Analysis for the N80 and N80-Mod Feed Mixtures $\ldots \ldots \ldots \ldots \ldots$ P-3-1

Appendix P-4-MMT Analysis for the N80-IV and N80-IV-Mod Feed Mixtures . . . . . . . P-4-1

Appendix P-5-MMT Analysis for the M60 and M60-Mod Feed Mixtures $\ldots \ldots \ldots \ldots$ P-5-1

Appendix P-6-Partitioning of Feed Material, Toxic, and Structural Metals $\ldots \ldots \ldots \ldots$ P-6-1

Appendix Q-Overview of the Integrated Melting Facility $\ldots \ldots \ldots \ldots \ldots \ldots \ldots \ldots$ Q-1

Appendix R-Molar Basicity and Slag Viscosity $\ldots \ldots \ldots \ldots \ldots \ldots \ldots \ldots \ldots$ R-1

Appendix S-Comparison of Offgas Flowrates, Temperatures, and

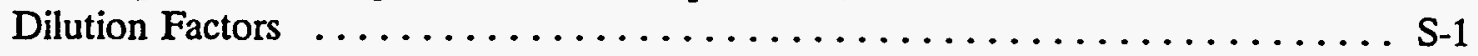

Appendix T-In-Furnace Velocity and Particle Size Entrainment Calculations $\ldots \ldots \ldots \ldots$ T-1

Appendix U-Mass Balances of Individual Elements $\ldots \ldots \ldots \ldots \ldots \ldots \ldots \ldots \ldots$ U-1 


\section{FIGURES}

2-1. Schematic diagram of the Arc Furnace Integrated Waste Processing Test

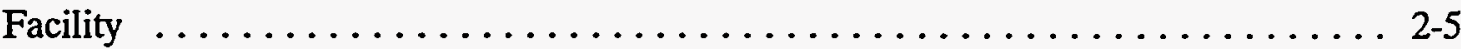

3-1. Exterior of feed tube showing corrosion products $\ldots \ldots \ldots \ldots \ldots \ldots \ldots$

4-1. Simplified process model of the furnace $\ldots \ldots \ldots \ldots \ldots \ldots \ldots \ldots \ldots \ldots \ldots$

4-2 (a). Feed material partitioning to the output products $\ldots \ldots \ldots \ldots \ldots \ldots \ldots$

4-2 (b). Feed material partitioning to entrained feed and condensed volatiles $\ldots \ldots \ldots$. $4-6$

4-3. Total APCS solids compared to measured feed mixture volatiles content . . . . . 4-10

4-4. Partitioning of toxic metals in the surrogate feed mixtures to the slag $\ldots \ldots \ldots 4-14$

4-5. Partitioning of $\mathrm{P}, \mathrm{Pb}, \mathrm{Cu}$, and $\mathrm{Hg}$ to the fume traps and the baghouse $\ldots \ldots .4-16$

4-6. Partitioning of $\mathrm{Ba}, \mathrm{Zn}, \mathrm{Cr}$, and $\mathrm{Ni}$ to the fume traps and the baghouse $\ldots \ldots 4-17$

4-7. Partitioning of $\mathrm{Ce}, \mathrm{Cd}, \mathrm{As}$, and Se to the fume traps and the baghouse $\ldots \ldots .4-18$

4-8. Partitioning of $\mathrm{Ag}$ to the fume traps and the baghouse $\ldots \ldots \ldots \ldots \ldots$

4-9. Boiling point of selected metals, metal oxides, and metal chlorides . . . . . . 4-27

4-10 (a). Metals partitioning of the $\mathrm{M} 60$ feed $\operatorname{mix} \ldots \ldots \ldots \ldots \ldots \ldots \ldots$

4-10 (b). Metals partitioning of the M60 and M60-Mod feed mix . . . . . . . . . 4-31

4-11. Mass balances of individual elements $\ldots \ldots \ldots \ldots \ldots \ldots \ldots \ldots \ldots \ldots$

5-1. Elemental dissolution of the slag compared to slag basicity $\ldots \ldots \ldots \ldots \ldots$

5-2. Elemental dissolution of slag compared to $\mathrm{TiO} 2$ and $\mathrm{ZrO} 2$ in the slag ...... 5-9

5-3. Elemental dissolution of the APCS solids $(\mathrm{mg} / \mathrm{kg}) \ldots \ldots \ldots \ldots \ldots \ldots \ldots$

6-1. $\quad$ Furnace outlet offgas composition for melt $S 60 \ldots \ldots \ldots \ldots \ldots \ldots$

6-2. $\quad$ Furnace outlet composition for melt $S 60-I V \ldots \ldots \ldots \ldots \ldots \ldots \ldots \ldots \ldots$

6-3. Furnace outlet composition for melts $\mathrm{N} 80$ and N80-Mod $\ldots \ldots \ldots \ldots$. $\ldots \ldots$

6-4. Furnace outlet composition for melts N80-IV and N80-IV-Mod . . . . . . 6 6-14 
6-5. Furnace outlet offgas composition for melts M60 and N80-IV-Mod

\section{TABLES}

2-1. Measurements and instrumentation during the baseline tests $\ldots \ldots \ldots \ldots$

2-2. Sample collection summary $\ldots \ldots \ldots \ldots \ldots \ldots \ldots \ldots \ldots \ldots \ldots \ldots \ldots \ldots \ldots \ldots$

2-3. Description of buried wastes and surrogate mixtures $\ldots \ldots \ldots \ldots \ldots \ldots$

2-4. Calculated elemental composition of the surrogate waste mixtures $\ldots \ldots \ldots 2-15$

2-5. Species compositions of the surrogate waste mixtures $\ldots \ldots \ldots \ldots \ldots \ldots \ldots$

3-1. Global summary of baseline tests $\ldots \ldots \ldots \ldots \ldots \ldots \ldots \ldots \ldots \ldots \ldots$

3-2. Calibrated auger feedrate compared to gravimetric feedrate $\ldots \ldots \ldots \ldots \ldots$

4-1. Total mass balance closure $\ldots \ldots \ldots \ldots \ldots \ldots \ldots \ldots \ldots \ldots \ldots \ldots$

4-2. Volatilization of feed mixture components and offgas composition $\ldots \ldots \ldots$. .

4-3. Particle size and density of RWMC soil and additives $\ldots \ldots \ldots \ldots \ldots \ldots$. $\ldots \ldots$

4-4. Evaluation of elemental entrainment and volatilization $\ldots \ldots \ldots \ldots \ldots \ldots$.22

4-5. Carbon balance for the baseline tests $\ldots \ldots \ldots \ldots \ldots \ldots \ldots \ldots \ldots \ldots \ldots$

5-1. Specific gravity of large slag ingots $\ldots \ldots \ldots \ldots \ldots \ldots \ldots \ldots \ldots \ldots \ldots$

5-2. Compositions of the slag products $\ldots \ldots \ldots \ldots \ldots \ldots \ldots \ldots \ldots \ldots \ldots$

6-1. Detailed overview of baseline test results $\ldots \ldots \ldots \ldots \ldots \ldots \ldots \ldots \ldots \ldots \ldots$

6-2. Comparison of particulate results from the MMT sampling tests and the fume trap/baghouse catches $\ldots \ldots \ldots \ldots \ldots \ldots \ldots \ldots \ldots \ldots \ldots \ldots . \ldots \ldots$

6-3. Distribution of particulate in fume traps and baghouse $\ldots \ldots \ldots \ldots \ldots \ldots$

6-4. Metals and TRU surrogate concentrations in the offgas $(\mathrm{mg} / \mathrm{dscm}) \ldots \ldots$

6-5. Mass emission rates for metals and TRU surrogate in the offgas $(\mathrm{g} / \mathrm{hr}) \ldots \ldots$ 



\section{ACRONYMS}

APCS

ASME

BWID

CEMS

DAS

DOE

EPA

HEPA

IEB

ID

ID

INEL

LOI

MCC-1

MMT

MRSC

PCT-1

QA

RCRA

RWMC

TC

TCLP

TRU
Air Pollution Control System

American Society for Mechanical Engineers

Buried Waste Integrated Demonstration

Continuous Emissions Monitoring System

Data Acquisition System

U.S. Department of Energy

Environmental Protection Agency

High Efficiency Particulate Air

Iron Enriched Basalt

Induced Draft

inside diameter

Idaho National Engineering Laboratory

Loss on Ignition

Materials Characterization Center

Multiple Metals Train

most representative slag composition

Product Characterization Test

quality assurance

Resource Conservation and Recovery Act

Radioactive Waste Management Complex

thermocouple

Toxicity Characteristic Leachability Procedure

transuranic 
USBM

VRF

XRD
U.S. Bureau of Mines

Volume Reduction Factor

X-Ray Diffraction 


\section{Arc Melter Demonstration Baseline Test Results}

\section{EXECUTIVE SUMMARY}

An initial series of pilot-scale electric arc melter baseline tests were conducted on five mixtures of surrogate buried mixed wastes and soil. This test series was the first of several planned by the Buried Waste Integrated Demonstration Program (BWID) of the U.S. Department of Energy (DOE) in cooperation with the U.S. Bureau of Mines (USBM) in Albany, Oregon for evaluating and demonstrating commercially available electric arc furnace technology for potential waste treatment applications. The baseline tests were conducted in a small industrial scale, three phase ac electric arc furnace waste processing system at the USBM Albany Research Center. The system was originally designed by the USBM and the American Society for Mechanical Engineers (ASME) for a series of municipal waste incinerator ash vitrification tests conducted in 1992. The system included an automated feed system, an $800 \mathrm{kVA}$ ac power supply, a graphite electrode arc furnace designed for a steel capacity of 1 ton in the hearth, and an air pollution control system. Minor modifications to this system were made for the baseline tests based upon the ASME test experience.

Surrogate waste mixtures that simulated "as incinerated" buried wastes and soils located at the Idaho National Engineering Laboratory (INEL) were melted in this baseline test series. The mixtures were designated: S60 (60\% soil and 40\% simulated "as incinerated" organic oils and solvents solidified in inorganic absorbent material), S60-IV (S60 with zircon and ilmenite added to provide around $3 \% \mathrm{ZrO}_{2}$ and $6 \% \mathrm{TiO}_{2}$ in the mixture, $\mathrm{N} 80(80 \%$ soil and $20 \%$ simulated evaporator nitrate salts), N80-IV (N80 with zirconia and ilmenite added to provide around 3\% $\mathrm{ZrO}_{2}$ and $6 \% \mathrm{TiO}_{2}$ in the mixture), and $\mathrm{M} 60(60 \%$ soil and $40 \%$ metallic $\mathrm{Fe}, \mathrm{Pb}, \mathrm{Zn}, \mathrm{Cu}, \mathrm{Al}$, stainless steel, etc.). The $\mathrm{TiO}_{2}$ and $\mathrm{ZrO}_{2}$ were added to investigate processing of lower leachability, higher durability, tailored glass-ceramic final waste form materials.

All waste mixtures contained $0.35-0.42 \%$ cerium oxide added as a surrogate for transuranic (TRU) oxides. The M60 test also included the addition of elemental cerium, in the form of a metal alloy ingot with iron, to investigate partitioning of TRUs potentially present in the metal state.

\subsection{Results}

A shakedown melting test was conducted on soil in June 93 followed by the baseline test series in July 93 . All feed types were successfully processed. Over $55,000 \mathrm{lb}$ of total material was melted and processed. Average feed and tap rates ranged from 600 to $1,200 \mathrm{lb} / \mathrm{hr}$ with a maximum of $2,000 \mathrm{lb} / \mathrm{hr}$. These rates are similar to expected full scale processing rates for buried wastes. Waste volume was reduced by a factor of 2.58 even though the initial feed density was higher (and thus lower specific volume) than would be expected for actual as received wastes and soil.

The baseline tests were conducted in five consecutive test days, following one preheat day. The actual operating time for each test day was 7.7-10.7 hours. Average power input ranged between $350-550 \mathrm{~kW}$. Average energy use was $0.51 \mathrm{kWh} / \mathrm{lb}$, which is very thermally efficient 
despite the relatively small size of this arc furnace. Electrode consumption over the course of the tests was not excessive (11.9 lb/ton or $12 \mathrm{lb} / \mathrm{MWh})$ and well within industrial norms even though the furnace was operated with excess air (oxidizing conditions in the plenum).

Sidewall and roof refractories experienced essentially no wear. This indicates the effectiveness of the water cooled side walls for skull (frozen slag layer) operation, and the effective thermal shielding of the cold top.

No downtime failures were incurred with the exception of a partial feed blockage in the feed tubes within the furnace during the early $\$ 60$ test. A short downtime was required to clear the blockage. The blockage was caused by process induced positive pressure spikes in the furnace, leading to backflow of moist process gases into the feed tubes and moist agglomeration bridging of the feed material. This was successfully prevented in subsequent tests by increasing the negative pressure in the furnace and better controlling furnace pressure fluctuations to ensure no positive pressure backflow.

Slag was continuously tapped through the water cooled tapping fixture at average temperatures ranging from 1,450 to $1,800^{\circ} \mathrm{C}$. Slag tapping rates as high as $2,000 \mathrm{lb} / \mathrm{hr}$ were achieved. The slags were highly viscous due to high silica and alumina content. Mill scale $\left(\mathrm{Fe}_{3} \mathrm{O}_{4}\right)$ and limestone $\left(\mathrm{CaCO}_{3}\right)$, were added to the $\mathrm{N} 80$ feed mixture, while mill scale and pebble lime $(\mathrm{CaO})$ were added to the N80-IV feed mixture, to increase slag fluidity and reduce required slag tapping temperatures. The pebble lime was found to be most effective of the two sources of lime.

The $\mathrm{MgO}$ ramming mix used to formulate the hemispherical hearth was dissolved by the highly siliceous $\mathrm{S} 60$ slag at high temperatures in the initial baseline test run. The Ruby brick (90\% alumina, $\mathrm{Al}_{2} \mathrm{O}_{3}$ ) underlying the hearth was not affected. The hearth dissolution increased the effective volume of the hearth at a level below the bottom metal tap hole and prevented separate tapping of reduced and melted metals present on the hearth. Capability for separate tapping through the bottom metal tap hole was demonstrated by draining the furnace at the end of each test day.

Although not directly measured, mass balances indicated that some iron was reduced from iron oxide in each test run and accumulated on the hearth from test to test. Some slag was also retained each day in the increased hearth volume. Much more metal was added to the reduced iron from the M60 feed, which contained $40 \%$ metals. Observations of the metal heel removed at the end of the test series indicate this metal was melted and could have been separately tapped if the hearth had not been dissolved.

Overall mass and elemental partitioning results were generally consistent with expectations and desired separations for all test feeds. Eighty-four percent of the feed material mass was melted or dissolved into the molten slag phase, tapped, and cooled, yielding a durable glass/ceramic solid. Approximately $2.9 \%$ of the feed mass partitioned as a separate tappable metal alloy product phase (over $90 \% \mathrm{Fe}$ ) in the bottom of the furnace below the slag phase. Approximately $13 \%$ of the feed material decomposed or reacted to produce typical combustion gases $\mathrm{H}_{2} \mathrm{O}, \mathrm{CO}_{2}, \mathrm{CO}, \mathrm{SO}_{2}, \mathrm{HCl}$, and $\mathrm{NO}_{x}$. These gases were ducted to the Air Pollution Control 
System (APCS) for cooling and filtration. Roughly $1.5 \%$ was entrained in APCS flow as feed particulate and $0.5 \%$ of the mass was volatilized and transported as fume solids (condensed particulate) captured in the APCS. Overall mass balance closure (total mass out divided by total mass in) at 1.01 was very good.

Around $98 \%$ of the Ce (TRU surrogate) reported to the slag phase. No Ce was detected in the metal product. Less than $2 \%$ reported to the offgas (APCS) solids and can be attributed solely to entrainment of the fine $\mathrm{CeO}_{2}$ powder that was used in the feed. The elemental cerium added as a metal alloy was completely oxidized in the melter and reported to the slag.

Toxic and structural metals partitioning was determined by elemental mass balances for the product slag, metal, and APCS solids. No metal was recovered until after the entire test series, but this metal was produced primarily during the M60 run, which was the final test condition of the series. The amounts of metals in the offgas were determined by two methods, by the Environmental Protection Agency (EPA) Multiple Metals Train (MMT) and by quantitative collection and analysis of the APCS baghouse and fume trap catches.

Most metals were only present in the feed in trace amounts during all feed tests, with much larger amounts of selected metals added in the M60 tests. During all but the M60 tests most of the trace metals partitioned to the slag phase at levels ranging from $65 \%$ to $100 \%$ with even the more volatile metals $(\mathrm{Pb}, \mathrm{Zn})$ reporting largely to the slag. Some of the metals $(\mathrm{Fe}, \mathrm{Cu}, \mathrm{P}, \mathrm{As}$, and $\mathrm{Ni}$ ) reported significantly to the metal product during the M60 test. The remainder of the trace metals reported to the offgas. Except for the more highly volatile species of $\mathrm{As}, \mathrm{K}, \mathrm{Na}, \mathrm{Se}$, $\mathrm{Hg}, \mathrm{Pb}, \mathrm{Zn}$, and $\mathrm{Cd}$, the carryover to the offgas was essentially all attributable to feed entrainment of fine particulate. Feed mixtures were made up of small particle-sized materials with fine particulate susceptible to entrainment. For some volatile metals, however, it was difficult to separate feed entrainment from volatilization followed by capture of condensed metal particulate.

In the $\mathrm{M} 60$ test significant quantities of metals $(\mathrm{Fe}, \mathrm{Al}, \mathrm{Cu}, \mathrm{Pb}, \mathrm{Ni}, \mathrm{Cr}$, and $\mathrm{Zn}$ ) were added as shot, flakes, or metal powder less susceptible to entrainment. With much larger metal amounts present, essentially all of the nonvolatile metals partitioned to the slag or the metal phase as expected. Iron partitioned under $15 \%$ to the slag as oxide and over $85 \%$ to the tappable metal phase. Even the more volatile $\mathrm{Pb}$ and $\mathrm{Zn}$ partitioned significantly to the combined slag and metal products $(80 \%$ for $\mathrm{Pb}$ and $44 \%$ for $\mathrm{Zn}$ ), with the remainder partitioning to the offgas. Most of the $\mathrm{Pb}$ and $\mathrm{Zn}$ partitioning to the offgas was from volatilization rather than entrainment because of the unlikelihood of $\mathrm{Pb}$ and $\mathrm{Zn}$ additives to be entrained.

The glass/ceramic (slag) product easily passed the Toxicity Characteristic Leachability Procedure (TCLP) for all eight TCLP metals. Offgas solids also passed TCLP in many cases, but failed as expected in some. The glass/ceramic and metal products were homogeneous and readily analyzed. Process gases were monitored and typical of those expected $\left(\mathrm{CO}_{2}, \mathrm{H}_{2} \mathrm{O}, \mathrm{NO}_{x}\right.$, $\mathrm{SO}_{2}, \mathrm{HCl}$ ) from volatilization, thermal decomposition, and gas evolution from components in these feed materials. 


\subsection{Conclusions and Recommendations}

The first overall conclusion is that the baseline tests have satisfied the primary test objectives as the first test campaign in a planned three campaign series. Results have provided a better understanding of arc melter performance for treating "as incinerated" surrogate wastes. Results also provide information useful for test system modification for future tests, and for designing and performing future tests. In the second series of tests, arc melting of raw, as received buried and mixed wastes (without prior incineration) will be evaluated using nonradioactive, surrogate waste mixtures. The second test series is necessary to evaluate arc furnace applicability for treating asreceived buried and mixed wastes, as opposed to treating ash residuals from a preincinerator step.

The second overall conclusion is that it is feasible to use existing industrial arc melter technology as a thermal treatment system to successfully process "previously incinerated" buried mixed wastes and soils on a production basis. Extensive additional design, testing, and evaluation is required to optimize the arc furnace system and improve operations to reduce the level of personnel involvement and risk for mixed/buried waste applications. Current design and operating practices used for this test system are based on those commonly used in the metals smelting industry. The test system and procedures were further modified for optimum personnel access to the equipment and process materials. This access is necessary for researchers to monitor and control conditions and understand the melter process operations. Modifications such as an enhanced feed system, overall system containment, and a remote tapping operation will enable application of the existing technology represented by the USBM system to radioactive waste treatment. Automation of many activities such as tapping is done currently to some extent in the commercial metals industry.

The arc melter technology is capable of reliable production operation for this application. Furnace operating parameters were generally within expected values and typical of reliable industrial arc furnace practice norms. Electrode wear was not excessive even though the furnace plenum was operated under excess air flow conditions (oxidizing conditions in the plenum). Slag was continuously tapped at steady state. Separate bottom tapping capability for use with metals was partially demonstrated by draining the furnace through the bottom tap hole each day. Insufficient metal was present for separate metals tapping due to the hearth erosion volume increase. The small industrial scale graphite electrode ac powered arc furnace system $(800 \mathrm{kVA}$, 1 ton hearth) was able to process over $52,000 \mathrm{lbs}$ of surrogate materials at rates representative of those anticipated as needed for full scale production processing of buried mixed wastes and soils $(1,000$ to $2,000 \mathrm{lb} / \mathrm{hr})$ during a semi-continuous $80 \mathrm{hr}$ test period essentially without failure (unplanned downtime).

The highly viscous, high-silica melts of some of the soil and feed mixtures required melt temperatures exceeding $1,800^{\circ} \mathrm{C}$ in order to achieve sufficient fluidity to tap the slag. While the arc furnace easily achieved the required temperatures, additions of mill scale $\left(\mathrm{Fe}_{3} \mathrm{O}_{4}\right)$ and either limestone $\left(\mathrm{CaCO}_{3}\right)$ or pebble lime $(\mathrm{CaO})$ were also used to substantially reduce viscosity and required tapping temperatures, to reduce concerns for potential metals volatilization and refractory wear. The magnesium oxide hearth was also dissolved by the acidic (high silica) S60 feed slag at high temperatures. This did not require a shut-down during the test, but prevented complete draining of the furnace through the bottom metal tap hole in all subsequent tests. The metal product at the bottom of the hearth could not be tapped as a result. Additional testing and 
analytical modeling evaluations are recommended to improve tapping of higher viscosity slags, and to determine optimum slag conditions for maximum glass/ceramic waste form durability (high silica, high temperature slag) while minimizing additives, furnace wear, and metals volatilization (lower silica, lower viscosity, lower temperature slag).

The arc furnace produced process conditions desired for controlled separations, destruction of complex waste compounds, and stabilization of TRU and selected toxic metals in the slag. The slag was the primary product material and yielded a homogeneous, durable glass/ceramic product upon cooling that easily passed TCLP leachability tests. A separate, tappable, -homogeneous metal alloy product was also produced, as were relatively small amounts of condensed fume and entrained feed particulate which were successfully captured and retained in the APCS. Each product material was essentially homogeneous (much more so than the waste feeds), and properties evaluated were generally acceptable. The APCS solids collected would likely require additional processing. Recycling through the furnace would be the first recommended approach for the APCS solids after agglomeration into a larger feed size.

Based upon observed partitioning of the cerium metal and cerium oxide in the tests, any TRU metal or oxide fed into the high temperature melt would be rapidly oxidized or remain oxidized and partition to the slag as desired.

A small amount of the $\mathrm{CeO}_{2}$ additive was entrained in the offgas. This entrainment was due to the small particle size of the $\mathrm{CeO}_{2}$ additive. Such entrainment is not representative for actual TRU elements that are contaminants of actual waste. Elimination of feed entrainment in general is a controllable design and operations issue that needs to be addressed but is largely independent of process temperature. Entrainment can be minimized by increasing the feed material size distribution and by reducing furnace plenum gas velocities.

Powdered materials and fines in the soil used in the feed mixtures were entrained and increased the solids collected in the APCS. This entrainment biased APCS elemental partitioning analyses and made it difficult to differentiate between volatilization and entrainment for some elements. The only materials too large to be easily entrained were mullite, pollucite, $\mathrm{NaCl}$, pebble line, aluminum, copper, lead, and zinc. Results have been interpreted with this in mind, but future tests should avoid entrainment of feed materials by using larger-sized additives or pelletizing feed additives as much as possible. Added feed and APCS solids analyses are also recommended for better determination of metals transport mechanisms. Predictions based on analytical models should be developed to better understand the data and as design tools. Excessive downsizing of actual wastes, leading to entrainable particulates during feed preparation and treatments should be avoided.

Metal vaporization and carryover was very low for all but the most volatile metals, $\mathrm{Pb}, \mathrm{Zn}$, and $\mathrm{Hg}$. Cold top operation may have helped to reduce volatilization by condensing and refluxing vapors into the melt. Cold top operations clearly reduced temperatures in the plenum of both gases and surface materials. The thermal insulation effect of the cold top likely contributed significantly to the high thermal efficiency of the melter. These conclusions are based upon qualitative comparison of the baseline test results with similar tests run earlier by the USBM and ASME on municipal incinerator ashes. 
A cold top was present most of the time for all runs during the baseline tests. The thickness varied and was difficult to monitor and control with the manual means utilized. No effects of thickness variation were detectable. Future tests should include operation both with and without the cold top to better quantify cold top effects under identical operating conditions.

Although all measured temperatures were useful for interpreting performance additional measurements, measurement methods, and analytical support for data interpretation and extrapolation is needed. Measurement and interpretation of temperature readings in the high temperature environment of the arc furnace are difficult at best. Tapped slag.temperatures determined using an external infrared pyrometer were the most representative and accurate indicator of slag temperatures achieved in the furnace, but were lower than actual melt temperatures within the furnace. The slag cooled as it flowed through the water cooled tapping fixture, and infrared pyrometer readings were sensitive to placement of the visual spot on the slag pour. Refractory temperatures were measured at several locations, but furnace temperatures at key locations (in the metal phase, at the metal/slag interface, at locations in the slag, in the furnace plenum, cold top, etc.) could not be directly measured using instrumentation available during the baseline tests. Clearly the temperature distribution within the furnace is a key to understanding and controlling the process. Analytical modeling is also recommended for interpretation of data and prediction of temperatures of other regions.

The dissolution of the magnesium oxide hearth points out the need to evaluate hearth and slag compatibility similar operations, and especially prior to the next test series. Although the magnesium oxide ramming mix that made up the hemispherical hearth was dissolved, the underlying bottom and side Ruby refractory bricks were unaffected. A hearth made of Ruby ramming mix may be more durable. Operation with a protective metal heel or slag skull should also be further investigated. 


\section{INTRODUCTION}

This report describes the test results and evaluation for the Phase 1 (baseline) arc melter vitrification test series conducted for the BWID program. Phase 1 tests were conducted on surrogate mixtures of "as-incinerated" wastes and soil according to the scope of the overall demonstration project defined in the BWID Technical Task Plan ID 132010, Revision 0, and based on the detailed test plan. ${ }^{1}$ Phases 2 and 3 test series are planned for FY-94 and FY-95 to address waste streams containing raw organics, varied soil mixtures, and other process variations.

Some buried wastes, soils, and stored wastes at the INEL and other DOE sites, are contaminated with transuranic (TRU) radionuclides and hazardous organics and metals. The high temperature environment in an electric arc furnace may be used to process these wastes to produce materials suitable for final disposal. An electric arc furnace system can treat heterogeneous wastes and contaminated soils by (a) dissolving and retaining TRU elements and selected toxic metals as oxides in the slag phase, (b) destroying organic materials by dissociation, pyrolyzation, and combustion, and (c) capturing separated volatilized metals in the offgas system for further treatment. Structural metals in the waste may be melted and tapped separately for recycle or disposal, or these metals may be oxidized and dissolved into the slag. The molten slag, after cooling, will provide a glass/ceramic final waste form that is homogeneous, highly nonleachable, and extremely durable. These features make this waste form suitable for immobilization of TRU radionuclides and toxic metals for geologic timeframes. Further, the volume of contaminated wastes and soils will be substantially reduced in the process.

\subsection{Background}

Industrial arc melter technology is well developed for high-temperature pyrometallurgical applications for routinely processing large volumes of heterogeneous ore materials similar to buried wastes and soils. Electric arc furnaces are available in various design configurations for various applications. Possible configurations can include (a) three-phase alternating current (ac) with three or more electrodes, (b) single-phase ac with two or more electrodes, and (c) direct current (dc) with two side-by side top electrodes, or with one top electrode and a hearth electrode(s) under the melt. Power levels up to $105 \mathrm{MW}$ have been built that are capable of processing up to $130 \mathrm{ton} / \mathrm{hr}$ of ore material. Units built for processing phosphorous have been well sealed to prevent influx of air (tramp air) or fugitive emissions. High processing temperatures are possible in the arc furnace. For example, melt processing of refractory oxides, such as magnesia, can achieve temperatures of $2,800^{\circ} \mathrm{C}$.

Among arc melter processes, three-phase ac electric arc furnaces have been the most widely used for industrial applications and represent a baseline arc melter technology. Most recently, dc powered configurations have reemerged in the steel industry and may offer lower carbon electrode consumption and more efficient electrical power use, although advanced process control technologies for smoothing line power fluctuations in the ac systems are also being utilized.

Electric arc furnace processing technologies have not yet been proven for mixed, radioactive, and hazardous waste processing applications. Heterogeneous, buried radioactive and mixed wastes represent a complex materials processing problem because the chemical, radiological, and physical 
makeup and properties vary widely and are often difficult to characterize. Buried wastes and similar retrievably stored wastes at the INEL consist of (a) discarded lab and shop materials such as paper, cloth, rubber, glass, various metals, and graphite items, (b) construction debris such as wood, metals, concrete, brick, drywall, and plastic, (c) secondary sludges and salts from nuclear fuels reprocessing, and (d) contaminated soils. These wastes are contaminated primarily with TRU radionuclides, Resource Conservation and Recovery Act (RCRA) hazardous organics (oils and solvents), and toxic metals ( $\mathrm{Pb}$, etc.) in small, but significant, quantities dispersed throughout the waste materials. ${ }^{2,3}$

An electric arc furnace thermal treatment system can accept a wide variety of heterogeneous solid wastes and soils. The electric arc furnace will provide a controllable, thermally-driven, chemical processing environment for the complete breakdown of complex waste compounds. It will also provide the desired partitioning of elements of concern into a few simpler homogeneous product materials. The primary product materials-glass/ceramic from the molten slag phase, metal alloy from the metal phase, and product gases-will be more readily characterized and suitable for either final disposal or recycle.

Based upon earlier thermal treatment system scoping studies ${ }^{2,4}$ two primary system concepts for using an arc melter were identified. The first concept employs an up-front incinerator to combust organic components in the waste and thermally decompose and volatilize nitrates and/or hydrated compounds. The melter then processes the incinerator ash and noncombustible wastes such as soils and metals. The second concept specifies arc melting for waste feeds without a preincineration step.

In the arc melter high temperature environment, organics will pyrolyze and partially oxidize in the furnace with complete gaseous combustion in a secondary oxidizer. Inorganic waste feed materials, including toxic and TRU metal oxides, will melt and dissolve into the high temperature molten slag. Structural metals may be melted into a reduced metal product phase or oxidized and dissolved into the slag phase. Gaseous volatilization, decomposition, and oxidation products go to the APCS for cooling, scrubbing, filtration, and analysis before release to the environment.

A key advantage that arc melter technologies have over many other thermal treatment technologies is the ability to process waste into a glass ceramic waste form that easily meets regulatory requirements, is more durable, is more resistant to physical dispersion, and is more leach resistant than other waste forms, such as compacted or cemented incinerator ash. ${ }^{a}$ For this reason, considerable motivation exists for performing demonstration tests to collect engineering data and optimize arc melter technology for processing radioactive and mixed wastes.

a. P. C. Kong, G. A. Reimann, S. O. Bates, B. A. Detering, and G. L. Anderson, Final Waste Form Option Scoping Studies for RWMC Wastes, Unpublished Report, EG\&G Idaho, Inc., March 1993. 


\subsection{Objectives}

\subsubsection{Project Objectives}

The primary objective of the BWID Arc Melter Vitrification Project is to evaluate and demonstrate the application of existing industrial arc melter processing technology to the treatment of buried/mixed wastes and soils. Other top level project objectives include:

- Obtain performance data for systems design

- Provide data on a large scale for use in developing or verifying analytical tools, models, and scaling relationships for melter system and process design evaluations

- Identify technology gaps and development needs that require closure for deployment of the technology in a production environment

- Define and evaluate potential process, equipment, and operations improvement modifications

- Cooperatively extend applications evaluations and development to related public and private sector waste needs.

\subsubsection{Baseline Test Objectives}

The BWID arc melter vitrification demonstration test and evaluation project has been organized to include three sequential test series. The initial series was the baseline (Phase 1) test series, conducted in July 1993 on "as-incinerated" surrogate wastes and soils. Based upon thermal systems scoping studies $2,4,5$ and previous municipal incinerator ash vitrification tests performed for the USBM and ASME, ${ }^{6}$ specific objectives and conditions were defined for the FY-94 baseline test series. This report presents an evaluation of the baseline test results with respect to these objectives:

- Evaluate equipment capability to achieve the desired melting and vitrification process conditions and products for a range of "as-incinerated" surrogate buried mixed wastes and soil compositions.

- Evaluate continuous slag tapping and on-demand metals tapping capability. The highly variable metals content and variable composition of the waste feeds make this a more complex problem than a tightly controlled metals melting operation.

- Determine partitioning (thermal separations and distribution) of TRUs (using a surrogate) and toxic metals among the slag, offgas, and metal phases.

- Determine composition, homogeneity, and properties of the slag (glass/ceramic final waste form), metal product, and offgas solid materials (particulates in the offgas from feed dust entrainment or from volatilization from the melt). 
- Determine the effectiveness of operation with a layer of the unmelted feed material (cold top) on top of the melted slag for controlling volatilization of metals and the TRU surrogate and reducing thermal radiation and temperatures in the furnace plenum.

- Determine the effectiveness of water-cooled feed tubes on particulate generation control. Feed tubes deliver the feed to the surface of the melt, reducing the entrainment of feed components in the furnace offgas.

- Evaluate effects of slag chemistry, feed composition, and process temperature on process products, particularly TRU and metals partitioning, retention, and properties.

- Evaluate feed subsystem performance.

- Evaluate air pollution control subsystem performance.

\subsection{Arc Furnace Waste Treatment Test System}

The BWID baseline tests were performed using an existing pilot-scale, three-phase electric arc melter system at the USBM Albany Research Center in Albany, Oregon. The system includes an automated feed system, an electric arc furnace, and an air pollution control system (APCS). This system has been previously described in detail in the test plan, ${ }^{1}$ in the baseline test data report, ${ }^{7}$ and in a USBM Report of Investigations. ${ }^{8}$ A schematic of the system is shown in Figure 2-1. For convenience, Appendix $Q$ provides a more detailed description of the facility.

The furnace is a stationary, carbon steel shell, refractory-lined, small industrial-scale ac electric arc melting furnace that is sealed for atmospheric control. The furnace has three moveable $4 \mathrm{in}$. diameter solid graphite electrodes, with automatic power and electrode vertical positioning control. Power is supplied by a fully instrumented $800 \mathrm{kVA} 3$-phase supply. The electrodes are positioned at the apexes of an equilateral triangle 11.25 in. from electrode center to center. The electrodes and four water-cooled feed tubes extend through ports in the furnace roof. The feed tubes, furnace roof, sidewalls, and copper slag tapping fixture are water-cooled. The external furnace base is air cooled. Slag can be continuously tapped from the furnace; metal is tapped (and the hearth is emptied) when desired through a tap hole in the bottom center of the hearth.

The finished inside diameter of the furnace is about 46 in. at mid-height. The hearth is hemispherical in shape and constructed of magnesium oxide $(\mathrm{MgO})$ refractory ramming mix over Ruby (high alumina, $\mathrm{Al}_{2} \mathrm{O}_{3}$ ) bricks. The volumetric capacity of the hearth below the slag tap hole is approximately $5 \mathrm{ft}^{3}$, or 1 ton of steel. The slag tap hole is a water-jacketed, copper fixture 6 in. outside diameter by 10 in. long, that penetrates through the refractory and steel side-wall. The slag tap hole is 1 in. in diameter.

The carbon steel shell of the furnace is 65 in. high and tapers from 60 in. inside diameter (ID) at the bottom to 56 in. ID at the top. Three carbon steel straps ( 2 in. wide by 0.060 in. thick) were welded to the inside bottom of the shell in a triangular array prior to placing the refractory lining in the shell. These straps were worked between the bricks and through the 


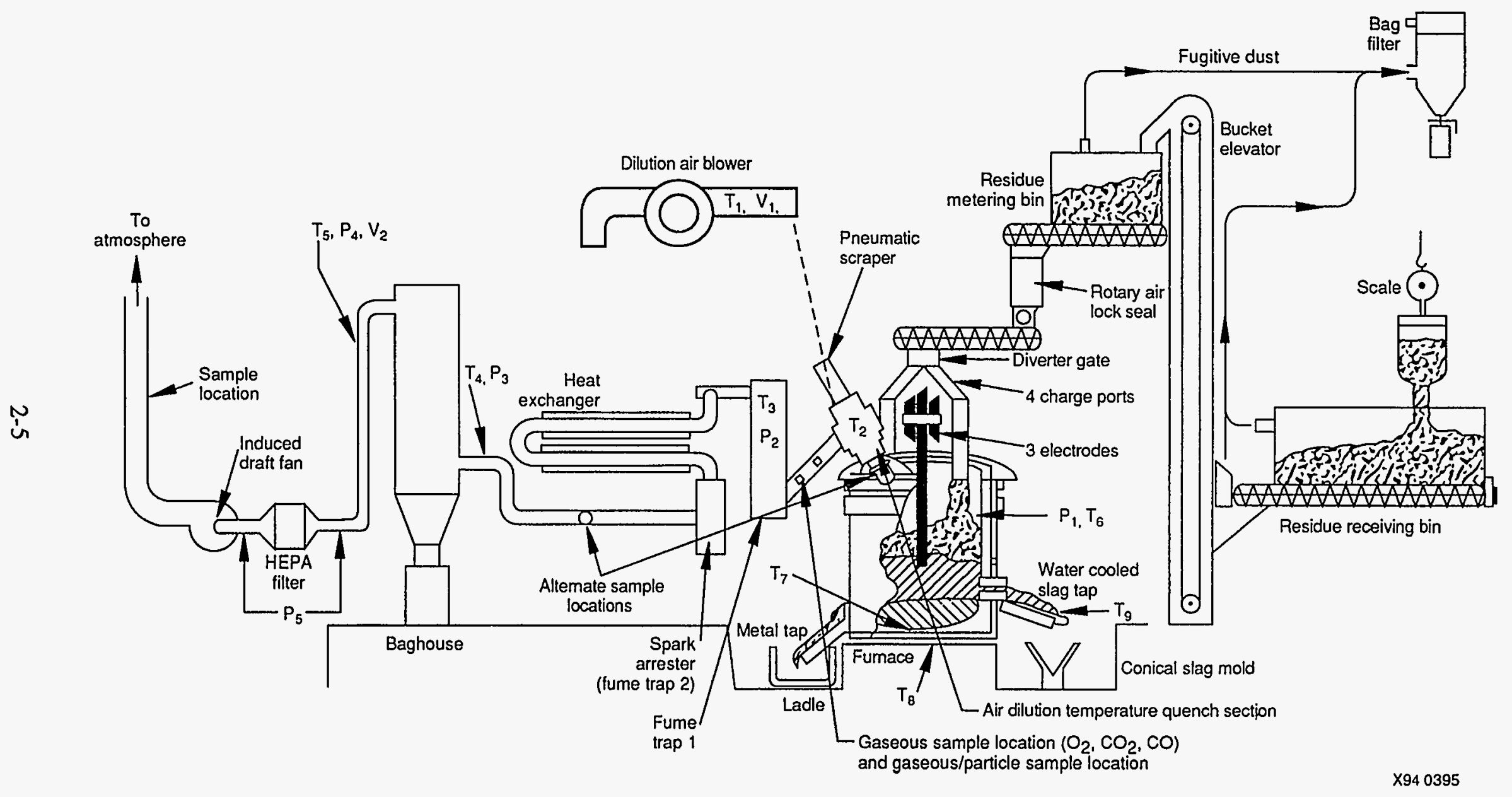

Figure 2-1. Schematic diagram of the Arc Furnace Integrated Waste Processing Test Facility. 
refractory ramming mix during construction of the hearth to provide an electrical circuit to ground between each pair of electrodes. The furnace shell was then securely grounded on the outside.

The feed system can deliver material to the furnace at a maximum rate of about $2,000 \mathrm{lb} / \mathrm{hr}$. The feed system is comprised of the: receiving bin, bucket elevator, metering bin with calibrated delivery screws, rotating air lock, splitter screw, and two feed screws. Each feed screw delivers to a pneumatically operated diverter gate that routes material equally through an inverted $\mathrm{Y}$ downcomer to two water-cooled feed tubes. Materials to be melted thereby are delivered uniformly to the furnace through four feed tubes which extend to within 18 in. of the surface of the molten slag and are located between the electrodes and sidewall of the furnace.

The air pollution control system (APCS), is comprised of: a double-walled, water-cooled, 8 in. ID offgas exit duct through the furnace roof; an air dilution temperature quench section with ambient air supplied by a 5 -hp blower immediately following the water-cooled section; a linear section of duct 6 in. ID by $10 \mathrm{ft}$ long with four 3-in. diameter by 4 -in. long pipe nipples for offgas sampling; a vertical settling chamber 14 in. ID by $90 \mathrm{in.} \mathrm{high} \mathrm{(fume} \mathrm{trap} \mathrm{1);} \mathrm{a} \mathrm{double-pipe} \mathrm{heat}$ exchanger 6 in. ID by $40 \mathrm{ft}$ long with a Supertrol control unit to modify the temperature of the offgas; a settling chamber 36 in. ID by 48 in. high (fume trap 2); a 2,000 acfm capacity baghouse; a High Efficiency Particulate-Air (HEPA) filter; 10-hp induced draft (ID) fan, and exhaust stack. The short section of water-cooled duct through the furnace roof and the interior of the wind box are cleaned by a mechanical scraper driven by a pneumatic cylinder to prevent the accumulation of deposits. The APCS has numerous additional access ports for offgas sampling and for temperature, pressure, and velocity sensors.

The melter system includes a control room with operator panels and a computer data acquisition system (DAS) for monitoring and controlling process conditions. The following permanently installed data acquisition instrumentation is used to continuously monitor, record, and control process conditions:

- Thermocouples (TCs) for temperature measurement at many furnace locations, fume trap 1, baghouse inlet, and baghouse outlet.

- Rotation rate indicator for indicating feed rate of the calibrated feed screws in the metering bin.

- A infrared pyrometer for monitoring slag temperature during continuous tapping.

- A hot-wire anemometer and standard pitot tube (with pressure transducer) for monitoring the quench air and the baghouse outlet gas velocities and flowrates.

- Static pressure taps with pressure transducers for measuring furnace and APCS static pressures.

- A true RMS Power and Demand Analyzer for monitoring electrode power, voltage and current. 
All instruments and sensors reported to a data logger which applied a scaling factor, if needed, and then digitized and transmitted the integral values to a personal computer (PC) for storage and display.

\subsection{Measurements, Sample Collection, and Analyses}

During the shakedown and baseline tests, various parameters were monitored to assure safe operation, maintain process control, and provide test data for evaluating performance of the arc melter system. Much of the data was automatically collected using the installed process instrumentation and a computer-based data acquisition system (DAS). Some redundant and additional data were taken using manual sampling and instrumentation.

More extensive data was collected during the baseline tests than during the earlier shakedown and preheat periods. A separate continuous emissions monitoring system (CEMS) was used to monitor the offgas composition. Numerous process samples were collected for subsequent analysis. A detailed listing of measurements and data collected during the baseline tests is shown in Table 2-1. The samples collected and analyses performed for the baseline tests are shown in Table 2-2. The shakedown test and the preheat day did not include continuous gas monitoring of the offgas or isokinetic particulate and metals sample collection.

Results from the sample analyses are shown in Appendices $H$ through $N$. Identifying labels, prepared beforehand for all anticipated furnace products, were affixed to the appropriate product as it was collected to avoid confusion during the tests. Furnace products were indicated by. a furnace feed designation and a descriptor for the collector or form of the product. Slag was indicated by $\mathrm{S}$, metal by $\mathrm{M}$, and slag or metal collected from the metal tap hole in a ladle were indicated by $\mathrm{L}$. All of the tapped slag was collected in conical slag molds that were numbered sequentially as collected. For example, $\mathrm{S} 60-\mathrm{S} 1$ designates the first slag mold filled during melting of $\mathrm{S} 60$ waste mixture.

A $2 \mathrm{~kg}$ slag grab sample was collected mid-way through the filling of each slag pot. This grab sample was collected in a small steel ladle placed in the slag stream as it flowed off of the slag launder. Slag was not tapped from the furnace during melting of unmodified M60. The only available sample of M60 slag obtained prior to adding the modified composition is the rod sample, designated M60-RS, which was obtained by immersing a cold iron rod into the molten pool. The sample was chipped off of the immersed portion of the rod after it was removed from the furnace. A sample of the M60 metal product was also obtained from the very tip of the rod, but this sample was too contaminated with slag particles for use in data evaluation.

For analysis, each slag sample was crushed to pass an 80-mesh sieve (particulate size $<0.175 \mathrm{~mm}$ ), coned, and quartered to obtain representative split samples for chemical, X-ray diffraction (XRD), and TCLP analysis. The TCLP leachability analysis only requires that particles pass a $1 / 4$-in. $(<6.35 \mathrm{~mm})$ sieve, so the leachability tests of $<80$-mesh material are much more severe than required.

The solid residues recovered from the APCS are indicated in the analysis tables by $\mathrm{T} 1$ for fume trap 1, T2 for fume trap 2, and BH for the baghouse. These residues were sampled individually for elemental and phase structure (XRD, phase identification) analysis and then 
Table 2-1. Measurements and instrumentation during the baseline tests.

\begin{tabular}{|c|c|c|c|}
\hline Measurement & Sensor location & $\begin{array}{c}\text { DAS } \\
\text { channel }\end{array}$ & Frequency/duration/comments \\
\hline $\begin{array}{l}\text { Weights of all feed } \\
\text { materials }\end{array}$ & $\begin{array}{l}\text { Manual measurement at receiving } \\
\text { bin. }\end{array}$ & - & $\begin{array}{l}\text { Every time feed material was added to the } \\
\text { receiving bin. This measurement, the measured } \\
\text { amount of feed dust collected in the feed system } \\
\text { baghouse (material not fed to the furnace), any } \\
\text { material fed by hand, and the operating time } \\
\text { were used to determine the average feed rate for } \\
\text { each test. }\end{array}$ \\
\hline
\end{tabular}

Weight of feed system fugitive dust

Feed rate, $\mathrm{lb} / \mathrm{hr}$

Electrode phase to ground voltage, $\mathrm{V}$

Electrode phase to phase current, A

Furnace power, $\mathrm{kW}$

Furnace energy, kWh

Furnace cold top depth measurement

$T_{6}$, furnace upper inner sidewall temperature, ${ }^{\circ} \mathrm{C}$

$\mathrm{T}_{7}$, furnace hearth temperature, ${ }^{\circ} \mathrm{C}$

$\mathrm{T}_{8}$, furnace shell bottom temperature, ${ }^{\circ} \mathrm{C}$

$\mathrm{T}_{9}$, slag (at tap hole) temperature, ${ }^{\circ} \mathrm{C}$

Slag bath temperature (inside the furnace)
Manual measurement of feed system fugitive dust in facility baghouse.

Feed metering screws.

$-$

$-$

$-$

$-$

"Plumb Bob" weight on steel cable through one of the feed tubes indicated height of solid surface in furnace. The height difference between the slag tap hole and the solid surface was assumed to be the thickness of the cold top.

K-type TC located in the wall refractory near the inner refractory surface; not inserted through refractory into the plenum gas.

$K$-type TC grouted into the metal tap hole, positioned near the center of the hearth; not inserted above the hearth into the melt.

K-type TC welded to the bottom outside metal shell of the furnace.

Infrared pyrometer measurement of the slag stream during tapping.

Sacrificial TC, manually inserted through side wall port into slag.
- $\quad$ At the end of every test the feed fugitive dust collection system baghouse hopper was emptied and weighed.

0 Continuous indication from the two calibrated metering augers; used for instantaneous monitoring and controlling feed rate.

17 Continuous

18 Continuous

19 Continuous.

20 Continuous

- This measurement was made at least several times per hour.

6 Continuous

7 Continuous; replaced every time after the metal tap hole is tapped.

$8 \quad$ Continuous

9 Continuous during tapping.

- Typically performed prior to tapping to obtain slag temperature when slag temperature could not be measured at the slag tap hole. These temperature readings were provided for a short time (a few seconds) until each TC was destroyed. 
Table 2-1. (continued).

\begin{tabular}{|c|c|c|c|}
\hline Measurement & Sensor location & $\begin{array}{c}\text { DAS } \\
\text { channel }\end{array}$ & Frequency/duration/comments \\
\hline $\begin{array}{l}\mathrm{P}_{1} \text {, furnace chamber } \\
\text { pressure, in. } \mathrm{H}_{2} \mathrm{O}\end{array}$ & $\begin{array}{l}\text { Uses the same port in the upper side- } \\
\text { wall occupied by } T_{6} \text {. }\end{array}$ & 10 & Continuous. \\
\hline $\begin{array}{l}\mathrm{T}_{2} \text {, furnace outlet duct } \\
\text { wall temperature, }{ }^{\circ} \mathrm{C}\end{array}$ & $\begin{array}{l}\text { K-type TC inserted almost flush with } \\
\text { the inner sidewall of the outlet duct. }\end{array}$ & 2 & $\begin{array}{l}\text { Continuous; this temperature is considerably } \\
\text { lower than the actual offgas temperature } \\
\text { because it does not insert into the gas stream } \\
\text { and may be affected by conductive heat transfer } \\
\text { to the adjacent water-cooled section. }\end{array}$ \\
\hline $\begin{array}{l}\text { Furnace outlet offgas } \\
\text { temperature }\end{array}$ & $\begin{array}{l}\text { K-type TC manually inserted into the } \\
\text { gas stream through a small port in } \\
\text { the furnace outlet duct, occasionally } \\
\text { during the testing. }\end{array}$ & - & $\begin{array}{l}\text { Periodically up to several times per test } \\
\text { condition for several minutes each time; } \\
\text { observed temperature may be slightly increased } \\
\text { due to radiation heat transfer from molten pool } \\
\text { or arc zone. }\end{array}$ \\
\hline $\begin{array}{l}\text { Furnace outlet gas } \\
\text { moisture content }\end{array}$ & $\begin{array}{l}\text { Wet/dry TC probe manually inserted } \\
\text { into the gas stream through a small } \\
\text { port occasionally during the testing. }\end{array}$ & 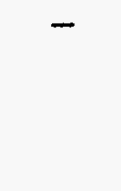 & $\begin{array}{l}\text { Periodically up to several times per test } \\
\text { condition for several minutes each time; } \\
\text { observed dry bulb temperature may be slightly } \\
\text { increased due to radiation heat transfer from } \\
\text { molten pool or arc zone. }\end{array}$ \\
\hline $\begin{array}{l}\mathrm{T}_{1} \text {, quench air } \\
\text { temperature, }{ }^{\circ} \mathrm{C}\end{array}$ & $\begin{array}{l}\text { K-type TC inserted into the quench } \\
\text { air duct downstream of the blower. }\end{array}$ & 1 & Continuous. \\
\hline $\begin{array}{l}v_{1} \text {, quench air flowrate, } \\
\text { cfm }\end{array}$ & $\begin{array}{l}\text { Hot-wire anemometer in the quench } \\
\text { air duct downstream of the blower. }\end{array}$ & 15 & Continuous. \\
\hline $\begin{array}{l}\text { Quench outlet gas } \\
\text { temperature, velocity and } \\
\text { flowrate }\end{array}$ & $\begin{array}{l}\text { K-type TC and S-type pitot manually } \\
\text { inserted in sample ports. }\end{array}$ & - & $\begin{array}{l}\text { Periodically during each test condition before, } \\
\text { during and after each MMT sampling run; both } \\
\text { traversing and single point. }\end{array}$ \\
\hline $\begin{array}{l}\text { Quench outlet gas } \\
\text { composition }\left(\mathrm{O}_{2}, \mathrm{CO}_{2}\right. \\
\left.\mathrm{CO}, \mathrm{NO}_{\mathbf{x}}, \mathrm{SO}_{2}\right)\end{array}$ & $\begin{array}{l}\text { Extractive sample probe inserted in } \\
\text { sample ports. }\end{array}$ & - & $\begin{array}{l}\text { Continuous during sample collection, single } \\
\text { point following initial traverse to evaluate } \\
\text { stratification. }\end{array}$ \\
\hline $\begin{array}{l}\mathrm{T}_{3} \text {, fume trap } 1 \text { gas } \\
\text { temperature, }{ }^{\circ} \mathrm{C}\end{array}$ & $\begin{array}{l}\text { K-type TC inserted into the gas } \\
\text { stream. }\end{array}$ & 3 & Continuous. \\
\hline $\begin{array}{l}\mathrm{P}_{2} \text {, fume trap } 1 \text { pressure, } \\
\text { in. } \mathrm{H}_{2} \mathrm{O}\end{array}$ & $\begin{array}{l}\text { Pressure tap in the port where } T_{3} \text { is } \\
\text { located. }\end{array}$ & 11 & Continuous. \\
\hline $\begin{array}{l}\text { Baghouse inlet gas } \\
\text { temperature }\end{array}$ & $\begin{array}{l}\text { K-type TC manually inserted in } \\
\text { sample ports upstream of baghouse. }\end{array}$ & - & $\begin{array}{l}\text { Only occasionally during the testing, as } \\
\text { corroboration to the continuous baghouse inlet } \\
\text { temperature measurement. }\end{array}$ \\
\hline $\begin{array}{l}\text { Baghouse inlet gas } \\
\text { composition }\left(\mathrm{O}_{2}, \mathrm{CO}_{2}\right. \\
\left.\mathrm{NO}_{x}, \mathrm{SO}_{2}\right)\end{array}$ & $\begin{array}{l}\text { Extractive sample probe manually } \\
\text { inserted in sample ports upstream of } \\
\text { baghouse. }\end{array}$ & - & $\begin{array}{l}\text { Only occasionally during the testing, to estimate } \\
\text { the degree of air dilution (if any) between the } \\
\text { quench outlet and the baghouse inlet. }\end{array}$ \\
\hline $\begin{array}{l}\mathrm{T}_{4}, \text { baghouse inlet gas } \\
\text { temperature, }{ }^{\circ} \mathrm{C}\end{array}$ & K-type TC in baghouse inlet duct. & 4 & Continuous. \\
\hline $\begin{array}{l}\mathrm{P}_{3}, \text { baghouse inlet } \\
\text { pressure, in. } \mathrm{H}_{2} \mathrm{O}\end{array}$ & $\begin{array}{l}\text { Pressure tap at the baghouse inlet } \\
\text { location. }\end{array}$ & 12 & Continuous. \\
\hline $\begin{array}{l}\mathrm{T}_{5}, \text { baghouse outlet offgas } \\
\text { temperature, }{ }^{\circ} \mathrm{C}\end{array}$ & K-type TC in baghouse outlet duct. & 5 & Continuous. \\
\hline
\end{tabular}


Table 2-1. (continued).

\begin{tabular}{|c|c|c|c|}
\hline Measurement & Sensor location & $\begin{array}{c}\text { DAS } \\
\text { channel }\end{array}$ & Frequency/duration/comments \\
\hline $\begin{array}{l}\mathrm{P}_{4} \text {, baghouse outlet } \\
\text { pressure, in. } \mathrm{H}_{2} \mathrm{O}\end{array}$ & $\begin{array}{l}\text { Pressure tap at the baghouse outlet } \\
\text { location. }\end{array}$ & 13 & Continuous. \\
\hline $\begin{array}{l}\mathrm{V}_{2} \text {, baghouse outlet } \\
\text { velocity head of standard } \\
\text { pitot, in. } \mathrm{H}_{2} \mathrm{O}\end{array}$ & $\begin{array}{l}\text { Standard pitot at the baghouse outlet } \\
\text { location. }\end{array}$ & 16 & Continuous. \\
\hline $\begin{array}{l}\mathrm{P}_{5}, \text { HEPA filter } \\
\text { differential pressure, in. } \\
\mathrm{H}_{2} \mathrm{O}\end{array}$ & $\begin{array}{l}\text { Pitot taps upstream and downstream } \\
\text { of the HEPA filter. }\end{array}$ & 14 & Continuous. \\
\hline $\begin{array}{l}\text { Stack gas composition }\left(\mathrm{O}_{2}\right. \\
\left.\mathrm{CO}_{2}, \mathrm{CO}, \mathrm{NO}_{\mathrm{x}}, \mathrm{SO}_{2}\right)\end{array}$ & $\begin{array}{l}\text { Extractive sample probe manually } \\
\text { inserted in sample ports in the stack. }\end{array}$ & - & $\begin{array}{l}\text { Only occasionally during the testing, to estimate } \\
\text { the degree of air dilution (if any) between the } \\
\text { baghouse inlet and the baghouse outlet. }\end{array}$ \\
\hline
\end{tabular}


Table 2-2. Sample collection summary.

\begin{tabular}{|c|c|c|c|}
\hline Sample & Sample location & $\begin{array}{c}\text { Analysis } \\
\text { parameters }^{\mathrm{a}}\end{array}$ & Sample frequency \\
\hline Metal product & $\begin{array}{l}\text { Metal dip rod (during } \\
\text { M60 test) and metal } \\
\text { heel }\end{array}$ & $\begin{array}{l}\text { Full set metals, P, S; } \\
\text { total } \mathrm{C}, \mathrm{Cl}\end{array}$ & $\begin{array}{l}\text { Once during } \mathrm{M} 60 \text { melt, and once } \\
\text { from metal heel after test series }\end{array}$ \\
\hline Slag product & $\begin{array}{l}\text { Slag launder (and } 1 \\
\text { sample from metal dip } \\
\text { rod during M60 test) }\end{array}$ & $\begin{array}{l}\text { Full set metals, } \mathrm{Hg} \text {, } \\
\mathrm{P}, \mathrm{S} \text {; total } \mathrm{C} ; \mathrm{Cl}\end{array}$ & $\begin{array}{l}\text { Once per slag pot ( } 8-11 \text { per test } \\
\text { day) }\end{array}$ \\
\hline $\begin{array}{l}\text { Fume traps } 1 \text { and } \\
2 \text { solids } b\end{array}$ & Fume trap 1 & $\begin{array}{l}\text { Total weight; full set } \\
\text { metals, } \mathrm{Hg}, \mathrm{P}, \mathrm{S} \text {; } \\
\text { total } \mathrm{C}, \mathrm{Cl}\end{array}$ & End of each test condition \\
\hline Baghouse ash ${ }^{b}$ & Baghouse hopper & $\begin{array}{l}\text { Total weight; full set } \\
\text { metals, } \mathrm{Hg}, \mathrm{P}, \mathrm{S} \text {; } \\
\text { total } \mathrm{C}, \mathrm{Cl}\end{array}$ & End of each test condition \\
\hline MMT samples & Quench outlet duct & $\begin{array}{l}\text { Total particulate, } \\
\text { front half metals, } \\
\text { back half metals }\end{array}$ & Two per test day \\
\hline \multicolumn{4}{|c|}{$\begin{array}{l}\text { a. Full set metals }=\mathrm{Ag}, \mathrm{Al}, \mathrm{As}, \mathrm{Ba}, \mathrm{Ca}, \mathrm{Cd}, \mathrm{Ce}, \mathrm{Cr}, \mathrm{Cu}, \mathrm{Cs}, \mathrm{Fe}, \mathrm{Hg}, \mathrm{K}, \mathrm{Mg}, \mathrm{Na}, \mathrm{Ni}, \mathrm{Pb}, \mathrm{Se}, \mathrm{Si}, \mathrm{Ti}, \mathrm{Zn} \text {, } \\
\text { and } \mathrm{Zr} \text {. } \\
\text { b. The offgas system residues were collected as completely as possible from the baghouse hopper and fume } \\
\text { traps. }\end{array}$} \\
\hline
\end{tabular}


were thoroughly mixed and sampled to provide material for TCLP leachability analysis. The samples of mixed APCS solids are designated by FS.

Offgas measurements during the baseline tests were made by personnel from Entropy Environmental Inc. Particulate and metals sample collection and analysis was done using EPA Draft Method 29 Multiple Metals Train $(M M T)^{9}$ for isokinetic sample collection and analysis of metals emissions from stationary sources. The duration of each sampling interval was around $1.5 \mathrm{hr}$, of which $1 \mathrm{hr}$ was actual sample collection. Two valid EPA Method 29 samples were collected for each test day. The designations for these samples are prefixed by. MMT and followed by the collecting solvent or solution. All samples were analyzed by the USBM analytical laboratory. Operating parameters including feed rate, cold top depth, and power to the furnace, were maintained as constant as possible during the sampling interval.

Gaseous emissions from the furnace were analyzed continuously for $\mathrm{O}_{2}, \mathrm{CO}_{2}, \mathrm{CO}, \mathrm{NO}_{\mathrm{x}}$, and $\mathrm{SO}_{2}$ at the quench section outlet, with occasional checks for short periods of time at the baghouse inlet and at the stack. EPA Methods ${ }^{9} 3 \mathrm{~A}, 6 \mathrm{C}, 7 \mathrm{E}$, and 10 were used for these measurements.

\subsection{Feed Mixtures}

The baseline test feed mixtures were prepared by mixing soil from the Radioactive Waste Management Complex (RWMC) with selected buried waste surrogate materials. The description of each feed mixture is shown in Table 2-3. The surrogate waste materials were specified to represent buried wastes that have been previously incinerated. Mixture proportions of the soil and surrogate waste materials were calculated so that the resultant vitrified slag product would be chemically similar to iron-enriched basalt (IEB) or IEB-4, which is IEB that is enriched in Group IV elements ( $\mathrm{Ti}$ and $\mathrm{Zr}$ ). IEB-4 potentially provides longer duration immobilization of TRU elements and better leach resistance. ${ }^{10}$ Other additives [limestone $\left(\mathrm{CaCO}_{3}\right)$, pebble lime $(\mathrm{CaO})$, and magnetite $\left(\mathrm{Fe}_{3} \mathrm{O}_{4}\right)$ ] were also used in some of the tests to reduce the slag viscosity and enable continuous slag tapping at more reasonable slag temperatures consistent with the existing furnace design capability. A general background discussion of slag chemistry and related properties is provided in Appendix R.

The elemental compositions (shown in Table 2-4) of the feed mixtures were calculated from the compound compositions (Table 2-5) and amounts of each additive in the feed mixtures as given in Appendix G. The compositions of the feed mixtures were not determined by analysis of feed mixture samples because of the potential for error due to segregation of the different additives during sampling. Such segregation is common when, as in this case, mixtures of materials of different particle sizes, shapes, and densities are handled. Rather, the calculated feed mixture compositions based on the known quantity and compositions of additives in the mixtures are considered more accurate. The compositions of the additives were obtained from the suppliers of the materials. In many cases, the materials specifications only provided a range of typical compositions, and identified a certain small percentage of the material as "other."

The soil (without additives) was analyzed for moisture content (weight loss after heating to $110^{\circ} \mathrm{C}$ for $12 \mathrm{hr}$ ), for Loss on Ignition [(LOI) weight loss after heating to $1,000^{\circ} \mathrm{C}$ for $1 \mathrm{hr}$ ] and elemental composition prior to testing. The moisture content (not including water of hydration) ranged from 2 to $3.5 \%$. The LOI ranged up to $10 \%$ (in addition to the moisture content). The 
Table 2-3. Description of buried wastes and surrogate mixtures.

Feed mixture

designation

Description of buried wastes and surrogate mixtures

560

The S-0 series of wastes describes organic oils and solvents immobilized by mixing with Micro-Cell E $\left(\mathrm{CaSiO}_{3}\right)$ and Oil-Dri $\left(\mathrm{SiO}_{2}\right)$. These wastes were generated at EG\&G's Rocky Flats Plant, and include Organic Setups (prefix 743, also identified as INEL Content Code 3). ${ }^{\mathrm{a}}$ Waste mixture $\mathrm{S} 60$ is $60 \%$ RWMC soil (A-100) and $40 \%$ simulated thermally oxidized S-0. Gypsum $\left(\mathrm{CaSO}_{4} \cdot 2 \mathrm{H}_{2} \mathrm{O}\right)$ and $\mathrm{NaCl}$ were added to provide the desired sulfur and chlorine concentrations, respectively.

S60-IV This waste mixture is the $\mathrm{S} 60$ mixture with added zircon $\left(66 \% \mathrm{ZrO}_{2}\right)$ and ilmenite $\left(65 \% \mathrm{TiO}_{2}\right)$ to provide around $3 \% \mathrm{ZrO}_{2}$ and $6 \% \mathrm{TiO}_{2}$ in the feed mixture.

N80 The N-0 series of wastes contains evaporator salts from solar drying liquid wastes and consists mostly of sodium and potassium nitrates with limited amounts of other wastes and small amounts of Oil-Dri. These wastes were generated at EG\&G Rocky Flats Plant, and include prefix 745 (Content Code 5) evaporator salts. The surrogate waste mixture $\mathrm{N} 80$ is $80 \%$ RWMC soil and $20 \%$ simulated thermally oxidized $\mathrm{N}-0$.

Preincineration of the nitrate salts would be expected to yield alkali metal oxides and evolve substantial quantities of gas. The subsequent melting of sodium and potassium oxides would not be difficult. The direct processing of nitrate salts in the melter could, however, produce a vigorous reaction rapidly generating gas affecting the slag and burden layers by causing foaming and dusting and resulting in furnace pressure spikes. For these baseline tests sodium and potassium carbonates were used in the surrogate waste mixtures to approximate effects of rapid gas generation by sodium and potassium nitrates to investigate potential problems with rapid chemical reaction of the nitrates during melting.

N80-Mod The N80 waste mixture was modified during the melting test (to reduce the slag viscosity) with limestone and mill scale in the ratio $100 \mathrm{lb}$ N-80: $37.5 \mathrm{lb}$ limestone: $20.7 \mathrm{lb}$ mill scale.

N80-IV This waste mixture is the N80 mixture with additions of zirconia and ilmenite to provide around $3 \% \mathrm{ZrO}_{2}$ and $6 \% \mathrm{TiO}_{2}$ in the feed mixture.

N80-IV-Mod The N80-IV waste mixture was modified (to reduce the slag viscosity) with pebble lime and mill scale in the ratio $22.4 \mathrm{lb} \mathrm{CaO}$ and $20.7 \mathrm{lb}$ mill scale for every $100 \mathrm{lb}$ N80-IV. 
Table 2-3. (continued).

Feed mixture designation

Description of buried wastes and surrogate mixtures

M60

The M-0 waste (from EG\&G Rocky Flats Plant, Content Code 480 ) is a variety of unleached scrap metals (some bagged in plastic) and loaded into boxes and drums. The surrogate waste mixture M60 is $60 \%$ RWMC soil and $40 \%$ simulated thermally oxidized M-0 waste, assumed to be primarily elemental metals, not.metal oxides.

Notes:

1. All waste mixtures contained $0.35-0.42 \% \mathrm{CeO}_{2}$ added as a surrogate for the TRU radionuclides, particularly $\mathrm{PuO}_{2}$.

2. The N80-IV-Mod feed mixture with additional pebble lime was fed during the M60-Mod condition.

3. During the M60-Mod test a 3-1b metal alloy ingot $(50 \% \mathrm{Ce}, 50 \% \mathrm{Fe})$ was added to investigate partitioning of added metallic $\mathrm{Ce}$ ( $\mathrm{Pu}$ surrogate).

a. W. S. Roesener, N. R. Soelberg, and A. L. Ayers, Identification of a Treatment Process for the Idaho Waste Processing Facility Project-A Preconceptual Design Study, unpublished report, September 1992. 
Table 2-4. Calculated elemental composition of the surrogate waste mixtures.

\begin{tabular}{|c|c|c|c|c|c|c|c|c|c|}
\hline \multirow[b]{2}{*}{ Element } & \multicolumn{9}{|c|}{ Surrogate waste mixture elemental composition (as received ppm) } \\
\hline & RWMC soil & 560 & S60-IV & N80 & N80-Mod & N80-IV & N80-IV-Mod & M60 & M60-Mod \\
\hline $\mathrm{Ag}$ & 8.00 & 4.52 & 3.97 & 5.95 & 4.90 & 5.24 & 4.47 & 5.14 & 4.35 \\
\hline Al & 55,100 & 39,927 & 35,819 & 43,513 & 35,860 & 37,920 & 32,515 & 58,501 & 31,696 \\
\hline As & 11 & 6.21 & 5.46 & 8.24 & 6.79 & 7.27 & 6.36 & 6.94 & 6.24 \\
\hline $\mathrm{Ba}$ & 100 & 463 & 467 & 321 & 264 & 311 & 266 & 341 & 259 \\
\hline $\mathrm{Bi}$ & - & - & - & - & - & - & - & $2.21 E-03$ & - \\
\hline C & 15,588 & 8,840 & 7,778 & 29,081 & 37,444 & 27,679 & 23,780 & 9,855 & 23,197 \\
\hline $\mathrm{Ca}$ & 52,863 & 64,685 & 62,164 & 39,865 & 77,330 & 35,043 & 80,940 & 42,046 & 96,566 \\
\hline $\mathrm{Cd}$ & 0.50 & 0.28 & 0.25 & 0.37 & 0.31 & 0.33 & 0.28 & 0.32 & 0.27 \\
\hline $\mathrm{Ce}$ & 45 & 3,384 & 3,475 & 3,446 & 2,840 & 3,437 & 2,934 & 3,780 & 2,955 \\
\hline $\mathrm{Cl}$ & 40 & 12,358 & 12,702 & 83 & 68 & 79 & 68 & 25 & 66 \\
\hline $\mathrm{Cr}$ & 200 & 359 & 382 & 259 & 267 & 296 & 313 & 17,219 & 305 \\
\hline $\mathrm{Cs}$ & 50 & 3,956 & 4,063 & 37 & 31 & 33 & 28 & 32 & 27 \\
\hline $\mathrm{Cu}$ & 45 & 25 & 22 & 33 & 190 & 29 & 208 & 7,392 & 202 \\
\hline F & - & 579 & 596 & 589 & 485 & 588 & 525 & 647 & 519 \\
\hline $\mathrm{Fe}$ & 30,600 & 116,317 & 116,628 & 66,772 & 99,881 & 63,262 & 104,418 & 267,971 & 101,745 \\
\hline $\mathrm{H}$ & 11,222 & 7,488 & 6,880 & 8,398 & 6,959 & 7,630 & 6,805 & 7,107 & 6,725 \\
\hline Hf & - & - & 13,638 & - & - & 543 & 463 & - & 451 \\
\hline $\mathrm{Hg}$ & 0.10 & 0.06 & 0.05 & 0.08 & 0.06 & 0.07 & 0.06 & 0.06 & 0.06 \\
\hline $\mathrm{K}$ & 20,109 & 11,708 & 10,299 & 50,425 & 41,556 & 48,597 & 41,489 & 12,757 & 40,381 \\
\hline $\mathrm{Li}$ & - & 41 & 42 & - & - & - & - & - & - \\
\hline $\mathrm{Mg}$ & 13,702 & 14,790 & 14,082 & 10,816 & 9,240 & 9,446 & 8,248 & 8,689 & 8,091 \\
\hline $\mathbf{M n}$ & - & 313 & 755 & 125 & 441 & 926 & 1,194 & 22 & 1,171 \\
\hline $\mathbf{N}$ & - & - & - & - & - & - & - & 17 & - \\
\hline $\mathrm{Na}$ & 9,500 & 13,628 & 13,213 & 53,366 & 43,980 & 52,475 & 44,817 & 6,013 & 43,626 \\
\hline $\mathrm{Ni}$ & 34 & 19 & 17 & 25 & 115 & 22 & 124 & 9,597 & 121 \\
\hline 0 & 541,353 & 477,294 & 456,138 & 499,650 & 483,494 & 483,613 & 456,322 & 359,704 & 452,429 \\
\hline $\mathbf{p}$ & 950 & 573 & 528 & 722 & 604 & 672 & 591 & 618 & 578 \\
\hline $\mathrm{Pb}$ & 23 & 13 & 11 & 18 & 15 & 16 & 14 & 7,380 & 13 \\
\hline $\mathbf{R b}$ & - & 99 & 102 & - & - & - & - & - & - \\
\hline $\mathbf{s}$ & 140 & 13,507 & 13,837 & 431 & 355 & 346 & 341 & 238 & 348 \\
\hline $\mathbf{S b}$ & - & - & - & - & - & - & - & 0.01 & - \\
\hline $\mathrm{Se}$ & 1.12 & 0.63 & 0.56 & 0.83 & 0.68 & 0.73 & 0.62 & 0.71 & 0.61 \\
\hline $\mathbf{S i}$ & 270,000 & 207,759 & 185,066 & 202,594 & 167,024 & 178,368 & 152,617 & 178,622 & 148,635 \\
\hline Sn & - & - & - & - & - & - & - & 0.03 & - \\
\hline $\mathrm{Sr}$ & - & 383 & 394 & 157 & 129 & 157 & 134 & 174 & 130 \\
\hline $\mathrm{Te}$ & - & - & - & - & - & - & - & 7.37E-03 & - \\
\hline Th & - & 14 & 15 & 15 & 12 & 20 & 17 & 16 & 17 \\
\hline $\mathrm{Ti}$ & 2,600 & 12,706 & 30,368 & 6,964 & 5,739 & 39,211 & 33,498 & 1,656 & 32,612 \\
\hline U & - & - & - & - & - & 8.44 & 7.21 & - & 7.01 \\
\hline V & - & 793 & 806 & 356 & 293 & 337 & 288 & - & 280 \\
\hline$Y$ & - & - & - & - & - & 42 & 35 & - & 35 \\
\hline $\mathrm{Zn}$ & 110 & 62 & 55 & 82 & 67 & 72 & 62 & 14,742 & 60 \\
\hline $\mathrm{Zr}$ & 100 & 56 & 7,034 & 74 & 61 & 24,878 & 21,239 & 63 & 20,672 \\
\hline Other & $-24,495$ & $-12,153$ & 2,615 & $-18,232$ & $-14,758$ & $-16,070$ & $-14,313$ & $-15,239$ & $-13,931$ \\
\hline Total & $1,000,000$ & $1,000,000$ & $1,000,000$ & $1,000,000$ & $1,000,000$ & $1,000,000$ & $1,000,000$ & $1,000,000$ & $1,000,000$ \\
\hline
\end{tabular}


Table 2-5. Species compositions of the surrogate waste mixtures.

\begin{tabular}{|c|c|c|c|c|c|c|c|c|c|}
\hline \multirow[b]{2}{*}{ Specia } & \multicolumn{9}{|c|}{ Surrogu s wane mideture pecies somposition (u recéved ppon) } \\
\hline & RWMC soil & $\mathbf{s 6 0}$ & S60.IV & N80 & $\mathrm{N} 80-\mathrm{Mad}$ & N80-IV & NBO-IV.Mod & $\mathrm{M} 60$ & MOO-Mod \\
\hline $\mathbf{A} 203$ & 104,114 & 75,443 & 67,682 & 82,219 & 67.758 & 71.652 & 61,438 & 75,745 & 59,890 \\
\hline$A 82 O$ & 839 & 4.85 & 4.27 & 6.39 & 3.26 & 3.63 & 480 & 5.41 & 468 \\
\hline$A 20$ & 12.17 & 6.87 & 6.05 & 9.05 & 7.46 & 7.97 & 681 & 7.67 & 662 \\
\hline B.o & 112 & 63 & s5 & 83 & 68 & 73 & 62 & 78 & 61 \\
\hline $\mathrm{CaCO} 3$ & 130,000 & 73.730 & 64,868 & 96,616 & 190,682 & 85.131 & 73,925 & 81,953 & 72,385 \\
\hline CaO & 1,120 & 28,444 & 27.243 & 1,640 & 1.352 & 1.328 & 71,828 & 12,908 & 94,553 \\
\hline C2sOr & - & 576 & 392 & - & - & - & - & - & - \\
\hline $\mathrm{C} 2 \mathrm{SO}=2 \mathrm{H}_{2} \mathrm{O}$ & - & 68,863 & 70,798 & - & - & - & - & - & - \\
\hline $\mathrm{C \infty O}$ & 0.57 & 032 & 0.28 & 0.42 & 035 & 0.37 & 0.32 & 0.36 & 031 \\
\hline $\mathrm{CeO}$ & - & - & - & - & - & - & - & 406 & - \\
\hline $\mathrm{CeO} 2$ & 53 & 4.157 & 4.269 & 4.232 & 3,488 & 4.221 & 3.604 & 4.638 & 3.508 \\
\hline$C 2 O_{3}$ & 292 & 525 & 359 & 379 & 391 & 433 & 458 & 184 & 446 \\
\hline C.2O & $\$ 3$ & 30 & 26 & 39 & 32 & 33 & 30 & 33 & 29 \\
\hline coo & 56 & 32 & 28 & 42 & 238 & 37 & 260 & 39 & 253 \\
\hline Fe203 & - & 1.135 & 15,624 & 1.07 & 0.88 & 26,743 & 22,892 & 189 & 22,302 \\
\hline Fe3O4 & 42.288 & 159582 & 146,004 & 92.277 & 138,032 & 61.577 & 122,176 & 26.643 & 118.914 \\
\hline n20 & 101,000 & 00,187 & 34,513 & 75,577 & 62,625 & 88,661 & 61,242 & 63,967 & 60,522 \\
\hline $\mathrm{HrO}_{2}$ & - & - & - & - & - & 640 & 546 & - & 532 \\
\hline $\mathrm{H}_{8} \mathrm{O}$ & 011 & 0.06 & 0.05 & 0.08 & 007 & 007 & 006 & 007 & 0.06 \\
\hline $\mathrm{K}_{2} \mathrm{CO} 3$ & - & . & - & 62,643 & 51,625 & 62.532 & $\$ 3.403$ & - & 31.977 \\
\hline $\mathrm{KCI}$ & - & - & - & 3.14 & 2.59 & 3.13 & 268 & - & 2.60 \\
\hline $\mathrm{K} 2 \mathrm{O}$ & 24.223 & 13,994 & 12,294 & 18,003 & 14,836 & 15,863 & 13,543 & 15,367 & 13.181 \\
\hline $\mathrm{KOH}$ & - & - & - & 44 & 36 & 4 & 37 & - & 36 \\
\hline $\mathrm{K} 2 \mathrm{SO}$ & - & - & - & 3.77 & 3.10 & 3.76 & 321 & - & 312 \\
\hline $\mathrm{M}_{8} \mathrm{CO} 3$ & - & - & - & - & 1,133 & - & - & - & - \\
\hline $\mathrm{M}_{8} \mathrm{O}$ & 22,721 & 24,517 & 23,344 & 17,935 & 14,781 & 15.663 & 13,676 & 14,408 & 13,417 \\
\hline $\mathrm{M}=\mathrm{O}$ & - & 402 & 973 & 161 & 133 & 1.196 & 1,021 & 25 & 994 \\
\hline $\mathrm{MnO2}$ & - & - & - & - & 535 & - & 638 & - & 634 \\
\hline $\mathrm{N} 22 \mathrm{CO}_{3}$ & - & - & - & 106,507 & 87,775 & 106.352 & 90,797 & - & 88,373 \\
\hline Nect & - & 20,339 & 20,910 & 86 & 71 & 85 & 73 & - & 71 \\
\hline N2O & 12,804 & 7.248 & 6.376 & 9.516 & 7.842 & 8,406 & 7,199 & 8.105 & 7.015 \\
\hline $\mathrm{N} 22 \mathrm{sO}$ & - & - & - & 100 & 132 & 160 & 137 & - & 133 \\
\hline Nio & 43 & 24 & 21 & 32 & 146 & 28 & 158 & 27 & 154 \\
\hline 02 & - & . & - & - & - & - & - & 2.21E-04 & - \\
\hline $\mathrm{POA}$ & 2,913 & 1,645 & 1,447 & 2.165 & 1,811 & 1,908 & 1,659 & 1,835 & 1,613 \\
\hline P2OS & - & 72 & 110 & 32 & 27 & 98 & 99 & - & 102 \\
\hline FOO & 25 & 14 & 12 & 18 & 15 & 16 & 14 & 16 & 13 \\
\hline so3 & - & - & - & - & - & - & 114 & - & 151 \\
\hline so4 & 420 & 631 & 614 & 696 & 574 & 658 & 562 & 686 & $\$ 47$ \\
\hline seo & 1.20 & 0.68 & 060 & 089 & 074 & 0.79 & 0.67 & 0.76 & 0.65 \\
\hline $\mathrm{SiO2}$ & 577.583 & 443,984 & 395,422 & 433,387 & 357,296 & 381,565 & 326,477 & 380.253 & 317,980 \\
\hline Sro & - & - & - & - & - & - & - & 1 & - \\
\hline ThO2 & - & 16 & 17 & 17 & 14 & 17 & 14 & 18 & 14 \\
\hline T102 & 4,337 & 21,194 & 50,636 & 11,616 & 9,573 & 65,403 & 55.877 & 2,763 & 54,399 \\
\hline V203 & - & - & 111 & $\cdot$ & - & 205 & 175 & - & 170 \\
\hline v2os & - & 1,260 & 1,160 & 565 & 466 & 315 & 269 & - & 261 \\
\hline Y2O3 & - & - & . & . & - & 53 & 45 & . & 44 \\
\hline $2 \cap 0$ & 137 & 77 & 68 & 102 & 84 & 90 & 77 & 86 & 73 \\
\hline 2002 & 135 & 76 & 86 & 100 & 83 & 33.605 & 28.690 & 85 & 27.924 \\
\hline Brotsro & - & 453 & 466 & 461 & 380 & 460 & 393 & 506 & 392 \\
\hline $\mathrm{ZrO2+H}$ & - & - & 25,476 & - & - & - & - & - & - \\
\hline$A_{B}$ & - & - & - & - & - & - & - & 0.10 & - \\
\hline $\mathbf{A}$ & - & - & - & - & - & . & - & 18,415 & - \\
\hline A & - & - & - & - & - & - & - & $7.37 \mathrm{E}-03$ & - \\
\hline $\mathrm{Bi}$ & - & - & - & - & - & - & - & 2.21E-03 & - \\
\hline c & - & - & - & - & - & - & - & 28 & - \\
\hline $\mathrm{cr}$ & - & - & - & - & - & - & - & 25 & - \\
\hline$a$ & - & - & . & - & - & - & - & 17,093 & - \\
\hline cu & - & - & - & - & - & - & - & 7,364 & - \\
\hline $\mathbf{F}$ & - & - & - & - & - & - & - & 647 & - \\
\hline Fe & - & - & - & - & - & - & - & 248,560 & - \\
\hline $\mathrm{Mr}$ & - & - & - & - & - & - & - & 2 & - \\
\hline N & - & - & - & - & - & - & - & 17 & - \\
\hline $\mathbf{N i}$ & - & - & - & - & - & - & - & 9,576 & $=$ \\
\hline 0 & - & - & - & - & - & - & - & 86 & - \\
\hline $\mathbf{P}$ & - & - & . & - & - & - & - & 20 & - \\
\hline Pb & - & - & - & - & - & - & - & 7,366 & - \\
\hline $\mathbf{s}$ & - & - & - & - & - & - & - & 9 & - \\
\hline so & - & - & - & - & - & - & - & o & - \\
\hline Se & - & - & - & - & - & - & - & $7.3 \mathrm{FE}-03$ & - \\
\hline si & - & - & - & - & - & - & - & 867 & - \\
\hline $\mathrm{sin}$ & - & - & - & - & - & - & - & 0 & - \\
\hline Te & - & - & - & - & - & - & - & 7.3TE-03 & - \\
\hline $\mathbf{z n}$ & - & - & - & - & - & - & - & 14.673 & - \\
\hline Oaner & -24.455 & -6.727 & 8.165 & $-17,377$ & -14.053 & -15.296 & $-13,626$ & -15.324 & -13.096 \\
\hline Total & 1.000 .000 & $1,000,000$ & $1,000,000$ & $1,000,000$ & $1,000,000$ & 1.000 .000 & $1.000,000$ & $1,000,000$ & $1.000,000$ \\
\hline
\end{tabular}


LOI includes weight loss of the solid sample from gases evolved from the decomposition of carbonates and sulfates, evolution of water of hydration, and volatilization of any other materials at that temperature. The combined moisture content and LOI weight loss for the soils averaged around $12 \%$. Since soil comprised $60-80 \%$ of the feed mixtures, this is also the general range of moisture content and LOI expected for the feed mixtures. Soil samples were obtained by conventional cone-and-quartering procedures from $200 \mathrm{lb}$ of thoroughly mixed soil.

The carbon content (including carbon from carbonates and from small amounts of organic matter in the soil) was under $4 \%$. Sulfur and chlorine content ranged under $1.5 \%$ for the $\$ 60$ and S60-IV feed mixtures, and under $0.1 \%$ for the other mixtures. The composition of each feed mixture in terms of oxides, carbonates and sulfates is shown in Appendix G-2. 


\section{TEST OBSERVATIONS AND MELTER SYSTEM PERFORMANCE}

The performance of the melter system was evaluated during an initial shakedown test day on soil feed, during a preheat day on calcium oxide and silicon dioxide feed prior to the baseline tests, and on the waste surrogate soil feed mixtures during the five day baseline test series.

Process monitoring and sample collection were performed during each furnace operating period in order to monitor and control system operation and to obtain operating data to satisfy the test objectives listed in Section 2.2. An overview of the operating conditions and an evaluation of performance for the melter system components are presented in this section.

\subsection{Operating Conditions and Results Summary}

A global summary of the operating conditions and results parameters from the shakedown test, the preheat day, and the semi-continuous baseline tests is shown in Table 3-1. The following subsections briefly discuss each test period.

\subsubsection{Shakedown Test}

The shakedown test was conducted on June 3,1993. This test was conducted to assure suitable performance of the modified system and facility prior to the baseline tests. RWMC soil with added mill scale was the feed material, because the soil was expected to be one of the more challenging, highly viscous melt compositions. Satisfactory performance of all system modifications was demonstrated. Arc furnace system modifications had been made based on the experience obtained in processing municipal incinerator ash for the ASME test program, and to meet the objectives of the BWID baseline tests. Modifications included (a) installation of water-cooled feed tubes, (b) installation of a video camera in the furnace inspection port, (c) elimination of the nitrogen gas inerting system, (d) modification of the furnace offgas duct to minimize solids deposition, (e) installation of an air-dilution temperature quench system for cooling the furnace offgas, (f) elimination of the afterburner at the outlet of the baghouse, and (g) installation of a HEPA filter at the outlet of the baghouse. All modifications performed as intended, as discussed in Section 3.2.3.

Trends of operating parameters including the furnace pressure, offgas flowrates, and offgas temperatures are shown in Appendices A-F. The furnace was started and operated for about $3 \mathrm{hr}$ to melt $1,962 \mathrm{lb}$ of soil and mill scale $\left(\mathrm{Fe}_{3} \mathrm{O}_{4}\right)$ in the ratio of $10 \mathrm{lb}$ mill scale per $100 \mathrm{lb}$ soil ( $9.1 \%$ mill scale in the mixture). This feed mixture had a calculated basicity ratio of 0.31 (Appendix R). Tapping of slag was difficult owing to inadequate fluidity, but possible at undesirably high tapping temperatures $\left(1,800^{\circ} \mathrm{C}\right)$; therefore, in an attempt to fluidize the slag, the proportion of mill scale was increased to the ratio $20 \mathrm{lb}$ per $100 \mathrm{lb}$ soil (basicity ratio 0.37 ) for the remaining $10 \mathrm{hr}$ of the test. Additional mill scale, added from time to time to further fluidize the slag, increased the average ratio of mill scale to soil during the shakedown test to $25.3 \mathrm{lb}$ per $100 \mathrm{lb}$ soil $(20.2 \%$ in the mixture).

At 2330 the metal tap hole was opened to drain the hearth from which $1,050 \mathrm{lb}$ of slag was recovered. Metal was neither observed during the tap nor in the slag mold after cooling, although 
Table 3-1. Global summary of baseline tests.

\begin{tabular}{|c|c|c|c|c|c|c|c|c|c|c|c|}
\hline $\begin{array}{l}\text { Feed } \\
\text { type }\end{array}$ & $\begin{array}{l}\text { Test } \\
\text { day }\end{array}$ & $\begin{array}{l}\text { Operating } \\
\text { run } \\
\text { duration } \\
\text { (hr)(j) }\end{array}$ & $\begin{array}{l}\text { Average } \\
\text { power } \\
(\mathrm{kW}) \\
\end{array}$ & $\begin{array}{c}\text { Total } \\
\text { electrode } \\
\text { energy input } \\
(\mathrm{MWh}) \\
\end{array}$ & $\begin{array}{c}\text { Total } \\
\text { feed } \\
\text { material } \\
\text { (lb) } \\
\end{array}$ & $\begin{array}{c}\mathrm{MgO} \\
\text { dissolved } \\
\text { from } \\
\text { refractory } \\
\text { (lb) }\end{array}$ & $\begin{array}{l}\text { Total } \\
\text { feed } \\
\text { input to } \\
\text { furnace } \\
\text { (lb) }\end{array}$ & $\begin{array}{c}\text { Average } \\
\text { feedrate } \\
(\mathrm{lb} / \mathrm{hr}) \\
\end{array}$ & $\begin{array}{c}\text { Average slag } \\
\text { tapping } \\
\text { rate (a) } \\
(\mathrm{lb} / \mathrm{hr})\end{array}$ & $\begin{array}{l}\text { Slag bath } \\
\text { temperature } \\
\text { (C)(i) }\end{array}$ & $\begin{array}{c}\text { Tap } \\
\text { temperature } \\
\text { (C)(a) }\end{array}$ \\
\hline RWMC soil \& mill scale & 3-Jun & 13 & & & 7,516 & 10 & 7,526 & 579 & 464 & & \\
\hline $\mathrm{CaO}+\mathrm{SiO} 2$ & 18-Jul & 7.3 & 356 & 2.97 & 4,301 & 0 & 4,301 & 589 & 592 & 1530 & $1450-1700$ \\
\hline$S 60$ & 19-Jul & 9.25 & 544 & 5.09 & 9,806 & 910 & 10,716 & 1,158 & 977 & 1430 & $1550-1600$ \\
\hline S60-IV & 20-Jul & 10.7 & 422 & 4.62 & 8,273 & 57 & 8,330 & 779 & 656 & 1380 & $1550-1650$ \\
\hline $\mathrm{N} 80$ & 21-Jul & 4.2 & & 1.92 & 4,601 & 0 & 4,601 & 1,095 & 969 & 1300 & $1650-1800$ \\
\hline \multirow[t]{2}{*}{ N80-Mod (h) } & 21-Jul & 4.3 & & 1.73 & 3,778 & 0 & 3,778 & 879 & 777 & NM & $1450-1550$ \\
\hline & Daily total & 8.5 & 462 & 3.65 & 8,379 & 0 & 8,379 & 987 & 872 & & \\
\hline \multirow[t]{2}{*}{ N80-IV-Mod (h) } & 22-Jul & 4.25 & & 2.40 & 4,986 & 0 & 4,986 & 1,173 & 981 & NM & $1550-1590$ \\
\hline & Daily total & 9.45 & 540 & 5.18 & 10,504 & 0 & 10,504 & 1,117 & 929 & & \\
\hline M60 & 23-Jul & 3.1 & & 1.32 & 3,263 & 0 & 3,263 & 1,053 & 0 & NM & no tap \\
\hline \multirow[t]{2}{*}{ M60-Mod (h) } & 23-Jul & 4.6 & & 2.19 & 3,403 & 0 & 3,403 & 740 & 1,136 & NM & $1550-1690$ \\
\hline & Daily total & 7.7 & 473 & 3.51 & 6,666 & 0 & 6,666 & 897 & 678 & & \\
\hline Average (Baseline tests) & & 5.7 & 483 & 2.76 & 5,454 & 121 & 5,574 & 992 & 798 & & \\
\hline Average (for all days) & & 6.59 & 441 & 2.78 & 5,545 & 97.7 & 5,642 & 911 & 744 & & \\
\hline Subtotal (Baseline tests) & & 45.6 & & 22.1 & 43,628 & 967 & 44,595 & 7,938 & 6,382 & & \\
\hline Totals (for all days) & & 65.9 & & 25.0 & 55,445 & 977 & 56,422 & 9,106 & 7,438 & & \\
\hline
\end{tabular}

Notes:

1. The 4,322 lb of slag obtained for the $\mathrm{CaO}+\mathrm{SiO} 2$ feed type includes the addition of residual soil from the shakedown test conducted on June 3, 1993.

2. $\mathrm{NM}=$ Not measured; $\mathrm{NC}=$ Not calculated due to insufficient measurements.

a. During continuous tapping period(s) only. The reported tap temperatures are corrected for deviations in the optical pyrometer measurements when the slag did not completely fill the pyrometer fieid of view. The correction was determined each day by manual, closer pyrometer measurements.

b. Total solid material collected and quantitatively removed from fume trap 1, fume trap 2, and the baghouse.

c. Mass of feed material volatilized and measured in the form of vapor, $\mathrm{H} 2 \mathrm{O}, \mathrm{SO}, \mathrm{CO}$ (from carbonates) and $\mathrm{HCl}$ (See Table 4-1). This corresponds to \% Loss On Ignition (LOI).

Minor amounts of potentially vaporized metals (oxides, sulfates and chlorides) are not included in this calculation.

d. Electrode consumption calculated for baseline tests, not including 8.5 hour run to preheat the furnace on 7/18/93.

e. Calculated from the density and mass of the feed material and the density and mass of the vitrified slag. The relatively smaller amounts of fume solids and metal product are not included.

f. Calculated from (Sum output mass -Sum input mass)/Sum input mass. 
Table 3-1. (continued).

\begin{tabular}{|c|c|c|c|c|c|c|c|c|}
\hline \multirow[b]{2}{*}{$\begin{array}{l}\text { Feed } \\
\text { type }\end{array}$} & \multicolumn{2}{|c|}{ Total slag tapped } & \multicolumn{2}{|c|}{ Total metal product (g) } & \multicolumn{2}{|c|}{ Total APCS solids (b) } & \multicolumn{2}{|c|}{$\begin{array}{c}\text { Total amount of } \\
\text { vaporized material (c) }\end{array}$} \\
\hline & (lb) & $\begin{array}{c}\text { (wt \% of initial } \\
\text { feed mass) }\end{array}$ & (lb) & $\begin{array}{c}\text { (wt \% of initial } \\
\text { feed mass) }\end{array}$ & (lb) & $\begin{array}{c}\text { (wt } \% \text { of initial } \\
\text { feed mass) }\end{array}$ & (lb) & $\begin{array}{c}\text { (wt \% of initial } \\
\text { feed mass) }\end{array}$ \\
\hline RWMC soil \& mill scale & 6,030 & 80.1 & 162 & 2.15 & 65 & 0.86 & NM & $\mathrm{NM}$ \\
\hline $\mathrm{CaO}+\mathrm{SiO}_{2}$ & 4,322 & 100.5 & 0 & 0 & $\mathrm{NM}$ & NM & NM & NM \\
\hline S60 & 9,040 & 84.4 & 40 & 0.37 & 141 & 1.32 & 1,100 & 10.3 \\
\hline S60-IV & 7,019 & 84.3 & 1 & 0.01 & 164 & 1.97 & 1,109 & 13.3 \\
\hline N80 & 4,069 & $\cdot$ & 33 & 0.72 & 109 & 2.37 & NM & NC \\
\hline \multirow[t]{2}{*}{ N80-Mod } & 3,341 & - & 28 & 0.74 & 122 & 3.23 & 613 & 16.2 \\
\hline & 7,410 & 88.4 & 61 & 0.73 & 231 & 2.76 & $\mathrm{NC}$ & NC \\
\hline N80-IV & 4,612 & - & 96 & 1.74 & 112 & 2.03 & 976 & 17.7 \\
\hline \multirow[t]{2}{*}{ N80-IV-Mod } & 4,168 & - & 86 & 1.72 & 126 & 2.53 & 530 & 10.6 \\
\hline & 8,780 & 83.6 & 182 & 1.73 & 238 & 2.27 & 1,506 & 14.3 \\
\hline M60 & 0 & - & 789 & 24.2 & 53 & 1.62 & 357 & 11.0 \\
\hline \multirow[t]{2}{*}{ N80-IV-Mod } & 5,224 & - & 0 & 0 & 68 & 2.00 & 353 & 10.4 \\
\hline & 5,224 & 78.4 & 789 & 11.8 & 121 & 1.82 & 711 & 10.7 \\
\hline Average (Baseline tests) & 4,684 & 83.8 & 134 & 2.94 & 112 & 2.02 & 720 & 13.0 \\
\hline Average (for all days) & 4,783 & 85.7 & 124 & 3.16 & 107 & 1.99 & 720 & 12.8 \\
\hline Subtotal (Baseline tests) & 37,473 & & 1,073 & & 895 & & 5,038 & \\
\hline Totals (for all days) & 47,825 & & 1,235 & & 960 & & 5,038 & \\
\hline
\end{tabular}

g. No metal was tapped from the furnace, although it was molten based on post test observations. The metal resided in the region of the eroded hearth below the metal tap hole.

h. The N80-Mod mixture included powdered limestone (mainly $\mathrm{CaCO}$ ) and millscale to reduce slag viscosity. The N80-IV-Mod mixture included pebble lime (mostly CaO) and millscale to reduce slag viscosity.

i. Bath temperatures measured during non-tapping periods, usually when slag was too viscous to tap.

j. Duration was taken from power on to power off. 


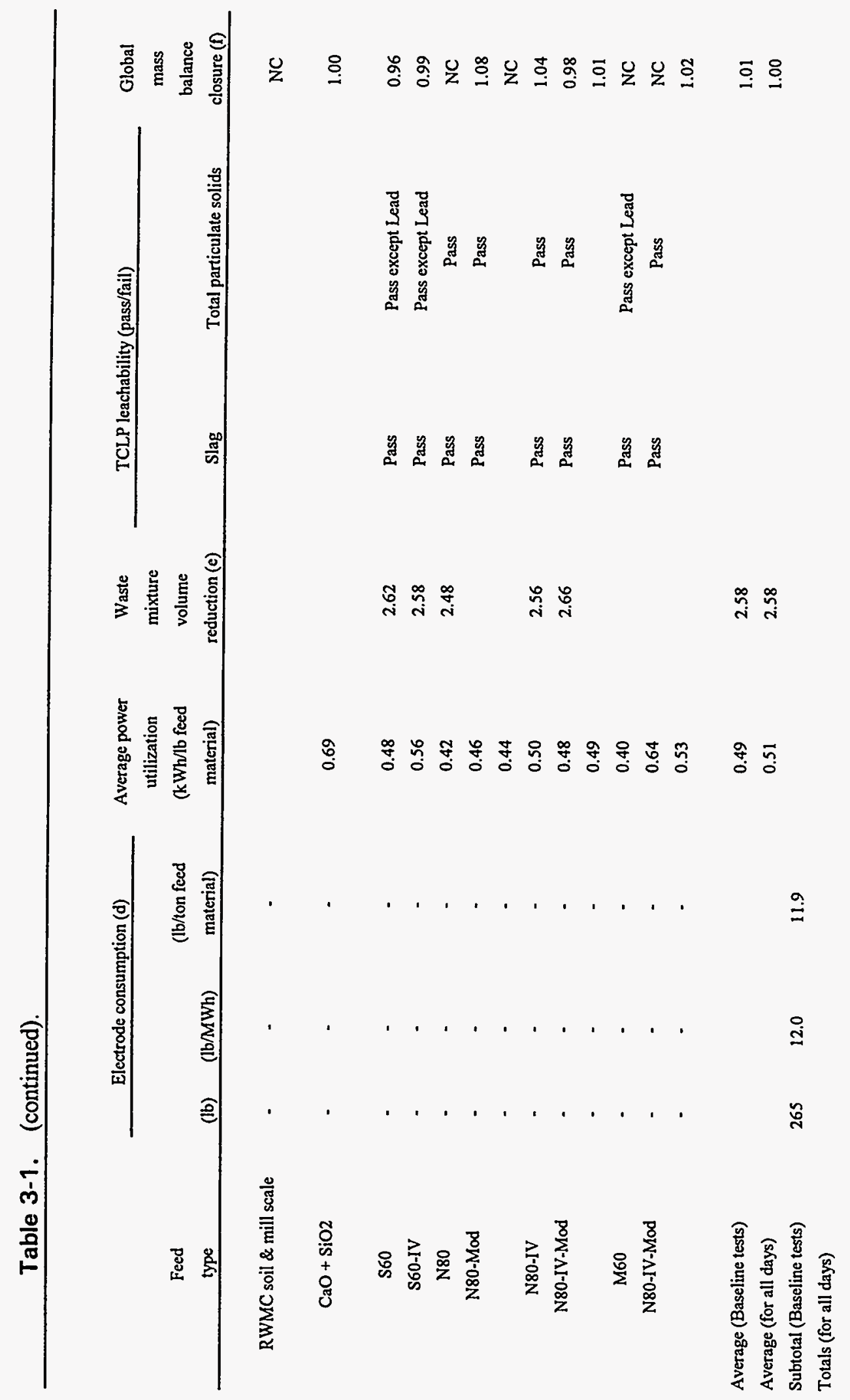


some reduced iron was expected. Based on iron material balance calculations, $162 \mathrm{lb}$ of metallic iron was produced by carbothermic reduction of a portion of the mill scale during the test.

Observation of the interior of the furnace after cooling to room temperature revealed a band 6 to 8 in. thick of sintered, but unmelted, feed material extending about 6 in. up the sidewall from the slag line, and additional melted material on the hearth that had been melted but was too viscous to tap from the furnace. The combined weight of materials remaining in the furnace was estimated to be about $600 \mathrm{lb}$, which decreased the weight of material actually melted and tapped to 5,510 lb RWMC soil and 1,390 lb mill scale. Soil and mill scale remaining in the furnace from the shakedown test were later removed during the preheat day prior to the semi-continuous baseline tests.

\subsubsection{Preheat Day}

The furnace was preheated on July 18 during operation for about $12 \mathrm{hr}$ on an equimolar mixture of $<1 / 4$ in. pebble lime (mostly $\mathrm{CaO}$ ) and silica sand $\left(\mathrm{SiO}_{2}\right)$. The basicity ratio of the resulting calcium silicate slag was 1.0. In addition to preheating the furnace for the baseline tests the preheat run was used to (a) remove the residual sintered deposits of soil material in the furnace from the shakedown test, (b) startup and stabilize the Supertrol control unit for the offgas heat exchanger and other supporting equipment including the water-cooling tower, water distribution pumps, city water, compressed air, dilution air blower, and induced-draft blower, and (c) verify the operational status of the system. The melter system did not and was not expected to achieve completely steady-state temperatures during the preheat run.

Continuous slag tapping was achieved within $3 \mathrm{hr}$ of startup after feeding only $900 \mathrm{lb}$ of preheat material to the furnace, thereby confirming that appreciable material (estimated $600 \mathrm{lb}$ ) remained in the furnace from the shakedown test. At 1138 a fuse failed in the electrode control circuit for phase A, causing the phase A electrode to withdraw from the furnace. The source of the problem was not identified until later in the evening, but in the meantime (beginning at 1250), the furnace was operated successfully with manual control of phase A. Continuous tapping was regained at 1325 , and slag temperatures measured by a slag tap pyrometer ranged from 1,450 to $1,700^{\circ} \mathrm{C}$ throughout the test. After $6 \mathrm{hr}$ of operation, a constant cold top of 6 to $8 \mathrm{in}$. was achieved at a feed rate of $675 \mathrm{lb} / \mathrm{hr}$ and a power input of about $450 \mathrm{~kW}$.

The quench air flowrate ranged from 485 to $588 \mathrm{acfm}$ at $25^{\circ} \mathrm{C}$, and the offgas flowrate at the baghouse outlet ranged from 640 to $700 \mathrm{scfm}$ at a maximum temperature of $80^{\circ} \mathrm{C}$. Furnace pressure was maintained in the range -0.1 to -0.3 in. water gage by adjusting the ID fan. Operating conditions were within design parameters. The temperature of the hearth, as measured by a thermocouple in the metal tap hole, increased to about $1,200^{\circ} \mathrm{C}$, and the bottom of the steel furnace shell increased to about $120^{\circ} \mathrm{C}$ during the melting test. At 1750 the metal tap hole was opened to drain the hearth. Metal was not observed during the tap. Power to the Supertrol and water-cooling tower, and water flow to all circuits were maintained throughout the following night. 


\subsubsection{Baseline Tests}

Following the preheat day the surrogate waste mixtures were melted in succession in five consecutive, daily, semi-continuous tests. The actual operating time for each day was 7.7-10.7 hours, with additional time each day for test preparation, sample collection and handling, maintenance, and data handling.

Five surrogate waste mixtures were consecutively melted each on a separate day in the baseline tests. The five surrogate waste mixtures had been prepared to simulate soil mixed with preincinerated (a) solidified organic oils and solvents (denoted S60 and S60-IV), (b) solidified evaporator salts containing potassium and sodium nitrates (denoted N80 and N80-IV), and (c) contaminated scrap metals (denoted M60). In order to achieve sufficiently low molten slag viscosities to enable continuous slag tapping at reasonable temperatures, some of these mixtures were further modified during the testing by adding mill scale $\left(\mathrm{Fe}_{3} \mathrm{O}_{4}\right)$ and either limestone $\left(\mathrm{CaCO}_{3}\right)$ or pebble lime $(\mathrm{CaO})$ with additional feed material to the existing molten mass in the furnace.

The furnace was generally operated with a cold top of feed material ranging from 3 to 10 inches during all but the early startup portion of each test day.

Waste mixtures S60 and S60-IV were successfully melted without modifying the compositions. Continuous tapping of slag was achieved at temperatures ranging from 1,550 to $1,650^{\circ} \mathrm{C}$. The $\mathrm{N} 80$ and $\mathrm{N} 80$-IV waste mixtures were more viscous and required higher tapping temperatures, up to $1,800^{\circ} \mathrm{C}$. These waste feeds were processed for about 4 hours each while process and offgas data and samples were collected. Following a full set of sample and data collection (except for metal samples) these melts were modified by adding limestone or pebble lime and mill scale to the feed mixture to decrease the slag viscosity for easier tapping. Another full set of sample and data collection (except for metal samples) was obtained while operating with the modified mixtures.

The M60 surrogate waste was a mixture of $60 \%$ soil and $40 \%$ metal powders, flakes, and shot. About 3,260 lb of M60 was melted in 4 hours at feed rates up to 1,500 lb/hr, while process and offgas data and samples (except for metal samples) were collected. During this time highly viscous slag could not be successfully tapped at the existing power and at slag temperatures up to $1,850^{\circ} \mathrm{C}$. Further increasing the temperature (power), while possible, was not desirable and could potentially damage the furnace refractory, feed tubes, or other components. Since the slag was not tappable for this condition, samples could not be obtained from the slag tap. Therefore, a slag sample was collected using a steel probe inserted through a port in the furnace. Following the sample and data collection, the melt was modified to reduce viscosity for tapping by feeding 3,006 lb of N80-IV-Mod plus an additional $400 \mathrm{lb}$ of pebble lime over the following 4 hours. After decreasing the melt viscosity, continuous slag tapping was successfully initiated and continued at tapping temperatures from $1,550-1,690^{\circ} \mathrm{C}$. Another set of process data and sample collection was performed at this operating condition.

During the M60-Mod run a $3 \mathrm{lb}$ metal alloy ingot ( $50 \mathrm{wt} \% \mathrm{Ce}, 50 \mathrm{wt} \% \mathrm{Fe}$ ) was added to the melt to investigate the partitioning of $\mathrm{Ce}$ metal as a surrogate for plutonium. This was in addition to the $0.38 \mathrm{wt} \%$ of Ce oxide present in the M60 feed mixture. As later discussed, the plutonium 
surrogate (Ce) metal oxidized and partitioned to the slag. No Ce was detected in the metal phase.

The $\mathrm{MgO}$ hearth was determined to have been dissolved early in the baseline test series by the siliceous, acidic S60 slag. The increased hearth capacity, consequently led to daily carryover of reduced metals and slag in the region below the metal tap hole. The hearth bricks were not, however, affected.

\subsection{Arc Melter System Performance .}

The performance of the sealed melter system and system components was evaluated during the shakedown test, the preheat, and the baseline tests. Primary subsystems included the feed system, the furnace, and the APCS.

\subsubsection{Feed System Performance}

Operation of the feed system, including the baghouse and ducting for collecting fugitive dust within the building, was satisfactory and as expected. The feed system was designed for measuring, controlling, and delivering aggregate and soil-type materials of sizes less than 1 inch diameter to the furnace. The feed system was sealed from the receiving bin onward to control fugitive dust release. A rotary air lock seal downstream of the metering bin minimized air inleakage through the feed system. Segregation of aggregate, granular, and powder materials is a frequent occurrence in handling equipment due to vibration and stirring of augers. Larger-sized and less dense materials tend to float to the surface while denser and smaller particles tend to sink to the bottom of processing hoppers that contain these kinds of materials. The feed mixtures, especially the M60 metals mixture, contained additives of various particle sizes and densities. Efforts made to minimize segregation in the feed hoppers included adding the feed mixtures one barrel at a time and achieving near emptiness in the receiving bin before adding another barrel. Samples were collected periodically from the metering bin. Bulk density measurements showed little variation during the baseline tests.

There were no significant failures of measurement, control, or feed equipment during the baseline tests. Dust generation was minimized by using a 2-barrel-capacity charge hopper for charging the receiving bin and to serve as a mixing vessel for preparing the modified furnace feeds. There was no jamming of the feed screws that was observed occasionally during the earlier ASME ash tests. This was prevented in the baseline tests by using feed materials of low aspect ratio that were smaller than one-half inch in diameter. On the first day of the test program, the feed tubes bridged with feed material after several hours of operation. This occurred apparently when furnace moisture, evolved from the feed material, were forced back into the feed tubes during positive pressure fluctuations and condensed. The dampened feed material in the feed tubes adhered to the tube walls and bridged. The furnace feed and power had to be shut down while the feed tubes were cleaned out before continuous feeding was resumed. The furnace positive pressure fluctuations occurred primarily when sample ports in the offgas system were temporarily opened for offgas and particulate measurements. This feed blockage occurrence was prevented on subsequent test days by reducing the frequency and duration that sample ports were open, and by increasing furnace draft. Occasional inspections of the feed tubes confirmed that these measures were effective and no additional blockage occurred. 
Feed rate measurement and control were generally very reliable. The two variable-speed delivery screws used to meter the feed material into the furnace were calibrated for feed rate. Feed material density measurements were made, by which the instantaneous feed rate measurements were corrected during the tests. The mass of material fed during each test day averaged from the calibrated feed screws typically agreed to within $10 \%$ with weight measurements for all of the processed barrels as shown in Table 3-2. Metering variations greater than $10 \%$ occurred occasionally when the feed hopper was purposely allowed to run empty to clear feed material from the feed system, when the auger feed rate was less than the gravimetric feed rate. For two test conditions, the auger feed rate was much higher than the gravimetric feed rate. The daily average feed input masses and average feed rates were determined from the weight measurements rather than from the feed screw measurements.

Water-cooled feed tubes were installed prior to the test series so the feed material could be delivered through the feed tubes to within 18 in. of the top of the melt. During the earlier ASME test series, the steel feed tubes were not water cooled and were melted off completely to the furnace roof during early test operations. For the baseline test series, the feed tubes easily tolerated the high temperatures in the furnace at cooling water rates of $20-25 \mathrm{gpm}$. The maximum temperature rise of the feed tube cooling water was $15^{\circ} \mathrm{C}$.

Following the baseline tests, the feed tubes were removed, inspected, and cleaned. A light, fluffy deposit about $1 / 2$ in. thick covered the entire length of the tubes while the tubes were in the furnace, but most of that material was scraped away as the tubes were removed through the roof ports. It is likely that the light, fluffy deposit was an effective thermal insulator during the melting tests. The very thin layer (less than 0.1 inches) of material remaining on the feed tube surface consisted largely of corrosion products (Figure 3-1), which were readily removed by sand blasting. The thin corrosion layer did not penetrate significantly into the steel of the feed tubes.

Feed tube corrosion was not problematic in any way during the operating time of 66 hours for the shakedown test, the preheat day, and the semi-continuous tests. Some corrosion of the feed tubes is unavoidable due to the high plenum gas temperatures and acid-forming chlorides and sulfates in the furnace gas. Corrosion observed in the baseline tests may be conservatively high. The various test conditions may have been more severe than continuous production operations would be due to the repeated heating and cooling cycles during the semi-continuous tests. Furnace gas temperatures were high during each day but were allowed to cool during the night. Corrosion in thermal processes is typically less severe when such temperature cycling is limited. Long-term corrosion may be very low in a continuous operation following the initial buildup of a relatively inert insulating layer of corrosion products. Longer term corrosion resistance, however, is an issue requiring further evaluation for a production arc melter waste processing facility.

By using the feed tubes to deliver the feed material to the top of the melt, a "cold top" of unmelted feed material on the surface of the molten melt was successfully maintained. Also, feed dust generation was minimized. The cold top and the reduced dust generation resulted in far less dust entrainment and fume generation in these tests compared to results of the ASME ash tests. In the ASME ash tests, the feed material fell several feet from the entry ports at the roof of the furnace to the surface of the melt since the uncooled feed tubes had been melted off to the level of the furnace roof during early operations. 
Table 3-2. Calibrated auger feedrate compared to gravimetric feedrate.

\begin{tabular}{|c|c|c|c|c|c|c|c|c|c|}
\hline \multirow[b]{2}{*}{ Feed type } & \multirow[b]{2}{*}{ Test day } & \multicolumn{4}{|c|}{ Auger feedrate $(\mathrm{lb} / \mathrm{hr})$} & \multicolumn{3}{|c|}{ Gravimetric feedrate $(\mathrm{lb} / \mathrm{hr})$} & \multirow[b]{2}{*}{$\begin{array}{c}\text { Feedrate } \\
\text { difference (\%) }\end{array}$} \\
\hline & & $\begin{array}{c}\text { Operating } \\
\text { time (hr) }\end{array}$ & Maximum & Minimum & $\begin{array}{l}\text { Average } \\
\text { feedrate }\end{array}$ & $\begin{array}{l}\text { Operating } \\
\text { time (hr) }\end{array}$ & $\begin{array}{c}\text { Total } \\
\text { feed (lb) }\end{array}$ & $\begin{array}{l}\text { Average } \\
\text { feedrate }\end{array}$ & \\
\hline$\overline{S 60}$ & $7 / 19 / 93$ & 9.02 & 1,613 & 325 & 966 & 9.25 & 9,806 & 1,060 & 8.85 \\
\hline N80 & $7 / 21 / 93$ & 4.62 & 1,581 & 294 & 954 & 4.20 & 4,601 & 1,095 & 12.87 \\
\hline N80-Mod & $7 / 21 / 93$ & 4.13 & 2,058 & 260 & 881 & 4.30 & 3,778 & 879 & 0.28 \\
\hline M60 & $7 / 23 / 93$ & 4.55 & 1,685 & 110 & 1,061 & 3.10 & 3,263 & 1,053 & 0.79 \\
\hline N80-IV-Mod & $7 / 23 / 93$ & 2.87 & 2,048 & 1,002 & 1,716 & 4.60 & 3,403 & 740 & 132 \\
\hline Total average & & 5.47 & 1,762 & 414 & 1,119 & 5.70 & 5,454 & 979 & 27.1 \\
\hline
\end{tabular}

Notes:

1. Auger feedrate was obtained from the data acquisition system.

2. Gravimetric feedrate computed as total feed divided by the operating time.

3. Feedrate difference (\%) is the percent difference between the auger feedrate and the gravimetric feedrate. 



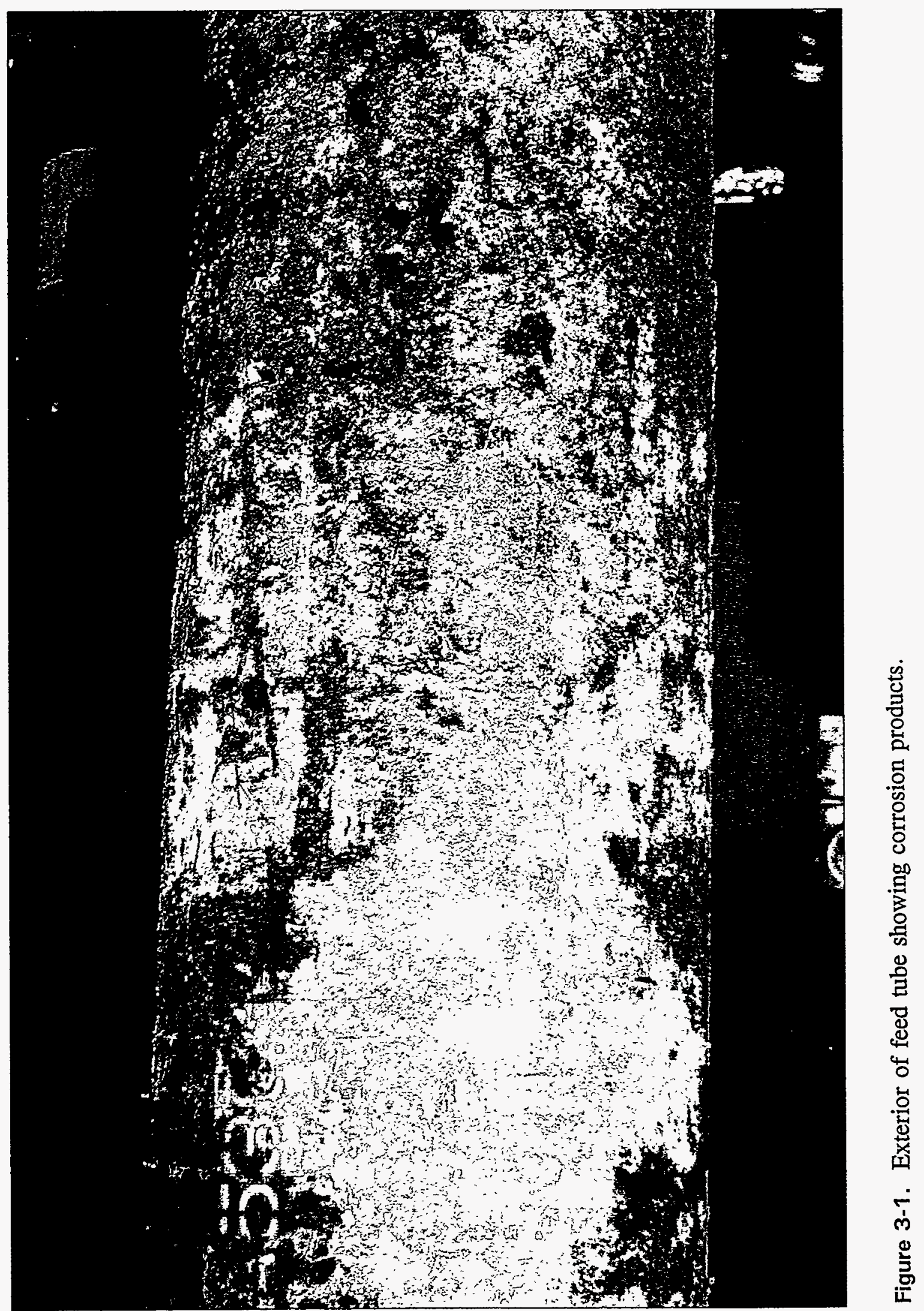


- 


\subsubsection{Furnace Performance}

Continuous melting of feed material was successfully demonstrated in the furnace. Procedures for starting, operating, and tapping were established and demonstrated. Cold top operations were routinely achieved. The furnace power controls, seals, refractory and cooling systems performed satisfactorily. Operating parameters were all well within design conditions and typical of industrial arc furnace practices. Problems that were encountered were:

- A fuse failed in the electrode control circuit. This was resolved by operating the electrode in manual instead of automatic operation until the fuse was replaced.

- Tapping the highly viscous slags through the water-cooled copper slag tapping fixture was difficult. $\mathrm{RWMC}$ soil melts at about $1,250^{\circ} \mathrm{C}$, but its high viscosity precluded tapping at temperatures below about $1,600^{\circ} \mathrm{C}$, with $1,800^{\circ} \mathrm{C}$ needed to achieve fluidity for continuous tapping. Additions of mill scale increased the fluidity somewhat, but did not significantly lower tapping temperatures. The maximum slag temperature recorded during melting and continuous tapping was $2,000^{\circ} \mathrm{C}$, which is considered unnecessarily high, can cause increased metals volatilization, and can cause refractory concerns. The fluidity of the slag was slightly improved by the mill scale, but additional improvement was needed. Limestone $\left(\mathrm{CaCO}_{3}\right)$ or pebble lime $(\mathrm{CaO})$ was also added and more effectively reduced the slag viscosity for improved tapping at lower temperatures. Other possible solutions to aid slag tapping could include increasing the diameter or reducing the length of the water-cooled, copper, tapping fixture (to reduce slag cooling while passing through the fixture) or further revising the slag tapping design.

- Dissolution of the furnace hearth refractory $(\mathrm{MgO})$ occurred during some of the test conditions, especially the early S60 test, due to high hearth and slag temperatures, and a slag composition that was very corrosive for the $\mathrm{MgO}$ cast refractory. Prior soil contamination in and under the cast refractory due to localized patching over older, used refractory and soil residues may have also contributed. The underlying Ruby ( $90 \%$ alumina, $\mathrm{Al}_{2} \mathrm{O}_{3}$ ) brick readily withstood the furnace and slag conditions during the duration of the testing. The refractory dissolution lowered the bottom of the hearth below the level of the metal tap hole, so some material remained continuously in the furnace from one test to another, even after tapping the entire melt through the metal tap hole.

3.2.2.1 Startup. The furnace was started each test day after feeding in several hundred pounds of feed material into the furnace. Since the cold feed material had very high electrical resistance, a triangular course of crushed graphite (from graphite electrode material) and steel turnings was placed on the surface of the feed material in the furnace. Steel turnings alone were not suitable owing to a tendency to cause an open circuit on arc initiation. Crushed graphite, or a duplex layer of graphite and steel turnings, was satisfactory. The latter was used for the baseline tests because of momentarily high $\mathrm{CO}$ and temperature peaks observed in the offgas during startup when using graphite only. Lower $\mathrm{CO}$ and temperature spikes resulted from using the layered graphite and steel turnings, due to smaller amounts of graphite or dissolution and slower oxidation of some of the $\mathrm{C}$ in the melted steel turnings. This conductive starting material was placed so that the three electrodes could contact the graphite/steel starting material when lowered 
onto the surface of the feed material. With power applied to the electrodes, arcing to the graphite/steel mixture quickly initiated melting of the feed material. After a few moments, sufficient feed material was molten (with significantly reduced conductivity in the molten phase) to enable continued arcing and initiation of continuous feeding to the furnace.

3.2.2.2 Process Operations. Following initiation of a molten slag, the feed rate and power levels were quite rapidly increased to steady operating levels. Trend charts showing feed rate and power level for each test are shown in Appendices A-F. For each test day, power was typically increased to around $400 \mathrm{~kW}$ within just a few minutes after startup. The feed rate was typically increased to over $500 \mathrm{lb} / \mathrm{hr}$ within 10 minutes after the power was increased to about $400 \mathrm{~kW}$. Typically within 1-2 hours, the power levels and feed rates were increased to operating levels of up to $600 \mathrm{~kW}$ and up to $1,325 \mathrm{lb} / \mathrm{hr}$. The highest short-term power levels and feed rates that were demonstrated ranged to $800 \mathrm{~kW}$ (maximum transformer output) and 2,000 lb/hr. Operation on different voltage taps $(\mathrm{A}, \mathrm{B}, \mathrm{C}$, or $\mathrm{D})$ for providing phase-to-ground voltages ranging from 192-134 V was demonstrated. The phase-to-ground voltage was established by operating on one of the taps A-D. Then the rheostat was adjusted for the desired current level. The current level was the set-point for the automatic electrode positioning controller. When the automatic controller reads actual current as below the set-point, the electrodes were automatically lowered slightly into the furnace for closer contact with the melt (reduced resistance) and higher current. When the current exceeded the set-point, the electrodes were slightly raised by the controller to reduce contact with the melt (increased resistance) and thereby reduce the current. The most stable operation for the feed materials processed was typically achieved using voltage tap B or C, with phase to ground voltage ranges of 168 and $145 \mathrm{~V}$ respectively, with the rheostat set at $50-82$.

This operation was achieved with the electrodes penetrating slightly into the molten slag bath. In this mode of operation, there was little arcing; heat was generated by joule heating in the melt rather than by electric arc from the electrodes. Lack of an arc was indicated by the power wave-forms on an oscilliscope. These wave-forms were typically smooth curves rather than curves with sharp peaks.

The furnace was generally operated with a "cold top" of unmelted feed burden on top of the molten bath. The cold top was established by initially feeding in material at a rate sufficiently higher relative to the melting rate to produce a layer of unmelted feed material on the top of the melt. The ability of the feed tubes to deliver the feed material in a relatively quiescent manner to the top of the melt also contributed to the ease with which the cold top was established for all of the tests. The theoretical benefits from operating with a cold top include (a) reduced evolution of volatile toxic metals from the melt due to the cooling and refluxing effect of the cold top as volatile gases from the melt pass through the cold top, (b) slower, less violent heatup of feed materials (with reduced dust generation) as they add to the cold top rather than immediately fall into the high temperature melt, (c) cooler plenum gas and upper furnace surface temperatures due to the shielding effect of the cold top on radiation heat transfer from the melt, and (d) higher bulk slag temperatures for a given power input due to the thermal insulating effect of the cold top layer. Cooler plenum gas temperatures also reduce the formation of thermal $\mathrm{NO}_{\mathrm{x}}$ from oxidation of $\mathrm{N}_{2}$ in the furnace plenum. 
The presence of the cold top did indeed have significant effects. In comparison with the previous ASME tests where the cold top was not maintained, the particulate entrainment and gas temperatures in these baseline tests were indeed significantly lower. However, no quantitative correlations were established between the thickness of the cold top and the furnace outlet $\mathrm{NO}_{x}$ levels, the upper furnace refractory wall temperature, or the furnace outlet duct wall temperature. Apparently, from the existing data, the presence of any measurable cold top was as effective as many inches of cold top on the melt for achieving the above listed benefits. While the cold top thickness and related pool surface area covered should theoretically affect furnace temperatures, the measurement of the cold top depth under only one of the feed tubes was not sufficiently representative of the entire surface of the melt to reliably correlate to measured temperatures or other parameters. A more representative measurement method should be developed for subsequent tests to determine cold top depth and coverage.

During startup, furnace plenum temperatures quickly reached steady state levels while slag temperatures increased and the melt front moved out towards the furnace wall. Heatup of a completely cold furnace can take more than six to eight hours. For the baseline tests, a preheat day was used to allow near steady state temperatures to be achieved before the waste feed test processing series. Partial furnace cooldown at night was then overcome within the first two to four hours of heatup each subsequent test day.

Electrode consumption was reasonably low, averaging $11.9 \mathrm{lb} /$ ton of feed material, even though (a) the furnace operated in a relatively oxidizing mode, with oxygen levels at the outlet of the furnace ranging between 8 to $15 \%$ (dry basis), and (b) the electrodes were still exposed in the hot furnace after shutdown each test day, while no material was fed to the furnace. It is likely that electrode consumption compared to feed input would be even lower in continuous operation. The electrodes were not severely tapered. This has two important implications: (a) the electrodes were not severely attacked by hot gases in the furnace plenum during processing, and (b) oxidation of the hot electrodes within the furnace after feeding was stopped and power shut off (but while the furnace interior was still warm) was not severe. The relatively cool furnace gases (typically ranging from $300-700^{\circ} \mathrm{C}$ during operation) contributed to the low electrode consumption.

Plots of furnace pressure versus time are provided in Appendices A-E. The furnace operated at an average draft of -0.8 to +0.008 in. $\mathrm{H}_{2} \mathrm{O}$. The furnace draft was established by manually adjusting the speed of the ID fan. Initially, the furnace draft was set to be -0.1 to -0.2 in. $\mathrm{H}_{2} \mathrm{O}$, but in order to better control fugitive emissions and avoid back-pressuring gases into the feed system, the average draft was increased as the baseline tests progressed until the draft reached -0.8 in. $\mathrm{H}_{2} \mathrm{O}$. The higher draft provided better control of short-duration positive pressure excursions in the furnace. Such occasional pressure fluctuations of 0.1 to 0.5 in. $\mathrm{H}_{2} \mathrm{O}$ occurred largely due to temporarily opening sampling ports in the APCS for inserting and removing sample probes. This condition would not typically occur in a production waste treatment system, so such pressure fluctuations would not be expected.

Frequent, but smaller, furnace pressure variations have been attributed to variations in gas temperatures and variable gas generation rates due to periodic sluffing of feed material into the melt from the cold top. The amount of pressure fluctuation related to volatilization and material sluffing may be affected by the gas and melt temperatures, the furnace power input, and the feed 
composition. At higher temperatures and power levels, the pressure fluctuations from a given material sluff can be more extreme due to the more rapid heatup and evolution of volatiles in the sluffed material. The feed composition, particularly the presence of solids such as carbonates that evolve gases upon heating, also strongly influences the magnitude of pressure fluctuations due to sluffing. These effects were observed for the N80, N80-Mod, and the N80-IV-Mod tests. During the N80 test, the furnace operated stably with the phase-to-ground voltage setting of $168 \mathrm{~V}$ (transformer tap B). Furnace pressure fluctuations increased and electrode control became unstable during the N80-Mod test at the same phase-to-ground voltage setting (transformer tap) as for the N80 test. Furnace conditions were restabilized by reducing furnace voltage to $145 \mathrm{~V}$ (which reduced the furnace power). The furnace instability appeared to be related to the difference in the amount of volatile materials and particle sizes of the two feed mixtures. The main difference was the addition of finely divided limestone in the N80-Mod mixture, which increased the combined calcium, sodium, and potassium carbonates from 27 to $33 \%$, compared to the N80 mixture. The limestone in the N80-Mod test may also have affected the rheology of the feed material, resulting in more periodic slumping of cold top material into the melt and attendant rapid gas generation than for N80. For the later N80-IV-Mod test, pebble lime $(\mathrm{CaO})$ was used instead of limestone $\left(\mathrm{CaCO}_{3}\right)$. Furnace stability was improved, confirming the limestone as the source of instability during the N80-Mod test.

Almost all thermal systems, including furnaces, typically operate under slight negative pressure to prevent positive pressurization during pressure fluctuations. Even when well sealed, furnaces operating under negative pressure will experience some inleakage of "tramp" air. Avenues of normal air leakage into the furnace were (a) the feed tubes, along with the feed material flow, (b) seals around the three moveable electrodes, and (c) other entry points such as seals around the feed tubes. Air inleakage with the feed material through the feed tubes was minimized using a rotary valve in the feed system at the top of the furnace. Air inleakage through stationary seals in the joint between the furnace lid and the sidewalls, and between the feed tubes and ports in the furnace roof, was minimized by tightly packing and sealing these connections. Air inleakage around the electrodes was less easy to minimize because the seals had to be sufficiently loose to allow up and down movement of the electrodes without binding.

This air inleakage provided oxygen for oxidizing components in the feed materials such as trace amounts of organic materials, chlorides, reduced metals, and reduced sulfur. With the small amount of organic and reduced (unoxidized) materials present in the feed mixtures the amount of air inleakage was sufficient to provide an oxidizing atmosphere in the furnace plenum.

The amount of reactant air (or oxygen) supplied to the furnace plenum will need to be increased in future planned tests when feeding materials with significantly higher amounts of fixed carbon (such as solidified organics, wood, graphite waste, etc.) to oxidize the carbon and remove it from the melt. Maximum levels of carbon in the cooled slag (glass/ceramic), that are compatible with acceptable immobilization performance of metals and radionuclides in the slag, are not yet well established. Also, excess carbon buildup in the furnace may impair electrical performance by short circuiting the arc and joule heating pathways. Minimization of carbon in the slag via complete oxidation is therefore desirable.

Some of the feed mixtures exhibited significant gas evolution, primarily through water vaporization (moisture content and also water of hydration) and decomposition of carbonates and 
sulfates to $\mathrm{CO}_{2}$ and $\mathrm{SO}_{2}$. The measured mass of feed material that evolved as gas from the melt averaged $13 \%$ by weight. The furnace and APCS readily tolerated these amounts of volatilization, although the gas flow (air inleakage and evolved gases) from the furnace tended to entrain the less dense and finer feed material particles.

Solid material captured in the furnace offgas system resulted from a combination of (a) the entrainment of feed material fines, and (b) volatilization of materials from the high temperature melt followed by condensation in the APCS. Comparison of the solid material captured in the fume traps and the baghouse with the total solid and condensible particulate collected in the MMT samples indicates that essentially all of the volatilized material condensed and was captured as particulate in the APCS. Volatilized matter may homogeneously condense as very fine fume particles in the gas flow or heterogeneously condense on the surfaces of entrained feed particles in the gas flow, or on the interior surfaces of the furnace and the APCS. Total particulate, by definition, includes all entrained feed material, condensed fume and volatilized material that has not yet condensed to solid form, but would do so at ambient conditions. The total particulate measured in the baseline tests APCS flow averaged $2.0 \%$ of the feed material.

The total particulate concentration (13-38 $\mathrm{gr} / \mathrm{dscf})$ in the furnace offgas was determined from MMT measurements made downstream of the air dilution quench section. These particulate concentration levels are high compared to other combustion equipment, such as controlled-air incinerators that are designed and operated to minimize particulate entrainment. However, the levels are not high compared to fluidized bed combustors and aggregate processing equipment such as sieves and crushers where significant fines generation exists. Good APCS designs, commonly used for controlling such high concentrations of particulate, include cyclonic separators to remove coarse material, followed by a baghouse to efficiently remove the fine particulate. The USBM arc melter facility APCS uses this approach, with the added assurance of a HEPA filter for redundant, high efficiency, particulate filtration.

Continuous slag tapping was achieved when the slag viscosity was sufficiently low (fluid) to enable flow through the slag tap hole. Slag viscosity is a function of slag temperature and composition. Higher slag temperatures (which lowers viscosity) were required for continuous tapping when the slag composition basicity ratio was significantly less than unity. The basicity ratio is the molar ratio of total basic oxides to total acidic oxides in the slag. The basicity ratio is a useful indicator of slag viscosity, melting temperature, and refractory compatibility. A slag with basicity ratio less than 1 is considered acidic, greater than 1 is basic. Acidic slags are more viscous. With high proportions of soil in the surrogate waste mixtures, the resultant slags had high silica $\left(\mathrm{SiO}_{2}\right)$ levels and were highly acidic (viscous). Appendix $\mathrm{R}$ contains additional background discussion. High silica content in the cooled slag product (glass/ceramic) is desirable for low leachability, high strength, and durability.

The water-cooled copper tapping fixture performed successfully over a wide operating range, from a tapping rate minimum of about $800 \mathrm{lb} / \mathrm{hr}$ to a maximum in excess of $2,000 \mathrm{lb} / \mathrm{hr}$. The tapping fixture doesn't assert any active control over tapping rate. It simply acts as a port, on or off, and is designed to be resistant to erosion and corrosion under repeated usage. The flow rate is fixed by slag viscosity, tap fixture inside diameter and length, and the static pressure head from the height of molten slag above the tap hole. Slag viscosity is determined by temperature and composition and the static pressure head is determined by feed rate versus tap flow rate. The 
water cooled tap fixture cools the slag to some extent as it passes through. The slag temperature was continuously measured at the slag tap (during tapping) using an external infrared pyrometer. Once slag tapping was initiated, it was maintained continuously by maintaining existing slag temperature and feed to the furnace.

Many components of the furnace system were water-cooled to ensure safe operation and provide better material resistance to the high heat loads. These included the power supply equipment (transformer, electrode arms, cables, and clamps), feed tubes, the furnace roof and sidewalls, the roof seal, the slag tapping fixture and launder, and the metal tap.hole. The cooling system operated well during the test program. Water flowrates and outlet temperatures were measured separately for each cooled component during furnace operation. Flowrates ranged around $25 \mathrm{gpm}$ for each cooled component, and the water temperature increase was typically less than $6^{\circ} \mathrm{C}$ except for the feed tube cooling water, which had a temperature increase of up to $15^{\circ} \mathrm{C}$.

Thermal conditions in the furnace were indicated during operation using thermocouples at various locations in the furnace. Temperature measurement in electric furnaces is difficult for many reasons, including thickness of the refractory, high temperatures, high dust levels, electrical continuity and grounding, radiant heat transfer, and growth of deposits that shield thermocouples. This test furnace was no exception, but was instrumented with several thermocouples where possible. Locations and temperatures observed were:

- Hearth refractory temperature ( $T_{7}$ on Channel 7 of the DAS). Since the thermocouple (TC) was embedded in the grout sealing the metal tap hole, this measurement was not expected to be the temperature at the interface of the hearth refractory and the melt, but was an intermediate temperature between the interface temperature and the steel shell temperature. Typical temperatures at startup were $35-75^{\circ} \mathrm{C}$, and temperatures typically increased to $115-450^{\circ} \mathrm{C}$ by the end of each test day. This TC was destroyed at the end of each test day when the metal tap hole was opened to drain the furnace. It was then replaced prior to the next test.

- Furnace bottom shell outside temperature ( $\mathrm{T}_{8}$ on Channel 8 of the DAS). This TC was used to monitor the shell temperature at the furnace bottom, where the surface was not cooled by the water curtain cooling the sidewalls. Typical temperatures at startup were $90-150^{\circ} \mathrm{C}$, and temperatures typically increased to $190-315^{\circ} \mathrm{C}$ by the end of each test day.

- Sidewall refractory temperature $\left(\mathrm{T}_{6}\right.$ on Channel 6 of the DAS). This TC was near the inner surface of the wall refractory, and was frequently covered with melt material deposits. Since the TC was usually covered with deposits, it did not indicate the temperature of the inner surface of the refractory, but an intermediate temperature between the refractory surface temperature and the water-cooled steel shell. Typical temperatures at startup were $50-115^{\circ} \mathrm{C}$, and temperatures typically increased to $150-500^{\circ} \mathrm{C}$ by the end of each test day.

- Furnace offgas outlet duct wall temperature $\left(\mathrm{T}_{2}\right.$ on.Channel 2 of the DAS). This TC was located in a small access port almost flush with the inner wall of the steel duct, just downstream from the water-cooled furnace roof connection. This temperature was an 
intermediate temperature between the offgas temperature and the temperature of the water-cooled section.

The measured temperatures indicate that the water cooling was effective in thermally protecting the furnace sidewall refractory and the furnace shell. Post test observations showed that there was no thermal damage to the steel shell or the sidewall refractory.

Bulk slag temperature readings were taken at a single location in the furnace slag melt by inserting a sacrificial platinum-rhodium TC through a furnace roof port and into the slag near the melt center. These single manual TC readings were taken prior to attempting tapping and they indicate lower temperatures due to lower power conditions at the time of measurement. Later slag tap temperatures measured by an infrared pyrometer are higher since, upon attempted tapping, insufficient slag fluidity was observed and power levels were raised to increase slag temperature to achieve steady tap flow. Analytical modeling to relate the various temperature readings taken at different locations and conditions to the slag temperature is being developed, but is not presently available. Therefore, the infrared pyrometer readings are believed to be the best indication of slag temperatures for the baseline tests.

Additional and more direct temperature readings within the furnace are needed. A proposed method using a millimeter wave radiometer is currently under development at MIT that may be useful for future tests. In the interim, additional TCs are needed as are analytical heat transfer models to properly interpret $\mathrm{TC}$ readings.

3.2.2.3 Furnace Refractory Performance. The hearth was constructed of $\mathrm{MgO}$ cast refractory with underlying Ruby bricks. Even though the hearth temperature measurement did not indicate temperatures sufficiently high for melting the $\mathrm{MgO}$ cast refractory hearth, significant dissolution of this refractory occurred. Mass balances for $\mathrm{MgO}$ show that a minor amount (10 lb) of refractory dissolved into the melt during the soil shakedown test, and the remainder of the $\mathrm{MgO}$ refractory $(910 \mathrm{lb}$ ) was dissolved during the S60 and S60-IV tests. Dissolution occurred due to contact with high temperature slag that was very corrosive for the $\mathrm{MgO}$ cast refractory. Prior soil contamination in and under the cast refractory (from localized repair of the original refractory) may have also physically contributed to the hearth erosion by weakening the refractory and enabling penetration of slag into cracks. The Ruby bricks used to line the steel shell were undamaged and showed no evidence of contact with or attack by molten slag. A metal heel remained for all subsequent tests and may have aided in protecting the bottom brick from high temperature slag attack. Essentially all of the $\mathrm{MgO}$ refractory was dissolved during the S60 test day. It is clearly necessary to evaluate the compatibility of alternative hearth refractory materials with the acidic slags produced for future applications testing. Operation with a metal heel as a hearth protective measure should also be considered.

The refractory dissolution lowered the bottom of the hearth below the level of the metal tap hole. Therefore some material remained in the furnace from one test to another, even after tapping the entire melt through the metal tap hole. The estimated slag carryover from test to test following the $S 60$ test was $600 \mathrm{lb}$.

3.2.2.4 Localized Iron Reduction. High power input to increase slag temperature and decrease slag viscosity resulted in the carbothermic reduction of iron oxide to metal during several 
of the tests. Viscous (high silica) slags are susceptible to localized high temperature reduction of metal oxides by electrode carbon under conditions of high power input. This occurred during the baseline tests. The high energy density near the electrodes and the inability of the viscous, low conductivity slag to dissipate heat led to high local temperatures and reduction of some of the iron oxide by oxidation of some of the carbon in the electrodes. Material balances in Section 4 indicate that iron was produced in this manner in all tests but the M60 test, in which elemental Fe was fed to the furnace and melted directly. Table 3-1 shows the amount of metal product provided by this reduction in each test. Metal was not observed, however, either while tapping the hearth or in the tapped slag ingots after cooling. The metal was retained within the furnace hearth and carried over to each succeeding melt. During the baseline tests, following dissolution of the entire $\mathrm{MgO}$ hearth, there was plenty of room in the furnace below the metal tap hole for this reduced metal to reside.

In the soil shakedown test, when significant $\mathrm{MgO}$ dissolution did not occur, the metal was also not tapped from the metals tap hole. In this case the reduced metal present on the hearth was not molten at the time of furnace draining. It is not unusual for reduced or melted metal to remain on the hearth as a semi-consolidated agglomeration of prills if the temperature of the hearth does not exceed the melting temperature of the metal. The short time devoted to the shakedown test, together with a very viscous slag having poor thermal conductivity, renders it likely that the metal on the hearth was not molten when the hearth was tapped. Solid metal on the hearth at the end of the melting test equates to low hearth temperature and also explains the absence of significant dissolution of the hearth by the slag.

\subsubsection{APCS Performance}

The APCS was designed to cool the hot furnace offgases and control furnace particulate emissions while minimizing fouling of the ductwork from deposited solids. Evaluation of the offgas emissions (both gaseous and particulate) and system performance was done using measurements and analyses of gas temperatures, velocities and flowrates, static pressures, gas composition, total particulate, and particulate composition. Without exception, the APCS performed as designed.

3.2.3.1 Offgas Cooling and Accretion Control. Hot offgas exited from a port in the roof of the furnace through a water-cooled duct that connected to the temperature quench section. The offgas was cooled by dilution with ambient air in the quench section. The average temperature difference between the furnace outlet and the inlet to the baghouse was $350^{\circ} \mathrm{C}$ for all runs except $\mathrm{M} 60$, where the temperature difference was approximately $1,040^{\circ} \mathrm{C}$. The $\mathrm{M} 60$ runs produced higher overall temperatures than any of the other runs.

With a design dilution factor (ratio of the quench outlet flowrate compared to the furnace outlet flowrate) of 5:1, the temperature quench section had the capacity to cool the furnace offgas from over 900 to $200^{\circ} \mathrm{C}$, the maximum temperature for preventing thermal damage of the bags in the baghouse. Baghouse inlet temperatures never exceeded the $200^{\circ} \mathrm{C}$ limit except for a few moments at startup on the $\$ 60$ test, when oxidation of the graphite starting material in the furnace, and possibly oxidation of resultant $\mathrm{CO}$ in the offgas, caused high offgas temperatures. Temperature excursions at startup were less severe on successive test days due to the use of less 
graphite starting material, and possibly some dissolution of some of the starter graphite in the molten starter iron.

During operation, there was no perceptible buildup of accretions in the furnace outlet duct, the wind box for the quench section, or the horizontal ductwork and heat exchange section leading to the baghouse. Post-test inspection of these sections verified only a minimal dust layer on the inside surfaces of the APCS equipment and duct. This minimal deposition was very much lower than rapid deposition and consequent duct blockage observed during the previous ASME municipal incinerator ash vitrification tests. Differences between the BWID baseline tests and the ASME ash tests that could have contributed to the reduced deposition include:

- Different particle sizes of the feed mixtures-the municipal incinerator ashes were 8-75 wt\% less than 100 mesh $(150 \mu \mathrm{m})$ compared to around $3 \%$ less than 100 mesh for the soil (based on measured particle sizes for soil at the INEL Test Reactor Area Warm Waste Pond, several miles from the RWMC). ${ }^{10}$

- Lesser amounts of potentially fouling elements in the feed mixtures-Potentially fouling elements include $\mathrm{Cl}, \mathrm{Na}$, and $\mathrm{S}$. Carbon can also contribute to fouling if present as soot, high-molecular weight oils and tars that can condense on cooler APCS surfaces. There was very little organic carbon in the surrogate waste mixtures, and organic carbon was present only as trace amounts of organic matter in the soil. Carbon levels in the municipal incinerator ashes were $3.8-16.1 \%$, and much of this carbon was likely organic carbon that could form soot or other condensed compounds in the APCS. Cl, $\mathrm{Na}$, and $\mathrm{S}$ in the BWID surrogate waste mixtures were below $1.3 \%, 5.3 \%$, and $1.4 \%$ respectively. $\mathrm{Cl}, \mathrm{Na}$, and $\mathrm{S}$ in the municipal incinerator ashes were up to $20.2 \%, 3.1 \%$, and $4.1 \%$ respectively.

- Different operating conditions-furnace gas temperatures were higher during the municipal incinerator ash tests, and oxygen levels from air leakage into the furnace atmosphere were maintained under $5 \%$ using $\mathrm{N}_{2}$ blanket gas. This more reducing condition during the municipal incinerator ash tests likely increased the propensity for soot, tar, and oil formation and condensation, and also increased the formation of condensible chlorides and sulfur compounds that would have been oxidized under more oxidizing conditions. A cold top could not be maintained on the melt for the municipal incinerator tests. The cold top during the BWID baseline tests reduced volatilization of condensible metals, and also reduced gas temperatures in the plenum by minimizing thermal radiation from the melt.

- Recent modifications-Several modifications were made to the furnace and offgas system following the ASME tests. These included a mechanical scraper at the outlet of the furnace, the use of air dilution to rapidly quench the offgas and increase entraining flow velocities for particulate condensed and present in the ductwork, and two fume traps. The furnace outlet duct was water-cooled steel, and the mechanical scraper was used to physically scrape off any deposits on the cooled wall. The scraper was used less and less during the baseline tests, because no deposits built up on the cooled surface. The cooled surface may have tended to prevent the formation of strong bonding between potential particulate deposits or sticky condensates and the surface. 
Rapid cooling of the offgas to form solid particulate in the temperature quench section, coupled with high flow velocities and rapid mixing, is believed to have minimized condensation and deposition of solid material on the duct surfaces. The added dilution air also increased gas velocities and minimized opportunity for solids deposition in the downstream ductwork. Gas velocities in the 6-in. diameter APCS ductwork typically exceeded $50 \mathrm{ft} / \mathrm{s}$, high enough to maintain significant particulate entrainment. Typical duct velocities for particulate laden offgas streams range in thermal processes between $10-60 \mathrm{ft} / \mathrm{s}$.

The furnace outlet offgas temperatures were measured periodically during the demonstration tests using a thermocouple inserted into the offgas stream through a port in the furnace outlet duct. The furnace outlet offgas temperatures were also calculated using an energy balance and the gas temperature measured downstream of the temperature quench section, the temperature of incoming quench air, and the quench air flow rate (dilution factor). Furnace outlet offgas temperatures were around $300-700^{\circ} \mathrm{C}$ for all baseline tests except the $\mathrm{M} 60$ test, which averaged almost $1,200^{\circ} \mathrm{C}$. Oxidation of elemental metals in the M60 feed mixture may have contributed to this increase in furnace gas temperature. Metals partitioning results for the M60 test show that essentially all of the aluminum (5.85\% of the feed), almost all of the chromium (1.7\% of the feed), over $90 \%$ of the copper ( $0.74 \%$ of the feed), approximately one-third of the iron ( $26.8 \%$ of the feed), and significant portions of the lead and zinc $(0.74 \%$ and $1.5 \%$ in the feed) oxidized and dissolved into the slag. 


\section{FATE OF FEED MATERIALS, METALS, AND TRU SURROGATE}

Arc melter vitrification of radioactive and mixed wastes can thermally separate heterogeneous waste mixtures into a few, more homogeneous, easily handled and characterized output streams. The TRU elements and most toxic metals can be permanently stabilized in the glass/ceramic product, which can have very durable, nonleaching properties suitable for shipping and permanent disposal. Other metals, such as recyclable structural metals, may be decontaminated of radionuclides and RCRA hazardous components and separated in the metal alloy product. Hazardous organic contaminants are thermally destroyed. Furthermore, arc melting can achieve substantial waste volume reduction and homogenization of product materials, resulting in direct cost savings for subsequent waste characterization, shipping, storage, and disposal.

Successful implementation of arc melter technology for vitrifying radioactive and mixed wastes depends not only on the production of a durable and nonleachable slag, but also the minimization and control of offgas, particulates in the offgas, and production of a metal product only if readily disposable or recyclable. Most critical is the control of hazardous and radioactive contaminants by oxidizing the hazardous organic matter and immobilizing the hazardous metals and radionuclides, especially the TRU isotopes, in the slag monolith. Much of the sample collection, sample analysis, and on-line measurements were made during the shakedown and baseline tests to evaluate the fate and partitioning of feed materials, toxic metals, and a TRU surrogate during the arc furnace vitrification process.

\subsection{Input and Output Mass Balances and Feed Material Partitioning}

Mass balances were performed to compare the mass of output products to the mass of input products and to identify partitioning (distribution) of the feed materials among the output products (slag, metal, and offgas). A simplified process model of the furnace is shown in Figure 4-1. Mass inputs to the furnace include the feed material, oxidation of the graphite electrodes, air inleakage with the feed material and through seals in the furnace and dissolution of the hearth refractory (as discussed in Section 3).

Heat was generated during the baseline tests primarily by joule heating in the slag between the electrodes rather than by electric arc from the electrodes. The electrodes slightly penetrated into the slag, as indicated by the power wave-forms and the related reduction of iron oxide in the high temperature zone near the electrodes.

Furnace mass outputs include the tapped glass/ceramic slag product, the tappable metal product, and the furnace offgas. The offgas includes the gases evolved from the melt, gaseous oxidation products, air inleakage into the furnace that mixes with the evolved gases, entrained feed dust, and volatilized materials (that condense upon cooling).

In normal operation, the feeding and slag tapping was continuous. A cold top was formed by initially feeding in material at a rate faster than the melting rate. The thickness of the cold top was maintained relatively constant by matching the feed rate and the melting rate. With the three electrodes arranged near the center of the furnace and the four feed tubes arranged outside the 

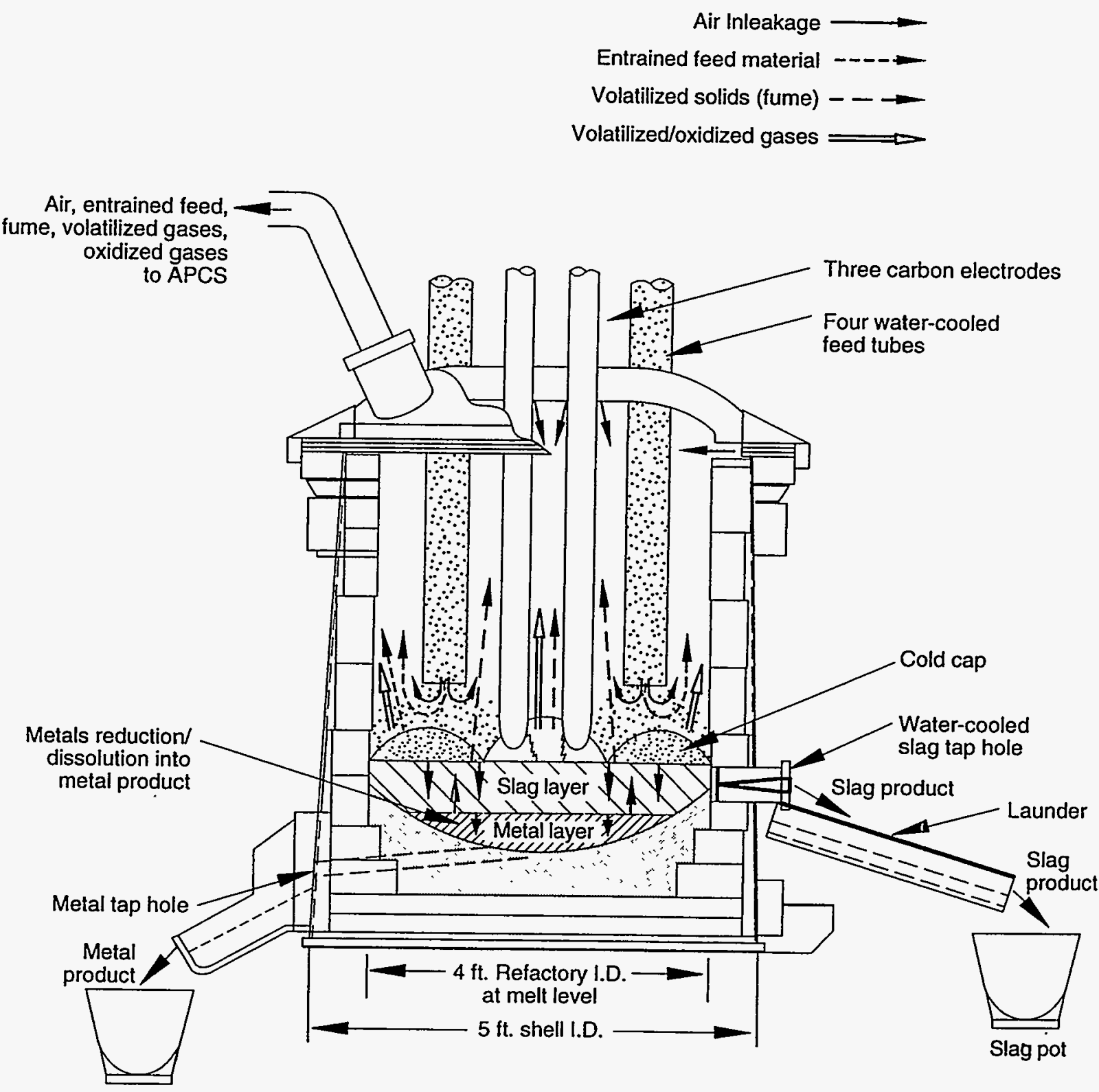

N94 0029

Figure 4-1. Simplified process model of the furnace. 
perimeter of the electrodes, unmelted feed material (cold top) probably built up under each feed tube. The buildup potentially was up to 18 inches, which was the distance between the level of the slag tap hole (top of the melt during continuous tapping) and the end of each feed tube. Cold top depth at one location beneath a feed tube was determined from measurement of surface locations using a manual depth plumb bob. Cold top depth ranged from 3 to 10 inches during all but the early startup portions of each test feed run.

Continuous cold top coverage may have occurred on the melt between the feed tubes and the furnace wall. The continuity of this coverage depends on the angle of repose and height of the cold feed material under each feed tube, crusting or agglomeration of the feed material, and turbulence of the melt. This could not be visually observed during operation due to dust generation in the furnace. Dust was generated from (a) direct entrainment of feed material in the air entering the furnace through the feed tubes with the feed material, (b) feed dust entrainment from the cold top in gases evolved from the melt, and (c) dust blown into the furnace gases from turbulence during rapid heating and from the arc zone.

Cold top coverage was unlikely within the perimeter of the three graphite electrodes in the center of the furnace. In this high temperature zone between the electrodes and in the melt directly below the electrodes, the high melting rate and turbulence may prevent the formation of an unmelted cold top. Temperatures in this central area may be much higher than needed for melting the feed material, due to relatively low thermal conductivity of the slag, on the order of 10 times lower than metal thermal conductivity. The localized redox conditions in this zone may also be more reducing in both the molten bath and the local gas above the bath, due to (a) limited ingress of oxygen-containing plenum air as gases evolve from the melt, and (b) consumption of available oxygen through oxidation of feed materials and the graphite electrodes.

If, as expected, a cold top effectively covers the melt outside the region of the electrodes, then metals volatilization from the melt between the feed tubes and the furnace wall may be minimized by the cooling and reflux filtering action of the cold top as hot gases and volatilized metals pass through the cold top. The greatest amount of metals volatilization may be from the small but high temperature area between the electrodes, where there is no cold top and local gas and melt temperatures are the highest. The relatively more reducing conditions in this area would be expected to increase the generation of more volatile reduced metal species including elemental metals and metal chlorides.

The total furnace mass balance is shown in Table 4-1. The percentage distribution of the total input mass among the output streams is shown graphically in Figures 4-2 (a) and (b). Overall mass balance closure (the value of the sum of output masses divided by the sum of the input masses) was 0.96 to 1.08 , and averaged 1.01. An average of $84 \%$ of the feed material stayed in the slag, $2.9 \%$ separated as metal product, and only $2.0 \%$ evolved with the offgas as total particulate. About $13 \%$ of the feed material volatilized as $\mathrm{H}_{2} \mathrm{O}, \mathrm{CO}_{2}, \mathrm{CO}, \mathrm{HCl}$, and $\mathrm{SO}_{2}$. These gases were from absorbed moisture, water of hydration, carbonates, small amounts of organic material, chlorides, and sulfates in the feed mixtures. This level of gas evolution was consistent with expectations based upon pre-test LOI measurements on the feed mixtures.

Total input mass partitioning to the slag and the offgas products varied little for all of the baseline test conditions. Most of the input mass reported to the slag phase. The total APCS 
Table 4-1. Total mass balance closure.

\begin{tabular}{|c|c|c|c|c|c|c|c|c|c|c|}
\hline \multirow[b]{2}{*}{ Test day } & \multirow[b]{2}{*}{ Feed type } & \multirow{2}{*}{$\begin{array}{c}\text { Total } \\
\text { input } \\
\text { feed } \\
\text { amount (a) } \\
\text { (lbs) }\end{array}$} & \multirow{2}{*}{$\begin{array}{c}\begin{array}{c}\text { Electrode } \\
\text { consumption } \\
\text { (lb) }\end{array} \\
\end{array}$} & \multicolumn{2}{|c|}{ Total slag tapped (b) } & \multicolumn{2}{|c|}{ Total metal product } & \multicolumn{2}{|c|}{ Total APCS solids (c) } & \multirow{2}{*}{$\begin{array}{c}\text { Total } \\
\text { moisture } \\
\text { evolution (d) } \\
\text { (lb) }\end{array}$} \\
\hline & & & & (lb) & feed mass) & (lb) & feed mass) & (b) & feed mass) & \\
\hline $7 / 19 / 93$ & $\mathbf{S 6 0}$ & 10,716 & 63.7 & 9,040 & 84.4 & 40 & 0.37 & 141 & 1.32 & 624 \\
\hline $7 / 20 / 93$ & S60-IV & 8,330 & 49.5 & 7,019 & 84.3 & 1 & 0.01 & 164 & 1.97 & 606 \\
\hline $7 / 21 / 93$ & N80 & 4,601 & 27.3 & 4,069 & $\cdot$ & 33 & 0.72 & 109 & 2.37 & 289 \\
\hline 7/21/93 & N80-Mod-1 & 3,778 & 22.5 & 3,341 & - & 28 & 0.74 & 122 & 3.23 & 222 \\
\hline & Daily total & 8,379 & 49.8 & 7,410 & 88.4 & 61 & 0.73 & 231 & 2.76 & 510 \\
\hline $7 / 22 / 93$ & N80-IV & 5,518 & 32.8 & 4,612 & $\cdot$ & 96 & 1.74 & 112 & 2.03 & 414 \\
\hline $7 / 22 / 93$ & N80-IV-Mod-1 & 4,986 & 29.6 & 4,168 & - & 86 & 1.72 & 126 & 2.53 & 257 \\
\hline & Daily total & 10,504 & 62.4 & 8,780 & 83.6 & 182 & 1.73 & 238 & 2.27 & 671 \\
\hline $7 / 23 / 93$ & $\mathrm{M} 60$ & 3,263 & 19.4 & 0 & $\cdot$ & 789 & 24.2 & 53 & 1.62 & 187 \\
\hline $7 / 23 / 93$ & M60-Mod & 3,403 & 20.2 & 5,224 & - & 0 & 0 & 68 & 2.00 & 136 \\
\hline & Daily total & 6,666 & 39.6 & 5,224 & 78.4 & 789 & 11.8 & 121 & 1.82 & 323 \\
\hline & Average & 8,919 & 53.0 & 7,495 & 83.8 & 215 & 2.94 & 179 & 2.02 & 547 \\
\hline & Totals & 44,595 & 265 & 37,473 & & 1,073 & & 895 & & 2,734 \\
\hline $\begin{array}{l}\text { a. Based } \\
\text { b. Calcul } \\
\text { c. From c } \\
\text { d. From o } \\
\text { process } \\
\text { feed m } \\
\text { e. CO anc } \\
\text { f. Assume } \\
\text { g. Calcul } \\
\text { h. Sum of } \\
\text { NC = Not }\end{array}$ & $\begin{array}{l}\text { weight of feed ma } \\
\text { m slag pots collect } \\
\text { ed catches in fume } \\
\text { noisture measurem } \\
\text { ing the metals/parti } \\
\text { is assumed to be } n \\
\text { from oxidation of } t \\
\text { SO2 evolves from } \\
\mathrm{Cl} \text { levels based on } \\
\mathrm{t} \text { mass/Sum input n } \\
\text { lated. }\end{array}$ & $\begin{array}{l}\text { dial plus } \mathrm{MgC} \\
\text { d } \\
\text { ap 1, fume tra } \\
\text { ts during off } \\
\text { ulate runs con } \\
\text { gligible. } \\
\text { graphite elec } \\
\text { e feed and tha } \\
\text { mass balance } \\
\text { ass. }\end{array}$ & $\begin{array}{l}\text { efractory dissol } \\
\text {, and baghouse } \\
\text { metals/particul } \\
\text { ared to the entir } \\
\text { des is assumed } \\
\text { le contribution } \\
\text { ssuming no pro }\end{array}$ & $\begin{array}{l}\text { runs, calc } \\
\text { est (less } \mathrm{m} \\
\text { be negligi } \\
\text { reduced su } \\
\text { ction of } \mathrm{Cl}\end{array}$ & $\begin{array}{l}\text { ated for entire test } \\
\text { ture contribution } \\
\text { although it is ac } \\
\text { ir species in feed }\end{array}$ & $\begin{array}{l}\text { ation in pr } \\
\text { ambient } \\
\text { ted for in } \\
2 \mathrm{~S} \text {, etc.) }\end{array}$ & $\begin{array}{l}\text { ortion with the rel } \\
\text { humidity). Wate } \\
\text { total mass balan } \\
\text { oxidize to } \mathrm{SO} 2\end{array}$ & $\begin{array}{l}\text { e amount } \\
\text { combusti } \\
\text { or all test } \\
\text { gligible. }\end{array}$ & $\begin{array}{l}\text { feed material } \\
\text { from } \mathrm{H} \text { in } \\
\text { s. }\end{array}$ & \\
\hline
\end{tabular}


Table 4-1. (continued).

\begin{tabular}{|c|c|c|c|c|c|c|c|c|}
\hline \multirow[b]{2}{*}{ Feed type } & \multicolumn{2}{|c|}{$\begin{array}{c}\text { Total carbon } \\
\text { dioxide evolution(e) }\end{array}$} & \multirow[b]{2}{*}{$\begin{array}{c}\mathrm{SO} 2 \\
\text { evolution( } \mathrm{f}) \\
\end{array}$} & \multirow[b]{2}{*}{$\begin{array}{c}\mathrm{HCl} \\
\text { evolution(g) }\end{array}$} & \multicolumn{2}{|c|}{$\begin{array}{c}\text { Total gaseous } \\
\text { evolution }\end{array}$} & \multirow{2}{*}{$\begin{array}{l}\text { Total } \\
\text { corrected } \\
\text { output } \\
\text { mass } \\
\text { (lb) }\end{array}$} & \multirow[b]{2}{*}{$\begin{array}{c}\text { Mass } \\
\text { balance } \\
\text { closure(h) }\end{array}$} \\
\hline & $\begin{array}{c}\text { As CO } \\
\text { (lb) }\end{array}$ & $\begin{array}{c}\text { As CO2 } \\
\text { (lb) }\end{array}$ & & & (lb) & $\begin{array}{c}\text { (wt. \% of initial } \\
\text { feed mass) }\end{array}$ & & \\
\hline$S 60$ & 38.4 & 239 & 112 & 86.1 & 1,100 & 10.3 & 10,321 & 0.96 \\
\hline S60-IV & 56.4 & 254 & 137 & 55.7 & 1,109 & 13.3 & 8,293 & 0.99 \\
\hline N80 & $\mathrm{NC}$ & $\mathrm{NC}$ & 0.052 & 0 & NM & $\mathrm{NC}$ & $\mathrm{NC}$ & $\mathrm{NC}$ \\
\hline N80-Mod-1 & 48.4 & 343 & 0.205 & 0 & 613 & 16.2 & 4,104 & 1.08 \\
\hline Daily total & $\mathrm{NC}$ & $\mathrm{NC}$ & 0.256 & 0 & $\mathrm{NC}$ & NC & NC & NC \\
\hline N80-IV & 54.1 & 506 & 1.48 & 0 & 976 & 17.7 & 5,796 & 1.04 \\
\hline N80-IV-Mod-1 & 31.6 & 241 & 0.63 & 0 & 530 & 10.6 & 4,910 & 0.98 \\
\hline Daily total & 85.7 & 747 & 2.11 & 0 & 1,506 & 14.3 & 10,706 & 1.01 \\
\hline M60 & 12.5 & 158 & 0.044 & 0 & 357 & 11.0 & 1,199 & NC \\
\hline M60-Mod & 16.0 & 201 & 0.042 & 0 & 353 & 10.4 & 5,645 & $\mathrm{NC}$ \\
\hline Daily total & 28.5 & 359 & 0.086 & 0 & 711 & 10.7 & 6,845 & 1.02 \\
\hline Average & 51.5 & 388 & 50.3 & 28.4 & 1,008 & 13.0 & 8,054 & 1.01 \\
\hline Totals & 257 & 1,942 & 251 & 142 & 5,038 & & 40,268 & 1.01 \\
\hline
\end{tabular}




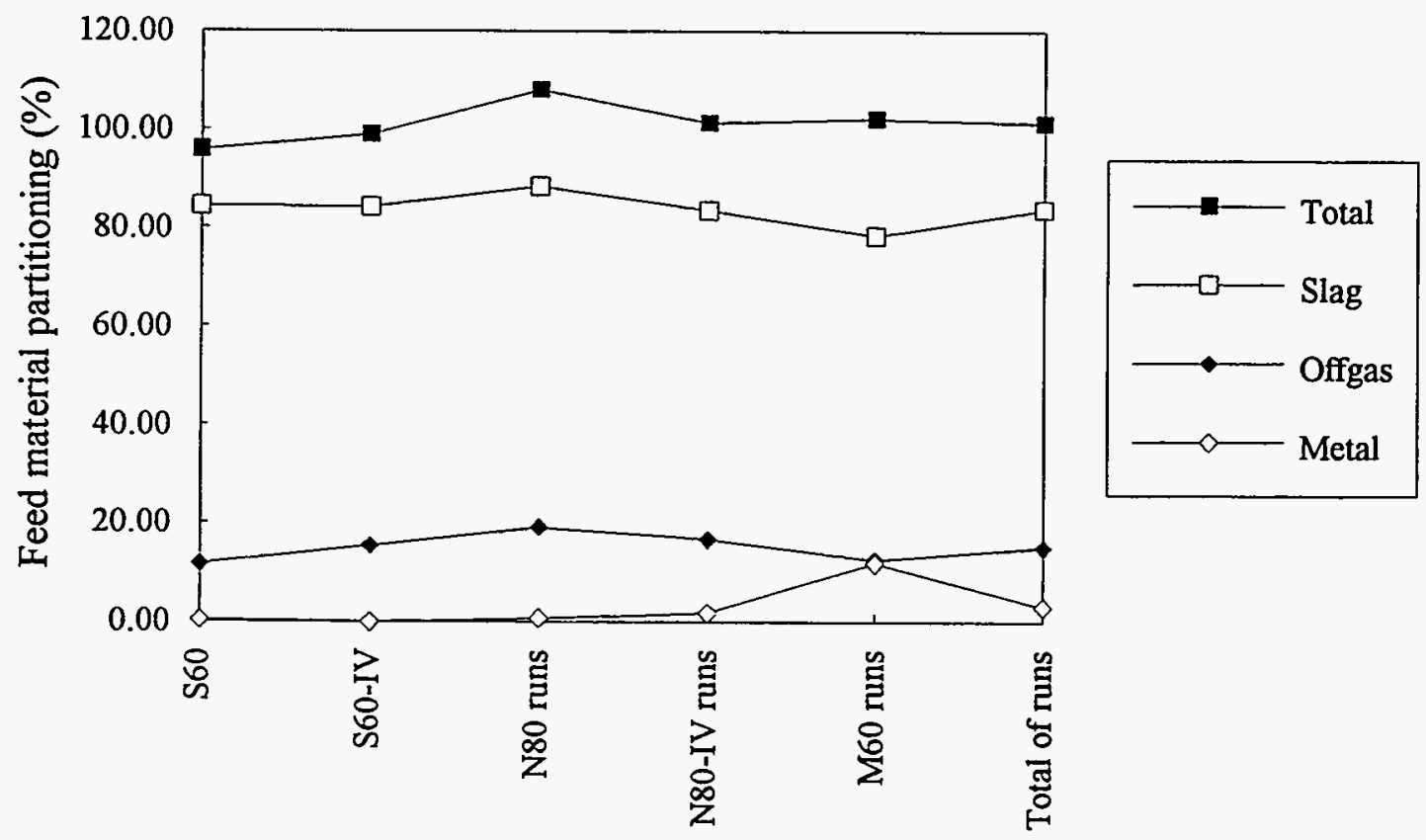

Figure 4-2 (a). Feed material partitioning to the output products [Total is the sum of the slag, metal, offgas, and APCS solids (from MMT)].

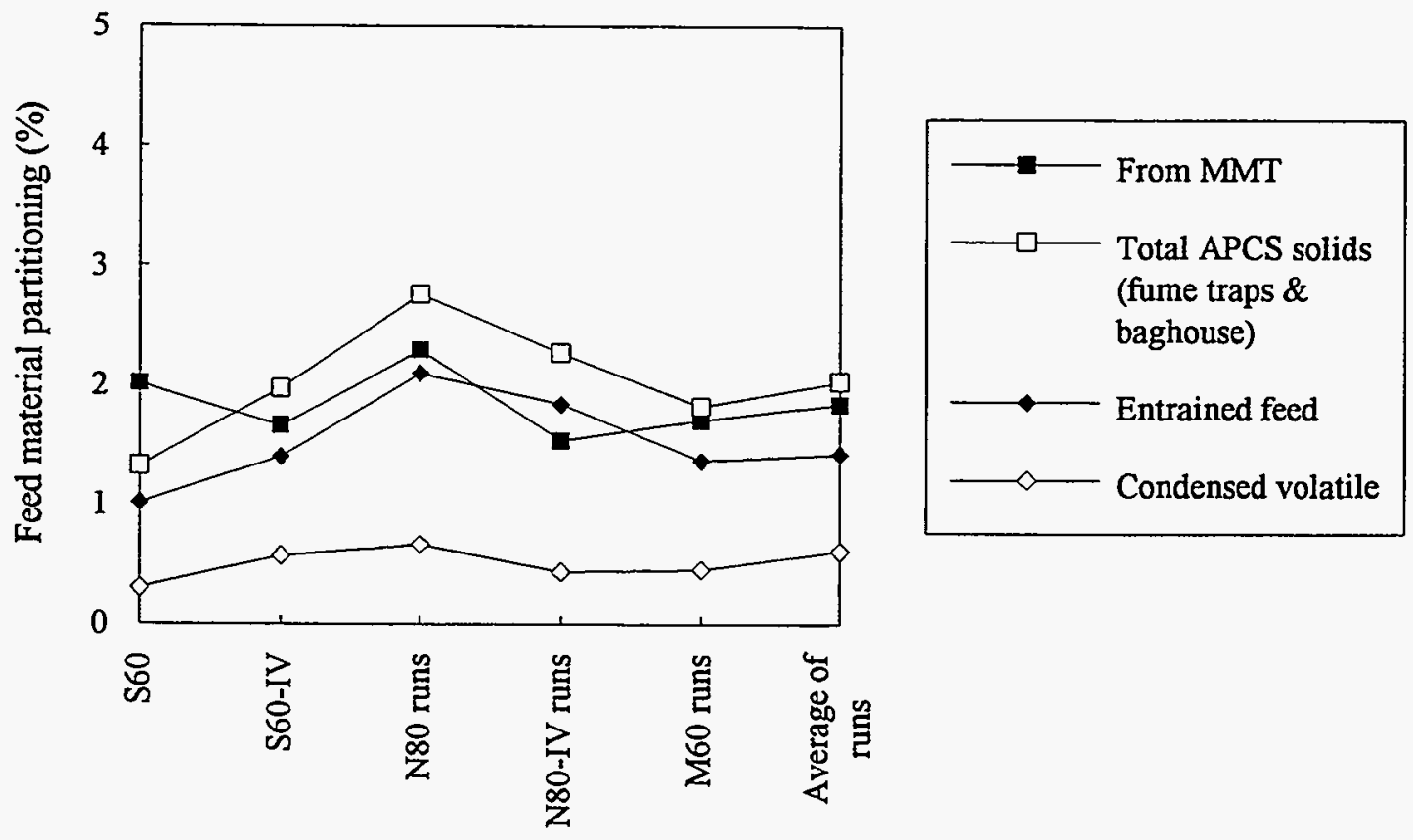

Feed type

Figure 4-2 (b). Feed material partitioning to entrained feed and condensed volatiles.

Notes: 1. Entrained feed includes material from the fume traps as well as a portion of the baghouse catch that was assumed to be entrained feed material.

2. Condensed volatiles was the portion of the baghouse catch assumed to be condensed volatile material. 
solids were a small fraction of the total process mass and included both directly entrained feed dust and also volatilized materials from the melt. Because of the small amounts of APCS solids, there was greater relative variation in APCS solids from test condition to test condition.

The volatilized metal compounds (reduced and oxidized forms) began to condense as soon as the offgas cooled in the offgas system. The entrained feed dust and the condensed fume particulate were captured in the APCS fume traps and the baghouse. There were two independent determinations of APCS solids made during the baseline tests. Solid particulate emissions were determined by (a) quantitative recovery of the solids captured in the fume traps and baghouse, and (b) isokinetic sampling and analysis of the APCS flow using the EPA MMT modified to quantify not only emissions of individual metals but also total particulate. The solids recovered in the fume traps and the baghouse are representative of the integrated emissions to the APCS during the entire run time of each test condition. Since the operating temperatures and feed rate varied during each test condition from startup to completion, the amounts and composition of the recovered solids may be somewhat different than would be obtained from a long-term continuous operation under more constant conditions. The MMT samples were collected during discrete sample times for each test condition, when the operating conditions were more constant. The MMT results may be considered more representative of long-term continuous operation under more constant conditions.

The MMT is designed to sample all of the solid material in the offgas and also any volatilized metals not yet condensed. The MMT results would be significantly higher than the total captured APCS solids if the slag temperatures were higher, causing more metals volatilization during the MMT test periods, or if significant amounts of volatilized metals were not captured in the baghouse or fume traps.

The measured levels of many metals from the MMT samples were indeed larger than the measured levels from the APCS catches, even though the total particulate mass emission rate measured using the MMT and from the APCS catches were very similar. The masses of metals collected in the MMT samples was done during slag tapping periods for all test conditions except the M60 test, so slag temperatures were higher than during earlier periods in each test when the slag bath was being heated up to tapping temperatures. Higher amounts of metals collected during the MMT runs were likely, due to higher metals volatilities caused by the higher slag temperatures. Incomplete capture of volatilized metals in the fume traps and the baghouse, or deposition onto the internal APCS duct surfaces, may also contribute to this difference. The HEPA filter was used as a final, high efficiency filtration step to assure that even a small amount of sub-micron fume that may have passed through the baghouse was not vented to the atmosphere. However, no data from the HEPA filter is available.

Because of the possible presence of some uncondensed or otherwise uncollected volatile metals in the offgas, the metals mass emission rates reported in Section 6 are based on the MMT flow sampling results rather than the integral APCS catches. The overall total and elemental mass balances, based on the day-long operation, however, were calculated using the measurements from the APCS catches because the mass of volatilized metals not captured in the APCS was very small relative to those in the other output streams. Also, the differentiation between entrained and volatilized particulate was easier to determine using the fume trap and baghouse catches, as discussed in the following section. 


\subsubsection{Entrained and Volatilized Particulate}

Fume condensation may be heterogeneous as materials condense onto existing particles entrained in the offgas or onto internal surfaces in the APCS. Condensation may also be homogeneous as vapors condense onto nucleation sites, resulting in new fume particles. Unless significant agglomeration of these fume particles occurs, these particles are characteristically very small, under 1 micron in diameter. Even in heterogeneous condensation, the condensed toxic metals are often concentrated on smaller particles due to their larger surface areas compared to particle mass. Conversely, the largest mass of entrained feed dust may be concentrated in the larger particle sizes, because of the smaller surface area compared to particle mass.

Chemical and physical analysis of the fume trap and baghouse catches (discussed in Section 5) suggests that the material captured in the fume traps was primarily larger particles of entrained feed material, while the baghouse catch was smaller particles enriched in some condensed volatile species (fume). This finding was consistent with the expected performance of the fume traps, which were designed to be quasi-cyclonic collectors of larger-sized particulate. The baghouse was a much more efficient total filtration collector of even very small-sized particulate. Well designed and operated baghouses can readily exceed $99 \%$ collection efficiency. The higher concentrations of condensed volatiles in the baghouse are also consistent with the expected homogeneous and heterogeneous condensation of volatile material in and on small sized particulate, with minimal condensed volatile matter associated with larger particles.

The assumption that all entrained feed is caught in the fume traps, and that the baghouse contains only condensed fume is not totally correct. In reality, some of the fume likely condensed on the surfaces of the entrained particulate, and was captured in the fume traps. Also, much of the fine material in the baghouse was certainly entrained feed material fines too small to be captured in the fume traps. The mineralogy analysis (Section 5) suggests that the material in the fume traps and much of the material captured in the baghouse was entrained feed particles. For this analysis, it was assumed that the fume traps contained only entrained feed, and the baghouse contained both entrained feed and condensed volatiles.

The amounts of entrained and volatilized particulate in the baghouse were estimated for each test condition by comparing the concentrations of the different elements in fume trap 1 , fume trap 2, and the baghouse. As discussed in Section 4.2.2, increasing concentrations from fume trap 1 to the baghouse suggest volatilization of those elements rather than entrainment. Oxides of those elements in the baghouse catches that increased in concentration from fume trap 1 to the baghouse were summed to approximate the total portion of each baghouse catch represented by volatilized matter. The remainder (the sum of the oxides of those elements that did not increase in concentration from fume trap 1 to the baghouse) was used to approximate the material in the baghouse catches that was entrained feed. Assuming only oxides for these elements rather than also carbonates and chlorides can introduce some error in these approximations. However, this error is within $10 \%$ or less, as shown by summing all of the oxides in Appendix $\mathrm{K}$.

The partitioning of feed material to entrained feed and to volatilized matter approximated in this manner is shown in Figure 4-2 (b). The total partitioning of feed material to the offgas solids (both entrained feed and volatilized matter) as measured by the total fume trap and baghouse 
catches and as measured by the MMT sampling is also shown. These two independent measures of total APCS solids are in relatively good agreement, with the combined fume trap and baghouse measurement somewhat higher than the MMT measurement for four of the five runs and the total average of all runs.

Attempts to correlate the variations in the mass partitioning to the APCS solids from test to test with theoretical causes for the variations such as slag temperatures, feed compositions, feed particle sizes, furnace feed rate, presence of cold top, and power levels were largely unsuccessful. This was due to a combination of the limited amount of replicate data, slight but competing variations in operating conditions from test to test, and limited feed particle size data. One comparison that did show a correlation as expected for the total APCS solids is shown in Figure 4-3. This figure shows empirically an increase in the total APCS solids (measured from the fume traps and baghouse catches) with increasing volatiles (evolved gas) content of the feed mixtures. The volatiles content was calculated by mass balance using the flowrate and composition of the offgas for each test. The increase is attributed to the increased entrainment of feed dust and fume in the increased gas evolution from the melt.

\subsubsection{Volatilization (Gas Evolution) from the Feed Materials}

The feed mixtures contained varied levels of constituents that decomposed, vaporized, or chemically reacted and then vaporized to gaseous products upon heating to slag temperatures. These included absorbed moisture, water of hydration, carbonates, sulfates, chlorides, and small amounts of organic matter. Gas evolution from the feed mixtures based on offgas measurements is shown in Table 4-2. Total volatiles ranged from 6.1 to $18.3 \%$ of the input feed mixtures. The amounts of measured $\mathrm{CO}$ and $\mathrm{CO}_{2}$ were corrected for the amount of these gases produced from oxidation of the graphite electrodes. The portion of combined $\mathrm{CO}$ and $\mathrm{CO}_{2}$ that was derived from graphite oxidation ranged from 18.2 to $51.9 \%$.

\subsection{Elemental Mass Balances and Partitioning}

Mass balances and partitioning calculations were done for individual elements to compare the elemental output measurements to the elemental input measurements, and to determine the distribution of the TRU surrogate, toxic metals, and other elements between the slag, metal, and APCS solids. Elemental partitioning between the furnace output products was calculated as follows:

$P_{i, j}=c_{i, j} m_{j} / \sum_{j}\left(c_{i, j} m_{j}\right) \times 100 \%$

where

$\mathrm{P}=$ Partitioning value (mass fraction) in \%

$\mathrm{i}=$ Element

$\mathrm{j} \quad=$ Output product

c $=$ Mass concentration 


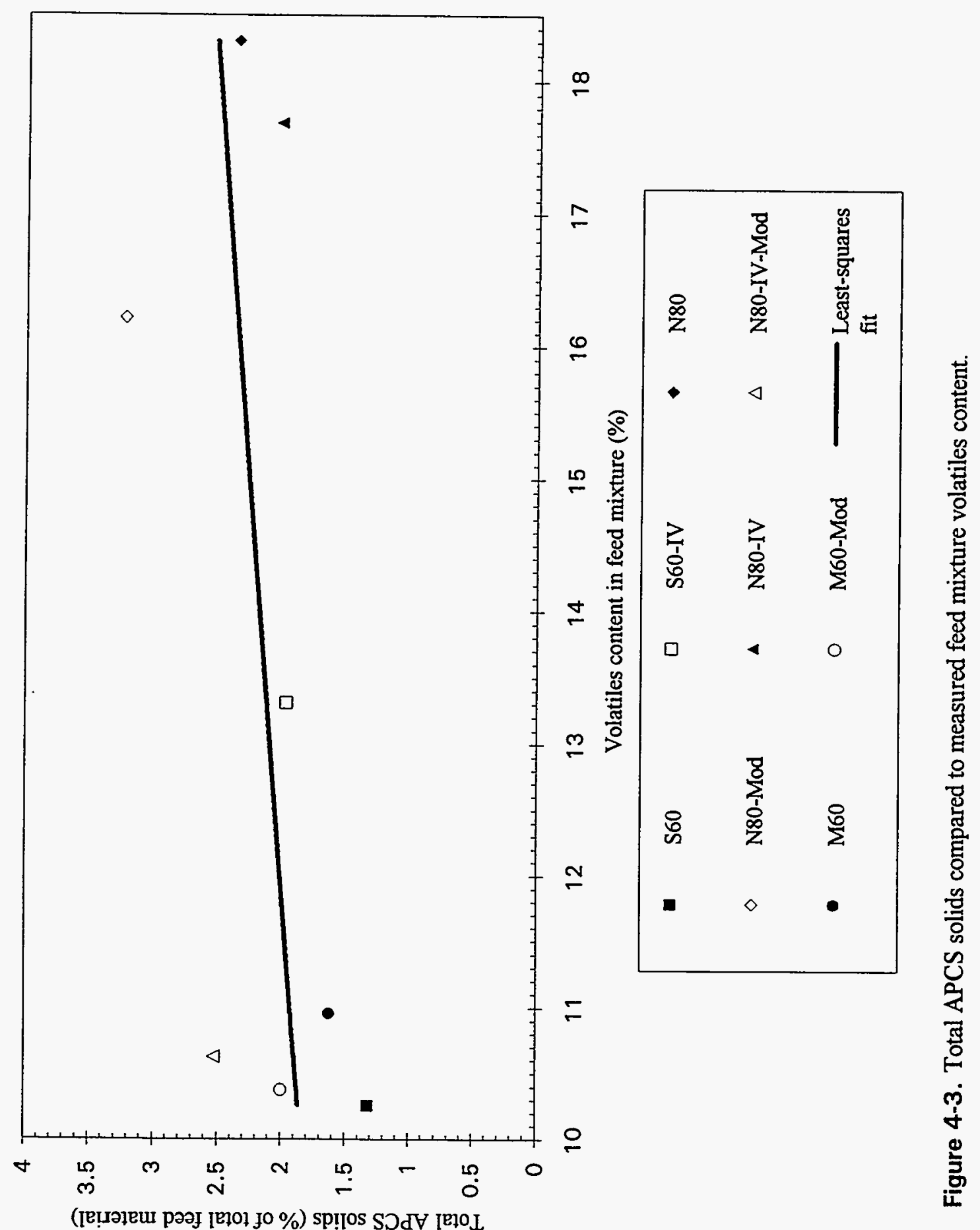


Table 4-2. Volatilization of feed mixture components and offgas composition.

\begin{tabular}{|c|c|c|c|c|c|c|c|c|c|c|c|c|c|c|c|c|c|c|c|}
\hline \multirow[b]{2}{*}{$\begin{array}{l}\text { Feed } \\
\text { type }\end{array}$} & \multirow{2}{*}{$\begin{array}{c}\text { Stable } \\
\text { averaging } \\
\text { period }\end{array}$} & \multirow{2}{*}{$\begin{array}{c}\text { Input } \\
\text { feedrate } \\
(\mathrm{lb} / \mathrm{hr}) \\
\end{array}$} & \multirow{2}{*}{$\begin{array}{c}\text { Electrode } \\
\text { usage } \\
\text { (lb/hr) }\end{array}$} & \multicolumn{7}{|c|}{$\begin{array}{c}\text { Quench outlet } \\
\text { offgas composition }\end{array}$} & \multirow{2}{*}{$\begin{array}{l}\text { Quench } \\
\text { air } \\
\text { flowrate } \\
\text { (wscfm) }\end{array}$} & \multirow{2}{*}{$\begin{array}{c}\text { Furnace } \\
\text { outlet air } \\
\text { and } \\
\text { quench } \\
\text { air } \\
\text { flowrate } \\
\text { (dscfin) }\end{array}$} & \multicolumn{7}{|c|}{$\begin{array}{c}\text { Total offgas species mass } \\
\text { emission rate (lb/hr) }\end{array}$} \\
\hline & & & & $\begin{array}{l}02 \\
(\%)\end{array}$ & $\begin{array}{l}\mathrm{CO} 2 \\
(\%)\end{array}$ & $\begin{array}{c}\mathrm{CO} \\
(\mathrm{ppm})\end{array}$ & $\begin{array}{c}\text { NOx } \\
\text { (ppm) }\end{array}$ & $\begin{array}{c}\mathrm{SO} 2 \\
(\mathrm{ppm})\end{array}$ & $\begin{array}{l}\mathrm{H} 2 \mathrm{O} \\
(\%)\end{array}$ & $\begin{array}{c}\mathrm{HCl}(\mathrm{d}) \\
(\mathrm{ppm})\end{array}$ & & & $\mathrm{O} 2$ & $\mathrm{CO} 2$ & $\mathrm{CO}$ & NOx & $\mathrm{SO} 2$ & $\mathrm{H} 2 \mathrm{O}$ & $\mathrm{HCl}(\mathrm{d})$ \\
\hline S. 60 & $10: 13-11: 31$ & 1,400 & 7.37 & 19.9 & 2.17 & 3,362 & 35.7 & 1,045 & 6.44 & 5,198 & 308 & 457 & 454 & 68.0 & 6.71 & 0.076 & 4.77 & 82.6 & 13.3 \\
\hline S-60 & $14: 06-15: 22$ & 975 & 7.30 & 20.3 & 1.58 & 1,372 & 14.4 & 4,846 & 6.89 & 3,709 & 308 & 446 & 453 & 48.3 & 2.67 & 0.030 & 21.6 & 86.2 & 9.3 \\
\hline S-60-IV & $12: 29-13: 40$ & 1,340 & 6.80 & 19.7 & 2.70 & 6,224 & 31.4 & 6,287 & 9.00 & 4,210 & 286 & 450 & 442 & 83.4 & 12.2 & 0.066 & 28.3 & 114 & 10.6 \\
\hline S-60-IV & $15: 23-16: 45$ & 997 & 4.68 & 20.6 & 1.60 & 2,689 & 9.00 & 3,060 & 6.60 & 3,051 & 329 & 462 & 475 & 50.7 & 5.42 & 0.019 & 14.1 & 85.6 & 7.91 \\
\hline $\mathrm{N}-80$ & $10: 50-12: 08$ & 1,243 & 6.17 & 20.2 & NM & NM & 0.820 & 2.54 & 5.81 & 0 & 501 & 511 & 514 & $\mathrm{NC}$ & $\mathrm{NC}$ & 0.002 & 0.013 & 83.3 & 0.00 \\
\hline N-80-Mod-1 & $15: 20-16: 25$ & 686 & 6.03 & 20.0 & 3.21 & 5,682 & 4.62 & 10.5 & 4.80 & 0 & 497 & 474 & 474 & 104 & 11.8 & 0.010 & 0.050 & 63.9 & 0.00 \\
\hline N-80-IV & $12: 20-13: 34$ & 1,240 & 7.17 & 19.6 & 3.87 & 5,211 & 7.54 & 62.2 & 6.95 & 0 & 423 & 477 & 467 & 127 & 10.85 & 0.017 & 0.297 & 93.0 & 0.00 \\
\hline N-80-IV-Mod-1 & $16: 31-16: 55$ & 1,324 & 7.70 & 19.9 & 3.01 & 4,228 & 1.53 & 36.9 & 6.09 & 0 & 342 & 447 & 444 & 92.3 & 8.25 & 0.003 & 0.165 & 76.4 & 0.00 \\
\hline$M-60$ & $10: 05-11: 25$ & 1,015 & 5.61 & 19.9 & 2.09 & 1,766 & 43.7 & 2.73 & 4.87 & 0 & 441 & 513 & 510 & 73.6 & 3.96 & 0.105 & 0.014 & 70.1 & 0.00 \\
\hline N-80-IV-Mod-2 & $14: 12-15: 22$ & 1,804 & 6.70 & 20.1 & 2.79 & 2,519 & 11.5 & 2.88 & 4.08 & 0 & 496 & 530 & 532 & 101 & 5.83 & 0.028 & 0.015 & 60.7 & 0.00 \\
\hline Notes: & $\begin{array}{l}\text { 1. Values used } \\
\text { 2. No } \mathrm{H} 2 \mathrm{O} \text { or } \\
\text { 3. Feed nitroge } \\
\text { 4. The amounts }\end{array}$ & $\begin{array}{l}\text { calculati } \\
\text { are assum } \\
\text { is assume } \\
\text { of } \mathrm{CO}, \mathrm{NC}\end{array}$ & $\begin{array}{l}\text { ng are from } \\
\text { 1ed to partit } \\
\text { d to be zcro } \\
\mathrm{x} \text { and } \mathrm{SO} 2\end{array}$ & from th & ambi & nt air wa & assume & to be $z$ & s. & & & & & & & & & & \\
\hline $\begin{array}{l}\text { a. Amount of ox } \\
\text { b. Determined u- } \\
\text { c. Determined fr } \\
\text { d. } \mathrm{HCl} \text { values } \mathrm{w}\end{array}$ & $\begin{array}{l}\text { dized carbon fron } \\
\text { ing electrode usa } \\
\text { m the input feed } \\
\text { re calculated fron }\end{array}$ & $\begin{array}{l}\text { electrode } \\
\text { e. } \\
\text { te and the } \\
\text { a mass be }\end{array}$ & $\begin{array}{l}\text { is proporti } \\
\text { sum of the } \\
\text { Lance of fee }\end{array}$ & $\begin{array}{l}\text { nately } \\
\text { orrecte } \\
\text { i, slag, }\end{array}$ & $\begin{array}{l}\text { ubtrac } \\
\text { and offea } \\
\text { and }\end{array}$ & $\begin{array}{l}\text { ed from } \mathrm{t} \\
\text { species } \\
\text { al } \mathrm{HCl} v\end{array}$ & $\begin{array}{l}\mathrm{CO} 2 \\
\text { nass em } \\
\text { lues. }\end{array}$ & $\begin{array}{l}\text { mount. } \\
\text { sion ratc }\end{array}$ & & & & & & & & & & & \\
\hline
\end{tabular}


Table 4-2. (continued).

\begin{tabular}{|c|c|c|c|c|c|c|c|c|c|c|c|c|c|c|c|c|}
\hline \multirow[b]{2}{*}{$\begin{array}{l}\text { Feed } \\
\text { type }\end{array}$} & \multicolumn{3}{|c|}{$\begin{array}{c}\text { Offgas species } \\
\text { mass emission rates } \\
\text { from ambient air } \\
(\mathrm{lb} / \mathrm{hr})\end{array}$} & & & ected of & $\begin{array}{l}\text { gas speci } \\
\text { n rates (a) } \\
(\mathrm{lb} / \mathrm{hr})\end{array}$ & $s$ mass & & & \multirow{2}{*}{$\begin{array}{c}\text { Portion of } \\
\text { combined } \\
\mathrm{CO} 2 / \mathrm{CO} \\
\text { that is from } \\
\text { electrode } \\
\text { oxidation(b) } \\
(\%)\end{array}$} & \multicolumn{5}{|c|}{ Percent of feed material that is: } \\
\hline & $\mathrm{O} 2$ & $\mathrm{CO} 2$ & $\mathrm{H} 2 \mathrm{O}$ & $\mathrm{O} 2$ & $\mathrm{CO} 2$ & $\mathrm{CO}$ & NOx & $\mathrm{SO} 2$ & $\mathrm{H} 2 \mathrm{O}$ & $\mathrm{HCl}(\mathrm{d})$ & & $\begin{array}{c}\text { Total } \\
\text { volatiles(c) }\end{array}$ & Moisture & $\mathrm{SO} 2$ & $\begin{array}{l}\mathrm{CO} 2 \text { from } \\
\text { carbonates }\end{array}$ & $\mathrm{HCl}(\mathrm{d})$ \\
\hline$S-60$ & 478 & 1.03 & 9.62 & -23.6 & 40.0 & 6.71 & 0.076 & 4.77 & 73.0 & 13.3 & 34.8 & 8.16 & 5.21 & 0.34 & 1.86 & 0.952 \\
\hline s-60 & 466 & 1.01 & 9.39 & -13.5 & 20.6 & 2.67 & 0.030 & 21.6 & 76.9 & 9.3 & 51.9 & 12.1 & 7.88 & 2.21 & 1.02 & 0.952 \\
\hline S-60-IV & 470 & 1.02 & 9.47 & -28.0 & 57.4 & 12.2 & 0.066 & 28.3 & 104 & 10.6 & 24.5 & 13.8 & 7.78 & 2.11 & 3.23 & 0.794 \\
\hline S-60-IV & 483 & 1.05 & 9.72 & -8.0 & 32.5 & 5.42 & 0.019 & 14.1 & 75.9 & 7.91 & 29.5 & 12.8 & 7.61 & 1.42 & 2.30 & 0.794 \\
\hline $\mathrm{N}-80$ & 534 & 1.16 & 10.8 & -20.3 & $\mathrm{NC}$ & $\mathrm{NC}$ & 0.002 & 0.013 & 72.6 & 0.00 & $\mathrm{NC}$ & $\mathrm{NC}$ & 5.84 & 0.00 & $\mathrm{NC}$ & 0.000 \\
\hline N-80-Mod-1 & 495 & 1.07 & 9.98 & -21.4 & 81.2 & 11.8 & 0.010 & 0.050 & 53.9 & 0.00 & 18.2 & 18.3 & 7.85 & 0.01 & 9.69 & 0.000 \\
\hline N-80-IV & 499 & 1.08 & 10.0 & -31.6 & 99.3 & 10.85 & 0.017 & 0.297 & 83.0 & 0.00 & 18.4 & 13.1 & 6.69 & 0.02 & 6.53 & 0.000 \\
\hline N-80-IV-Mod-I & 467 & 1.01 & 9.41 & -23.3 & 63.1 & 8.25 & 0.003 & 0.165 & 67.0 & 0.00 & 27.1 & 8.70 & 5.06 & 0.01 & 3.47 & 0.000 \\
\hline$M-60$ & 536 & 1.16 & 10.8 & -26.0 & 51.8 & 3.96 & 0.105 & 0.014 & 59.3 & 0.00 & 26.1 & 8.79 & 5.84 & 0.00 & 3.77 & 0.000 \\
\hline N-80-IV-Mod-2 & 554 & 1.20 & 11.2 & -21.8 & 75.7 & 5.83 & 0.028 & 0.015 & 49.5 & 0.00 & 22.4 & 6.06 & 2.75 & 0.00 & 3.25 & 0.000 \\
\hline
\end{tabular}


$\mathrm{m}=$ Mass of each output product for each test.

This method uses the measured elemental concentrations and the output masses to calculate elemental partitioning fractions of the feed materials among the output products. The input masses of each element based on the feed rate and feed mixture concentrations were not used. This approach was used because even though the overall, total mass balance closure (value of total output mass divided by the total input mass), at 1.01 is very close to unity, the mass balance closure for many individual elements deviates more significantly from unity. This deviation is due largely to inaccuracies in the specified elemental concentrations in the input feed mixtures, especially for many of the trace level metals. Elemental mass partitioning determinations were more accurate when based upon the measured concentrations and masses of the output products.

Eight metals are listed in the EPA TCLP leachability procedure for evaluation of leachability for solid wastes: $\mathrm{Ag}, \mathrm{As}, \mathrm{Ba}, \mathrm{Cd}, \mathrm{Cr}, \mathrm{Hg}, \mathrm{Pb}$, and $\mathrm{Se}$. The EPA Multiple Metals Train is, however, designed for measuring 16 toxic or otherwise potentially hazardous metals emissions from stationary sources. These include the eight TCLP metals plus $\mathrm{Be}, \mathrm{Cu}, \mathrm{Mn}, \mathrm{Ni}, \mathrm{P}, \mathrm{Sb}, \mathrm{Tl}$, and $\mathrm{Zn}$. These additional metals can also be considered toxic, and all but $\mathrm{Be}, \mathrm{Mn}, \mathrm{Sb}$, and $\mathrm{Tl}$ were included in the sample analyses of the melter product streams. The four metals that were excluded were not expected, even in reasonable trace levels, in the feed mixtures. Essentially all of the other toxic metals were present at only trace levels in the feed mixtures, so some of the measured concentrations in some of the product streams were at or near detection limits. Analytical error near the detection limits can increase and cause variability in measured concentrations and partitioning results that are not related to process conditions or feed variations. Analytical results below detection limits are shown as "less than the detection limit value" in the product composition tables of Appendices $\mathrm{H}$ and $\mathrm{K}$.

Metals measurements in the output streams were subject to some inaccuracy due to low or nondetectable levels of some elements. Spiking additional toxic metals into the feed materials can improve the data quality but was not done in the baseline tests because metal spiking would have made the feed mixtures less representative of the actual buried wastes. Elemental partitioning for elements in very low concentrations (at or near the detection limit) in either the slag, metal, or APCS solids should be considered semi-quantitative. In addition, partitioning to the APCS solids should be considered less accurate because only a small fraction (2\%) of the feed material partitioned to the APCS solids, resulting in greater relative error.

\subsubsection{Elemental Partitioning to the Glass/Ceramic Slag Product}

Partitioning of $\mathrm{Ce}$ (the TRU surrogate) and the toxic metals to the slag is shown in Figure 4-4. The partitioning behavior for the M60 and M60-Mod tests that had added elemental metals was somewhat different from the partitioning for the other tests when there were no added elemental metals. Some metals were present only at trace levels as metal compounds in the soil and additives. Of these trace metals, $\mathrm{Ag}$ and $\mathrm{Cd}$, shown in Figure 4-4, were not detected in most of the slag samples. The reported partitioning to the slag for these two elements was calculated using their detection limits in the slag, and are maximum values. The actual partitioning for these metals is between $0 \%$ and the reported values. 

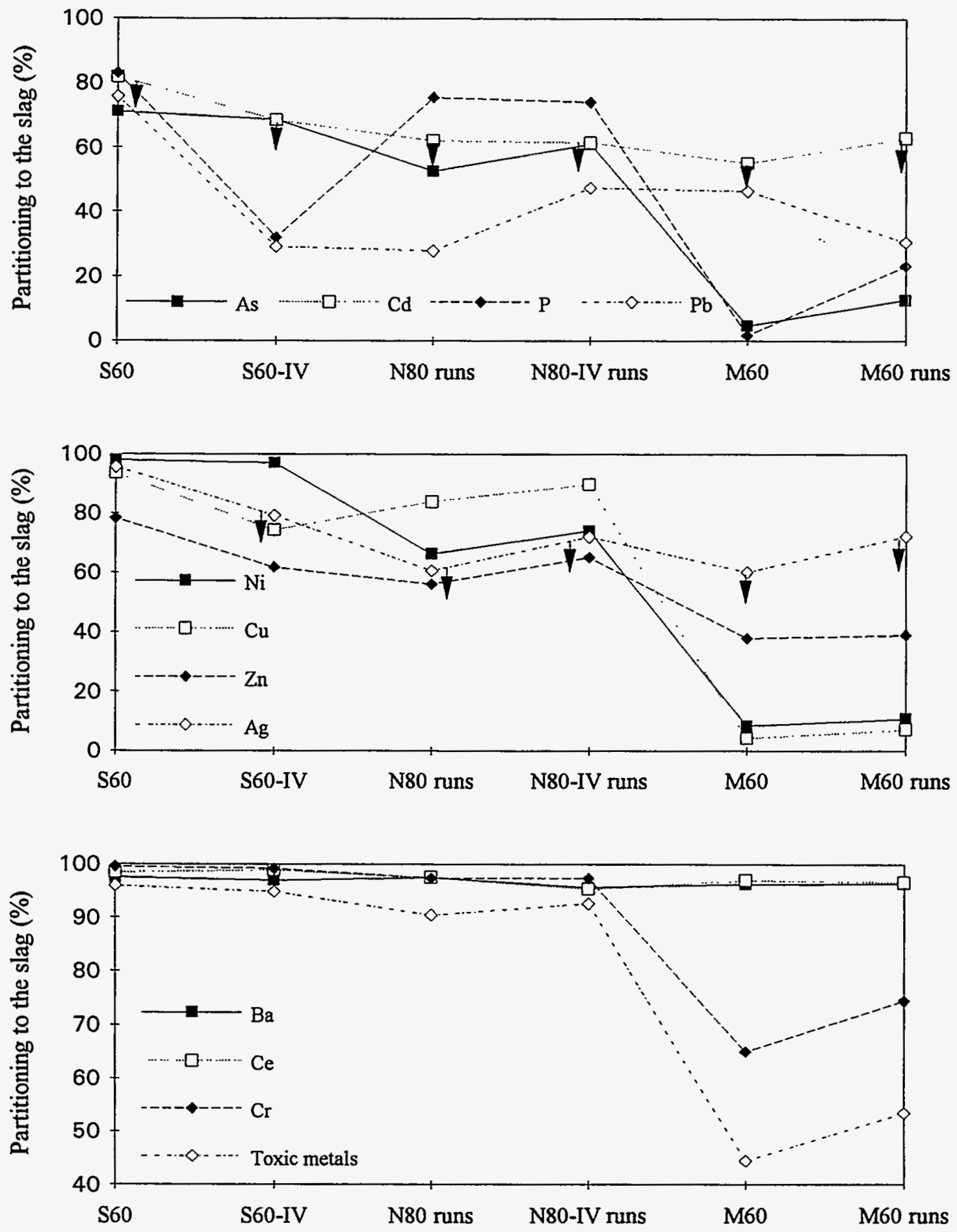

Figure 4-4. Partitioning of toxic metals in the surrogate feed mixtures to the slag.

Notes: 1. Toxic metals $=\mathrm{Ag}, \mathrm{As}, \mathrm{Ba}, \mathrm{Cd}, \mathrm{Ce}, \mathrm{Cr}, \mathrm{Cu}, \mathrm{Ni}, \mathrm{P}, \mathrm{Pb}$, and $\mathrm{Zn}$.

2. Down arrows indicate that levels were non-detectable in the slag, where data point indicates maximum partitioning value based on the detection limit. 
Toxic metals that significantly partitioned to the slag ( $>80 \%$ for most runs, excluding the $\mathrm{M} 60$ run) included $\mathrm{Ba}, \mathrm{Cr}, \mathrm{Cu}$, and $\mathrm{Ni}$. Cerium also partitioned almost entirely to the slag for all runs. These metals existed in the S60 series and $\mathrm{N} 80$ series feed mixtures primarily as oxides and were effectively dissolved into the slag. Toxic metals that were less effectively captured in the slag include $\mathrm{As}, \mathrm{P}, \mathrm{Pb}$, and $\mathrm{Zn}$. Species of these elements, especially the chlorides, are known to have lower boiling points and higher volatilities, and tend to volatilize significantly to the offgas under some operating conditions.

The oxides of $\mathrm{As}, \mathrm{Ba}, \mathrm{Cd}, \mathrm{Ce}, \mathrm{Cr}, \mathrm{Cu}, \mathrm{Ni}, \mathrm{P}, \mathrm{Pb}$, and $\mathrm{Zn}$ reported sufficiently to the slag for most runs (30-100\%) so that APCS residues containing these metals could be recycled to the furnace by mixing with fresh feed material to achieve effective net capture of these elements in the slag product. Many metals such as $\mathrm{As}, \mathrm{Ni}$, and Se will also partition significantly to the metal product, if present, as discussed in Section 4.2.3. This behavior was also observed in the prior ASME municipal incinerator ash vitrification tests.

\subsubsection{Elemental Partitioning to the APCS}

The APCS solids included both entrained feed material (dust) and volatilized feed material. Feed entrainment and volatilization should be evaluated separately for determining the elemental partitioning to the APCS. Separate determinations of entrainment and volatilization are important because the physical and chemical properties of the entrained material will be different from the properties of volatilized/condensed fume. Different particle size, mineralogy, and chemical content for entrained and volatilized materials can lead to different methods for control via APCS equipment designs and final disposal of the collected material. For example, volatilized/condensed fume is often very small particle sized and enriched by the more volatile toxic metals. It is, therefore, more difficult to capture in an APCS and can require stabilization of fines and leachable metals prior to disposal. Entrained feed material by comparison is often larger-sized particles, easier to collect, and can be readily recycled to the furnace without increased volatilization and further concentration of volatile metals. Entrained feed may contain radionuclides that are not volatile and would otherwise not partition to the APCS. Mechanisms and approaches to control of feed entrainment in the furnace are much different than in-furnace mechanisms and control of volatilization. It is therefore important to be able to quantify the relative presence of both types of elemental partitioning.

Toxic metals and $\mathrm{Ce}$ partitioning to the fume traps (assumed to be primarily entrained feed as discussed earlier) and partitioning to the baghouse (assumed for some metals to be volatilized/condensed fume) is shown in Figures 4-5 through 4-8. As shown in Appendix K, only $1 / 3$ to $1 / 2$ of the total mass collected in the baghouse for each test was from fume volatilized from the melt. Much of the material captured in the baghouse was entrained feed material fines rather than volatilized/condensed material. Considerable variability existed in some of the reported values due to low measured concentrations of trace elements and due to variation in furnace operating conditions from test to test. Some metals $(\mathrm{Hg}, \mathrm{Cd}, \mathrm{Se}$, and $\mathrm{Ag}$ ) were not detected in the slag samples. Partitioning to the APCS for these metals was calculated using the slag detection limit. The data points in the figures represent minimum partitioning values. The actual partitioning values for these metals to the APCS is between the reported values and $100 \%$. 

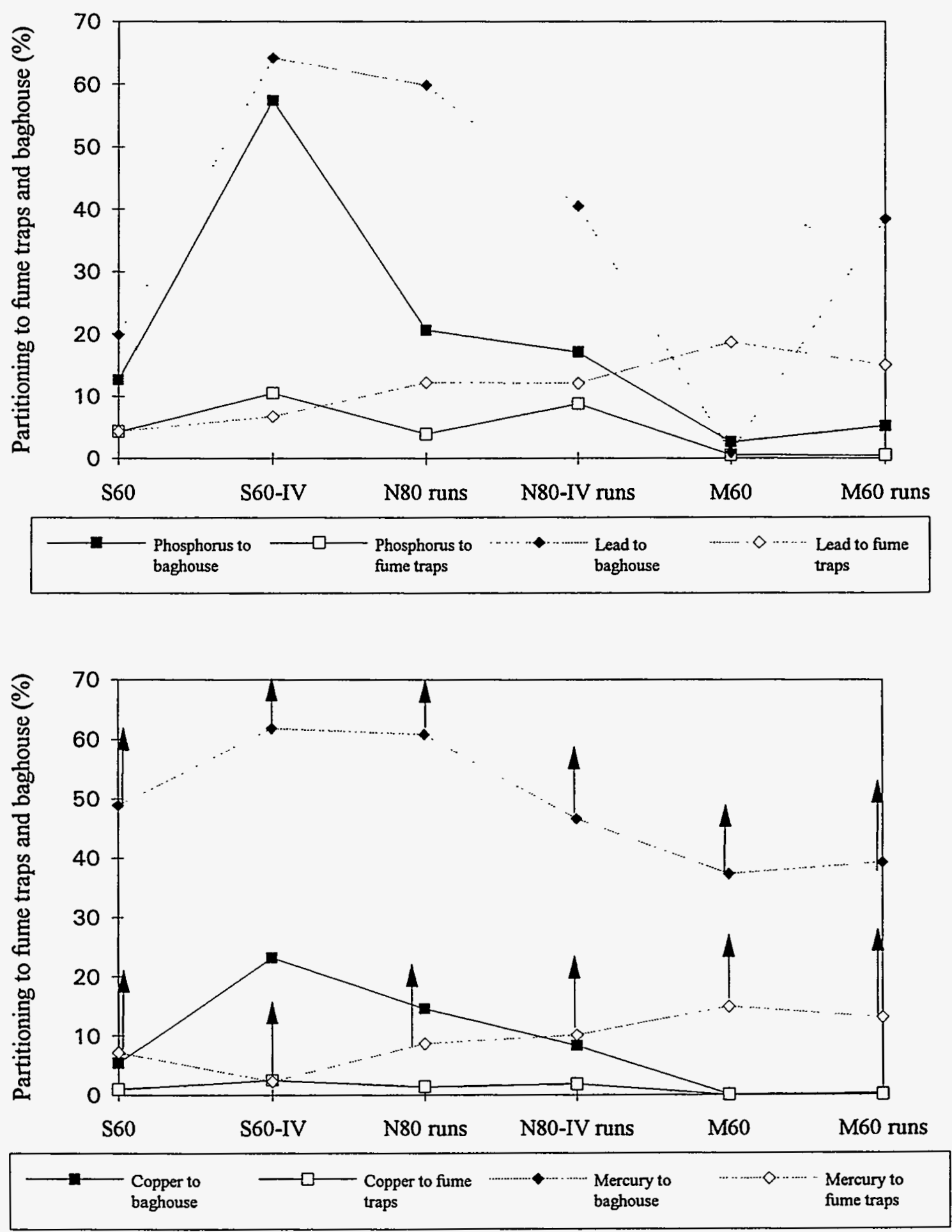

Figure 4-5. Partitioning of $\mathrm{P}, \mathrm{Pb}, \mathrm{Cu}$, and $\mathrm{Hg}$ to the fume traps and the baghouse.

Note: Up arrows indicate that levels were non-detectable in the slag samples, where data point indicates minimum partitioning value based on the detection limit. 

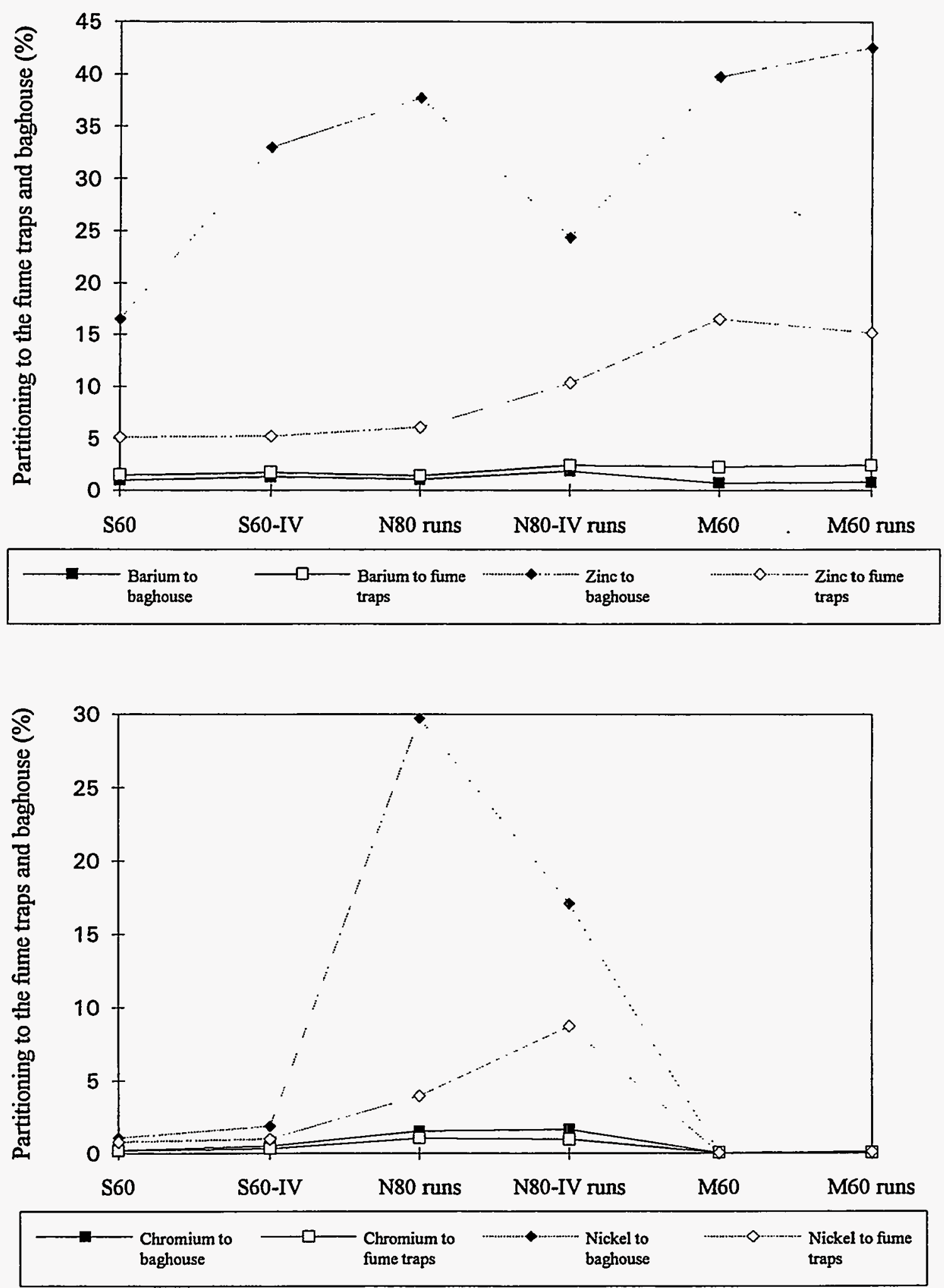

Figure 4-6. Partitioning of $\mathrm{Ba}, \mathrm{Zn}, \mathrm{Cr}$, and $\mathrm{Ni}$ to the fume traps and the baghouse. 

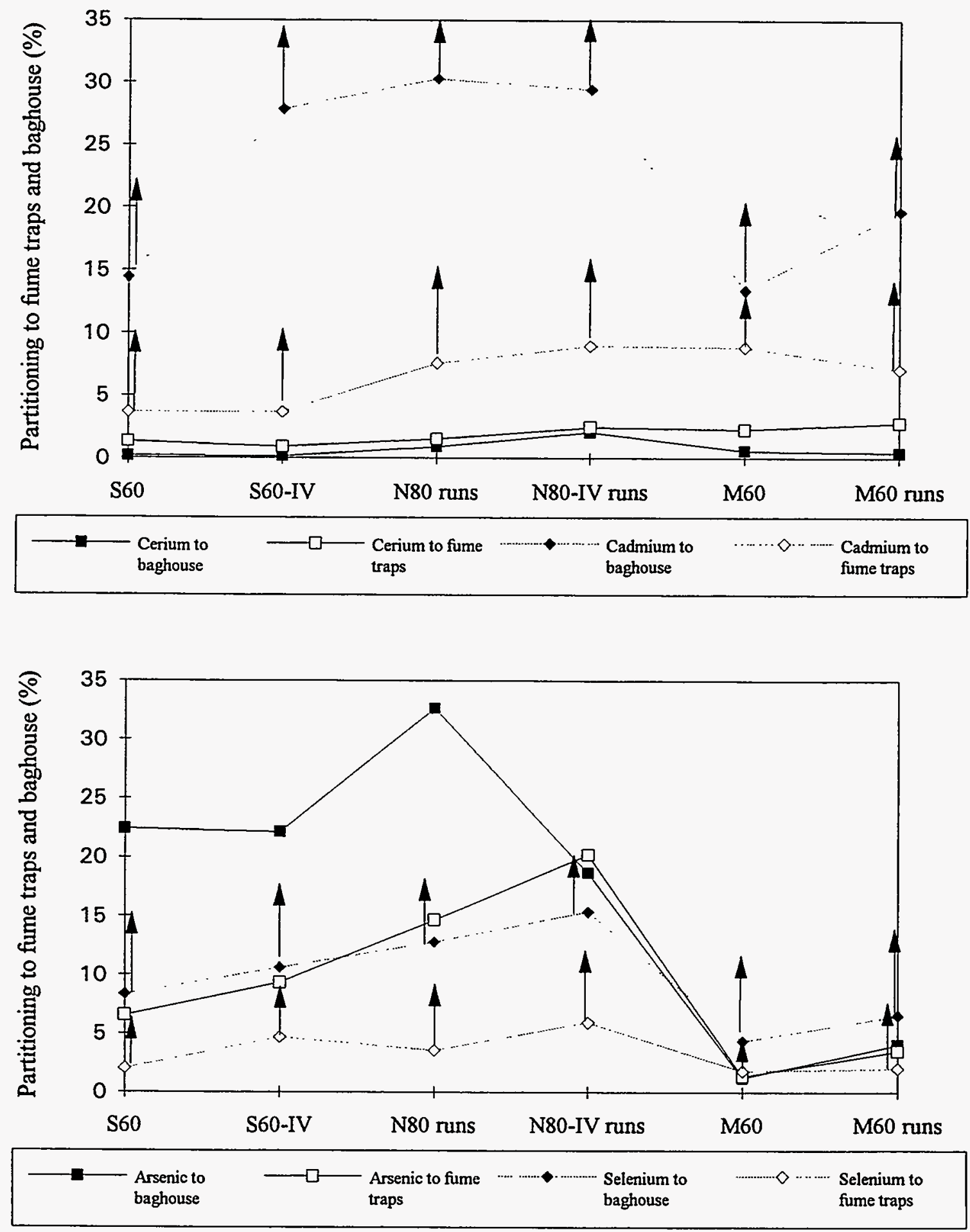

Figure 4-7. Partitioning of $\mathrm{Ce}, \mathrm{Cd}, \mathrm{As}$, and Se to the fume traps and the baghouse.

Note: Up arrows indicate that levels were non-detectable in the slag samples, where data point indicates minimum partitioning value based on the detection limit. 


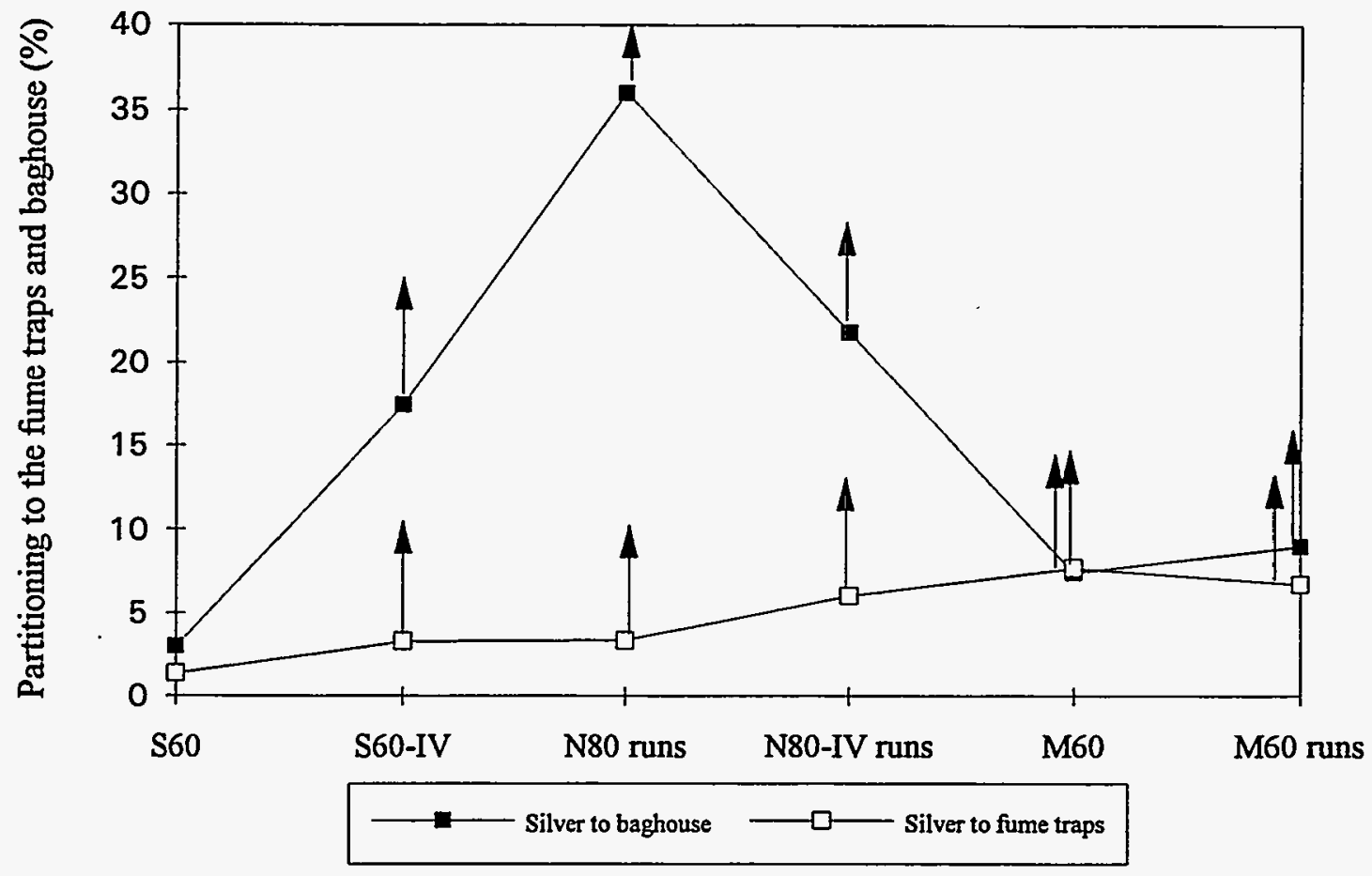

Figure 4-8. Partitioning of $\mathrm{Ag}$ to the fume traps and the baghouse.

Note: Up arrows indicate that levels were non-detectable in the slag samples, where data point indicates minimum partitioning value based on the detection limit. 
The key to understanding the transport mechanism (entrainment versus volatilization) for each element is to observe the concentration trends in each of the two fume traps and baghouse and the trend from fume trap 1 to the baghouse. If the concentration increased from fume trap 1 to the baghouse, then either that element was concentrated in very fine particles in the feed, or else the element (or compounds of that element) volatilized from the melt and then condensed to fine particulate prior to the baghouse. If the concentration of an element increased from fume traps 1 and 2 to the baghouse, then the element was included with material possibly volatilized from the melt in the calculations of Appendix $\mathrm{K}$. If the concentration was greater in fume trap 1 and 2 catches than in the baghouse catch, then the element was likely transported in entrained feed dust as oxides, carbonates, or other species in the feed mixtures.

The furnace gas temperatures, flowrates, and compositions were not directly measured during the baseline tests, but were estimated using mass and energy balances from offgas measurements made in the APCS. These estimates are discussed in Section 5. These estimates of furnace gas conditions should be considered semi-quantitative, but may be used to get a perspective of the feed material entrainment from the furnace. From tables in Section 5, the average furnace gas temperature was $511^{\circ} \mathrm{C}$, and the average furnace offgas flowrate was $110 \mathrm{wscfm}$. The average gas velocity in the furnace, and the diameter of a spherical particle that can be entrained at that average velocity may be estimated (Appendix T). At the estimated average gas velocity of $0.5 \mathrm{ft} / \mathrm{sec}$, a particle diameter of 66 microns $(0.066 \mathrm{~mm}$, or slightly smaller than 200 mesh) was estimated as the maximum entrainable diameter using Stokes' Law. ${ }^{11}$ Particles smaller than this diameter may be able to be entrained in the gas flow, while entrainment of larger particles is less likely. The actual gas velocity gradient (variation in local velocities) for each test likely varied widely, with somewhat higher gas velocities near the feed tubes and the electrodes from feed tube air influx and from gas evolution from the melt, while gas recirculation (downward or negative velocities) was likely near the sidewalls.

The kinds of minerals in the feed mixtures most likely to be entrained may be estimated by considering particles sizes for the different feed additives. Although full particle size analyses are not available for the feed mixture additives, Table 4-3 shows the weight percentage of each additive for the feed mixtures that is less than $0.175 \mathrm{~mm}(80 \mathrm{mesh})$. Those additives with large fractions less than 80 mesh also likely have significant fractions under 200 mesh. The only additives for which at least some entrainment was not likely were mullite, pollucite, $\mathrm{NaCl}$, pebble lime, aluminum, copper, lead, and zinc. The other additives, including soil (with a large variety of major and trace compounds) had potential for at least some entrainment based on their small particle sizes. Other studies for similar INEL soils report soil particle sizes of $1.6 \%$ $<200$ mesh. $^{12}$ This size range correlates well with the estimated total feed entrainment of $1.5 \%$.

The possible mechanisms for partitioning to the offgas of each element may be evaluated by considering relative volatilities, mineralogy, possible chemical reactions, and feed entrainment. This evaluation of elemental entrainment and volatilization is summarized in Table 4-4. Boiling points for various metal species are shown in Figure 4-9. The chlorides of many toxic metals have relatively low boiling points, indicating that the metal chlorides will be relatively volatile in the furnace. However, only the S-series tests had significant amounts of chlorine. Also, the furnace gas and the melt in each test except the M60 test was relatively oxidizing, which would minimize the formation of the metal chloride in favor of the oxide. One exception to this for each test is 
Table 4-3. Particle size and density of RWMC soil and additives.

\begin{tabular}{|c|c|c|c|}
\hline Feed Component & Physical form & $\begin{array}{l}\text { Bulk density } \\
\left(\mathrm{lb} / \mathrm{ft}^{3}\right)\end{array}$ & $\begin{array}{c}\text { Particle size } \\
\left(\%<0.175 \mathrm{~mm}^{\mathrm{a}}\right)\end{array}$ \\
\hline RWMC soil & Dried & 82 & 35 \\
\hline Cerium oxide, $\mathrm{CeO}_{2}$ & Mineral concentrate & 122 & 100 \\
\hline Gypsum, $\mathrm{CaSO}_{4} \cdot 2 \mathrm{H}_{2} \mathrm{O}$ & Fine grind & 58 & 64 \\
\hline Ilmenite, $\mathrm{FeTiO}_{3}$ & Mineral concentrate & 136 & 98 \\
\hline Magnetite, $\mathrm{Fe}_{3} \mathrm{O}_{4}$ & Mineral concentrate & 160 & 27 \\
\hline Mullite, $\mathrm{Al}_{6} \mathrm{Si}_{2} \mathrm{O}_{13}$ & Sintered & 180 & 1 \\
\hline Pollucite, $\mathrm{Cs}_{2} \mathrm{Al}_{2} \mathrm{Si}_{4} \mathrm{O}_{12} \bullet \mathrm{H}_{2} \mathrm{O}$ & Mineral concentrate & 107 & 2 \\
\hline Potash, $\mathrm{K}_{2} \mathrm{CO}_{3}$ & Powder & 82 & $>60$ \\
\hline Silica, $\mathrm{SiO}_{2}$ & Masonry sand & 91 & 19 \\
\hline $\mathrm{NaCl}$ & Table salt & 76 & $<5$ \\
\hline Soda ash, $\mathrm{Na}_{2} \mathrm{CO}_{3}$ & Powder & 62 & $>60$ \\
\hline Talc, $\mathrm{Mg}_{3} \mathrm{Si}_{4} \mathrm{O}_{10}(\mathrm{OH})_{2}$ & Fine grind & 77 & 56 \\
\hline Wollastonite, $\mathrm{CaSiO}_{3}$ & Acicular & 36 & 16 \\
\hline Limestone, $98 \% \mathrm{CaCO}_{3}$ & Fine grind & 89 & 85 \\
\hline Pebble lime, $93 \% \mathrm{CaO}$ & $-1 / 4$ in. & NA & $<5$ \\
\hline Mill Scale, $\mathrm{Fe}_{3} \mathrm{O}_{4}$ & Flake & 151 & 12 \\
\hline Zirconia, $\mathrm{ZrO}_{2}$ & Fine grind & 85 & 100 \\
\hline Zircon, $\mathrm{ZrSiO}_{4}$ & Mineral concentrate & 177 & 25 \\
\hline Aluminum & Shot & NA & 0 \\
\hline Copper & Shot & NA & 0 \\
\hline Iron & Flake & 210 & $<50$ \\
\hline Lead & Shot & NA & $\mathbf{0}$ \\
\hline Zinc & Coarse powder & NA & $<5$ \\
\hline Stainless steel & Fine powder & 137 & 27 \\
\hline Not analyzed & & & \\
\hline
\end{tabular}


Table 4-4. Evaluation of elemental entrainment and volatilization.

\begin{tabular}{|c|c|c|c|c|c|}
\hline Element & $\begin{array}{l}\text { Present as (species) in (additive), } \\
\text { at (concentration) in feed } \\
\text { mixtures }\end{array}$ & $\begin{array}{c}\text { Likelihood of } \\
\text { entrainment based } \\
\text { on\% }<0.175 \mathrm{~mm}\end{array}$ & $\begin{array}{l}\text { Partitioning } \\
\text { to baghouse } \\
(\%)\end{array}$ & $\begin{array}{l}\text { Volatilized } \\
\text { or } \\
\text { entrained }\end{array}$ & Mechanism \\
\hline $\mathrm{Ag}$ & $\begin{array}{l}\mathrm{Ag}_{2} \mathrm{O} \text { in soil, } 4-9 \mathrm{ppm} ; \mathrm{Ag} \text { in } \\
\text { copper powder, } 14 \mathrm{ppm}\end{array}$ & $\begin{array}{l}\text { Likely. Soil } 35 \% \\
<0.175 \mathrm{~mm} \text {, and } \\
1.6 \%<75\end{array}$ & $\begin{array}{l}>3-100 \\
\text { (Ag detected } \\
\text { in only } 1 \text { slag } \\
\text { sample) }\end{array}$ & $\begin{array}{l}\text { Insufficient } \\
\text { data }\end{array}$ & $\begin{array}{l}\text { With moderate volatility, the } \mathrm{Ag} \text { could be volatilized, especially as } \\
\mathrm{AgCl} \text { during the S-series tests. Entrainment of } \mathrm{Ag} \text { in soil fines is } \\
\text { also possible. }\end{array}$ \\
\hline Al & $\begin{array}{l}\mathrm{Al}_{2} \mathrm{O}_{3} \text { in magnetite, mullite, } \\
\text { pollucite, silica, soil, talc, } \\
\text { wollastonite, pebble lime, ilmenite, } \\
\text { and zirconia, } 0.35-73.1 \% ; \mathrm{Al} \text { in } \\
\text { aluminum shot, } 100 \%\end{array}$ & High & $0.09-0.4$ & Entrained & $\begin{array}{l}\text { The minimal partitioning of Al to the baghouse is most likely due } \\
\text { to entrainment of } \mathrm{Al} \text { due its presence in both ilmenite and } \\
\text { zirconia which are } 98 \text { and } 100 \%<0.175 \mathrm{~mm} \text {, respectively }\end{array}$ \\
\hline As & $\begin{array}{l}\mathrm{As}_{2} \mathrm{O} \text { in soil, } 12.2 \mathrm{ppm} ; \text { As in } \\
\text { copper powder, pebble lime, and } \\
\text { potash, } 1-2 \mathrm{ppm}\end{array}$ & Somewhat & $1-33$ & $\begin{array}{l}\text { Insufficient } \\
\text { data }\end{array}$ & $\begin{array}{l}\text { With a relatively low boiling point, and high volatility, As likely } \\
\text { was volatilized and recondensed in the baghouse. }\end{array}$ \\
\hline $\mathrm{Ba}$ & $\begin{array}{l}\mathrm{BaO} \text { in mullite and soil, } \\
100-600 \mathrm{ppm}\end{array}$ & Somewhat & $0.7-2$ & Entrained & $\begin{array}{l}\text { The minimal partitioning of } \mathrm{Ba} \text { to the baghouse is most likely due } \\
\text { to entrainment of } \mathrm{Ba} \text { in soil fines. }\end{array}$ \\
\hline $\mathrm{Ca}$ & $\begin{array}{l}\mathrm{CaCO}_{3} \text { in silica, soil, wollastonite, } \\
\text { limestone, and pebble lime, } \\
0.2-98 \% \text {; CaO in magnetite, } \\
\text { sitica, soil, talc, wollastonite, } \\
\text { pebble lime, cerium oxide, } \\
\text { ilmenite, and zirconia, } 0.03-93 \% \text {; } \\
\mathrm{CaSO}_{4} \text { in gypsum, } 0.8 \% \text {; } \\
\mathrm{CaSO}_{4} \cdot 2 \mathrm{H}_{2} \mathrm{O} \text { in gypsum, } 95.7 \% \text {; } \\
\mathrm{Ca} \text { in pollucite and salt, } \\
0.03-0.3 \%\end{array}$ & High & $0.2-1$ & Entrained & $\begin{array}{l}\text { Ca was most likely entrained as } \mathrm{CaCO}_{3} \mathrm{CaO} \text {, and } \mathrm{CaSO}_{4} \cdot 2 \mathrm{H}_{2} \mathrm{O} \text {; } \\
\text { There may have been insufficient time and temperatures (around } \\
1,000^{\circ} \mathrm{C} \text { ) in the furnace for decomposition. }\end{array}$ \\
\hline $\mathrm{Cd}$ & $\mathrm{CdO}$ in soil, $0.57 \mathrm{ppm}$ & Somewhat & $\begin{array}{l}>13-100 \\
\text { (not } \\
\text { detected in } \\
\text { slag samples) }\end{array}$ & Volatilized & $\begin{array}{l}\text { A volatile metal, Cd most likely vaporized and recondensed in the } \\
\text { baghouse. }\end{array}$ \\
\hline
\end{tabular}


Table 4-4. (continued).

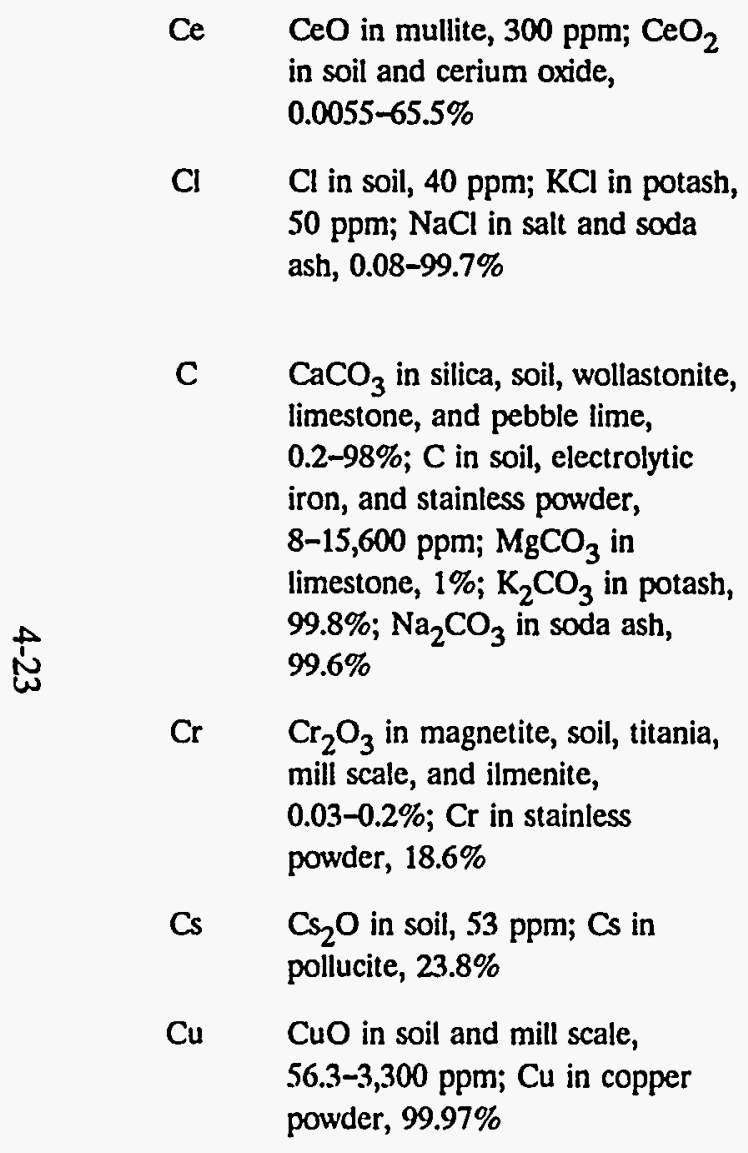

High

Somewhat

Likely

$1-26$

$62-94$

$0.2-2$

Entrained

Ce was most likely carried to the baghouse as entrained feed dust.

Volatilized

$\mathrm{Cl}$ most likely reacted to $\mathrm{HCl}$ gas in the furnace, and then reacted with entrained carbonates in the baghouse filter cake to form alkali chlorides in the baghouse. Some $\mathrm{Cl}$ may have formed metal chlorides in the furnace and volatilized.

Entrained $C$, present as carbonates in the feed mixtures, mostly formed $\mathrm{CO} 2$ upon heating to slag temperatures in an oxidizing atmosphere. $\mathrm{C}$ in baghouse was entrained as carbonates.

A less volatile metal, $\mathrm{Cr}$ was likely carried to the baghouse as entrained feed dust and may also have reduced to the metal within the furnace. $\mathrm{Cr}$ (with $\mathrm{Ni}$ and $\mathrm{Fe}$ ) was likely entrained as stainless steel powder in the M60 run.

Slight

Volatilized

With moderate volatility, the $\mathrm{Cs}$ could be volatilized, especially as $\mathrm{CsCl}_{2}$ during the S-series tests.

Slight

0.3-23 Volatilized

The highest partitioning of $\mathrm{Cu}$, excluding the M60 test, occurred for the S60 or S60-IV tests, when there was large amounts of $\mathrm{Cl}$, consistent with the known higher volatilities of toxic metals in the presence of $\mathrm{Cl}$. Thus, copper was likely transported to the baghouse as the volatile chloride trimer, $\mathrm{Cu}_{3} \mathrm{Cl}_{3}$. 
Table 4-4. (continued).

$\mathrm{Fe}_{2} \mathrm{O}_{3}$ in mullite, silica, talc,

titania, wollastonite, pebble lime,

ilmenite, soda ash, and zirconia,

$0.001-30 \% ; \mathrm{Fe}_{3} \mathrm{O}_{4}$ in magnetite,

soil, and mill scale, 4.23-99.09\%;

$\mathrm{Fe}$ in pollucite, copper powder,

electrolytic iron, stainless powder, mill scale, and potash,

$1 \mathrm{ppm}-99.97 \%$

$\mathrm{Hg} \quad \mathrm{HgO}$ in soil, $0.11 \mathrm{ppm} ; \mathrm{Hg}$ in potash, 0.04 ppm

$\mathrm{K} \quad \mathrm{K}_{2} \mathrm{O}$ in mullite, silica, and soil, $0.51-2.42 \% ; \mathrm{KCl}$ in potash, 50 ppm; $\mathrm{K}_{2} \mathrm{CO}_{3}$ in potash, $99.8 \%$; $\mathrm{KOH}$ in potash, $0.07 \% ; \mathrm{K}_{2} \mathrm{SO}_{4}$ in potash, $60 \mathrm{ppm} ; \mathrm{K}$ in salt and pollucite, $0.04-0.5 \%$

$\mathrm{Mg} \quad \mathrm{MgO}$ in magnetite, mullite, silica, soil, talc, wollastonite, pebble lime, ilmenite, and zirconia, 0.01-26\%; $\mathrm{MgCO}_{3}$ in limestone, $1 \% ; \mathrm{Mg}$ in salt, 0.02 wt\%
High

$0.05-0.6$

Entrained

Somewhat

$>37-100$

Volatilized

(not

detected in

slag)

Somewhat

2-21

Insufficient
data

High

$0.06-0.8$

Entrained
Entrainment of Fe is most likely due to its presence in ilmenite and zirconia which are 98 and $100 \%<0.175 \mathrm{~mm}$, respectively. It was likely transported to the baghouse as entrained feed dust.

About $1 / 2$ of the $\mathrm{Hg}$ partitioned to the baghouse while $<10 \%$ was detected in the fume traps, suggesting significant volatilization of $\mathrm{Hg}$ compounds.

A more volatile metal, $\mathrm{K}$ may have vaporized to a reasonable degree, although any carbonates of $\mathrm{K}$ were most likely entrained due to insufficient time and temperatures in the furnace for decomposition. Large amounts of $\mathrm{KCl}$ in the baghouse for the Sseries was probably from volatilization before or after reaction to form $\mathrm{KCl}$. $\mathrm{KCl}$ in the baghouse for the $\mathrm{N}$-series tests and the M60-Mod test were likely from feed entrainment of $\mathrm{K}_{2} \mathrm{CO}_{3}$ (up to $6 \%$ in the feed) followed by reaction to form $\mathrm{KCl}$. $\mathrm{KCl}$ was not observed in the baghouse for the M60 test, when there was little $\mathrm{KCl}$ or $\mathrm{K}_{2} \mathrm{CO}_{3}$ in the feed, but still $1.5 \% \mathrm{~K}_{2} \mathrm{O}$ in the feed.

The minimal partitioning of $\mathrm{Mg}$ to the baghouse and small particle size of $\mathrm{Mg}$-containing additives suggests that it was largely entrained feed dust. 
Table 4-4. (continued).

$\mathrm{Na} \quad \mathrm{Na}_{2} \mathrm{O}$ in mullite, silica, soil, pebble lime, and zirconia, $0.03-1.28 \% ; \mathrm{NaCl}$ in salt and soda ash, $0.08-99.7 \% ; \mathrm{Na}_{2} \mathrm{CO}_{3}$ in soda ash, $99.6 \% ; \mathrm{Na}_{2} \mathrm{SO}_{4}$ in soda ash, $0.15 \% ; \mathrm{Na}$ in pollucite, $1.5 \%$

$\mathrm{Ni} \quad \mathrm{NiO}$ in soil and mill scale, 43.3-1,900 ppm; Ni in copper powder, electrolytic iron, and stainless powder, $0.0012-10.4 \%$

$\mathrm{PO}_{4}$ in soil and mill scale, 0.04-0.29\%; $\mathrm{P}_{2} \mathrm{O}_{5}$ in magnetite, $0.02-0.09 \%$; $P$ in electrolytic iron, stainless powder, mill scale, and titania, 8-200 ppm shot, pebble lime, and potash, 5 ppm-100\% salt, $0.04-6 \% ; \mathrm{SO}_{3}$ in pebble lime, $0.15 \% ; S$ in magnetite, titania, copper powder, electrolytic iron, and stainless powder, 6-2,000 ppm

Likely

2-16

Insufficient data

The presence of $\mathrm{Pb}$ in the baghouse catch from $\mathrm{M} 60$ and $\mathrm{M} 60$. Mod tests indicates that $\mathrm{Pb}$ volatilized appreciably from the melt in elemental, oxide, or chloride forms. $\mathrm{Pb}$, with a high vapor pressure and low boiling point, has extreme volatility under all conditions \& experienced enhanced vaporization in the $S 60$ and S60-IV melts as the chloride.

$\mathrm{S}$ was primarily oxidized to gaseous $\mathrm{SO}_{2}$ and may have been scrubbed from the gas by carbonates in the baghouse filter cake; some $\mathrm{CaSO}_{4}$ may have been entrained. powder, $1 \mathrm{ppm}$ 
Table 4-4. (continued).

Si

$\mathrm{SiO}_{2}$ in magnetite, mullite,

pollucite, silica, soil, talc, titania,

wollastonite, pebble lime, mill

scale, cerium oxide, ilmenite, and

zirconia, 0.21-96\%; Si in

wollastonite, electrolytic iron,

stainless powder, and mill scale,

25-8,000 ppm

$\mathrm{Ti} \mathrm{TiO}_{2}$ in magnetite, mullite, silica, soil, titania, wollastonite, pebble lime, ilmenite, and zirconia,

$0.01-95.8 \%$

$\mathrm{Zn} \quad \mathrm{ZnO}$ in soil, $100 \mathrm{ppm} ; \mathrm{Zn}$ in copper powder and zinc powder, 1 ppm-99.6\%

$\mathrm{Zr} \quad \mathrm{ZrO}_{2}$ in soil, titania, ilmenite, and zirconia, 0.01-95\%; $\mathrm{ZrO}_{2}+\mathrm{HfO}_{2}$ in zircon, $60 \%$
High

$0.3-0.7$

Entrained

The minimal partitioning of $\mathrm{Si}$ to the baghouse was most likely due to entrainment of $\mathrm{Si}$ from the feed material fines such as cerium oxide, ilmenite, and zirconia, which are 100,98 , and $100 \%$ $<0.175 \mathrm{~mm}$, respectively.

$0.04-0.2$

Entrained

Ti was most likely carried as entrained feed dust to the baghouse due to its low volatility.

$\mathrm{Zn}$ primarily volatilized to the baghouse due to its high vapor pressure and low boiling point.

High

$0.01-0.8$

Entrained

Present in ilmenite and zirconia, (with particle size of 98 and $100 \%<0.175 \mathrm{~mm}$ ), $\mathrm{Zr}$ was most likely entrained in the offgas from the feed material fines. 


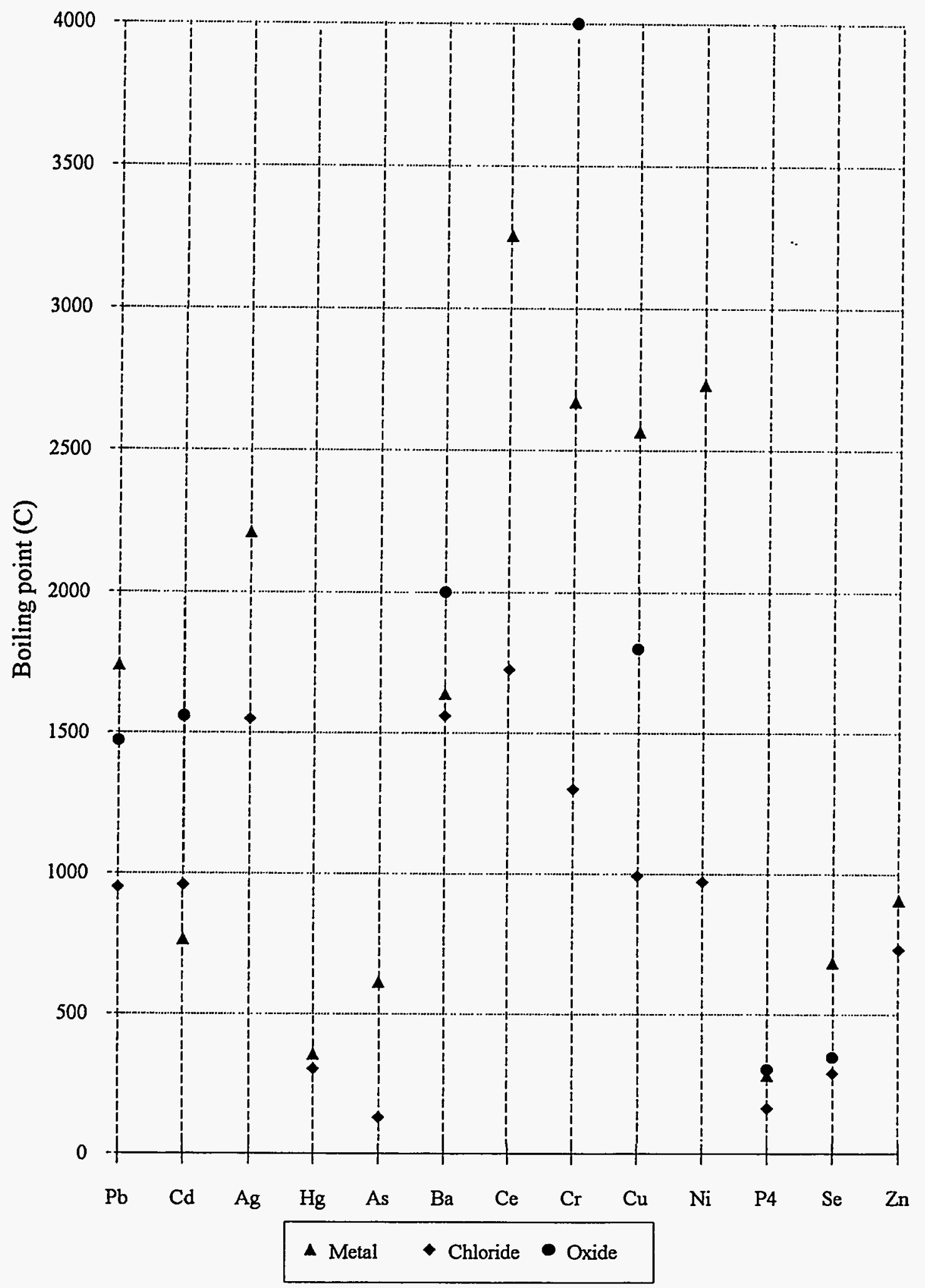

Figure 4-9. Boiling point of selected metals, metal oxides, and metal chlorides. 
the gas and melt region around the electrodes, where conditions may be more reducing due to the reducing effect of the graphite electrodes. Chlorides of some metal species may volatilize from this region especially during the S-series tests. The relatively cool offgas temperatures during the baseline tests may have tended to "freeze" redox and other reactions in very nonequilibrium proportions, increasing the potential for chlorides and other reduced metal species.

The partitioning to the baghouse increases significantly for compounds with boiling points below $1,600^{\circ} \mathrm{C}$, which is the range of most of the slag temperatures during the baseline tests. Perhaps the main reasons that partitioning to the baghouse for these low-boiling point compounds was not much higher were (a) the effect of the cold top, (b) the solubility of the oxides of these species in the slag, and (c) the solubility of some of the metal elements in the metal heel.

Up to about $64 \%$ of the $\mathrm{Pb}$ and $43 \%$ of the $\mathrm{Zn}$ in the feed partitioned to the baghouse, while about $18 \%$ of the $\mathrm{Pb}$ and less than $15 \%$ of the $\mathrm{Zn}$ was detected in the fume traps. This enrichment of $\mathrm{Pb}$ and $\mathrm{Zn}$ suggests significant volatilization of $\mathrm{Pb}$ and $\mathrm{Zn}$ compounds as was expected at melt temperatures up to $1,800^{\circ} \mathrm{C}$. $\mathrm{Pb}$ was present in the $\mathrm{M} 60$ feed as large shot which could not be entrained. It was clearly transported as a vapor from the melt to the APCS. Excluding the M60 test when several of the toxic metals were spiked into the feed mixture, the highest partitioning of $\mathrm{Pb}, \mathrm{Cu}$, and $\mathrm{P}$ occurred for the $\mathrm{S} 60$ or S60-IV tests, when large amounts of $\mathrm{Cl}$ existed. This result is consistent with known higher volatilities of toxic metals in the presence of $\mathrm{Cl}^{11,13,7}$

Tables K.1 through K.9 in Appendix K, list for each furnace feed the most representative slag composition (MRSC) and the composition of residues recovered from the fume traps and baghouse. The concentrations of metal with known higher vapor pressure, such as $\mathrm{As}, \mathrm{Pb}$, and $\mathrm{Zn}$, were higher in the baghouse solids, less in the fume trap residues, and least in the slags. Concentration factors for $\mathrm{Pb},(\mathrm{mg} / \mathrm{kg}$ in feed compared to $\mathrm{mg} / \mathrm{kg}$ in fume trap and baghouse solids) were very large ( 71 for S60, 83 for S60-IV, 58 for N80, and 48 for N80-IV), indicating extreme volatility under all conditions and enhanced vaporization in the S60 and S60-IV melts as the chloride.

Other volatile metals, such as $\mathrm{Cd}, \mathrm{Cs}, \mathrm{K}, \mathrm{Na}$, and $\mathrm{Se}$, were also concentrated in the baghouse solids. Transport of these metals may occur by reduction of the oxide to metal in the vicinity of the electric arc, or distillation of the metal from the molten slag, followed by reaction with atmospheric species to form very fine particles including oxides, hydroxides, chlorides, and sulfates. The resulting fine particles could then be entrained within the offgas and carried out of the furnace. The concentrations of chlorine and sulfur in the baghouse were also higher than in the fume traps, probably due to reaction or absorption of gaseous $\mathrm{HCl}$ and $\mathrm{SO}_{2}$ with carbonates of sodium and potassium in the filter cake.

Copper, which also was concentrated in the baghouse solids, was likely transported as the volatile chloride trimer, $\mathrm{Cu}_{3} \mathrm{Cl}_{3}$, suggesting that the volatility of $\mathrm{Cu}$ is similar to the volatility of $\mathrm{Pb}$ in the presence of $\mathrm{Cl}, \mathrm{Cd}$, and $\mathrm{Hg}$.

The volatility of $\mathrm{Ag}$ is also increased in the presence of $\mathrm{Cl} . \mathrm{Ag}_{2} \mathrm{O}$ was not detected in the slags (detection limit of $1 \mathrm{mg} / \mathrm{kg}$ ), except for the $S 60 \mathrm{slag}$, for which the last four slag molds filled during the $\mathrm{S} 60$ test (4,000 lb of slag) contained from 5 to $9 \mathrm{mg} / \mathrm{kg} \mathrm{Ag}_{2} \mathrm{O}$ (Table $\mathrm{H}-2$ in 
Appendix $\mathrm{H}$ ). The concentration of $\mathrm{Ag}_{2} \mathrm{O}$ paralleled the concentration of $\mathrm{CuO}$ in the $\mathrm{S} 60$ slag as the test progressed, with both reaching maximum concentrations in the seventh large slag ingot $(6,000 \mathrm{lb}) . \mathrm{CuO}$, present in the soil at the $56 \mathrm{mg} / \mathrm{kg}$ level, was present at the $3,300 \mathrm{mg} / \mathrm{kg}$ level in the mill scale, which was melted with RWMC soil in the shakedown test. The correlation indicates that $\mathrm{Ag}$ and $\mathrm{Cu}$ originated from the same source, and that source is likely the mill scale. A plausible explanation is that copper was carried over in the metal ingot that was formed during the shakedown test. The delay in the appearance of $\mathrm{Ag}_{2} \mathrm{O}$ and $\mathrm{CuO}$ in the $\mathrm{S} 60$ slag is the time interval required to melt the metal ingot.

\subsubsection{Partitioning of the M60 Feed Mixture}

The M60 feed mixture was unlike the other feed mixtures in that it contained significant quantities $(32.4 \%)$ of elemental metals including iron (27\% of the total mixture), nickel $(0.96 \%)$, chromium (1.7\%), aluminum (5.85\%), lead (0.74\%), and copper (0.74\%). Cerium alloyed with iron was also added as a single feed spike input to the M60 bath during the M60-Mod test. The partitioning of these metals plus the oxides of these metals in the soil and other feed additives for both the single M60 run and the combined M60 plus M60-Mod tests are shown in Figures 4-10 (a) and (b).

Some metals that partitioned significantly to the slag or the APCS solids during the other feed mixtures partitioned significantly to the metal phase during the M60 and M60-Mod tests. The slag was not sufficiently oxidizing to oxidize all of the metals in the M60-test, although out of $1,057 \mathrm{lb}$ of total elemental metals fed during the M60 run, only $789 \mathrm{lb}$ were added to the metal heel. Approximately one-fourth of the elemental metal was oxidized into the slag, with some volatilized into the offgas. Like the other tests, the $\mathrm{Pb}$ and $\mathrm{Zn}$ partitioned significantly to the furnace offgas and were captured in the APCS. Zinc was retained only slightly in the metal phase. Over half of the $\mathrm{Zn}$ partitioned to the offgas due to its volatility, while most of the remainder was oxidized and retained in the slag. As, $\mathrm{Cr}$, and $\mathrm{P}$ partitioned to the offgas in significantly decreasing amounts compared to the earlier tests. Very little chromium was evolved to the APCS. Three-fourths of the $\mathrm{Cr}$ was oxidized to the slag, and the remainder was retained as metal in the metal phase. No $\mathrm{Ce}$ was detected in the metal product, even after the ingot of $\mathrm{Ce} / \mathrm{Fe}$ alloy was added to the furnace.

With the presence of the metal heel and elemental metal additives, $\mathrm{Fe}, \mathrm{Ni}, \mathrm{As}, \mathrm{P}$, and $\mathrm{Cu}$ partitioned significantly ( $85 \%$ or more) to the metal phase. Most (>97\%) of the $\mathrm{Al}$ and $\mathrm{Ce}$ partitioned to the slag, implying nearly complete oxidation and retention of these elements in the slag. The behavior of $\mathrm{Ce}$ in this test indicates that essentially all plutonium will partition to the slag as desired, leaving the metal product uncontaminated.

As shown in Figure 4-10 (b), there were some subtle changes in the partitioning for the combined M60 and M60-Mod test day compared to the single M60. During the M60 test, carbon partitioned over $60 \%$ to the metal phase and less than $30 \%$ to the slag. Partitioning values for the all-day test showed carbon partitioning less than $30 \%$ to the metal and almost $60 \%$ to the slag. Partitioning to the metal for $\mathrm{P}, \mathrm{As}, \mathrm{S}$, and $\mathrm{Cr}$ also decreased. This suggests that as the test proceeded, there was continued oxidation of these metal alloy components and net mass transfer from the heel to the slag. As, $\mathrm{S}$, and $\mathrm{Pb}$ were further volatilized from the slag into the offgas 


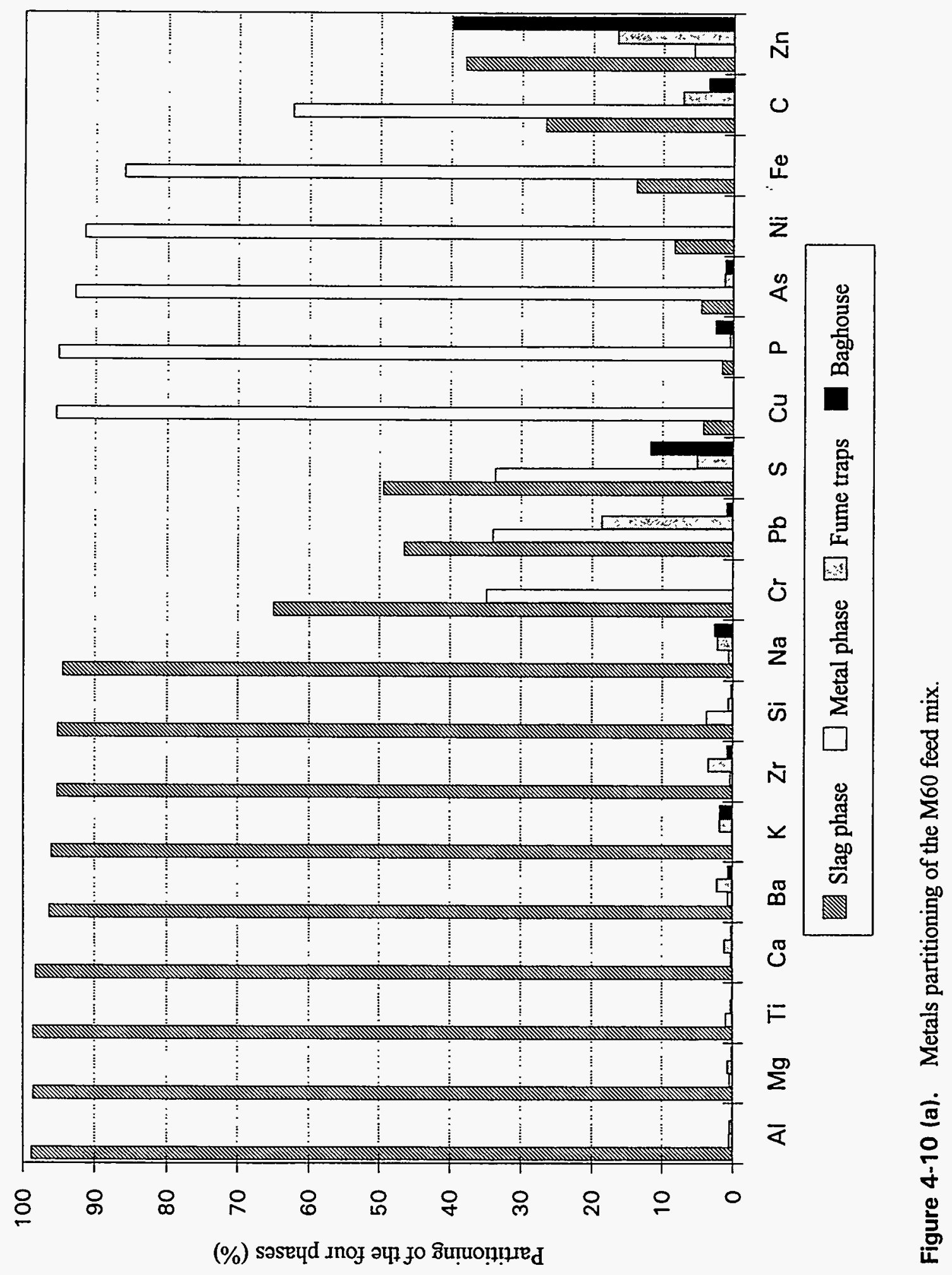




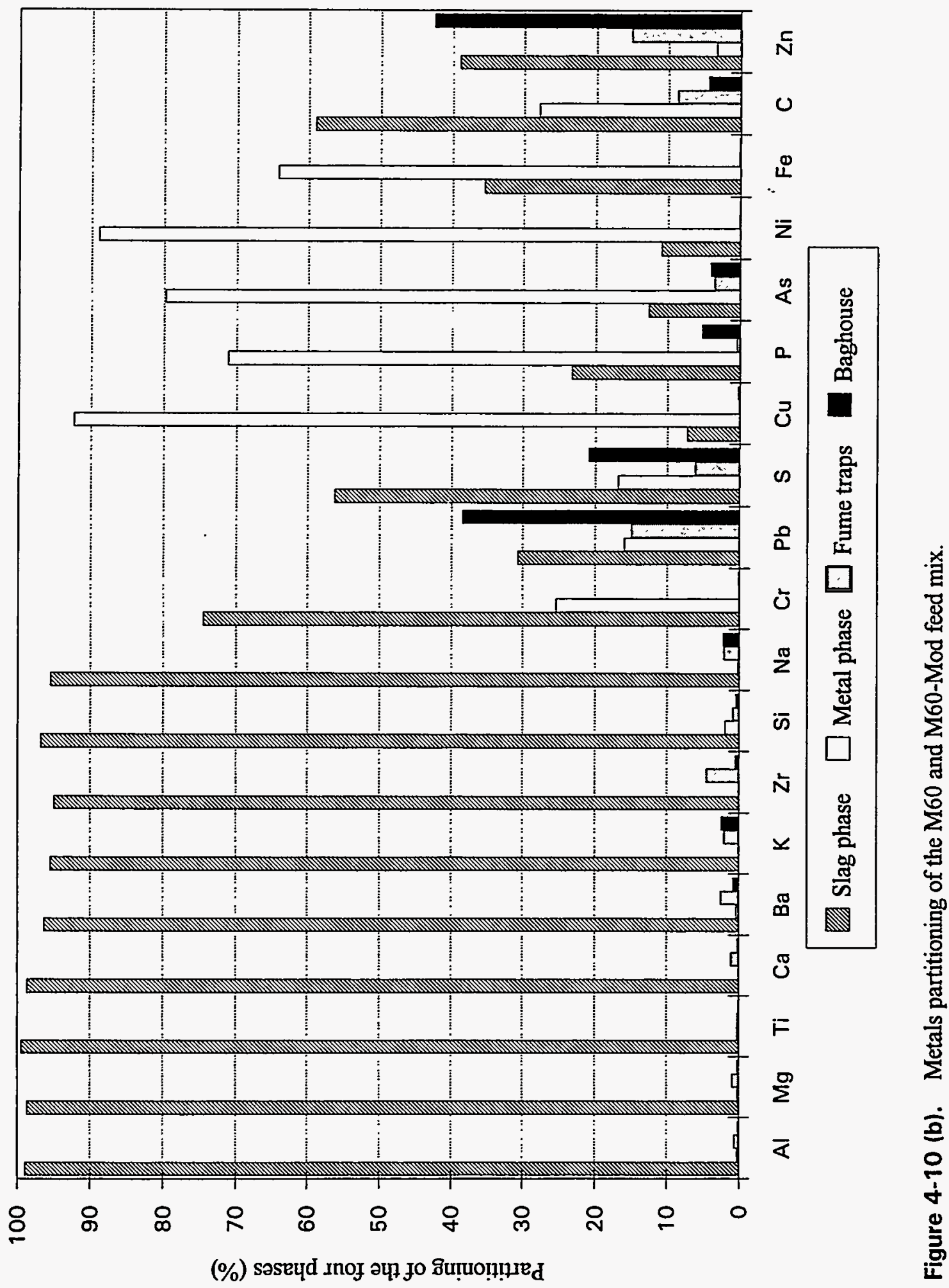


where they were captured in the APCS, increasing the partitioning values to the baghouse. Thus, for $\mathrm{C}, \mathrm{P}$, and $\mathrm{Cr}$, the rate of oxidation was greater than the rate of volatilization while for As, $\mathrm{S}$, and $\mathrm{Pb}$ rate of volatilization from the slag exceeded the rate of oxidation from the metal.

The amounts of even the more volatile $\mathrm{Pb}$ and $\mathrm{Zn}$ retained in the slag or the metal suggest that up to one-half or more of these demands may be retained in the glass-ceramic product or in the recyclable metal alloy. This partitioning also suggests that APCS solids can be recycled back into the furnace for a net reduction in the amount of these volatile metals and total APCS solids that must be disposed of.

\subsubsection{Elemental Mass Balances}

Mass balances for individual elements are shown in Tables U-1 through U-5, Appendix U, and are also shown graphically in Figure 4-11. The input and output mass balances were used to calculate the amount of $\mathrm{MgO}$ hearth refractory dissolution by assuming unity (mass out divided by mass in $=1$ ) for the $\mathrm{Mg}$ balance. The difference between the output mass of $\mathrm{Mg}$ and the input mass of $\mathrm{Mg}$ from the feed was assumed to be due to dissolution of the $\mathrm{MgO}$ refractory. The mass balances suggest that only a small amount of $\mathrm{MgO}$ hearth refractory dissolution (10 lb of $\mathrm{MgO}$ ) occurred during the shakedown test, but that the S60 slag at the operating melt temperatures was very corrosive to the refractory, causing dissolution of $910 \mathrm{lb} \mathrm{MgO}$ during the S60 test and $57 \mathrm{lb}$ during the S60-IV test. Smaller amounts, thought to be within the analysis accuracy of the feed mixtures and the products, were calculated for the subsequent test days. Since these amounts of potential refractory dissolution were small, they were not included in the mass balance; $\mathrm{Mg}$ closure for these test days was not assumed to be unity.

There was also a difference between the amount of iron measured in the furnace products compared to the input amount in the feeds. No metal product was tapped for any of the feed mixtures, including the M60 feed mixture that contained $32.4 \%$ elemental metals. All of the metal product that may have been produced during the shakedown and baseline tests was removed as a solidified metal heel after completion of the test program. This metal heel could not be tapped out of the furnace due to the lowering of the hearth below the metal tap hole by the dissolution of the $\mathrm{MgO}$ refractory hearth early in the test program. Therefore, the iron balance closure for the different test days was also assumed to be unity, to estimate the amount of iron that apparently was added to the metal heel for each test. Between 1-180 lb of iron was calculated as added to the metal heel for each of the feed mixtures except for the M60 mixture. For the M60 feed mixture, $666 \mathrm{lb}$ of iron was calculated for addition to the metal heel. The added iron (and other metals) to the heel for the M60 test was due to added elemental metals in the feed mixture, rather than from reduction of oxides as suspected for the other tests.

Iron, added to the metal heel for all feed mixtures except the M60 feed mixture, was from reduction of iron oxide in the melt by carbon from the graphite electrodes. This was possible within the immediate vicinity of the electrodes, where the levels of oxygen were likely considerably lower than the average levels in the furnace, and the carbon in the graphite electrodes can act as a reducing agent for metal oxides. Metal formation by carbothermic reduction of metal oxides is increased by viscous slags like those of the baseline tests that have poor thermal and electrical conductivity, elevating the minimum slag temperatures needed for continuous tapping. 
$\varepsilon \varepsilon-\triangleright$

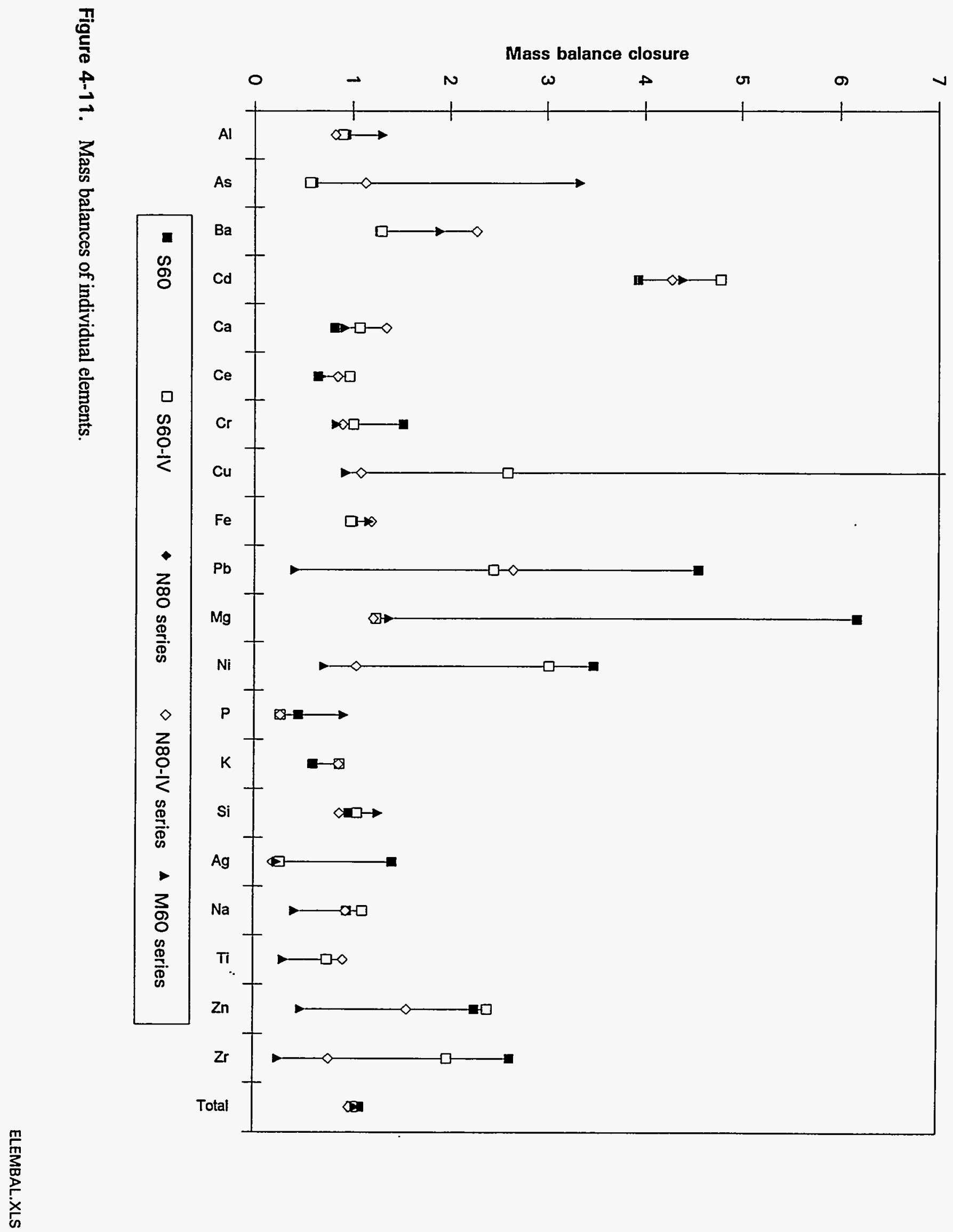


Mass balance closure was significantly above or below unity for many of the metals. Causes for closure deviating from unity for individual metals included (a) low or nondetectable measured levels in the feed or output streams, (b) incomplete feed material analyses from suppliers, or (c) erroneous feed material analyses from suppliers. Very low or nearly nondetectable levels of measured values in the feed mixtures or in the product was the most prevalent cause of mass balance deviation. Elements in this category for which the analyses and mass balances are very inaccurate include $\mathrm{As}, \mathrm{Cd}, \mathrm{Hg}, \mathrm{Mn}$, and Se. Other elements have especially low or high closure values due probably to inaccurate assays of feed additives. These assays were provided by the additive suppliers. Some feed material analyses provided by suppliers were partially proprietary, and some others did not include complete analyses. These inaccuracies can have a large effect especially when the feed concentrations used in the calculations are low or nondetectable. Elements with undesirably high closure values include $\mathrm{Cd}, \mathrm{Cu}, \mathrm{Pb}, \mathrm{Hg}, \mathrm{Ni}, \mathrm{Se}$, and $\mathrm{Zn}$.

The closure for Ce, the TRU surrogate, was below unity for some of the tests ( $660, \mathrm{~N} 80$, N80-Mod, M60, and M60-Mod). This was due to erroneous composition information from the $\mathrm{CeO}_{2}$ supplier. The supplier claimed $60 \% \mathrm{CeO}_{2}$ in the cerium oxide concentrate, whereas the measured concentration (by neutron activation) of one canister was $35 \% \mathrm{CeO}_{2}$.

A carbon balance (Table 4-5) can lend insight into the fate of carbon in the system. Sources of carbon include the graphite electrodes (oxidizing to $\mathrm{CO}$ and $\mathrm{CO}_{2}$ ), inorganic carbonates in the feed mixtures, and trace amounts of organic carbon in the feed mixtures. This carbon balance is based on the comparison of the measured total output carbon ( $\mathrm{CO}$ and $\mathrm{CO}_{2}$ in the offgas and the much smaller output levels of carbon in the slag, metal product, and APCS solids) to the total input carbon measured in the feed mixtures and from graphite electrode weight loss. The carbon balance for the S60 and S60-IV tests is reasonably good except for a low mass balance closure of 0.71 for the second S60 sampling period. This was likely due to lower input amounts of feed carbonates due to segregation during feeding for the sample period or lower carbonate levels than expected in the feed mixtures. Erroneous offgas $\mathrm{CO}$ and $\mathrm{CO}_{2}$ measurements were not likely because the continuous monitoring procedure strictly followed the EPA sampling methods for $\mathrm{CO}$ and $\mathrm{CO}_{2}$, including all specified calibrations, bias checks, leak checks, and drift calculations. These quality assurance (QA) activities are used in source emissions testing to verify the validity of the measured data. Any data found to be questionable from the QA checks was invalidated and not used. The QA checks have validated the accuracy of the measured $\mathrm{CO}$ and $\mathrm{CO}_{2}$ for the other reported time periods.

The carbon balance for the M60 test (mass closure of 0.90 ) was somewhat low but within reasonable combined accuracies for the input and output measurements. The carbon balance for all of the valid N80 series of mixtures (N80-Mod, N80-IV, N80-IV-Mod and M60-Mod) was generally low, ranging from 0.57 to 0.69 . This low carbon balance trend for the same series of mixtures (all $\mathrm{N}$-series) suggests that the carbonate material was lower in the original N80 mixture than was calculated. 
Table 4-5. Carbon balance for the baseline tests.

\begin{tabular}{|c|c|c|c|c|c|c|c|c|c|c|c|c|c|c|}
\hline $\begin{array}{l}\text { Feed } \\
\text { type }\end{array}$ & $\begin{array}{c}\text { Feed } \\
\text { conc. } \\
(\%) \\
\end{array}$ & $\begin{array}{l}\text { Amt. of C } \\
\text { in feed } \\
(\mathrm{lb} / \mathrm{hr})\end{array}$ & $\begin{array}{c}\text { Electrode } \\
\text { consumption } \\
(\mathrm{lb} / \mathrm{hr})\end{array}$ & $\begin{array}{c}\text { Conc. of C } \\
\text { in slag } \\
(\mathrm{ppm}) \\
\end{array}$ & $\begin{array}{l}\text { Amt of C } \\
\text { in slag } \\
(\mathrm{lb} / \mathrm{hr})\end{array}$ & $\begin{array}{c}\text { Conc. of C } \\
\text { in APCS } \\
\text { solids } \\
\text { (ppm) }\end{array}$ & $\begin{array}{c}\text { AmL of C } \\
\text { in APCS } \\
\text { solids } \\
\text { (b/hr) }\end{array}$ & $\begin{array}{c}\text { Conc. of C } \\
\text { in metal } \\
\text { product } \\
\text { (ppm) } \\
\end{array}$ & $\begin{array}{c}\text { Amt of C } \\
\text { in metal } \\
\text { product } \\
(\mathrm{lb} / \mathrm{hr}) \\
\end{array}$ & $\begin{array}{c}\text { Conc. of CO } \\
\text { at quench } \\
\text { outlet } \\
(\%) \\
\end{array}$ & $\begin{array}{l}\text { Conc. of CO } \\
\text { at quench } \\
\text { outlet } \\
(\mathrm{ppm})\end{array}$ & $\begin{array}{c}\text { Amt. of C } \\
\text { from } \mathrm{CO} 2 \\
\text { in offgas } \\
(\mathrm{b} / \mathrm{hr})\end{array}$ & $\begin{array}{c}\text { Amt of C } \\
\text { from CO } \\
\text { in offgas } \\
(\mathrm{b} / \mathrm{hr})\end{array}$ & $\begin{array}{c}\text { Mass } \\
\text { balance } \\
\text { closure }\end{array}$ \\
\hline$\$ 60$ & 0.88 & 9.8 & 6.61 & 245 & 0.0352 & 1,280 & 0.0312 & 0 & 0 & 2.17 & 3,362 & 15.8 & 2.44 & 1.12 \\
\hline S60 & 0.88 & 8.6 & 5.80 & 245 & 0.0276 & 1,280 & 0.0230 & 0 & 0 & 1.58 & 1,372 & 10.9 & 0.94 & 0.83 \\
\hline S60-IV & 0.78 & 12.5 & 9.54 & 443 & 0.0801 & 1,250 & 0.0312 & 0 & 0 & 2.68 & 6,224 & 18.6 & 4.31 & 1.04 \\
\hline S60-IV & 0.78 & 7.77 & 5.93 & 443 & 0.0475 & 1,250 & 0.0218 & 0 & 0 & 1.63 & 2,689 & 11.6 & 1.90 & 0.99 \\
\hline $\mathrm{N} 80$ & 2.91 & 36.2 & 7.40 & 576 & 0.1962 & 2,850 & 0.0542 & 0 & 0 & $\mathrm{NM}$ & $N M$ & NC & NC & NC \\
\hline N80-Mod & 3.74 & 25.6 & 4.08 & 185 & 0.0282 & 37,400 & 0.7819 & 0 & 0 & 3.21 & 5,682 & 22.4 & 3.96 & 0.91 \\
\hline N80-IV & 2.77 & 34.3 & 7.38 & 225 & 0.0553 & 14,700 & 0.3713 & 0 & 0 & 3.21 & 4,302 & 22.1 & 2.96 & 0.61 \\
\hline N80-IV-Mod & 2.38 & 31.7 & 7.92 & 327 & 0.0999 & 14,213 & 0.1934 & 0 & 0 & 3.01 & 4,228 & 19.1 & 2.68 & 0.56 \\
\hline M60 & 0.99 & 10.1 & 6.04 & 260 & 0.0000 & 4,205 & 0.0951 & 4,340 & 1.70 & 2.09 & 1,766 & 12.0 & 1.01 & 0.92 \\
\hline M60-Mod & 2.32 & 41.9 & 10.73 & 702 & 0.4931 & 5,480 & 0.1157 & 1,490 & 0 & 2.79 & 2,519 & 20.3 & 1.83 & 0.43 \\
\hline Notes: & $\begin{array}{l}\text { 1. Feedr } \\
\text { 2. Electr } \\
\text { 3. Slag } \\
\text { 4. Metal } \\
\text { 5. APCS }\end{array}$ & $\begin{array}{l}\text { ate for each se } \\
\text { ode consump } \\
\text { roduct rates } \\
\text { product rates } \\
\text { solids rates }\end{array}$ & $\begin{array}{l}\text { ampling run wa: } \\
\text { tion for each sar } \\
\text { were calculated } \\
\text { were calculate } \\
\text { were determined }\end{array}$ & $\begin{array}{l}\text { as determined } \\
\text { ampling period } \\
\text { from the con } \\
\text { ed from the cor } \\
\text { f from the con }\end{array}$ & $\begin{array}{l}\text { from the DAS } \\
\text { was determi } \\
\text { centration of } \\
\text { ncentration of } \\
\text { centration of }\end{array}$ & $\begin{array}{l}\text { system as the } \\
\text { led by multiply } \\
\text { arbon in the sl } \\
\text { carbon in the } \\
\text { carbon in the fi }\end{array}$ & $\begin{array}{l}\text { verage feedr } \\
\text { g the avera } \\
\text { times the w } \\
\text { etal product } \\
\text { ne multiplie }\end{array}$ & $\begin{array}{l}\text { ate for the resp } \\
\text { ge feedrate by } \\
\text { eighted slag to } \\
\text { times the weig } \\
\text { d by the partic }\end{array}$ & $\begin{array}{l}\text { ective time } p \\
\text { the pounds el } \\
\text { ap rate. } \\
\text { hhted amount } \\
\text { ulate emissio }\end{array}$ & $\begin{array}{l}\text { lectrode consur } \\
\text { of metal produ } \\
\text { on rate for the } r\end{array}$ & $\begin{array}{l}\text { med per ton of } \mathrm{fe} \\
\text { est divided by th } \\
\text { espective MMT }\end{array}$ & $\begin{array}{l}\text { eed material. } \\
\text { test. }\end{array}$ & respective & r test. \\
\hline
\end{tabular}




\section{PROPERTIES OF FURNACE PRODUCTS}

The ability to thermally treat complex heterogeneous mixtures and produce a homogeneous solid slag (glass/ceramic) waste form is a key advantage of arc melting for the treatment of radioactive and mixed wastes.

In addition to the primary slag product, other products from arc melting may include a tappable metal alloy product, offgas, and total particulate (entrained feed material and condensed material volatile) in the offgas. Slag and metal products, particulate collected in the fume traps and baghouse, and particulate collected isokinetically using Multiple Metals Train were analyzed in this test series to determine physical properties, chemical composition, crystalline makeup, and leachability.

\subsection{Slag Density and Waste Volume Reduction}

Volume reduction, an important consideration when handling, shipping, and storing the final waste form material, was determined by comparing the volume of the furnace feed material with the volume of the resultant slag. The volume reduction factor [(VRF) the ratio of feed volume to solid slag volume] is defined as:

$V R F=\frac{V_{\text {feed }}}{V_{\text {slag }}}=\frac{\rho_{\text {slag }}}{\rho_{\text {feed }}} \frac{m_{\text {feed }}}{m_{\text {slag }}}$

where $V_{\text {feed }}$ and $V_{\text {slag }}$ are the respective volumes of the material fed to the furnace and the slag tapped from the furnace, calculated using the densities $(\rho)$ and masses $(m)$ of the feed and the slag.

Values for VRF are shown in Table 3-1 (in Section 3). The feed density used in the calculations was the measured bulk density of the feed, while the slag density was measured from the 2-kg samples of slag. This comparison is based on a monolithic product slag, as obtained by casting slag into containers that would serve as shipping and storage containers.

Overall, the volume reduction factor for these surrogate wastes was 2.58 . The average volume of the product slag was the inverse of this value, or $39 \%$, of the feed material volume. This volume reduction is primarily due to the differences in the feed material density and the slag density, but also due to the reduction of solid material through gas evolution. The small volumes of APCS solids and metal product were not included in this evaluation, since the production of these other products can be tailored according to operating conditions.

Appreciable segregation of solid solution phases occurred during natural cooling of the large slag (glass/ceramic) ingots, leading to speculation about changes in chemical composition and mineralogy from edge to center of each ingot. This segregation occurred when the center of each slag ingot cooled much more slowly than the outside edge. The rate of cooling is known to affect the solid solution phase formation. ${ }^{10}$ No attempt was made in this series of tests to tailor the glass ceramic formation via controlled cooling due to limited funding. Glass ceramic tailoring by controlled cooling and analysis of resultant mineralogy is strongly recommended for future studies. 
Fiscal constraints also precluded detailed chemical and morphological characterization of each ingot, but archived samples provide that option in the future.

The specific gravity of rim and core material was determined for the ingot of slag that was most representative of each waste mixture. The results, listed in Table 5-1, reveal generally that slag in the core was more dense than slag in the rim, thereby supporting the visual observation of phase segregation during cooling. Crystalline phases were also visually identifiable in the cores of numerous slag ingots.

\subsection{Mineralogy of the Furnace Products}

The mineralogy of the 2-kg slag samples was provided by X-ray diffraction (XRD) analyses. The resulting data are in Appendix J. The data indicate nearly complete vitrification of these relatively small samples of molten slag undergoing natural but rapid cooling. The only significant exception is the $\mathrm{S} 60$ slag, which contained about $16 \% \mathrm{MgO}$ (partially from dissolution of cast hearth refractory). The sample of S60, obtained after tapping nearly 6,000 lb of slag from the furnace, contained the mineral forsterite $\left(\mathrm{Mg}_{2} \mathrm{SiO}_{4}\right)$, which is a very stable naturally occurring mineral. Each of the waste mixtures, in the absence of major contamination, produced a vitreous slag by moderately rapid cooling.

Residues from the fume traps and baghouse were also characterized by XRD analysis (Appendix J). The results indicate that the contents of the fume traps were comprised largely of minerals present in the soil and additives from which the furnace feeds were compounded. This result is to be expected from entrainment of feed considering the particle size range of the soil and most of the additives, which were finely divided mineral concentrates. Examples of feed minerals that were detected in the APCS solids include calcite, cerium oxide, ilmenite, lime, magnetite, potassium carbonate, quartz, sodium carbonate, talc, wollastonite, zircon, zirconia, and common minerals in the soil including albite, forsterite, and plagioclase feldspar. Clearly the minerals such as calcite and carbonates of sodium and potassium represent entrained feed material that also did not experience sufficient time and temperatures (around $1,000^{\circ} \mathrm{C}$ ) in the furnace for decomposition.

The only minerals detected by XRD analyses of the baghouse catches not traceable to direct entrainment of these minerals from the feed materials were the alkali metal chlorides and compounds of $\mathrm{Pb}$ and $\mathrm{Zn}$. The concentrations of these materials in the XRD analyses increased from trace levels $(1-10 \mathrm{wt} \%)$ in fume trap 1 to secondary levels $(20-60 \%)$ in the baghouse. The significant presence of $\mathrm{NaCl}$ and $\mathrm{KCl}$ in the baghouse must be due to either (a) volatilization of materials from the melt preceded by or followed by chemical reactions, or (b) reaction of entrained feed materials (sodium and potassium carbonates or lime) in the baghouse filter cake with gaseous $\mathrm{HCl}$ in the baghouse.

The highest baghouse $\mathrm{NaCl}$ levels were observed for the S-series tests, when there was $2 \%$ $\mathrm{NaCl}$ in the feed mixtures. While $\mathrm{NaCl}$ volatilization was likely for the S-series tests, reactions of entrained feed material carbonates in the baghouse with gaseous $\mathrm{HCl}$ is also a likely source of alkali chlorides in the baghouse. Indeed, this is the principle of dry acid gas scrubbing, and carbonates and lime were present in large amounts in all of the feed mixtures as components of the soil and additives. 
Table 5-1. Specific gravity of large slag ingots.

\begin{tabular}{|c|c|c|c|}
\hline \multirow[b]{2}{*}{ Slag ingot } & \multicolumn{2}{|c|}{ Specific gravity } & \multirow{2}{*}{$\begin{array}{c}\text { Specific gravity } \\
\text { increase in core } \\
(\%)\end{array}$} \\
\hline & Rim & Core & \\
\hline S60-S1 & 2.83 & 3.06 & 7.5 \\
\hline S60-S6 & 2.92 & 2.96 & 1.4 \\
\hline S60-S7 & 2.94 & $\mathrm{NA}$ & $\mathrm{NC}$ \\
\hline S60 Average & 2.90 & 3.01 & 3.7 \\
\hline S60-IV-S3 & 3.01 & 3.10 & 2.9 \\
\hline S60-IV-S6 & 2.99 & 3.00 & 0.3 \\
\hline S60-IV Average & 3.00 & 3.05 & 1.6 \\
\hline N80-S3 & 2.70 & 2.73 & 1.1 \\
\hline N80-Mod-S6 & 2.97 & 3.02 & 1.7 \\
\hline N80-Mod-S7 & 3.13 & 2.97 & 5.4 \\
\hline N80-Mod-Mean & 3.05 & 3.00 & 1.7 \\
\hline N80-IV-S4 & 2.81 & 2.84 & 1.1 \\
\hline N80-IV-Mod-S10 & 3.08 & 3.16 & 2.5 \\
\hline M60-Mod-S1 & NA & 2.92 & $\mathrm{NC}$ \\
\hline M60-Mod-S2 & 2.87 & 2.91 & 1.7 \\
\hline M60-Mod-Mean & 2.87 & 2.91 & 1.7 \\
\hline
\end{tabular}


$\mathrm{Pb}$ and $\mathrm{Zn}$ were metal additives in the $\mathrm{M} 60$ feed. The particle sizes and densities of these metals were too large for entrainment to be a likely scenario. Also, the volatilities of these metals and post reaction species of these metals are relatively high (Section 6.2.2) so volatilization in the furnace followed by condensation in the APCS and collection in the baghouse is the most likely cause for the appearance of $\mathrm{Pb}$ and $\mathrm{Zn}$ species in the baghouse. This is especially true for the final M60-Mod feed test, when $\mathrm{Pb}$ and $\mathrm{Zn}$ were not included as components in the N80-IV-Mod feed material used during this test. $\mathrm{Pb}$ and $\mathrm{Zn}$ were present in the existing melt inventory from when M60 was fed to the furnace.

\subsection{Elemental Composition of Furnace Product Slag, Metal, and APCS Solids}

The 2-kg samples of slag obtained during the filling of each conical slag mold were chemically analyzed for 26 elements. In the slag, it can be accurately assumed that the elements exist as oxides. The chemical analyses weighted in terms of slag oxides are shown in Appendix $H$. This appendix also shows the weight of each slag ingot and the weighted mean composition of product slag for each furnace feed. The analyses for individual slag ingots do not add up to exactly $100 \%$ as they should, owing to analytical error for specific components, incomplete analysis for all components, different oxidation states for components within the analytical sample, and the absorption of moisture by the analytical samples. The analyses were not normalized to $100 \%$ to avoid changing any of the analyses and to show the combined accuracy of the analyses. Since the total compositions add up to very near $100 \%$ in most cases, the assumptions regarding the oxides and the analytical results are believed to be quite accurate for most of the elements.

Significant changes in the composition of the slag occurred as each melting test progressed. These changes are highlighted by the graphs in Appendix I, which present the concentrations of important slag-forming oxides and heavy metals $\left(\mathrm{Cs}_{2} \mathrm{O}, \mathrm{PbO}\right.$, and $\mathrm{ZnO}$, and the TRU surrogate $\mathrm{CeO}_{2}$ ) in the product slags as a function of the weight of slag tapped from the furnace. The slag compositions at the beginning of each different test condition were affected by slag remaining in the furnace from the prior feed mixture, even after the metal tap hole was opened to drain the furnace. Approximately $600 \mathrm{lb}$ of slag and metal heel remained in the furnace from test to test, in the region below the metal tap hole where the $\mathrm{MgO}$ cast refractory hearth was dissolved.

After some hours of operation on each feed mixture while the residual slag was diluted and tapped out of the furnace, the slag tended to reach a steady state composition, termed "most representative slag composition" (MRSC). The MRSC for each furnace feed is shown in Table 5-2 and Appendix K. The MRSC for slag derived from each furnace feed is the weighted mean composition of slag tapped from the furnace after the product slag reached a steady state composition. For most furnace feeds, the slag reached a steady state composition after 3,000 to 4,000 lb was tapped from the furnace. The modified feeds, N80-Mod, N80-IV-Mod, and M60-Mod, were fed to existing molten pools of N80, N80-IV, and M60 slag, respectively. Therefore, the initial slags tapped after feeding the modified compositions were diluted with existing slag in the furnace. The weight of product slag derived from each modified furnace feed was calculated on the assumption that the weight of product slag was proportional to the weight of furnace feed. 
Table 5-2. Compositions of the slag products.

Most representative slag compositions (MRSC) ( $\mathrm{mg} / \mathrm{kg}$ ) from the different surrogate waste mixtures

\begin{tabular}{|c|c|c|c|c|c|c|c|c|}
\hline Component & RWMC soil & S60 & S60-IV & N80 & N80-Mod & N80-IV & N80-IV-Mod & M60 rod sample) \\
\hline Ag2O & $<1$ & 7 & $<1$ & $<1$ & $<1$ & $<1$ & $<1$ & $<1$ \\
\hline $\mathrm{Al} 2 \mathrm{O} 3$ & 88,003 & 74,960 & 70,969 & 91,998 & 68,557 & 69,435 & 59,324 & 139,823 \\
\hline As2O3 & 10 & 4 & 3 & 3 & 8 & 3 & 11 & 3 \\
\hline $\mathrm{BaO}$ & 940 & 696 & 770 & 931 & 637 & 979 & 683 & 1,082 \\
\hline $\mathrm{CaO}$ & 32,065 & 78,918 & 108,042 & 81,763 & 163,595 & 71,489 & 184,136 & 113,755 \\
\hline $\mathrm{CdO}$ & $<1$ & $<1$ & $<1$ & $<1$ & $<1$ & $<1$ & $<1$ & $<1$ \\
\hline $\mathrm{CeO} 2$ & $\mathrm{NC}$ & 2,852 & 4,679 & 2,436 & 2,138 & 4,034 & 3,392 & 4,825 \\
\hline $\mathrm{Cl}$ & $<100$ & 151 & 100 & 25 & 30 & 8 & 8 & 60 \\
\hline $\mathrm{CO} 2$ & 247 & 1,151 & 2,511 & 1,682 & 539 & 781 & 1,174 & 953 \\
\hline $\mathrm{CrO} 2$ & 1,120 & 947 & 727 & 350 & 555 & 442 & 591 & 21,004 \\
\hline $\mathrm{Cs} 2 \mathrm{O}$ & 10 & 1,573 & 2,194 & 366 & 543 & 62 & 58 & 66 \\
\hline $\mathrm{CuO}$ & 715 & 651 & 63 & 49 & 248 & 56 & 300 & 413 \\
\hline $\mathrm{Fe} 3 \mathrm{O} 4$ & 229,175 & 173,293 & 183,757 & 146,714 & 221,287 & 115,935 & 212,407 & 81,538 \\
\hline $\mathrm{HgO}$ & $<0.1$ & $<0.1$ & $<0.1$ & $<0.1$ & $<0.1$ & $<0.1$ & $<0.1$ & $<0.1$ \\
\hline $\mathrm{K} 2 \mathrm{O}$ & 20,262 & 7,506 & 9,550 & 60,693 & 39,410 & 60,317 & 46,234 & 24,092 \\
\hline $\mathrm{MgO}$ & 20,464 & 163,917 & 33,705 & 24,847 & 27,152 & 23,809 & 17,859 & 24,208 \\
\hline $\mathrm{Na} 2 \mathrm{O}$ & 17,380 & 5,979 & 20,228 & 75,491 & 53,507 & 79,489 & 61,412 & 17,793 \\
\hline $\mathrm{NiO}$ & 311 & 90 & 74 & 85 & 143 & 59 & 165 & 842 \\
\hline $\mathrm{P} 2 \mathrm{O} 5$ & 708 & 527 & 121 & 675 & 1,392 & 12 & 730 & 34 \\
\hline $\mathrm{PbO}$ & 20 & 52 & 10 & 10 & 10 & 26 & 23 & 1,217 \\
\hline $\mathrm{SO} 3$ & 17 & 8 & 114 & 390 & 200 & 231 & 206 & 750 \\
\hline $\mathrm{SeO} 2$ & $<1$ & $<1$ & $<1$ & $<1$ & $<1$ & $<1$ & $<1$ & $<1$ \\
\hline $\mathrm{SiO} 2$ & 458,015 & 462,101 & 484,504 & 509,025 & 383,023 & 439,043 & 278,494 & 549,815 \\
\hline $\mathrm{TiO}_{2}$ & 8,873 & 17,467 & 44,580 & 15,413 & 13,562 & 80,686 & 50,557 & 11,376 \\
\hline $\mathrm{ZnO}$ & 178 & 149 & 119 & 115 & 118 & 110 & 108 & 3,299 \\
\hline $\mathrm{ZrO} 2$ & 526 & 217 & 22,211 & 1,717 & 3,184 & 31,367 & 24,935 & 4,593 \\
\hline Total & 879,000 & 994,000 & 991,000 & $1,014,777$ & 979,837 & 976,000 & 942,806 & $1,001,541$ \\
\hline
\end{tabular}

Concentration (mg/kg) for the M60 waste mixture (from single M60 rod sample) 
The elemental composition of the metal phase remaining in the hearth is shown in Appendix K. Cerium, the TRU surrogate, was not detectable at a detection limit of $10 \mathrm{mg} / \mathrm{kg}$. The pad sample was taken following the spike of elemental cerium alloyed in a 3-lb ingot with $50 \%$ iron that was added during the M60/M60-Mod test day. Lack of detectable Ce in this sample supports the feasibility of decontaminating structural metals of TRU contaminants by oxidizing the TRU elements which then partition totally to the slag phase. It is apparent from the increase in the Ce concentration in the slag, and from lack of detectable $\mathrm{Ce}$ in the metal, that this desirable selective separation was accomplished in this test.

\subsection{Slag and APCS Solids Leachability}

Slag samples and APCS solids for each of the baseline tests were analyzed for leachability using the EPA Toxicity Characteristic Leachability Procedure (TCLP). The separate samples from the fume traps and baghouse for each test were combined and a single integrated APCS sample was analyzed for each test. Since the slag composition was known to change during each test, $2 \mathrm{~kg}$ samples taken during the filling of the first and the last slag molds were used for TCLP analysis. These two samples represent the extreme composition range for each product slag. Cerium, the TRU surrogate, was included in the TCLP analysis in lieu of conducting a separate analysis such as Materials Characterization Center (MCC-1) or Product Characterization Test (PCT-1) for the leachability of radionuclides. Archived samples may be further analyzed for leachability with later funding.

\subsubsection{Slag Leachability}

Cooling of these small $2 \mathrm{~kg}$ samples was uncontrolled and much more rapid than required to allow for the formation of tailored zirconolite crystals known to capture Ce even more effectively than the vitreous IEB product. The cooled slag product that was leach tested is representative of the glassy (vitreous) IEB.

Each sample was crushed to $<80$ mesh $(0.175 \mathrm{~mm})$, whereas the TCLP requires sizing to only $<1 / 4$ in. $(6.35 \mathrm{~mm})$. The specific surface area of $<80$ mesh particles is over 36 times the area of $<1 / 4$-in. particles, and since leachability increases with increasing surface area, these TCLP tests were much more severe than required.

The TCLP results for the slag samples are shown in Appendix N. Where possible (when the slag concentration of Ce or the RCRA TCLP metal was measurable), the percent of that element that leached was calculated based on the measured concentration in the slag and the amount that dissolved into the TCLP solution. Results are summarized as follows:

- All of the slags passed the TCLP test. TCLP metal leachability results were typically below detection limits, and less than one-tenth of the TCLP limits. Slags from the M60 and M60-Mod furnace feeds provided a severe test regarding chromium, which was present at levels exceeding $1 \%$ in the M60-S1 slag sample.

- The percent of dissolution (leaching) of cerium and toxic metals present in the slag was also typically low, when the detected concentrations were sufficient to enable calculation of the percent dissolved into the leachate. Percent of barium dissolved 
(leached) was fairly constant, under $8 \%$ of the barium in the slags. Chromium dissolution varied from essentially zero to around $19 \%$ of the chromium in the slag. Lead dissolution ranged under $6 \%$, while cerium dissolution ranged from near zero to $13 \%$. Ce dissolution was low or lower than for other metals, even without the presence of zirconolite crystals. Leaching percentages for the other metals could not be calculated due to low levels of those metals present in the slags or undetectable levels in the leachate.

- Increasing molar basicity slightly increased the tendency for chromium and cerium to leach from the slag (Figure 5-1), although the barium was not affected. The data indicate a positive correlation between molar basicity and the tendency for $\mathrm{Ce}$ to leach from the slag, consistent with the expectation that acidic slags are more resistant to weathering than basic slags. Even so, only a small or nondetectable amount of $\mathrm{Ce}$ and other metals were leached from the slag in any of the leach tests. Higher leach resistance of more acidic slags was expected, because higher levels of $\mathrm{SiO}_{2}$ (occurring in more acidic slags) increase the formation of silicate lattice structures.

- The presence of $\mathrm{TiO}_{2}$ and $\mathrm{ZrO}_{2}$ in the slag did not seem to affect the leachability of barium, chromium, lead, or cerium (Figure 5-2). This was not surprising because the samples were cooled too fast to enable formation of the zirconolite crystals expected regardless of the levels of $\mathrm{TiO}_{2}$ and $\mathrm{ZrO}_{2}$ used in the baseline tests. Specific post furnace cooling rate control for the slag will be required to obtain the tailored zirconolite crystals.

- The slag most susceptible to leaching of Ce was M60-Mod-S5, which contained the highest concentration of $\mathrm{Fe}_{3} \mathrm{O}_{4}$, thereby indicating a tenuous positive correlation between the iron oxide content of the slag and the tendency for $\mathrm{Ce}$ to leach from the slag.

\subsubsection{Leachability of APCS Residues}

The APCS residues represented primarily very finely divided feed material that was entrained into the offgas, and condensed volatile matter. Relative surface area for these samples was very large compared to that of the crushed slag samples. Also, the APCS residues were enriched in $\mathrm{As}, \mathrm{Ba}, \mathrm{Cd}, \mathrm{Ce}, \mathrm{Cl}, \mathrm{C}, \mathrm{Hg}, \mathrm{K}, \mathrm{Na}, \mathrm{Pb}, \mathrm{SO}_{3}$, Se, and $\mathrm{Zn}$. In a mixed waste vitrification operation, the APCS solids are not necessarily expected to pass TCLP leachability for all elements due to the high surface area and possible enrichment of TCLP metals.

The TCLP results for the APCS solid samples are shown in Appendix N. Where possible (when the concentration of Ce or the TCLP metal was measurable), the percent dissolution of that element was calculated based on the measured concentration in the APCS solids and the amount that dissolved into the TCLP solution. Results are summarized as follows:

- APCS solids, owing to their very small particle size and the prevalence of chlorides, were more susceptible to leaching than the associated slags. Nevertheless, TCLP metal leachability results were typically below detectable limits, and less than one-tenth of the TCLP limits for all elements except for $\mathrm{Cd}, \mathrm{Pb}$, and $\mathrm{Hg}$. Cd and $\mathrm{Hg}$ were passing but 


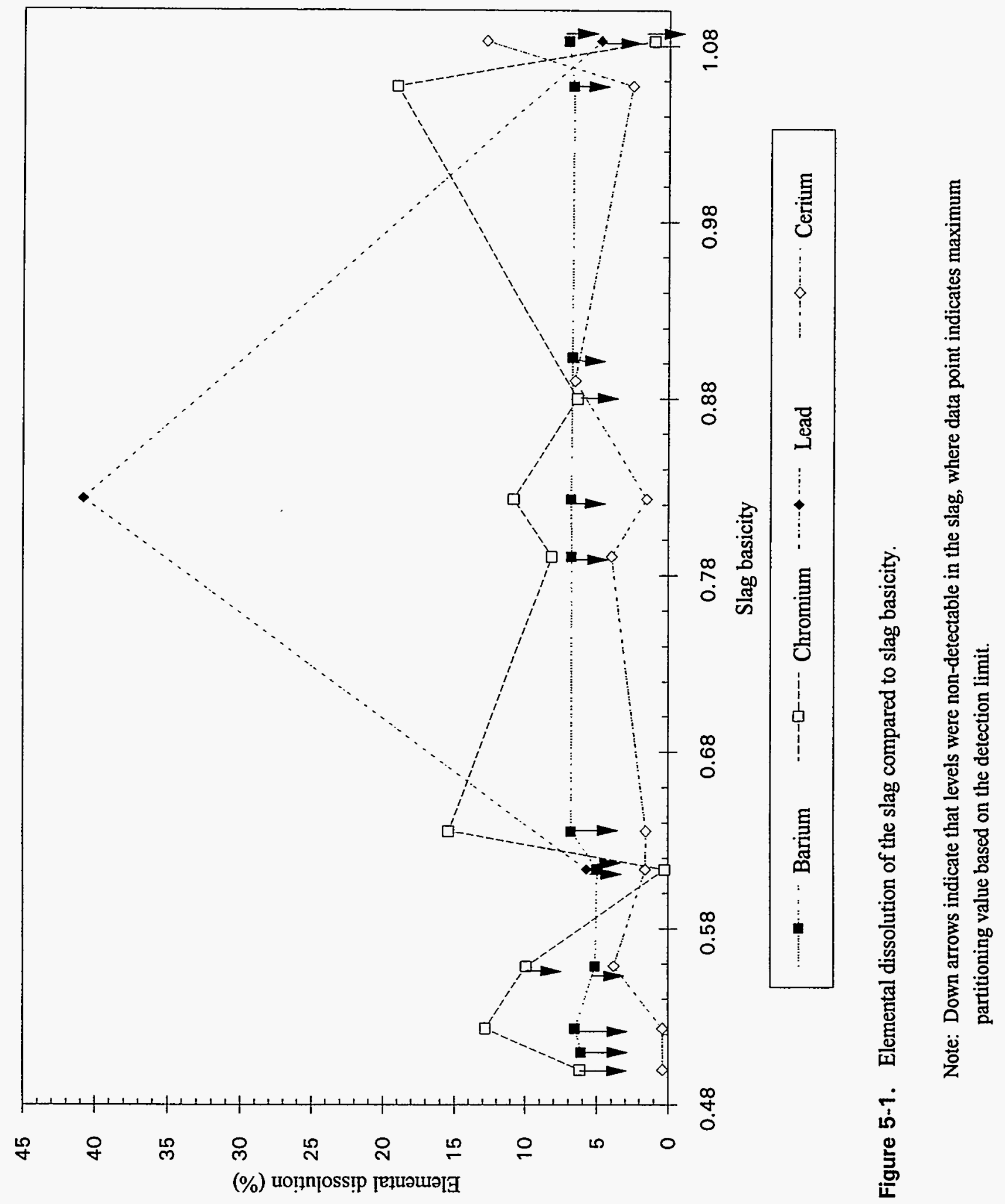




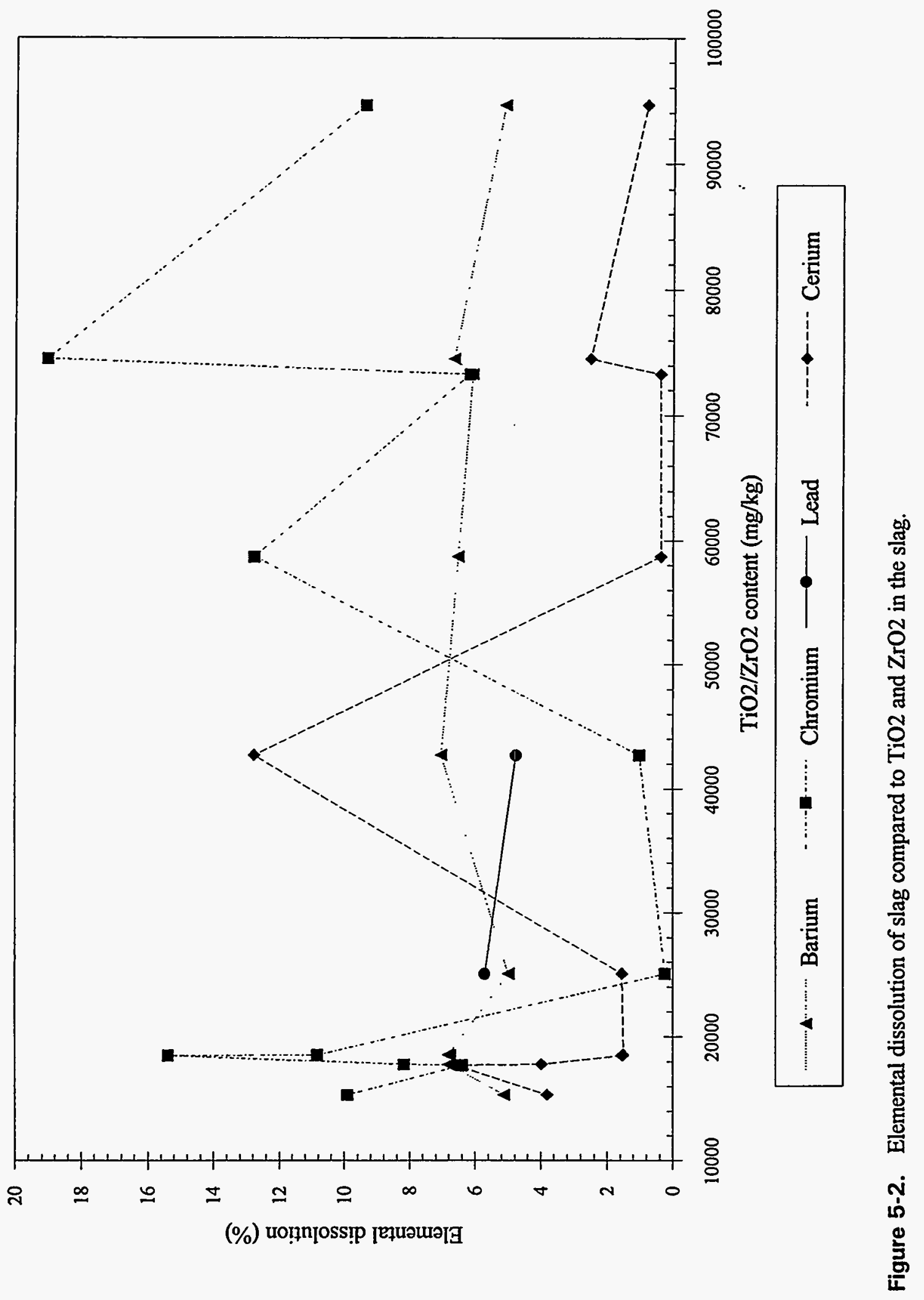


approached the limits in some cases. Although $\mathrm{Hg}$ was typically not detected, the detection limit was only one-half of the TCLP limit of $0.2 \mathrm{mg} / 1$, which is much lower than the limits for the other metals. Pb did not pass the TCLP limit for the APCS residues from the $\mathrm{S} 60, \mathrm{~S} 60-\mathrm{IV}$, and M60 tests. $\mathrm{Pb}$ was 33 times higher than the limit for the residues from the M60 test when the feed mixture contained $0.74 \%$ elemental $\mathrm{Pb}$.

- The percent dissolution of many of the elements was much higher than for the slag samples.

- The percent dissolution for Ce correlated strongly with the chloride content of the residue (Figure 5-3). The dissolution for barium, chromium, and lead was only slightly affected by the chloride content in the measured ranges. 


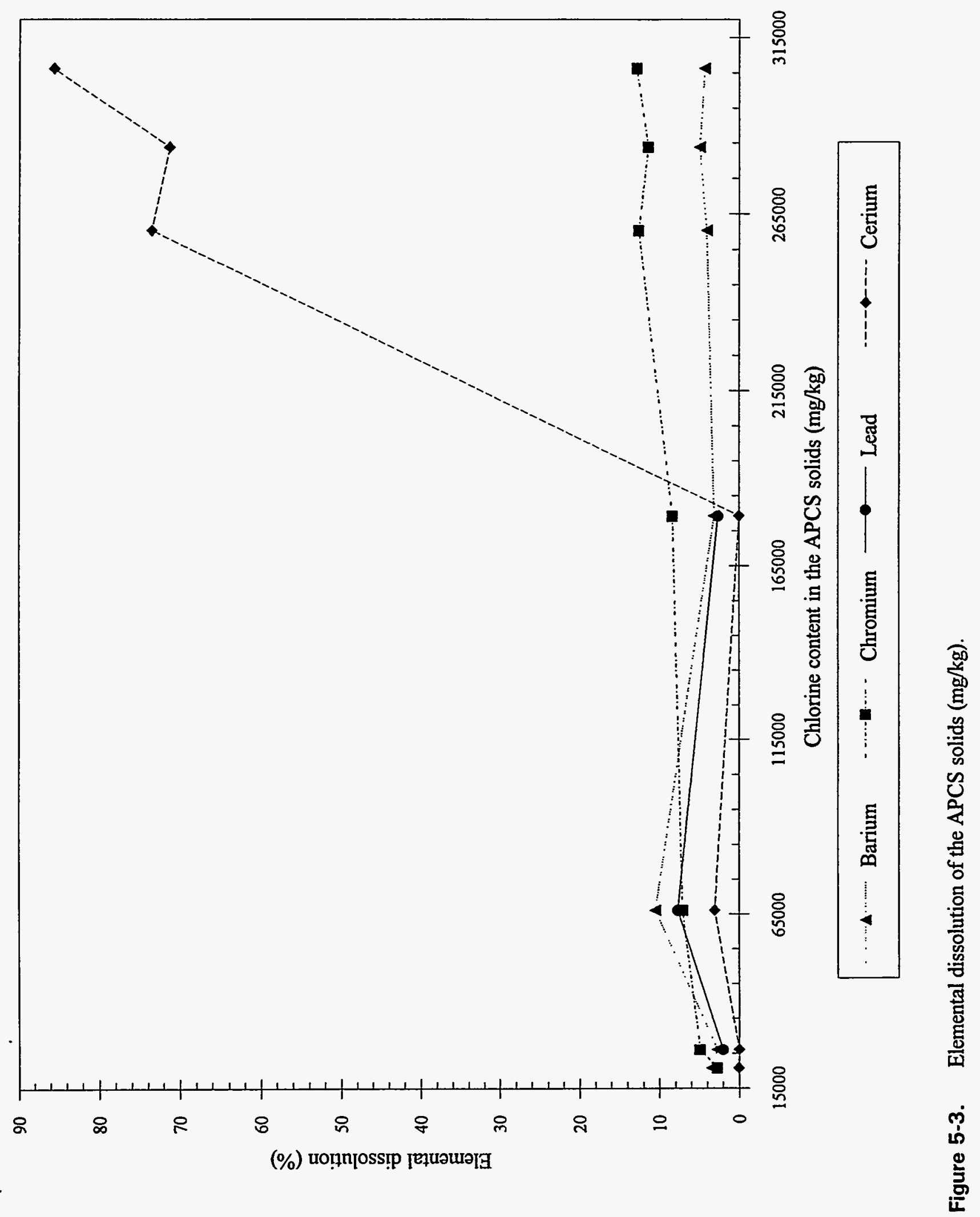




\section{OFFGAS EMISSIONS}

\subsection{Operating Conditions and Emissive Summary}

A summary of the furnace emissions and the operating conditions for distinct sampling periods during the baseline tests is provided in Table 6-1. During these sampling periods, concurrent offgas composition, velocity, flowrate, temperature, particulate loading, and metals emissions measurements were made. These measurements were made primarily at the quench section outlet, upstream of the fume traps and the baghouse. The particulate and metals emissions were measured using the EPA Draft Multiple Metals Train (MMT). Temperature and flowrate measurements were redundant with installed temperature and flowrate sensors in the APCS, to assure accuracy and determine comparability of the measurements. Occasionally during the baseline tests, offgas composition measurements were also made immediately upstream of the baghouse and at the stack. Occasional gas temperature measurements were also made at the furnace outlet location.

The furnace outlet gas composition, temperature, and flowrate were calculated using the measurements at the quench section outlet and the quench section dilution factor. The dilution factor was calculated two different ways: (a) using independent mass and energy balances from temperature and flowrate measurements for the offgas at the quench section outlet for the quench air, and (b) occasional temperature measurements at the furnace outlet. However, considerable variability existed in the calculated dilution factors due to the variability in the infrequent furnace outlet temperature measurements and variability in the quench air flowrate measurements. Since the design dilution factor was 5:1, the calculated dilution factors nearest to 5 were used in the furnace outlet gas composition, temperature, and flowrate calculations (Appendix S). Due to the potential variability of the dilution factor, the calculated furnace outlet values should be considered semi-quantitative.

Operating conditions shown in Table 6-1 are slightly different from those shown in Table 3-1 because the Table 6-1 conditions represent a discrete sampling time for each test while Table 3-1 shows average conditions and totals for each feed mixture. Two replicate MMT sampling runs were made for the S60 and S60-IV feed mixtures. Only a single MMT sampling run was made for the other feed mixtures. The sampling periods were during the most stable operating conditions for the S60 melt. The power level, feed rate, offgas flowrate, and offgas temperatures were relatively constant. Operating conditions for the S60-IV sampling periods were stable for each sampling period, but the power level and the feed rate were much lower for the second sampling period than for the first sampling period.

For the N80 sampling period, the furnace power was very stable, but the feed rate varied from 1,000-1,300 lb/hr. Furnace operation for the N80-Mod period was less stable, with the power ranging as high as $600 \mathrm{~kW}$ but occasionally dropping as low as $200 \mathrm{~kW}$, and the feed rate ranging from 800 to $1,000 \mathrm{lb} / \mathrm{hr}$. Also, the cold top in the furnace melted into the melt during a portion of this sampling run. When the cold top melted, the gas temperature at the quench outlet rose from 74 to $97^{\circ} \mathrm{C}$, which equates to an increase in the furnace temperature of $76^{\circ} \mathrm{C}$. Conditions in the furnace for the N80-Mod feed mixture were less stable, likely due to the 
Table 6-1. Detailed overview of baseline test results.

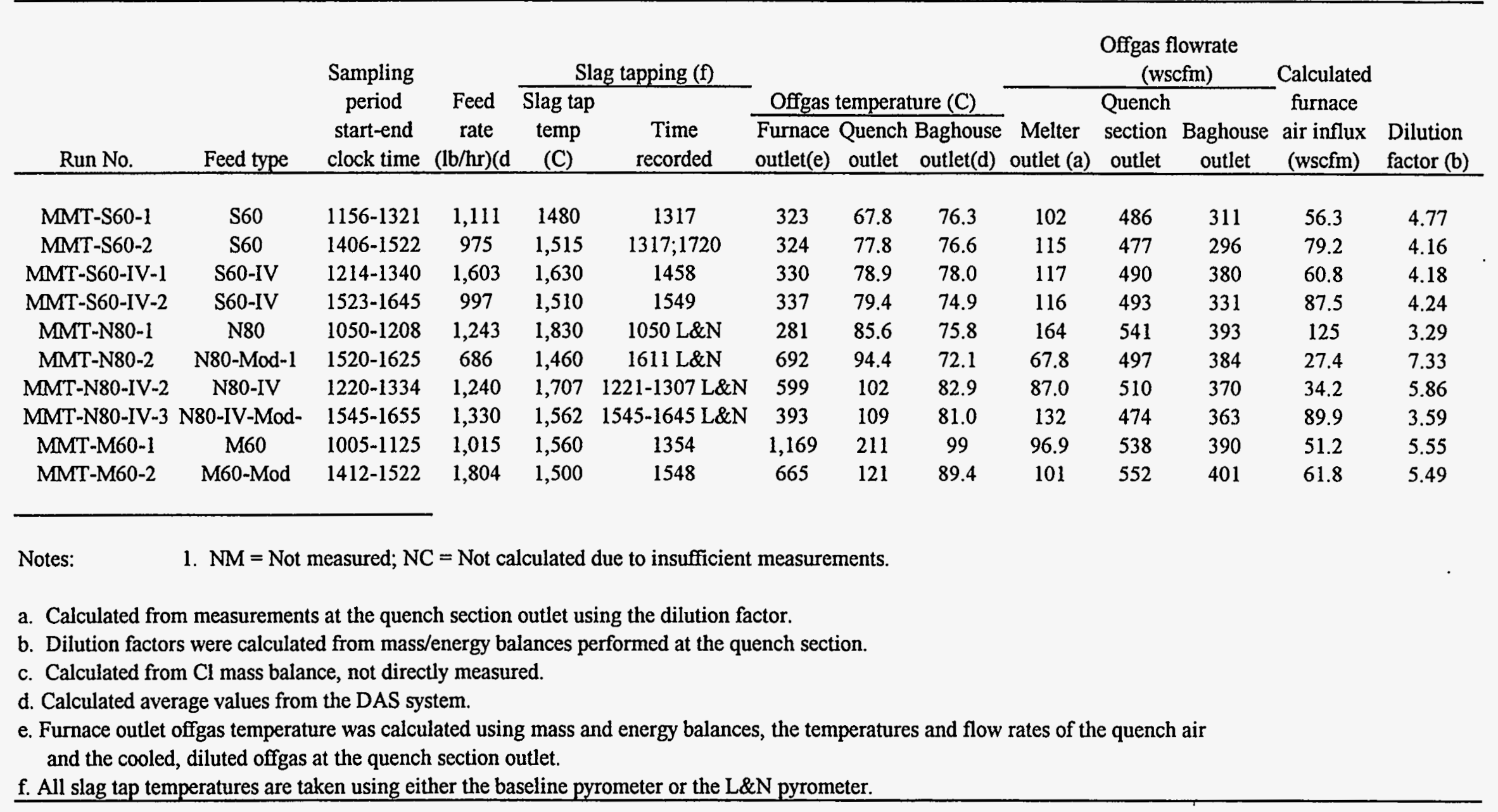


Table 6-1. (continued)

\begin{tabular}{|c|c|c|c|c|c|c|c|c|c|c|c|c|c|c|c|c|}
\hline \multirow[b]{2}{*}{ Run No. } & \multirow{2}{*}{$\begin{array}{c}\text { Average } \\
\text { furnace } \\
\text { pressure } \\
\text { (in } \mathrm{H} 2 \mathrm{O} \text { )(d) }\end{array}$} & \multicolumn{7}{|c|}{$\begin{array}{l}\text { Calculated offgas composition, furnace outlet } \\
\text { (dry basis except as noted) (a) }\end{array}$} & \multicolumn{6}{|c|}{$\begin{array}{l}\text { Offgas composition, quench outlet (dry basis } \\
\text { except as noted) }\end{array}$} & \multirow[b]{2}{*}{$\begin{array}{l}\mathrm{HCl}(\mathrm{c}) \\
(\mathrm{ppm})\end{array}$} & \multirow{2}{*}{$\begin{array}{c}\text { Baghouse } \\
\text { delta } \mathrm{P} \\
\text { (in } \mathrm{H} 2 \mathrm{O})(\mathrm{d}\end{array}$} \\
\hline & & $\begin{array}{l}\mathrm{O} 2 \\
(\%)\end{array}$ & $\begin{array}{l}\mathrm{CO} 2 \\
(\%)\end{array}$ & $\begin{array}{c}\mathrm{CO} \\
(\mathrm{ppm})\end{array}$ & $\begin{array}{l}\text { NOx } \\
\text { (ppm) }\end{array}$ & $\begin{array}{c}\mathrm{SO} 2 \\
(\mathrm{ppm})\end{array}$ & $\begin{array}{c}\mathrm{H} 2 \mathrm{O} \\
\text { (wet \%) }\end{array}$ & $\begin{array}{l}\mathrm{HCl}(\mathrm{c}) \\
(\mathrm{ppm})\end{array}$ & $\begin{array}{l}\mathrm{O} 2 \\
(\%)\end{array}$ & $\begin{array}{l}\mathrm{CO} 2 \\
(\%)\end{array}$ & $\begin{array}{c}\mathrm{CO} \\
(\mathrm{ppm})\end{array}$ & $\begin{array}{l}\text { NOx } \\
(\mathrm{ppm})\end{array}$ & $\begin{array}{c}\mathrm{SO} 2 \\
(\mathrm{ppm})\end{array}$ & $\begin{array}{r}\mathrm{H} 2 \mathrm{O} \\
\text { (wet \% }\end{array}$ & & \\
\hline MMT-S60-1 & -0.060 & 11.6 & 10.4 & 16,036 & 170 & 4,986 & 28.9 & 22,796 & 19.9 & 2.17 & 3,362 & 35.7 & 1,045 & 6.05 & 4,779 & 1.32 \\
\hline MMT-S60-2 & 0.008 & 14.5 & 6.56 & 5,708 & 60.0 & 20,161 & 26.8 & 18,042 & 20.3 & 1.58 & 1,372 & 14.4 & 4,846 & 6.45 & 4,337 & 1.31 \\
\hline MMT-S60-IV-1 & -0.178 & 10.9 & 11.2 & 26,026 & 131 & 26,288 & 34.4 & 17,598 & 19.7 & 2.68 & 6,224 & 31.4 & 6,287 & 8.20 & 4,210 & 1.62 \\
\hline MMT-S60-IV-2 & -0.254 & 15.8 & 6.92 & 11,399 & 38.3 & 12,972 & 26.2 & 12,665 & 20.6 & 1.63 & 2,689 & 9.04 & 3,060 & 6.20 & 2,987 & 1.62 \\
\hline MMT-N80-1 & -0.206 & 15.9 & $\mathrm{NC}$ & NC & 2.70 & 8.37 & 18.1 & 0 & 20.2 & NM & NM & 0.82 & 2.54 & 5.49 & 0 & 2.01 \\
\hline MMT-N80-2 & -0.257 & 8.50 & 23.5 & 41,647 & 33.8 & 77.1 & 33.6 & 0 & 20.0 & 3.21 & 5,682 & 4.62 & 10.5 & 4.58 & 0 & 2.51 \\
\hline MMT-N80-IV-2 & -0.339 & 8.26 & 18.8 & 25,210 & 44.0 & 326 & 38.1 & 0 & 19.8 & 3.21 & 4,302 & 7.51 & 55.7 & 6.50 & 0 & 2.13 \\
\hline MMT-N80-IV-3 & -0.294 & 14.3 & 10.8 & 15,177 & 5.50 & 132 & 20.6 & 0 & 19.9 & 3.01 & 4,228 & 1.53 & 36.9 & 5.74 & 0 & 2.26 \\
\hline MMT-M60-1 & -0.362 & 11.1 & 11.6 & 9,802 & 242 & 15.1 & 25.8 & 0 & 19.9 & 2.09 & 1,766 & 43.7 & 2.73 & 4.64 & 0 & 2.47 \\
\hline MMT-M60-2 & -0.843 & 12.9 & 15.3 & 13,831 & 63.1 & 15.8 & 21.5 & 0 & 20.1 & 2.79 & 2,519 & 11.5 & 2.88 & 3.92 & 0 & 2.35 \\
\hline
\end{tabular}


thermal decomposition and gas evolution of the limestone $\left(\mathrm{CaCO}_{3}\right)$ additive, used to modify the slag viscosity for tapping at lower slag temperatures.

During the N80-IV sampling period, the furnace power decreased from 700 to $550 \mathrm{~kW}$, while the feed rate decreased from 1,400 to $1,300 \mathrm{lb} / \mathrm{hr}$. There were several changes in the power . and feed rate for this feed mixture, in an attempt to achieve an optimum, stable power level and feed rate. Operating time was insufficient to establish a long-term stable condition until the operation on the N80-IV-Mod feed mixture. Furnace power and feed rate were relatively stable for the N80-IV-Mod sampling period at approximately $600 \mathrm{~kW}$ and $1,250-1,350 \mathrm{lb} / \mathrm{hr}$.

Furnace conditions for the M60 feed mixture varied somewhat, and operating time was insufficient to establish a long-term stable condition. Since slag tapping could not be initiated due to high viscosity slag, the M60 feed mixture was stopped after 3.1 hours, and feeding with N80-IV-Mod feed mixture was started. Manual additions totalling $400 \mathrm{lb}$ of pebble lime $(\mathrm{CaO})$ were also added to adjust the slag viscosity and enable continuous slag tapping. Furnace operation during the M60-Mod sampling period was relatively stable with a power level of $500-550 \mathrm{~kW}$ and a feed rate of $1,700-1,800 \mathrm{lb} / \mathrm{hr}$.

\subsection{Offgas Compositions}

The offgas compositions depended upon the compositions of the feed mixtures and the feed rates, relative to the furnace air inleakage. Air leakage into the furnace occurred due to the furnace negative pressure through the feed tubes with the feed, and through seals in the roof around the feed tubes and the electrodes. While this inleakage was not measured directly, it was calculated by difference from the furnace outlet gas flowrate (also a calculated variable) and the amount of volatilization from the feed material, calculated from the measured $\mathrm{CO}_{2}, \mathrm{CO}, \mathrm{SO}_{2}$, and $\mathrm{H}_{2} \mathrm{O}$ values in the offgas. For the $\mathrm{S} 60$ and $\mathrm{S} 60$-IV feed mixtures that contained significant $\mathrm{Cl}$, the calculated amount of $\mathrm{Cl}$ volatilization was also included in the total feed volatilization calculation.

Since the air inleakage was calculated by mass balance from other calculated and measured variables, there was a variation in the inleakage values, ranging from 27 to $125 \mathrm{scfm}$. The data shows no correlation between the furnace draft and the air inleakage, although one would be expected. This poor correlation is due to the method used to calculate the air inleakage. The air inleakage was calculated by subtracting two numbers, the furnace outlet gas flowrate and the feed material volatilization rate. These calculated inleakage values should be considered qualitative. The air inleakage as a function of furnace draft may be determined experimentally prior to the FY-94 tests by operating all of the systems without feeding soil through the feeder, and measuring the furnace draft and the flowrate at the furnace outlet.

Oxygen levels were relatively high (8.3-15.9\%, dry basis) indicating oxidizing conditions in the furnace atmosphere. Only a portion of the oxygen in the air inleakage was consumed through oxidation of reduced species (organic carbon, sulfur and chlorine compounds, and in the M60 test, elemental metals) in the feed mixtures and from oxidation of the graphite electrodes.

Moisture in the offgas (18-38\%) resulted from vaporized water and water of combustion. The majority of the carbon was carbon dioxide in the offgas (up to $23.5 \%$ carbon dioxide, compared to carbon monoxide levels under $42,000 \mathrm{ppm}$ ). Nitrogen oxide levels were typically 
under $100 \mathrm{ppm}$ except for the M60 test condition, when $\mathrm{NO}_{\mathrm{x}}$ levels averaged $242 \mathrm{ppm}$. These are relatively low $\mathrm{NO}_{\mathrm{x}}$ levels compared to many other types of thermal and combustion equipment, due to negligible amounts of fuel nitrogen (source of fuel $\mathrm{NO}_{\mathrm{x}}$ ) and low gas temperatures (source of thermal $\mathrm{NO}_{\mathrm{x}}$ ). The higher $\mathrm{NO}_{\mathrm{x}}$ level for $\mathrm{M} 60$ occurred due to thermal $\mathrm{NO}_{\mathrm{x}}$ formation when the gas temperatures and furnace outlet gas temperatures averaged almost $1,200^{\circ} \mathrm{C}$ compared to temperatures of 300 to $700^{\circ} \mathrm{C}$ for the other test conditions. Sulfur dioxide levels ranged up to $325 \mathrm{ppm}$ or less except for the S60 and S60-IV melts, when higher levels ranging up to $26,000 \mathrm{ppm}$ resulted from decomposition of $6.9-7.1 \%$ calcium sulfate in the feed mixtures.

The offgas $\mathrm{CO}_{2}$ and $\mathrm{CO}$ levels for the second $\mathrm{S} 60$ sampling period were significantly lower than for the first test period, even though the feed rate was only slightly lower for the second sampling period. This same trend was also true for the S60-IV sampling periods, when the same feed mixture, with the exception of added cerium and zirconium oxides, was fed to the furnace. $\mathrm{CO}_{2}$ and $\mathrm{CO}$ in the offgas was primarily from decomposition of carbonates in the feed mixtures, and to a smaller extent, oxidation of the graphite electrodes and trace amounts of organic carbon in the soil. The lower $\mathrm{CO}_{2}$ and $\mathrm{CO}$ levels for the second S60-IV sampling period were due at least partially to significantly lower feed rates of the S60-IV feed mixture $(997 \mathrm{lb} / \mathrm{hr}$ compared to $1,603 \mathrm{lb} / \mathrm{hr}$ ). However, the variation in $\mathrm{CO}_{2}$ and $\mathrm{CO}$ levels for the $\mathrm{S} 60$ feed mixture and also the S60-IV feed mixture may also be due to size segregation of carbonate-containing feed materials in the feed system. The $\mathrm{SO}_{2}$ in the offgas also varied from that in the $\mathrm{S} 60$ and S60-IV tests, due to variations in the furnace feed rate and to feed segregation. Variations in the feed mixture compositions due to incomplete mixing or due to stratification during shipping and handling is also a likely cause for offgas composition variations. While the soil particle size ranged $10 \mathrm{wt} \%$ less than 80 mesh $(0.175 \mathrm{~mm})$, the gypsum $\left(\mathrm{CaSO}_{4} \cdot \mathrm{H}_{2} \mathrm{O}\right)$ particle size was much finer at $64 \%$ less than 80 mesh. If calcium carbonate in the soil was concentrated in larger soil particles, then the calcium carbonate may segregate opposite to the gypsum, as the offgas composition data suggests.

\subsection{Particulate and Metals Emissions}

The total particulate in the offgas includes (a) feed dust entrained in the furnace gas, (b) material volatilized from the hot melt that has condensed as particles or droplets (also termed fume) in the cooler offgas sections, and (c) material volatilized from the hot melt that would condense at ambient temperatures (given sufficient time and nucleation sites), but that has not yet condensed in the APCS. The volatilized material can condense on the surfaces of entrained feed material and also form very small particle-size fume particles that may or may not grow in size with continued condensation or agglomeration. The entrained feed particles, having possibly bypassed higher temperatures in the furnace, can have the same appearance, mineral content, and composition as particles of the same size in the feed mixtures. The fume particles and the very fine entrained feed particles can be enriched with materials volatilized from the melt such as toxic metals.

Levels of total particulate concentrations shown in Table 6-2 were measured using the isokinetic MMT. This procedure is designed to capture not only the solid particulate but also any metals in gaseous form at the conditions and location in the APCS. The total particulate concentrations are within the range of particulate emissions for fluidized bed combustors and aggregate processing equipment, where the process material is soil and other finely divided, dusty materials such as the feed mixtures in this test program. 
Table 6-2. Comparison of particulate results from the MMT sampling tests and the fume trap/baghouse catches.

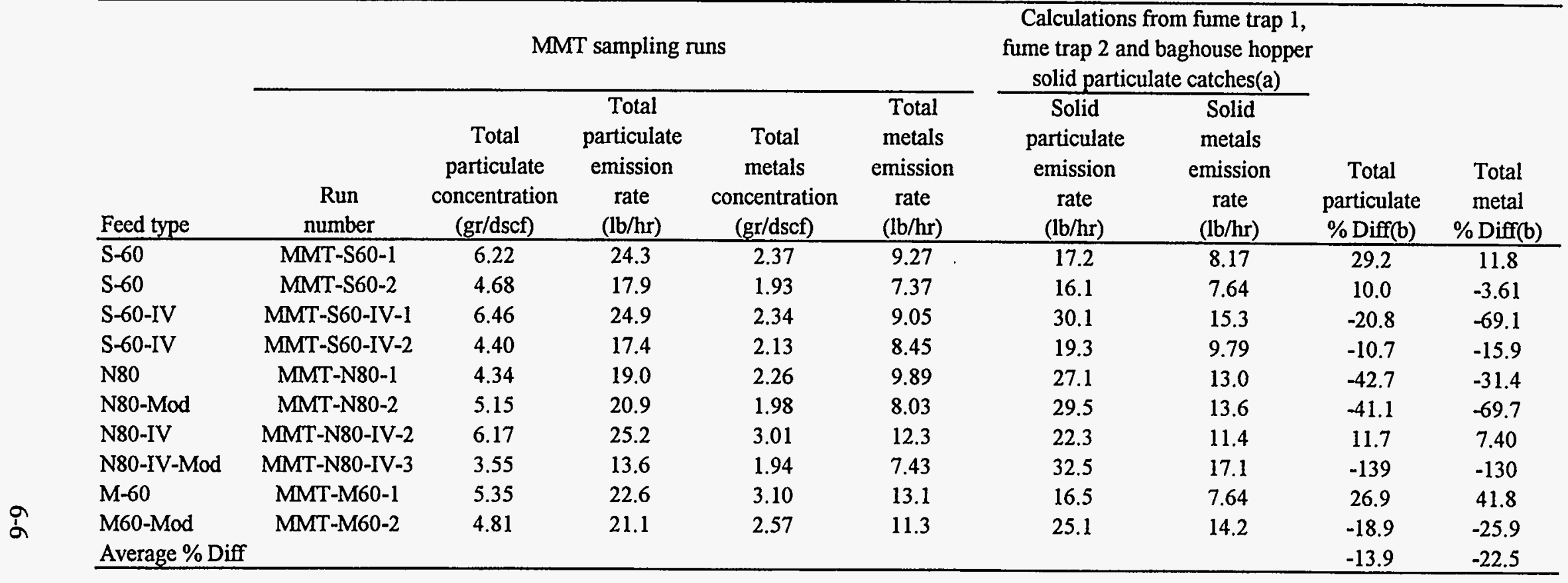

a. Emission rates proportioned to MMT test feed rates.

b. $\%$ Diff $=($ Total particulate/metals emission rate - Solid emission rate $) /$ Total particulate/metals emission rate $* 100$ 
The material collected in the two fume traps tended to be particles too large and too dense to stay entrained in the offgas as the offgas passed through the traps. While these traps were not designed as cyclones, the gas entrances to the traps induced a cyclonic action in the offgas to better disengage particles from the gas stream. Of the total particulate, portions that were collected in these fume traps are shown in Table 6-3. Analysis of the fume trap samples indicates that the material collected in the fume traps was mostly feed material. X-ray diffraction results show that the physical forms match very closely to the denser components of the feed mixtures. $\mathrm{X}$-ray diffraction of the baghouse samples shows that the material captured in the baghouse was enriched with recondensed fume that volatilized from the slag melt.

The amounts of material captured in the fume traps and the baghouse should depend on such furnace operating conditions as slag temperature, power input, feed rate, cold top depth, or offgas velocity in the fume traps. Values for these variables are listed in Table 6-4. However, no apparent measurable correlation exists to any of these other variables.

Concentrations and mass emission rates for the metals and Ce, the TRU surrogate, are shown in Tables 6-4 and 6-5. The concentrations and mass emission rates were determined from the MMT samples at the outlet of the quench section. Furnace outlet concentrations were estimated from the quench section outlet measurements by multiplying the reported values by the calculated dilution factors. These levels are indicative of the amounts of material that would need to be controlled in a full-scale processing facility, unless the process is configured to have less entrainment of feed material and less volatilization from the melt. Each of these phenomenon may be controlled by different mechanisms. For example, feed entrainment may be minimized by reducing levels of volatile material (carbonates, organics, sulfates, etc) in the feed material, by pelletizing the feed, removing or tuyere injection of soil fines, or by minimizing the amount of gas flow and turbulence in the furnace plenum above the melt. Volatilization of toxic metals from the melt can be controlled by minimizing temperatures, maintaining oxidizing conditions in the melt, or by operating with a cold top.

\subsection{Offgas Composition Trends}

The gas species concentrations in the offgas were continuously monitored downstream of the quench section. These concentrations are shown in Figures 6-1 through 6-5. Concentrations varied widely due to variations in feed volatilization rates and pressure fluctuations (that caused variations in the rate of air leakage into the furnace). 
Table 6-3. Distribution of particulate in fume traps and baghouse.

\begin{tabular}{|c|c|c|c|c|c|c|c|c|c|c|}
\hline \multirow[b]{3}{*}{ Feed mixture } & & & \multirow{3}{*}{$\begin{array}{c}\text { Feedrate } \\
(\mathrm{lb} / \mathrm{hr})\end{array}$} & \multirow{3}{*}{$\begin{array}{c}\text { Power input } \\
(\mathrm{kWh} / \mathrm{b})\end{array}$} & \multirow{3}{*}{$\begin{array}{c}\text { Slag } \\
\text { temp (C) }\end{array}$} & \multirow{3}{*}{$\begin{array}{c}\text { Total } \\
\text { particulate } \\
\text { concentration } \\
\text { (gr/dscf) } \\
\end{array}$} & \multicolumn{4}{|c|}{$\begin{array}{l}\text { Percent of total solid particulate } \\
\text { collected in: }\end{array}$} \\
\hline & \multicolumn{2}{|c|}{ old top depth (in.) } & & & & & & & Total in & \\
\hline & Range & Average & & & & & Fume Trap 1 & Fume Trap 2 & Fume Traps & Baghouse \\
\hline$S 60$ & $3-8$ & 5.0 & 1,180 & 0.017 & $1550-1600$ & 24.5 & 5.70 & 34.9 & 40.6 & 59.4 \\
\hline S60-IV & $0-14$ & 6.5 & 1,251 & 0.013 & $1550-1650$ & 22.8 & 6.70 & 26.2 & 32.9 & 67.1 \\
\hline N80 & $0-11$ & 6.5 & 1,155 & 0.015 & $1650-1800$ & 14.3 & 13.8 & 12.4 & 26.2 & 73.7 \\
\hline N80-Mod & $0-13$ & 5.5 & 917 & 0.018 & $1450-1550$ & 37.8 & 10.5 & 38.7 & 49.2 & 50.8 \\
\hline N80-IV & $0-6$ & 3.0 & 1,106 & 0.016 & $1650-1750$ & 36.1 & 23.1 & 34.8 & 57.9 & 42.1 \\
\hline N80-IV-Mod & $0-6$ & 3.5 & 1,302 & 0.015 & $1550-1590$ & 12.7 & 11.3 & 35.3 & 46.6 & 53.4 \\
\hline M60 & $0-8$ & 4.0 & 1,033 & 0.014 & no tap & 29.7 & 9.10 & 37.3 & 46.4 & 53.6 \\
\hline M60-Mod & $2-12$ & 5.5 & 1,240 & 0.014 & no tap & 26.4 & 16.7 & 36.9 & 53.6 & 46.4 \\
\hline Average & & 4.9 & 1,148 & 0.015 & - & 25.5 & 12.1 & 32.1 & 44.2 & 55.8 \\
\hline
\end{tabular}


Table 6-4. Metals and TRU surrogate concentrations in the offgas (mg/dscm).

\begin{tabular}{|c|c|c|c|c|c|c|c|c|c|c|c|c|c|c|c|c|c|}
\hline \multirow[b]{2}{*}{ Element } & \multicolumn{5}{|c|}{ S-60 } & \multicolumn{4}{|c|}{ S60-IV } & \multirow[b]{2}{*}{ N80 } & \multirow[b]{2}{*}{ N80-Mod } & \multicolumn{4}{|c|}{ N80-IV } & \multirow{2}{*}{\multicolumn{2}{|c|}{$\begin{array}{l}\text { N80-IV } \\
\text { Mod-2 }\end{array}$}} \\
\hline & & Test 1 & & Test 2 & Average & & Test 1 & Test 2 & Average & & & & N80-IV & Mod-1 & M60 & & \\
\hline Arsenic & $<$ & 2.96 & $<$ & 2.23 & $<2.59$ & $<$ & 3.06 & $<2.11$ & $<2.59$ & 2.72 & 2.46 & & 2.92 & 2.02 & $<2.56$ & $<$ & 2.28 \\
\hline Aluminum & & 258 & & 163 & 210 & & 195 & 143 & 169 & 388 & 138 & & 326 & 182 & 190 & & 257 \\
\hline Barium & & 15.1 & & 10.4 & 12.7 & & 18.5 & 6.04 & 12.3 & 10.9 & 12.6 & & 21.2 & 16.5 & 16.3 & & 16.8 \\
\hline Boron & & 0.168 & & 0.342 & 0.255 & & 0.297 & 0.176 & 0.237 & 0.246 & $<0.106$ & $<$ & 0.101 & $<0.082$ & $<0.112$ & $<$ & 0.083 \\
\hline Cadmium & & 0.143 & & 0.118 & 0.131 & & 0.178 & 0.121 & 0.150 & 0.199 & 0.130 & & 0.142 & 0.147 & 0.160 & & 0.143 \\
\hline Calcium & & 613 & & 333 & 473 & & 621 & 2,388 & 1,505 & 495 & 414 & & 463 & 1,064 & 368 & & 1,123 \\
\hline Cerium & & 48.2 & & 15.5 & 31.8 & & 50.5 & 25.8 & 38.2 & 30.4 & 23.3 & & 107 & 75.2 & 20.8 & & 74.6 \\
\hline Chromium & & 1.87 & & 2.61 & 2.24 & & 2.05 & 1.61 & 1.83 & 3.10 & 1.40 & & 4.54 & 2.79 & 5.68 & & 20.7 \\
\hline Copper & & 8.95 & & 43.6 & 26.3 & & 4.80 & 3.96 & 4.38 & 2.01 & 3.60 & & 1.86 & 5.24 & 5.19 & & 8.67 \\
\hline Iron & & 656 & & 488 & 572 & & 706 & 254 & 480 & 431 & 644 & & 387 & 336 & 159 & & 468 \\
\hline Lead & & 5.67 & & 11.5 & 8.59 & & 7.98 & 2.61 & 5.29 & 5.37 & 6.64 & & 6.60 & 5.01 & 1,762 & & 60.0 \\
\hline Magnesium & & 133 & & 86.7 & 110 & & 111 & 94.5 & 103 & 101 & 78.0 & & 98.1 & 65.2 & 53.9 & & 83.9 \\
\hline Manganese & & 6.25 & & 6.32 & 6.28 & & 8.04 & 3.03 & 5.53 & 3.82 & 7.24 & & 5.36 & 3.65 & 4.93 & & 5.48 \\
\hline Mercury & $<$ & 2.92 & $<$ & 2.23 & $<2.58$ & $<$ & 3.06 & $<2.11$ & $<2.59$ & $<2.09$ & 2.46 & $<$ & 2.92 & $<\quad 1.71$ & $<2.56$ & $<$ & 2.28 \\
\hline Nickel & & 0.829 & & 0.772 & 0.801 & & 0.707 & 0.508 & 0.608 & 1.30 & 0.757 & & 0.688 & 0.687 & 1.54 & & 1.79 \\
\hline Phosphorus & & 53.2 & & 147 & 100 & & 51.7 & 35.3 & 43.5 & 125 & 60.5 & & 117 & 38.7 & 18.9 & & 56.8 \\
\hline Potassium & & 999 & & 977 & 988 & & 923 & 674 & 798 & 769 & 877 & & 1,206 & 651 & 203 & & 888 \\
\hline Selenium & $<$ & 2.92 & $<$ & 2.23 & $<2.58$ & $<$ & 3.06 & $<2.11$ & $<2.59$ & $<2.09$ & $<\quad 2.46$ & $<$ & 2.92 & $<1.71$ & $<2.56$ & $<$ & 2.28 \\
\hline Silicon & & 1,579 & & 1,125 & 1,352 & & 1,371 & 756 & 1,064 & 1,759 & 1,163 & & 2,046 & 1,064 & 1,444 & & 1,386 \\
\hline Silver & $<$ & 0.30 & $<$ & 0.24 & $<0.27$ & $<$ & 0.32 & $<0.23$ & $<0.27$ & $<0.23$ & $<0.26$ & & 4.02 & 1.77 & 0.69 & & 2.45 \\
\hline Sodium & & 967 & & 945 & 956 & & 1,208 & 462 & 835 & 968 & 1,025 & & 1,338 & 579 & 127 & & 798 \\
\hline Strontium & & 5.26 & & 3.60 & 4.43 & & 5.91 & 3.54 & 4.73 & 3.12 & 4.08 & & 5.81 & .5 .35 & 4.38 & & 6.28 \\
\hline Titanium & & 30.9 & & 16.4 & 23.6 & & 35.4 & 12.0 & 23.7 & 30.9 & 23.4 & & 48.7 & 24.9 & 11.3 & & 30.9 \\
\hline Vanadium & & 3.39 & & 2.87 & 3.13 & & 3.72 & 1.64 & 2.68 & 2.89 & 3.35 & & 5.13 & 1.87 & 0.35 & & 2.08 \\
\hline Zinc & & 25.2 & & 27.3 & 26.3 & & 27.0 & 10.1 & 18.6 & 25.4 & 27.7 & & 15.4 & 6.59 & 2,691 & & 154 \\
\hline Zirconium & & 0.687 & & 0.483 & 0.585 & & 1.45 & 0.548 & 1.00 & 0.859 & 2.37 & & 662 & 301 & 6.65 & & 419 \\
\hline
\end{tabular}

$<$ Value below detection limit. 
Table 6-5. Mass emission rates for metals and TRU surrogate in the offgas (g/hr).

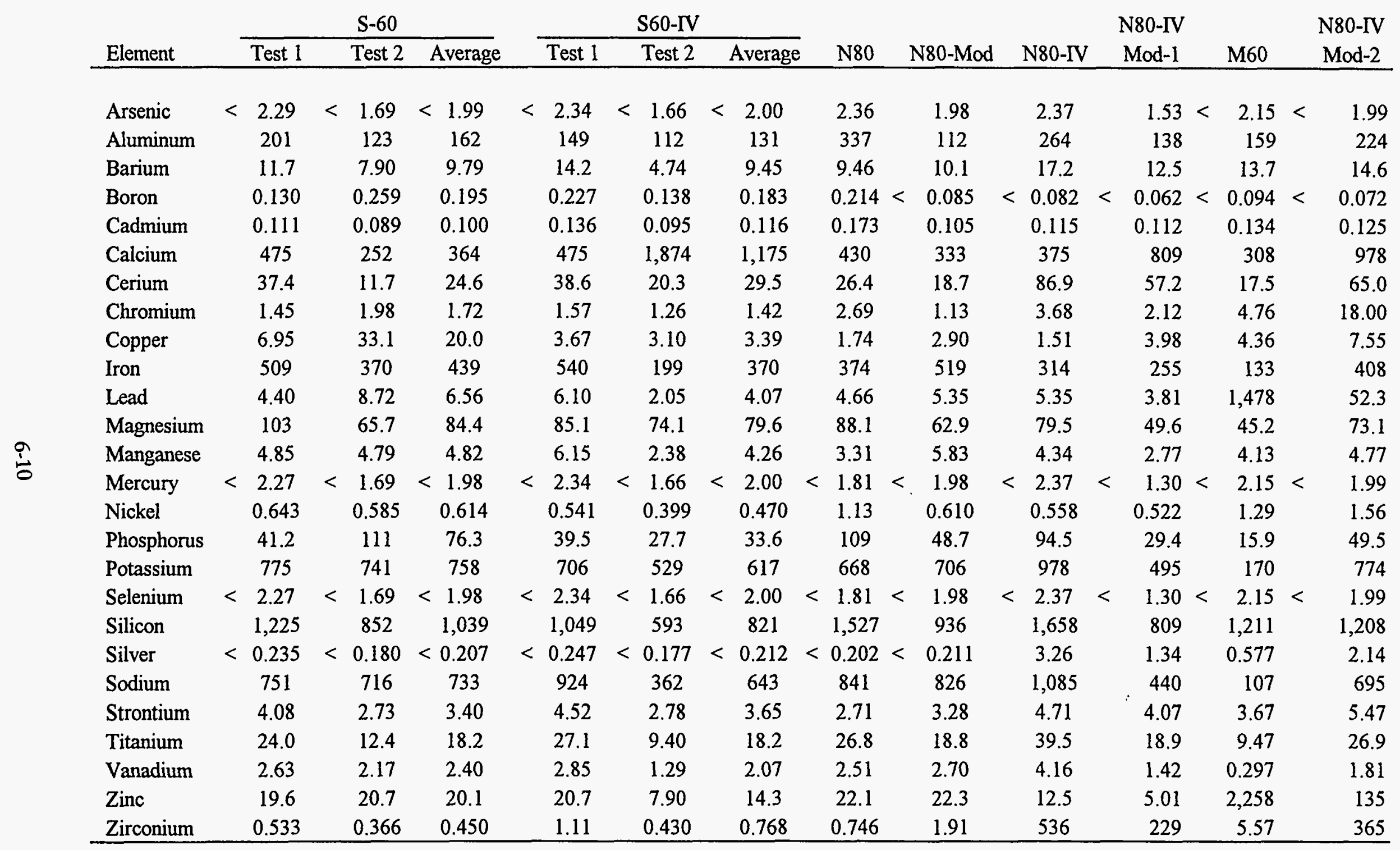

$<$ Value below detection limit. 
Furnace outlet offgas composition for melt $\$ 60$
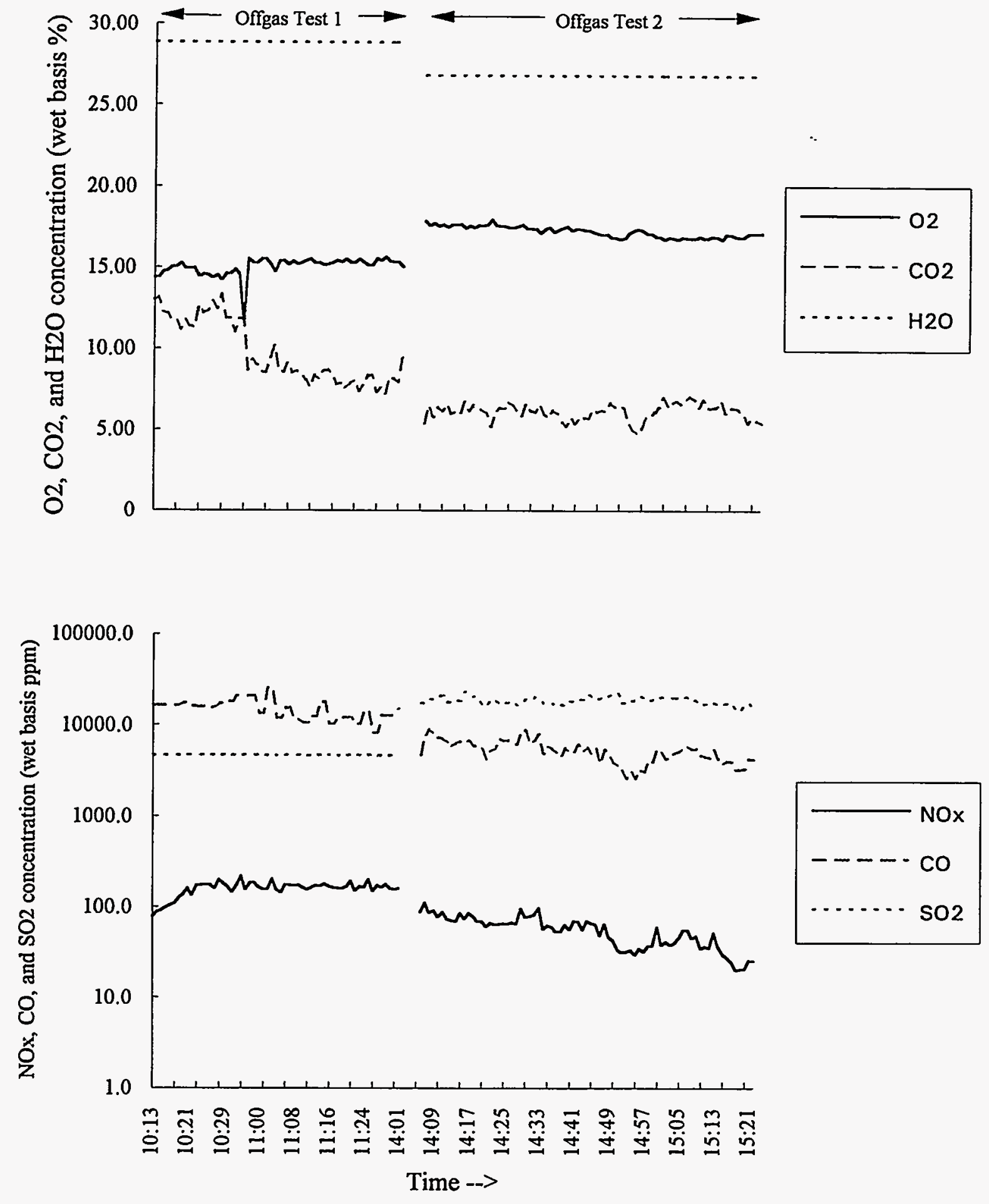

Figure 6-1. Furnace outlet offgas composition for melt S60. 
Furnace outlet offgas composition for melt S60-IV
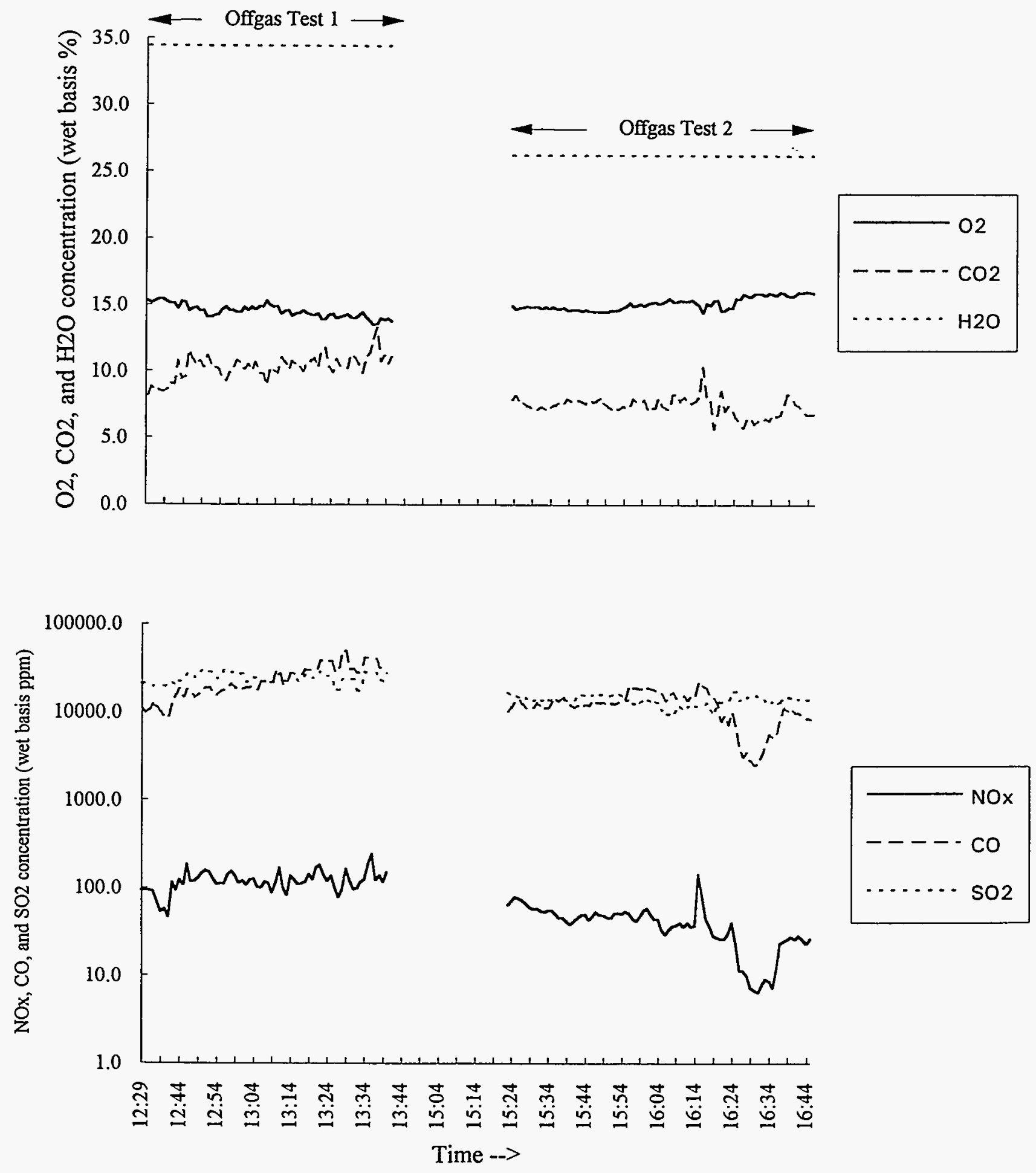

Figure 6-2. Furnace outlet composition for melt S60-IV. 
Furnace outlet offgas composition for melts N80 and N80-Mod
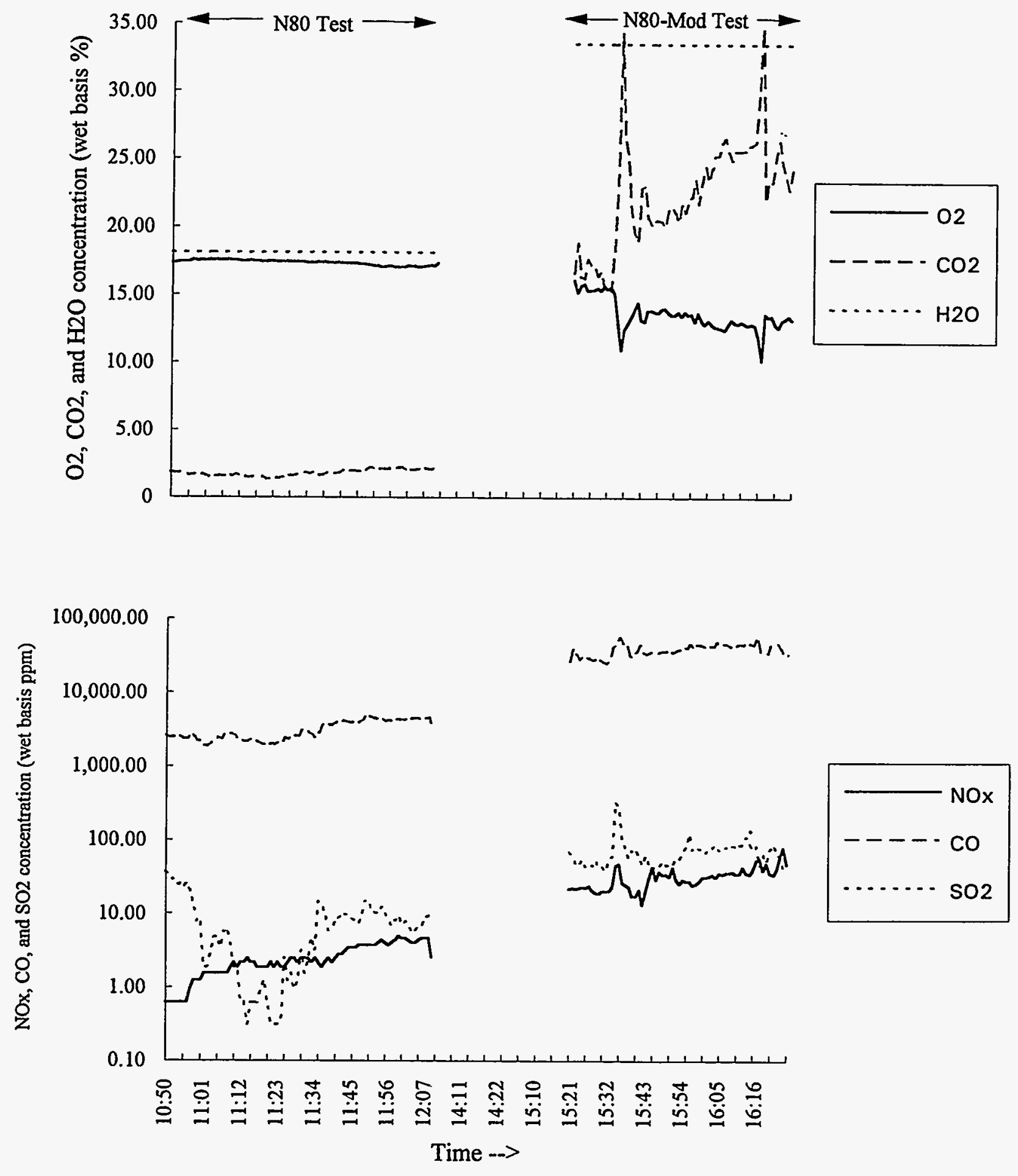

Figure 6-3. Furnace outlet composition for melts N80 and N80-Mod. 
Furnace outlet offgas composition for melts N80-IV and N80-IV-Mod
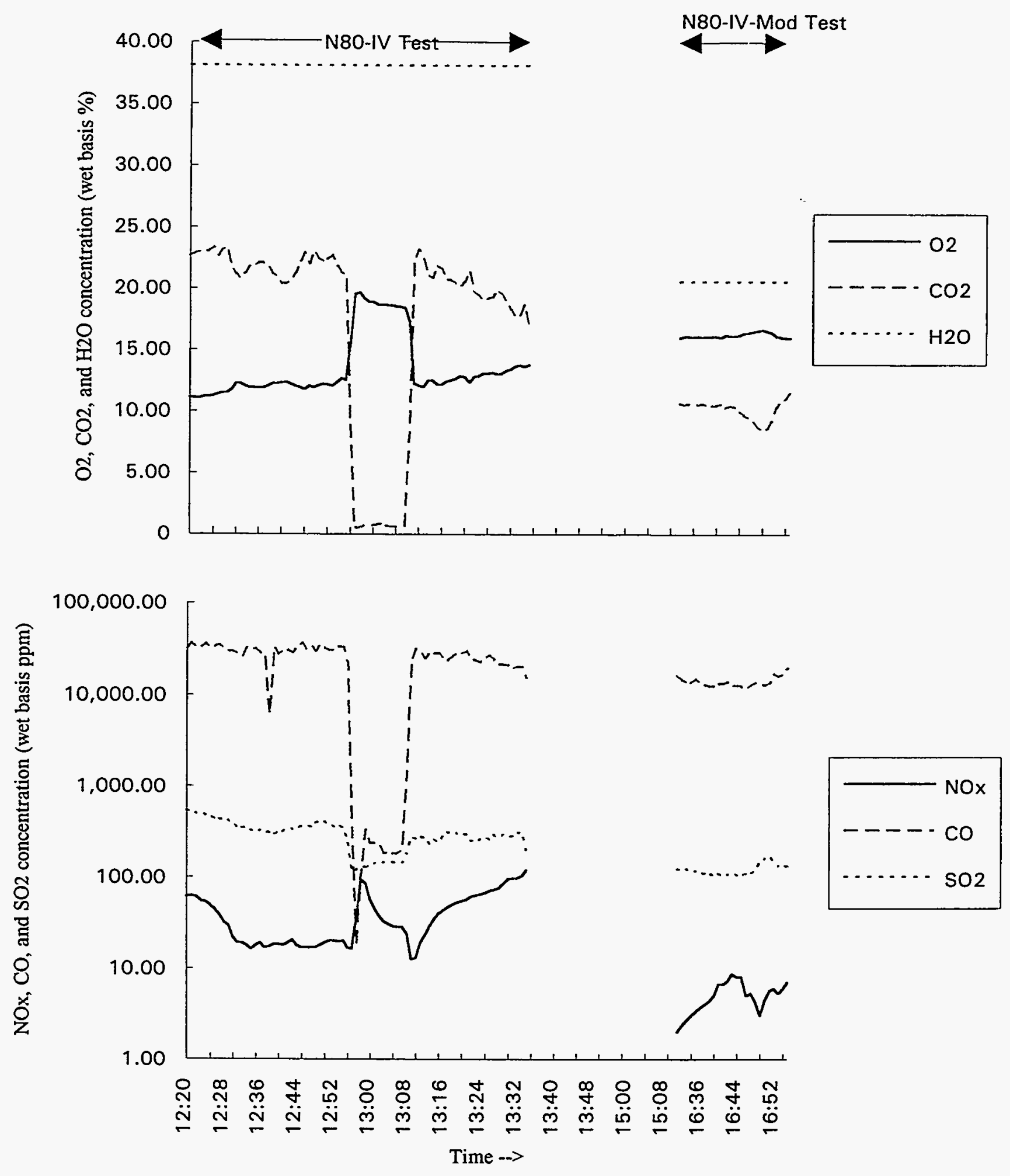

Figure 6-4. Furnace outlet composition for melts N80-IV and N80-IV-Mod. 


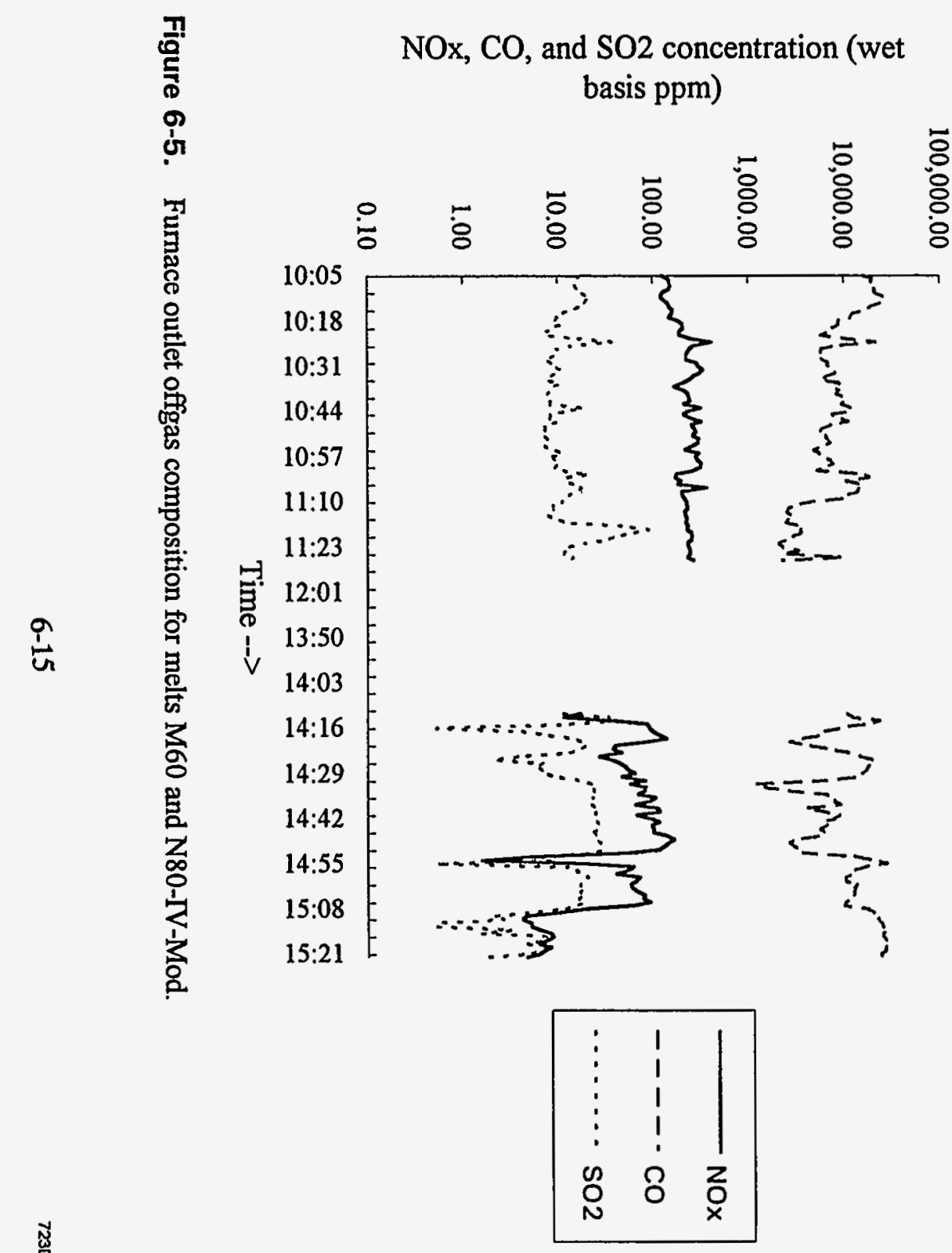

$\mathrm{O} 2, \mathrm{CO} 2$, and $\mathrm{H} 2 \mathrm{O}$ concentration (wet basis \%)

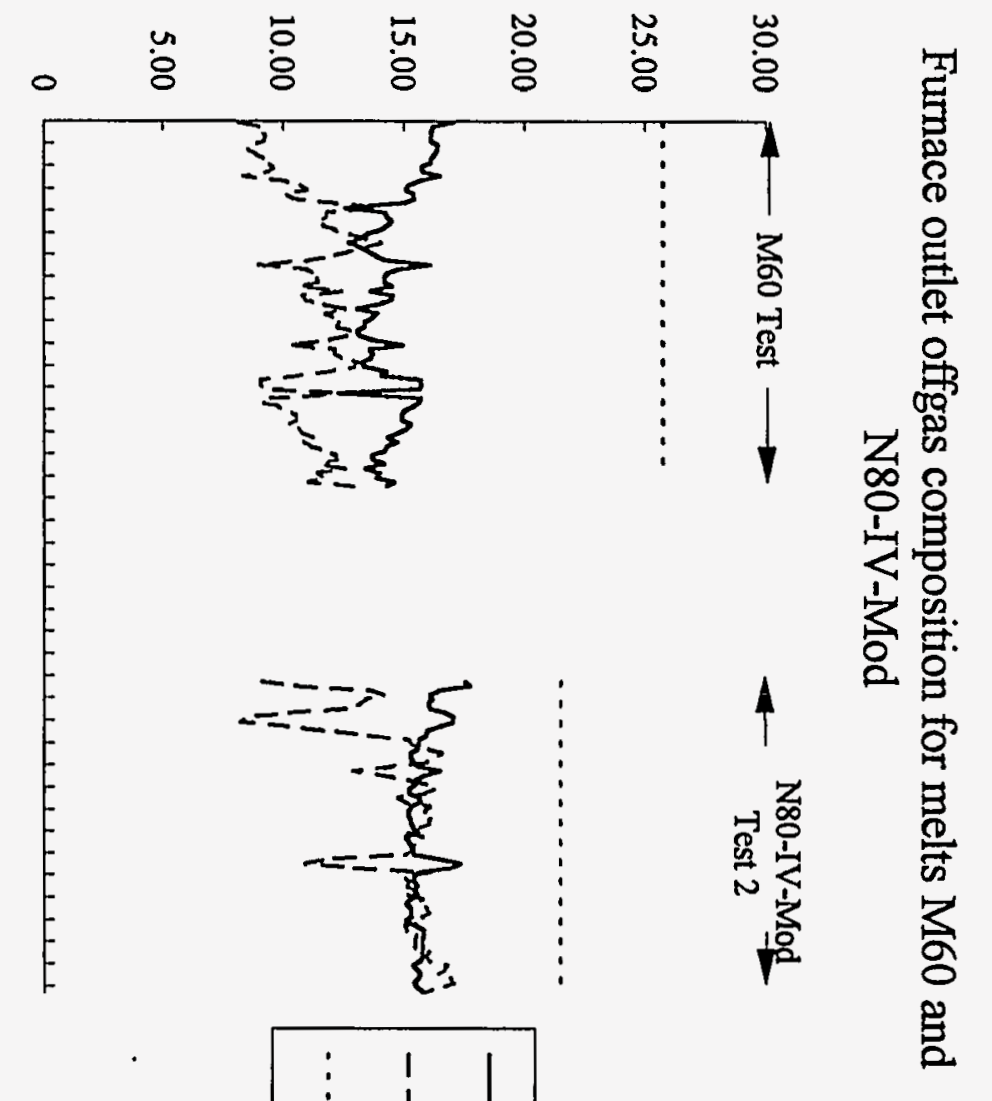




\section{CONCLUSIONS AND RECOMMENDATIONS}

The baseline tests represent the initial test series campaign in a three phase BWID test and evaluation project. The extensive amount of data has required considerable evaluation effort to date, yet further evaluation is always possible. These baseline test results are being used in the planning of future test series, evaluations, and supporting studies. The following are key conclusions and recommendations from the baseline test results.

1. The first overall conclusion is that the baseline tests have successfully addressed the primary test objectives identified in Section 2.2, as the first test campaign in a planned three campaign series. Results have provided a better understanding of arc melter performance for treating "as incinerated" surrogate wastes. Results also provide information useful for test system modification for future tests, and for designing and performing future tests. In the second series of tests, arc melting of raw, as received buried and mixed wastes (without prior incineration) will be evaluated using nonradioactive, surrogate waste mixtures. The second test series is necessary to evaluate arc furnace applicability for treating as-received buried and mixed wastes, as opposed to treating ash residuals from a preincinerator step.

2. The second overall conclusion is that it is feasible to use existing industrial arc melter technology as a thermal treatment system to successfully process "previously incinerated" buried mixed wastes and soils on a production basis. Extensive additional design, testing, and evaluation is required to optimize the arc furnace system and improve operations to reduce the level of personnel involvement and risk for mixed/buried waste applications. Current design and operating practices used for this test system are based on those commonly used in the metals smelting industry. The test system and procedures were further modified for optimum personnel access to the equipment and process materials. This access is necessary for researchers to monitor and control conditions and understand the melter process operations. Modifications such as an enhanced feed system, overall system containment, and a remote tapping operation will enable application of the existing technology represented by the USBM system to radioactive waste treatment. Automation of many activities such as tapping is done currently to some extent in the commercial metals industry.

3. The arc melter technology is capable of reliable production operation for this application. Furnace operating parameters were generally within expected values and typical of reliable industrial arc furnace practice norms. Electrode wear was not excessive even though the furnace plenum was operated under excess air flow conditions (oxidizing conditions in the plenum). Slag was continuously tapped at steady state. Separate bottom tapping capability for use with metals was partially demonstrated by the draining of the furnace each day. Insufficient metal was present for separate metals tapping due to the volume increase of the hearth from dissolution of the hearth refractory. Over $52,000 \mathrm{lbs}$ of surrogate materials were processed at rates representative of those anticipated as needed for full scale production processing of buried mixed wastes and soils $(1,000$ to $2,000 \mathrm{lbs} / \mathrm{hr})$ during a semi-continuous $80 \mathrm{hr}$ test period essentially without failure (unplanned downtime).

There were two minor and preventable downtime problems incurred. The first was a fuse failure in the control circuit for the Phase A electrode. This was quickly resolved by operating that electrode manually while the failed fuse was diagnosed and replaced without difficulty. The 
second downtime occurrence was a partial blockage of the feed tubes in the furnace due to positive pressure spikes in the furnace leading to back flow of moist process gases into the feed tubes and agglomeration and blockage of the feed. After a short shut-down to clear the blockage, operation with increased negative pressure in the furnace (higher ID fan suction) and more control over open ports in the APCS (used for sample collection) satisfactorily prevented further occurrences. The positive pressure also caused very short duration but undesirable leakage of furnace gases into the melter room.

4. Although the arc furnace technology can clearly produce a wide range of process conditions, additional process optimization work is needed. The highly viscous, high-silica melts of some of the soil and feed mixtures required melt temperatures exceeding $1,800^{\circ} \mathrm{C}$ in order to achieve sufficient fluidity to tap the slag. While the furnace easily achieved the required temperatures, additions of mill scale $\left(\mathrm{Fe}_{3} \mathrm{O}_{4}\right)$ and either limestone $\left(\mathrm{CaCO}_{3}\right)$ or pebble lime $(\mathrm{CaO})$ were used to substantially reduce viscosity and required tapping temperatures, to reduce concerns for potential metals volatilization and refractory wear. The magnesium oxide hearth was also dissolved by the acidic (high silica) S60 feed slag at high temperatures. This did not require a shut-down during the test, but prevented complete draining of the furnace through the bottom metal tap hole in all subsequent tests. The metal product at the bottom of the hearth could not be tapped as a result. Additional testing and analytical modeling evaluations are recommended to improve tapping of higher viscosity slags, and to determine optimum slag conditions for maximum glass/ceramic waste form durability (high silica, high temperature slag) while minimizing additives, furnace wear, and metals volatilization (lower silica, lower viscosity, lower temperature slag).

5. The arc furnace produced process conditions desired for controlled separations, destruction of complex waste compounds, and stabilization of TRU and selected toxic metals in a highly durable glass/ceramic product (slag phase). Overall mass and elemental partitioning results were generally consistent with expectations and desired separations for all test feeds. An average of $84 \%$ of the feed material mass was melted or dissolved into the fluid slag phase, tapped, and cooled to produce a durable glass/ceramic solid. Approximately $2.9 \%$ of the feed mass partitioned as a separate tappable metal product phase (over $90 \% \mathrm{Fe}$ ) in the bottom of the furnace (hearth) below the slag phase. Approximately $15 \%$ of feed material decomposed or reacted to produce typical combustion gases $\left(\mathrm{H}_{2} \mathrm{O}, \mathrm{CO}_{2}, \mathrm{CO}, \mathrm{SO}_{2}, \mathrm{HCl}, \mathrm{NO}_{\mathrm{x}}\right)$ flowing out through the APCS. Roughly $1.5 \%$ was entrained feed particulate and $0.5 \%$ of the mass was volatilized fume solids (condensible particulate).

6. The slag was the primary furnace product material and yielded a homogeneous, durable glass/ceramic phase (tapped slag) upon cooling that easily passed TCLP. A separate tappable, homogeneous, structural metal alloy phase material product was also produced, as were relatively small amounts of secondary furnace product solids (condensed fume and entrained feed particulate) which were successfully captured and retained in the APCS. Each product material was essentially homogeneous (much more so than the waste feeds), and properties evaluated were generally acceptable. The APCS solids would likely require additional processing. Recycling through the furnace is recommended for the entrained particulate after agglomeration into a larger feed size. In a continuous operation, the amount of effluent APCS solids may be significantly reduced by recycling most of this material to the melter. 
7. The arc furnace system process should be capable of partitioning essentially all TRU in the waste to the desired glass/ceramic (slag) phase without volatilization of any TRU or contamination of tappable metal. No cerium (the TRU surrogate) was detected in the metals product. Only $2 \%$ of the Ce was transported into the APCS system, due to direct feed entrainment. The feed entrainment of $\mathrm{Ce}$ was due to the presence of very fine particle-sized $\mathrm{CeO}_{2}$ concentrate, and would not be normal under normal processing of actual buried and mixed wastes.

Results of the M60 test indicate that any TRU metal in waste processed under these conditions would rapidly oxidize and partition to the slag. In addition to the $\mathrm{CeO}_{2}$ concentrate that was added in all the tests, elemental Ce was added to the M60 test. This Ce rapidly oxidized. No Ce was detected in the metal product, and the Ce detected in the APCS solids did not increase. The measured increase in $\mathrm{Ce}$ in the slag also confirmed this partitioning. This oxidation of $\mathrm{Ce}$ and partitioning to the slag occurred even though conditions in the furnace slag were locally reducing enough to not oxidize over $95 \%$ of the copper, over $90 \%$ of the nickel, and over $85 \%$ of the iron that were added as elemental metals. These elements reported primarily to the melted metal phase in the bottom of the furnace. The lack of any Ce in the APCS solids that was attributable to volatilization is consistent with the low volatility of $\mathrm{CeO}_{2}$, and meets expectations that this readily oxidized material would entirely report to the slag phase even under high temperature melt conditions. The presence of the cold top may have also contributed to the lack of any volatile Ce carryover.

The presence of $\mathrm{CeO}_{2}$ in the feed mixtures represents a worst case situation for potential feed entrainment and consequent Ce carryover to the APCS. Despite the small size of the $\mathrm{CeO}_{2}$ powder in the feed, an average of $98 \%$ of the Ce partitioned to the slag. This is due in part to the effectiveness of the feed tubes and the cold top in minimizing dusting.

There was also little change in the partitioning of $\mathrm{Ce}$ to the baghouse from run to run, even for the higher temperature N80, N80-IV, and M60 runs. Since there was no apparent influence of temperature on the partitioning of Ce to the APCS, the small amount of Ce that was partitioned to the APCS was from entrainment of the fine Ce oxide powder in the feed. Elimination of feed entrainment and carryover may be minimized by design and operation modifications, such as increasing the feed material size distribution and reducing furnace plenum gas velocities.

8. Additives used in preparing the surrogate feed mixtures tended to have fine particle size distributions and contributed markedly to the solids collected in the APCS. This entrainment biased APCS elemental partitioning analyses and made it very difficult to detect volatilization versus entrainment for most materials and elements. Only a few of the additives (mullite, pollucite, $\mathrm{NaCl}$, pebble line, aluminum, copper, lead, and zinc) had particle sizes too large to be at least partly entrained. All of the other materials had sufficient fines to be at least partially entrained. Especially critical additives that had large amounts of fine material included the soil, cerium oxide concentrate, limestone, potash, and soda ash. Even iron was entrainable, as oxides in magnetite powder in all tests but the M60 test, in mill scale flakes in all of the modified composition tests (N80-Mod, N80-IV-Mod, and M60-Mod), as elemental iron in stainless steel powder and iron flake in the M60 test, and as oxides in the soil of all tests. Partitioning results have been interpreted with consideration of this entrainment potential, and estimates of 
volatilized and entrained amounts for different components have been made. However, measures are recommended for future tests to avoid or better differentiate between entrained and volatilized materials in the offgas. Such measures may include reducing entrainment of feed materials by using larger feed particle sizes, pelletizing feed additives, reducing plenum gas velocities, or more effectively identifying and separating entrained and volatilized materials. Excessive size reduction of actual wastes during feed preparation for production operations should be avoided.

9. Toxic metal vaporization and carryover was very low for all but the most volatile species of $\mathrm{As}, \mathrm{Cd}, \mathrm{Pb}, \mathrm{P}, \mathrm{Hg}, \mathrm{Se}$, and $\mathrm{Zn}$. Correlations for less volatile metals were difficult and masked by feed entrainment carryover. Also, most of the metals were present at only trace levels as metal oxides in the feed mixtures except for the M60 feed mixture, so small or nondetectable amounts of some metals affected the partitioning calculations. While metals volatilization was expected to increase with increasing melt temperatures and with increasing $\mathrm{Cl}$ in the feed, these trends were not clearly evident for all metals due to the hour-to-hour variations in melt temperatures and the difficulty in differentiating between entrainment and volatilization of tracelevel metals. However, the highest volatilization for $\mathrm{As}, \mathrm{Cd}, \mathrm{Pb}, \mathrm{P}$ and $\mathrm{Hg}$ occurred during the S-series (high chlorine) and N80 (highest melt temperature) tests. Volatilization was also high for $\mathrm{Zn}$ during these tests, but was even higher during the M60 test.

While the trace metals in the soil and in the $\mathrm{N}$ and S-series tests were present as oxides, the metals in the M60 were added as metals, not metal oxides. The oxides were typically higher melting point compounds, so they tended to be less volatile than the elemental metals in the M60 test. However, the presence of chlorine in the S-series tests and the high melt operating temperatures $\left(1,650-1,800^{\circ} \mathrm{C}\right)$ for the $\mathrm{N} 80$ and N80-Mod tests resulted in significant metals volatilization. At the higher melt temperatures, there may have been more volatilization from the oxide forms and also from metals reduced from oxides in the more reducing area surrounding the graphite electrodes. In future tests, activities to better characterize metals transport mechanisms are recommended. These include feed preparation to reduce entrainment, physical separation of entrained and volatilized materials, better control and measurement of parameters that affect volatilization such as chlorine content and bath temperature, and added feed and APCS solids analyses. Predictions based on analytical models should be developed to better understand the data and allow for developing design tools.

10. Although all measured temperatures were useful for interpreting performance, temperature measurement in furnace environments is an area where additional measurements, measurement methods, and analytical support for data interpretation and extrapolation is needed. In-furnace TC measurements were difficult due to TC material failure at the high temperatures. Short-duration sacrificial TC measurements were done occasionally but involved opening ports to access the furnace and were not continuous. In-furnace infrared temperature measurements were not possible due to dust levels in the furnace plenum. Tapped slag temperatures determined with an external infrared pyrometer were the most representative and accurate indicators of slag bath temperatures, but were lower than actual melt temperatures within the furnace. The slag was cooled as it passed through the water cooled tapping fixture. The slag occasionally formed a cooler crust on the surface of the slag stream, and infrared pyrometer readings are sensitive to placement of the visual spot on the slag stream. 
Furnace hearth, refractory, and wall temperatures were measured at several locations as reported. These generally track well with each other consistently over time. They are useful indicators but do not provide furnace temperatures in the metal phase, at the metal/slag interface, at locations throughout the slag, in the furnace plenum, cold top, etc. Clearly the temperature distribution within the furnace is a key to understanding and controlling the process. Analytical modeling is needed to interpret data and to predict temperatures of other regions. Development of analytical modeling is in process under other BWID funding, but should be accelerated, focused, and simplified wherever possible. Additional furnace TCs should be utilized in future tests, and potential alternative temperature measurement techniques such as the millimeter wave radiometer under development in a related BWD project should be tested in the next test series.

11. The arc furnace has the capability to melt metals and separate the metal product from the slag for tapping, if desired or needed. Although tapping of metal was not possible in the baseline series due to the hearth dissolution by high temperature viscous slag during the early S60 test, tapping through the bottom tap hole was demonstrated successfully by draining slag from the furnace through the bottom tap hole at the end of each test day.

12. The metal heel in the bottom of the hearth may not have been molten during every test. While mass balances indicate the formation of a metal heel from reduced iron for many of the test days prior to the M60 test, complete melting of the metal product may not have occurred until the M60 test. The M60 test was the last test of the series, and the metal heel was removed following furnace cool-down after this test. The monolithic, alloyed appearance of the metal heel indicates that the metal was completely molten at least at the end of or following the M60 test. Since the melting temperature of iron is $1,550^{\circ} \mathrm{C}$, the temperature at the bottom of the hearth exceeded this temperature late in the M60 or M60-Mod tests, though such high temperatures at the bottom of the hearth may also have occurred sooner.

Iron metal reduced from the mill scale in the earlier tests may have resolidified at the bottom of the hearth if the temperature was less than $1,550^{\circ} \mathrm{C}$. According to mass balances, about $162 \mathrm{lb}$ of iron was reduced from the oxide in the shakedown test when soil was the feed material. Although the melt temperatures were high enough to tap the slag, the low slag thermal conductivity and short run time may have resulted in a relatively cool bottom temperature compared to later tests such as the S60 test, in which the MgO refractory portion of the hearth was dissolved. Some slag was present in the hearth after draining the furnace through the metal tap hole. This indicates that the hearth was too cool during this run to have molten metal or slag on the hearth.

Analytical modeling of the heat transfer conditions are recommended to estimate if the metal heel was molten at other times during the baseline tests.

13. The dissolution of the $\mathrm{MgO}$ refractory indicates the need to evaluate hearth and slag compatibility prior to the next test series. Although the $\mathrm{MgO}$ ramming mix that made up the hemispherical hearth was dissolved, the underlying bottom and side Ruby refractory bricks were unaffected. A hearth made of Ruby ramming mix may be more durable.

The hearth bottom brick may have been protected in part by the metal heel on the hearth. Maintaining a noncorrosive metal heel or a cooled slag layer (skull) in the hearth may be an 
acceptable strategy for protecting the hearth refractory. This practice is used in some industrial metallurgical and waste treatment processes. The metal heel or skull may only be removed occasionally to completely drain the furnace. This mode of operation should be further evaluated as a means for hearth protection.

14. The existence of a cold top reduced volatilization transport from the melt and reduced plenum surface and gas temperatures. Although the melt temperatures ranged to $1,800^{\circ} \mathrm{C}$ or higher, the plenum wall temperatures and gas temperatures were far lower, typically in the $300-700^{\circ} \mathrm{C}$ range. A cold top was present almost continuously during operation. The thickness varied and was difficult to monitor with the manual means utilized, but no effects of thickness variation were detectable. The next test series should include operation both with and without a cold top under otherwise identical operating conditions to better quantify cold top effects. 


\section{REFERENCES}

1. G. L. Anderson, A. D. Donaldson, and N. R. Soelberg, Test Plan for the FY-93 Phase 1 Baseline Tests for the BWID Arc Melter Vitrification Project, EGG-WTD-10862, Revision 0, July 1993.

2. J. L. Mayberry, W. J. Quapp, F. Feizollahi, J. C. Del Signore, and J. McFee, Preliminary Systems Design Study Assessment Report, EGG-WTD-9594, EG\&G Idaho, Inc., June 1991.

3. M. D. Argyle, A. L. Rubert, J. C. Tozer, and L. Meikle, INEL Radioactive Waste Stream Characterization Data (Draft), EGG-WM-10909, August 1993.

4. T. L. Eddy, P. C. Kong, B. D. Raivo, and G. L. Anderson, Thermal Processing Systems Concepts and Considerations for RWMC Buried Wastes, EGG-WTD-10058, EG\&G Idaho, Inc., February 1992.

5. A. D. Donaldson, R. J. Carpenedo, and G. L. Anderson, Melter Development Needs Assessment for RWMC Buried Wastes, EGG-WTD-9911, EG\&G Idaho, Inc., February 1992.

6. L. L. Oden and W. K. O'Connor, ASME/U.S. Bureau of Mines Investigative Program Report on Vitrification of Residue (Ash) from Municipal Waste Combustion Systems, CRTD-Vol. 24, American Society of Mechanical Engineers, June, 1994.

7. L. L. Oden et al., Baseline Tests for Arc Melter Vitrification of INEL Buried Wastes, Vol. 1, EGG-WTD-10981, November 19, 1993.

8. A. D. Hartman, L. L. Oden, and L. C. White, Facility for Melting Residues From Municipal Waste Combustion: Design Criteria and Description of Equipment, RI 9476, U. S. Department of the Interior, Bureau of Mines, 1993.

9. 40 CFR 60 Appendix A, July 1, 1992.

10. Reimann, G. A. and P. C. Kong, Improving Iron-Enriched Basalt With Additions of $\mathrm{ZrO}_{2}$ and $\mathrm{TiO}_{2}$, EGG-MS-10642, June 1993.

11. R. B. Bird, W. E. Stewart, and E. N. Lightfoot, Transport Phenomena, John Wiley and Sons, Inc., New York, 1960.

12. N. R. Soelberg, R. A. Montgomery, R. A. Bessent and D. Gombert, Results of the Pilot-Scale Treatability Study for the Test Reactor Area Warm Waste Pond, EGG-ER-10616, April 1993.

13. J. M. Hillary and R. G. Barton, Interactions of Toxic and Transuranic Surrogate Metals During Thermal Treatment of INEL Wastes, EGG-IBPE-11060, September 1993. 


\section{Appendix A}

Operating Conditions During Shakedown Test of RWMC Soil and Mill Scale 
$$
\text { - }
$$ 


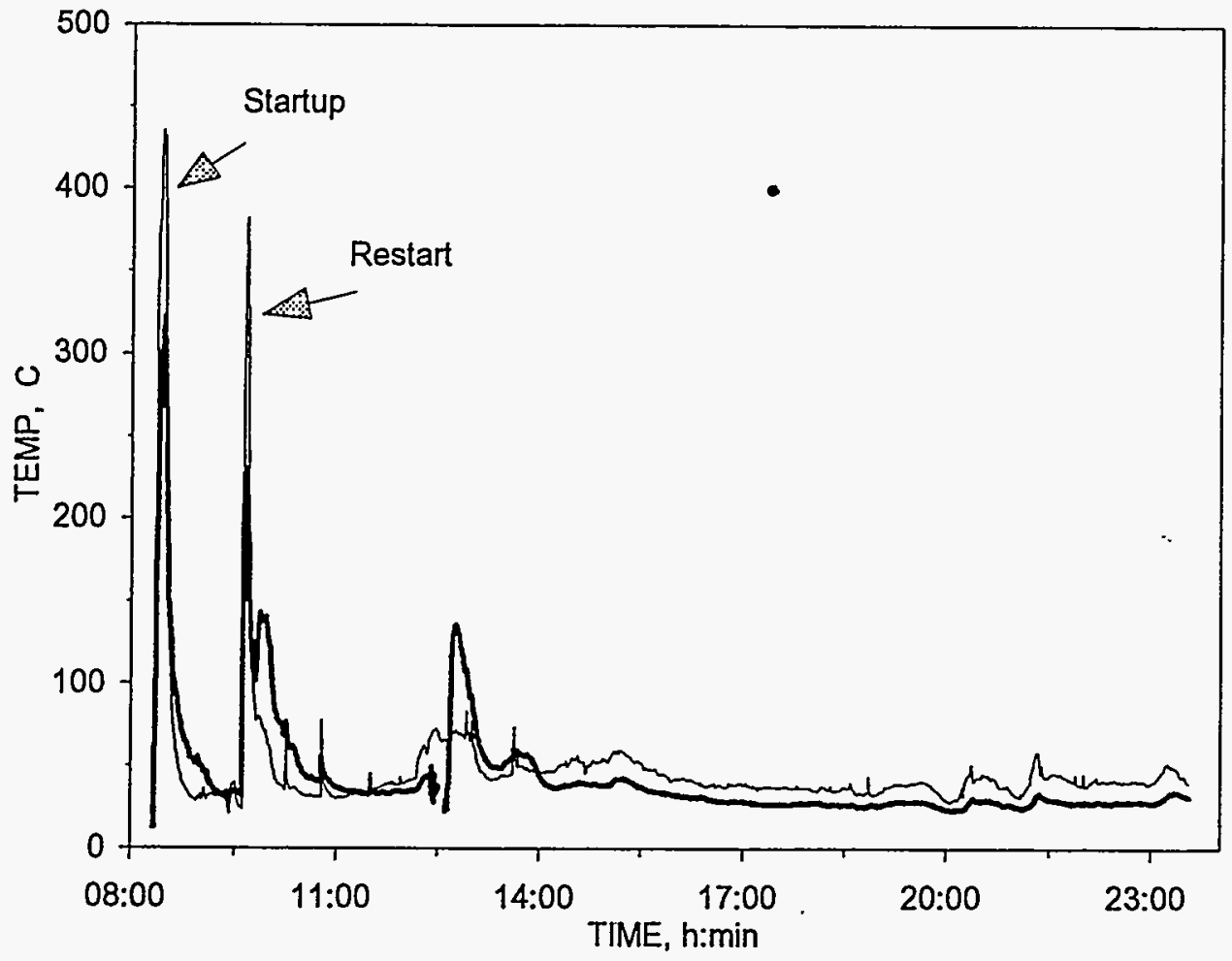

Figure A-1. Fumace exit wall temperature ( - ) and offgas temperature at the fume trap $1(-)$ for the shakedown test.

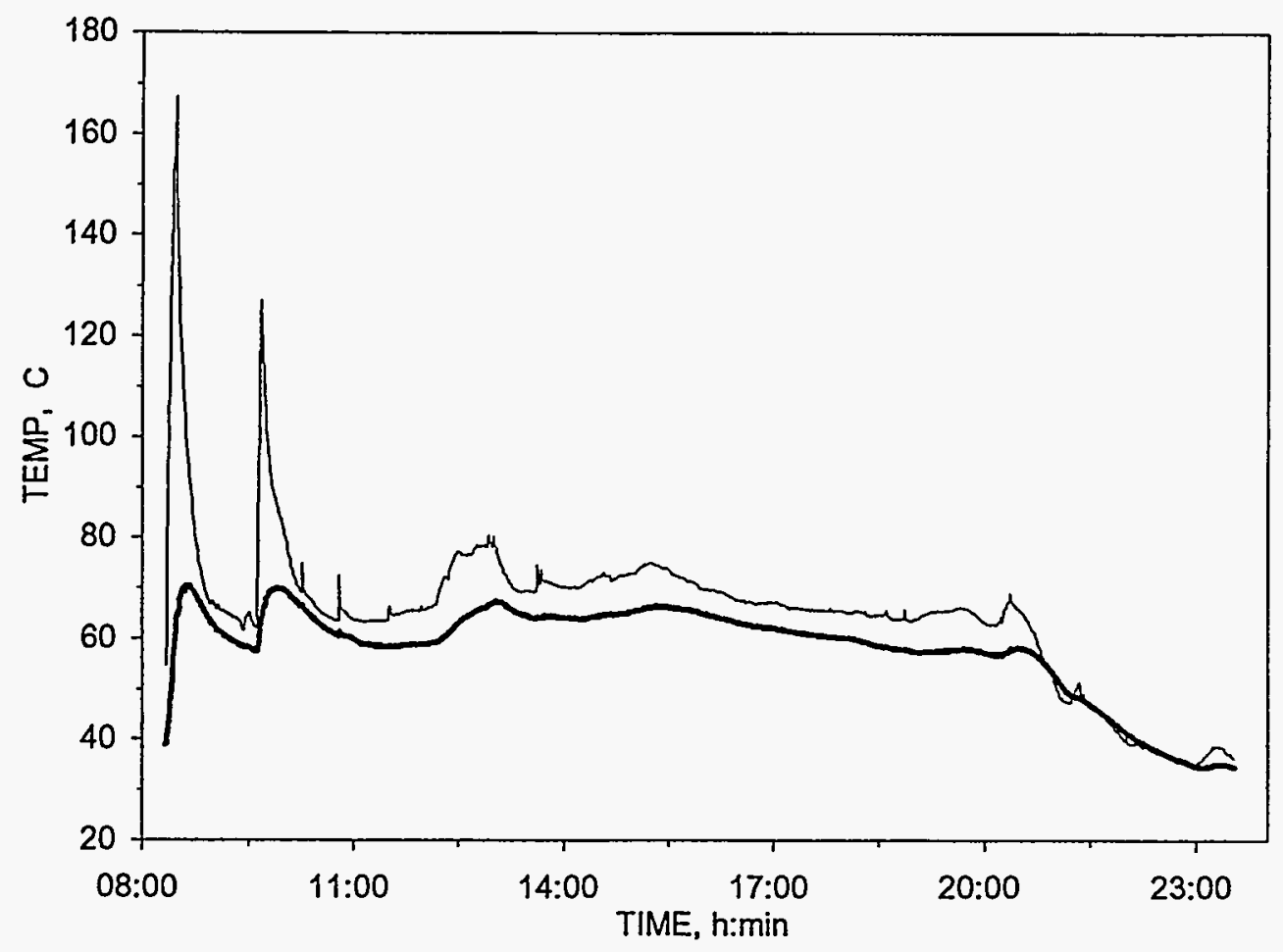

Figure A-2. Offgas temperatures upstream ( - ) and downstream ( - ) of the baghouse for the shakedown test. 


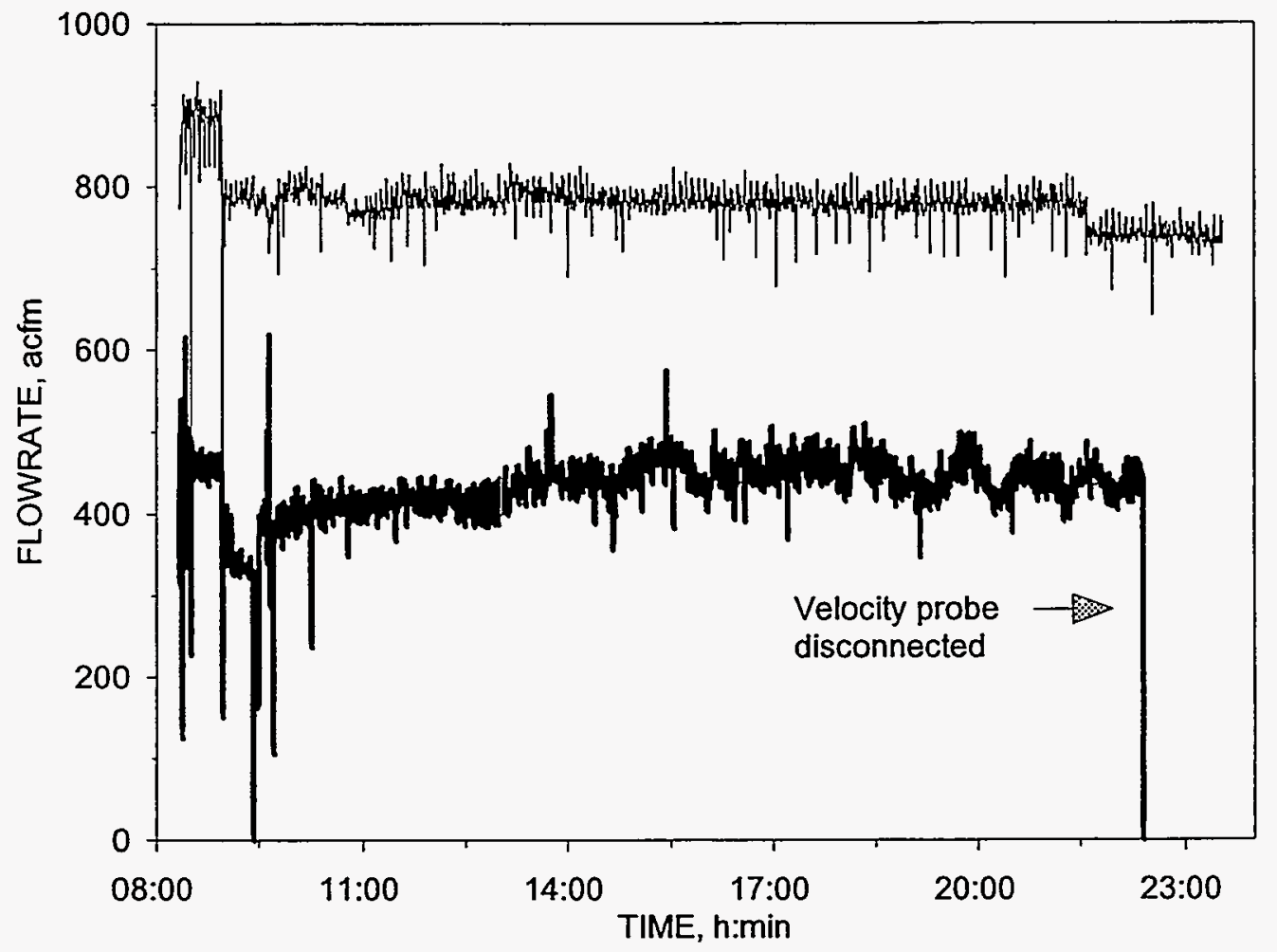

Figure A-3. Flow rate of quench air ( - ) and offgas at the baghouse outlet ( - ) for the shakedown test.

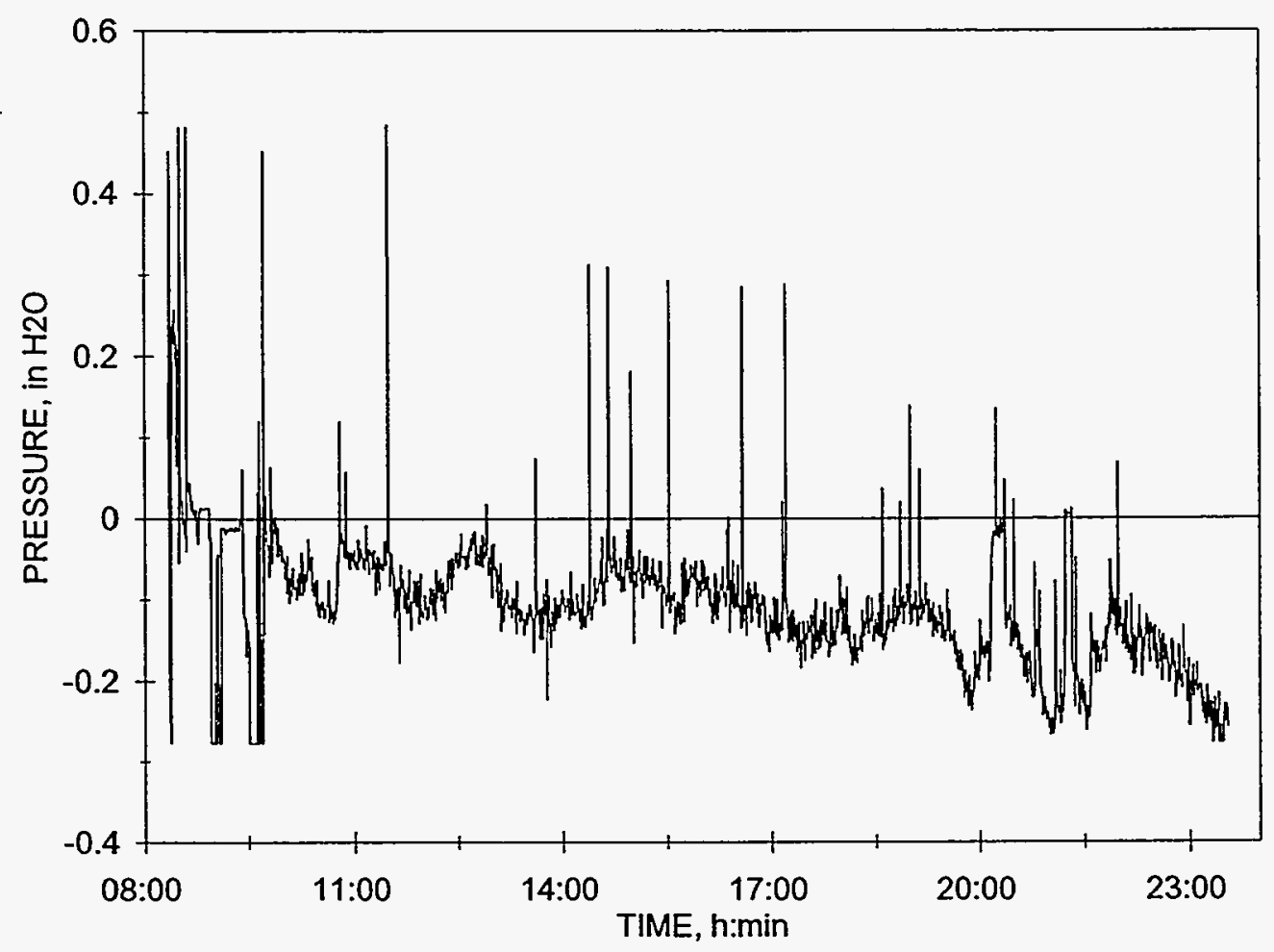

Figure A-4. Furnace pressure for the shakedown test. 


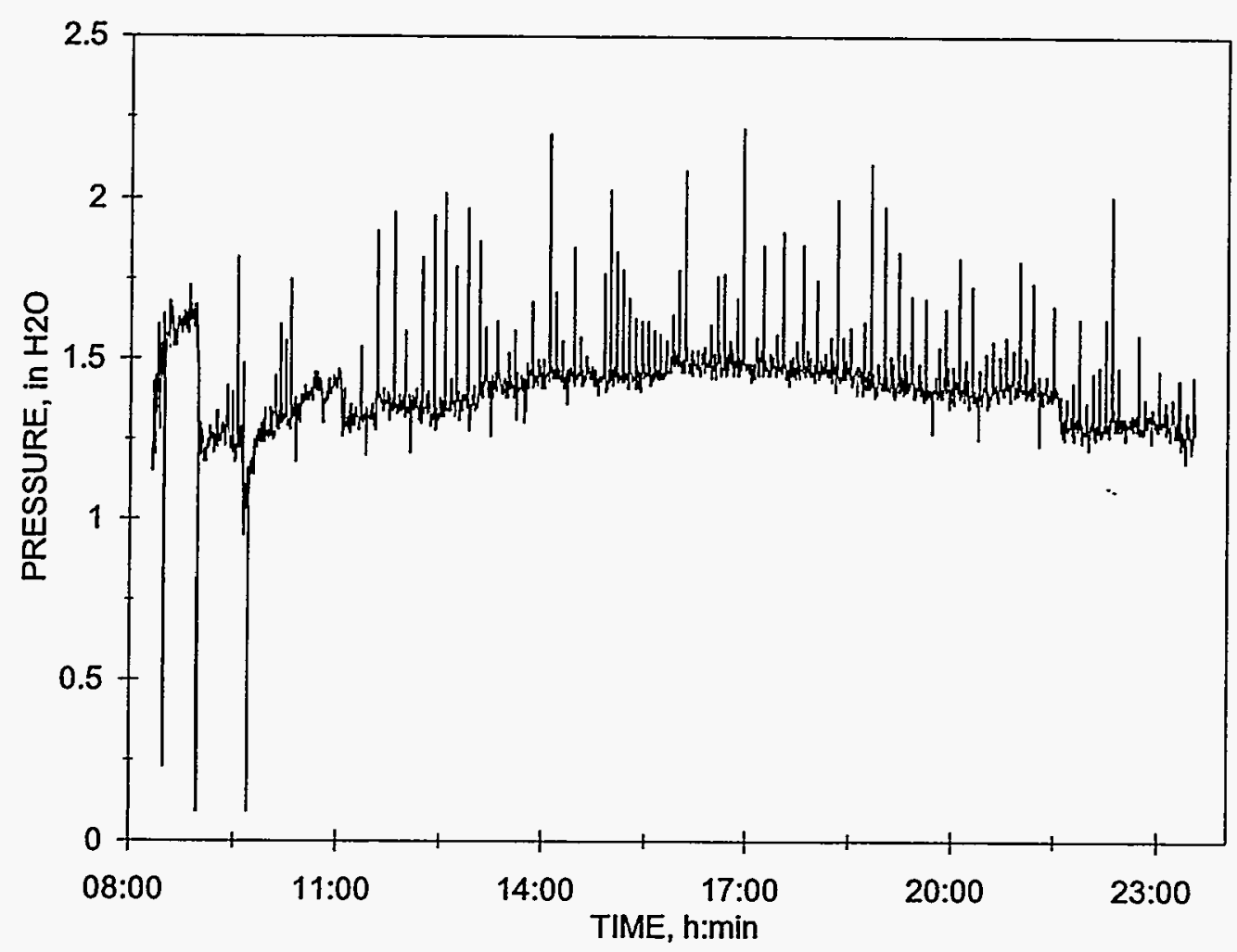

Figure A-5. Baghouse pressure drop for the shakedown test. 


\section{Appendix B}

Operating Conditions During Melting of S60 



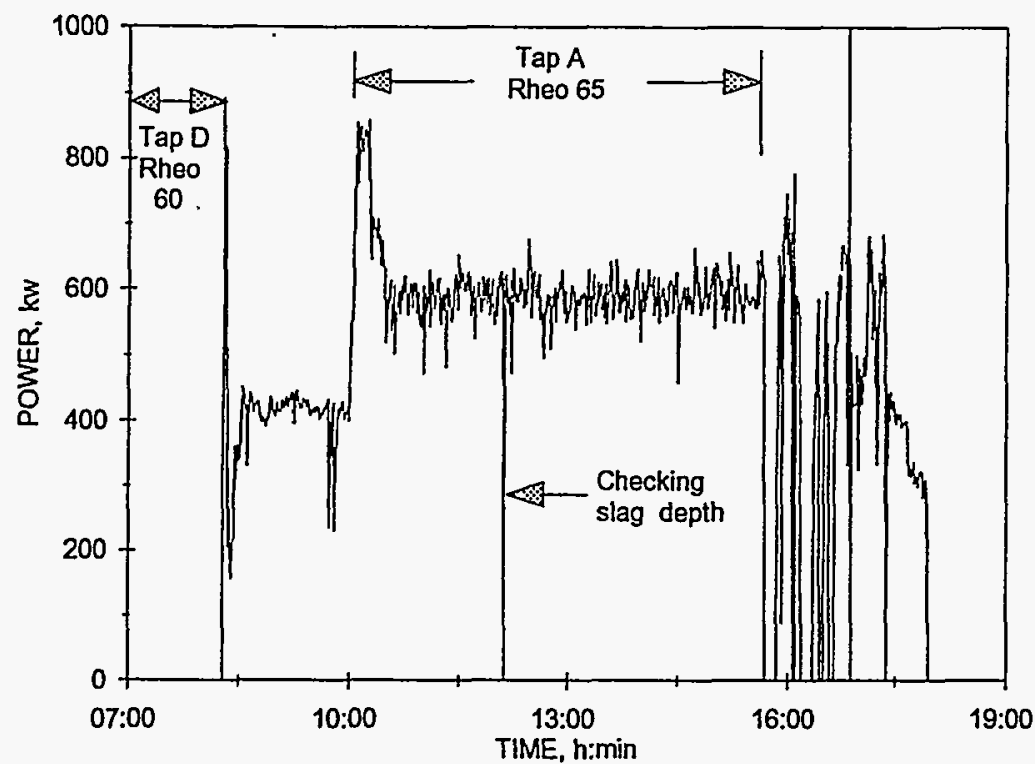

Overall Averages based on non-zero power

$\begin{array}{lr}\text { Voltage } & 179.0 \mathrm{~V} \\ \text { Current } & 1013.7 \mathrm{~A} \\ \text { Power } & 544.0 \mathrm{~kW}\end{array}$

Stable Operating Range (10:19 - 15:09) Averages

Voltage $194.4 \mathrm{~V}$

Current $999.8 \mathrm{~A}$

Power $586.8 \mathrm{~kW}$

Total Energy $5093 \mathrm{kwh}$

Figure B-1. Input power to the furnace for the $\mathbf{S 6 0}$ tests.

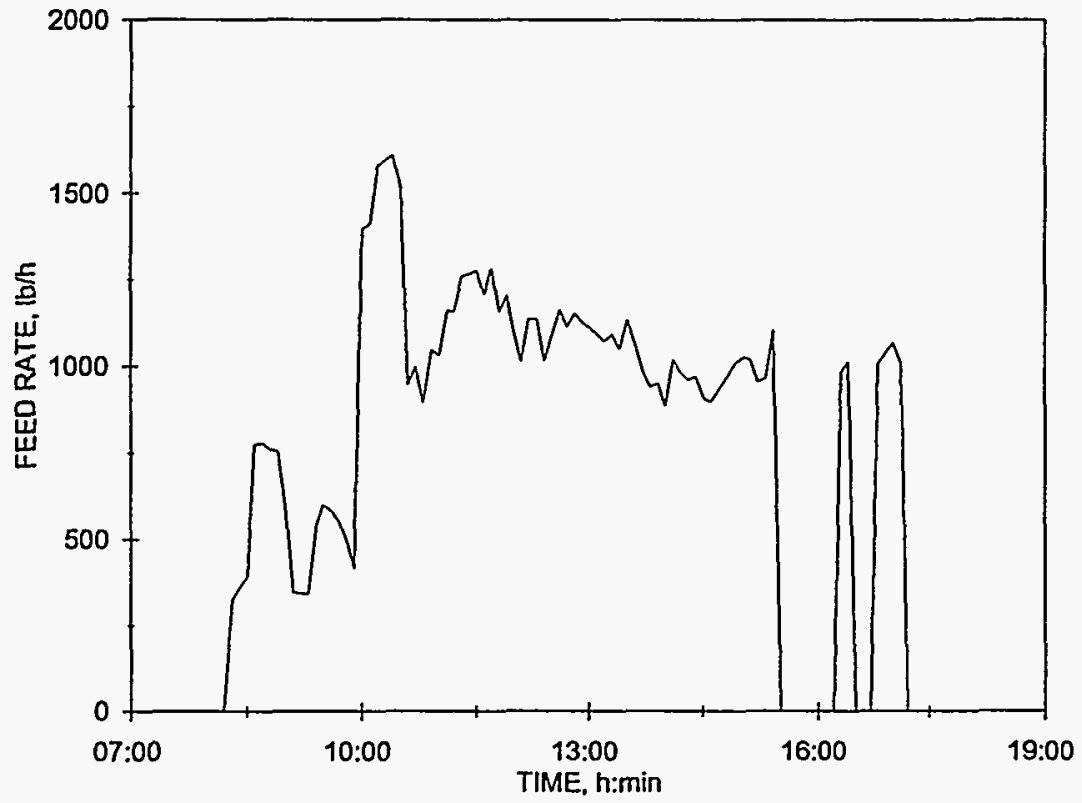

Overall Averages based on non-zero feed rate

Feed Rate $977 \mathrm{lb} / \mathrm{h}$

Total Feed $9806 \mathrm{lb}$

Energy Consumption $0.52 \mathrm{kWh} / \mathrm{lb}$

Stable Operating Range (10:19 - 15:09) Averages

Feed Rate $1041 \mathrm{lb} / \mathrm{h}$

Total Feed $5028 \mathrm{lb}$

Energy Consumption $0.56 \mathrm{kWh} / \mathrm{lb}$

Figure B-2. Feed rate for the S60 tests. 


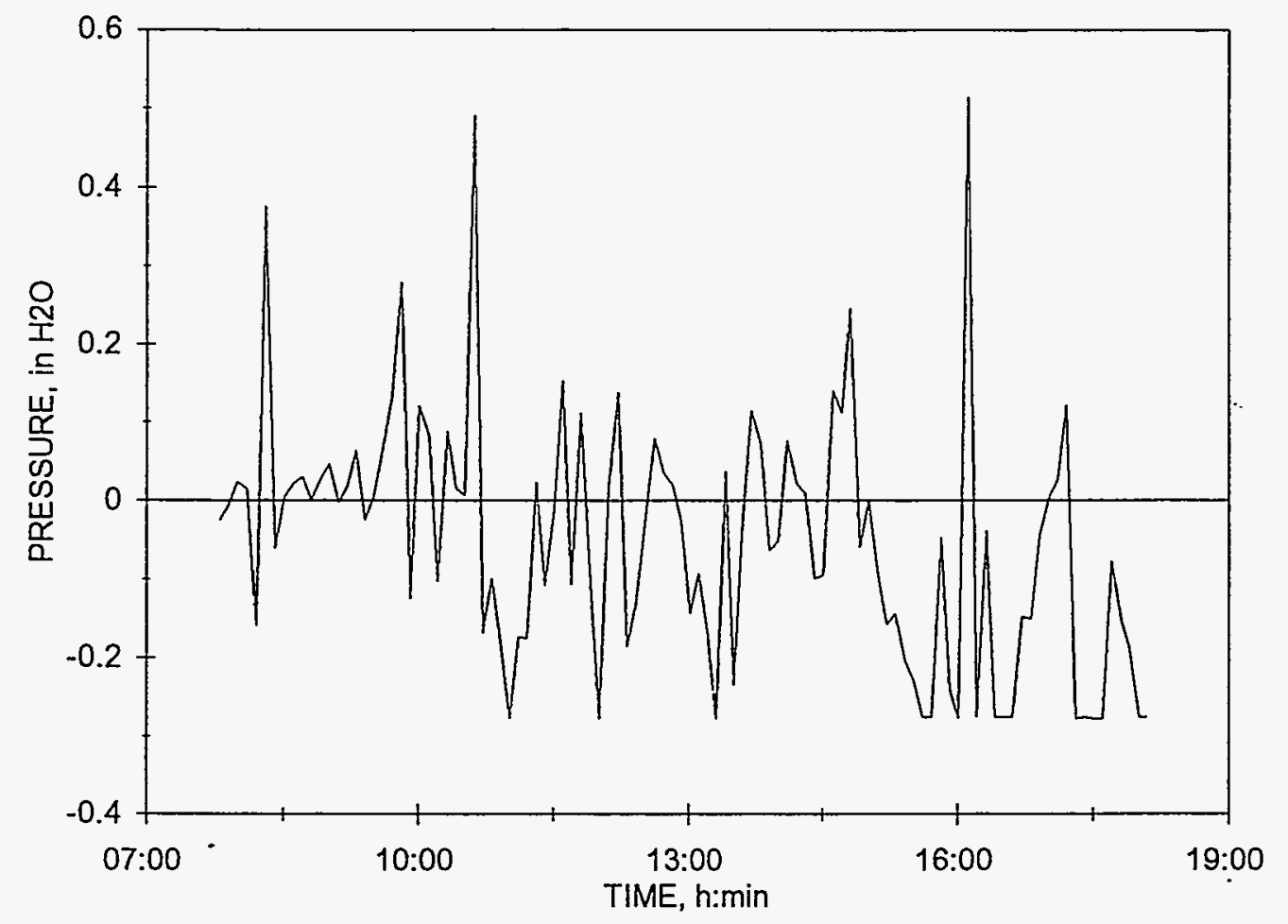

Figure B-3. Furnace pressure for the $\mathrm{S} 60$ tests.

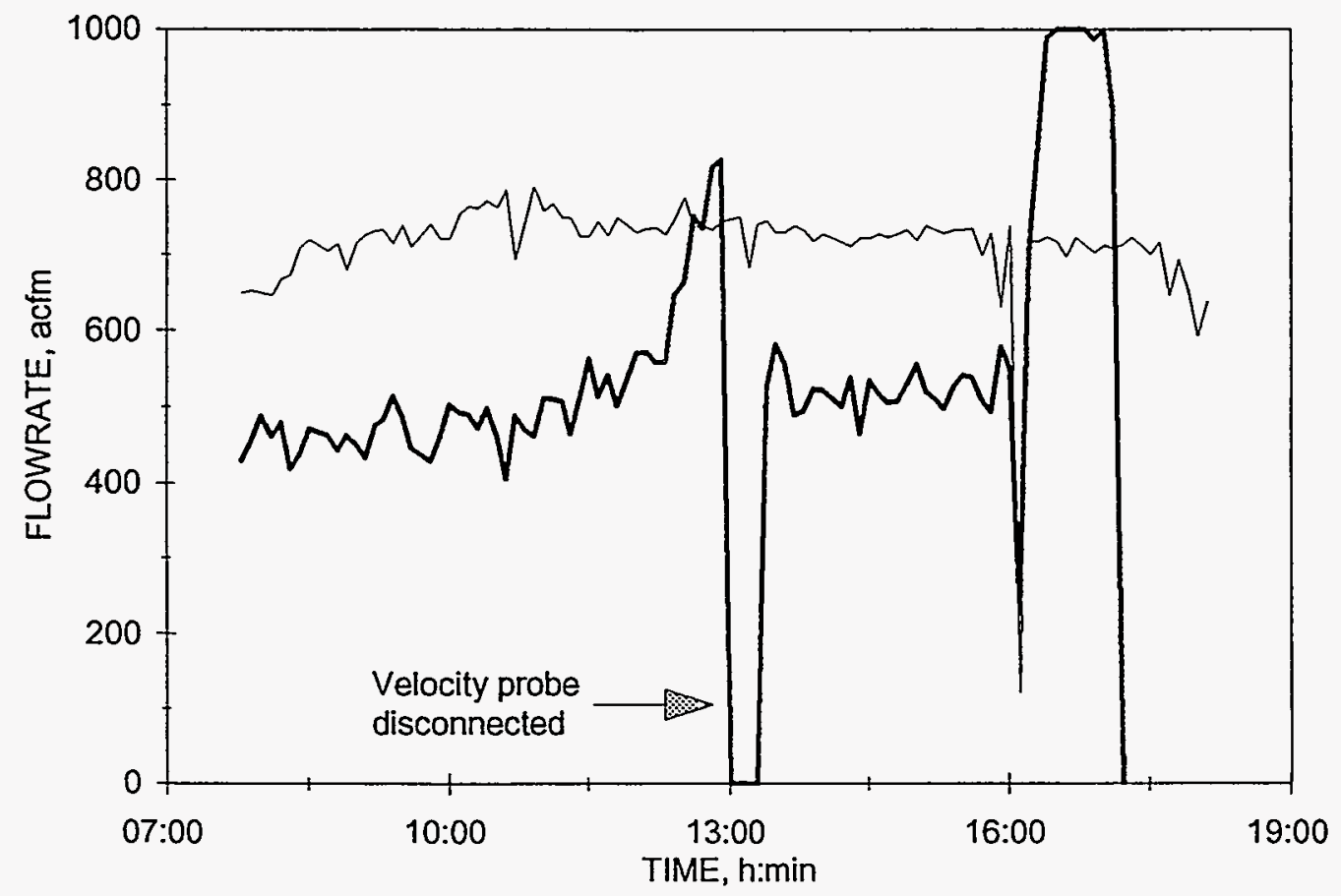

Figure B-4. Flow rate of quench air ( - ) and offgas at the baghouse outlet ( - ) for the S60 tests. 


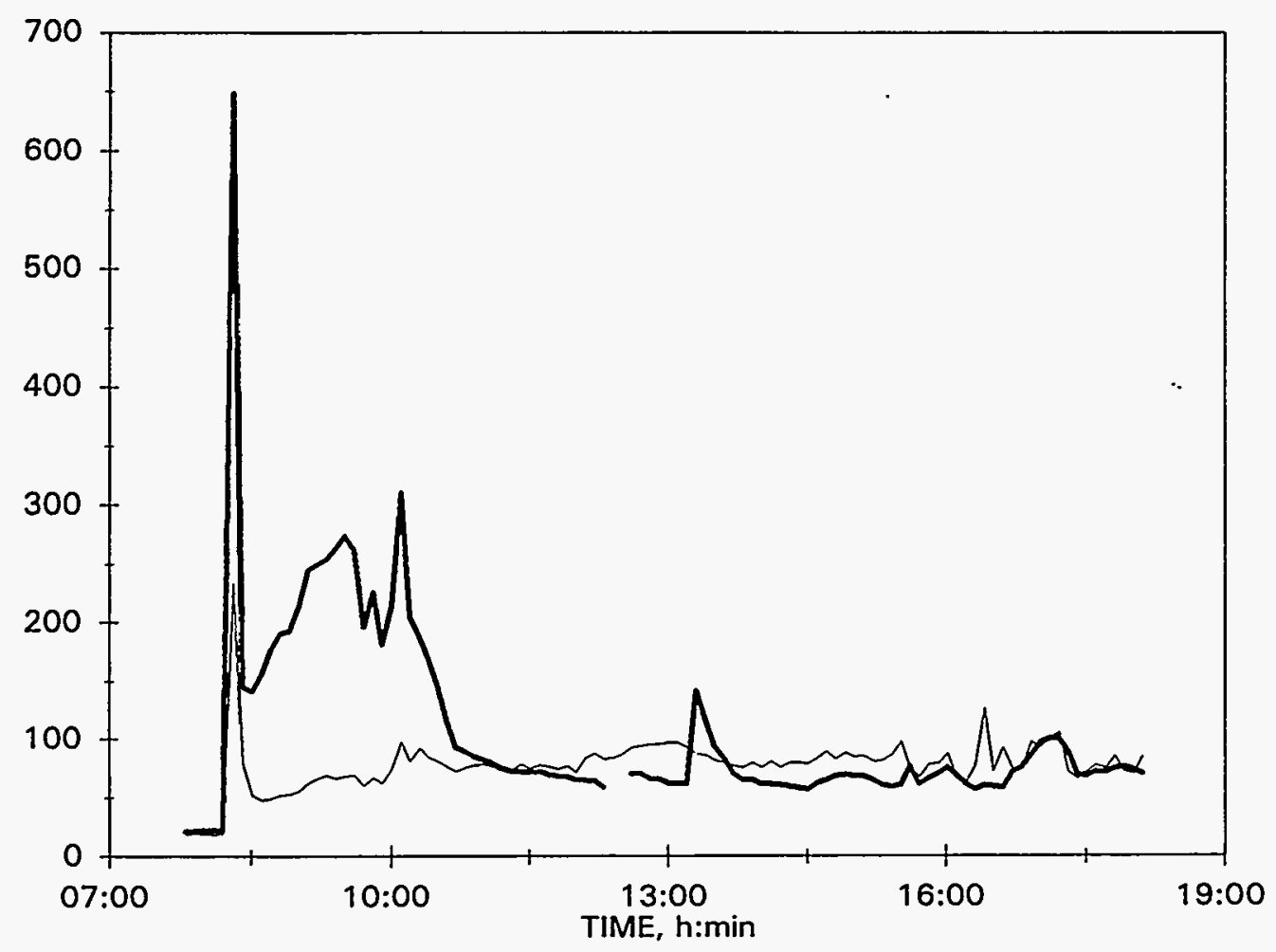

Figure B-5. Furnace exit wall temperature $(-)$ and offgas temperature at the fume trap $1(-)$ for the S60 tests

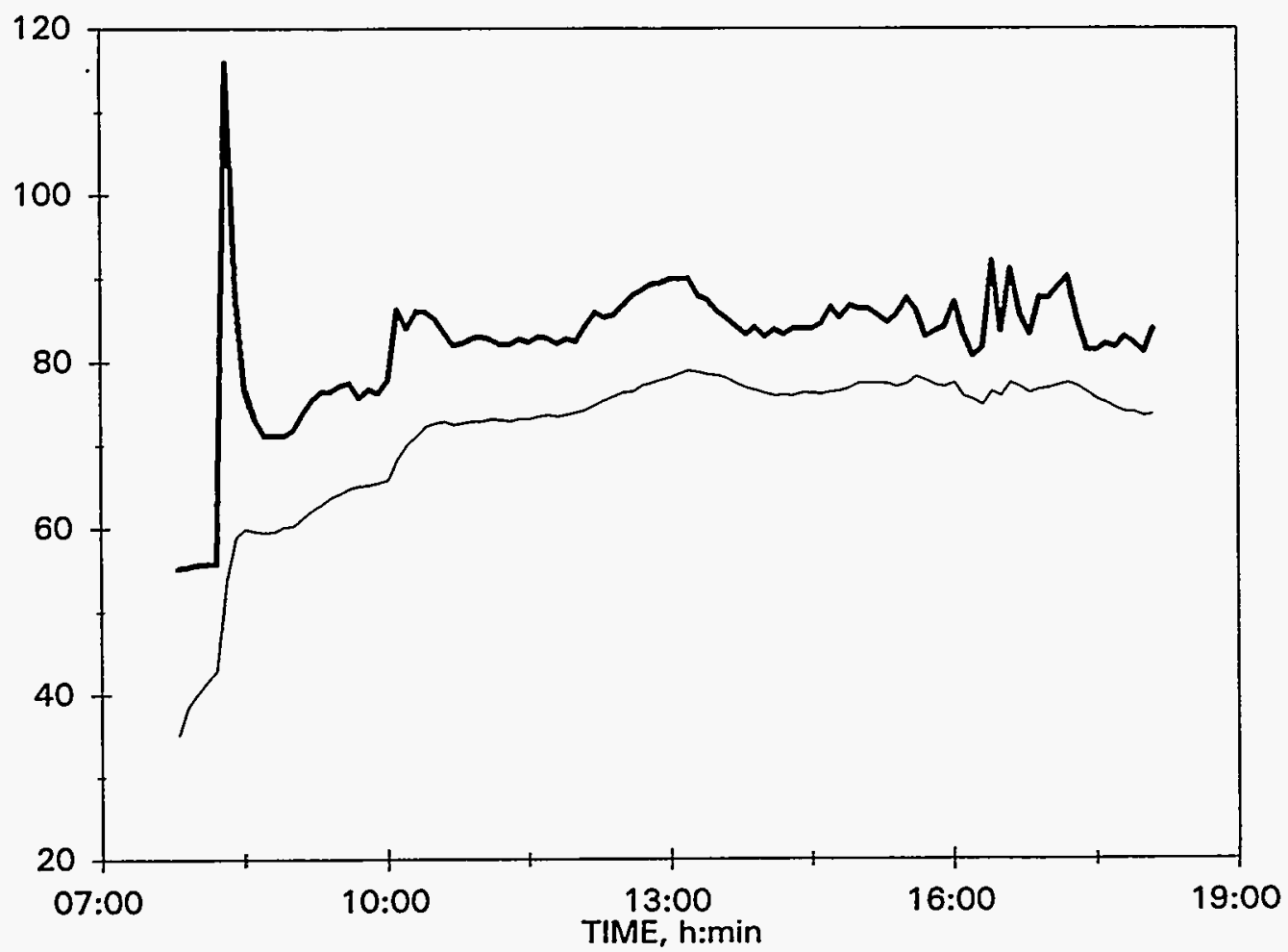

Figure B-6. Offgas temperatures upstream ( - ) and downstream (-) of the baghouse for the S60 tests. 


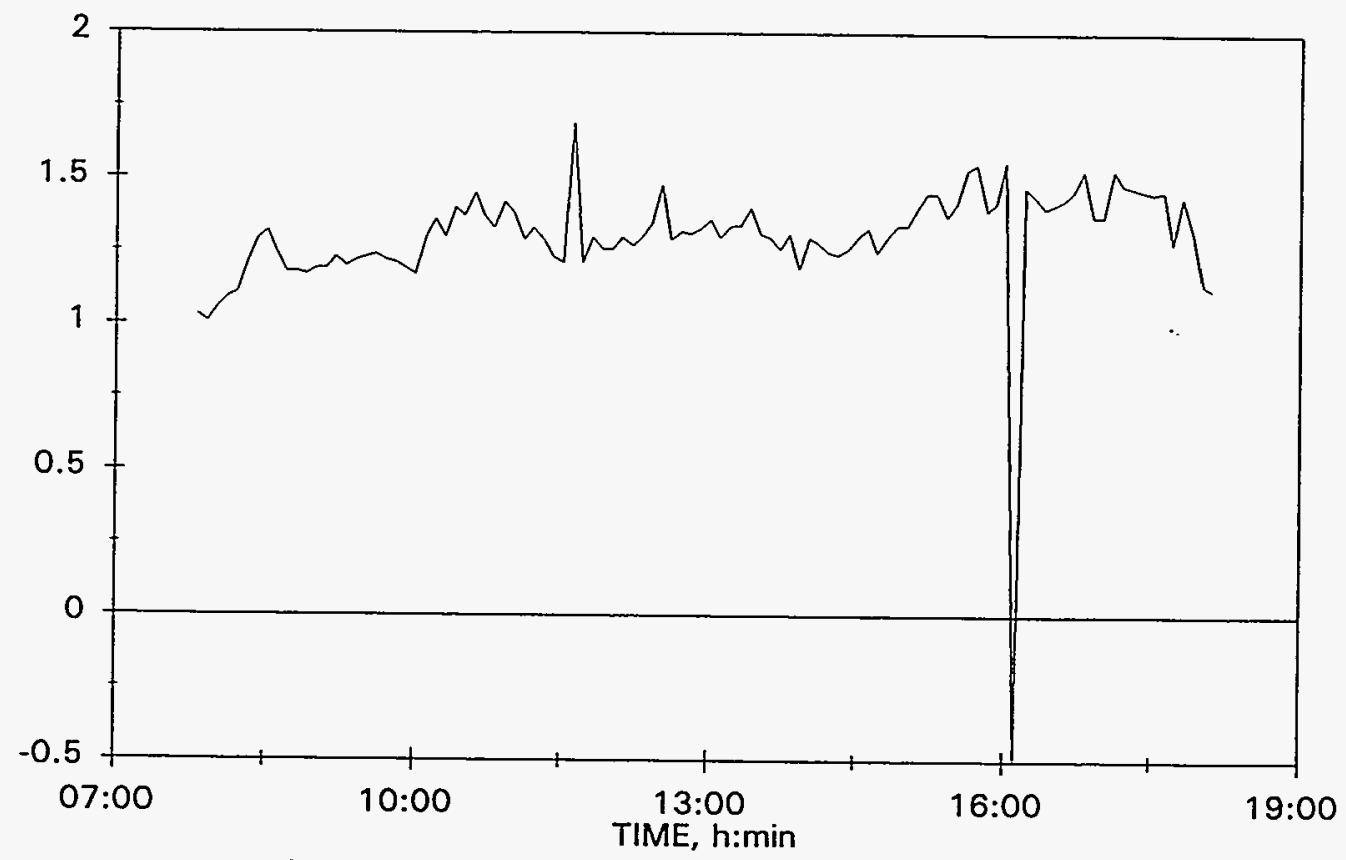

Figure B-7. Baghouse pressure drop for the S60 tests. 


\section{Appendix C}

\section{Operating Conditions During Melting of S60-IV}





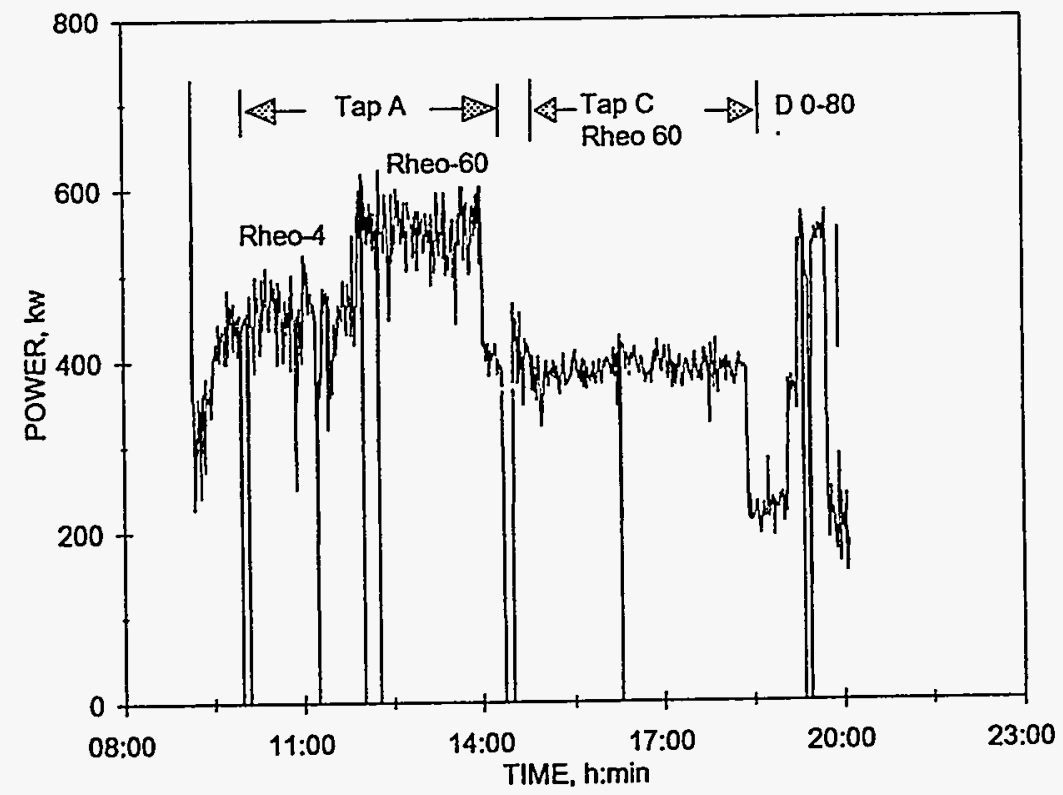

Overall Averages based on non-zero power

$\begin{array}{lr}\text { Voltage } & 164.8 \mathrm{~V} \\ \text { Current } & 859.7 \mathrm{~A} \\ \text { Power } & 421.6 \mathrm{~kW}\end{array}$

Stable Operating Range (14:23 - 17:43) Average

Voltage $161.6 \mathrm{~V}$

Current 838.9 A

Total Energy $4624 \mathrm{kwh}$

Figure $C-1$. Input power to the furnace for the S-60-IV tests.

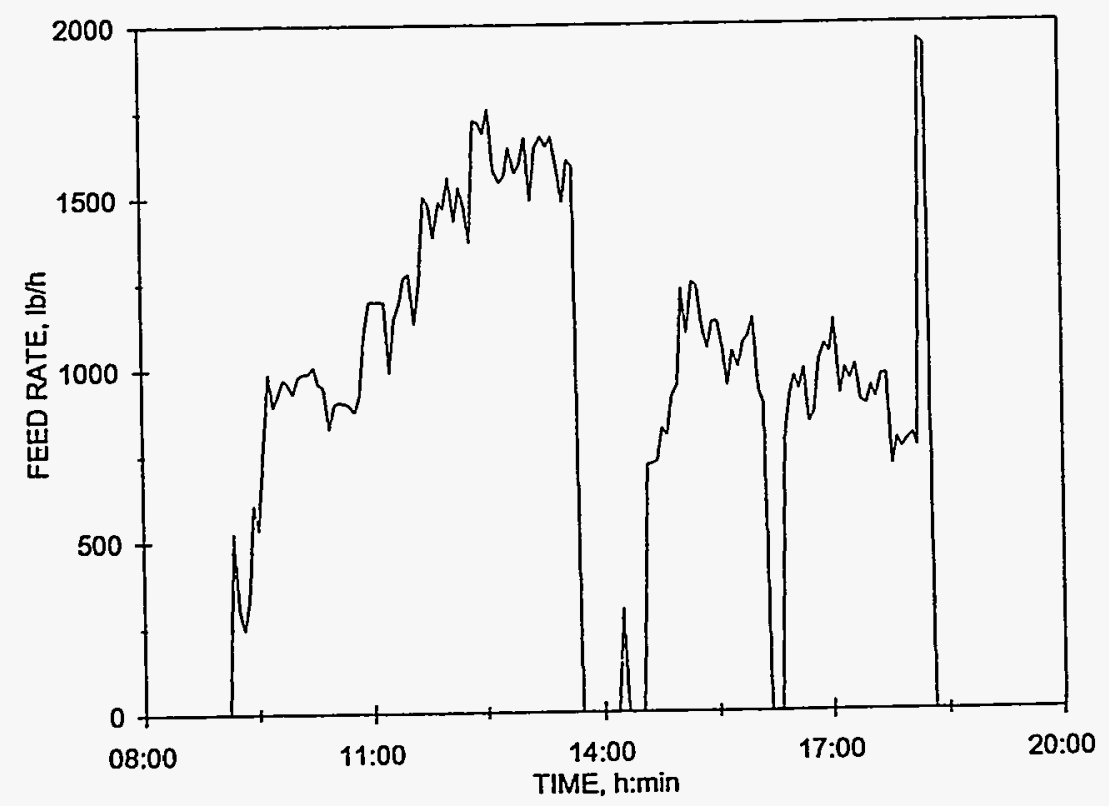

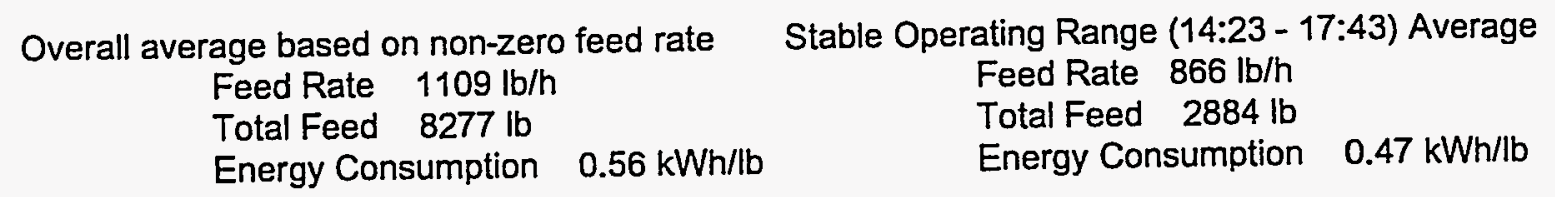

Figure $\mathrm{C}-2$. Feed rate for the S60-IV tests. 


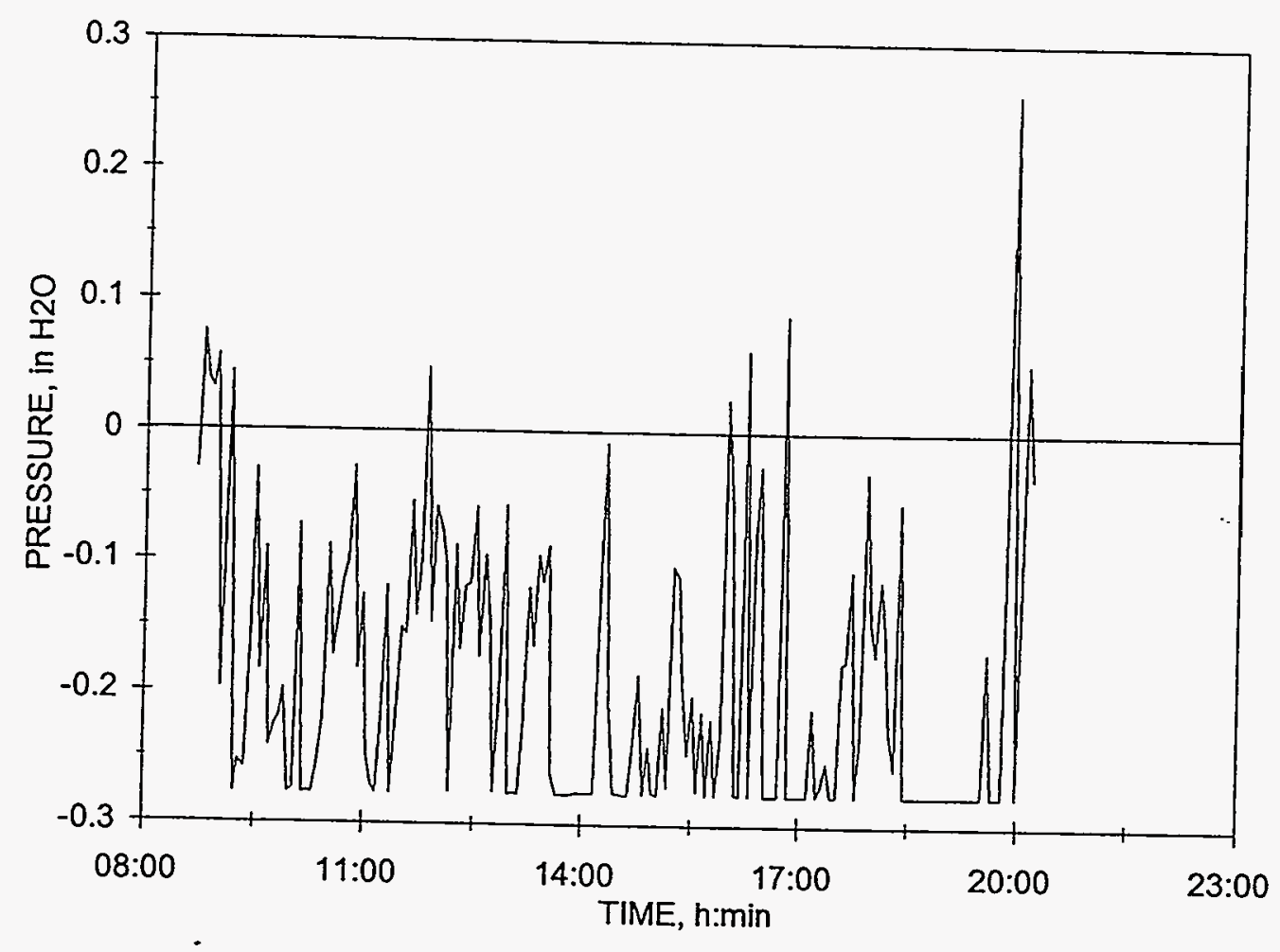

Figure C-3. Furnace pressure for the S60-IV tests.

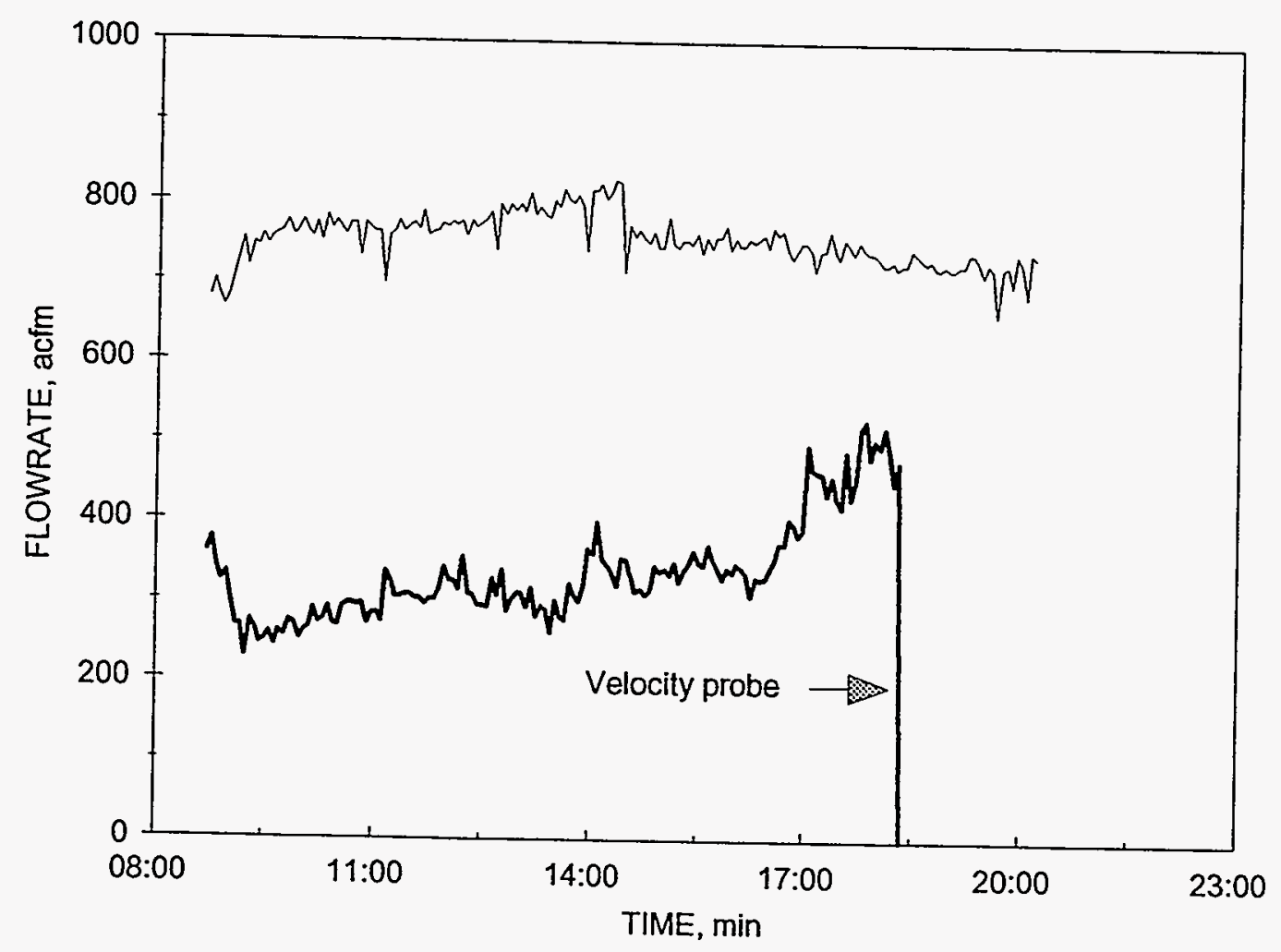

Figure $\mathrm{C}-4$. Flowrate of quench air ( - ) and offgas at the baghouse outlet $(-)$ for the S60-IV tests. 


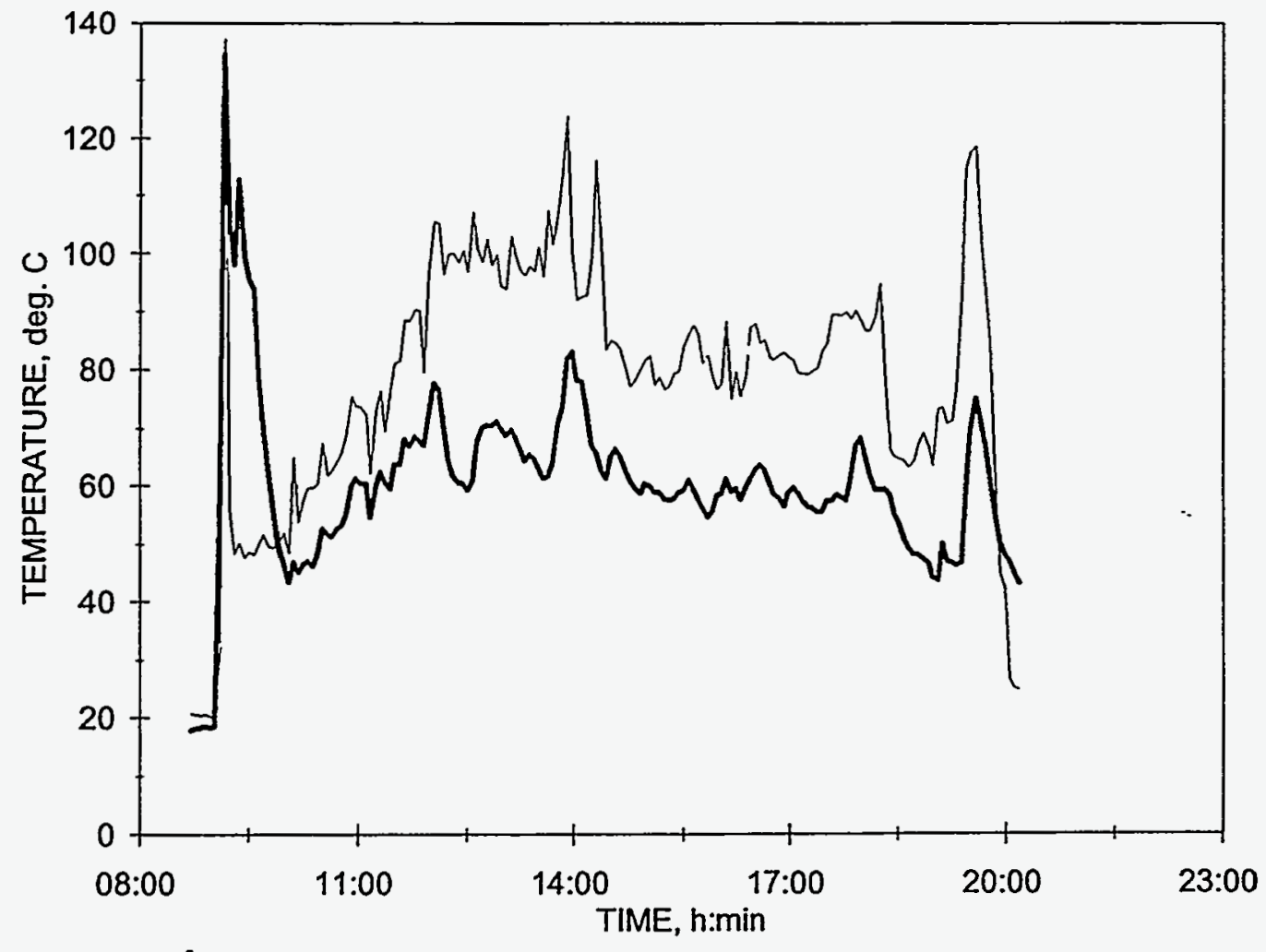

Figure $\mathrm{C}-5$. Furnace exit wall temperature $(-)$ and offgas temperature at the fume trap $1(-)$ for the S60-IV tests.

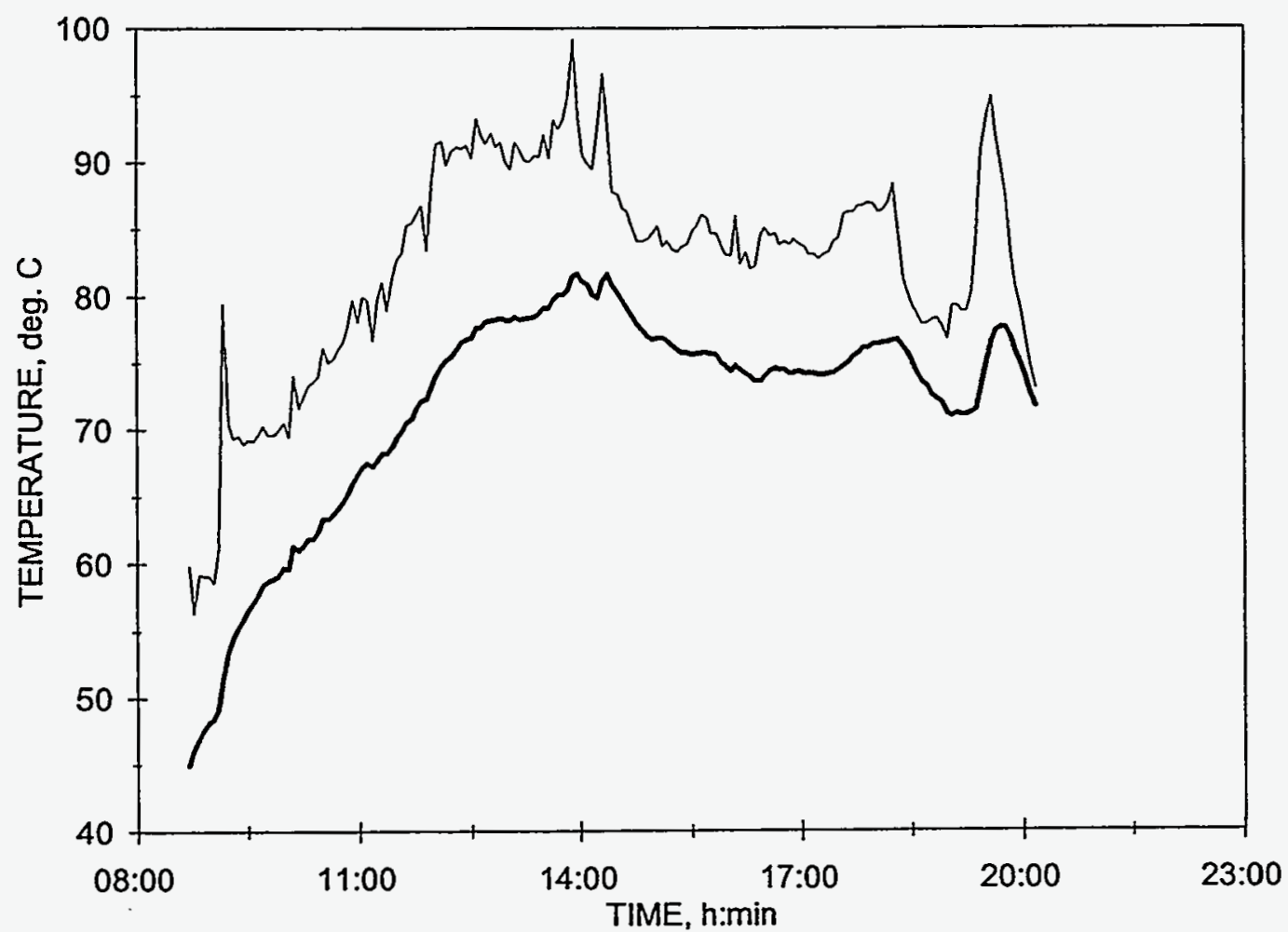

Figure $\mathrm{C}-6$. Offgas temperatures upstream $(-)$ and downstream $(-)$ of the baghouse for the S60-IV tests. 


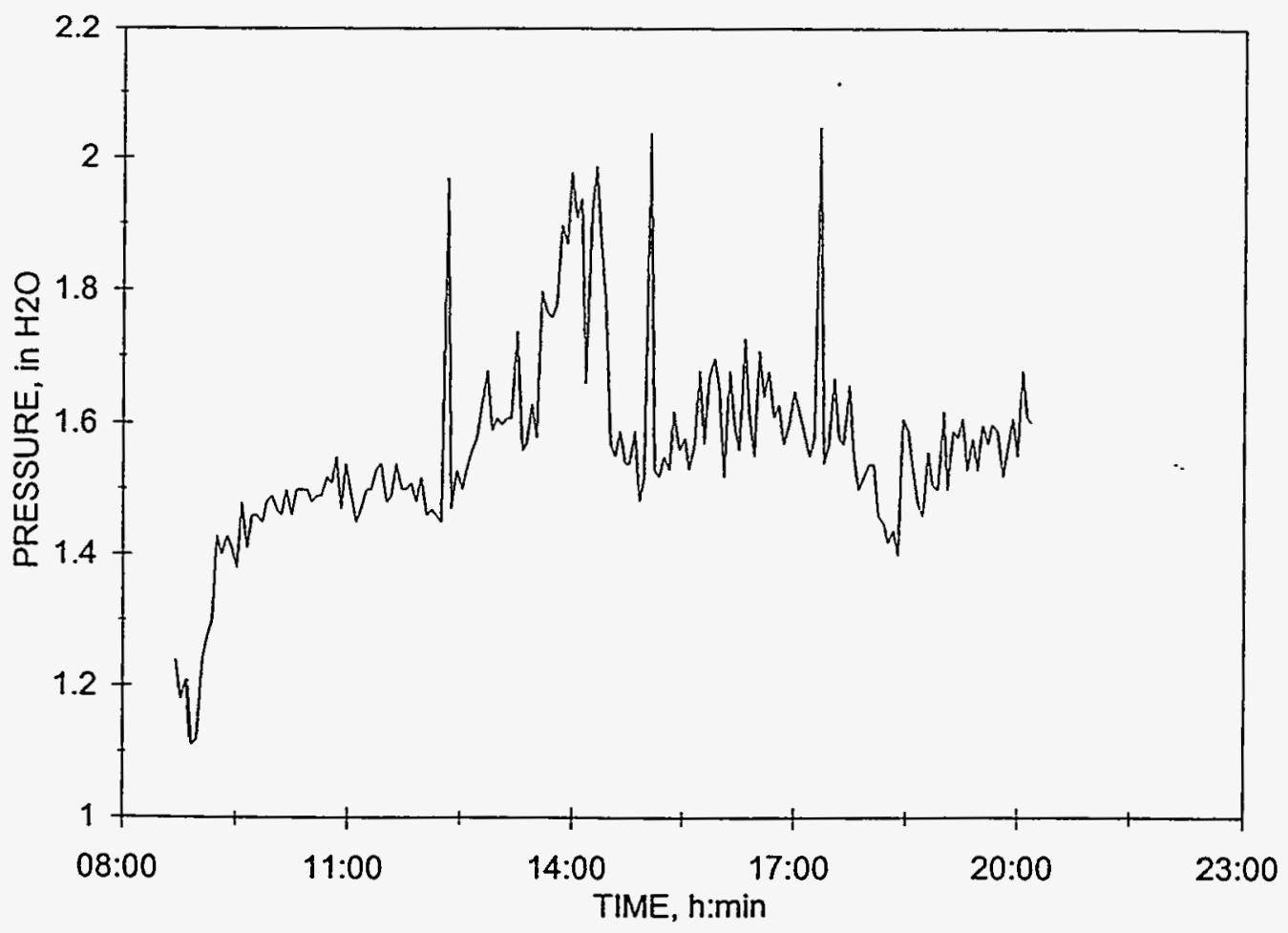

Figure C-7. Pressure drop over baghouse for the S60-IV tests.

S60-IV 7/20/93

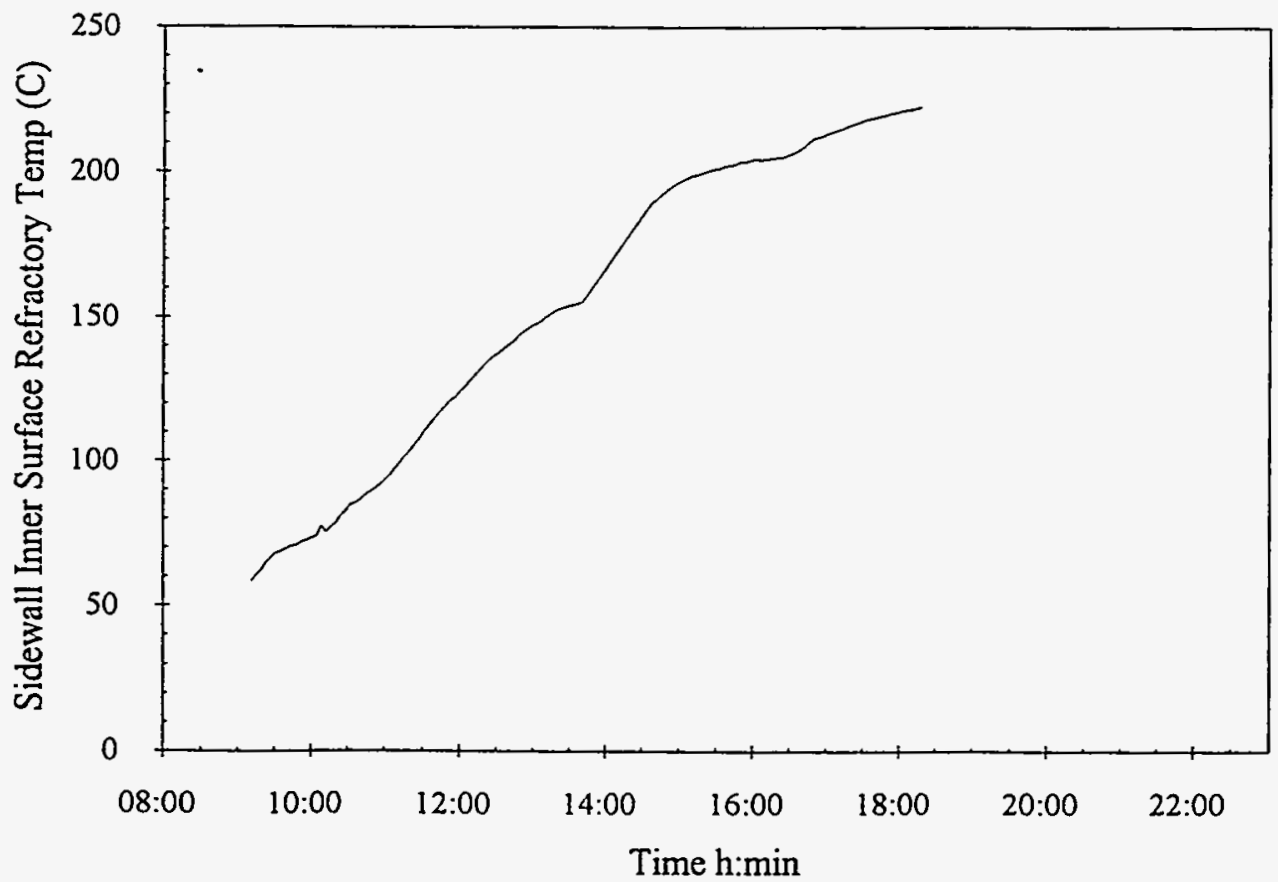

Figure C-8. Upper sidewall inner surface refractory temperature for S60-IV. 
S60-IV 7/20/93

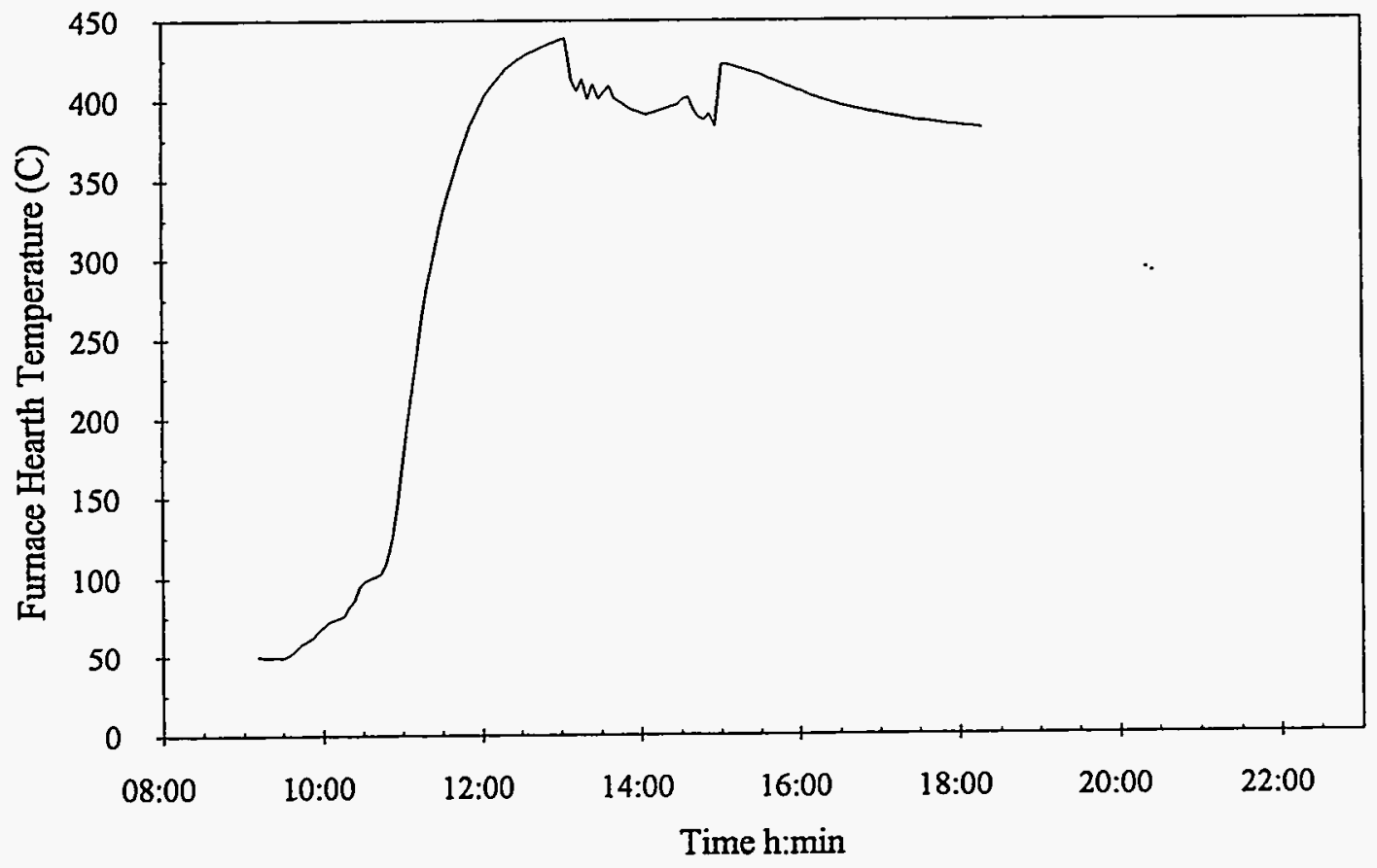

Figure C-9. Furnace hearth temperature for the S60-IV test. 
S60-IV 7/20/93

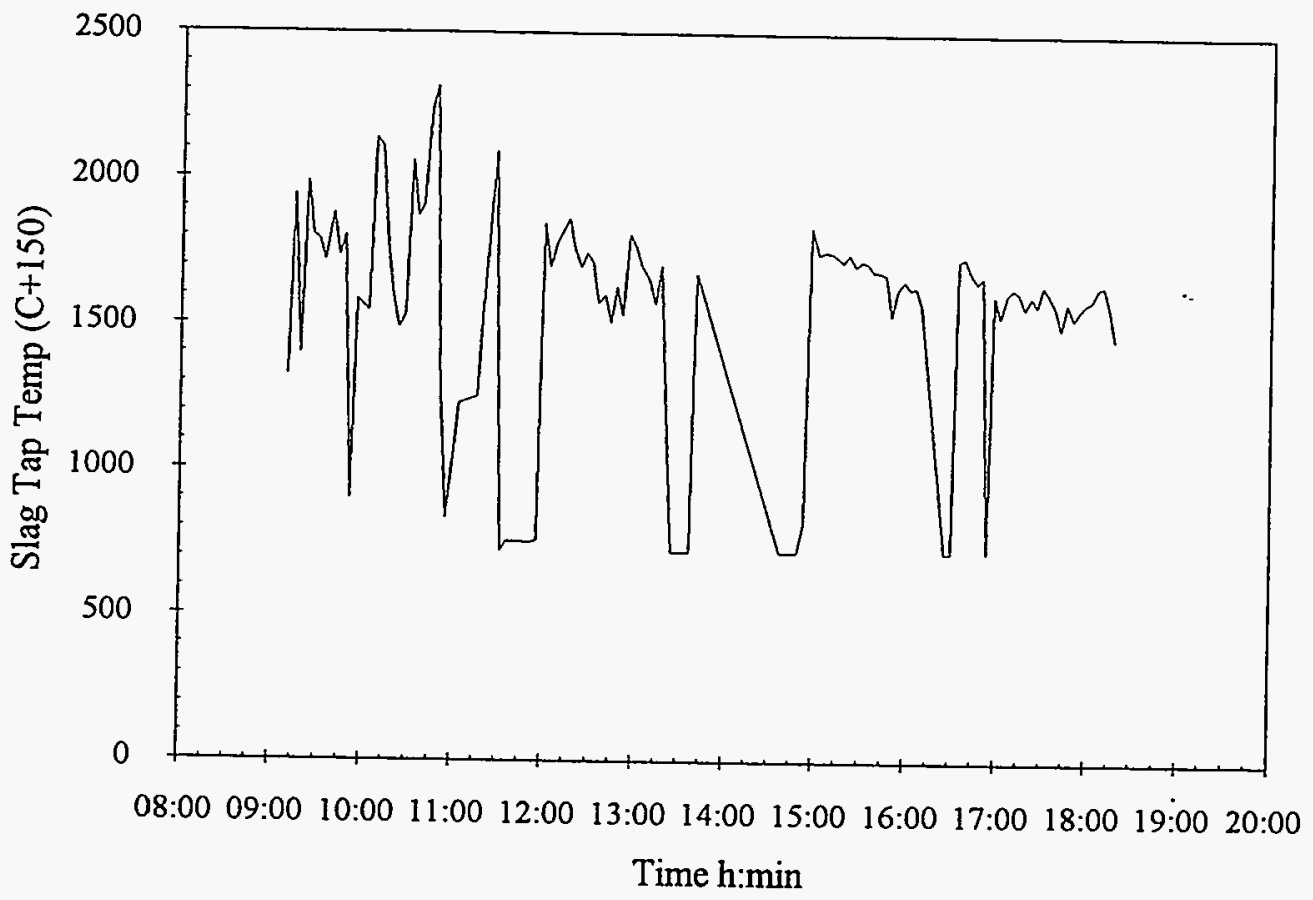

Figure $\mathrm{C}-10$. Slag tap temperature $(C+150)$ for the S60-IV test. 
Appendix D

Operating Conditions During Melting of N80 and N80-Mod 



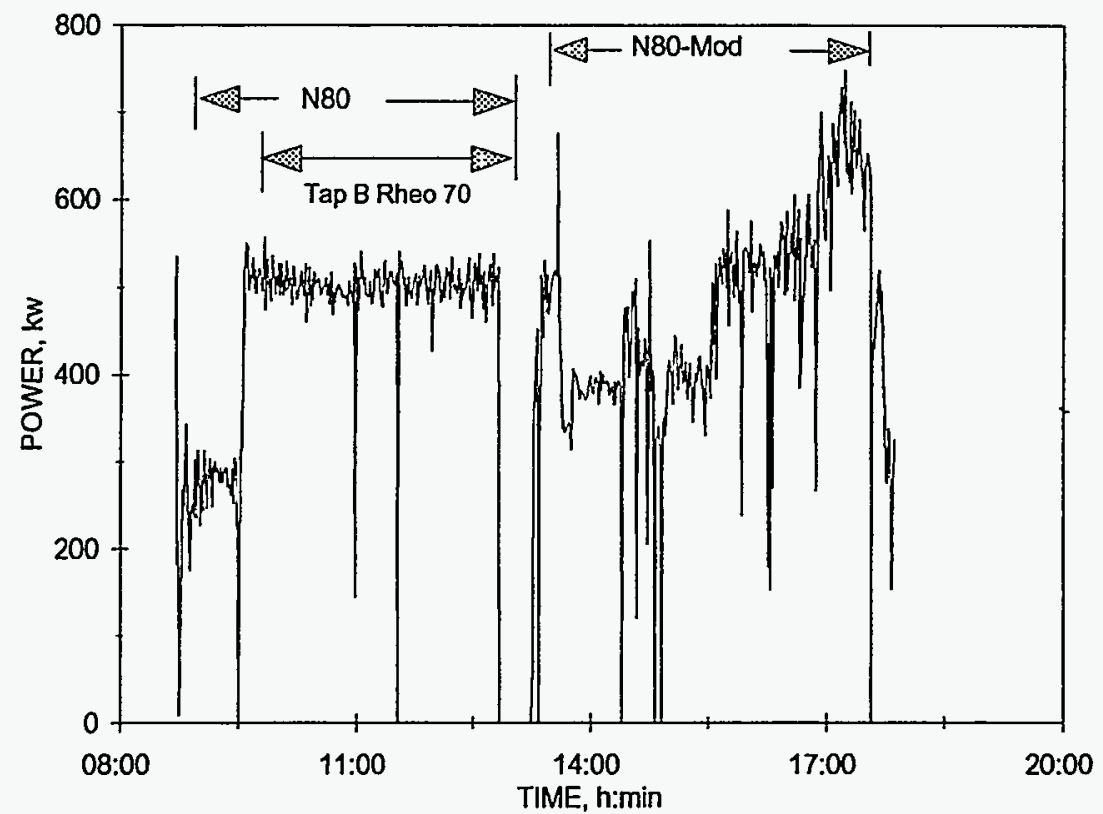

Overall Averages based on non-zero power

$\begin{array}{lr}\text { Voltage } & 162.1 \mathrm{~V} \\ \text { Current } & 950.0 \mathrm{~A} \\ \text { Power } & 461.6 \mathrm{~kW}\end{array}$

Stable Operating Range (8:57 - 12:15) Averages

Voltage $169.7 \mathrm{~V}$

Current $968.3 \mathrm{~A}$

Total Energy 4142 kwh

Power $497.4 \mathrm{~kW}$

Figure D-1. Input power for the N80 and N80-Mod tests.

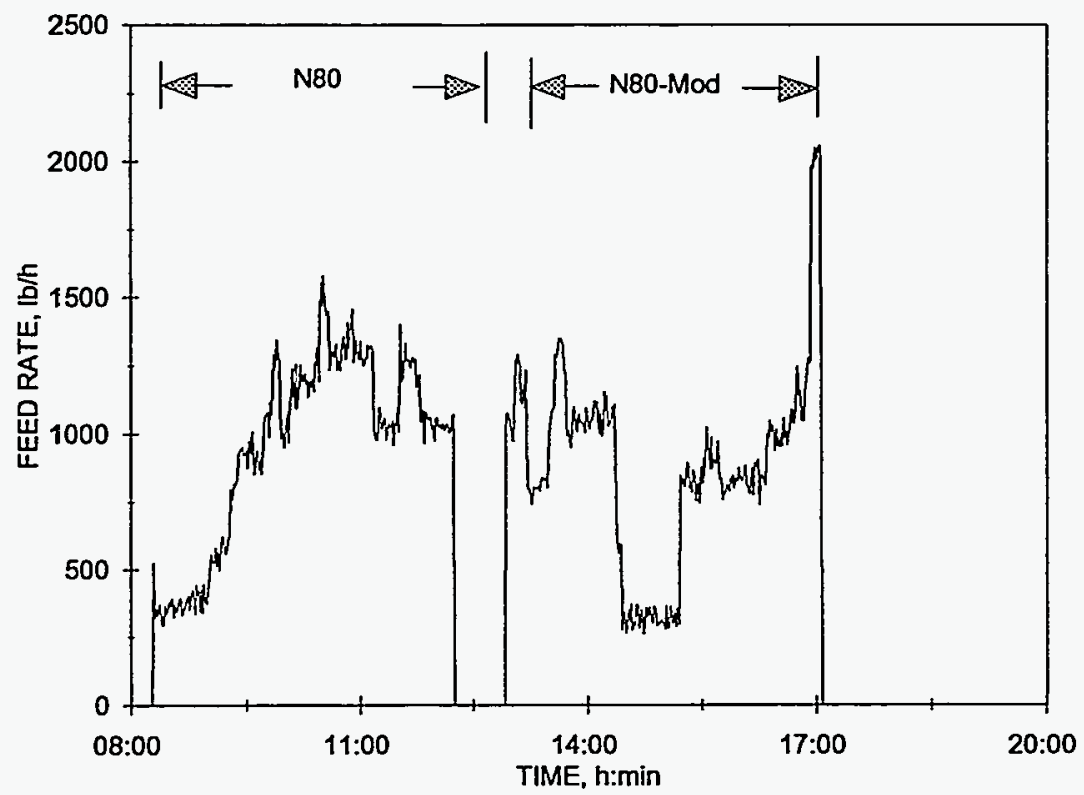

Overall average based on non-zero feed rate

Feed Rate $917 \mathrm{lb} / \mathrm{h}$

Total Feed $8366 \mathrm{lb}$

Energy Consumption $0.49 \mathrm{kWh} / \mathrm{lb}$
Stable Operating Range (8:57 - 12:15) Average Feed Rate $1067 \mathrm{lb} / \mathrm{h}$ Total Feed $3538 \mathrm{lb}$ Energy Consumption $0.47 \mathrm{kWh} / \mathrm{lb}$

Figure D-2. Feed rate for the N80 and N80-Mod tests. 


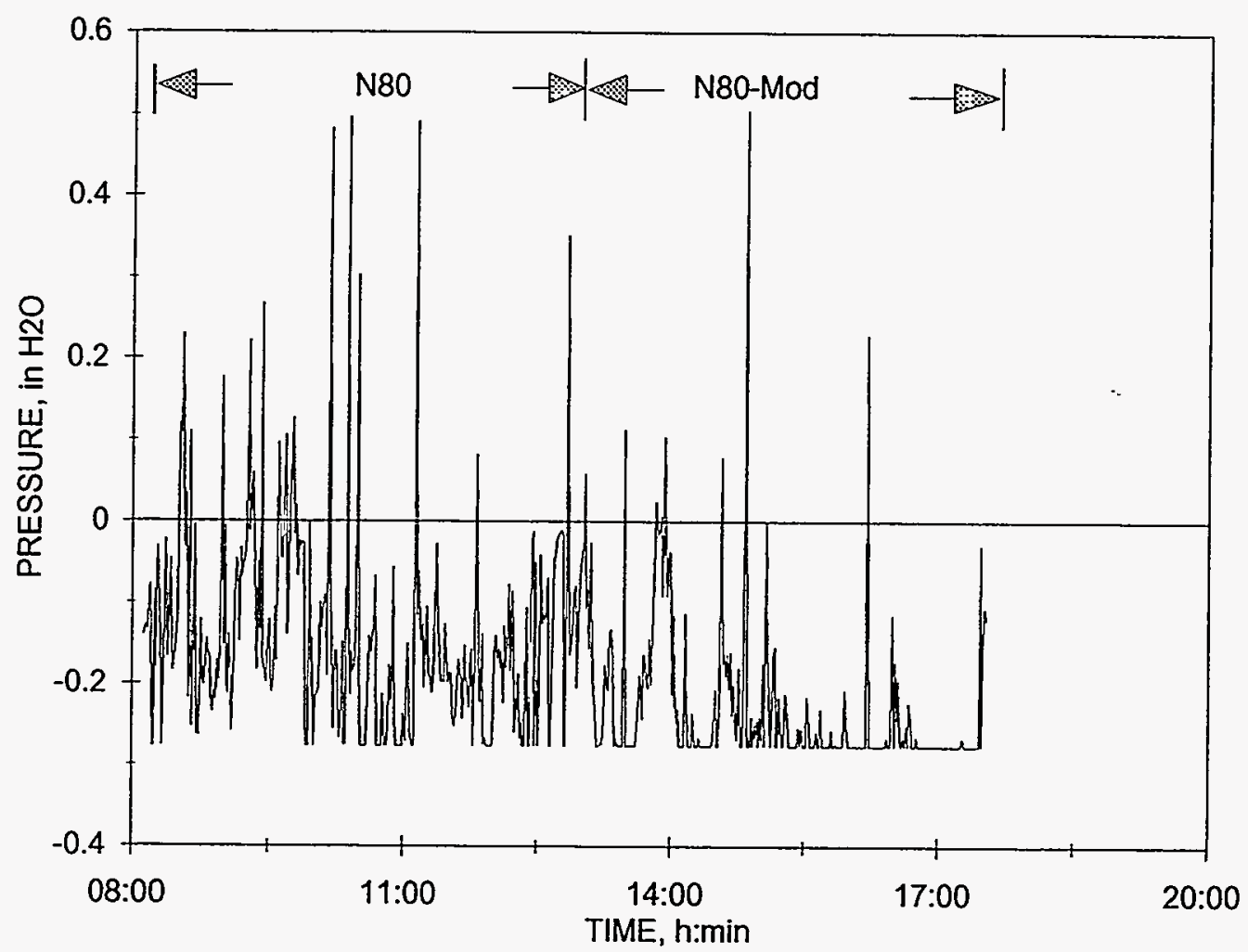

Figure D-3. Furnace pressure for the N80 and N80-Mod tests.

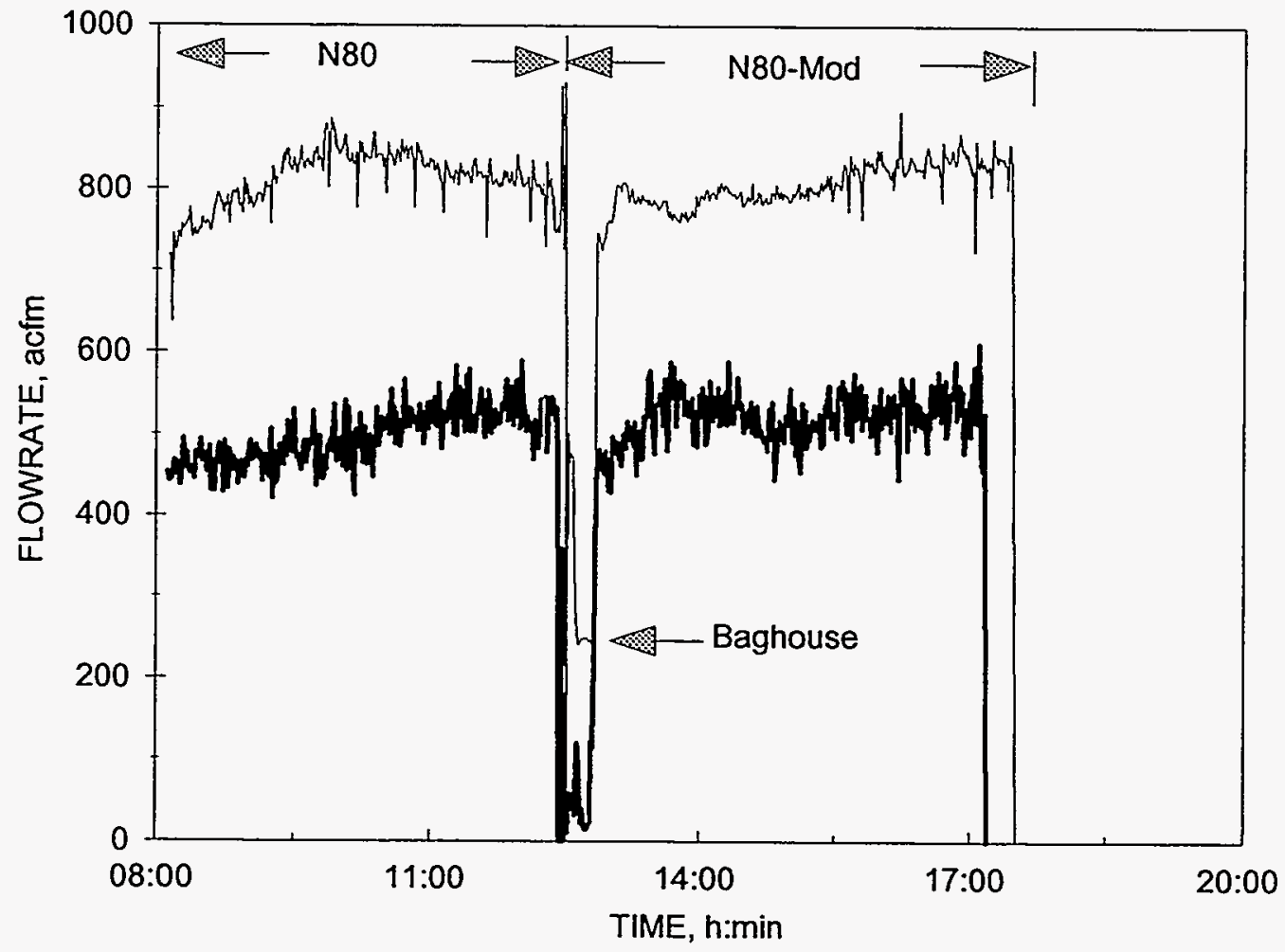

Figure D-4. Flowrate of quench air ( - ) and offgas at the baghouse outlet ( - ) for the N80 and N80-Mod tests. 


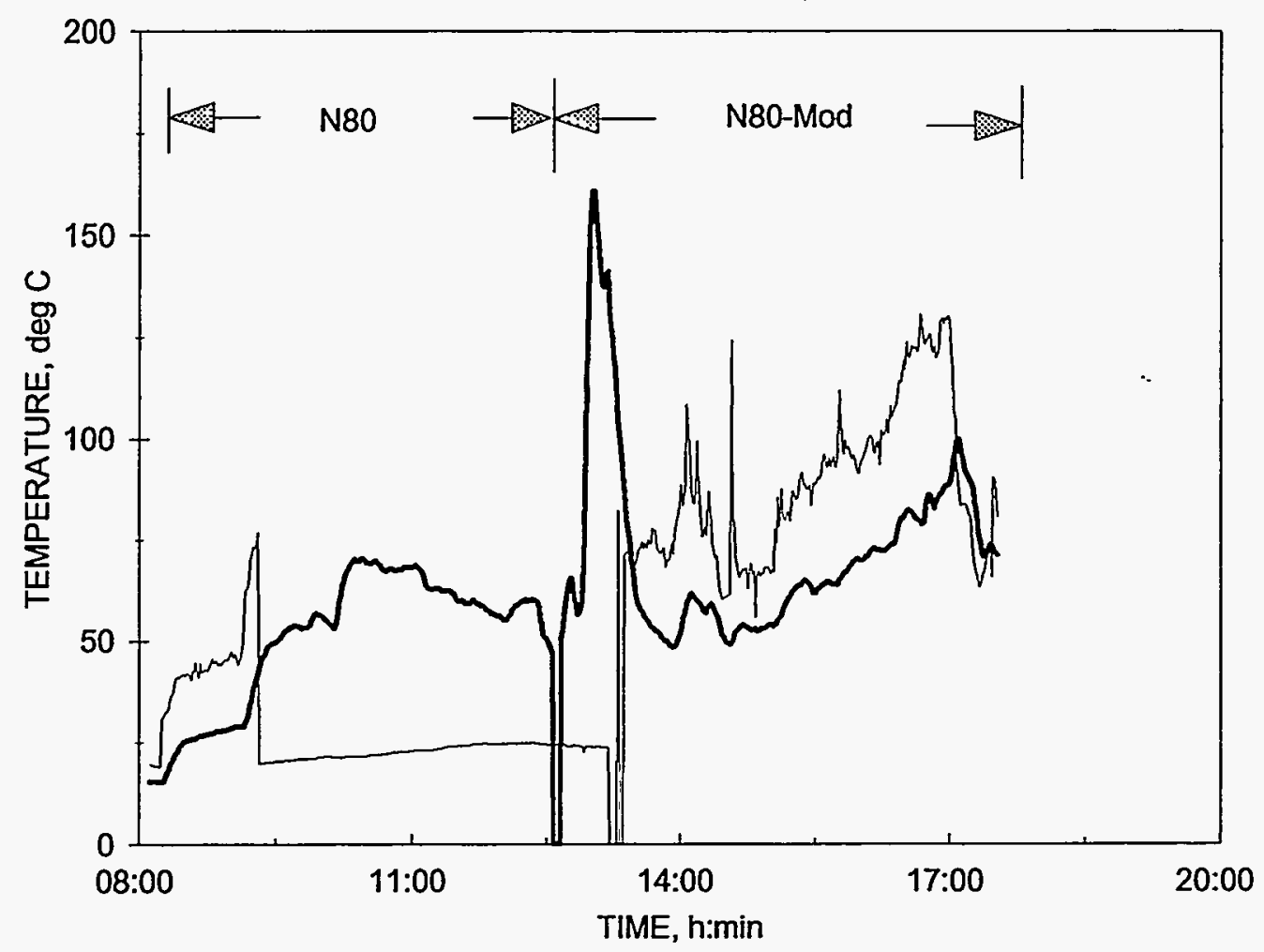

Figure D-5. Furnace exit wall temperature ( - ) and offgas temperature at the fume trap $1(-)$ for the N80 and N80-Mod tests.

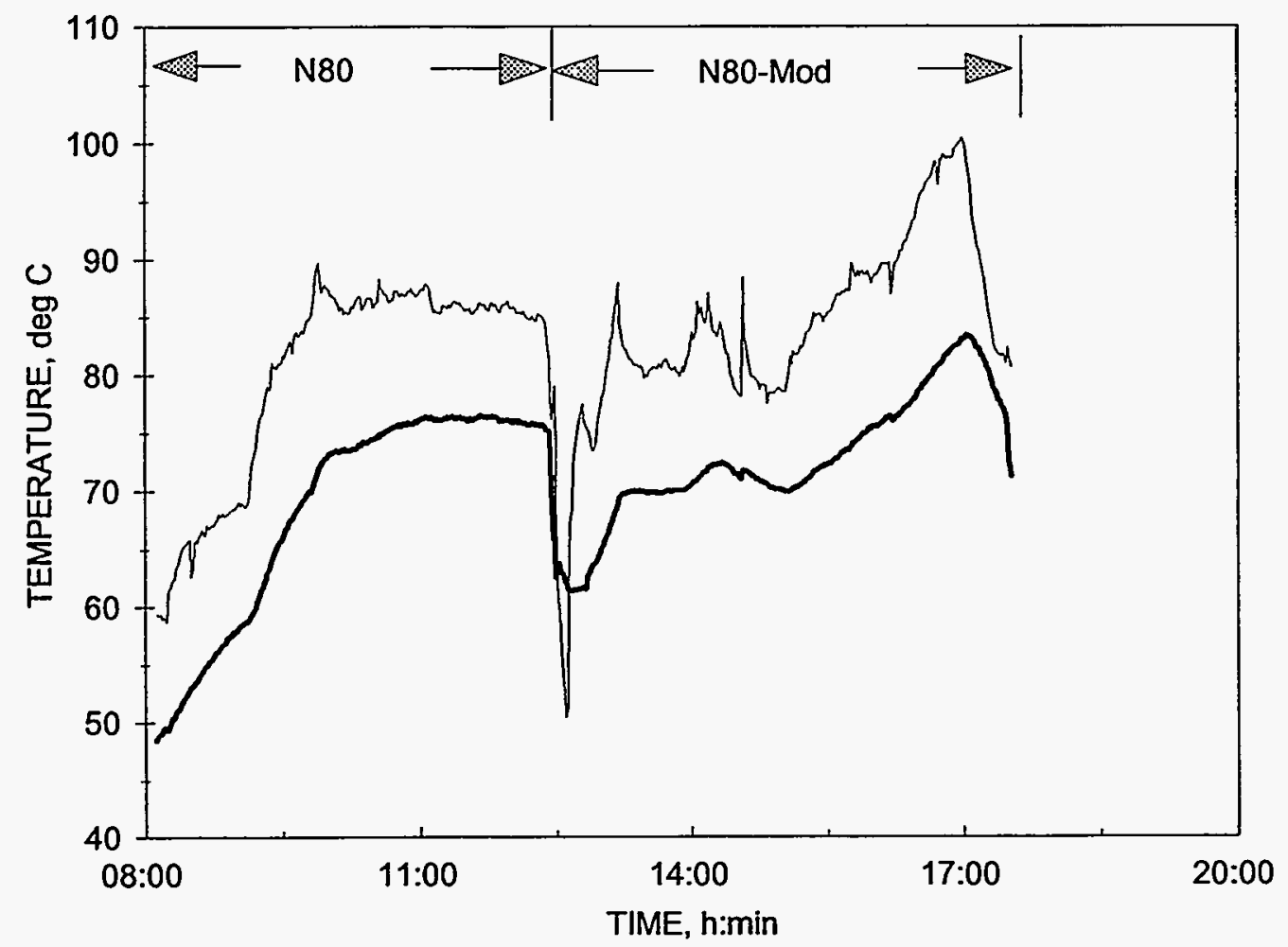

Figure D-6. Offgas temperatures upstream ( - ) and downstream ( - ) of the baghouse for the N80 and N80-Mod tests.

D-5 


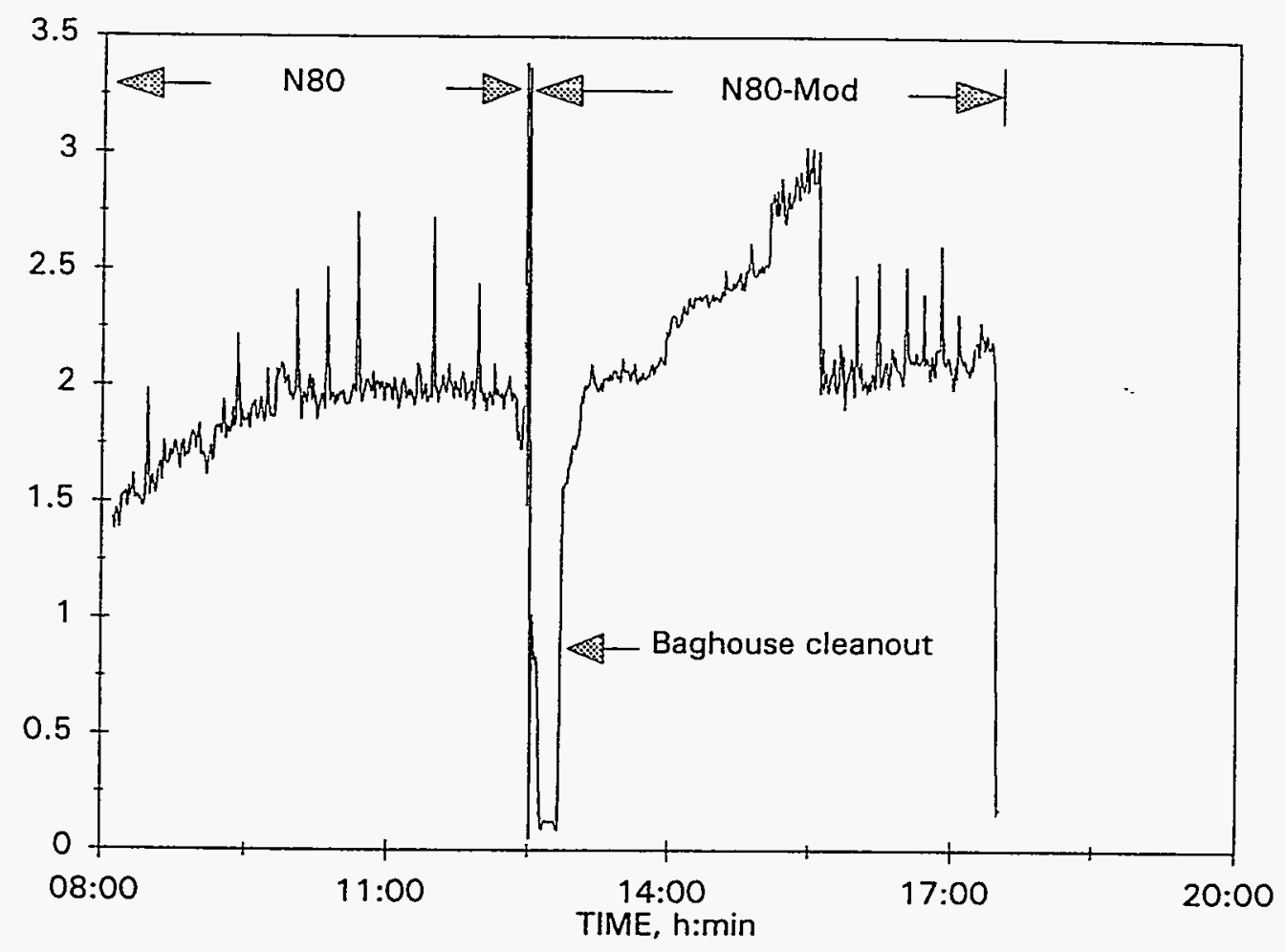

Figure D-7. Baghouse pressure drop for the N80 and N80-Mod tests.

N80/N80-Mod 7/21/93

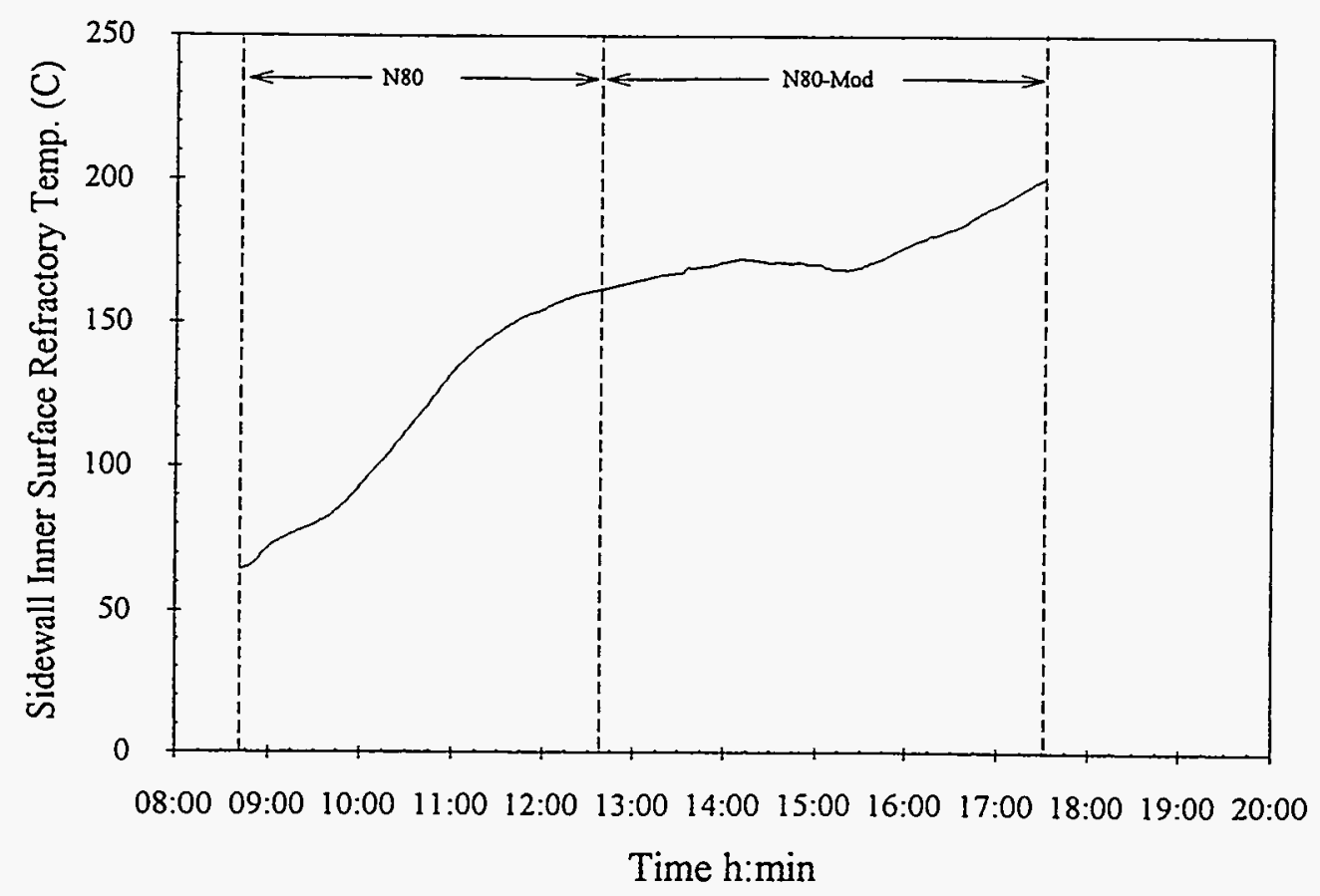

Figure D-8. Upper sidewall inner surface refractory temperature for N80 and N80-Mod.

[TIME6.XLW]A 


\section{N80/N80-Mod 7/21/93}

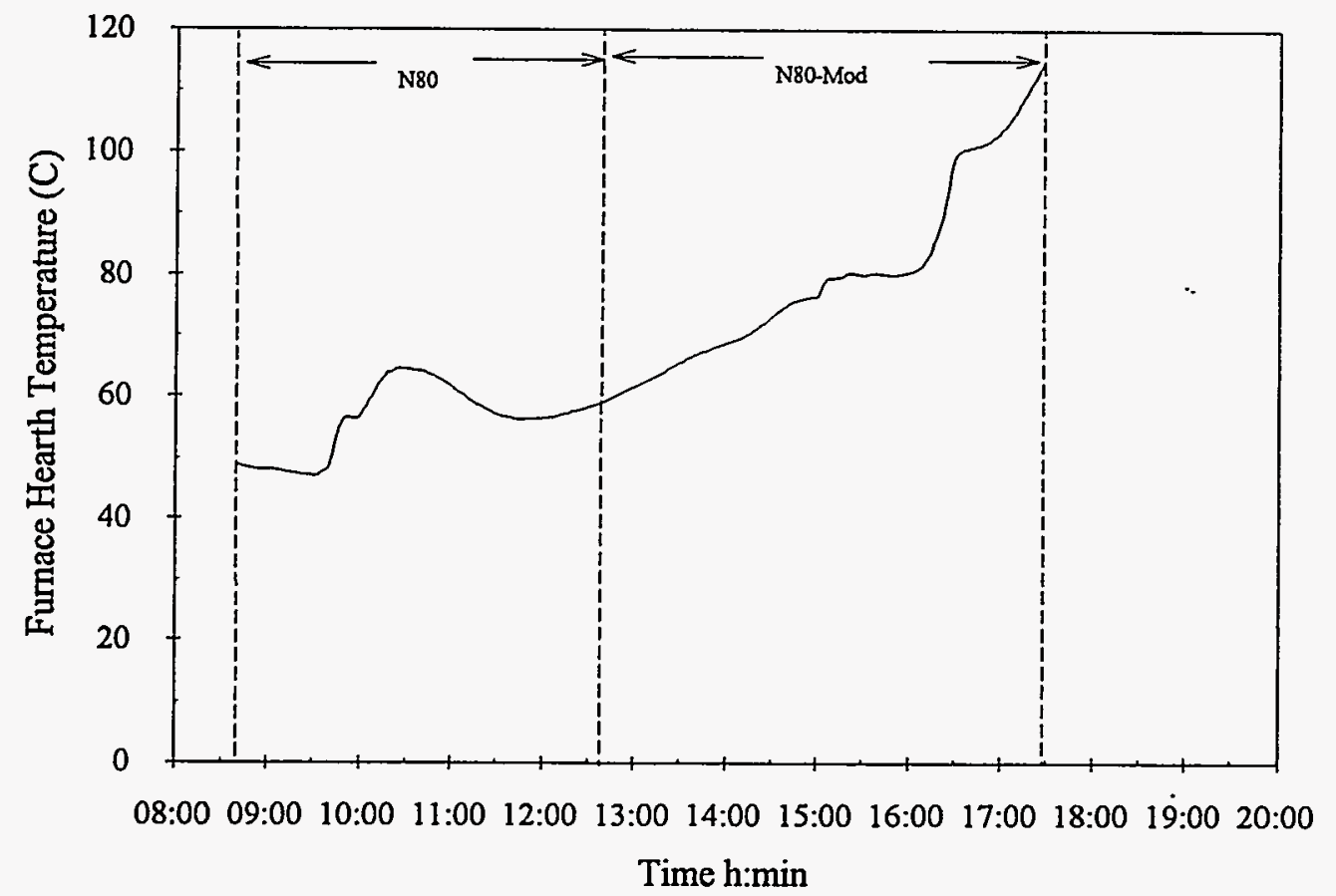

Figure D-9. Furnace hearth temperature for the N80/N80-Mod tests. 
N80/N80-Mod 7/21/93

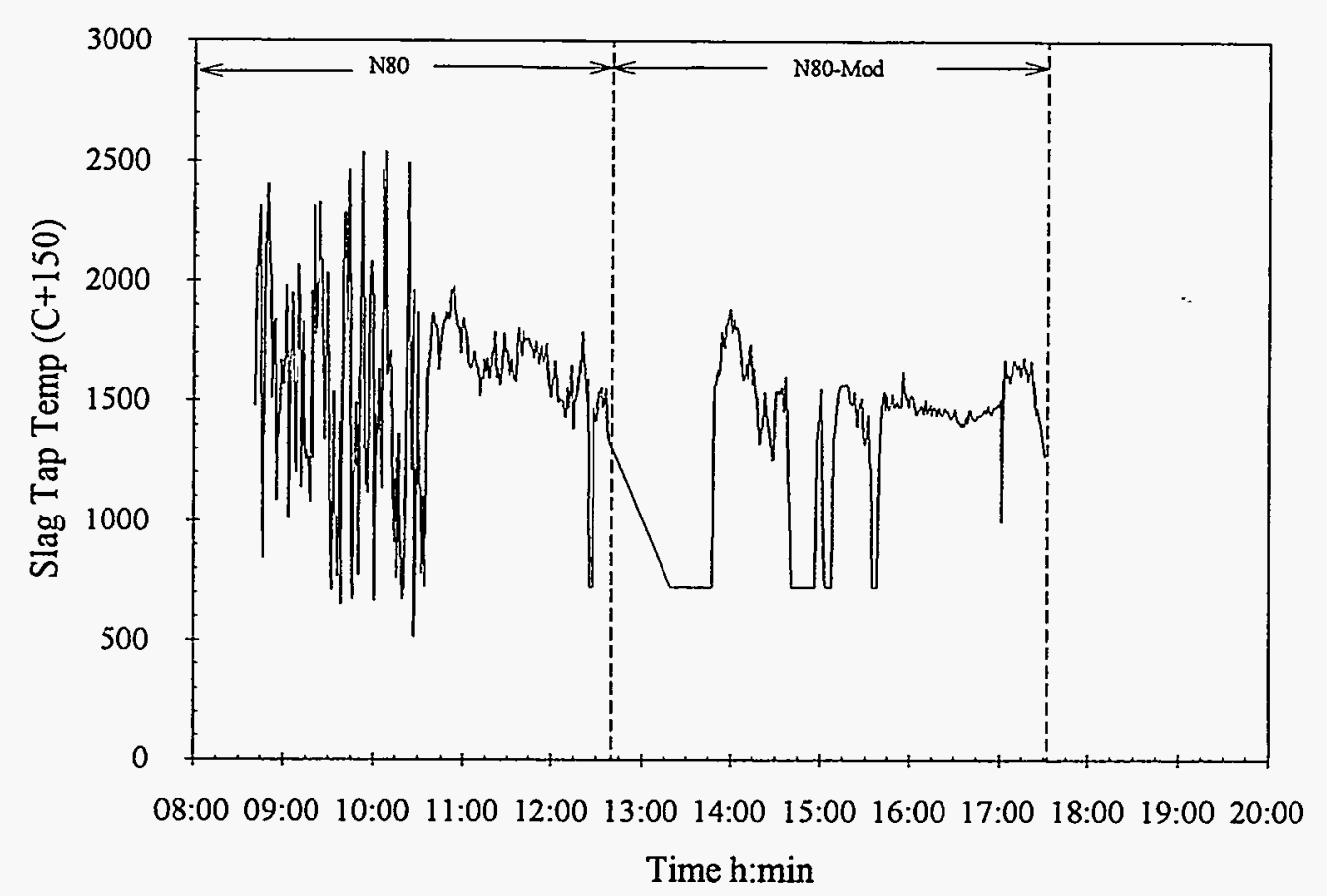

Figure D-10, Slag tap temperature for the N80/N80-Mod tests. 


\section{Appendix E}

\section{Operating Conditions During Melting of N80-IV and}

N80-IV-Mod 
, 


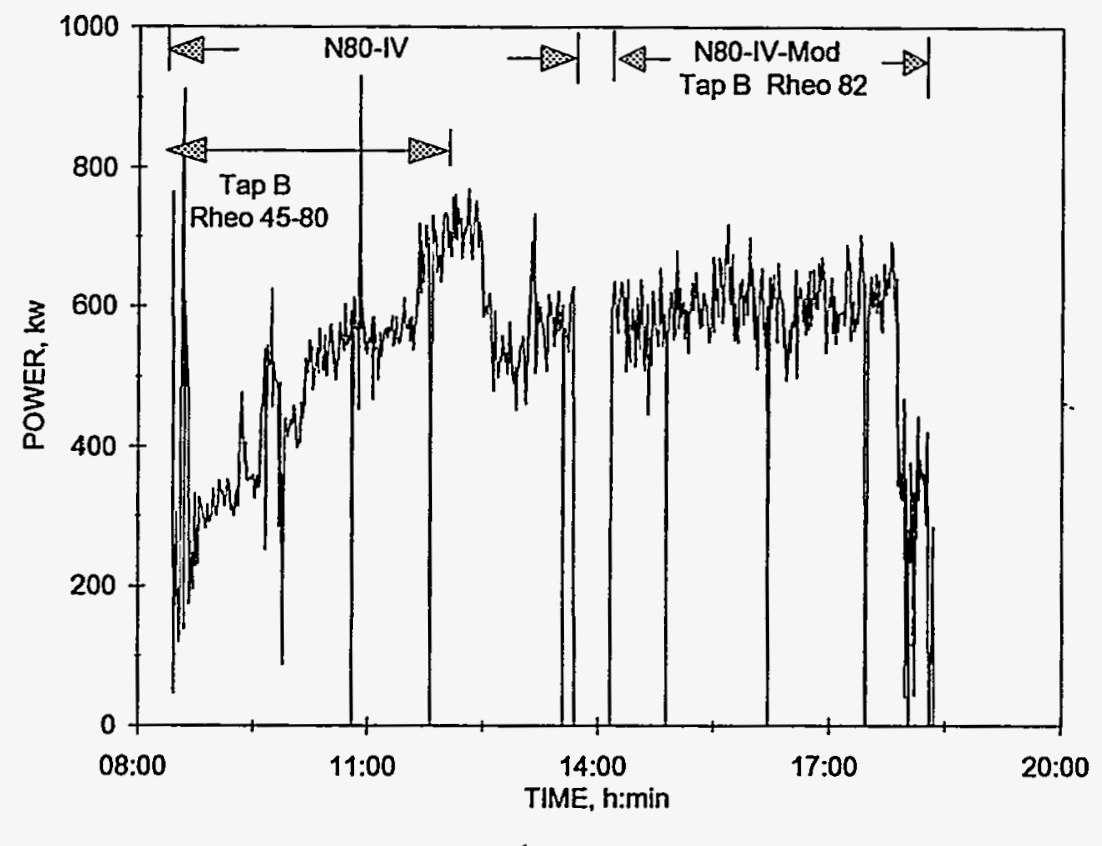

Overall Averages based on non-zero power Stable Operating Range (9:13 - 11:30) Average

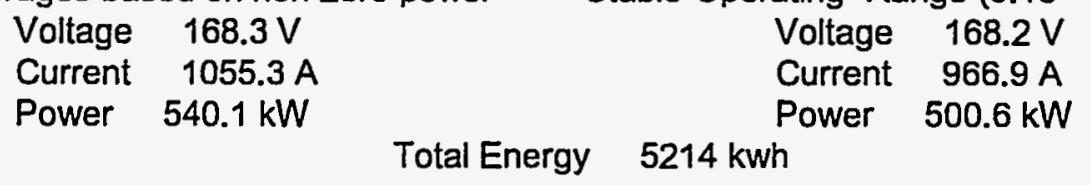

Figure E-1. Input power to the furnace for N80-IV and N80-IV-Mod tests.

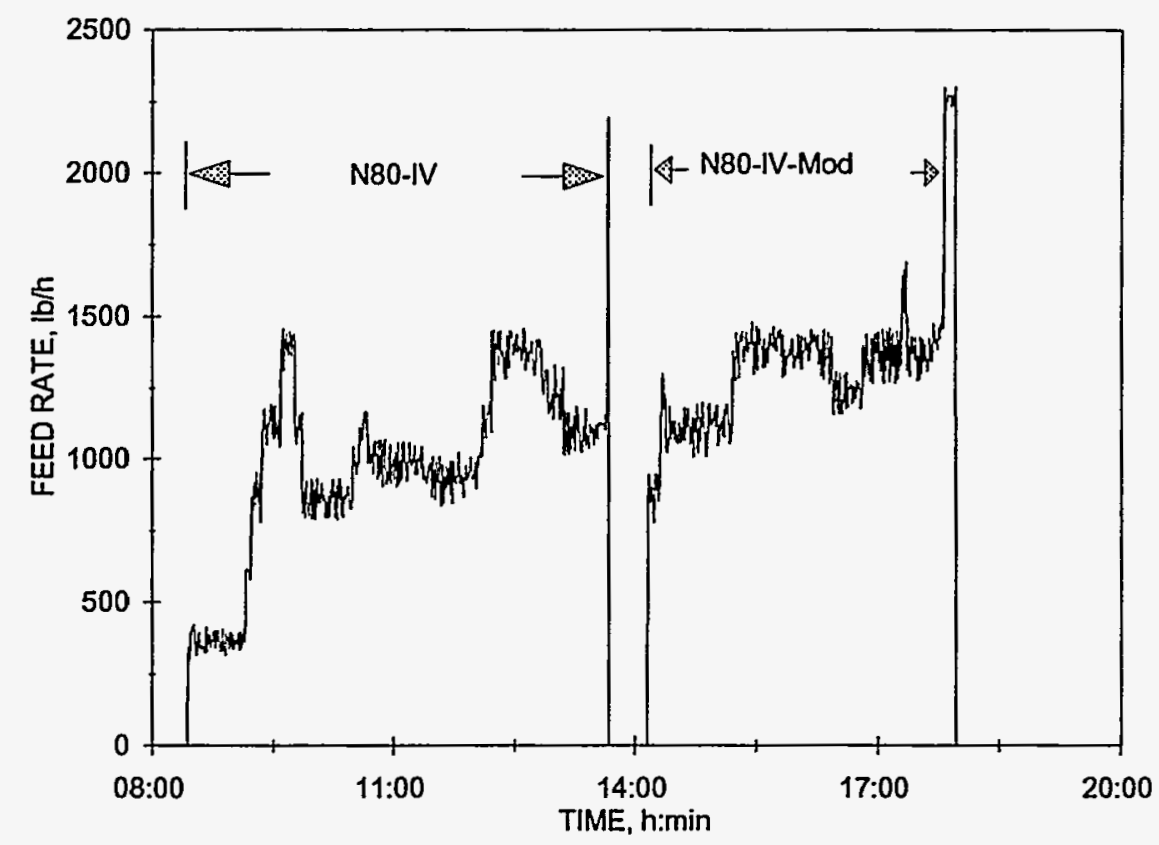

Overall Averages based on non-zero feed rate Stable Operating Range (9:13-11:30) Average Feed Rate $1124 \mathrm{lb} / \mathrm{h}$ Feed Rate $999 \mathrm{lb} / \mathrm{h}$ Total Feed $10504 \mathrm{lb}$ Energy Consumption $0.50 \mathrm{kWh} / \mathrm{lb}$ Total Feed $2331 \mathrm{lb}$ Energy Consumption $0.50 \mathrm{kWh} / \mathrm{lb}$

Figure E-2. Feed rate for N80-IV and N80-IV-Mod tests. 


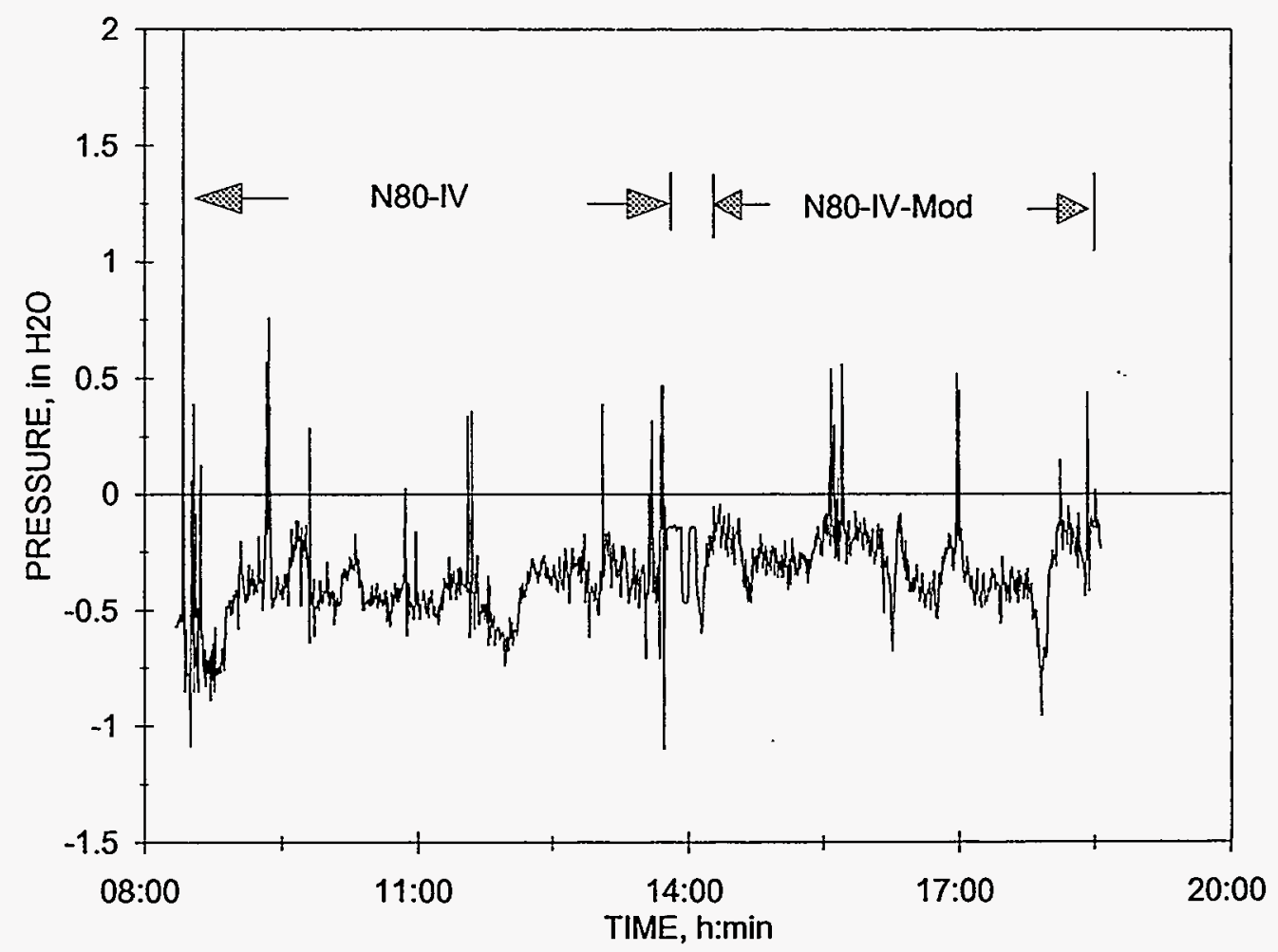

Figure E-3. Furnace pressure for N80-IV and N80-IV-Mod tests.

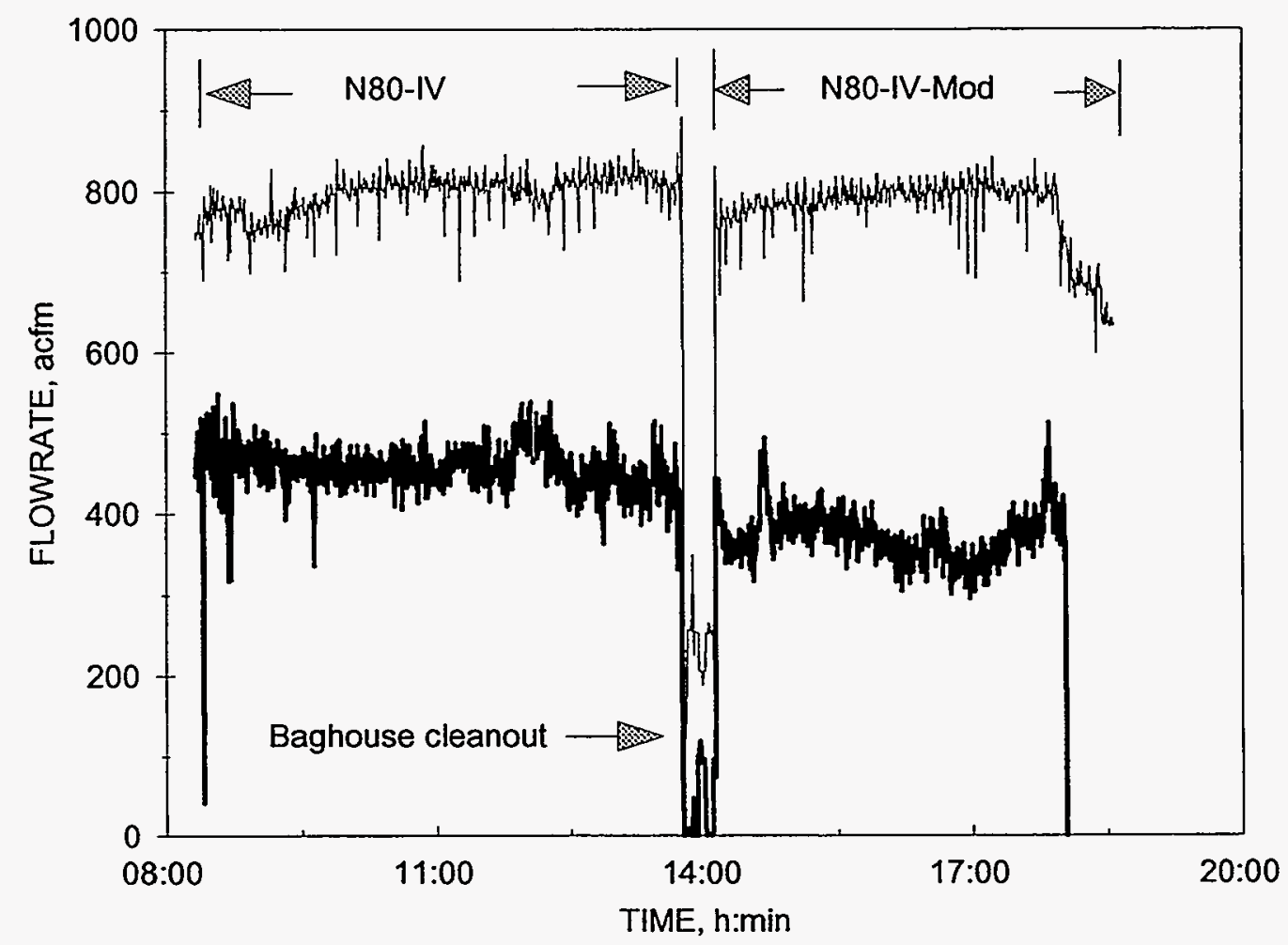

Figure E-4. Flowrate of quench air ( -$)$ and offgas at the baghouse outlet $(-)$ for the N80-IV and N80-IV-Mod tests. 

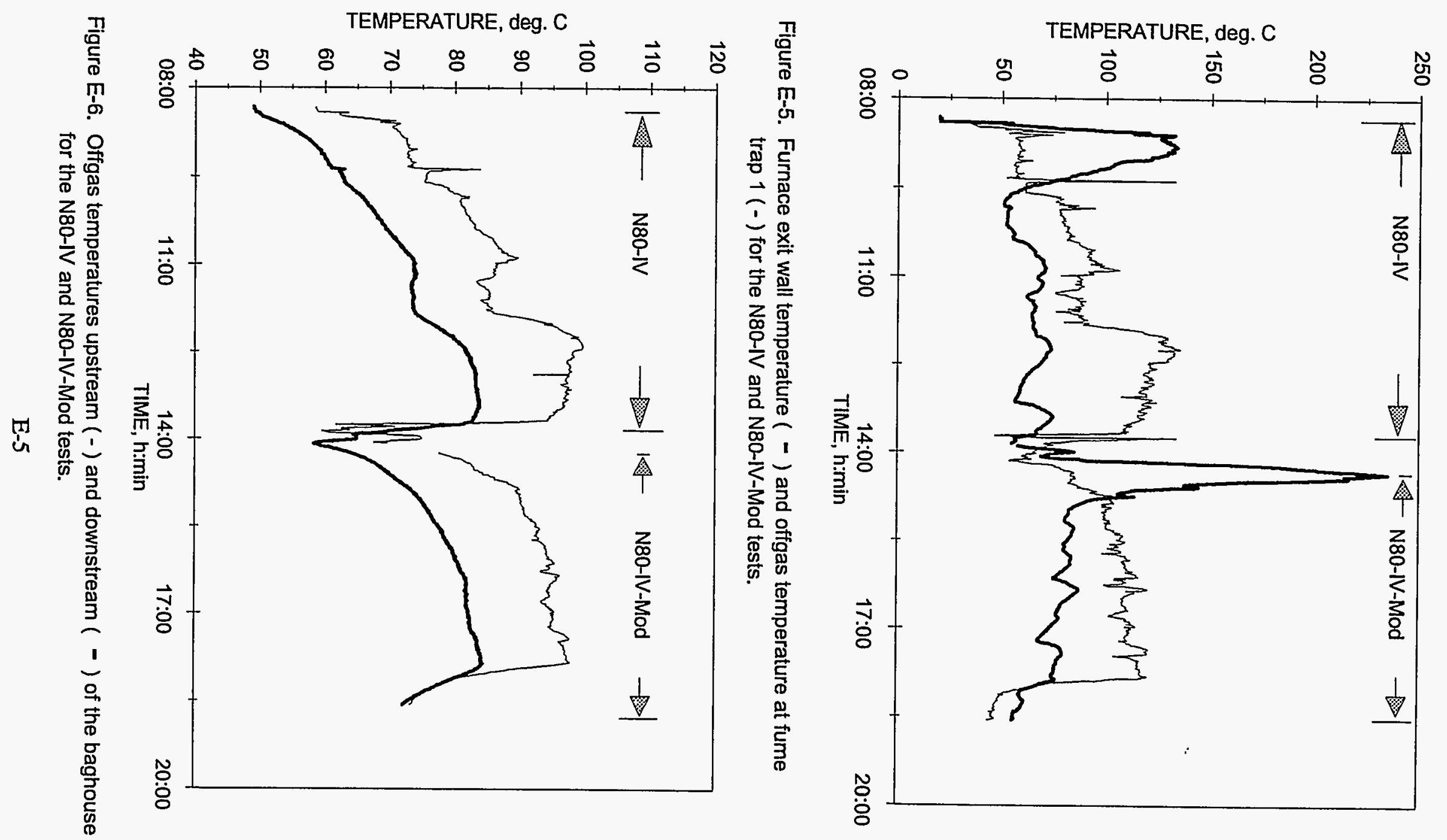


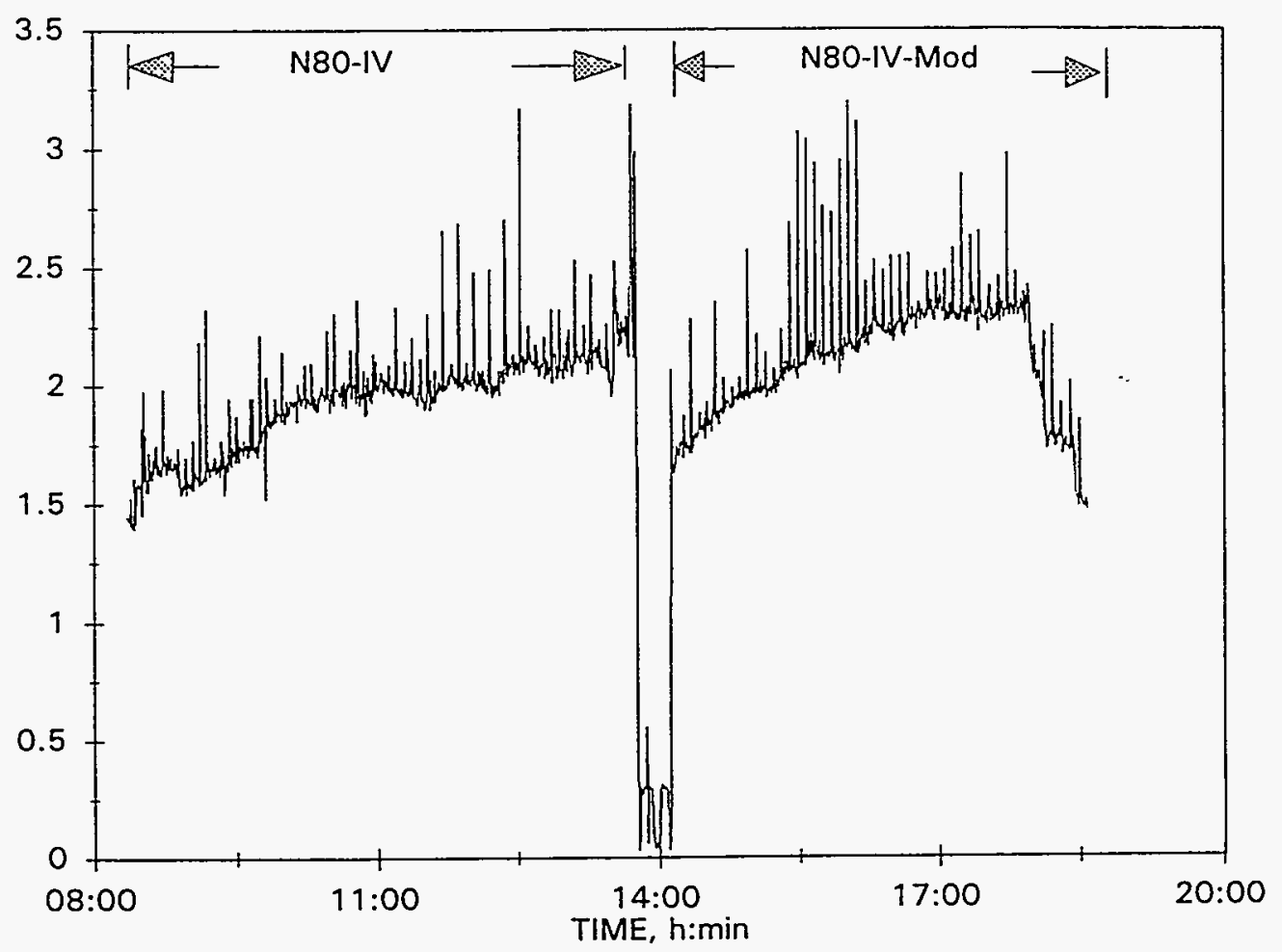

Figure E-7. Baghouse pressure drop for the N80-IV and N80-IV-Mod tests.

N80-IV/N80-IV-Mod 7/22/93

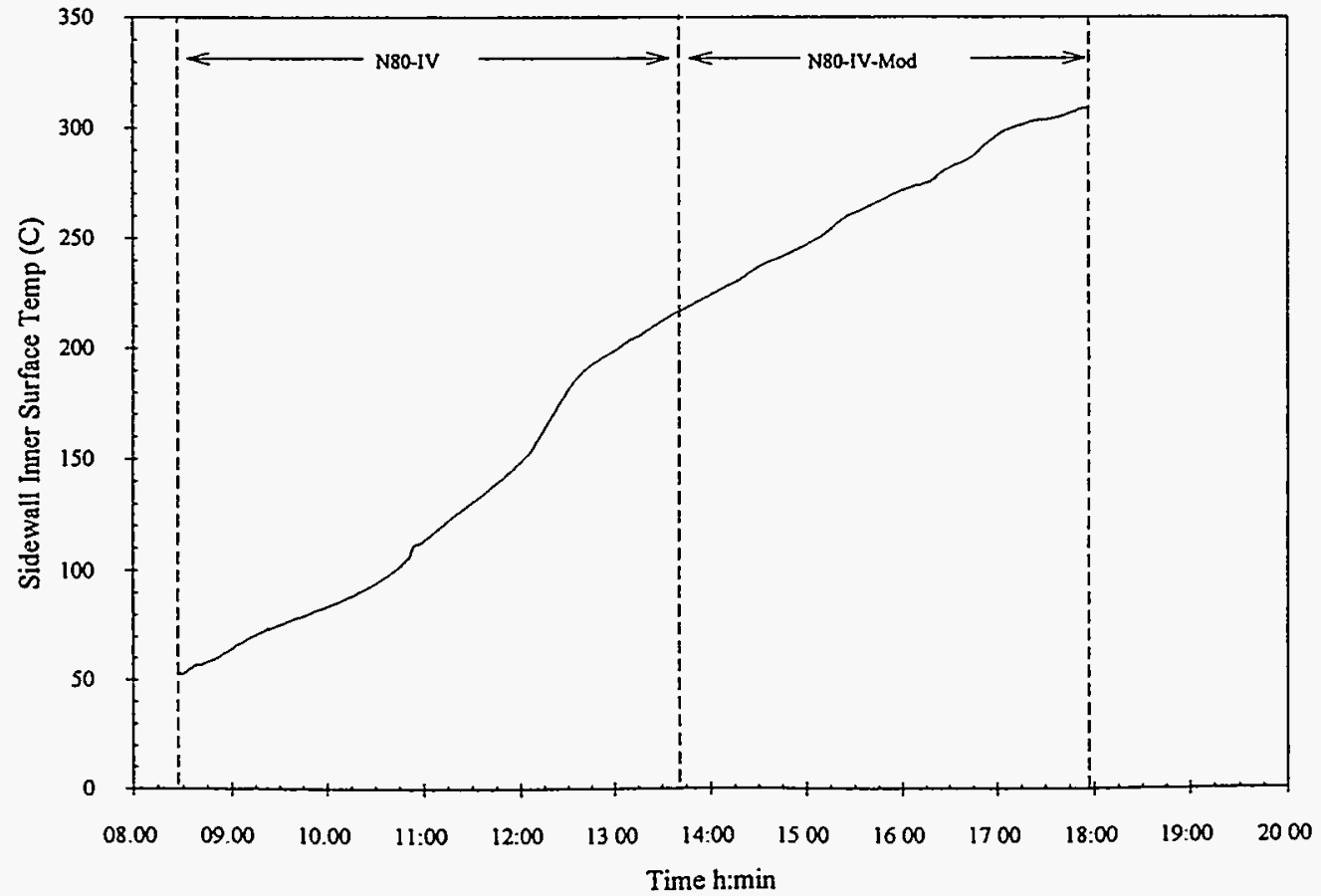

Figure E-8. Upper sidewall inner surface refractory temperature for N80-IV and N80-IV-Mod 
N80-IV/N80-IV-Mod 7/22/93

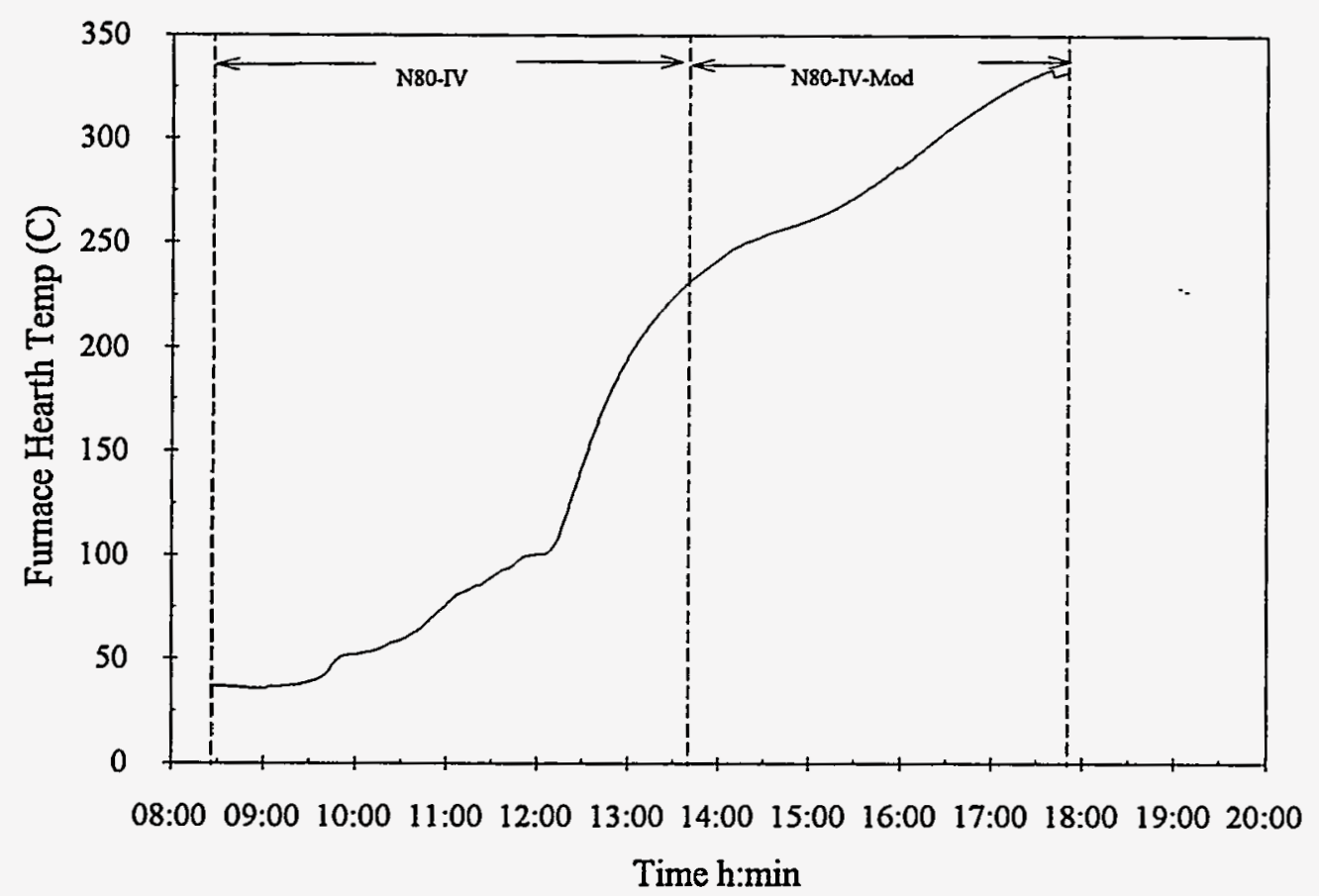

Figure E-9. Furnace hearth temperature for the N80-IV/N80-IV-Mod tests. 
N80-IV/N80-IV-Mod 7/22/93

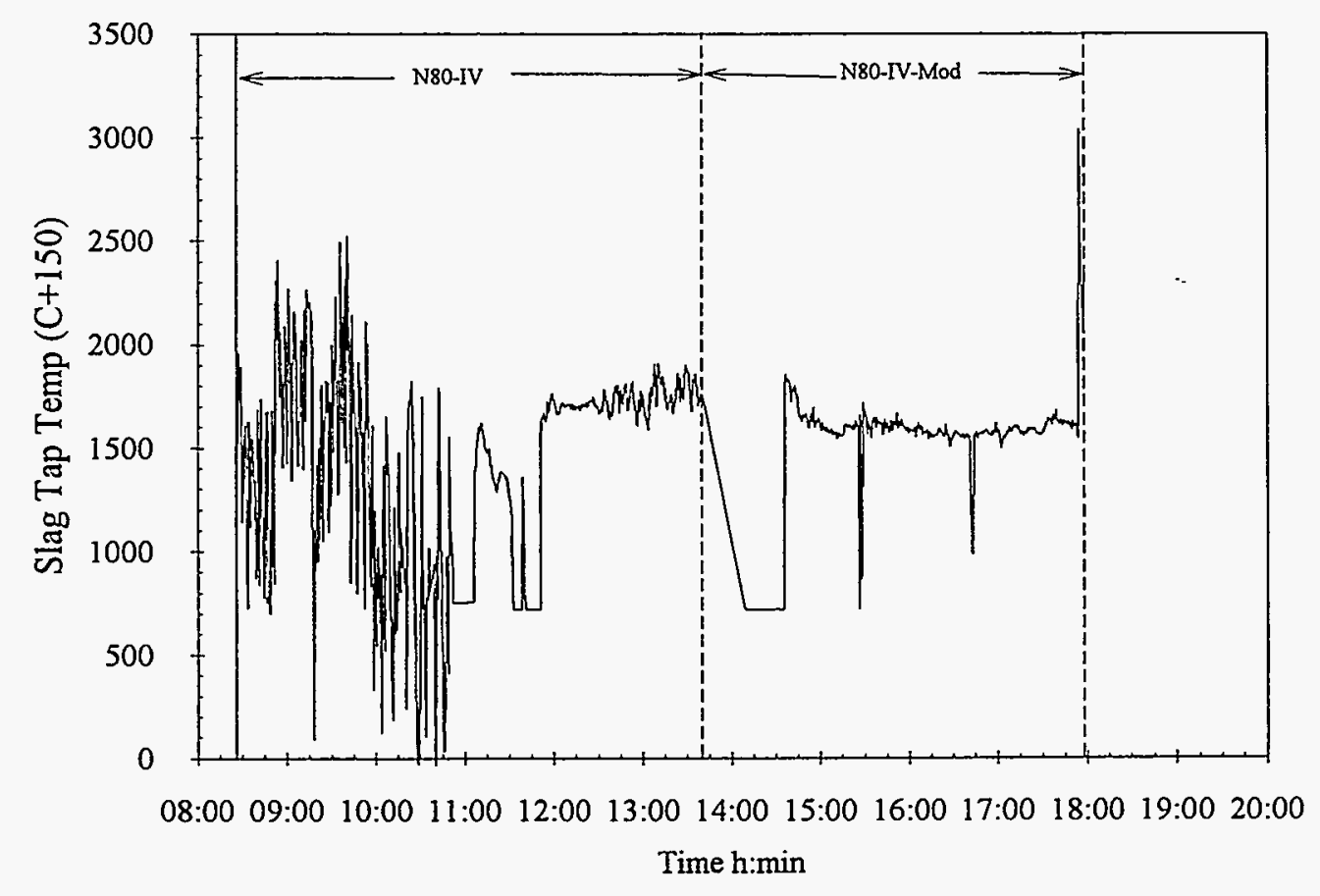

Figure E-10. Slag tap temperature for the N80-IV/N80-IV-Mod tests. 


\section{Appendix F}

Operating Conditions During Melting of M60 and M60-Mod 



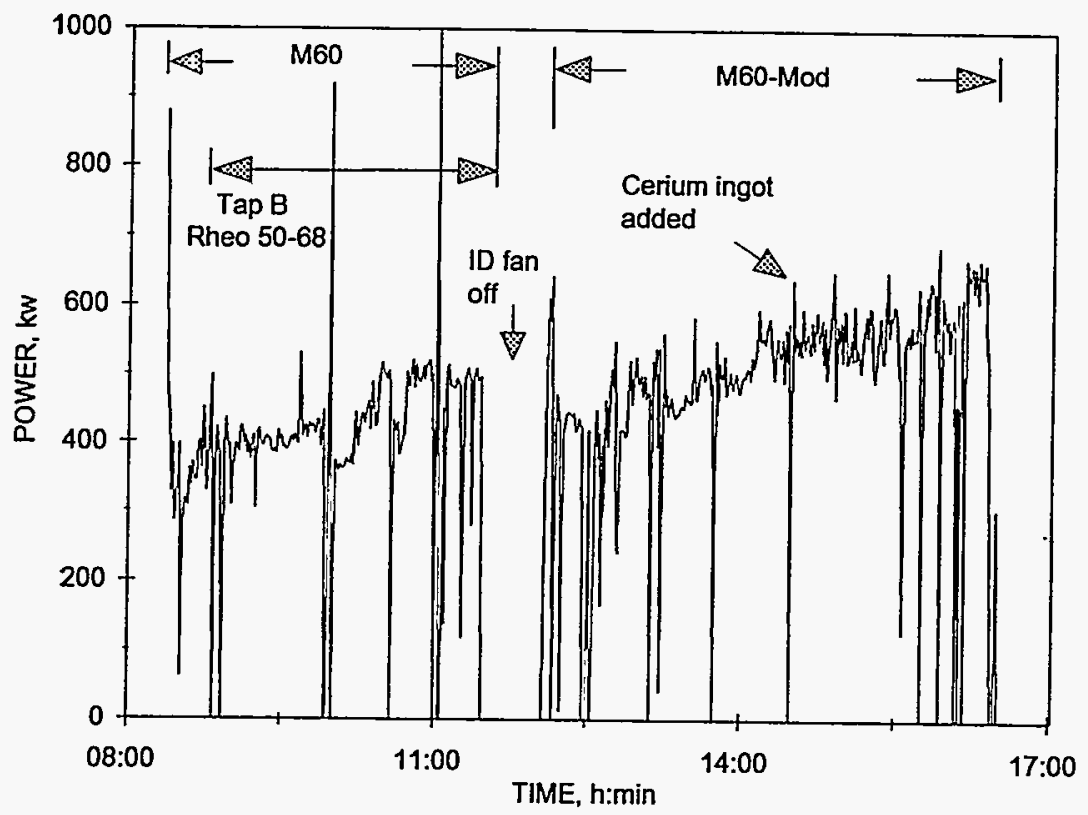

Overall Averages based on non-zero power $\begin{array}{lr}\text { Voltage } & 162.3 \mathrm{~V} \\ \text { Current } & 975.9 \mathrm{~A} \\ \text { Power } & 473.4 \mathrm{~kW}\end{array}$

Stable Operating Range (8:56 - 11:23) Averages $\begin{array}{lr}\text { Voltage } & 157.6 \mathrm{~V} \\ \text { Current } & 842.2 \mathrm{~A} \\ \text { Power } & 416.0 \mathrm{~kW}\end{array}$

Total Energy $3520 \mathrm{kwh}$

Figure F-1. Input power to the furnace for M60 and M60-Mod tests.

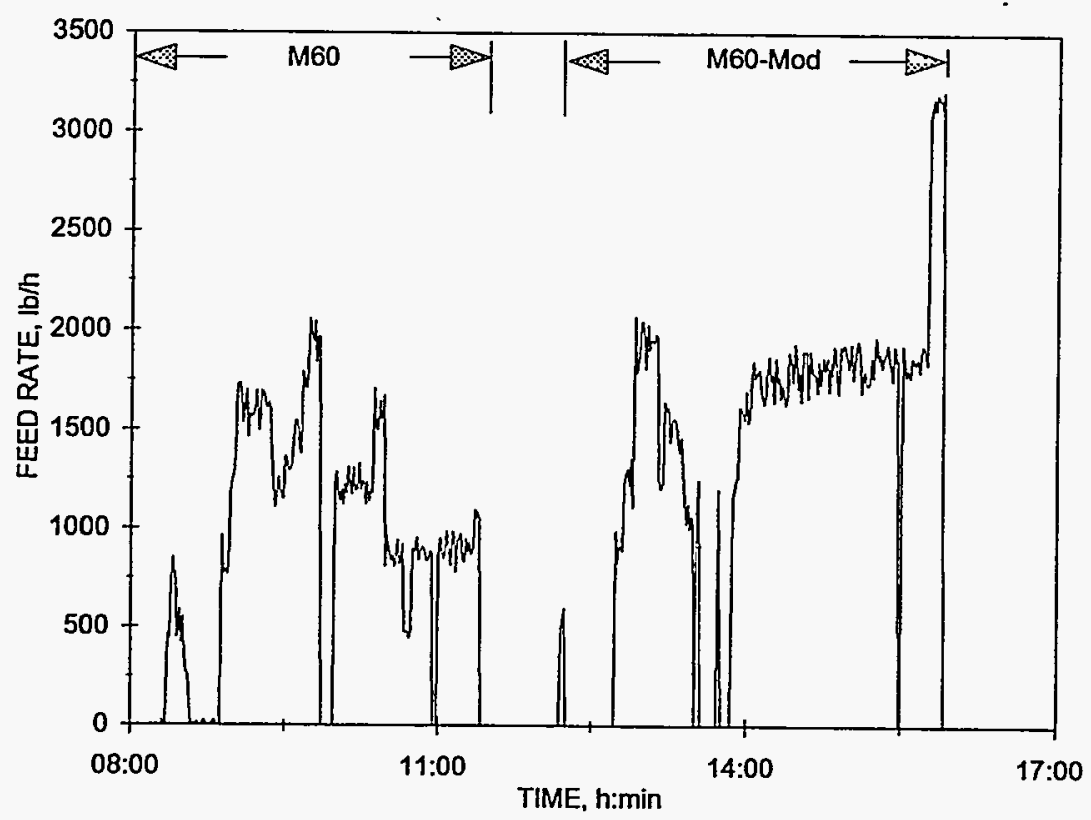

Overall Averages based on non-zero feed rate Stable Operating Range (8:56 - 11:23) Averages

Feed Rate $1425 \mathrm{lb} / \mathrm{h}$
Total Feed $6666 \mathrm{lb}$
Energy Consumption $0.53 \mathrm{kWh} / \mathrm{lb}$

Feed Rate $1132 \mathrm{lb} / \mathrm{h}$

Total Feed $2773 \mathrm{lb}$

Energy Consumption $0.37 \mathrm{kWh} / \mathrm{lb}$

Figure F-2. Feed rate for M60 and M60-Mod tests. 


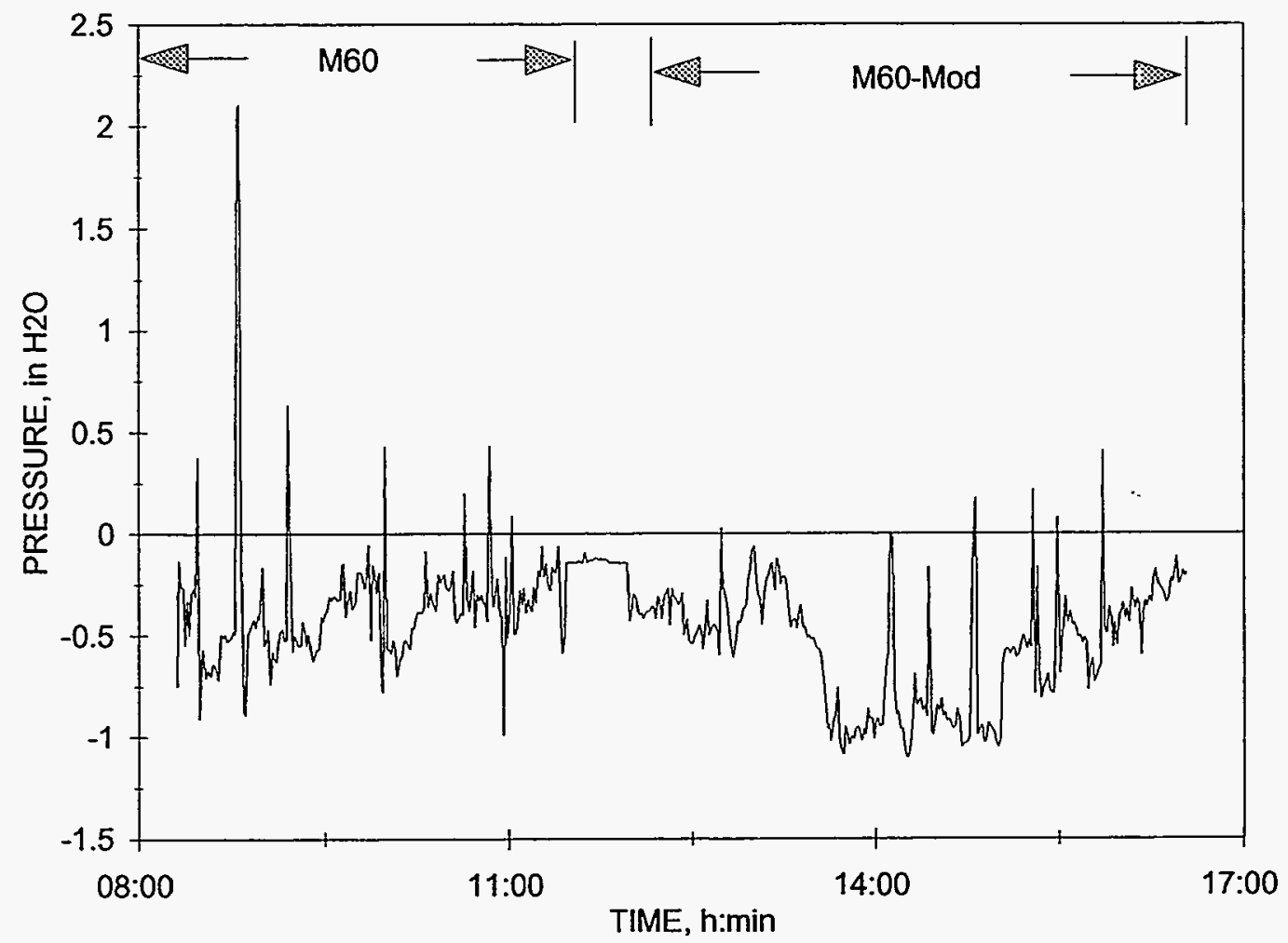

Figure F-3. Furnace pressure for M60 and M60-Mod tests.

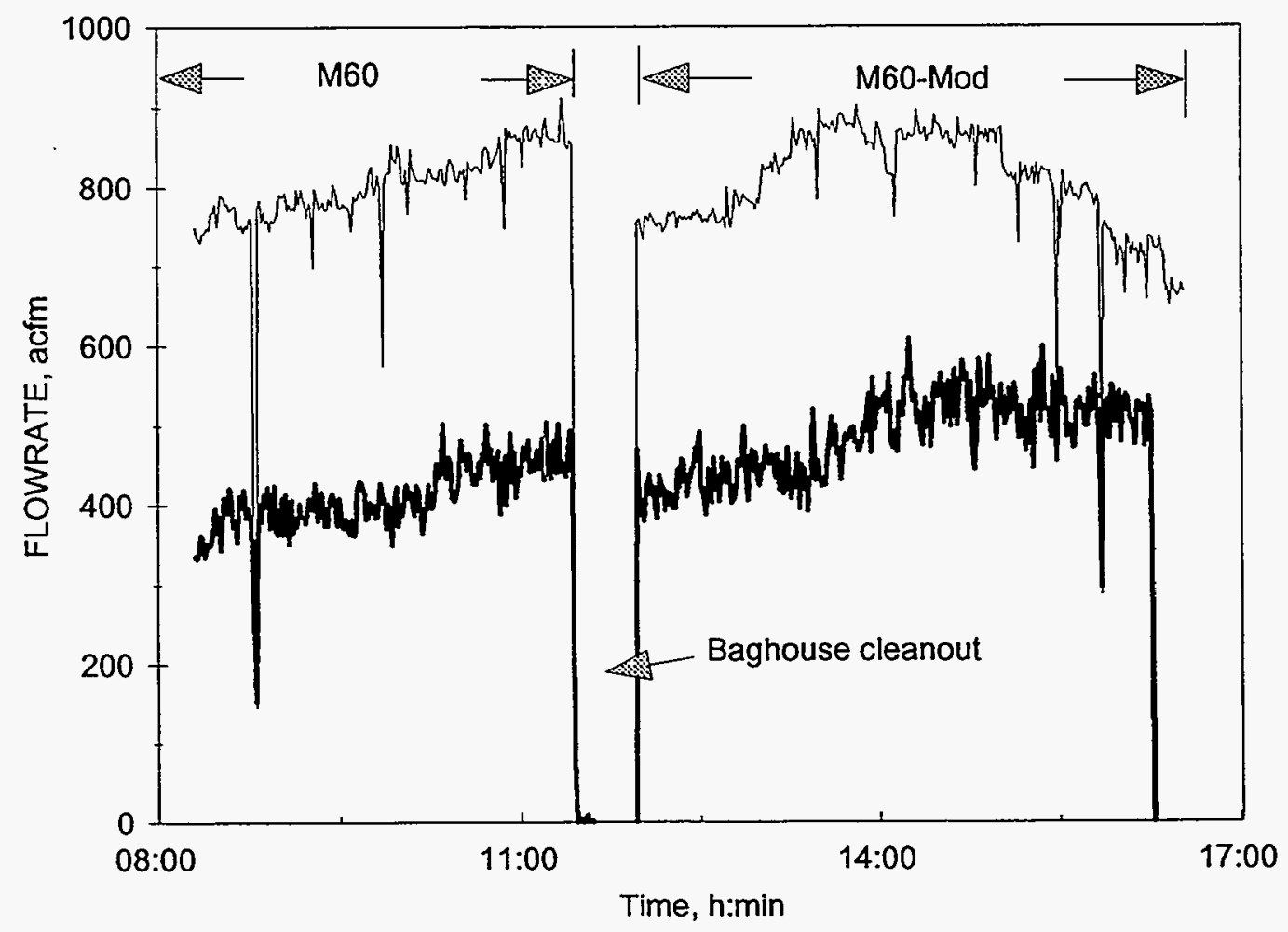

Figure F-4. Flowrate of quench air ( - ) and offgas at the baghouse outlet ( - ) for the M-60 and M60-Mod tests. 


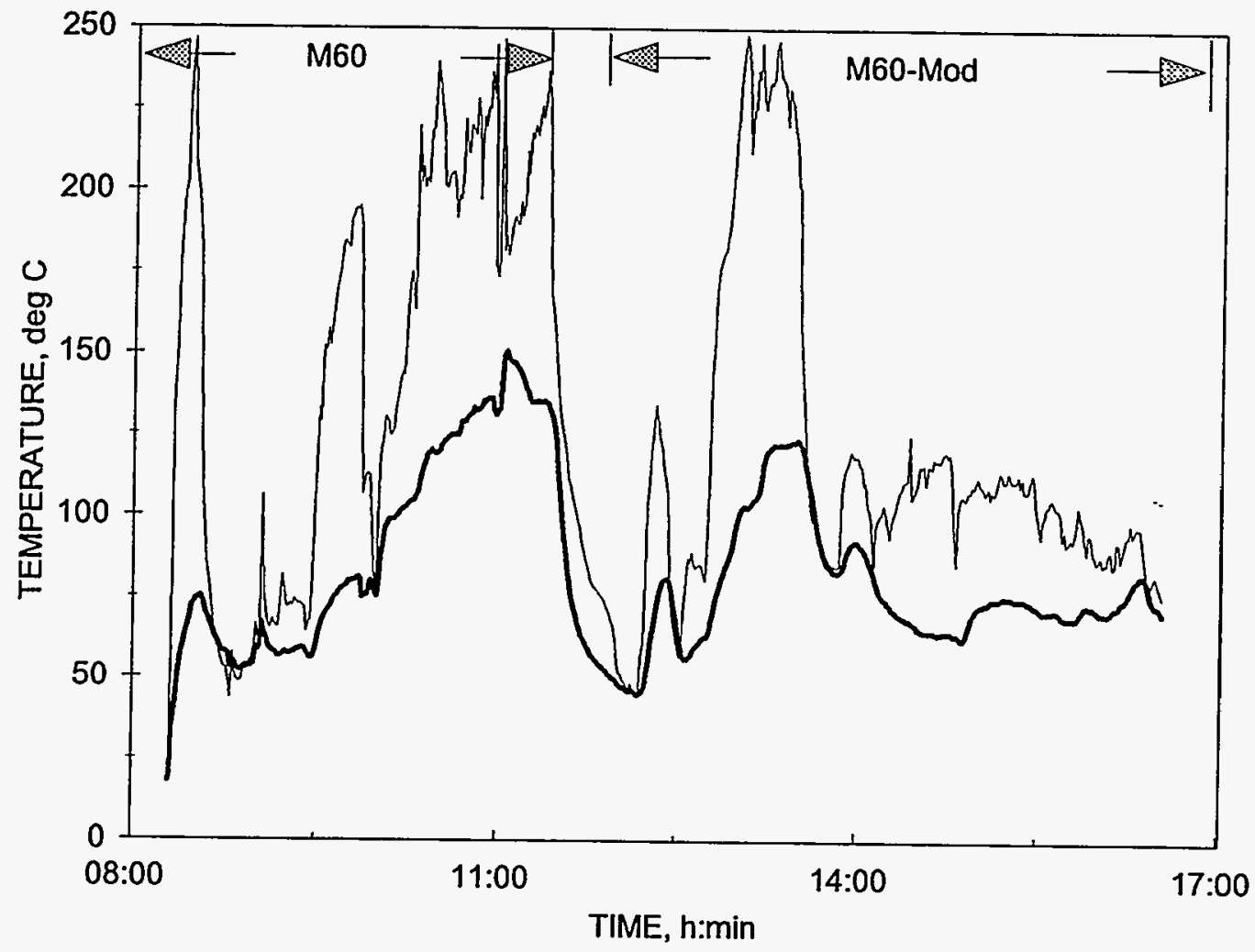

Figure F-5. Furnace exit wall temperature ( - ) and offgas temperature at fume trap $1(-)$ for the M60 and M60-Mod tests.

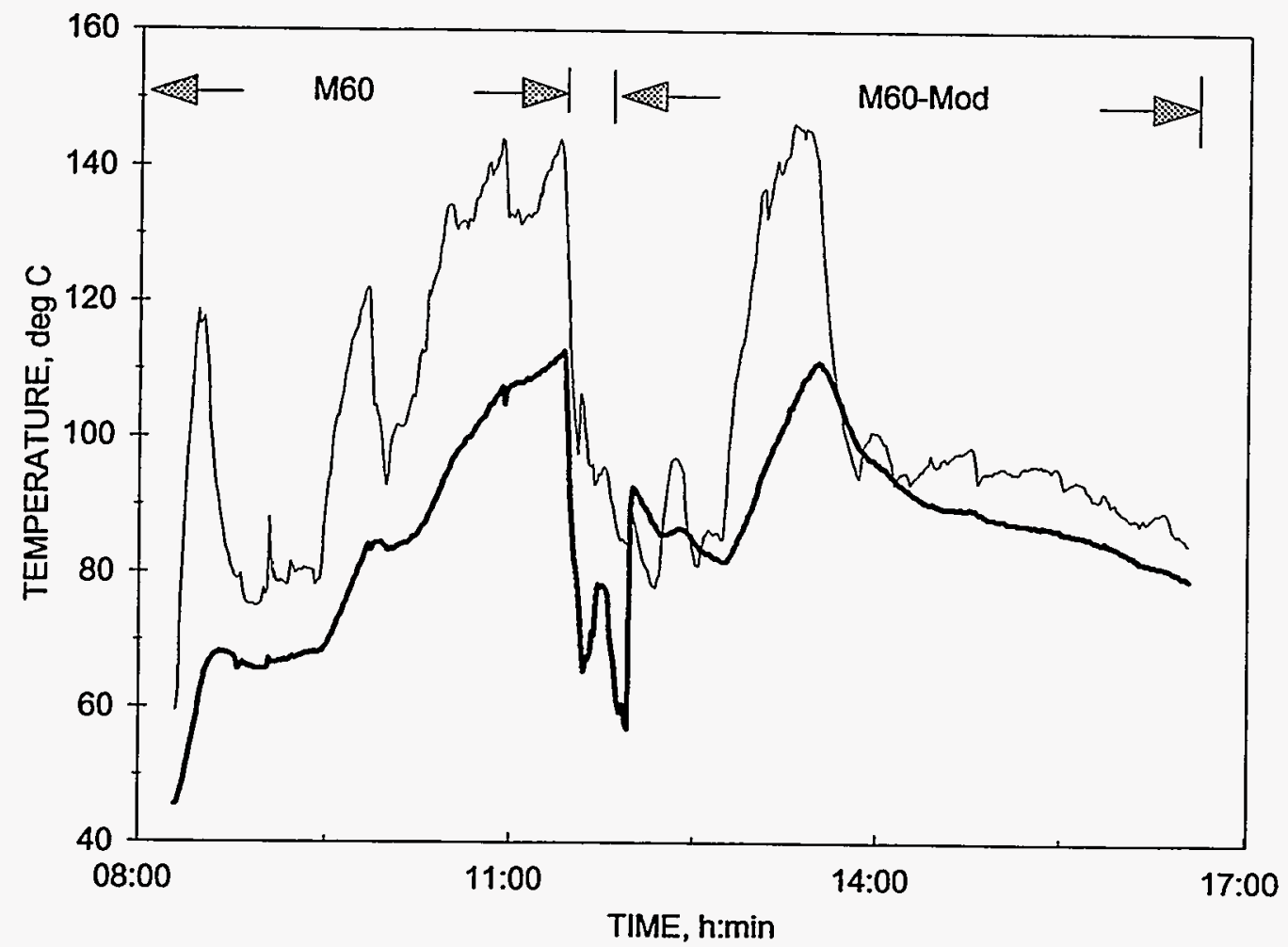

Figure F-6. Offgas temperatures upstream ( - ) and downstream ( - ) of the baghouse for the M60 and M60-Mod tests. 


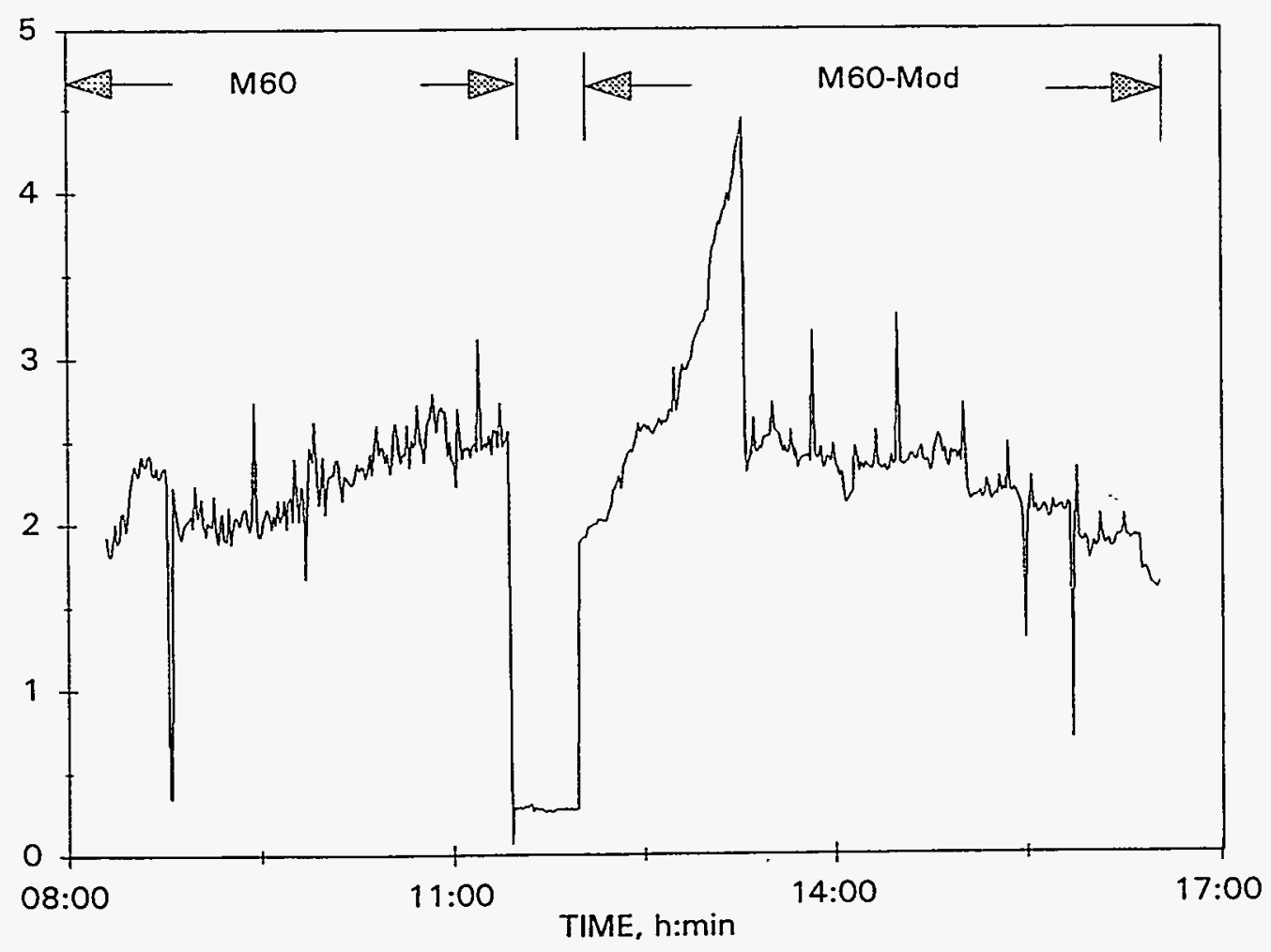

Figure F-7. Baghouse pressure drop for M60 and M60-Mod tests.

M60/M60-Mod 7/23/93

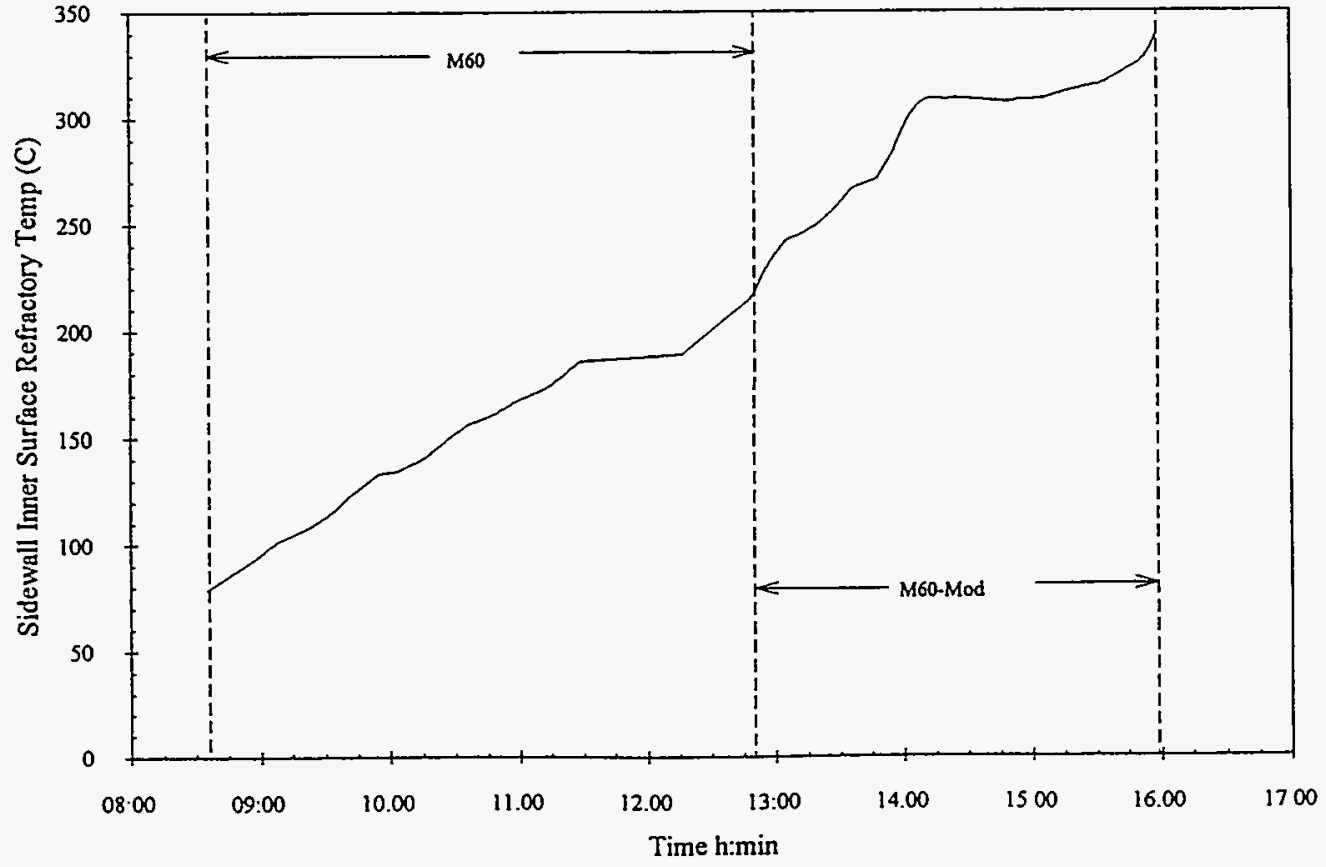

Figure F-8. Upper sidewall inner surface refractory temperature for M60 and M60-Mod. 


\section{M60/M60-Mod 7/23/93}

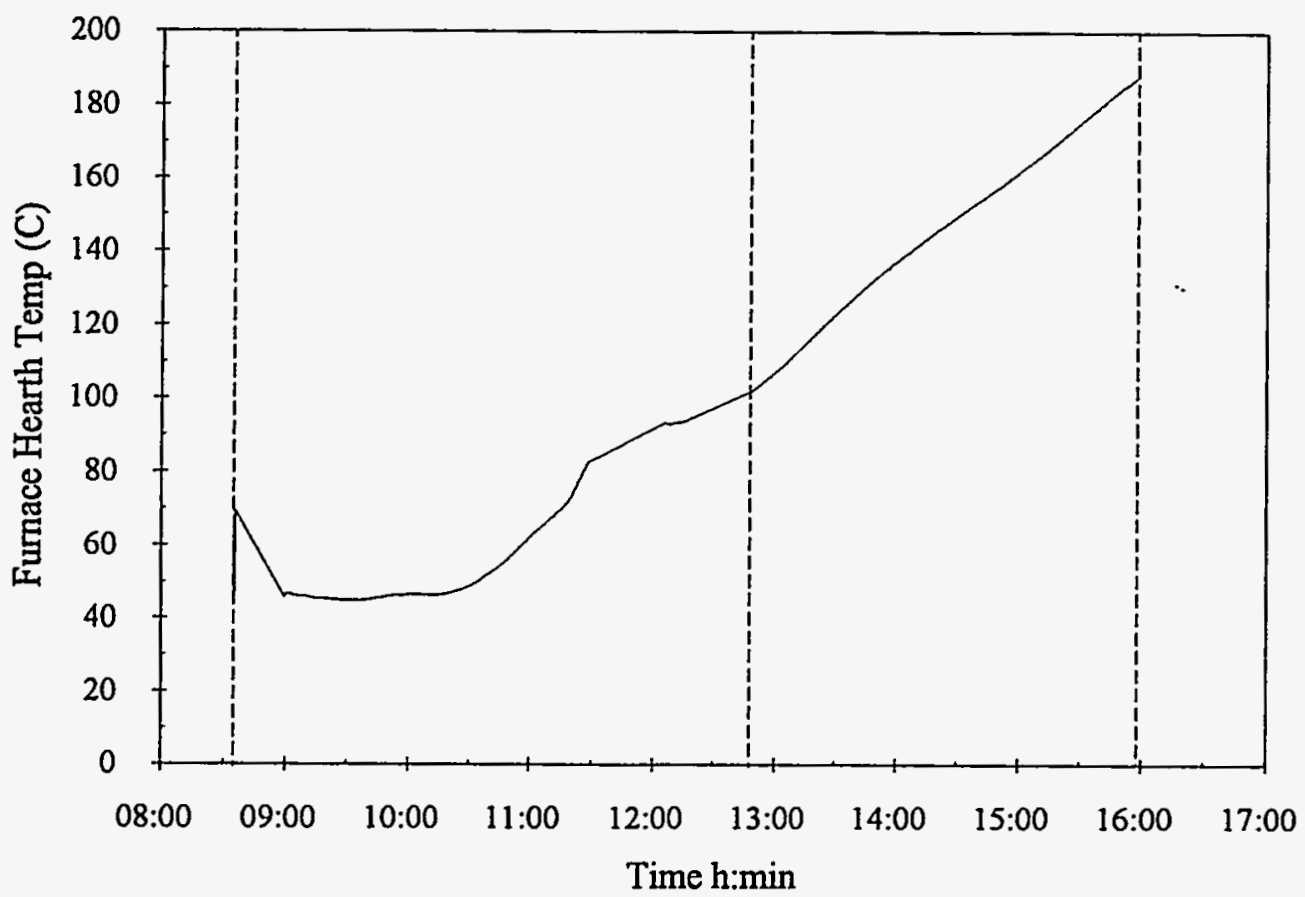

Figure F-9. Furnace hearth temperature for the M60/M60-Mod tests. 


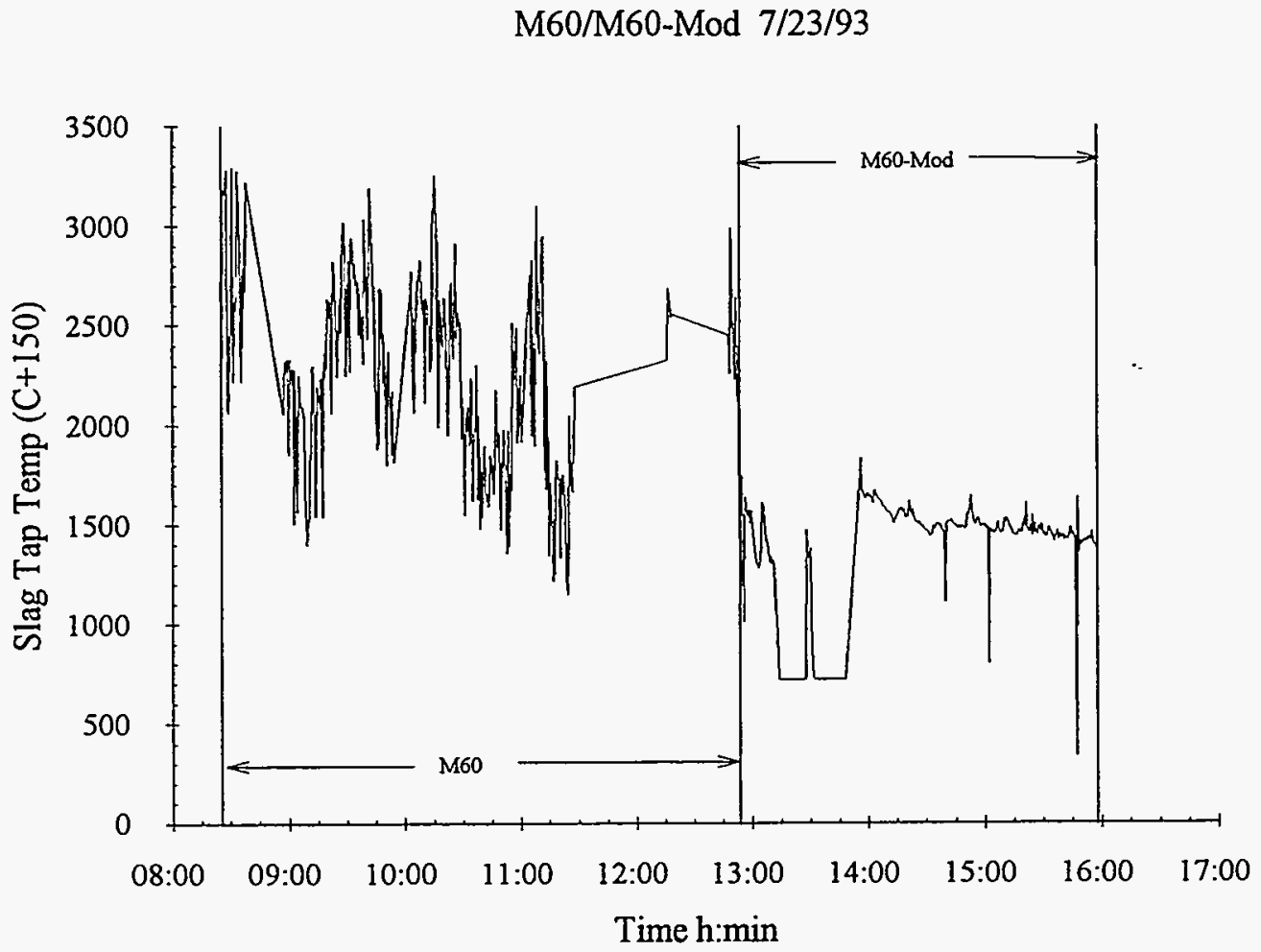

Figure F-10. Slag tap temperature for the M60/M60-Mod tests. 


\section{Appendix G}

Additive and Feed Mixture Compositions 


\section{Appendix G-1}

Compositions of Feed Mixture Additives 

Table G-1-1(a). Compositions of feed mixture additives.

\begin{tabular}{|c|c|c|c|c|c|c|c|c|c|}
\hline \multirow[b]{2}{*}{ Species } & \multicolumn{9}{|c|}{ Additive Component } \\
\hline & Magnetite & Mullite & Pollucite & Silica & Soil (a) & Soil (b) & Talc & Titania & Wollastonite \\
\hline $\mathrm{Ag}_{20}$ & - & - & - & - & $8.59 c-04$ & - & - & - & - \\
\hline $\mathrm{Al} 2 \mathrm{O} 3$ & 6.00 & 73.10 & 18.00 & 2.82 & 10.41 & - & 2.00 & - & 1.00 \\
\hline As2O & - & - & - & - & $1.22 t-03$ & - & - & - & - \\
\hline $\mathrm{BaO}$ & - & 0.06 & - & - & 0.01 & - & - & - & - \\
\hline $\mathrm{CaCO} 3$ & - & - & - & 0.40 & 13.00 & - & - & - & 0.20 \\
\hline $\mathrm{CaO}$ & 0.70 & - & - & 0.03 & 0.11 & - & 12.30 & - & 47.00 \\
\hline CdO & - & - & - & - & $5.71 e-05$ & - & - & - & . \\
\hline $\mathrm{CeO}$ & - & 0.03 & - & - & . & - & - & - & - \\
\hline $\mathrm{CcO} 2$ & - & - & - & - & $5.53 e-03$ & - & - & - & - \\
\hline $\mathrm{Cr} 2 \mathrm{O} 3$ & 0.20 & - & - & . & 0.03 & - & - & 0.20 & - \\
\hline Cs2O & - & - & . & - & $5.30 \mathrm{e}-03$ & - & - & - & - \\
\hline $\mathrm{CuO}$ & - & - & - & - & $5.63 e-03$ & - & - & - & - \\
\hline $\mathrm{Fe} 2 \mathrm{O} 3$ & - & 0.46 & - & 0.06 & - & - & 2.50 & 0.50 & 0.50 \\
\hline Fe3O4 & 75.40 & - & - & - & 4.23 & - & - & - & - \\
\hline $\mathrm{H} 2 \mathrm{O}$ & - & - & 0.75 & - & 10.10 & 10.10 & 0.50 & - & 0.20 \\
\hline $\mathrm{HgO}$ & - & - & - & - & $1.08 e-05$ & - & - & - & - \\
\hline $\mathrm{K} 2 \mathrm{O}$ & - & 0.78 & - & 0.51 & 2.42 & - & - & - & - \\
\hline $\mathrm{MgO}$ & 1.30 & 0.13 & - & 0.02 & 2.27 & - & 26.00 & - & 0.30 \\
\hline $\mathrm{MnO}$ & 0.20 & - & - & - & - & - & - & - & 0.10 \\
\hline $\mathrm{Na} 2 \mathrm{O}$ & - & 0.28 & - & 0.03 & 1.28 & - & - & - & - \\
\hline $\mathrm{NiO}$ & - & - & - & - & $4.33 e-03$ & - & - & - & - \\
\hline PO4 & - & - & . & - & 0.29 & - & - & - & - \\
\hline $\mathrm{P} 2 \mathrm{O} 5$ & 0.04 & . & - & - & - & $\therefore$ & - & - & - \\
\hline $\mathrm{PbO}$ & - & - & - & - & $248 e-03$ & - & - & - & - \\
\hline $\mathrm{SO} 4$ & - & - & - & - & 0.04 & - & - & - & - \\
\hline SeO & - & - & - & - & $1.20 \mathrm{e} .04$ & - & - & - & - \\
\hline $\mathrm{SiO} 2$ & 4.80 & 25.00 & 54.00 & 95.98 & 57.76 & - & 53.50 & 0.90 & 5000 \\
\hline Sro & - & 0.01 & . & - & - & - & - & - & - \\
\hline $\mathrm{TiO} 2$ & 10.40 & 0.13 & - & 0.01 & 0.43 & - & - & 95.80 & 005 \\
\hline V2O5 & 0.70 & - & - & - & - & - & - & 0.70 & - \\
\hline $2 \mathrm{no}$ & - & - & - & - & 0.01 & - & - & - & - \\
\hline $\mathrm{ZrO} 2$ & - & - & - & - & 0.01 & - & - & 1.10 & - \\
\hline $\mathrm{Ag}$ & - & - & - & - & - & $8.00 \mathrm{e}-04$ & - & - & - \\
\hline $\mathrm{Al}$ & - & - & - & - & - & 5.51 & - & - & - \\
\hline As & - & - & - & - & - & $1.10 c-03$ & - & - & - \\
\hline $\mathrm{Ba}$ & - & - & - & - & - & 0.01 & - & - & - \\
\hline c & - & - & - & - & - & 1.56 & - & - & - \\
\hline $\mathrm{Ca}$ & - & - & 0.30 & - & - & 5.28 & - & - & - \\
\hline $\mathrm{Cd}$ & - & - & - & - & - & $5.00 e-05$ & - & - & - \\
\hline Ce & . & - & - & - & - & $4.50 e-03$ & - & - & - \\
\hline $\mathrm{Cl}$ & - & - & - & - & $4.00<-03$ & $4.00 e-03$ & - & - & - \\
\hline $\mathrm{Cr}$ & . & - & - & - & - & 0.02 & - & - & - \\
\hline Cs & - & - & 23.80 & - & - & $5.00 c-03$ & - & - & - \\
\hline $\mathrm{Cu}$ & - & - & - & - & - & $4.50 e-03$ & - & - & - \\
\hline $\mathrm{Fe}$ & - & - & 0.30 & - & - & 3.06 & - & - & - \\
\hline $\mathrm{Hg}$ & - & - & - & - & - & $1.00 e-05$ & - & - & - \\
\hline $\mathrm{k}$ & - & - & 0.50 & - & - & 2.01 & - & - & - \\
\hline $\mathrm{Li}$ & - & - & 0.25 & - & - & - & - & - & - \\
\hline $\mathrm{Mg}$ & - & - & - & - & - & 1.37 & - & - & - \\
\hline $\mathrm{Mn}$ & - & - & - & $1.80 e-03$ & - & - & - & - & - \\
\hline $\mathrm{Na}$ & - & . & 1.50 & - & - & 0.95 & - & - & - \\
\hline $\mathrm{Ni}$ & - & - & - & - & - & $3.40 \varepsilon-03$ & - & - & - \\
\hline P & - & - & - & - & - & 0.10 & - & 0.02 & - \\
\hline $\mathrm{Pb}$ & - & - & - & - & - & $2.30 e-03$ & - & - & - \\
\hline $\mathbf{R b}$ & - & - & 0.60 & - & - & - & - & - & - \\
\hline s & 0.20 & - & - & - & - & 0.01 & - & $6.00 e-03$ & - \\
\hline $\mathrm{Se}$ & - & - & - & - & - & $1.00 e-04$ & - & - & - \\
\hline Si & - & - & - & - & - & 27.00 & - & - & 0.50 \\
\hline $\mathrm{Ti}$ & - & - & - & - & - & 0.26 & - & - & - \\
\hline $2 n$ & - & - & - & - & - & 0.01 & - & - & - \\
\hline $2 r$ & - & - & - & . & - & 0.01 & - & - & - \\
\hline Other & 0.06 & 0.02 & $1.42 e-14$ & 0.14 & $-2.45 e+00$ & 42.71 & 3.20 & 0.77 & 0.15 \\
\hline Total & 100.00 & 100.00 & 100.00 & 100.00 & 100.00 & 100.00 & 100.00 & 100.00 & 100.00 \\
\hline
\end{tabular}

(a) Species composition

(b) Elemental composition 
Table G-1-1 (b). Compositions of feed mixture additives.

\begin{tabular}{|c|c|c|c|c|c|c|c|c|c|c|}
\hline \multirow[b]{2}{*}{ Species } & \multicolumn{10}{|c|}{ Additive Component } \\
\hline & $\begin{array}{c}\text { Aluminum } \\
\text { Shot }\end{array}$ & $\begin{array}{l}\text { Copper } \\
\text { Powder }\end{array}$ & $\begin{array}{c}\text { Electrolytic } \\
\text { Iron }\end{array}$ & $\begin{array}{l}\text { Lead } \\
\text { Shot }\end{array}$ & $\begin{array}{c}\text { Stainless } \\
\text { Powder }\end{array}$ & $\begin{array}{c}\text { Zinc } \\
\text { Powder }\end{array}$ & Limestone & $\begin{array}{c}\text { Pebble } \\
\text { Lime }\end{array}$ & $\begin{array}{c}\text { Mill } \\
\text { Scale (a) } \\
\end{array}$ & $\begin{array}{c}\text { Mill } \\
\text { Scale (b) }\end{array}$ \\
\hline $\mathrm{A} 12 \mathrm{O} 3$ & - & - & - & $\cdot$ & - & - & - & 0.35 & - & - \\
\hline $\mathrm{CaCO} 3$ & - & - & - & - & - & - & 98.00 & 1.64 & - & - \\
\hline $\mathrm{CaO}$ & - & - & - & - & - & - & - & 93.00 & - & $\cdot$ \\
\hline $\mathrm{Cr} 2 \mathrm{O} 3$ & - & - & - & - & - & - & - & - & - & 0.13 \\
\hline $\mathrm{CuO}$ & - & - & - & - & - & - & - & - & - & 033 \\
\hline $\mathrm{Fe} 2 \mathrm{O} 3$ & - & - & - & - & - & - & - & 0.08 & - & - \\
\hline $\mathrm{Fe} 3 \mathrm{O} 4$ & - & - & - & - & - & - & - & - & - & 99.09 \\
\hline $\mathrm{H} 2 \mathrm{O}(1)$ & - & - & - & - & - & - & 0.30 & 345 & - & - \\
\hline $\mathrm{MgCO} 3$ & - & - & - & - & - & - & 1.00 & - & - & - \\
\hline $\mathrm{MgO}$ & - & - & - & - & - & - & - & 0.40 & $\therefore$ & - \\
\hline $\mathrm{MnO} 2$ & - & - & - & - & - & - & - & 0.05 & - & 0.85 \\
\hline $\mathrm{Na} 2 \mathrm{O}$ & $\cdot$ & . & - & - & - & - & - & 0.03 & - & - \\
\hline $\mathrm{NiO}$ & - & - & - & - & - & - & - & - & - & 0.19 \\
\hline $\mathrm{PO} 4$ & - & - & - & - & - & - & - & - & - & 004 \\
\hline P2O5 & - & - & - & - & - & - & - & 002 & - & - \\
\hline $\mathrm{SO} 3$ & - & . & - & - & - & - & - & 0.15 & - & - \\
\hline $\mathrm{SiO}_{2}$ & - & - & - & - & - & - & - & 0.75 & - & 021 \\
\hline $\mathrm{T}_{1} \mathrm{O} 2$ & - & - & - & - & - & - & - & 0.05 & - & - \\
\hline $\mathrm{Ag}_{\mathbf{B}}$ & - & $1.40 e-03$ & - & - & - & - & - & - & - & - \\
\hline $\mathrm{Al}$ & 100.00 & - & - & . & - & - & - & - & - & - \\
\hline As & - & $1.00 e-04$ & - & - & - & - & - & $200 e-04$ & - & - \\
\hline $\mathrm{Ba}$ & - & - & - & - & - & - & - & - & - & - \\
\hline $\mathrm{Bi}$ & - & $3.00 e-05$ & - & - & - & - & - & - & - & - \\
\hline $\mathrm{C}$ & - & - & $8.00 e-04$ & - & 0.03 & - & - & - & - & - \\
\hline $\mathrm{Ca}$ & - & - & $\cdot$ & - & - & - & - & - & - & - \\
\hline $\mathrm{Cd}$ & - & $\cdot$ & - & - & $\cdot$ & - & - & - & - & - \\
\hline $\mathrm{Ce}$ & - & - & - & - & - & - & - & - & - & - \\
\hline $\mathrm{Cl}$ & - & - & - & - & - & - & - & - & - & - \\
\hline $\mathrm{Cr}$ & - & - & - & - & 18.60 & - & - & - & 009 & - \\
\hline Cs & - & - & - & $\cdot$ & $\cdot$ & - & - & - & - & $\cdot$ \\
\hline $\mathrm{Cu}$ & - & 9997 & - & - & - & - & - & - & 0.26 & $\cdot$ \\
\hline$F$ & - & - & - & - & - & - & - & 003 & - & $\cdot$ \\
\hline $\mathrm{Fe}$ & - & $1.00 e-04$ & 99.97 & - & 70.05 & - & - & - & 71.70 & $\cdot$ \\
\hline $\mathrm{HB}_{\mathrm{B}}$ & - & - & - & - & - & - & - & - & - & - \\
\hline $\mathrm{K}$ & - & - & - & - & - & - & - & - & - & - \\
\hline $\mathbf{M g}$ & - & - & - & - & - & - & - & - & - & - \\
\hline $\mathrm{Mn}$ & - & - & $1.00 e-03$ & - & - & - & - & - & 0.54 & - \\
\hline$N$ & - & - & - & - & 0.02 & - & - & - & - & - \\
\hline $\mathrm{Na}$ & - & - & - & - & - & - & - & - & - & - \\
\hline $\mathrm{Ni}$ & - & $1.20 \mathrm{e}-03$ & 0.01 & - & 10.40 & - & - & - & 0.15 & - \\
\hline 0 & - & - & 0.01 & - & 0.07 & - & - & - & - & - \\
\hline $\mathrm{O} 2$ & - & $3.00 c-06$ & - & - & - & - & - & - & - & - \\
\hline $\mathrm{P}$ & - & - & $8.00 e-04$ & - & 0.02 & - & - & - & 001 & - \\
\hline $\mathrm{Pb}$ & - & - & - & 100.00 & - & - & - & $5.00 e-04$ & - & - \\
\hline $\mathbf{s}$ & - & $6.00 c-04$ & $1.50 e-03$ & - & $7.00 e-03$ & - & - & - & - & - \\
\hline $\mathrm{Sb}$ & - & $2.00 e-04$ & - & - & - & - & - & - & - & - \\
\hline $\mathrm{Se}$ & - & $1.00 e-04$ & - & - & - & - & - & - & - & - \\
\hline $\mathrm{Si}$ & - & - & $2.50 c-03$ & - & 080 & - & - & - & 0.10 & - \\
\hline Sn & - & $4.00 e-04$ & - & - & - & - & - & - & - & - \\
\hline Te & - & $1.00 \mathrm{e}-04$ & - & - & - & - & - & - & - & . \\
\hline $\mathrm{Ti}$ & - & - & - & - & - & - & - & - & - & - \\
\hline $\mathrm{Zn}$ & - & $1.00 \mathrm{e}-04$ & - & - & - & 99.60 & - & - & - & - \\
\hline $2 r$ & - & - & - & - & - & . & - & - & - & - \\
\hline Other & - & 0.03 & $3.40 \mathrm{e}-03$ & - & - & 040 & 0.70 & $2.73 \mathrm{e}-05$ & 27.15 & $-841 \mathrm{e}-01$ \\
\hline Total & 100.00 & 100.00 & 10000 & 100.00 & 100.00 & 100.00 & 100.00 & 100.00 & 10000 & 100.00 \\
\hline
\end{tabular}

(1) Balance for pebble lime was assumed to be water.

(a) Elemental composition

(b) Species composition 
Table G-1-1(c). $\quad$ Compositions of feed mixture additives.

\begin{tabular}{|c|c|c|c|c|c|c|c|c|}
\hline \multirow[b]{2}{*}{ Species } & \multicolumn{7}{|c|}{ Additive Component } & \multirow[b]{2}{*}{ Zirconia } \\
\hline & Cerium Oxide Conc. & Gypsum & Ilmenite & Potash & Salt & Soda Ash & Zircon & \\
\hline Al) $\cap 3$ & & & 070 & & & & & - \\
\hline $\begin{array}{c}\mathrm{A} 12 \mathrm{O} 3 \\
\mathrm{CaO}\end{array}$ & $3 . \overline{80}$ & - & 0.03 & - & $\begin{array}{l}- \\
-\end{array}$ & - & - & $\begin{array}{l}0.43 \\
0.03\end{array}$ \\
\hline $\mathrm{CaSO} 4$ & - & 0.80 & 0.03 & - & - & - & - & 0.03 \\
\hline $\mathrm{CaSO}^{*} 2 \mathrm{H} 2 \mathrm{O}$ & - & 95.70 & - & 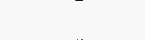 & - & - & - & - \\
\hline & & & - & - & - & - & - & - \\
\hline $\mathrm{CeO} 2$ & 65.50 & - & - & - & - & - & - & - \\
\hline $\mathrm{Cr} 2 \mathrm{O} 3$ & - & - & 0.17 & - & - & - & - & - \\
\hline $\mathrm{Fe} 2 \mathrm{O} 3$ & - & - & 29.97 & - & - & $1.00 e-03$ & - & 0.03 \\
\hline $\mathrm{H} 2 \mathrm{O}(1)$ & 4.04 & 3.50 & 2.25 & 0.12 & 0.03 & 0.17 & - & - \\
\hline $\mathrm{HFO}_{2}$ & - & - & - & - & - & - & - & 1.82 \\
\hline $\mathrm{KCl}$ & - & - & - & $5.00 \mathrm{e}-03$ & - & - & - & - \\
\hline $\mathrm{K} 2 \mathrm{CO} 3$ & - & - & - & 99.80 & - & - & - & - \\
\hline $\mathrm{KOH}$ & - & - & - & 0.07 & - & - & - & - \\
\hline $\mathrm{K} 2 \mathrm{SO} 4$ & - & - & - & $6.00 e-03$ & - & - & - & - \\
\hline $\mathrm{MgO}$ & - & - & 0.22 & - & - & - & - & 0.01 \\
\hline $\mathrm{MnO}$ & - & - & 1.24 & - & - & - & - & - \\
\hline $\mathrm{NaCl}$ & - & - & - & - & 99.70 & 0.08 & - & - \\
\hline $\mathrm{Na} 2 \mathrm{CO} 3$ & - & - & - & - & - & 99.60 & - & - \\
\hline $\mathrm{Na} 2 \mathrm{O}$ & - & - & - & - & - & - & - & 0.06 \\
\hline $\mathrm{Na} 2 \mathrm{SO} 4$ & - & - & - & - & - & 0.15 & - & - \\
\hline $\mathrm{P} 2 \mathrm{O} 5$ & - & - & 0.09 & - & - & - & - & - \\
\hline $\mathrm{SO} 4$ & 6.00 & - & - & - & 0.08 & - & - & - \\
\hline $\mathrm{SiO} 2$ & 4.00 & - & 0.26 & - & - & - & - & 1.95 \\
\hline ThO2 & 0.26 & - & - & - & - & - & - & - \\
\hline $\mathrm{TiO} 2$ & - & - & 64.80 & - & - & - & - & 0.27 \\
\hline $\mathrm{V} 2 \mathrm{O} 3$ & - & - & 0.23 & - & - & - & - & - \\
\hline$\cdot \mathrm{Y} 2 \mathrm{O} 3$ & - & - & - & - & - & - & - & 0.15 \\
\hline $\mathrm{ZrO} 2$ & - & - & 0.04 & - & - & - & - & 95.21 \\
\hline $\mathrm{BaO}+\mathrm{SrO}$ & 7.20 & - & - & - & - & - & - & - \\
\hline $\mathrm{ZrO} 2+\mathrm{HFO} 2$ & - & - & - & - & - & - & 66.08 & - \\
\hline As & - & - & - & $1.00 \mathrm{e}-04$ & - & - & - & - \\
\hline $\mathrm{Ca}$ & - & - & - & - & 0.03 & - & - & - \\
\hline$F$ & 9.20 & - & - & - & - & - & - & - \\
\hline $\mathrm{Fe}$ & - & - & - & $1.20 \mathrm{e}-04$ & - & - & - & - \\
\hline $\mathrm{Hg}$ & - & - & - & $4.00 e-06$ & - & - & - & - \\
\hline $\mathrm{K}$ & - & - & - & - & 0.04 & - & - & - \\
\hline $\mathrm{Mg}$ & - & - & - & - & 0.02 & - & - & - \\
\hline $\mathrm{Pb}$ & - & - & - & $9.00 e-04$ & - & - & - & - \\
\hline Th & - & - & - & - & - & - & - & 0.02 \\
\hline $\mathrm{U}$ & - & - & - & - & - & - & - & 0.02 \\
\hline Other & $-1.42 e-14$ & - & - & $1.42 \mathrm{e}-14$ & 0.10 & $-1.00 e-03$ & 33.92 & - \\
\hline Total & 100.00 & 100.00 & 100.00 & 100.00 & 100.00 & 100.00 & 100.00 & 100.00 \\
\hline
\end{tabular}

(1) Balance for some additives (gypsum, potash, soda ash), is assumed to be water. 


\section{Appendix G-2}

\section{Feed Mixture Additives and Compositions}


, 
Table G-2-1. ' S60 surrogate waste mixture composition.

\begin{tabular}{|c|c|c|c|c|c|c|c|c|c|c|c|}
\hline \multirow{2}{*}{ Species } & \multicolumn{9}{|c|}{ Amount of each species provided by the listed additives (b) } & \multirow{2}{*}{$\begin{array}{l}\text { Tot. amt. of ea. } \\
\text { species (lb) }\end{array}$} & \multirow{2}{*}{$\begin{array}{l}\text { Tot. wt. \% of } \\
\text { ea. species }\end{array}$} \\
\hline & $\begin{array}{l}\text { Cerium } \\
\text { Oxide Conc. }\end{array}$ & Gypsum & Magnetite & Pollucite & Salt & Silica & Soil & Talc & Wollastonit & & \\
\hline A1203 & - & - & 137.42 & 37.80 & - & 22.41 & 748.02 & 9.02 & 5.40 & 960.06 & 7.54 \\
\hline Ag2O & - & - & - & - & - & - & 0.06 & - & - & 0.06 & 4.85e-04 \\
\hline As 20 & - & - & - & - & - & - & 0.09 & - & - & 0.09 & $6.87 e-04$ \\
\hline $\mathrm{BaO}$ & - & - & - & - & - & - & 0.80 & - & - & 0.80 & $6.30 e-03$ \\
\hline $\mathrm{C}_{2} \mathrm{CO}_{3}$ & - & - & - & - & - & 3.18 & 934.00 & - & 1.08 & 938.26 & 7.37 \\
\hline $\mathrm{CaO}$ & 3.05 & - & 16.03 & - & - & 0.24 & 8.05 & 55.45 & 253.71 & 336.52 & 2.64 \\
\hline $\mathrm{CaSO} 4$ & - & 7.33 & - & - & - & - & - & - & - & 7.33 & 0.06 \\
\hline $\mathrm{CaSO} 4 * 2 \mathrm{H} 2 \mathrm{O}$ & - & 876.32 & - & - & - & - & - & - & - & 876.32 & 6.89 \\
\hline Cdo & - & - & - & - & - & - & $4.10 e-03$ & - & - & $4.10 e-03$ & $3.22 c-05$ \\
\hline $\mathrm{CeO} 2$ & 52.50 & - & - & - & - & - & 0.40 & - & - & 52.90 & 0.42 \\
\hline $\mathrm{Cr} 2 \mathrm{O} 3$ & - & - & 4.58 & - & - & - & 2.10 & - & - & 6.68 & 0.05 \\
\hline $\mathrm{Cs} 2 \mathrm{O}$ & - & - & - & - & - & - & 0.38 & - & - & 0.38 & $2.99 e-03$ \\
\hline $\mathrm{CuO}$ & - & - & - & - & - & - & 0.40 & - & - & 0.40 & $3.18 c-03$ \\
\hline $\mathrm{Fe} 2 \mathrm{O} 3$ & - & - & - & - & - & 0.48 & - & 11.27 & 2.70 & 14.45 & 0.11 \\
\hline $\mathrm{Fe} 3 \mathrm{O} 4$ & - & - & $1,726.96$ & - & - & - & 303.83 & - & - & $2,030.79$ & 15.96 \\
\hline $\mathrm{H} 2 \mathrm{O}$ & 3.24 & 32.05 & - & 1.58 & 0.08 & - & 725.64 & 2.25 & 1.08 & 765.92 & 6.02 \\
\hline $\mathrm{HgO}$ & - & - & - & - & - & - & $7.76 e-04$ & - & - & $7.76 \mathrm{e}-04$ & $6.10 c-06$ \\
\hline $\mathrm{K} 2 \mathrm{O}$ & - & - & - & - & - & 4.05 & 174.03 & - & - & 178.09 & 1.40 \\
\hline $\mathrm{MgO}$ & - & - & 29.78 & - & - & 0.16 & 163.24 & 117.21 & 1.62 & 312.00 & 2.45 \\
\hline Mno & - & - & 4.58 & - & - & - & - & - & 0.54 & 5.12 & 0.04 \\
\hline $\mathrm{NaCl}$ & - & - & - & - & 258.82 & - & - & - & - & 258.82 & 2.03 \\
\hline $\mathrm{Na} 2 \mathrm{O}$ & - & - & - & - & - & 0.24 & 91.99 & - & - & 92.23 & 0.72 \\
\hline $\mathrm{NiO}$ & - & - & - & - & - & - & 0.31 & - & - & 0.31 & $2.44 e-03$ \\
\hline PO4 & - & - & - & - & - & - & 20.93 & - & - & 20.93 & 0.16 \\
\hline P2O5 & - & - & 0.92 & - & - & - & - & - & - & 0.92 & $7.20 \mathrm{e}-03$ \\
\hline $\mathrm{PbO}$ & - & - & - & - & - & - & 0.18 & - & - & 0.18 & $1.40 e-03$ \\
\hline SO4 & 4.81 & - & - & - & 0.21 & - & 3.02 & - & - & 8.03 & 0.06 \\
\hline SeO & - & - & - & - & - & - & $8.64 e-03$ & - & - & $8.64 e-03$ & $6.79 c-05$ \\
\hline $\mathrm{SiO} 2$ & 3.21 & - & 109.94 & 113.40 & - & 762.66 & $4,149.70$ & 241.18 & 269.90 & $5,649.98$ & 44.40 \\
\hline ThO2 & 0.21 & - & - & - & - & - & - & - & - & 0.21 & $1.64 e-03$ \\
\hline TiO2 & - & - & 238.20 & - & - & 0.08 & 31.16 & - & 0.27 & 269.71 & 2.12 \\
\hline V2OS & - & - & 16.03 & - & - & - & - & - & - & 16.03 & 0.13 \\
\hline $\mathrm{ZnO}$ & - & - & - & - & - & - & 0.98 & - & - & 0.98 & $7.73 c-03$ \\
\hline $\mathrm{ZrO} 2$ & - & - & - & - & - & - & 0.97 & - & - & 0.97 & $7.63 e-03$ \\
\hline $\mathrm{BaO}+\mathrm{SrO}$ & 5.77 & - & - & - & - & - & - & - & - & 5.77 & 0.05 \\
\hline $\mathrm{Ca}$ & - & - & - & 0.63 & 0.08 & - & - & - & - & 0.71 & $5.56 e-03$ \\
\hline $\mathrm{CI}$ & - & - & - & - & - & - & 0.29 & - & - & 0.29 & $2.26 e-03$ \\
\hline Cs & - & - & - & 49.98 & - & - & - & - & - & 49.98 & 0.39 \\
\hline $\mathrm{F}$ & 7.37 & - & - & - & - & - & - & - & - & 7.37 & 0.06 \\
\hline $\mathrm{Fe}$ & - & - & - & 0.63 & - & - & - & - & - & 0.63 & $4.95 e-03$ \\
\hline $\mathrm{K}$ & - & - & - & 1.05 & 0.10 & - & - & - & - & 1.15 & $9.07 e-03$ \\
\hline L & - & - & - & 0.53 & - & - & - & - & - & 0.53 & $4.13 e-03$ \\
\hline $\mathrm{Mg}$ & - & - & - & - & 0.05 & - & - & - & - & 0.05 & $4.08 c-04$ \\
\hline Mn & - & - & - & - & - & 0.01 & - & - & - & 0.01 & $1.12 e-04$ \\
\hline $\mathrm{Na}$ & - & - & - & 3.15 & - & - & - & - & - & 3.15 & 0.02 \\
\hline $\mathbf{R b}$ & - & - & - & 1.26 & - & - & - & - & - & 1.26 & $9.90 e-03$ \\
\hline s & - & - & 4.58 & - & - & - & - & - & - & 4.58 & 0.04 \\
\hline $\mathbf{S i}$ & - & - & - & - & - & - & - & - & 2.70 & 2.70 & 0.02 \\
\hline Other & $-1.14 c-14$ & - & 1.37 & $2.98 \mathrm{e}-14$ & 0.26 & 1.10 & $-1.76 c+02$ & 14.43 & 0.81 & $-1.58 e+02$ & $-1.24 e+00$ \\
\hline Total & 80.15 & 915.70 & $2,290.40$ & 210.00 & 259.60 & 794.60 & $7,184.60$ & 450.80 & 539.80 & $12,725.65$ & 100.00 \\
\hline
\end{tabular}


Table G-2-2. S60-IV surrogate waste mixture composition.

\begin{tabular}{|c|c|c|c|c|c|c|c|c|c|c|c|c|c|}
\hline \multirow[b]{2}{*}{ Species } & \multicolumn{11}{|c|}{ Amount of each species provided by the listed additives (lb) } & \multirow{2}{*}{$\begin{array}{l}\text { Tot. amt. of } \\
\text { ea. species } \\
\text { (lb) }\end{array}$} & \multirow{2}{*}{$\begin{array}{c}\text { Tot. wt. } \% \\
\text { of each } \\
\text { species }\end{array}$} \\
\hline & $\begin{array}{l}\text { Cerium } \\
\text { Oxide }\end{array}$ & Gypsum & Ilmenite & Magnetite & Pollucite & Salt & Silica & Soil & Talc & $\begin{array}{l}\text { Wollas- } \\
\text { tonite }\end{array}$ & $\begin{array}{c}\text { Zircon } \\
\text { (ZrSiO4) }\end{array}$ & & \\
\hline Al2O3 & - & - & 4.18 & 123.12 & 37.80 & $=$ & 17.87 & 640.15 & 9.19 & $\overline{5.45}$ & - & 837.75 & 6.77 \\
\hline $\mathrm{Ag} 2 \mathrm{O}$ & - & - & - & - & - & - & - & 0.05 & - & - & - & 0.05 & $4.27 e-04$ \\
\hline As2O & - & - & - & - & - & - & - & 0.07 & - & - & - & 0.07 & $6.05 e-04$ \\
\hline $\mathrm{BaO}$ & - & - & - & - & - & - & - & 0.69 & - & - & - & 0.69 & $5.55 e-03$ \\
\hline $\mathrm{CaCO} 3$ & - & - & - & - & - & - & 2.54 & 799.31 & - & 1.09 & - & 802.93 & 6.49 \\
\hline $\mathrm{CaO}$ & 3.05 & - & 0.18 & 14.36 & - & - & 0.19 & 6.89 & 56.53 & 256.01 & - & 337.20 & 2.72 \\
\hline $\mathrm{CaSO}_{4}$ & - & 7.33 & - & - & - & - & - & - & - & - & - & 7.33 & 0.06 \\
\hline $\mathrm{CaSO}_{4} * 2 \mathrm{H} 2 \mathrm{O}$ & - & 876.32 & - & - & - & - & - & - & - & - & - & 876.32 & 7.08 \\
\hline $\mathrm{CdO}$ & - & - & - & - & - & - & - & $3.51 \mathrm{e}-03$ & - & - & - & $3.51 e-03$ & $2.84 c-05$ \\
\hline $\mathrm{CeO} 2$ & 52.50 & - & - & - & - & - & - & 0.34 & - & - & - & 52.84 & 0.43 \\
\hline $\mathrm{Cr} 2 \mathrm{O} 3$ & - & - & 1.01 & 4.10 & - & - & - & 1.80 & - & - & - & 6.92 & 0.06 \\
\hline $\mathrm{Cs} 2 \mathrm{O}$ & - & - & - & - & - & - & - & 0.33 & - & - & - & 0.33 & $2.63 e-03$ \\
\hline $\mathrm{CuO}$ & - & - & - & - & - & - & - & 0.35 & - & - & - & 0.35 & $2.80 \mathrm{e}-03$ \\
\hline $\mathrm{Fe} 2 \mathrm{O} 3$ & - & - & 178.80 & - & - & - & 0.38 & - & 11.49 & 2.72 & - & 193.39 & 1.56 \\
\hline $\mathrm{Fe} 3 \mathrm{O} 4$ & - & - & - & $1,547.21$ & - & - & - & 260.01 & - & - & - & $1,807.22$ & 14.60 \\
\hline $\mathrm{H} 2 \mathrm{O}$ & 3.24 & 32.05 & 13.42 & - & 1.58 & 0.08 & - & 621.00 & 2.30 & 1.09 & - & 674.75 & 5.45 \\
\hline $\mathrm{HgO}$ & - & - & - & - & - & - & - & $6.64 e-04$ & - & - & - & $6.64 e-04$ & $5.36 e-06$ \\
\hline $\mathrm{K} 2 \mathrm{O}$ & - & - & - & - & - & - & 3.23 & 148.94 & - & - & - & 152.17 & 1.23 \\
\hline $\mathrm{MgO}$ & - & - & 1.31 & 26.68 & - & - & 0.13 & 139.70 & 119.50 & 1.63 & - & 288.94 & 2.33 \\
\hline $\mathrm{MnO}$ & - & - & 7.40 & 4.10 & - & - & - & - & - & 0.54 & - & 12.05 & 0.10 \\
\hline $\mathrm{NaCl}$ & - & - & - & - & - & 258.82 & - & - & - & - & - & 258.82 & 2.09 \\
\hline $\mathrm{Na} 2 \mathrm{O}$ & - & - & - & - & - & - & 0.19 & 78.73 & - & - & - & 78.92 & 0.64 \\
\hline NiO & - & - & - & - & - & - & - & 0.27 & - & - & - & 0.27 & $2.15 e-03$ \\
\hline PO4 & - & - & - & - & - & - & - & 17.91 & - & - & - & 17.91 & 0.14 \\
\hline P2O5 & - & - & 0.54 & 0.82 & - & - & - & - & - & - & - & 1.36 & 0.01 \\
\hline $\mathrm{PbO}$ & - & - & - & - & - & - & - & 0.15 & - & - & - & 0.15 & $1.23 e-03$ \\
\hline $\mathrm{SO} 4$ & 4.81 & - & - & - & - & 0.21 & - & 2.58 & - & - & - & 7.60 & 0.06 \\
\hline $\mathrm{SeO}$ & - & - & - & - & - & - & - & $7.39 c-03$ & - & - & - & $7.39 e-03$ & $5.97 e-05$ \\
\hline $\mathrm{SiO} 2$ & 3.21 & - & 1.55 & 98.50 & 113.40 & - & 608.32 & $3,551.27$ & 245.89 & 272.35 & - & $4,894.48$ & 39.54 \\
\hline ThO2 & 0.21 & - & - & - & - & - & - & - & - & - & - & 0.21 & $1.68 \mathrm{e}-03$ \\
\hline $\mathrm{TiO} 2$ & - & - & 386.60 & 213.41 & - & - & 0.06 & 26.67 & - & 0.27 & - & 627.01 & 5.07 \\
\hline v2O3 & - & - & 1.37 & - & - & - & - & - & - & - & - & 1.37 & 0.01 \\
\hline V2Os & - & - & - & 14.36 & - & - & - & - & - & - & - & 14.36 & 0.12 \\
\hline $\mathrm{ZnO}$ & - & - & - & - & - & - & - & 0.84 & - & - & - & 0.84 & $6.80 c-03$ \\
\hline $\mathrm{ZrO2}$ & - & - & 0.24 & - & - & - & - & 0.83 & - & - & - & 1.07 & $8.64 c-03$ \\
\hline $\mathrm{BaO}+\mathrm{SrO}$ & 5.77 & - & - & - & - & - & - & - & - & - & - & 5.77 & 0.05 \\
\hline $\mathrm{ZrO} 2+\mathrm{HrO} 2$ & - & - & - & - & - & - & - & - & - & - & 315.33 & 315.33 & 2.55 \\
\hline $\mathrm{Ca}$ & - & - & - & - & 0.63 & 0.08 & - & - & - & - & - & 0.71 & $5.72 c-03$ \\
\hline $\mathrm{Cl}$ & - & - & - & - & - & - & - & 0.25 & - & - & - & 0.25 & $1.99 c-03$ \\
\hline $\mathrm{Cs}$ & - & - & - & - & 49.98 & - & - & - & - & - & - & 49.98 & 0.40 \\
\hline$F$ & 7.37 & - & - & - & - & - & - & - & - & - & - & 7.37 & 0.06 \\
\hline Fe & - & - & - & - & 0.63 & - & - & - & - & - & - & 0.63 & $5.09 e-03$ \\
\hline K & - & - & - & - & 1.05 & 0.10 & - & - & - & - & - & 1.15 & $9.32 e-03$ \\
\hline $\mathbf{L}$ & - & - & - & - & 0.53 & - & - & - & - & - & - & 0.53 & $4.24 e-03$ \\
\hline $\mathrm{Mg}$ & - & - & - & - & - & 0.05 & - & - & - & - & - & 0.05 & $4.19 e-04$ \\
\hline $\mathrm{Mn}$ & - & - & - & - & - & - & 0.01 & - & - & - & - & 0.01 & $9.22 e-05$ \\
\hline $\mathrm{Na}$ & - & - & - & - & 3.15 & - & - & - & - & - & - & 3.15 & 0.03 \\
\hline $\mathbf{R b}$ & - & - & - & - & 1.26 & - & - & - & - & - & - & 1.26 & 0.01 \\
\hline $\mathrm{s}$ & - & - & - & 4.10 & - & - & - & - & - & - & - & 4.10 & 0.03 \\
\hline $\mathrm{Si}$ & - & - & - & - & - & - & - & - & - & 2.72 & - & 2.72 & 0.02 \\
\hline Other & $-1.14 e-14$ & - & - & 1.23 & $2.98 e-14$ & 0.26 & 0.88 & $-1.51 e+02$ & 14.71 & 0.82 & 161.87 & 29.15 & 0.24 \\
\hline Total & 80.15 & 915.70 & 596.60 & $2,052.00$ & 210.00 & 259.60 & 633.80 & $6,148.50$ & 459.60 & 544.70 & 477.20 & $12,377.85$ & 100.00 \\
\hline
\end{tabular}


Table G-2-3. N80 surrogate waste mixture composition.

\begin{tabular}{|c|c|c|c|c|c|c|c|}
\hline \multirow[b]{2}{*}{ Species } & \multicolumn{5}{|c|}{ Amount of each species provided by the listed additives (lb) } & \multirow[b]{2}{*}{$\begin{array}{l}\text { Tot. amt. of ea. } \\
\text { species (lb) }\end{array}$} & \multirow[b]{2}{*}{$\begin{array}{l}\text { Tot. wt. \% of } \\
\text { ea. species }\end{array}$} \\
\hline & $\begin{array}{c}\text { Cerium } \\
\text { Oxide Conc. }\end{array}$ & Magnetite & Potash & Soda Ash & Soil & & \\
\hline $\mathrm{Al} 2 \mathrm{O} 3$ & - & 60.65 & - & - & 969.18 & $1,029.83$ & 8.22 \\
\hline Ag2O & - & - & - & - & 0.08 & 0.08 & $6.39 \mathrm{e}-04$ \\
\hline As2O & - & - & - & - & 0.11 & 0.11 & $9.05 e-04$ \\
\hline $\mathrm{BaO}$ & - & - & - & - & 1.04 & 1.04 & $8.30 \mathrm{e}-03$ \\
\hline $\mathrm{CaCO} 3$ & - & - & - & - & $1,210.14$ & $1,210.14$ & 9.66 \\
\hline $\mathrm{CaO}$ & 3.05 & 7.08 & - & - & 10.43 & 20.55 & 0.16 \\
\hline $\mathrm{CdO}$ & - & - & - & - & $5.32 \mathrm{e}-03$ & $5.32 e-03$ & $4.24 \mathrm{e}-05$ \\
\hline $\mathrm{CeO} 2$ & 52.50 & - & - & - & 0.51 & 53.01 & 0.42 \\
\hline $\mathrm{Cr} 2 \mathrm{O} 3$ & - & 2.02 & - & - & 2.72 & 4.74 & 0.04 \\
\hline $\mathrm{Cs} 2 \mathrm{O}$ & - & - & - & - & 0.49 & 0.49 & $3.94 \mathrm{e}-03$ \\
\hline $\mathrm{CuO}$ & - & - & - & - & 0.52 & 0.52 & $4.19 e-03$ \\
\hline $\mathrm{Fe} 2 \mathrm{O} 3$ & - & - & - & 0.01 & - & 0.01 & $1.07 e-04$ \\
\hline $\mathrm{Fe} 3 \mathrm{O} 4$ & - & 762.14 & - & - & 393.65 & $1,155.80$ & 9.23 \\
\hline $\mathrm{H} 2 \mathrm{O}$ & 3.24 & - & 0.93 & 2.28 & 940.19 & 946.63 & 7.56 \\
\hline $\mathrm{HgO}$ & - & - & - & - & $1.01 \mathrm{e}-03$ & $1.01 e-03$ & $8.02 e-06$ \\
\hline $\mathrm{K} 2 \mathrm{CO} 3$ & - & - & 784.63 & - & - & 784.63 & 6.26 \\
\hline $\mathrm{KCl}$ & - & - & 0.04 & - & - & 0.04 & $3.14 e-04$ \\
\hline $\mathrm{K} 2 \mathrm{O}$ & - & - & - & - & 225.49 & 225.49 & 1.80 \\
\hline $\mathrm{KOH}$ & - & - & 0.55 & - & - & 0.55 & $4.39 e-03$ \\
\hline $\mathrm{K} 2 \mathrm{SO} 4$ & - & - & 0.05 & - & - & 0.05 & $3.77 e-04$ \\
\hline $\mathrm{MgO}$ & - & 13.14 & - & - & 211.50 & 224.64 & 1.79 \\
\hline $\mathrm{MnO}$ & - & 2.02 & - & - & - & 2.02 & 0.02 \\
\hline $\mathrm{Na} 2 \mathrm{CO} 3$ & - & - & - & $1,334.04$ & - & $1,334.04$ & 10.65 \\
\hline $\mathrm{NaCl}$ & - & - & - & 1.07 & - & 1.07 & $8.55 e-03$ \\
\hline $\mathrm{Na} 2 \mathrm{O}^{\circ}$ & - & - & - & - & 119.19 & 119.19 & 0.95 \\
\hline $\mathrm{Na} 2 \mathrm{SO} 4$ & - & - & - & 2.01 & - & 2.01 & 0.02 \\
\hline $\mathrm{NiO}$ & - & - & - & - & 0.40 & 0.40 & $3.22 \mathrm{e}-03$ \\
\hline $\mathrm{PO} 4$ & - & - & - & - & 27.12 & 27.12 & 0.22 \\
\hline $\mathrm{P} 2 \mathrm{O} 5$ & - & 0.40 & - & - & - & 0.40 & $3.23 e-03$ \\
\hline $\mathrm{PbO}$ & - & - & - & - & 0.23 & 0.23 & $1.84 e-03$ \\
\hline $\mathrm{SO} 4$ & 4.81 & - & - & - & 3.91 & 8.72 & 0.07 \\
\hline $\mathrm{SeO}$ & - & - & - & - & 0.01 & 0.01 & $8.94 e-05$ \\
\hline $\mathrm{SiO} 2$ & 3.21 & 48.52 & - & - & $5,376.60$ & $5,428.33$ & 43.34 \\
\hline $\mathrm{ThO} 2$ & 0.21 & - & - & - & - & 0.21 & $1.66 e-03$ \\
\hline TiO2 & - & 105.12 & - & - & 40.37 & 145.50 & 1.16 \\
\hline V2O5 & - & 7.08 & - & - & - & 7.08 & 0.06 \\
\hline $\mathrm{ZnO}$ & - & - & - & - & 1.27 & 1.27 & 0.01 \\
\hline $\mathrm{ZrO} 2$ & - & - & - & - & 1.26 & 1.26 & 0.01 \\
\hline $\mathrm{BaO}+\mathrm{SrO}$ & 5.77 & - & - & - & - & 5.77 & 0.05 \\
\hline As & - & - & $7.86 e-04$ & - & - & $7.86 e-04$ & $6.28 \mathrm{e}-06$ \\
\hline $\mathrm{Cl}$ & - & - & - & - & 0.37 & 0.37 & $2.97 e-03$ \\
\hline F & 7.37 & - & - & - & - & 7.37 & 0.06 \\
\hline $\mathrm{Fe}$ & - & - & $9.43 e-04$ & - & - & $9.43 e-04$ & $7.53 e-06$ \\
\hline $\mathrm{Hg}$ & - & - & $3.14 \mathrm{e}-05$ & - & - & $3.14 \mathrm{e}-05$ & $2.51 e-07$ \\
\hline $\mathrm{Pb}$ & - & - & $7.08 \mathrm{e}-03$ & - & - & $7.08 e-03$ & $5.65 e-05$ \\
\hline $\mathbf{S}$ & - & 2.02 & - & - & - & 2.02 & 0.02 \\
\hline Other & $-1.14 e-14$ & 0.61 & $1.12 \mathrm{e}-13$ & $-1.34 e-02$ & $-2.28 \mathrm{e}+02$ & $-2.27 e+02$ & $-1.82 e+00$ \\
\hline Total & 80.15 & $1,010.80$ & 786.20 & $1,339.40$ & $9,308.80$ & $12,525.35$ & 100.00 \\
\hline
\end{tabular}




\begin{tabular}{|c|c|c|c|c|c|c|c|c|c|}
\hline 00.001 & $86^{\circ} 86 I^{\prime} S I$ & SLOS6 & $8 E Z Z L^{\circ} I$ & $0880 \varepsilon^{\prime} 6$ & $00^{\circ} 6 \varepsilon \varepsilon^{\prime} I$ & $0 \tau^{\circ} 98 \mathrm{~L}$ & $08^{\circ} 010^{6} \mathrm{I}$ & SI08 & [E1OL \\
\hline $00+\partial b^{\circ} l^{-}$ & $z 0+\partial E Z z-$ & $00+2008^{-}$ & $90 \% \mathrm{II}$ & $z 0+\partial 8 z z^{\circ}$ & $20^{-\partial}+E^{\circ} I^{-}$ & $\mathcal{E I} \cdot a Z I^{\circ} \mathrm{I}$ & $19^{\circ} 0$ & $t\left[-\partial t I^{\prime} I^{-}\right.$ & ІәЧमО \\
\hline 100 & $20 \tau$ & - & - & - & - & - & $20 z$ & - & $s$ \\
\hline $50-299^{\circ}$ & $\varepsilon 0^{-} \partial 80^{\circ} \mathrm{L}$ & - & - & - & - & $\varepsilon 0-280^{\circ} \mathrm{L}$ & - & - & qd \\
\hline$\angle 0^{-} \angle O^{\circ} Z$ & $\varsigma 0^{-ə}+I^{\circ} \varepsilon$ & - & - & - & - & $s 0^{-\partial \phi I^{-} \varepsilon}$ & - & - & 8H \\
\hline $90-21 \tau \cdot 9$ & $\downarrow 0-\partial \varepsilon t \cdot 6$ & - & - & - & - & $t 0^{-a \varepsilon t} 6$ & - & - & $\partial_{\mathbf{H}}$ \\
\hline so.0 & $\angle E L$ & - & - & - & - & $\cdot$ & - & $\angle E L$ & 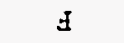 \\
\hline$\varepsilon 0^{-2} s t^{\prime} \tau$ & LEO & - & - & $\angle E^{*} 0$ & $\cdot$ & - & - & - & 10 \\
\hline $90^{-0} \mathrm{LI} \cdot S$ & $70-298^{\circ} \mathrm{L}$ & - & - & - & - & $70-298^{\circ} \mathrm{L}$ & - & - & SP \\
\hline$\$ 0^{\prime} 0$ & $L L S S$ & $\cdot$ & - & - & - & - & - & $\angle L S S$ & ors+org \\
\hline$\varepsilon 0^{-a}<\tau \cdot 8$ & $9 Z^{*} I$ & - & - & $9 Z^{*} \mathrm{I}$ & - & - & - & $\cdot$ & zorz \\
\hline$\varepsilon 0^{-2} 6 \varepsilon 8$ & $L Z^{\prime} I$ & - & - & $L Z I$ & - & - & - & - & $\mathrm{O}^{4} \mathrm{Z}$ \\
\hline So.0 & $80^{\circ} \mathrm{L}$ & - & - & $\cdot$ & - & - & $80^{\circ} \mathrm{L}$ & - & 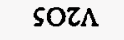 \\
\hline 960 & OSSTI & - & - & $\angle E^{\circ} O D$ & - & - & ZI`SOI & - & ZO!I \\
\hline$\varepsilon 0^{-\partial} \angle E I$ & 120 & $\cdot$ & - & $\cdot$ & - & $\cdot$ & $\cdot$ & I 20 & 2041 \\
\hline EL'SE & 9EOEt'S & $\varepsilon 0 \tau$ & - & $09^{\circ} 9 L E^{\star} \varsigma$ & - & - & $258 t$ & $I \tau \cdot \varepsilon$ & ZO!S \\
\hline SO-วLEL & $10^{\circ} 0$ & - & - & 100 & - & - & - & $\cdot$ & $\mathrm{O}^{2} \mathrm{~S}$ \\
\hline $90^{\circ} 0$ & $\tau L 8$ & $\cdot$ & - & $16 \varepsilon$ & - & - & - & $18^{\circ} t$ & tOS \\
\hline E0-əZS'I & $\varepsilon \tau^{\circ} 0$ & - & - & $\varepsilon \tau^{\circ} 0$ & - & - & - & - & Oqd \\
\hline $\mathcal{E} 0^{-399} Z$ & 0,0 & - & - & - & - & - & $0 b^{\circ} 0$ & - & sozd \\
\hline $8 I^{\circ} 0$ & $\varepsilon S: \angle \tau$ & $I+0$ & - & $2 I \% Z$ & - & $\cdot$ & - & - & tOd \\
\hline $10^{\circ} 0$ & $\tau \tau \cdot \tau$ & I8. I & - & $0+0$ & - & - & - & - & $\mathrm{OIN}$ \\
\hline $10^{\circ} 0$ & $10 z$ & - & - & - & $10 \%$ & - & - & - & tOSceN \\
\hline $8 L^{\circ} 0$ & $6 I \% 6 I I$ & - & - & $6 I^{\circ} 61 \mathrm{I}$ & - & - & - & - & OZEN \\
\hline $\mathrm{EO}^{-2} \mathrm{SO}^{\circ} \mathrm{L}$ & $\angle 0^{\circ} I$ & - & - & - & $\angle 0^{\circ} I$ & - & - & - & IDEN \\
\hline $8 L \cdot 8$ & 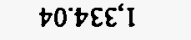 & - & - & - & $\neg 0^{\circ} \downarrow \varepsilon \varepsilon^{c} t$ & - & - & - & EOJZEN \\
\hline $50^{\circ} 0$ & $Z I \cdot 8$ & 2188 & - & $\cdot$ & - & - & - & - & roun \\
\hline $10^{\circ} 0$ & $20 \tau$ & - & - & - & - & - & $20 \tau$ & - & OUW \\
\hline $8 b^{\circ} I$ & $79^{\circ}+\tau \tau$ & $\cdot$ & $\cdot$ & OStII & $\cdot$ & $\cdot$ & $\diamond I^{\circ} \varepsilon I$ & - & ంశพ \\
\hline 110 & $\tau \tau \cdot L I$ & - & $\tau \tau \cdot L I$ & $\cdot$ & - & - & - & - & EOJ ${ }^{8} \mathrm{~N}$ \\
\hline 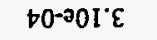 & 500 & - & - & - & - & SO० & - & - & $\operatorname{tOSCX}$ \\
\hline$\varepsilon 0^{-\partial Z 9^{\circ} \varepsilon}$ & $\$ S^{\circ} 0$ & - & - & - & - & $55^{\circ} 0$ & - & $\cdot$ & HOX \\
\hline $8 b^{\circ} I$ & $6 b^{\circ} 522$ & - & - & $6 t^{\circ} 5 Z Z$ & - & - & - & - & OZX \\
\hline$t 0-265 \tau$ & 700 & - & - & - & - & $\$ 00$ & - & - & IDX \\
\hline $9 I^{\prime} S$ & $\varepsilon 9^{\circ} \sqcup 8 L$ & - & - & - & - & $\varepsilon 9^{\circ} \downarrow 8 L$ & - & - & EOOZX \\
\hline $90^{-2}[9 \cdot 9$ & $\varepsilon 0^{-\partial I 0}$ I & - & - & E0-OI0'โ & $\cdot$ & - & - & - & $\mathrm{O}^{8} \mathrm{H}$ \\
\hline $92^{\circ} 9$ & $08^{\circ}$ IS 6 & - & $\angle I^{\prime} S$ & $610+6$ & 827 & $\varepsilon 60$ & - & $\nabla \tau \cdot \varepsilon$ & $\mathrm{OZH}$ \\
\hline $08^{\circ} \mathrm{EI}$ & $\angle 8^{\circ} \angle 60^{\circ} Z$ & $80 \tau \nvdash 6$ & - & $\$ 9^{\circ} \varepsilon 6 \varepsilon$ & - & - & bI Z9L & - & †OE्A \\
\hline $50^{-2} 18.8$ & 100 & - & - & $\cdot$ & 100 & - & - & - & દOZə] \\
\hline 200 & $\tau 9^{\circ} \varepsilon$ & $60^{\circ} \varepsilon$ & - & $\tau S^{\circ} 0$ & - & - & - & - & ono \\
\hline$\varepsilon 0-ə \varsigma \tau / \varepsilon$ & $6 t^{\circ} 0$ & - & - & $6 t^{\circ} 0$ & - & - & - & - & orso \\
\hline 50.0 & 76.5 & $0 Z^{*} I$ & - & $\tau L Z$ & - & - & $20 \tau$ & - & عOZد \\
\hline SEO & I0ES & - & - & 150 & - & - & - & $0 s z s$ & 2003 \\
\hline SO-20S'E & 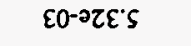 & - & - & દ0-əحદऽ $\varsigma$ & - & - & - & - & OPO \\
\hline$t t^{\circ} 0$ & $\$ 502$ & $\cdot$ & $\cdot$ & Et0I & - & - & $80 \mathrm{~L}$ & $\varsigma 0^{\circ} \varepsilon$ & OPO \\
\hline$\angle 0^{\circ} 61$ & $\angle 0^{\circ} 868^{\circ} \mathrm{Z}$ & - & $\varepsilon 6^{\circ} \angle 89^{\circ}$ I & $t I^{\circ} 0 I z^{*} !$ & - & - & - & - & عOว \\
\hline$\varepsilon 0-56899$ & $\$ 0 . I$ & - & - & $\$ 0^{\circ} I$ & - & - & - & - & org \\
\hline$\checkmark 0^{-2960} L$ & I I 0 & - & - & II 0 & - & - & - & - & OzS \\
\hline t0-29г's & $80^{\circ} 0$ & - & - & $80^{\circ} 0$ & - & - & - & - & OzôV \\
\hline $8 \angle \circ 9$ & $\mathrm{E}^{\prime} 620^{\circ} \mathrm{I}$ & - & - & $81 \cdot 696$ & - & - & $\$ 9.09$ & - & EOZIV \\
\hline \multirow{3}{*}{ 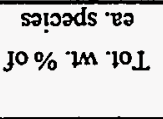 } & (q) sə!ords & शЕOS II!W & 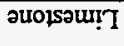 & I!os & पş epos & 4SEYOd & 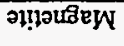 & 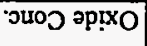 & \multirow{3}{*}{ sə!̣ads } \\
\hline & שa jo -jure 70.L & \multirow{2}{*}{\multicolumn{7}{|c|}{ 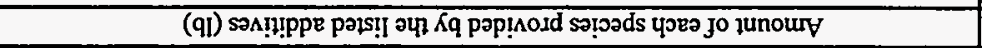 }} & \\
\hline & & & & & & & & & \\
\hline
\end{tabular}


Table G-2-5. N80-IV surrogate waste mixture composition.

\begin{tabular}{|c|c|c|c|c|c|c|c|c|c|}
\hline \multirow{2}{*}{ Species } & \multicolumn{7}{|c|}{ Amount of each species provided by the listed additives (lb) } & \multirow[b]{2}{*}{$\begin{array}{l}\text { Tot amt. of ea. } \\
\text { species (lb) }\end{array}$} & \multirow[b]{2}{*}{$\begin{array}{l}\text { Tot. wt. \% of } \\
\text { ea. species }\end{array}$} \\
\hline & $\begin{array}{c}\text { Cerium } \\
\text { Oxide Conc. }\end{array}$ & Ilmenite & Magnetite & Potash & Soda Ash & Soil & Zirconia & & \\
\hline $\mathrm{Al2O3}$ & - & 7.83 & 33.82 & - & - & 855.22 & 1.90 & 898.77 & 7.17 \\
\hline Ag2O & - & $\cdot$ & - & - & - & 0.07 & - & 0.07 & $5.63 \mathrm{e}-04$ \\
\hline As2O & - & - & - & - & - & 0.10 & - & 0.10 & $7.97 \mathrm{e}-04$ \\
\hline $\mathrm{BaO}$ & - & - & - & - & - & 0.92 & - & 0.92 & $7.31 \mathrm{e}-03$ \\
\hline $\mathrm{CaCO} 3$ & - & - & - & - & - & $1,067.86$ & - & $1,067.86$ & 8.51 \\
\hline $\mathrm{CaO}$ & 3.05 & 0.34 & 3.95 & - & - & 9.20 & 0.13 & 16.66 & 0.13 \\
\hline $\mathrm{CdO}$ & - & - & - & - & - & $4.69 \mathrm{e}-03$ & - & $4.69 e-03$ & $3.74 e-05$ \\
\hline $\mathrm{CeO} 2$ & 52.50 & - & - & - & - & 0.45 & - & 52.95 & 0.42 \\
\hline $\mathrm{Cr} 2 \mathrm{O} 3$ & - & 1.90 & 1.13 & - & - & 2.40 & - & 5.43 & 0.04 \\
\hline $\mathrm{Cs} 2 \mathrm{O}$ & - & - & - & - & - & 0.44 & - & 0.44 & $3.47 e-03$ \\
\hline $\mathrm{CuO}$ & - & - & - & - & - & 0.46 & - & 0.46 & $3.69 e-03$ \\
\hline $\mathrm{Fe} 2 \mathrm{O} 3$ & - & 335.30 & - & - & 0.01 & - & 0.13 & 335.45 & 2.67 \\
\hline $\mathrm{Fe} 3 \mathrm{O} 4$ & - & - & 425.03 & - & - & 347.37 & - & 772.40 & 6.16 \\
\hline $\mathrm{H} 2 \mathrm{O}$ & 3.24 & 25.17 & - & 0.93 & 2.28 & 829.64 & - & 861.26 & 6.87 \\
\hline $\mathrm{HfO}_{2}$ & - & - & - & - & - & - & 8.03 & 8.03 & 0.06 \\
\hline $\mathrm{HgO}$ & - & - & - & - & - & $8.87 e-04$ & - & $8.87 e-04$ & $7.07 e-06$ \\
\hline $\mathrm{K} 2 \mathrm{CO} 3$ & - & - & - & 784.63 & - & - & - & 784.63 & 6.26 \\
\hline $\mathrm{KCl}$ & - & - & - & 0.04 & - & - & - & 0.04 & $3.13 e-04$ \\
\hline $\mathrm{K} 2 \mathrm{O}$ & - & - & - & - & - & 198.98 & - & 198.98 & 1.59 \\
\hline $\mathrm{KOH}$ & - & - & - & 0.55 & - & - & - & 0.55 & $4.39 \mathrm{e}-03$ \\
\hline $\mathrm{K} 2 \mathrm{SO} 4$ & - & - & - & 0.05 & - & - & - & 0.05 & $3.76 \mathrm{e}-04$ \\
\hline $\mathrm{MgCO} 3$ & - & - & - & - & - & - & - & - & - \\
\hline $\mathrm{MgO}$ & - & 2.46 & 7.33 & - & - & 186.63 & 0.04 & 196.47 & 1.57 \\
\hline MnO & - & 13.87 & 1.13 & - & - & - & - & 15.00 & 0.12 \\
\hline $\mathrm{MnO} 2$ & - & - & - & - & - & - & - & - & - \\
\hline $\mathrm{Na} 2 \mathrm{CO} 3$ & - & - & - & - & $1,334.04$ & - & - & $1,334.04$ & 10.64 \\
\hline $\mathrm{NaCl}$ & - & - & - & - & 1.07 & - & - & 1.07 & $8.54 e-03$ \\
\hline $\mathrm{Na} 2 \mathrm{O}$ & - & - & - & - & - & 105.18 & 0.26 & 105.44 & 0.84 \\
\hline $\mathrm{Na} 2 \mathrm{SO} 4$ & - & - & - & - & 2.01 & - & - & 2.01 & 0.02 \\
\hline $\mathrm{NiO}$ & - & - & - & - & - & 0.36 & - & 0.36 & $2.83 e-03$ \\
\hline PO4 & - & - & - & - & - & 23.93 & - & 23.93 & 0.19 \\
\hline P2O5 & - & 1.01 & 0.23 & - & - & - & - & 1.23 & $9.82 e-03$ \\
\hline Pbo & - & - & - & - & - & 0.20 & - & 0.20 & $1.62 \mathrm{e}-03$ \\
\hline $\mathrm{SO} 4$ & 4.81 & - & - & - & - & 3.45 & - & 8.26 & 0.07 \\
\hline $\mathrm{SeO}$ & - & - & - & - & - & $9.88 \mathrm{e}-03$ & - & $9.88 \mathrm{e}-03$ & $7.88 \mathrm{e}-05$ \\
\hline $\mathrm{SiO} 2$ & 3.21 & 2.91 & 27.06 & - & - & $4,744.44$ & 8.60 & $4,786.21$ & 38.16 \\
\hline ThO2 & 0.21 & - & - & - & - & - & - & 0.21 & $1.66 \mathrm{e}-03$ \\
\hline $\mathrm{TiO}_{2}$ & - & 724.98 & 58.62 & - & - & 35.63 & 1.19 & 820.42 & 6.54 \\
\hline $\mathrm{V} 2 \mathrm{O} 3$ & - & 2.57 & - & - & - & - & - & 2.57 & 0.02 \\
\hline v205 & - & - & 3.95 & - & - & - & - & 3.95 & 0.03 \\
\hline $\mathrm{Y} 203$ & - & - & - & - & - & - & 0.66 & 0.66 & $5.27 e-03$ \\
\hline $\mathrm{ZnO}$ & - & - & - & - & - & 1.12 & - & 1.12 & $8.97 \mathrm{e}-03$ \\
\hline $\mathrm{ZrO} 2$ & - & 0.45 & - & - & - & 1.11 & 419.97 & 421.53 & 3.36 \\
\hline $\mathrm{BaO}+\mathrm{SrO}$ & 5.77 & - & - & - & - & - & - & 5.77 & 0.05 \\
\hline As & - & - & - & $7.86 e-04$ & - & - & - & $7.86 e-04$ & $6.27 e-06$ \\
\hline $\mathrm{Cl}$ & - & - & - & - & - & 0.33 & - & 0.33 & $2.62 e-03$ \\
\hline $\mathbf{F}$ & 7.37 & - & - & - & - & - & - & 7.37 & 0.06 \\
\hline $\mathrm{Fe}$ & - & - & - & $9.43 e-04$ & - & - & - & $9.43 e-04$ & $7.52 e-06$ \\
\hline $\mathrm{Hg}$ & - & - & - & $3.14 \mathrm{e}-05$ & - & - & - & $3.14 \mathrm{e}-0 \mathrm{~S}$ & $2.51 \mathrm{e}-07$ \\
\hline $\mathrm{Pb}$ & - & - & - & $7.08 \mathrm{e}-03$ & - & - & - & $7.08 \mathrm{e}-03$ & $5.64 e-05$ \\
\hline $\mathbf{s}$ & - & - & 1.13 & - & - & - & - & 1.13 & $8.99 e-03$ \\
\hline Th & - & - & - & - & - & - & 0.07 & 0.07 & $5.63 \mathrm{e}-04$ \\
\hline $\mathbf{u}$ & - & - & - & - & - & - & 0.11 & 0.11 & $8.44 e-04$ \\
\hline Other & $-1.14 e-14$ & - & 0.34 & $1.12 \mathrm{e}-13$ & $-1.34 \mathrm{e}-02$ & $-2.01 \mathrm{e}+02$ & - & $-2.01 e+02$ & $-1.60 e+00$ \\
\hline Total & 80.15 & $1,118.80$ & 563.70 & 786.20 & $1,339.40$ & $8,214.30$ & 441.10 & $12,543.65$ & 100.00 \\
\hline
\end{tabular}


Table G-2-6. N80-IV-Mod surrogate waste mixture composition.

\begin{tabular}{|c|c|c|c|c|c|c|c|c|c|c|c|}
\hline \multirow[b]{2}{*}{ Species } & \multicolumn{9}{|c|}{ Amount of each species provided by the listed additives (lb) } & \multirow{2}{*}{$\begin{array}{l}\text { Tot. amt. of } \\
\text { ea. species } \\
\text { (lb) }\end{array}$} & \multirow{2}{*}{$\begin{array}{l}\text { Tot. wt. \% } \\
\text { of each } \\
\text { species }\end{array}$} \\
\hline & $\begin{array}{c}\text { Cerium } \\
\text { Oxide Cone. }\end{array}$ & Ilmenite & Magnetite & Potash & Soda Ash & Soil & Zirconia & ebble Lim & Mill Scale & & \\
\hline $\mathrm{Al} 2 \mathrm{O3}$ & - & 7.83 & 33.82 & - & - & 855.22 & 1.90 & 3.91 & - & 902.68 & 6.14 \\
\hline Ag2O & - & - & - & - & - & 0.07 & - & - & - & 0.07 & $4.80 c-04$ \\
\hline As2O & - & - & - & - & - & 0.10 & - & - & - & 0.10 & $6.81 e-04$ \\
\hline $\mathrm{BaO}$ & - & - & - & - & - & 0.92 & - & - & - & 0.92 & $6.24 c-03$ \\
\hline $\mathrm{CO} 2$ & - & - & - & - & - & - & - & - & - & - & 0.00 \\
\hline $\mathrm{CaCO} 3$ & - & - & - & - & - & $1,067.86$ & - & 18.29 & - & $1,086.15$ & 7.39 \\
\hline $\mathrm{CaO}$ & 3.05 & 0.34 & 3.95 & - & - & 9.20 & 0.13 & $1,038.68$ & - & $1,055.34$ & 7.18 \\
\hline $\mathrm{CdO}$ & - & - & - & - & - & $4.69 \mathrm{e}-03$ & - & - & - & $4.69 e-03$ & $3.19 e-05$ \\
\hline $\mathrm{CeO} 2$ & 52.50 & - & - & - & - & 0.45 & - & - & - & 52.95 & 0.36 \\
\hline $\mathrm{Cr} 2 \mathrm{O} 3$ & - & 1.90 & 1.13 & - & - & 2.40 & - & - & 1.30 & 6.73 & 0.05 \\
\hline Cs2O & - & - & - & - & - & 0.44 & - & - & - & 0.44 & $2.96 \mathrm{e}-03$ \\
\hline $\mathrm{CuO}$ & - & - & - & - & - & 0.46 & - & - & 3.36 & 3.82 & 0.03 \\
\hline $\mathrm{Fe} 2 \mathrm{O} 3$ & - & 335.30 & - & - & 0.01 & - & 0.13 & 0.89 & - & 336.34 & 2.29 \\
\hline $\mathrm{Fe} 3 \mathrm{O} 4$ & - & - & 425.03 & - & - & 347.37 & - & - & $1,022.69$ & $1,795.09$ & 12.22 \\
\hline $\mathrm{H} 2 \mathrm{O}$ & 3.24 & 25.17 & - & 0.93 & 2.28 & 829.64 & - & 38.55 & - & 899.81 & 6.12 \\
\hline $\mathrm{HfO} 2$ & - & - & - & - & - & - & 8.03 & - & - & 8.03 & 0.05 \\
\hline $\mathrm{HgO}$ & - & - & - & - & - & $8.87 e-04$ & - & - & - & $8.87 e-04$ & $6.04 e-06$ \\
\hline $\mathrm{K} 2 \mathrm{CO} 3$ & - & - & - & 784.63 & - & - & - & - & - & 784.63 & 5.34 \\
\hline $\mathrm{KCl}$ & - & - & - & 0.04 & - & - & - & - & - & 0.04 & $2.68 c-04$ \\
\hline $\mathrm{K} 20$ & - & - & - & - & - & 198.98 & - & - & - & 198.98 & 1.35 \\
\hline $\mathrm{KOH}$ & - & - & - & 0.55 & - & - & - & - & - & 0.55 & $3.75 e-03$ \\
\hline $\mathrm{K} 2 \mathrm{SO} 4$ & - & - & - & 0.05 & - & - & - & - & - & 0.05 & $3.21 e-04$ \\
\hline $\mathrm{MgO}$ & - & 2.46 & 7.33 & - & - & 186.63 & 0.04 & 4.47 & - & 200.93 & 1.37 \\
\hline $\mathrm{MnO}$ & - & 13.87 & 1.13 & - & - & - & - & - & - & 15.00 & 0.10 \\
\hline $\mathrm{MnO} 2$ & - & - & - & - & - & - & - & 0.56 & 8.82 & 9.38 & 0.06 \\
\hline $\mathrm{Na} 2 \mathrm{CO} 3$ & - & - & - & - & $1,334.04$ & - & - & - & - & $1,334.04$ & 9.08 \\
\hline $\mathrm{NaCl}$ & - & - & - & - & 1.07 & - & - & - & - & 1.07 & $7.29 e-03$ \\
\hline $\mathrm{Na} 2 \mathrm{O}$ & - & - & - & - & - & 105.18 & 0.26 & 0.34 & - & 105.78 & 0.72 \\
\hline $\mathrm{Na} 2 \mathrm{SO} 4$ & - & - & - & - & 2.01 & - & - & - & - & 2.01 & 0.01 \\
\hline $\mathrm{NiO}$ & - & - & - & - & - & 0.36 & - & - & 1.97 & 2.33 & 0.02 \\
\hline $\mathrm{PO} 4$ & - & - & - & - & - & 23.93 & - & - & 0.44 & 24.37 & 0.17 \\
\hline P2O5 & - & 1.01 & 0.23 & - & - & - & - & 0.22 & - & 1.46 & $9.91 e-03$ \\
\hline $\mathrm{PbO}$ & - & - & - & - & - & 0.20 & - & - & - & 0.20 & $1.39 c-03$ \\
\hline $\mathrm{SO} 3$ & - & - & - & - & - & - & - & 1.68 & - & 1.68 & 0.01 \\
\hline $\mathrm{SO} 4$ & 4.81 & - & - & - & - & 3.45 & - & - & - & 8.26 & 0.06 \\
\hline $\mathrm{SeO}$ & - & - & - & - & - & $9.88 c-03$ & - & - & - & $9.88 c-03$ & $6.72 e-05$ \\
\hline $\mathrm{SiO} 2$ & 3.21 & 2.91 & 27.06 & - & - & $4,744.44$ & 8.60 & 8.38 & 2.21 & $4,796.80$ & 32.65 \\
\hline ThO2 & 0.21 & - & - & - & - & - & - & - & - & 0.21 & $1.42 e-03$ \\
\hline $\mathrm{TiO} 2$ & - & 724.98 & 58.62 & - & - & 35.63 & 1.19 & 0.56 & - & 820.98 & 5.59 \\
\hline V2O3 & - & 2.57 & - & - & . & - & - & - & - & 2.57 & 0.02 \\
\hline V2OS & - & - & 3.95 & - & - & - & - & - & - & 3.95 & 0.03 \\
\hline $\mathrm{Y} 2 \mathrm{O} 3$ & - & - & - & - & - & - & 0.66 & - & - & 0.66 & $4.50 e-03$ \\
\hline $\mathrm{ZnO}$ & - & - & - & - & - & 1.12 & - & - & - & 1.12 & $7.66 e-03$ \\
\hline $\mathrm{ZrO} 2$ & - & 0.45 & - & - & - & 1.11 & 419.97 & - & - & 421.53 & 2.87 \\
\hline $\mathrm{BaO}+\mathrm{SrO}$ & 5.77 & - & - & - & - & - & - & - & - & 5.77 & 0.04 \\
\hline As & - & - & - & $7.86 e-04$ & - & - & - & $2.23 c-03$ & - & $3.02 e-03$ & $2.06 e-05$ \\
\hline $\mathrm{Cl}$ & - & - & - & - & - & 0.33 & - & - & - & 0.33 & $2.24 c-03$ \\
\hline $\mathbf{F}$ & 7.37 & - & - & - & - & - & - & 0.34 & - & 7.71 & 0.05 \\
\hline Fe & - & - & - & $9.43 e-04$ & - & - & - & - & - & $9.43 e-04$ & $6.42 e-06$ \\
\hline $\mathrm{Hg}$ & - & . & - & $3.14 \mathrm{e}-05$ & - & - & - & - & - & $3.14 c-05$ & $2.14 e-07$ \\
\hline $\mathrm{Pb}$ & - & - & - & $7.08 \mathrm{e}-03$ & - & - & - & $5.58 e-03$ & - & 0.01 & $8.62 e-05$ \\
\hline$s$ & - & - & 1.13 & - & - & - & - & - & - & 1.13 & $7.67 c-03$ \\
\hline Th & - & - & - & - & - & - & 0.07 & - & - & 0.07 & $4.80 c-04$ \\
\hline$U$ & - & - & - & - & - & - & 0.11 & - & - & 0.11 & $7.21 e-04$ \\
\hline Other & $-1.14 e-14$ & - & 0.34 & $1.12 e-13$ & $-1.34 e-02$ & $-2.01 e+02$ & - & $3.05 e-04$ & $-8.68 e+00$ & $-2.10 e+02$ & $-1.43 e+00$ \\
\hline Total & 80.15 & $1,118.80$ & 563.70 & 786.20 & $1,339.40$ & $8,214.30$ & 441.10 & $1,116.86$ & $1,032.10$ & $14,692.62$ & 100.00 \\
\hline
\end{tabular}


Table G-2-7. M60 surrogate waste mixture composition.

\begin{tabular}{|c|c|c|c|c|c|c|c|c|c|c|c|c|}
\hline \multirow[b]{2}{*}{ Species } & \multicolumn{10}{|c|}{ Amount of each species provided by the listed additives (b) } & \multirow{2}{*}{$\begin{array}{c}\text { Tot. amt. of ca } \\
\text { species (lb) }\end{array} \mid$} & \multirow{2}{*}{$\begin{array}{l}\text { Tot. wt. \% of } \\
\text { ca. species }\end{array}$} \\
\hline & CeO2 Conc. & Mullite & Soil & Wollastonite & Aluminum & Copper & Iron & Lead & Stainless & Zinc & & \\
\hline Al2O3 & $\cdot$ & 112.87 & 748.02 & 2.90 & - & - & - & - & - & - & 863.78 & 7.57 \\
\hline $\mathrm{Ag} 2 \mathrm{O}$ & - & - & 0.06 & - & - & - & - & - & - & - & 0.06 & $5.41 e-04$ \\
\hline As2O & - & - & 0.09 & - & - & - & - & - & - & - & 0.09 & $7.67 e-04$ \\
\hline $\mathrm{BaO}$ & - & 0.09 & 0.80 & - & - & - & - & - & - & - & 0.89 & $7.85 e-03$ \\
\hline $\mathrm{CO} 2$ & - & - & - & - & - & - & - & - & - & - & - & - \\
\hline $\mathrm{CaCO} 3$ & - & - & 934.00 & 0.58 & - & - & - & - & - & - & 934.58 & 8.20 \\
\hline $\mathrm{CaO}$ & 3.05 & - & 8.05 & 136.11 & - & - & - & - & - & - & 147.20 & 1.29 \\
\hline CdO & - & - & $4.10 e-03$ & - & - & - & - & - & - & $-\cdot$ & $4.10 c-03$ & $3.60 e-05$ \\
\hline $\mathrm{CeO}$ & - & 0.05 & - & - & - & - & - & - & - & - & 0.05 & $4.06 e-04$ \\
\hline $\mathrm{CeO} 2$ & 52.50 & - & 0.40 & - & - & - & - & - & - & - & 52.90 & 0.46 \\
\hline $\mathrm{Cr} 2 \mathrm{O} 3$ & $=$ & - & 2.10 & - & - & - & - & - & - & - & 2.10 & 0.02 \\
\hline Cs2O & - & - & 0.38 & - & - & - & - & - & - & - & 0.38 & $3.34 e-03$ \\
\hline CuO & - & - & 0.40 & - & - & - & - & - & - & - & 0.40 & $3.550-03$ \\
\hline $\mathrm{Fe} 2 \mathrm{O} 3$ & - & 0.71 & - & 1.45 & - & - & - & - & - & - & 2.16 & 0.02 \\
\hline $\mathrm{Fe} 3 \mathrm{O} 4$ & - & - & 303.83 & - & - & - & - & - & - & - & 303.83 & 2.66 \\
\hline $\mathrm{H} 2 \mathrm{O}$ & 3.24 & - & 725.64 & 0.58 & - & - & - & - & - & - & 729.46 & 6.40 \\
\hline $\mathrm{HgO}$ & - & - & $7.76 e-04$ & - & - & - & - & - & - & - & $7.76 e-04$ & $6.80 e-06$ \\
\hline $\mathrm{K} 2 \mathrm{O}$ & - & 1.20 & 174.03 & - & - & - & - & - & - & - & 175.24 & 1.54 \\
\hline $\mathrm{MgO}$ & - & 0.20 & 163.24 & 0.87 & - & - & - & - & - & - & 164.31 & 1.44 \\
\hline $\mathrm{MnO}$ & - & - & - & 0.29 & - & - & - & - & - & - & 0.29 & $2.54 e-03$ \\
\hline $\mathrm{Na} 2 \mathrm{O}$ & - & 0.43 & 91.99 & - & - & - & - & - & - & - & 92.43 & 0.81 \\
\hline NiO & - & - & 0.31 & - & - & - & - & - & - & - & 0.31 & $2.73 e-03$ \\
\hline $\mathrm{O} 2$ & - & - & - & - & - & $2.52 e-06$ & - & - & - & - & $2.52 e-06$ & $2.21 c-08$ \\
\hline PO4 & - & - & 20.93 & - & - & - & - & - & - & - & 20.93 & 0.18 \\
\hline $\mathrm{PbO}$ & - & - & 0.18 & - & - & - & - & - & - & - & 0.18 & $1.56 e-03$ \\
\hline $\mathrm{SO} 3$ & - & - & - & - & - & - & - & - & - & - & - & - \\
\hline SO4 & 4.81 & - & 3.02 & - & - & - & - & - & - & - & 7.83 & 0.07 \\
\hline $\mathrm{SeO}$ & - & - & $8.64 c-03$ & - & - & - & - & - & - & - & $8.64 e-03$ & $7.58 e-05$ \\
\hline $\mathrm{SiO} 2$ & 3.21 & 38.60 & $4,149.70$ & 144.80 & - & - & - & - & - & - & $4,336.31$ & 38.03 \\
\hline Sro & - & 0.02 & - & - & - & - & - & - & - & - & 0.02 & $1.35 e-04$ \\
\hline ThO2 & 0.21 & - & - & - & - & - & - & - & - & - & 0.21 & $1.83 e-03$ \\
\hline $\mathrm{TiO} 2$ & - & 0.20 & 31.16 & 0.14 & - & - & - & - & - & - & 31.50 & 0.28 \\
\hline $\mathrm{ZnO}$ & - & - & 0.98 & - & - & - & - & - & - & - & 0.98 & $8.63 e-03$ \\
\hline $\mathrm{ZrO} 2$ & - & - & 0.97 & - & - & - & - & - & - & - & 0.97 & $8.51 e-03$ \\
\hline $\mathrm{BaO}+\mathrm{SrO}$ & 5.77 & - & - & - & - & - & - & - & - & - & 5.77 & 0.05 \\
\hline $\mathrm{Ag}$ & - & - & - & - & - & $1.18 e-03$ & - & - & - & - & $1.18 e-03$ & $1.03 c-05$ \\
\hline Al & - & - & - & - & 210.00 & - & - & - & - & - & 210.00 & 1.84 \\
\hline As & - & - & - & - & - & $8.40 c-05$ & - & - & - & - & $8.40 e-05$ & 7.37e-07 \\
\hline $\mathrm{Bi}$ & - & - & - & - & - & $2.52 e-05$ & - & - & - & - & $2.52 \pi-05$ & $2.21 c-07$ \\
\hline c & - & - & - & - & - & - & 0.02 & - & 0.30 & - & 0.32 & $2.81 e-03$ \\
\hline $\mathrm{Cl}$ & - & - & 0.29 & - & - & - & - & - & - & - & 0.29 & $2.52 e-03$ \\
\hline $\mathrm{Cr}$ & - & - & - & - & - & - & - & - & 194.93 & - & 194.93 & 1.71 \\
\hline $\mathrm{Cu}$ & - & - & - & - & - & 83.97 & - & - & - & - & 83.97 & 0.74 \\
\hline $\mathbf{F}$ & 7.37 & - & - & - & - & - & - & - & - & - & 7.37 & 0.06 \\
\hline $\mathrm{Fc}$ & - & - & - & - & - & $8.40 c-05$ & $2,100.37$ & - & 734.14 & - & $2,834.51$ & 24.86 \\
\hline $\mathrm{Mn}$ & - & - & - & - & - & - & 0.02 & - & - & - & 0.02 & $1.840-04$ \\
\hline $\mathbf{N}$ & - & - & - & - & - & - & - & - & 0.20 & - & 0.20 & $1.75 e-03$ \\
\hline $\mathrm{Ni}$ & - & - & - & - & - & $1.01 e-03$ & 0.21 & - & 108.99 & - & 109.20 & 0.96 \\
\hline 0 & - & - & - & - & - & - & 0.21 & - & 0.77 & - & 0.98 & $8.55 e-03$ \\
\hline $\mathbf{P}$ & - & - & - & - & - & - & 0.02 & - & 0.21 & - & 0.23 & $1.99 e-03$ \\
\hline $\mathrm{Pb}$ & - & - & - & - & - & - & - & 84.00 & - & - & 84.00 & 0.74 \\
\hline $\mathbf{s}$ & - & - & - & - & - & $5.04 e-04$ & 0.03 & - & 0.07 & - & 0.11 & $9.24 c-04$ \\
\hline Sb & - & - & - & - & - & $1.68 \mathrm{c}-04$ & - & - & - & - & $1.68 e-04$ & $1.47 e-06$ \\
\hline Se & - & - & - & - & - & $8.40 c-05$ & - & - & - & - & $8.40 e-05$ & 7.37e-07 \\
\hline $\mathrm{Si}$ & - & - & - & 1.45 & - & - & 0.05 & - & 8.38 & - & 9.88 & 0.09 \\
\hline Sn & - & - & - & - & - & $3.36 \mathrm{e}-04$ & - & - & - & - & $3.36 e-04$ & $2.95 e-06$ \\
\hline Te & - & - & - & - & - & $8.40 e-05$ & - & - & - & - & $8.40 e-05$ & 7.37e-07 \\
\hline $\mathrm{Zn}$ & - & - & - & - & - & $8.40 e-05$ & - & - & - & 167.33 & 167.33 & 1.47 \\
\hline Other & $-1.14 c-14$ & 0.03 & $-1.76 e+02$ & 0.43 & - & 0.02 & 0.07 & - & - & 0.67 & $-1.75 e+02$ & $-1.53 e+00$ \\
\hline Tolal & 80.15 & 154.40 & $7,184.60$ & 289.60 & 210.00 & 84.00 & $2,101.00$ & 84.00 & $1,048.00$ & 168.00 & $11,403.75$ & 100.00 \\
\hline
\end{tabular}


Table G-2-8. M60-Mod surrogate waste mixture composition.

\begin{tabular}{|c|c|c|c|c|c|c|c|c|c|c|c|c|}
\hline \multirow{2}{*}{ Species } & \multicolumn{10}{|c|}{ Amount of each species provided by the bsted additives (b) } & \multirow{2}{*}{$\begin{array}{l}\text { Tot. ant of } \\
\text { ea. species } \\
\text { (lb) }\end{array}$} & \multirow{2}{*}{$\begin{array}{c}\text { Tot wt. } \% \\
\text { of each } \\
\text { species }\end{array}$} \\
\hline & Oxide Conc. & Ingot & Ilmenite & Magnethte & Potash & Soda Ash & Soil & Zirconia & Pebble Lime & Mill Scale & & \\
\hline Al2O3 & - & - & 7.83 & 33.82 & - & - & 855.22 & 1.90 & 5.31 & - & 90408 & 5.99 \\
\hline Ag2O & - & - & - & - & - & - & 0.07 & - & - & - & 007 & $4.68=-04$ \\
\hline As2O & $\cdot$ & - & - & - & - & - & 0.10 & - & - & - & 0.10 & $662 e-04$ \\
\hline $\mathrm{BaO}$ & - & - & - & - & - & - & 092 & - & - & - & 0.92 & $608 e-03$ \\
\hline $\mathrm{CaCO} 3$ & - & - & - & $\cdot$ & - & - & $1,067.86$ & - & 2484 & - & $1,092.70$ & 7.24 \\
\hline $\mathrm{CaO}$ & 3.05 & $\cdot$ & 0.34 & 3.95 & - & - & 9.20 & 0.13 & $1,410.68$ & - & $1,427.34$ & 9.46 \\
\hline Cdo & - & - & - & - & - & - & $4.69 c-03$ & - & - & - & $4.69 \mathrm{e}-03$ & $3110-05$ \\
\hline $\mathrm{CeO} 2$ & 52.50 & - & - & - & - & - & 0.45 & - & - & - & $\$ 2.95$ & 0.35 \\
\hline $\mathrm{Cr} 2 \mathrm{O} 3$ & - & - & 1.90 & 1.13 & - & - & 2.40 & - & - & 1.30 & 6.73 & 0.04 \\
\hline $\mathrm{Cs} 2 \mathrm{O}$ & - & - & - & - & - & - & 0.44 & - & - & - & 0.44 & $2.88 \mathrm{e}-03$ \\
\hline cuo & - & - & - & - & - & - & 0.46 & - & - & 3.36 & 3.82 & 0.03 \\
\hline $\mathrm{Fe} 2 \mathrm{O} 3$ & - & - & 335.30 & - & - & 001 & - & 0.13 & 1.21 & - & 336.66 & 2.23 \\
\hline $\mathrm{Fe} 3 \mathrm{O}_{4}$ & - & - & - & 425.03 & - & - & 347.37 & - & - & $1,022.69$ & $1,795.09$ & 11.89 \\
\hline $\mathrm{H} 2 \mathrm{O}$ & 3.24 & - & 25.17 & - & 0.93 & 2.28 & 829.64 & - & $\$ 2.36$ & - & 91362 & 605 \\
\hline HPO2 & - & - & - & - & - & - & - & 8.03 & - & - & 8.03 & 0.05 \\
\hline $\mathrm{HgO}$ & - & - & - & - & - & - & $887 e-04$ & - & - & - & $8.87 e-04$ & $5.88 c-06$ \\
\hline $\mathrm{K} 2 \mathrm{CO} 3$ & - & - & - & - & 784.63 & - & - & - & - & - & 784.63 & 5.20 \\
\hline $\mathrm{KCl}$ & - & - & - & - & 0.04 & - & - & - & - & - & 0.04 & $2.60 e-04$ \\
\hline $\mathrm{K} 20$ & - & - & - & - & - & - & 198.98 & - & - & - & 198.98 & 1.32 \\
\hline $\mathrm{KOH}$ & - & - & - & - & 055 & - & - & - & - & - & $05 s$ & $3650-03$ \\
\hline $\mathrm{K} 2 \mathrm{SO} 4$ & - & - & - & - & 0.05 & - & - & - & - & - & 0.05 & $3.12 e-04$ \\
\hline $\mathrm{MgO}$ & - & - & 2.46 & 7.33 & - & - & 186.63 & 004 & 6.07 & - & 202.53 & 1.34 \\
\hline MnO & - & - & 13.87 & 1.13 & - & - & - & - & - & - & 15.00 & 010 \\
\hline $\mathrm{MnO} 2$ & - & - & - & - & - & - & - & - & 0.76 & 8.82 & 9.58 & 006 \\
\hline $\mathrm{Na} 2 \mathrm{CO} 3$ & - & - & - & - & - & $1,334.04$ & - & - & - & - & $1,334.04$ & 884 \\
\hline $\mathrm{NaCl}$ & - & - & - & - & - & 1.07 & - & - & - & - & 1.07 & $7.10<-03$ \\
\hline $\mathrm{Na} 2 \mathrm{O}$ & - & - & - & - & - & - & 105.18 & 0.26 & 046 & - & 105.90 & 070 \\
\hline $\mathrm{Na}_{2} \mathrm{SO}_{4}$ & - & - & - & - & - & 2.01 & - & - & - & - & 2.01 & 0.01 \\
\hline NiO & - & - & - & - & - & - & 0.36 & - & - & 1.97 & 2.33 & 002 \\
\hline PO4 & - & - & - & - & - & - & 23.93 & - & - & 0.44 & 2437 & 016 \\
\hline P2os & - & - & 1.01 & 0.23 & - & - & - & - & 0.30 & - & 1.54 & 0.01 \\
\hline $\mathrm{PbO}$ & - & - & - & - & - & - & 0.20 & - & - & - & 0.20 & $1.35 e-03$ \\
\hline $\mathrm{SO} 3$ & - & - & - & - & - & - & - & - & 2.28 & - & 2.28 & 0.02 \\
\hline SO4 & 4.81 & - & - & - & - & - & 3.45 & - & - & - & 8.26 & 005 \\
\hline SeO & - & - & - & - & - & - & $9.88 \mathrm{e}-03$ & - & - & - & $9.88 \mathrm{e}-03$ & $6.54 e-05$ \\
\hline $\mathrm{SiO} 2$ & 3.21 & - & 291 & 27.06 & - & - & $4,744.44$ & 8.60 & 11.38 & 2.21 & $4,799.80$ & 31.80 \\
\hline ThO2 & 0.21 & - & - & - & - & $\cdot$ & - & - & - & - & 0.21 & $1.38 c-03$ \\
\hline $\mathrm{TiO} 2$ & - & - & 724.98 & 5862 & - & $\cdot$ & 35.63 & 1.19 & 0.76 & - & 821.18 & 5.44 \\
\hline $\mathrm{V} 2 \mathrm{O} 3$ & - & - & 2.57 & - & - & - & - & - & - & - & 2.57 & 0.02 \\
\hline v20s & - & - & - & 3.95 & - & - & - & $=$ & - & - & 3.95 & 0.03 \\
\hline $\mathrm{Y} 2 \mathrm{O} 3$ & - & - & - & - & - & - & - & 0.66 & - & - & 0.66 & $438 e-03$ \\
\hline $\mathrm{ZnO}$ & $\cdot$ & - & - & - & - & - & 1.12 & - & - & - & 1.12 & $7.450-03$ \\
\hline $\mathrm{ZrO2}$ & - & - & 045 & $\cdot$ & - & - & 1.11 & 419.97 & - & - & 421.53 & 279 \\
\hline $\mathrm{BaO}+\mathrm{SrO}$ & 5.77 & - & - & - & - & - & - & - & - & $\cdot$ & 577 & 0.04 \\
\hline As & - & - & - & - & $7.86 e-04$ & - & - & - & $3.03 e-03$ & - & $382 c-03$ & $2.53 \mathrm{e}-05$ \\
\hline $\mathrm{Ce}$ & - & 1.50 & - & - & - & - & - & - & - & - & 1.50 & $9.94 e-03$ \\
\hline $\mathrm{Cl}$ & - & - & - & - & - & - & 0.33 & - & - & - & 0.33 & $2.18 e-03$ \\
\hline F & 737 & - & - & - & - & - & - & - & 0.46 & - & 7.83 & 0.05 \\
\hline $\mathrm{Fe}$ & $\cdot$ & 1.50 & - & - & $9.43 e-04$ & - & - & - & - & - & 1.50 & $9.94 c-03$ \\
\hline $\mathrm{H}_{8}$ & - & - & - & - & $3.14 e-05$ & - & - & - & - & - & $314 \mathrm{e}-05$ & $2.08 e-07$ \\
\hline $\mathrm{Pb}$ & - & - & - & - & $7.08 \mathrm{e}-03$ & - & - & - & $7.58 c-03$ & - & 0.01 & $9.71 \mathrm{c}-0 \mathrm{~s}$ \\
\hline$s$ & - & - & - & 1.13 & - & - & - & - & - & - & 1.13 & $7.47 e-03$ \\
\hline Th & - & - & - & - & - & - & - & 0.07 & - & - & 0.07 & $4.68 c-04$ \\
\hline $\mathrm{U}$ & - & - & - & - & - & - & - & 0.11 & - & - & 0.11 & $7.01 \mathrm{e}-04$ \\
\hline Other & $-1.14 c-14$ & $=$ & - & 0.34 & $1.12 \mathrm{e}-13$ & $-1.34 c-02$ & $-2.01 c+02$ & - & $4.14 \mathrm{e}-04$ & $-8.68 e+00$ & $-2.10 e+02$ & $-1.390+00$ \\
\hline Total & 80.15 & 3.00 & $1,118.80$ & $\$ 63.70$ & 786.20 & $1,339.40$ & $8,214.30$ & 441.10 & $1,516.86$ & $1,032.10$ & $15,095.62$ & 100.00 \\
\hline
\end{tabular}




\section{Appendix $\mathrm{H}$}

Chemical Composition of Individual Slag Molds 
- 
Table H-1. Melting test of the RWMC soil and mill scale.

\begin{tabular}{|c|c|c|c|c|c|c|c|c|}
\hline & \multicolumn{7}{|c|}{ Slag ingots } & \multirow[b]{2}{*}{ Subtotal } \\
\hline & RWMC-S1 & RWMC-S2 & RWMC-S3 & RWMC-S4 & RWMC-S5 & RWMC-S6 & RWMC-S7 & \\
\hline wh, lb & 770 & 730 & 768 & 696 & 506 & 790 & 1770 & 6030 \\
\hline wt, pct & 12.77 & 12.11 & 12.74 & 11.54 & 8.39 & 13.10 & 29.35 & 100 \\
\hline Component & \multicolumn{7}{|c|}{ Concentration, $\mathrm{mg} / \mathrm{kg}$} & wt. mean \\
\hline $\mathrm{Ag} 2 \mathrm{O}$ & $<1$ & $<1$ & $<1$ & $<1$ & $<1$ & $<1$ & $<1$ & $<1$ \\
\hline $\mathrm{Al} 2 \mathrm{O} 3$ & 104000 & 104000 & 97300 & 86500 & 89700 & 74600 & 76500 & 88000 \\
\hline As2O3 & 8 & 8 & 8 & 12 & 12 & 9 & 12 & 10 \\
\hline $\mathrm{BaO}$ & 834 & 1030 & 952 & 1000 & 958 & 969 & 903 & 940 \\
\hline $\mathrm{CaO}$ & 36100 & 30800 & 30800 & 30500 & 32800 & 33600 & 31100 & 32100 \\
\hline $\mathrm{CdO}$ & $<1$ & $<1$ & $<1$ & $<1$ & $<1$ & $<1$ & $<1$ & $<1$ \\
\hline $\mathrm{CeO} 2$ & NA & NA & NA & NA & $\mathrm{NA}$ & NA & NA & $\mathrm{NC}$ \\
\hline $\mathrm{Cl}$ & $<100$ & $<100$ & $<100$ & $<100$ & $<100$ & $<100$ & $<100$ & $<100$ \\
\hline $\mathrm{CO} 2$ & 180 & $\overline{170}$ & 160 & 210 & 710 & 240 & 230 & 247 \\
\hline $\mathrm{CrO} 2$ & 807 & 1170 & 1110 & 1040 & 1130 & 1180 & 1240 & 1120 \\
\hline $\mathrm{Cs} 2 \mathrm{O}$ & 11 & 11 & 8 & 13 & 8 & 10 & 8 & 10 \\
\hline $\mathrm{CuO}$ & 422 & 687 & 647 & 677 & 766 & 761 & 863 & 715 \\
\hline $\mathrm{Fe} 3 \mathrm{O} 4$ & 201000 & 213000 & 214000 & 204000 & 228000 & 229000 & 265000 & 229000 \\
\hline $\mathrm{HgO}$ & $<0.1$ & $<0.1$ & $<0.1$ & 0.1 & 0.1 & 1 & $<0.1$ & $<0.1$ \\
\hline $\mathrm{K} 2 \mathrm{O}$ & 21000 & 20500 & 20700 & 20800 & 20500 & 20200 & 19400 & 20300 \\
\hline $\mathrm{MgO}$ & 26200 & 22700 & 22500 & 18700 & 18200 & 19800 & 17800 & 20500 \\
\hline $\mathrm{Na} 2 \mathrm{O}$ & 20757 & 14300 & 18300 & 17000 & 12300 & 15100 & 19400 & 17400 \\
\hline $\mathrm{NiO}$ & 192 & 306 & 304 & 295 & 329 & 324 & 362 & 311 \\
\hline $\mathrm{P} 2 \mathrm{O} 5$ & 1120 & 137 & 69 & 1170 & 160 & 115 & 1280 & 708 \\
\hline $\mathrm{PbO}$ & 20 & 19 & 18 & 19 & 20 & 20 & 23 & 20 \\
\hline $\mathrm{SO} 3$ & 30 & 15 & 15 & 15 & 15 & 15 & 15 & 17 \\
\hline $\mathrm{SeO} 2$ & $<1$ & $<1$ & $<1$ & $<1$ & $<1$ & $<1$ & $<1$ & $<1$ \\
\hline$\overline{\mathrm{SiO} 2}$ & 540000 & 456000 & 471000 & 450000 & 452000 & 506000 & 401000 & 458000 \\
\hline TiO2 & 7210 & 9650 & 9350 & 9700 & 9150 & 9220 & 8510 & 8870 \\
\hline $\mathrm{ZnO}$ & 130 & 184 & 164 & 182 & 178 & 194 & 194 & 178 \\
\hline$\overline{\mathrm{ZrO} 2}$ & 392 & 560 & 530 & 557 & 541 & 542 & 546 & 526 \\
\hline Total & 959000 & 876000 & 888000 & 844000 & 868000 & 912000 & 844000 & 879000 \\
\hline
\end{tabular}


Table H-2. Melting test of the S60 waste mixture.

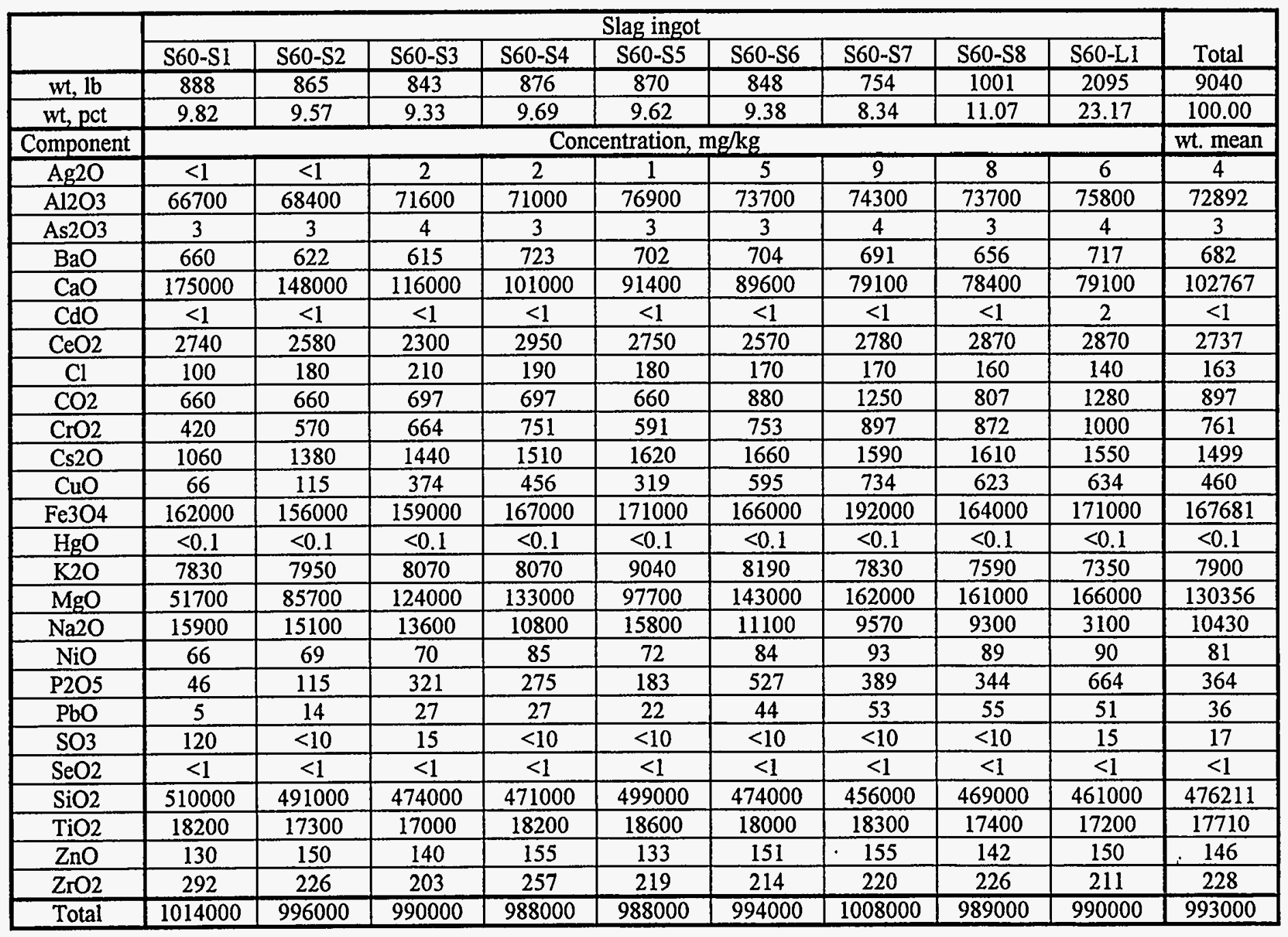


Table H-3. Melting test of the S60-IV waste mixture.

\begin{tabular}{|c|c|c|c|c|c|c|c|c|c|}
\hline \multirow[b]{2}{*}{ Slag ingot } & \multicolumn{8}{|c|}{ Slag Ingot } & \multirow[b]{2}{*}{ Total } \\
\hline & S60-IV-S1 & S60-IV-S2 & S60-IV-S3 & S60-IV-S4 & S60-IV-S5 & S60-IV-S6 & S60-IV-S7 & S60-IV-Ll & \\
\hline $\mathrm{wt}, \mathrm{lb}$ & 436 & 882 & 866 & 883 & 794 & 814 & 545 & 1799 & 7019 \\
\hline wt, pct & 6.21 & 12.57 & 12.34 & 12.58 & 11.31 & 11.60 & 7.76 & 25.63 & 100 \\
\hline Component & \multicolumn{8}{|c|}{ Concentration, $\mathrm{mg} / \mathrm{kg}$} & wt. mean \\
\hline $\mathrm{Ag} 2 \mathrm{O}$ & $<1$ & $<1$ & $<1$ & $<1$ & $<1$ & $<1$ & $<1$ & $\overline{<1}$ & $<1$ \\
\hline $\mathrm{Al} 2 \mathrm{O3}$ & 73900 & 75000 & 73100 & 74800 & 69900 & 71000 & 69500 & 71400 & 72282 \\
\hline As203 & 4 & 4 & 4 & 3 & 3 & 4 & 3 & 3 & 3 \\
\hline $\mathrm{BaO}$ & 685 & 733 & 678 & 758 & 719 & 731 & 745 & 796 & 742 \\
\hline $\mathrm{CaO}$ & 97900 & 101000 & 102000 & 103000 & 102000 & 102000 & 104000 & 112000 & 104464 \\
\hline $\mathrm{CdO}$ & $<1$ & $<1$ & $<1$ & $<1$ & $<1$ & $<1$ & $<1$ & $<1$ & $<1$ \\
\hline $\mathrm{CeO} 2$ & 3970 & 4430 & 4200 & 5040 & 4450 & 4430 & 4750 & 4770 & 4564 \\
\hline $\mathrm{Cl}$ & 120 & 110 & 130 & 100 & 100 & 110 & 120 & 90 & 106 \\
\hline $\mathrm{CO} 2$ & 623 & 550 & 843 & 1140 & 1250 & 4660 & 1650 & 1800 & 1627 \\
\hline $\mathrm{CrO} 2$ & 506 & 552 & 523 & 543 & 540 & 523 & 554 & 871 & 622 \\
\hline $\mathrm{Cs} 2 \mathrm{O}$ & 2410 & 2320 & 2510 & 2260 & 2160 & 2160 & 2260 & 2190 & 2267 \\
\hline $\mathrm{CuO}$ & 70 & 66 & 59 & 61 & 53 & 49 & 53 & 73 & 62 \\
\hline $\mathrm{Fe} 3 \mathrm{O} 4$ & 213000 & 186000 & 191000 & 184000 & 188000 & 214000 & 184000 & 170000 & 187260 \\
\hline $\mathrm{HgO}$ & $<0.1$ & $<0.1$ & $<0.1$ & $<0.1$ & $<0.1$ & $<0.1$ & $<0.1$ & $<0.1$ & $<0.1$ \\
\hline $\mathrm{K} 2 \mathrm{O}$ & 10000 & 9640 & 9400 & 9040 & 9040 & 8920 & 9400 & 9880 & 9449 \\
\hline $\mathrm{MgO}$ & 44300 & 41800 & 37800 & 34700 & 36200 & 34200 & 34300 & 33300 & 36293 \\
\hline $\mathrm{Na2O}$ & 21400 & 16600 & 18700 & 19500 & 17900 & 16600 & 19800 & 22000 & 19302 \\
\hline $\mathrm{NiO}$ & 62 & 65 & 64 & 71 & 70 & 71 & 67 & 78 & 70 \\
\hline $\mathrm{P} 2 \mathrm{O} 5$ & 344 & 412 & 366 & 275 & 183 & 275 & 137 & 46 & 228 \\
\hline $\mathrm{PbO}$ & 15 & 16 & 16 & 13 & 14 & 12 & 12 & 9 & 13 \\
\hline $\mathrm{SO} 3$ & $<10$ & $<10$ & 15 & 15 & 15 & 15 & 45 & 180 & 57 \\
\hline $\mathrm{SeO} 2$ & $<1$ & $<1$ & $<1$ & $<1$ & $<1$ & $<1$ & $<1$ & $<1$ & $<1$ \\
\hline $\mathrm{SiO} 2$ & 484000 & 476000 & 467000 & 478000 & 465000 & 467000 & 476000 & 495000 & 478220 \\
\hline $\mathrm{TiO} 2$ & 39400 & 45400 & 46400 & 47300 & 48300 & 48600 & 49400 & 41300 & 45349 \\
\hline $\mathrm{ZnO}$ & 141 & 155 & 142 & 135 & 147 & 130 & 131 & 110 & 133. \\
\hline $\mathrm{ZrO} 2$ & 19300 & 22200 & 23000 & 22900 & 24400 & 24700 & 24800 & 20300 & 22460 \\
\hline Total & 1011000 & 983000 & 978000 & 984000 & 969000 & 1001000 & 982000 & 985000 & 983000 \\
\hline
\end{tabular}


Table H-4. Melting test of the N80 and N80-Mod waste mixtures.

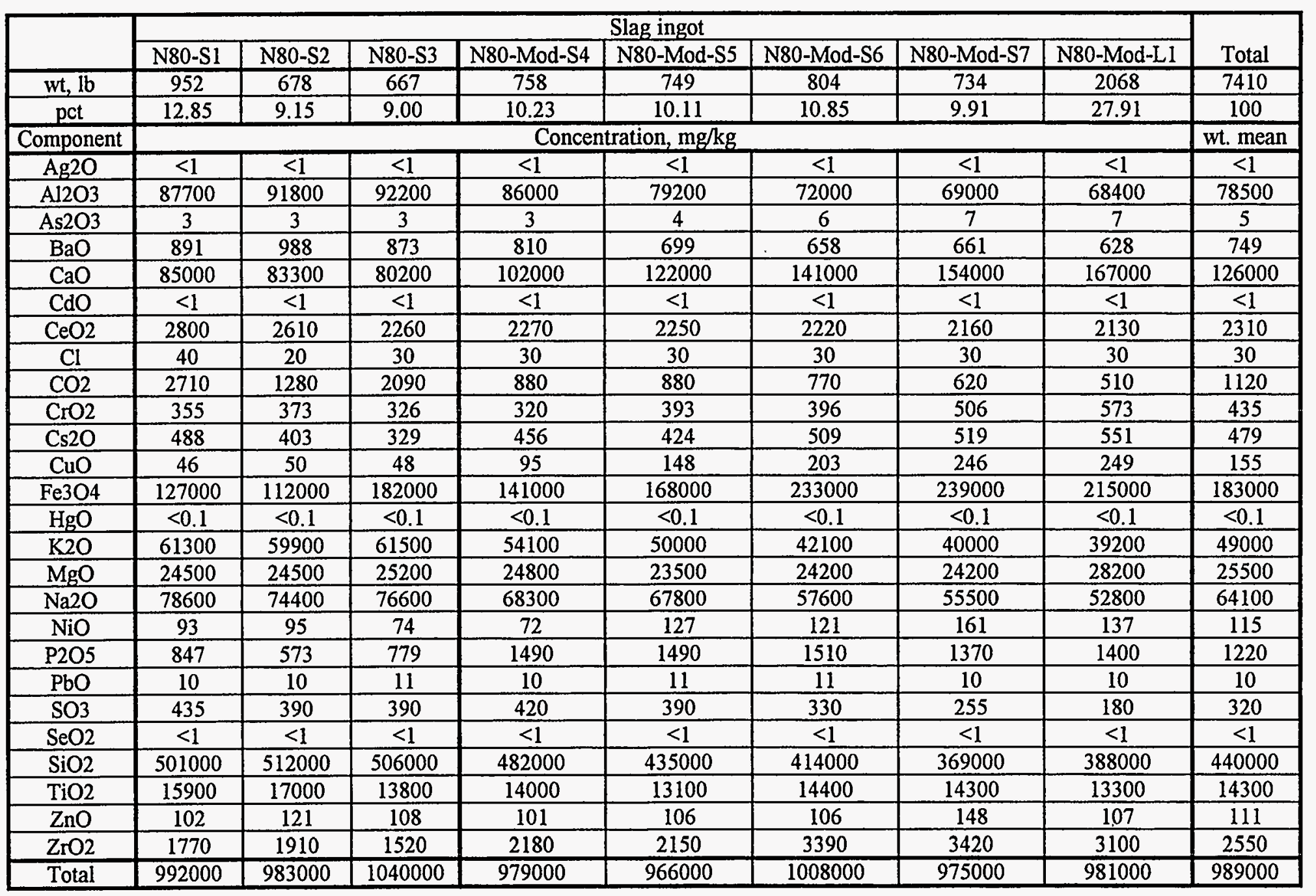


Table H-5. Melting test of the N80-IV and N80-IV-Mod waste mixtures.

\begin{tabular}{|c|c|c|c|c|c|c|c|c|c|c|c|c|}
\hline & \multicolumn{11}{|c|}{ Slag ingot } & \multirow[b]{2}{*}{ Total } \\
\hline & N80-IV-Sl & N80-IV-S2 & N80-IV-S3 & N80-IV-S4 & N80M-IV-S5 & N80M-IV-S6 & \begin{tabular}{|l|} 
N80M-IV-S7 \\
\end{tabular} & N80M-IV-S8 & \begin{tabular}{|l} 
N80M-IV-S9 \\
\end{tabular} & N80M-IV-S10 & N80M-IV-L1 & \\
\hline wt, lb & 762 & 721 & 717 & 347 & 739 & 842 & 788 & 818 & 732 & 317 & 1997 & 8780 \\
\hline pet & 8.68 & 8.21 & 8.17 & 3.95 & 8.42 & 9.59 & 8.97 & 9.32 & 8.34 & 3.61 & 22.74 & 100 \\
\hline Component & \multicolumn{11}{|c|}{ Concentration, $\mathrm{mg} / \mathrm{kg}$} & wt. mean \\
\hline Ag2O & $<1$ & $<1$ & $<1$ & $<1$ & $<1$ & $\leq 1$ & $<1$ & $<1$ & $<1$ & $<1$ & $<1$ & $<1$ \\
\hline $\mathrm{Al} 2 \mathrm{O} 3$ & 77500 & 76000 & 69500 & 69300 & 69900 & 65000 & 63700 & 57800 & 53800 & 59000 & 61400 & 51200 \\
\hline As2O3 & 3 & 4 & 3 & 4 & 5 & 8 & 9 & 9 & 11 & 9 & 11 & 5 \\
\hline $\mathrm{BaO}$ & 902 & 817 & 1030 & 873 & 806 & 755 & 723 & 659 & 656 & 670 & 695 & 14570 \\
\hline $\mathrm{CaO}$ & 79800 & 75000 & 71000 & 72500 & 97900 & 127800 & 147000 & 154000 & 176400 & 189000 & 186200 & 91000 \\
\hline CdO & $<1$ & $<1$ & $<1$ & $<1$ & $<1$ & $<1$ & $<1$ & $<1$ & $<1$ & $<1$ & $<1$ & $<1$ \\
\hline $\mathrm{CeO} 2$ & 4810 & 4510 & 4060 & 3980 & 4000 & 3660 & 3490 & 3280 & 3100 & 3130 & 3540 & 45300 \\
\hline $\mathrm{Cl}$ & 12 & 11 & 9 & 7 & 19 & 10 & 19 & 3 & 7 & 7 & 8 & 8 \\
\hline $\mathrm{CO} 2$ & 660 & 1060 & 660 & 1030 & 990 & 1870 & 1030 & 953 & 1250 & 770 & 1210 & 1620 \\
\hline $\mathrm{CrO} 2$ & 498 & 422 & 489 & 344 & 465 & 491 & 519 & 509 & 674 & 567 & 564 & 390 \\
\hline $\mathrm{Cs} 2 \mathrm{O}$ & 148 & 99 & 69 & 48 & 72 & 67 & 57 & 46 & 48 & 29 & 67 & 331 \\
\hline $\mathrm{CuO}$ & 81 & 64 & 54 & 61 & 111 & 180 & 236 & 261 & 291 & 305 & 303 & 255 \\
\hline $\mathrm{Fe} 304$ & 118000 & 116000 & 113000 & 122000 & 134000 & 166000 & 185000 & 200000 & 213000 & 264000 & 204000 & 124000 \\
\hline $\mathrm{HgO}$ & $<0.1$ & $<0.1$ & $<0.1$ & $<0.1$ & $<0.1$ & $<0.1$ & $<0.1$ & $<0.1$ & $<0.1$ & $<0.1$ & $<0.1$ & $<0.1$ \\
\hline $\mathrm{K} 2 \mathrm{O}$ & 61900 & 59500 & 61100 & 58700 & 54600 & 52700 & 50400 & 49000 & 46600 & 45600 & 46200 & 88200 \\
\hline $\mathrm{MgO}$ & 25300 & 25700 & 24200 & 23000 & 22200 & 20800 & 19500 & 18300 & 17500 & 17800 & 18000 & 16600 \\
\hline $\mathrm{Na} 2 \mathrm{O}$ & 84800 & 81300 & 79000 & 80500 & 69700 & 67900 & 66600 & 68100 & 62900 & 61200 & 60900 & 66300 \\
\hline $\mathrm{NiO}$ & 52 & 48 & 64 & 48 & 99 & 102 & 119 & 142 & 191 & 173 & 154 & 4170 \\
\hline $\mathrm{P} 205$ & $<1$ & 9 & 5 & 27 & $<1$ & 366 & 481 & 298 & 618 & 252 & 847 & 14020 \\
\hline $\mathrm{PbO}$ & 23 & 28 & 25 & 29 & 26 & 25 & 22 & 23 & 23 & 23 & 23 & 54 \\
\hline SO3 & 495 & 390 & 255 & 180 & 270 & 195 & 165 & 180 & 180 & 150 & 225 & 389 \\
\hline $\mathrm{SeO}$ & $<1$ & $<1$ & $<1$ & $<1$ & $<1$ & $<1$ & $<1$ & $<1$ & $<1$ & $<1$ & $<1$ & $<1$ \\
\hline $\mathrm{SiO}_{2}$ & 424000 & 435000 & 441000 & 435000 & 411000 & 377000 & 356000 & 339000 & 315000 & 317000 & 259000 & 298000 \\
\hline $\mathrm{TiO} 2$ & 71600 & 65600 & 87600 & 66400 & 58900 & 54200 & 54000 & 50000 & 49500 & 52100 & 50700 & 47000 \\
\hline $\mathrm{ZnO}$ & 106 & 199 & 112 & 107 & 110 & 106 & 103 & 117 & 102 & 107 & 110 & 59000 \\
\hline $\mathrm{ZrO2}$ & 31300 & 28700 & 32900 & 28200 & 27500 & 26300 & 25300 & 23800 & 23400 & 22400 & 25900 & 32500 \\
\hline Total & 982000 & 971000 & 986000 & 962000 & 953000 & 965000 & 974000 & 966000 & 966000 & 1034000 & 920000 & 954000 \\
\hline
\end{tabular}


Table H-6. Melting test of the M60 and M60-Mod waste mixtures.

\begin{tabular}{|c|c|c|c|c|c|c|c|c|}
\hline \multirow[b]{2}{*}{ Component } & \multicolumn{7}{|c|}{ Slag ingot } & \multirow[b]{2}{*}{ Total } \\
\hline & M60 & M60-Mod-S1 & M60-Mod-S2 & M60-Mod-S3 & M60-Mod-S4 & M60-Mod-S5 & M60-Mod-Ll & \\
\hline $\mathrm{wt}, \mathrm{lb}$ & 0 & 817 & 770 & 734 & 792 & 372 & 1739 & 5224 \\
\hline pct & 0.00 & 15.64 & 14.74 & 14.05 & 15.16 & 7.12 & 33.29 & 100 \\
\hline Component & \multicolumn{7}{|c|}{ Concentration, $\mathrm{mg} / \mathrm{kg}$} & wt. mean \\
\hline $\mathrm{Ag} 2 \mathrm{O}$ & $<1$ & $<1$ & $<1$ & $<1$ & $<1$ & $<1$ & $<1$ & $<1$ \\
\hline $\mathrm{Al} 2 \mathrm{O} 3$ & 140000 & 132000 & 112000 & 92600 & 82600 & 74400 & 76100 & 93300 \\
\hline As2O & 2 & $<1$ & $<1$ & $<1$ & $<1$ & $<1$ & $<1$ & $<1$ \\
\hline $\mathrm{BaO}$ & 1080 & 1180 & 895 & 728 & 639 & 634 & 664 & 782 \\
\hline $\mathrm{CaO}$ & 114000 & 153000 & 195000 & 224000 & 220000 & 242000 & 252000 & 219000 \\
\hline $\mathrm{CdO}$ & $<1$ & $<1$ & $<1$ & $<1$ & $<1$ & $<1$ & $<1$ & $<1$ \\
\hline $\mathrm{CeO} 2$ & 4830 & 5500 & 4750 & 3770 & 3870 & 3370 & 2790 & 3850 \\
\hline $\mathrm{Cl}$ & 60 & 10 & 15 & 15 & 10 & 19 & 21 & 16 \\
\hline $\mathrm{CO} 2$ & 953 & 2310 & 843 & 843 & 5350 & 2050 & 3040 & 2570 \\
\hline $\mathrm{CrO} 2$ & 21000 & 22000 & 13300 & 6700 & 2800 & 3160 & 3780 & 8300 \\
\hline $\mathrm{Cs} 2 \mathrm{O}$ & 66 & 66 & 64 & 54 & 39 & 148 & 170 & 100 \\
\hline $\mathrm{CuO}$ & 413 & 91 & 129 & 189 & 224 & 266 & 289 & 209 \\
\hline $\mathrm{Fe} 3 \mathrm{O} 4$ & 81500 & 33600 & 104000 & 132000 & 167000 & 257000 & 163000 & 137000 \\
\hline $\mathrm{HgO}$ & $<0.1$ & $<0.1$ & $<0.1$ & $<0.1$ & $<0.1$ & $<0.1$ & $<0.1$ & $<0.1$ \\
\hline $\mathrm{K} 2 \mathrm{O}$ & 24100 & 23600 & 27600 & 30500 & 35200 & 34100 & 33900 & 31100 \\
\hline $\mathrm{MgO}$ & 24300 & 24200 & 21700 & 19300 & 18000 & 17300 & 18300 & 19700 \\
\hline $\mathrm{Na} 2 \mathrm{O}$ & 17800 & 17800 & 26700 & 34500 & 42300 & 39900 & 39900 & 34100 \\
\hline $\mathrm{NiO}$ & 842 & 72 & 130 & 183 & 186 & 253 & 258 & 188 \\
\hline $\mathrm{P} 2 \mathrm{O} 5$ & $<1$ & $<1$ & $<1$ & $<1$ & $<1$ & $<1$ & $<1$ & $<1$ \\
\hline $\mathrm{PbO}$ & 1220 & 81 & 377 & 280 & 237 & 452 & 474 & 333 \\
\hline $\mathrm{SO} 3$ & 450 & 375 & 405 & 285 & 240 & 450 & 495 & 392 \\
\hline $\mathrm{SeO} 2$ & $<1$ & $<1$ & $<1$ & $<1$ & $<1$ & $<1$ & $<1$ & $<1$ \\
\hline SiO2 & 551000 & 527000 & 450000 & 386000 & 356000 & 341000 & 339000 & 394000 \\
\hline $\mathrm{TiO} 2$ & 11400 & 12200 & 17400 & 24100 & 29300 & 28200 & 29800 & 24200 \\
\hline $\mathrm{ZnO}$ & 3310 & 634 & 1970 & 1370 & 910 & 2540 & 2660 . & 1790 \\
\hline $\mathrm{ZrO} 2$ & 4590 & 5140 & 7690 & 10700 & 13600 & 14500 & 15070 & 11550 \\
\hline Total & 1002000 & 961000 & 985000 & 969000 & 978000 & 1060000 & 981000 & 982000 \\
\hline
\end{tabular}


Appendix I

Variation of Slag Composition During Melting Tests 

' 


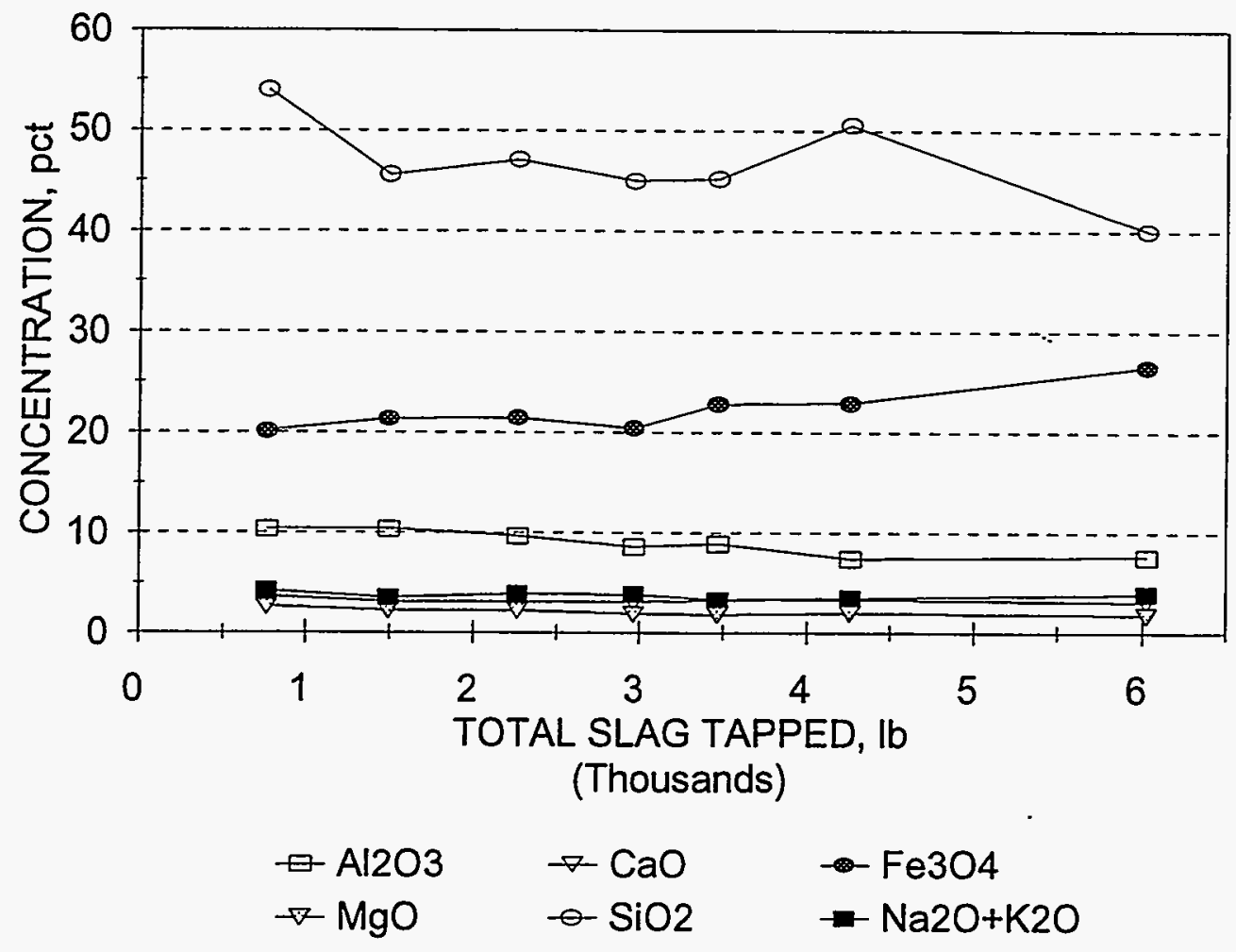

I-1.a. Concentrations of slag forming oxides in the RWMC slag.

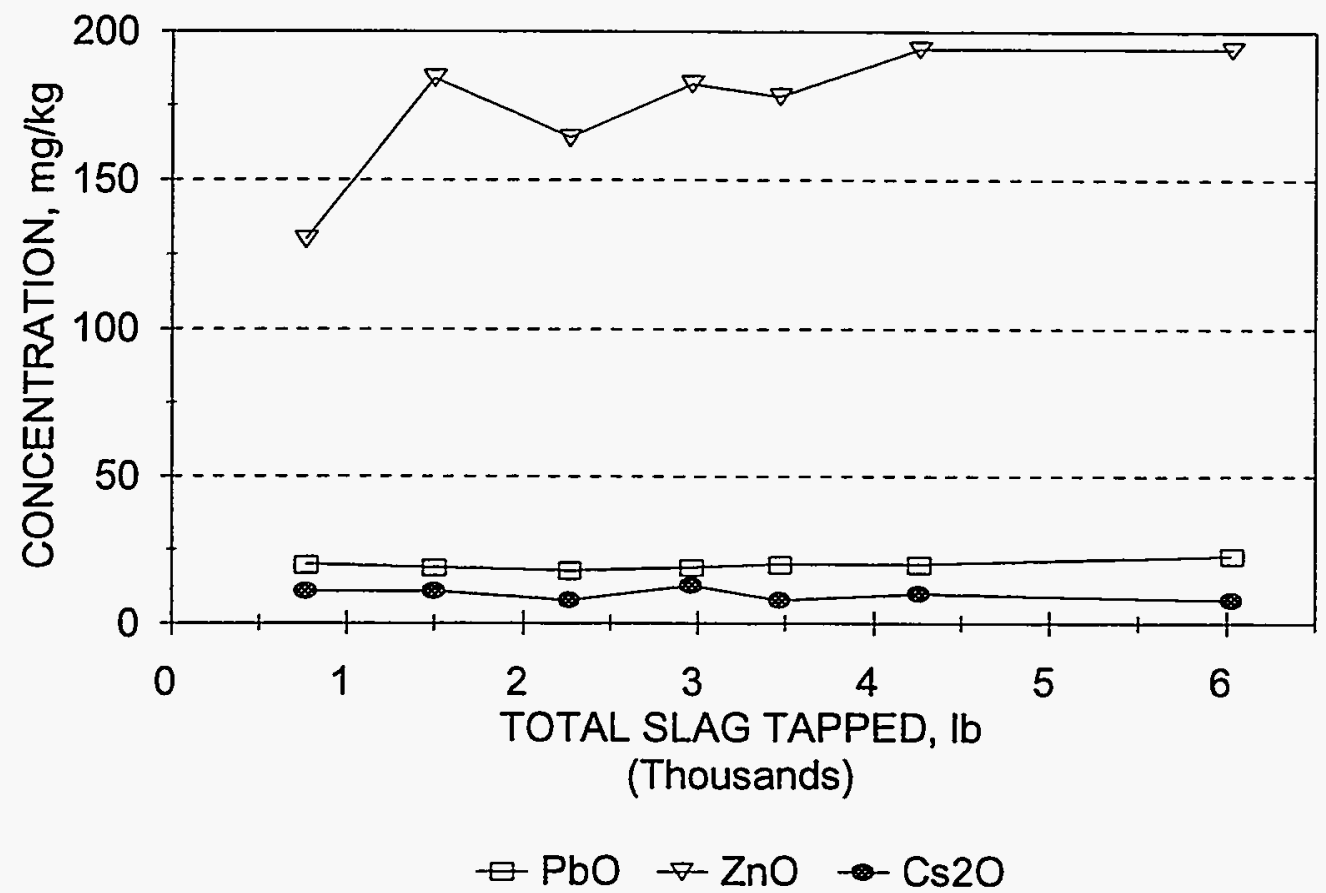

I-1.b. Concentrations of heavy metal and cesium oxides in the RWMC slag. 


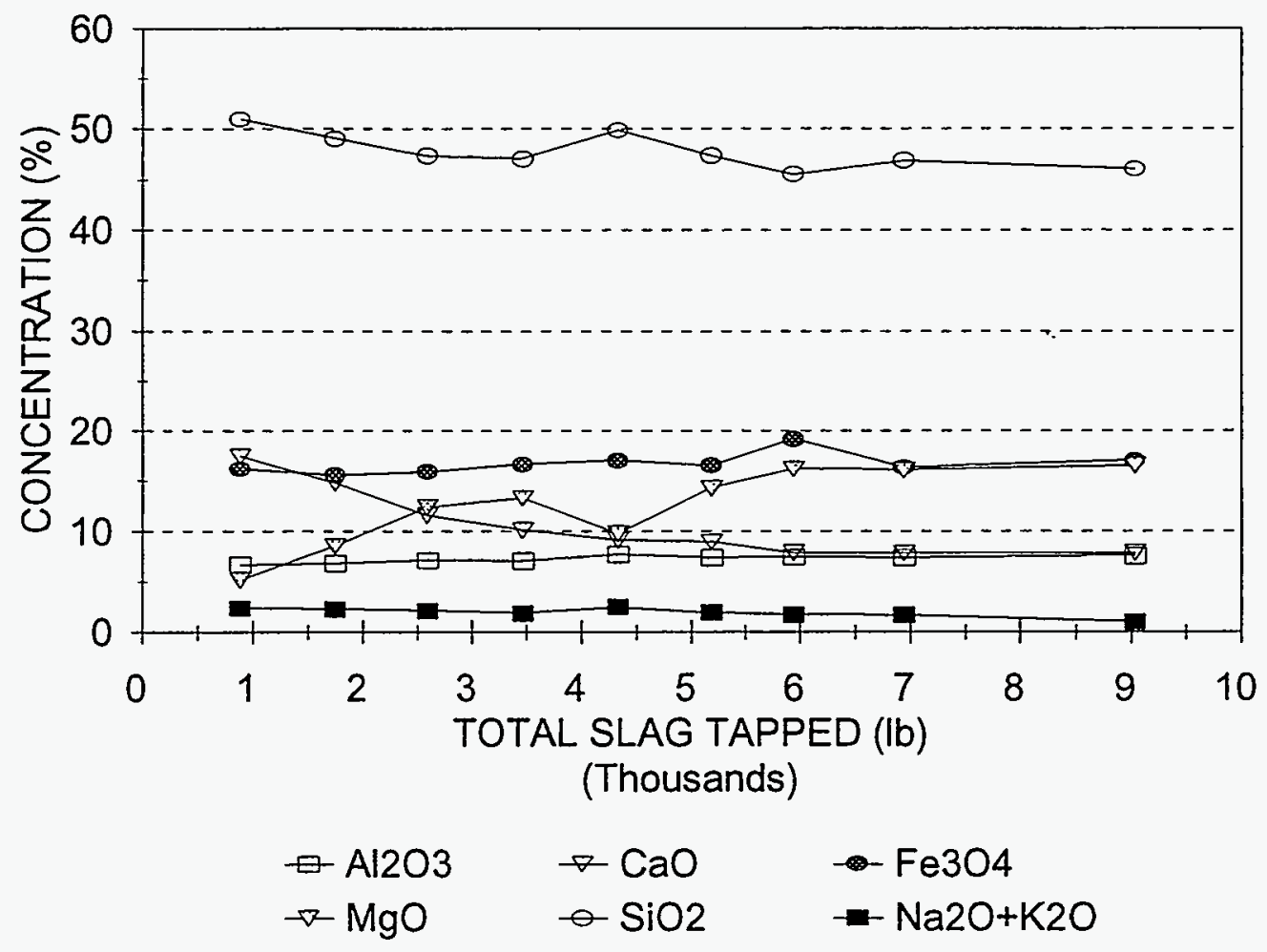

Figure I-2.a. Concentrations of slag forming oxides in the S60 slag.

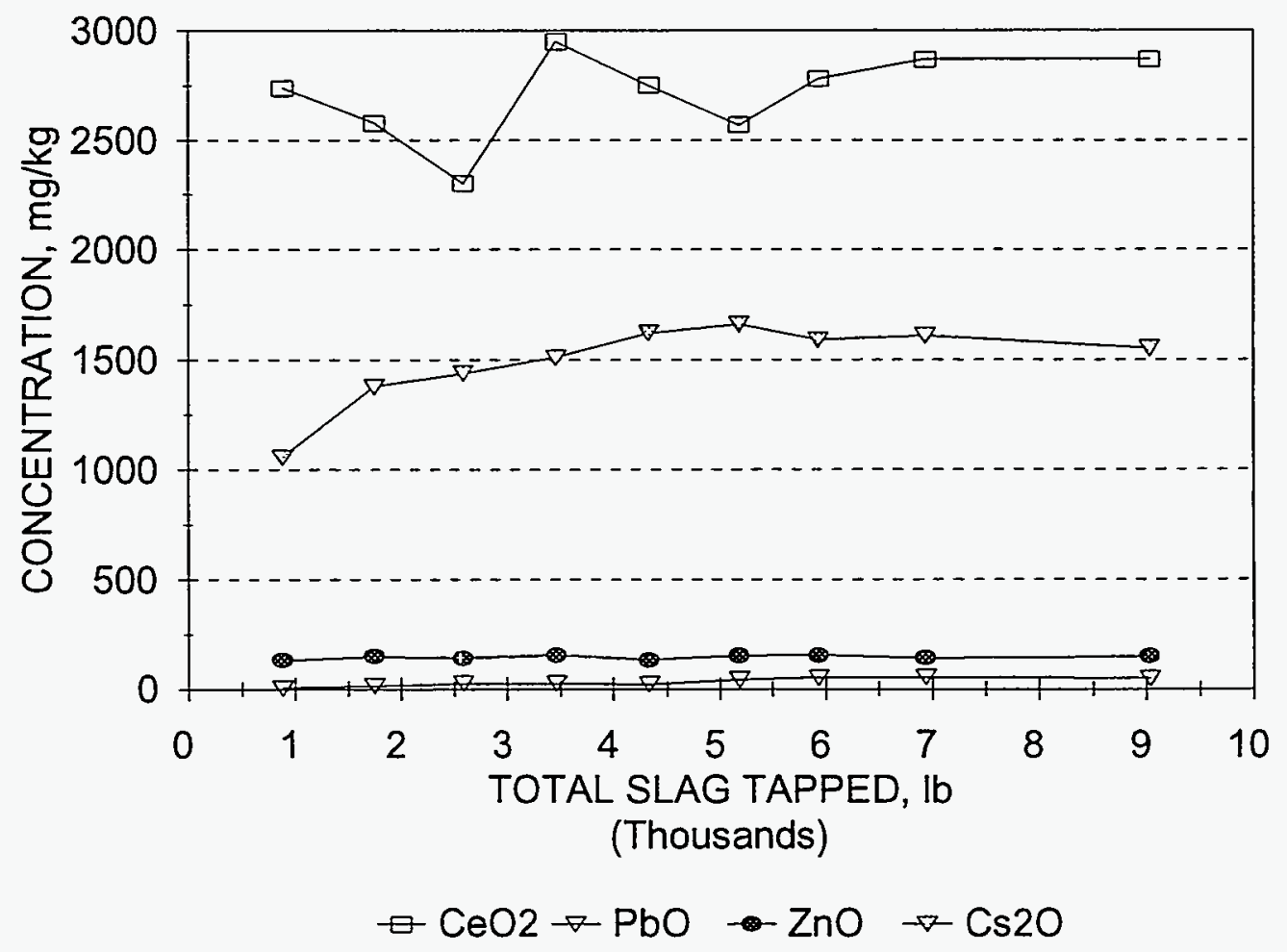

Figure I-2.b. Concentrations of heavy metal and cesium oxides in the S60 slag. 


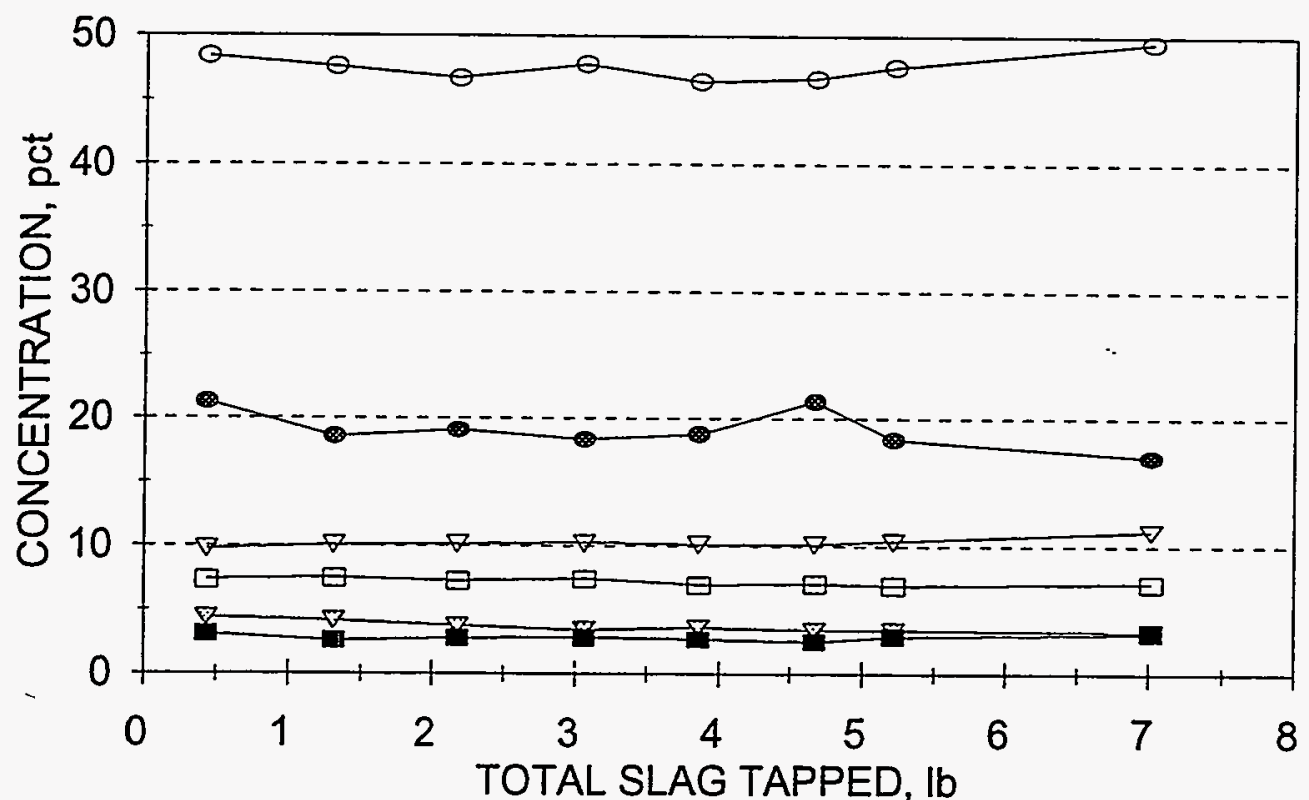

(Thousands)

$\begin{array}{lll}\rightarrow \mathrm{Al} 2 \mathrm{O} 3 & \rightarrow \mathrm{CaO} & -\mathrm{Fe} 3 \mathrm{O} 4 \\ \rightarrow-\mathrm{MgO} & -\mathrm{SiO} 2 & -\mathrm{Na} 2 \mathrm{O}+\mathrm{K} 2 \mathrm{O}\end{array}$

1-3.a. Concentrations of slag forming oxides in the S60-IV slag.

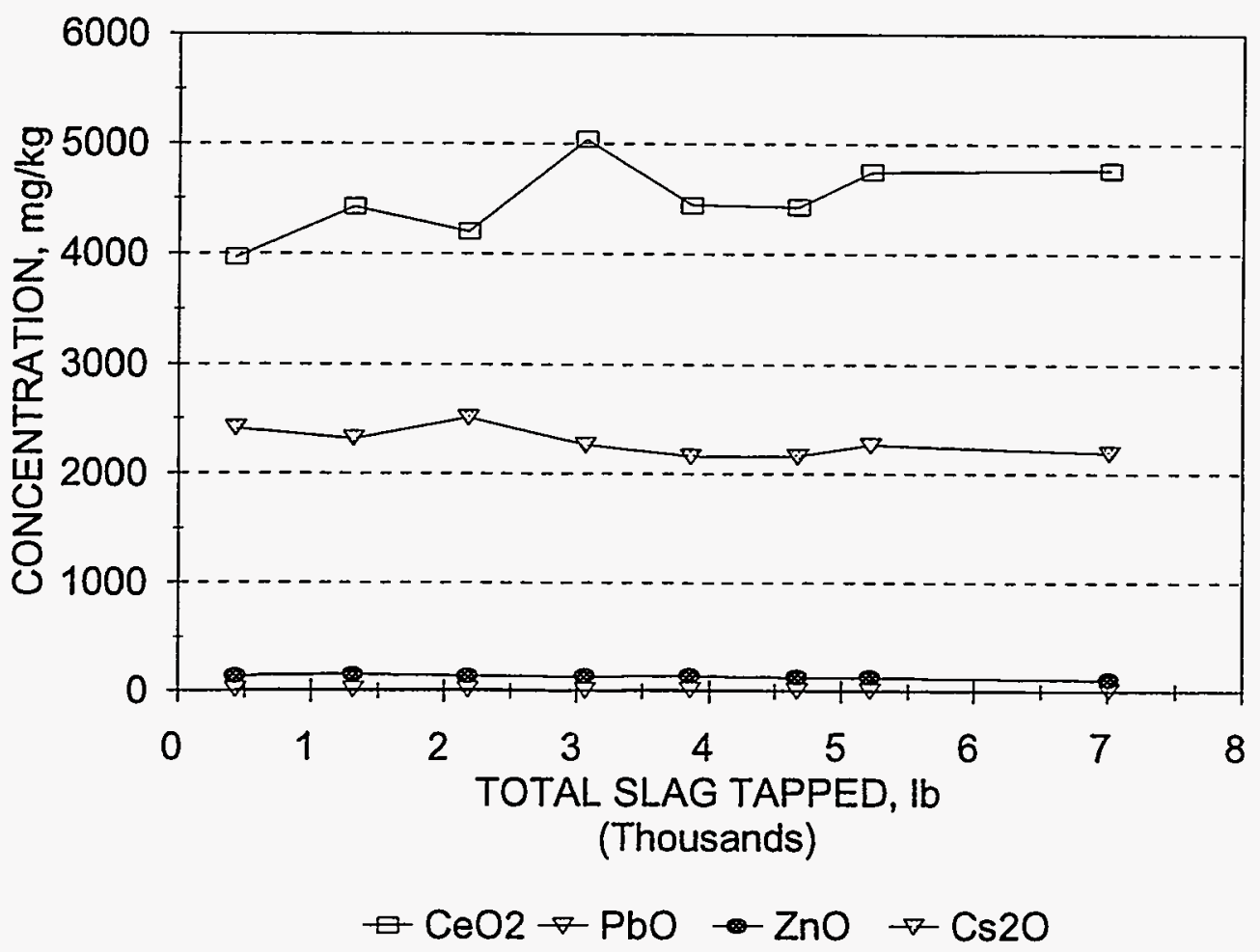

I-3.b. Concentrations of heavy metal and cesium oxides in the S60-IV slag. 


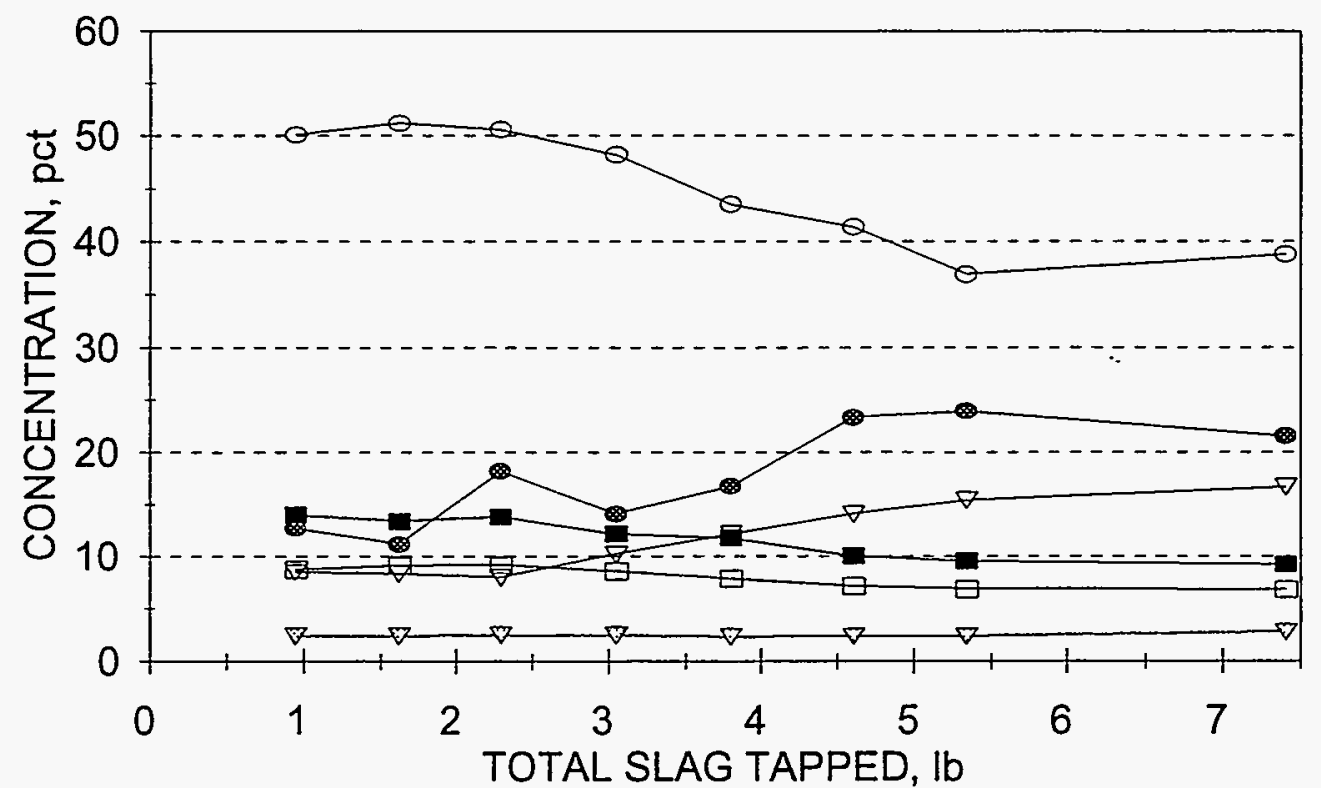

(Thousands)

$\begin{array}{lll}\varpi \mathrm{Al} 2 \mathrm{O} 3 & -\mathrm{CaO} & -\mathrm{Fe} 3 \mathrm{O} 4 \\ -\mathrm{MgO} & -\mathrm{SiO} 2 & -\mathrm{Na} 2 \mathrm{O}+\mathrm{K} 2 \mathrm{O}\end{array}$

1-4.a. Concentrations of slag forming oxides in the N80 slag.

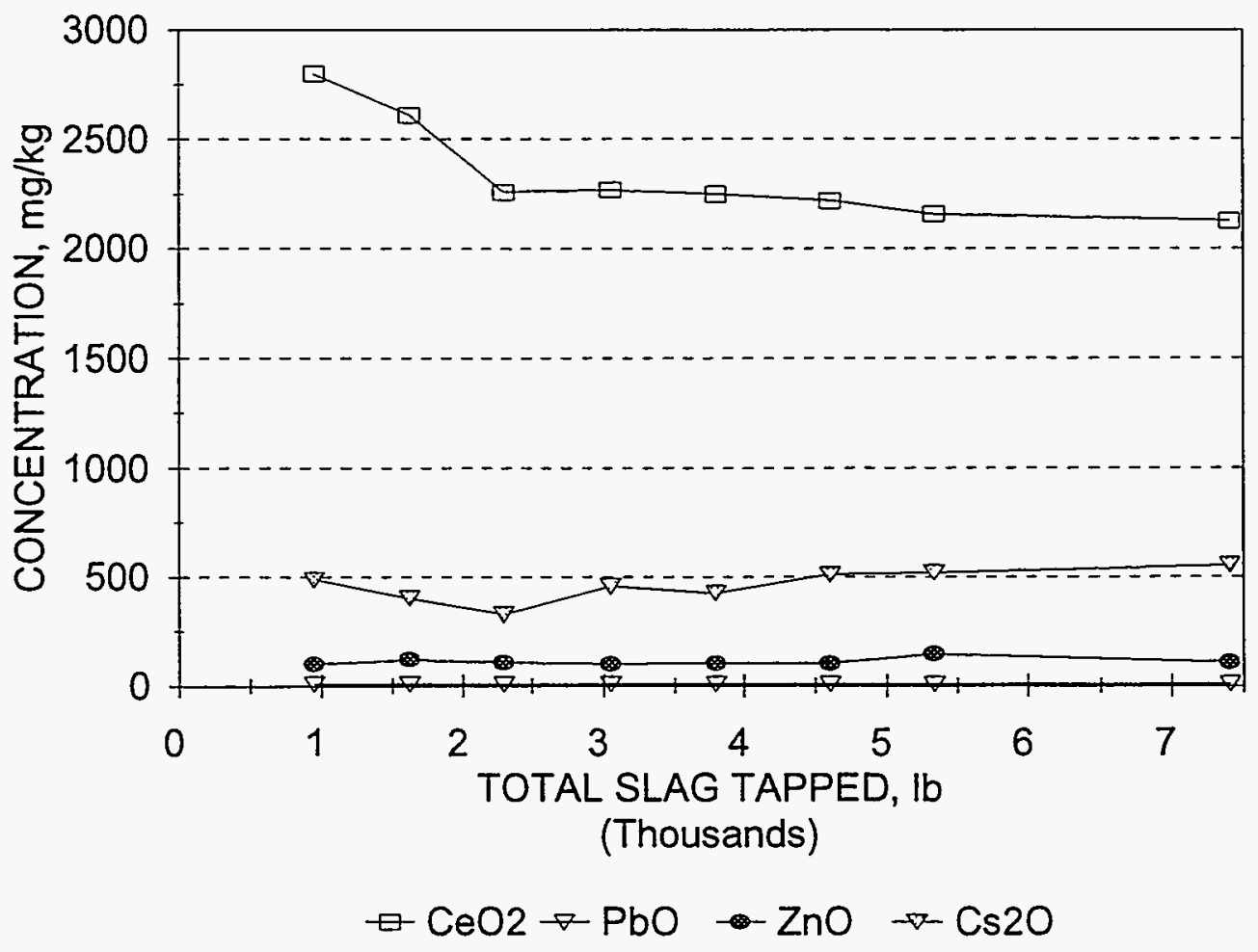

1-4.b. Concentrations of heavy metal and cesium oxides in the N80 slag. 


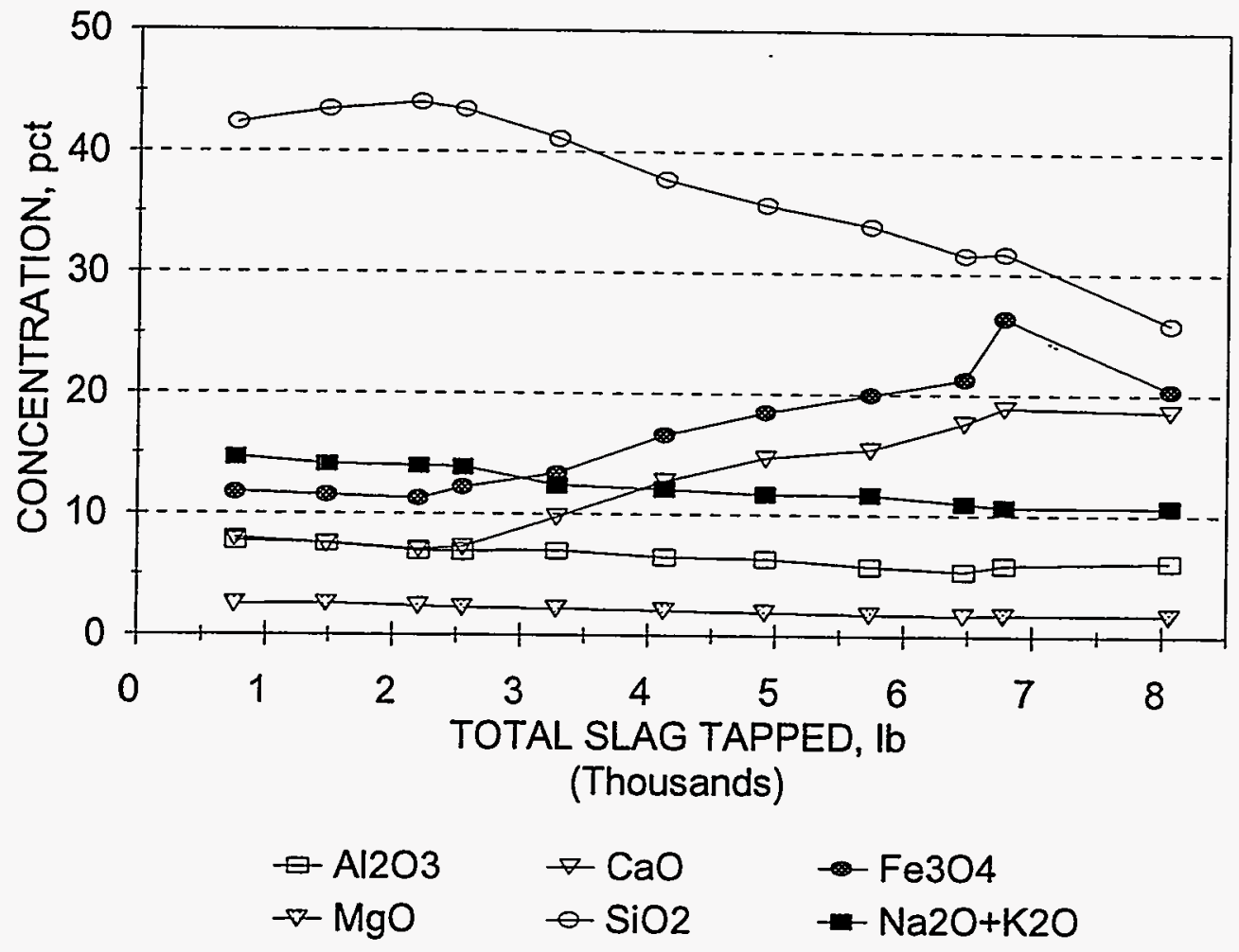

I-5.a. Concentrations of slag forming oxides in the $\mathbf{S 6 0}$ slag.

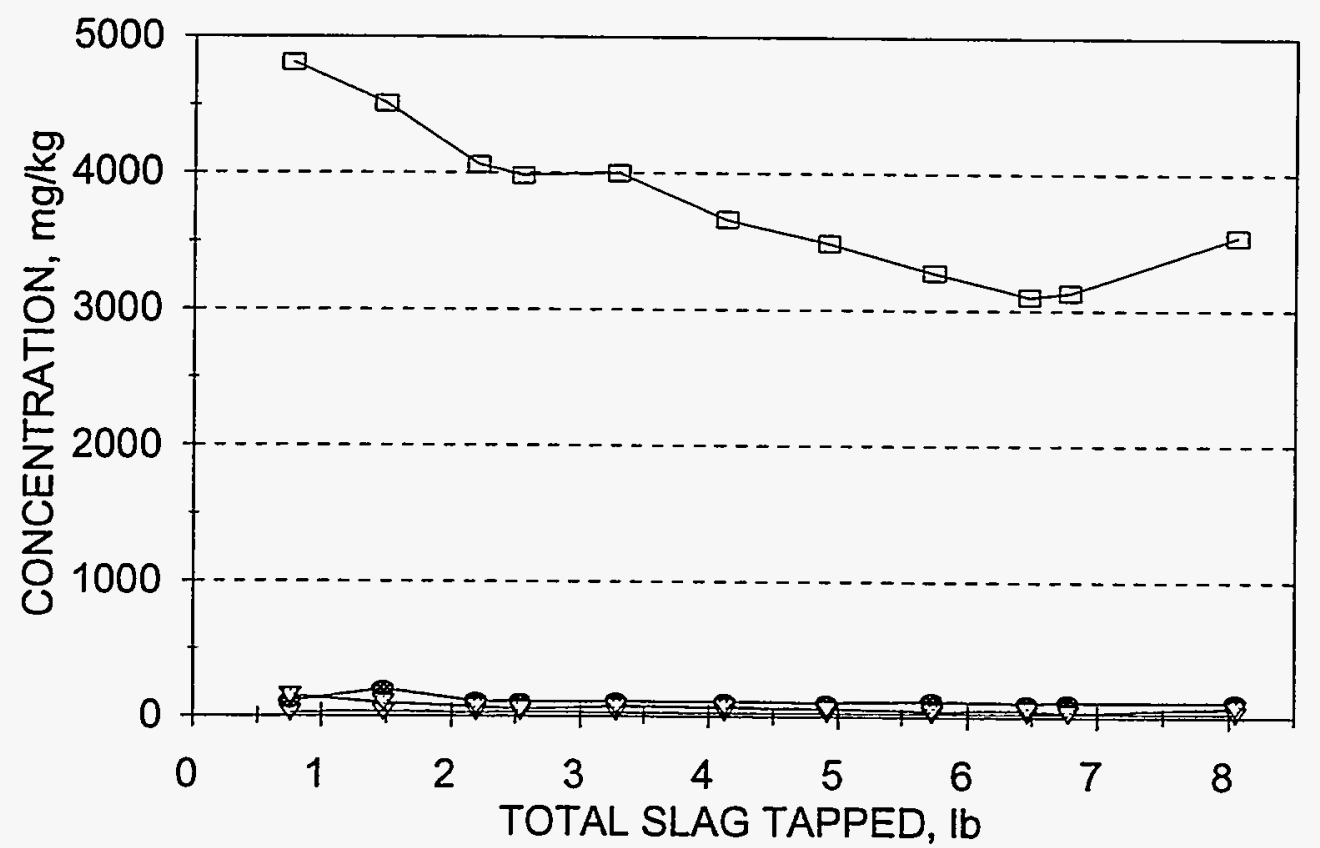

(Thousands)

$$
\because \mathrm{CeO} 2 \rightarrow \mathrm{PbO}-\mathrm{ZnO} \rightarrow \mathrm{Cs} 2 \mathrm{O}
$$

I-5.b. Concentrations of heavy metal and cesium oxides in the N80-IV slag. 


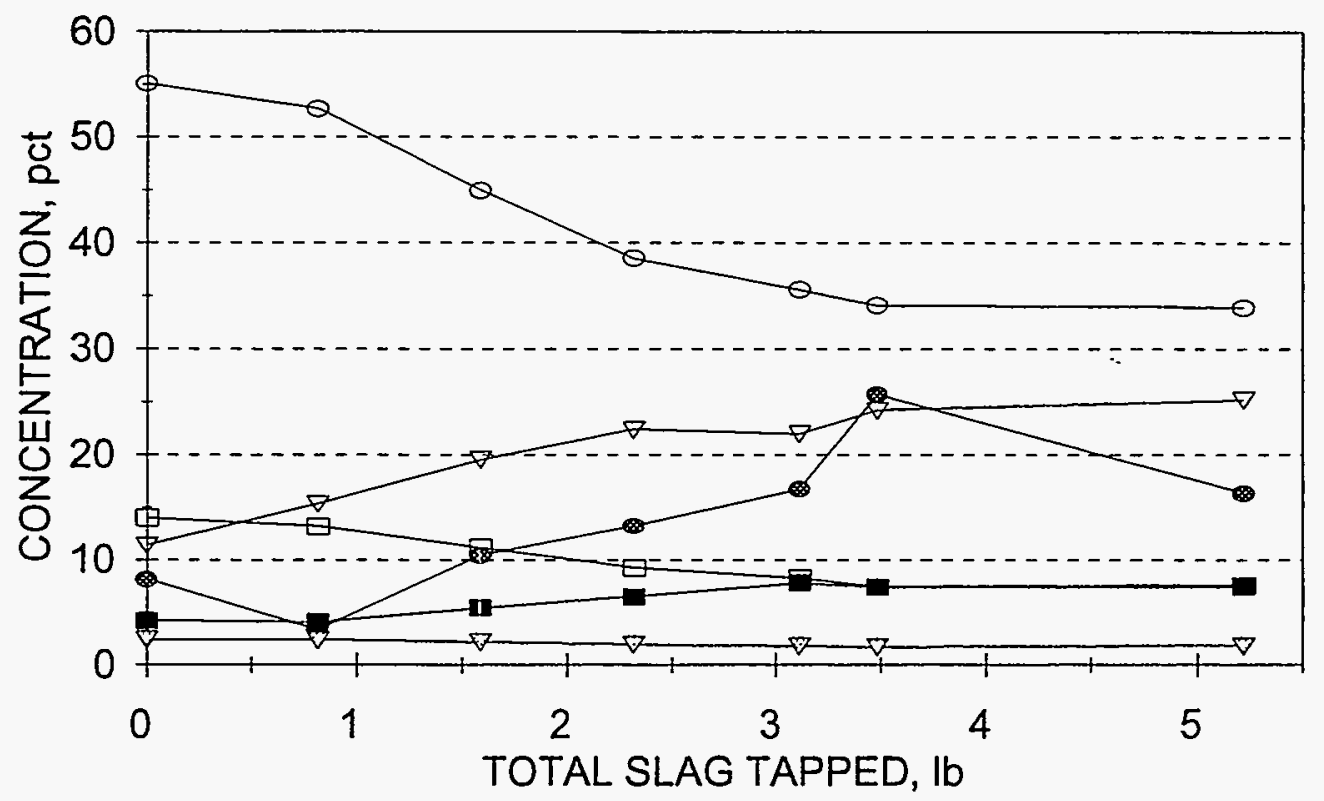

(Thousands)

$\begin{array}{lll}\varpi \mathrm{Al} 2 \mathrm{O} 3 & -\mathrm{CaO} & -\mathrm{Fe} 3 \mathrm{O} 4 \\ \rightarrow \mathrm{MgO} & -\mathrm{SiO} 2 & -\mathrm{Na} 2 \mathrm{O}+\mathrm{K} 2 \mathrm{O}\end{array}$

1-6.a. Concentrations of slag forming oxides in the M60 slag.

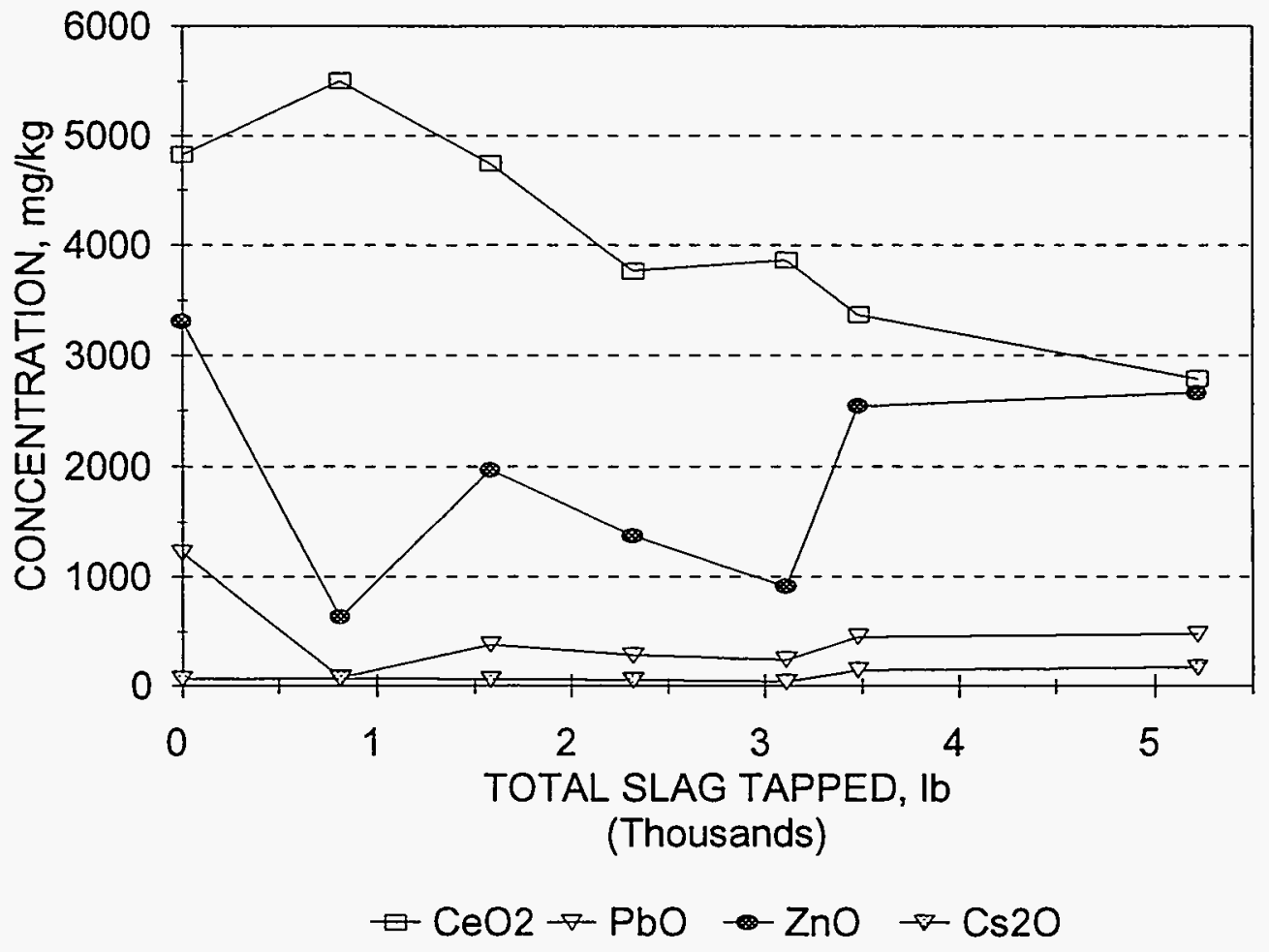

I-6.b. Concentrations of heavy metal and cesium oxides in the M60 slag. 
Appendix $\mathrm{J}$

X-Ray Diffraction Analysis of Furnace Products 

Table J-1. X-Ray diffraction analysis of the $\$ 60$ furnace products.

\begin{tabular}{|c|c|c|c|c|c|}
\hline \multirow[b]{2}{*}{ Phase } & \multicolumn{2}{|c|}{ Slag } & \multicolumn{3}{|c|}{ Fume Solids } \\
\hline & S60-S1 & S60-S7 & Fume Trap 1 & Fume Trap 2 & Baghouse \\
\hline Primary & non-crystalline & non-crystalline & ND & ND & ND \\
\hline Secondary & ND & ND & ND & ND & $\begin{array}{l}\mathrm{NaCl} \text { (Halite) } \\
\mathrm{KCl} \text { (Sylvite) }\end{array}$ \\
\hline Minor & ND & $\begin{array}{l}\text { [(Mg, } \mathrm{Fe}) 2 \mathrm{SiO} 4] \\
\text { Forsterite }\end{array}$ & $\begin{array}{l}\mathrm{SiO} 2 \text { (Quartz) } \\
\mathrm{NaCl} \text { (Halite) } \\
\mathrm{KCl} \text { (Sylvite) } \\
\end{array}$ & $\begin{array}{l}\mathrm{SiO} 2 \text { (Quartz) } \\
\mathrm{NaCl} \text { (Halite) } \\
\mathrm{KCl} \text { (Sylvite). }\end{array}$ & ND \\
\hline Trace & may contain Alpha $\mathrm{Fe}$ & $\begin{array}{l}\text { unidentified } \\
\text { compounds }\end{array}$ & $\begin{array}{c}\text { Fe304 (Magnetite) } \\
\text { CaSiO3 (Wollastonite) } \\
\text { NaAISi3O8 (Albite) } \\
\text { Mg3Si4O10(OH)2 (Talc) }\end{array}$ & $\begin{array}{c}\text { Fe304 (Magnetite) } \\
\text { CaSiO3 (Wollastonite) } \\
\text { NaAlSi3O8 (Albite) } \\
\text { Mg3Si4010(OH)2 (Talc) }\end{array}$ & $\begin{array}{l}\text { unidentified } \\
\text { compounds }\end{array}$ \\
\hline nary $\mathrm{Ph}$ & 40 to $100 \%$ & hase: 20 to $60 \%$ & Minor Phase: 5 to $30 \%$ & Trace: 1 to $10 \%$ & t detected \\
\hline
\end{tabular}

Table J-2. X-Ray diffraction analysis of the S60-IV furnace products.

\begin{tabular}{|c|c|c|c|c|c|}
\hline \multirow[b]{2}{*}{ Phase } & \multicolumn{2}{|c|}{ Slag } & \multicolumn{3}{|c|}{ Fume Solids } \\
\hline & S60-IV-SI & S60-IV-S6 & Fume Trap 1 & Fume Trap 2 & Baghouse \\
\hline Primary & $\begin{array}{l}\text { only non-crystaline } \\
\text { material detected }\end{array}$ & $\begin{array}{l}\text { only non-crystaline } \\
\text { material detected }\end{array}$ & ND & ND & ND \\
\hline Secondary & ND & ND & ND & $\begin{array}{l}\mathrm{NaCl} \text { (Halite) } \\
\mathrm{KCl} \text { (Sylvite) }\end{array}$ & $\begin{array}{l}\mathrm{NaCl} \text { (Halite) } \\
\mathrm{KCl} \text { (Sylvite) }\end{array}$ \\
\hline Minor & ND & ND & $\begin{array}{c}\mathrm{NaCl} \text { (Halite) } \\
\mathrm{KCl} \text { (Sylvite) } \\
\text { Fe3O4 (Magnetite) } \\
\mathrm{SiO} 2 \text { (Quartz) } \\
\text { CaSiO3 (Wollastonite) } \\
\end{array}$ & $\begin{array}{c}\mathrm{SiO} 2 \text { (Quartz) } \\
\text { CaSiO3 (Wollastonite) }\end{array}$ & $\begin{array}{l}\text { water soluble } \\
\text { Cs-Fe-Cl } \\
\text { compound }\end{array}$ \\
\hline Trace & ND & ND & $\mathrm{Mg} 3 \mathrm{Si} 4 \mathrm{O} 10(\mathrm{OH}) 2$ (Talc) & $\begin{array}{l}\text { Mg3Si4O10(OH)2 (Talc) } \\
\text { NaAISi3O8-CaAl2Si2O8 } \\
\text { (plagioclase) } \\
\text { unidentified compounds }\end{array}$ & $\begin{array}{c}\mathrm{Fe} 3 \mathrm{O} 4 \text { (Magnetite) } \\
\mathrm{Ca} 4(\mathrm{CaOH})(\mathrm{PO}) 3 \\
\text { (hydroxylapatite) } \\
\text { non-crystalline }\end{array}$ \\
\hline imary Phas & 0 to $100 \%$ & e: 20 to $60 \%$ & Phase: 5 to $30 \%$ & ND: Not det & \\
\hline
\end{tabular}

Table J-3. X-Ray diffraction analysis of N80 furnace products.

\begin{tabular}{|c|c|c|c|c|c|}
\hline \multirow[b]{2}{*}{ Phase } & \multicolumn{2}{|c|}{ Slag } & \multicolumn{3}{|c|}{ Fume Solids } \\
\hline & S60-IV-S1 & S60-IV-S6 & Fume Trap 1 & Fume Trap 2 & Baghouse \\
\hline Primary & $\begin{array}{l}\text { only non-crystaline } \\
\text { material detected }\end{array}$ & $\begin{array}{l}\text { only non-crystaline } \\
\text { material detected }\end{array}$ & ND & ND & ND \\
\hline Secondary & ND & ND & ND & $\begin{array}{l}\mathrm{NaCl} \text { (Halite) } \\
\mathrm{KCl} \text { (Sylvite) }\end{array}$ & $\begin{array}{l}\mathrm{NaCl} \text { (Halite) } \\
\mathrm{KCl} \text { (Sylvite) }\end{array}$ \\
\hline Minor & ND & ND & $\begin{array}{c}\mathrm{NaCl} \text { (Halite) } \\
\mathrm{KCl} \text { (Sylvite) } \\
\mathrm{Fe} 304 \text { (Magnetite) } \\
\mathrm{SiO} 2 \text { (Quartz) } \\
\text { CaSiO3 (Wollastonite) }\end{array}$ & $\begin{array}{c}\mathrm{SiO} 2 \text { (Quartz) } \\
\text { CaSiO3 (Wollastonite) }\end{array}$ & $\begin{array}{l}\text { water soluble } \\
\mathrm{Cs}-\mathrm{Fe}-\mathrm{Cl} \\
\text { compound }\end{array}$ \\
\hline Trace & ND & ND & Mg3Si4010(OH)2 (Talc) & $\begin{array}{l}\text { Mg3Si4010(OH)2 (Talc) } \\
\text { NaAlSi3O8-CaAl2Si2O } \\
\text { (plagioclase) } \\
\text { unidentified compounds }\end{array}$ & $\begin{array}{c}\text { Fe304 (Magnetite) } \\
\text { Ca4(CaOH)(PO4)3 } \\
\text { (hydroxylapatite) } \\
\text { non-crystalline }\end{array}$ \\
\hline Primary Pha & 40 to $100 \%$ & Phase: 20 to $60 \%$ & Minor Phase: 5 to $30 \%$ & Trace: 1 to $10 \%$ ND: & Not detected \\
\hline
\end{tabular}


Table J-4. X-Ray diffraction analysis of the N80-Mod furnace products.

\begin{tabular}{|c|c|c|c|c|c|}
\hline \multirow[b]{2}{*}{ Phase } & \multicolumn{2}{|l|}{ Slag } & \multicolumn{3}{|c|}{ Fume Solids } \\
\hline & N80-Mod-S6 & N80-Mod-S7 & Fume Trap 1 & Fume Trap 2 & Baghouse \\
\hline Primary & $\begin{array}{l}\text { only non-crystaline } \\
\text { material detected }\end{array}$ & $\begin{array}{l}\text { only non-crystaline } \\
\text { material detected }\end{array}$ & ND & ND & ND \\
\hline Secondary & ND & ND & ND & $\mathrm{CaCO} 3$ (Calcite) & ND \\
\hline Minor & ND & $\mathrm{ND}$ & $\begin{array}{c}\mathrm{CaCO} 3 \text { (Calcite) } \\
\mathrm{SiO} 2 \text { (Quartz) } \\
\mathrm{CaO} \text { (Lime) }\end{array}$ & $\begin{array}{c}\mathrm{SiO} 2 \text { (Quartz) } \\
\mathrm{CaO} \text { (Lime) }\end{array}$ & $\begin{array}{c}\mathrm{CaCO} 3 \text { (Calcite) } \\
\mathrm{NaCl} \text { (Halite) } \\
\mathrm{KCl} \text { (Sylvite) }\end{array}$ \\
\hline Trace & $\begin{array}{l}\text { unidentified } \\
\text { compounds }\end{array}$ & $\begin{array}{l}\text { unidentified } \\
\text { compounds }\end{array}$ & $\begin{array}{c}\mathrm{NaCl} \text { (Halite) } \\
\mathrm{KCl} \text { (Sylvite) } \\
\mathrm{NaAlSi} 3 \text { 8 (Albite) } \\
\text { Fe3O4 (Magnetite) }\end{array}$ & $\begin{array}{c}\mathrm{NaCl} \text { (Halite) } \\
\mathrm{KCl} \text { (Sylvite) } \\
\mathrm{NaAlSi} 3 \mathrm{O} \text { (Albite) } \\
\mathrm{Fe} 3 \mathrm{O} 4 \text { (Magnetite) }\end{array}$ & $\begin{array}{c}\mathrm{SiO} 2 \text { (Quartz) } \\
\text { unidentified compoun }\end{array}$ \\
\hline $\begin{array}{l}\text { imary Pha } \\
\text { D: Not de }\end{array}$ & $0 \%$ & $60 \%$ & $30 \%$ & & \\
\hline
\end{tabular}

Table J-5. X-Ray diffraction analysis of the N80-IV furnace products.

\begin{tabular}{|c|c|c|c|c|}
\hline \multirow[b]{2}{*}{ Phase } & Slag & \multicolumn{3}{|c|}{ Fume Solids } \\
\hline & N80-IV-S4 & Fume Trap I & Fume Trap 2 & Baghouse \\
\hline Primary & $\begin{array}{l}\text { only non-crystaline } \\
\text { material detected }\end{array}$ & ZrO2 (Zirconia) & ND & ND \\
\hline Secondary & $\mathrm{ND}$ & ND & $\mathrm{ZrO} 2$ (Zirconia) & $\mathrm{KCl}$ (Sylvite) \\
\hline Minor & ND & $\mathrm{SiO} 2$ (Quartz) & $\begin{array}{c}\mathrm{SiO} 2 \text { (Quartz) } \\
\mathrm{CaCO} 3 \text { (Calcite) }\end{array}$ & $\begin{array}{c}\mathrm{NaCl} \text { (Halite) } \\
\mathrm{ZrO2} \text { (Zirconia) } \\
\mathrm{CaCO} \text { (Calcite) }\end{array}$ \\
\hline Trace & ND & $\begin{array}{c}\mathrm{CaCO} 3 \text { (Calcite) } \\
\mathrm{Fe} 3 \mathrm{O} 4 \text { (Magnetite) } \\
\mathrm{Na} 2 \mathrm{CO} 3 \\
\text { unidentified compounds }\end{array}$ & $\begin{array}{c}\mathrm{Na} 2 \mathrm{CO} 3 \\
\mathrm{CaO}(\mathrm{Lime}) \\
\text { unidentified compounds }\end{array}$ & unidentified compounds \\
\hline $\begin{array}{l}\text { Primary Phe } \\
\text { Trace: } 1 \text { to }\end{array}$ & $\begin{array}{l}\text { to } 100 \% \text { Seconda } \\
\text { ND: Not detected }\end{array}$ & 20 to $60 \%$ Minor & 5 to $30 \%$ & \\
\hline
\end{tabular}

Table J-6. X-Ray diffraction analysis of the N80-IV-Mod furnace products.

\begin{tabular}{|c|c|c|c|c|}
\hline \multirow[b]{2}{*}{ Phase } & Slag & \multicolumn{3}{|c|}{ Fume Solids } \\
\hline & N80-IV-Mod-S10 & Fume Trap 1 & Fume Trap 2 & Baghouse \\
\hline Primary & $\begin{array}{l}\text { non-crystaline } \\
\text { material }\end{array}$ & ND & ND & $\begin{array}{l}\text { non-crystaline } \\
\text { material }\end{array}$ \\
\hline Secondary & ND & ND & ND & ND \\
\hline Minor & ND & $\begin{array}{c}\text { ZrO2 (Zirconia) } \\
\mathrm{CaO} \text { (Lime) } \\
\mathrm{SiO2} \text { (Quartz) }\end{array}$ & $\begin{array}{c}\mathrm{ZrO} 2 \text { (Zirconia) } \\
\mathrm{SiO} 2 \text { (Quartz) } \\
\mathrm{CaO} \text { (Lime) }\end{array}$ & ND \\
\hline Trace & MgO (Periclase) & $\begin{array}{c}\mathrm{CaCO} 3 \text { (Calcite) } \\
\mathrm{Na} 2 \mathrm{CO} 3 \\
\mathrm{~K} 2 \mathrm{CO} 3 \\
\mathrm{KCl} \text { (Sylvite) } \\
\mathrm{NaCl} \text { (Halite) } \\
\mathrm{CeO} 2 \\
\text { unidentified compounds }\end{array}$ & $\begin{array}{c}\mathrm{CaCO} 3 \text { (Calcite) } \\
\mathrm{Na} 2 \mathrm{CO} 3 \\
\mathrm{~K} 2 \mathrm{CO} 3 \\
\mathrm{KCl} \text { (Sylvite) } \\
\mathrm{NaCl} \text { (Halite) } \\
\text { possible } \mathrm{CeO} 2\end{array}$ & $\begin{array}{c}\mathrm{KCl} \text { (Sylvite) } \\
\mathrm{ZrO} 2 \text { (Zirconia) } \\
\mathrm{NaCl} \text { (Halite) } \\
\mathrm{SiO} 2 \text { (Quartz) }\end{array}$ \\
\hline $\begin{array}{l}\text { rimary Phas } \\
\text { race: } 1 \text { to } 1\end{array}$ & $\begin{array}{l}\text { to } 100 \% \text { Second } \\
\text { ND: Not detected }\end{array}$ & se: 20 to $60 \%$ Minor & 5 to $30 \%$ & \\
\hline
\end{tabular}


Table J-7. X-Ray diffraction analysis of the M60 furnace products.

\begin{tabular}{|c|c|c|c|c|}
\hline \multirow[b]{2}{*}{ Phase } & Slag & \multicolumn{3}{|c|}{ Fume Solids } \\
\hline & M60-S1 & Fume Trap 1 & Fume Trap 2 & Baghouse \\
\hline Primary & $\begin{array}{l}\text { non-crystaline } \\
\text { material detected }\end{array}$ & $\begin{array}{c}\text { non-crystaline } \\
\text { material detected }\end{array}$ & ND & ND \\
\hline Secondary & ND & ND & $\mathrm{ND}$ & $\begin{array}{c}\text { ZnO (Zincite) } \\
\text { non-crystaline } \\
\text { material detected }\end{array}$ \\
\hline Minor & ND & $\begin{array}{c}\mathrm{SiO} 2 \text { (Quartz) } \\
\text { CaSiO3 (Wollastonite) } \\
\text { NaAlSi3O8-CaAl2Si2O8 } \\
\text { (plagioclase) } \\
\text { ZnO (Zincite) } \\
\end{array}$ & $\begin{array}{c}\mathrm{ZnO} \text { (Zincite) } \\
\mathrm{SiO} 2 \text { (Quartz) } \\
\text { CaSiO3 (Wollastonite) } \\
\text { non-crystaline } \\
\text { material detected }\end{array}$ & $\mathrm{Pb}$ (Lead) \\
\hline Trace & $\begin{array}{c}\text { alpha Fe } \\
\text { unidentified } \\
\text { compounds }\end{array}$ & $\begin{array}{c}\mathrm{Pb} \text { (Lead) } \\
\text { Fe3O4 (Magnetite) }\end{array}$ & $\begin{array}{c}\mathrm{Pb}(\mathrm{Lead}) \\
\mathrm{NaAISi3O} \text {-CaAl2Si2O8 } \\
\text { (plagioclase) } \\
\mathrm{CaO} \text { (Lime) } \\
\mathrm{ZrO} 2 \text { (Zirconia) } \\
\mathrm{CaCO} \text { (Calcite) } \\
\text { unidentified compounds }\end{array}$ & $\begin{array}{l}\text { may contain } \mathrm{Zn}(\mathrm{OH}) 2 \\
\text { unidentified compounds }\end{array}$ \\
\hline
\end{tabular}

Table J-8, X-Ray diffraction analysis of the M60-Mod furnace products.

\begin{tabular}{|c|c|c|c|c|c|}
\hline \multirow[b]{2}{*}{ Phase } & \multicolumn{2}{|l|}{ Slag } & \multicolumn{3}{|c|}{ Fume Solids } \\
\hline & M60-Mod-S2 & M60-Mod-S5 & Fume Trap 1 & Fume Trap 2 & Baghouse \\
\hline Primary & $\begin{array}{c}\text { non-crystaline } \\
\text { material }\end{array}$ & $\begin{array}{c}\text { non-crystaline } \\
\text { material }\end{array}$ & ND & ND & ND \\
\hline Secondary & ND & ND & ND & ND & ZnO (Zincite) \\
\hline Minor & ND & ND & $\begin{array}{c}\mathrm{CaO} \text { (Lime) } \\
\mathrm{CaCO} 3 \text { (Calcite) } \\
\mathrm{ZrO2} \text { (Zirconia) } \\
\mathrm{SiO} 2 \text { (Quartz) }\end{array}$ & $\begin{array}{c}\mathrm{CaO} \text { (Lime) } \\
\mathrm{SiO} 2 \text { (Quartz) } \\
\mathrm{ZnO} \text { (Zincite) } \\
\mathrm{ZrO2} \text { (Zirconia) }\end{array}$ & ND \\
\hline Trace & Fe3O4 (Magnetite) & $\begin{array}{c}\text { Fe304 (Magnetite) } \\
\text { unidentified } \\
\text { compounds }\end{array}$ & $\begin{array}{c}\text { Fe3O4 (Magnetite) } \\
\mathrm{ZnO} \text { (Zincite) } \\
\text { CaSiO3 (Wollastonite) } \\
\text { unidentified compounds }\end{array}$ & $\begin{array}{c}\mathrm{Fe} 3 \mathrm{O} 4 \text { (Magnetite) } \\
\mathrm{CaCO} 3 \text { (Calcite) } \\
\mathrm{Pb} \text { (Lead) } \\
\mathrm{Na} 2 \mathrm{CO} 3 \\
\mathrm{~K} 2 \mathrm{CO} 3 \\
\mathrm{CaSiO} 3 \text { (Wollastonite) } \\
\text { NaAlSi3O8-CaAl2Si2O8 } \\
\text { (plagioclase) }\end{array}$ & $\begin{array}{c}\mathrm{Pb} \text { (Lead) } \\
\mathrm{KCl} \text { (Sylvite) } \\
\mathrm{CaCO} \text { (Calcite) } \\
\mathrm{ZrO} 2 \text { (Zirconia) } \\
\text { may contain Zn(OH)2 } \\
\text { unidentified compoun }\end{array}$ \\
\hline nary Pha & $0100 \%$ & 20 to $60 \%$ & lase: 5 to $30 \%$ & ND: Not detected & \\
\hline
\end{tabular}




\section{Appendix K}

Chemical Composition of Furnace Products 

Table K-1. Masses and chemical composition of furnace products from the melting test of RWMC soil and mill scale.

\begin{tabular}{|c|c|c|c|c|c|c|}
\hline & RWMC & & APCS so & & Total APCS & Volatilized \\
\hline & Slag & SD-T1 & SD-T2 & SD-BH & Solids & bag house \\
\hline$w t, 1 b$ & 6,030 & 1 & 29 & 35 & 65 & catch \\
\hline$w t, \%$ & 100 & 1.54 & 44.62 & 53.85 & 100 & components \\
\hline Component & & & Concentra & $\mathrm{n}, \mathrm{mg} / \mathrm{kg}$ & & \\
\hline $\mathrm{Ag} 2 \mathrm{O}$ & $<1$ & 2 & 20 & 15 & 17 & 15 \\
\hline $\mathrm{Al} 2 \mathrm{O} 3$ & 88,003 & 78,800 & 86,500 & 38,900 & 60,751 & \\
\hline As203 & 10 & 49 & 238 & 647 & 455 & \\
\hline $\mathrm{BaO}$ & 940 & 539 & 622 & 205 & 396 & \\
\hline $\mathrm{CaO}$ & 32,065 & 41,000 & 51,500 & 23,000 & 35,992 & \\
\hline $\mathrm{CdO}$ & $<1$ & 3 & 51 & 54 & 52 & 54 \\
\hline $\mathrm{CeO} 2$ & $\mathrm{NC}$ & $\mathrm{NA}$ & NA & NA & $\mathrm{NC}$ & \\
\hline $\mathrm{Cl}$ & $<100$ & 980 & 17,200 & 10,100 & 13,127 & \\
\hline $\mathrm{CO} 2$ & 247 & 8,800 & 3,990 & 2,640 & 3,337 & \\
\hline $\mathrm{CrO} 2$ & 1,120 & 414 & 543 & 352 & 438 & \\
\hline $\mathrm{Cs} 2 \mathrm{O}$ & 10 & 24 & 27 & 63 & 46 & \\
\hline $\mathrm{CuO}$ & 715 & 362 & 611 & 1,500 & 1,086 & \\
\hline $\mathrm{Fe} 3 \mathrm{O} 4$ & 229,175 & 93,000 & 78,000 & 72,000 & 75,000 & \\
\hline $\mathrm{HgO}$ & $<0.1$ & 1 & 14 & 17 & 15 & \\
\hline $\mathrm{K} 2 \mathrm{O}$ & 20,262 & 26,600 & 34,900 & 40,900 & 38,003 & 40,900 \\
\hline $\mathrm{MgO}$ & 20,464 & 18,200 & 19,800 & 8,830 & 13,868 & \\
\hline $\mathrm{Na2O}$ & 17,380 & 25,500 & 27,800 & 29,700 & 28,788 & 29,700 \\
\hline $\mathrm{NiO}$ & 311 & 118 & 132 & 226 & 182 & 226 \\
\hline P2O5 & 708 & 4,560 & 13,700 & 25,400 & 19,859 & 25,400 \\
\hline $\mathrm{PbO}$ & 20 & 119 & 3,090 & 1,370 & 2,118 & 1,370 \\
\hline $\mathrm{SO} 3$ & 17 & 1,040 & 4,880 & 6,980 & 5,952 & 6,980 \\
\hline $\mathrm{SeO} 2$ & $<1$ & 3 & 13 & 22 & 18 & 22 \\
\hline $\mathrm{SiO} 2$ & 458,015 & 639,000 & 568,000 & 651,000 & 613,785 & \\
\hline TiO2 & 8,873 & 3,480 & 5,820 & 1,310 & 3,356 & \\
\hline $\mathrm{ZnO}$ & 178 & 292 & 6,590 & 3,530 & 4,845 & 3,530 \\
\hline $\mathrm{ZrO} 2$ & 526 & 135 & 127 & 39 & 80 & \\
\hline Total & 879,000 & 943,000 & 927,000 & 919,000 & 920,000 & 108,197 \\
\hline
\end{tabular}

Notes: 1. The slag composition is the most representative slag composition for the RWMC soil + mill scale. (weighted mean composition of all slag molds)

2. The composition of the total APCS solids is from the weighted average composition for the combined fume traps and bag house.

3. Components in the baghouse catch that increased in concentration from the fume trap 1 to the fume trap 2 to the baghouse were assumed to be volatilized. 
Table K-2. Masses and chemical composition of furnace products from the melting test of S60 waste mixture.

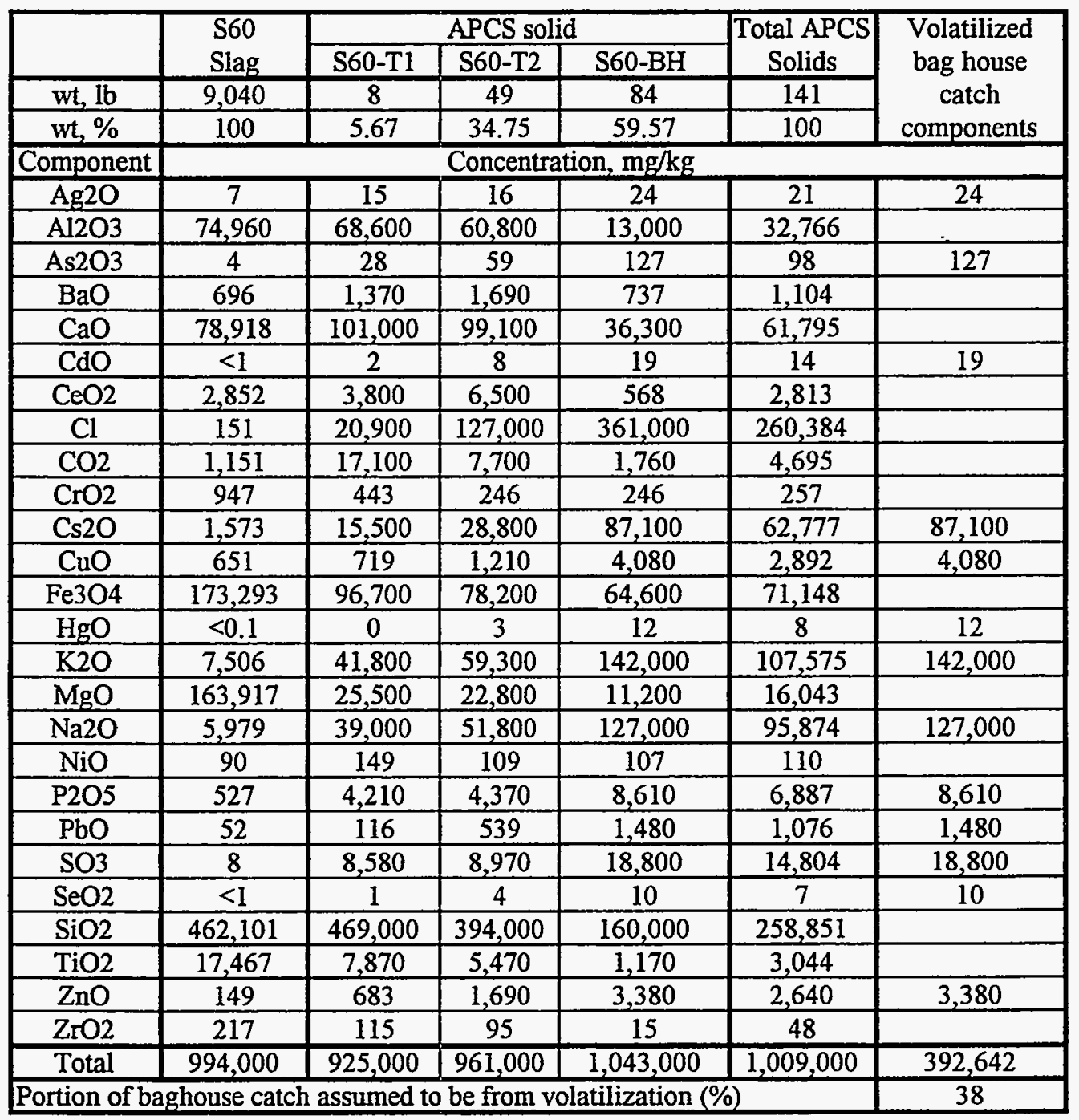

Notes: 1. The slag composition is the most representative slag composition for the $\mathrm{S} 60$ waste mixture. (weighted mean composition of last 3 slag molds)

2. The composition of the total APCS solids is from the weighted average composition for the combined fume traps and bag house.

3. Components in the baghouse catch that increased in concentration from the fume trap 1 to the fume trap 2 to the baghouse were assumed to be volatilized. 
Table K-3. Masses and chemical composition of furnace products from the melting test of S60-IV waste mixture.

\begin{tabular}{|c|c|c|c|c|c|c|}
\hline & \multirow{2}{*}{$\begin{array}{l}\text { S60-IV } \\
\text { Slag }\end{array}$} & \multicolumn{3}{|c|}{ APCS solid } & \multirow{2}{*}{$\begin{array}{l}\text { Total APCS } \\
\text { Solids }\end{array}$} & \multirow{4}{*}{$\begin{array}{l}\text { Volatilized } \\
\text { baghouse } \\
\text { catch } \\
\text { components }\end{array}$} \\
\hline & & S60-IV-T1 & S60-IV-T2 & S60-IV-BH & & \\
\hline wt, $1 \mathrm{lb}$ & 7,019 & 11 & 43 & 110 & 164 & \\
\hline $\mathrm{wt}, \%$ & 100 & 6.71 & 26.22 & 67.07 & 100 & \\
\hline Component & \multicolumn{5}{|c|}{ Concentration, $\mathrm{mg} / \mathrm{kg}$} & \\
\hline $\mathrm{Ag} 2 \mathrm{O}$ & $<1$ & 3 & 6 & 14 & 11 & $\overline{14}$ \\
\hline $\mathrm{Al} 2 \mathrm{O} 3$ & 70,969 & 57,100 & 47,200 & 8,300 & 21,773 & \\
\hline As2O3 & 3 & 37 & 63 & 67 & 64 & 67 \\
\hline $\mathrm{BaO}$ & 770 & 1,700 & 1,820 & 672 & 1,042 & \\
\hline $\mathrm{CaO}$ & 108,042 & 107,000 & 108,000 & 35,600 & 59,372 & \\
\hline $\mathrm{CdO}$ & $<1$ & 3 & 8 & 26 & 20 & 26 \\
\hline $\mathrm{CeO} 2$ & 4,679 & 6,960 & 5,130 & 472 & 2,128 & \\
\hline $\mathrm{Cl}$ & 100 & 94,000 & 154,000 & 387,000 & 306,256 & \\
\hline $\mathrm{CO} 2$ & 2,511 & 11,500 & 10,000 & 1,760 & 4,574 & \\
\hline $\mathrm{CrO} 2$ & 727 & 381 & 275 & 231 & 253 & 231 \\
\hline $\mathrm{Cs} 2 \mathrm{O}$ & 2,194 & 21,100 & 38,600 & 97,100 & 76,664 & 97,100 \\
\hline $\mathrm{CuO}$ & 63 & 203 & 300 & 1,260 & 937 & \\
\hline $\mathrm{Fe} 3 \mathrm{O} 4$ & 183,757 & 115,000 & 92,400 & 64,900 & 75,471 & \\
\hline $\mathrm{HgO}$ & $<0.1$ & 0 & 1 & 11 & 8 & 11 \\
\hline $\mathrm{K} 2 \mathrm{O}$ & 9,550 & 45,600 & 70,600 & 169,000 & 134,923 & 169,000 \\
\hline $\mathrm{MgO}$ & 33,705 & 30,700 & 24,700 & 7,330 & 13,452 & \\
\hline $\mathrm{Na} 2 \mathrm{O}$ & 20,228 & 41,200 & 60,800 & 164,000 & 128,705 & 164,000 \\
\hline $\mathrm{NiO}$ & 74 & 90 & 104 & 92 & 95 & \\
\hline $\mathrm{P} 2 \mathrm{O} 5$ & 121 & 4,030 & 5,430 & 13,800 & 10,950 & 13,800 \\
\hline $\mathrm{PbO}$ & 10 & 140 & 354 & 1,450 & 1,075 & 1,450 \\
\hline $\mathrm{SO} 3$ & 114 & 13,400 & 13,200 & 29,700 & 24,280 & 29,700 \\
\hline $\mathrm{SeO} 2$ & $<1$ & 4 & 8 & 8 & 8 & 8 \\
\hline $\mathrm{SiO} 2$ & 484,504 & 405,000 & 347,000 & 136,000 & 209,366 & \\
\hline $\mathrm{TiO} 2$ & 44,580 & 11,700 & 5,810 & 1,140 & 3,073 & \\
\hline $\mathrm{ZnO}$ & 119 & 961 & 1,390 & 4,050 & 3,145 & 4,050 \\
\hline $\mathrm{ZrO} 2$ & 22,211 & 264 & 158 & 120 & 140 & \\
\hline Total & 991,000 & 968,000 & 986,000 & $1,120,000$ & $1,080,000$ & 479,457 \\
\hline artion of $b$ & use ca & ssumed & be from vc & zation (\%) & & 43 \\
\hline
\end{tabular}

Notes: 1. For ease of use, all analyzed elements are reported as oxides, even though many of the elements such as $\mathrm{C}, \mathrm{Ca}, \mathrm{Cl}, \mathrm{Mg}$, and other metals may be present (especially in the fume traps and baghouse) as carbonates, chlorides, and sulfates.

2. The slag composition is the most representative slag composition for the S60-IV waste mixture. (weighted mean composition of last 3 slag molds).

3. The composition of the total APCS solids is from the weighted average composition for the combined fume traps and baghouse.

4. Components in the baghouse catch that increased in concentration from the fume trap 1 to the fume trap 2 to the baghouse were assumed to be volatilized.

INEL_RI.WB1 
Table K-4. Masses and chemical composition of furnace products from the melting test of $\mathrm{N} 80$ waste mixture.

\begin{tabular}{|c|c|c|c|c|c|c|}
\hline & \multirow{2}{*}{$\begin{array}{l}\text { N80 } \\
\text { Slag }\end{array}$} & \multicolumn{3}{|c|}{ APCS solid } & \multirow{2}{*}{\begin{tabular}{|c|} 
Total APCS \\
Solids
\end{tabular}} & \multirow{4}{*}{$\begin{array}{l}\text { Volatilized } \\
\text { bag house } \\
\text { catch } \\
\text { components }\end{array}$} \\
\hline & & $\mathrm{N} 80-\mathrm{Tl}$ & N80-T2 & N80-BH & & \\
\hline wt, lb & 4,069 & 15 & $\overline{14}$ & 80 & 109 & \\
\hline$w t, \%$ & 100 & 13.82 & 12.44 & $\overline{73.73}$ & 100 & \\
\hline Component & \multicolumn{5}{|c|}{ Concentration, $\mathrm{mg} / \mathrm{kg}$} & \\
\hline Ag2O & $<1$ & 2 & 11 & 45 & 35 & $\overline{45}$ \\
\hline $\mathrm{Al} 2 \mathrm{O} 3$ & 91,998 & 79,500 & 69,500 & 12,300 & 28,894 & \\
\hline As2O3 & 3 & 59 & 131 & 110 & 106 & 110 \\
\hline $\mathrm{BaO}$ & 931 & 1,129 & 1,606 & 746 & 909 & \\
\hline $\mathrm{CaO}$ & 81,763 & 70,100 & 81,900 & 29,500 & 41,817 & \\
\hline $\mathrm{CdO}$ & $<1$ & 7 & 18 & 24 & 21 & 24 \\
\hline $\mathrm{CeO} 2$ & 2,436 & 2,450 & 4,850 & 434 & 1,279 & \\
\hline $\mathrm{Cl}$ & 25 & 8,700 & 57,200 & 375,000 & 283,773 & \\
\hline $\mathrm{CO} 2$ & 1,682 & 28,500 & 33,900 & 3,150 & 10,588 & \\
\hline $\mathrm{CrO} 2$ & 350 & 289 & 494 & 249 & 286 & \\
\hline $\mathrm{Cs} 2 \mathrm{O}$ & 366 & 1,660 & 9,490 & 85,600 & 64,273 & 85,600 \\
\hline $\mathrm{CuO}$ & 49 & 56 & 216 & 1,530 & 1,158 & 1,530 \\
\hline $\mathrm{Fe} 3 \mathrm{O} 4$ & 146,714 & 72,800 & 75,000 & 62,000 & 65,156 & \\
\hline $\mathrm{HgO}$ & $<0.1$ & 0 & 4 & 13 & 10 & 13 \\
\hline $\mathrm{K} 2 \mathrm{O}$ & 60,693 & 58,300 & 70,900 & 145,000 & 123,551 & 145,000 \\
\hline $\mathrm{MgO}$ & 24,847 & 22,800 & 21,800 & 8,830 & 12,418 & \\
\hline $\mathrm{Na} 2 \mathrm{O}$ & 75,491 & 62,100 & 72,200 & 147,000 & 125,709 & 147,000 \\
\hline $\mathrm{NiO}$ & 85 & 498 & 2,430 & 4,490 & 3,676 & 4,490 \\
\hline $\mathrm{P} 2 \mathrm{O} 5$ & 675 & 3,640 & 6,940 & 13,400 & 11,227 & 13,400 \\
\hline $\mathrm{PbO}$ & 10 & 147 & 957 & 1,410 & 1,178 & 1,410 \\
\hline $\mathrm{SO} 3$ & 390 & 12,200 & 23,600 & 32,000 & 28,196 & 32,000 \\
\hline $\mathrm{SeO} 2$ & $<1$ & 1 & 8 & 8 & 7 & 8 \\
\hline $\mathrm{SiO} 2$ & 509,025 & 508,000 & 399,000 & 149,000 & 230,514 & \\
\hline $\mathrm{TiO} 2$ & 15,413 & 5,720 & 4,880 & 1,200 & 2,295 & \\
\hline $\mathrm{ZnO}$ & 115 & 488 & 2,380 & 4,400 & 3,602 & 4,400 \\
\hline $\mathrm{ZrO} 2$ & 1,717 & 120 & 151 & 82 & 96 & \\
\hline Total & $1,014,777$ & 939,000 & 939,000 & $1,070,000$ & $1,040,776$ & 435,030 \\
\hline Portion of $b$ & house catc & assumed & from vo & ization (\%) & & 41 \\
\hline
\end{tabular}

Notes: $\quad 1$ The slag composition is the most representative slag composition for the N80 waste mixture. (weighted mean composition of last 2 slag molds)

2. The composition of the total APCS solids is from the weighted average composition for the combined fume traps and bag house.

3. Components in the baghouse catch that increased in concentration from the fume trap 1

to the fume trap 2 to the baghouse were assumed to be volatilized.

4. The N80 slag weight was calculated from total slag(N80+N80-Mod)/total feed(N80+n80-Mod) $\bullet N 80$ feed.

INEL_RI.WB1 
Table K-5. Masses and chemical composition of furnace products from the melting test of N80-Mod waste mixture.

\begin{tabular}{|c|c|c|c|c|c|c|}
\hline & \multirow{2}{*}{$\begin{array}{l}\text { N80-Mod } \\
\text { Slag }\end{array}$} & \multicolumn{3}{|c|}{ APCS solid } & \multirow{2}{*}{$\begin{array}{c}\text { Total APCS } \\
\text { Solids }\end{array}$} & \multirow{4}{*}{$\begin{array}{c}\text { Volatilized } \\
\text { bag house } \\
\text { catch } \\
\text { components }\end{array}$} \\
\hline & & N80-Mod-T1 & N80-Mod-T2 & N80-Mod-BH & & \\
\hline $\mathrm{wt}, \mathrm{lb}$ & 3,341 & 13 & 47 & 62 & 122 & \\
\hline pct & 100 & 10.66 & 38.52 & 50.82 & 100 & \\
\hline Component & \multicolumn{6}{|c|}{ Concentration, $\mathrm{mg} / \mathrm{kg}$} \\
\hline Ag2O & $<1$ & 2 & 4 & 13 & 8 & 13 \\
\hline $\mathrm{Al} 2 \mathrm{O} 3$ & 68,557 & 41,800 & 37,600 & 19,100 & 28,646 & \\
\hline As2O3 & 8 & 104 & 145 & 247 & 192 & 247 \\
\hline $\mathrm{BaO}$ & 637 & 726 & 799 & 79 & 425 & \\
\hline $\mathrm{CaO}$ & 163,595 & 295,000 & 330,000 & 160,000 & 239,877 & \\
\hline $\mathrm{CdO}$ & $<1$ & 6 & 10 & 27 & 19 & 27 \\
\hline $\mathrm{CeO} 2$ & 2,138 & 2,360 & 2,900 & 2,060 & 2,416 & \\
\hline $\mathrm{Cl}$ & 30 & 25,800 & 22,100 & 108,000 & 66,148 & \\
\hline $\mathrm{CO} 2$ & 539 & 132,000 & 179,000 & 106,000 & 136,893 & \\
\hline $\mathrm{CrO} 2$ & 555 & 911 & 254 & 517 & 458 & \\
\hline $\mathrm{Cs} 2 \mathrm{O}$ & 543 & 3,180 & 3,060 & 17,810 & 10,569 & 17,810 \\
\hline $\mathrm{CuO}$ & 248 & 233 & 208 & 909 & 567 & 909 \\
\hline $\mathrm{Fe} 3 \mathrm{O} 4$ & 221,287 & 68,900 & 45,000 & 41,400 & 45,717 & \\
\hline $\mathrm{HgO}$ & $<0.1$ & 1 & 3 & 7 & 5 & 7 \\
\hline $\mathrm{K} 2 \mathrm{O}$ & 39,410 & 39,400 & 38,800 & 123,000 & 81,654 & 123,000 \\
\hline $\mathrm{MgO}$ & 27,152 & 19,200 & 20,300 & 12,300 & 16,117 & \\
\hline $\mathrm{Na2O}$ & 53,507 & 43,700 & 37,200 & 115,000 & 77,430 & 115,000 \\
\hline $\mathrm{NiO}$ & 143 & 318 & 107 & 160 & 156 & \\
\hline $\mathrm{P} 2 \mathrm{O} 5$ & 1,392 & 3,780 & 3,990 & 15,400 & 9,766 & 15,400 \\
\hline $\mathrm{PbO}$ & 10 & 106 & 357 & 813 & 562 & 813 \\
\hline $\mathrm{SO} 3$ & 200 & 14,600 & 14,200 & 58,400 & 36,705 & 58,400 \\
\hline $\mathrm{SeO} 2$ & $<1$ & 4 & 3 & 8 & 6 & 8 \\
\hline $\mathrm{SiO} 2$ & 383,023 & 264,000 & 209,000 & 150,000 & 184,877 & \\
\hline TiO2 & 13,562 & 3,400 & 2,530 & 1,610 & 2,155 & \\
\hline $\mathrm{ZnO}$ & 118 & 417 & 1,020 & 3,620 & 2,277 & 3,620 \\
\hline $\mathrm{ZrO} 2$ & 3,184 & 91 & 73 & 82 & 79 & \\
\hline Total & 979,837 & 959,000 & 948,000 & 936,000 & 943,726 & 335,254 \\
\hline Portion of bag & use catch as & ed to be fron & latilization & & & 36 \\
\hline
\end{tabular}

Notes: $\quad$ 1. The slag composition is the most representative slag composition for the N80-Mod waste mixture. (weighted mean composition of last 2 slag molds)

2. The composition of the total APCS solids is from the weighted average composition for the combined fume traps and bag house.

3. Components in the baghouse catch that increased in concentration from the fume trap 1

to the fume trap 2 to the baghouse were assumed to be volatilized.

4. The N80-Mod slag weight was calculated from: total slag(N80+N80-Mod)-N80 slag. 
Table K-6. Masses and chemical composition of furnace products from the melting test of N80-IV waste mixture.

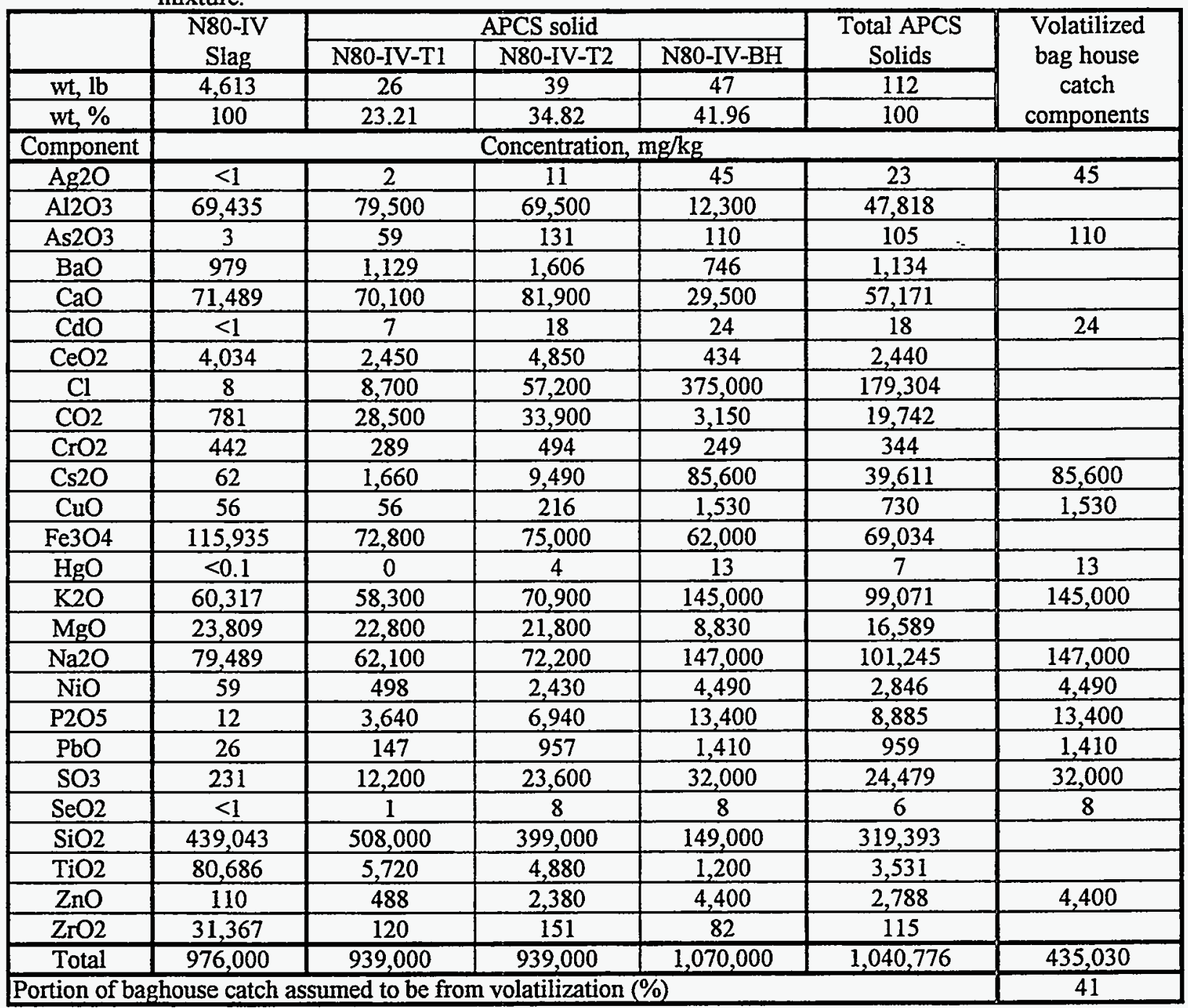

Notes: 1. The slag composition is the most representative slag composition for the N80-IV waste mixture. (weighted mean composition of last 2 slag molds)

2. The composition of the total APCS solids is from the weighted average composition for the combined fume traps and bag house.

3. Components in the baghouse catch that increased in concentration from the fume trap 1 to the fume trap 2 to the baghouse were assumed to be volatilized.

4. The N80-IV slag weight was calculated from: total slag(N80-IV+N80-IV-Mod)/total feed(N80-IV+N80-IV-Mod) • N80-IV feed. 
Table K-7. Masses and chemical composition of furnace products from the melting test of N80-IV-Mod waste mixture.

\begin{tabular}{|c|c|c|c|c|c|c|}
\hline & \multirow{2}{*}{$\begin{array}{c}\text { N80-IV-Mod } \\
\text { Slag }\end{array}$} & \multicolumn{3}{|c|}{ APCS solid } & \multirow{2}{*}{$\begin{array}{c}\text { Total APCS } \\
\text { Solids }\end{array}$} & \multirow{4}{*}{$\begin{array}{l}\text { Volatilized } \\
\text { bag house } \\
\text { catch } \\
\text { components }\end{array}$} \\
\hline & & N80-IV-Mod-T1 & N80-IV-Mod-T2 & N80-IV-Mod-BH & & \\
\hline$w t, 1 b$ & 4,167 & 14 & 45 & 67 & 126 & \\
\hline$w t, \%$ & 100 & 11.11 & 35.71 & 53.17 & 100 & \\
\hline Component & \multicolumn{2}{|l|}{ wt. mean" } & \multicolumn{2}{|c|}{ Concentration, $\mathrm{mg} / \mathrm{kg}$} & wt. mean & \\
\hline $\mathrm{Ag} 2 \mathrm{O}$ & $<1$ & 2 & 5 & 8 & 6 & 8 \\
\hline $\mathrm{Al} 2 \mathrm{O3}$ & 59,324 & 53,800 & 56,900 & 14,500 & 34,010 & \\
\hline As2O3 & 11 & 145 & 251 & 198 & 211 & 198 \\
\hline $\mathrm{BaO}$ & 683 & 1,320 & 1,680 & 1,620 & 1,608 & \\
\hline $\mathrm{CaO}$ & 184,136 & 196,000 & 196,000 & 77,700 & 133,094 & \\
\hline $\mathrm{CdO}$ & $<1$ & 3 & 8 & 46 & 28 & 46 \\
\hline $\mathrm{CeO} 2$ & 3,392 & 9,990 & 10,400 & 10,400 & 10,354 & \\
\hline $\mathrm{Cl}$ & 8 & 3,100 & 8,800 & 42,400 & 26,033 & \\
\hline $\mathrm{CO} 2$ & 1,174 & 29,800 & 45,500 & 61,200 & 52,104 & \\
\hline $\mathrm{CrO2}$ & 591 & 265 & 325 & 964 & 658 & 964 \\
\hline $\mathrm{Cs} 2 \mathrm{O}$ & 58 & 329 & 1,060 & 4,160 & 2,627 & 4,160 \\
\hline $\mathrm{CuO}$ & 300 & 325 & 376 & 1,030 & 718 & 1,030 \\
\hline $\mathrm{Fe} 304$ & 212,407 & 58,700 & 52,500 & 59,700 & 57,017 & \\
\hline $\mathrm{HgO}$ & $<0.1$ & 0 & 1 & 5 & 3 & 5 \\
\hline $\mathrm{K} 2 \mathrm{O}$ & 46,234 & 78,500 & 81,200 & 131,000 & 107,381 & 131,000 \\
\hline $\mathrm{MgO}$ & 17,859 & 16,700 & 18,200 & 9,830 & 13,583 & \\
\hline $\mathrm{Na} 2 \mathrm{O}$ & 61,412 & 70,200 & 79,000 & 174,000 & 128,538 & 174,000 \\
\hline $\mathrm{NiO}$ & 165 & 65 & 88 & 145 & 116 & 145 \\
\hline $\mathrm{P} 2 \mathrm{O} 5$ & 730 & $<1$ & 5 & 1,260 & 672 & 1,260 \\
\hline $\mathrm{PbO}$ & 23 & 101 & 280 & 1,770 & 1,052 & 1,770 \\
\hline $\mathrm{SO} 3$ & 206 & 12,000 & 14,600 & 50,000 & 33,135 & 50,000 \\
\hline $\mathrm{SeO}$ & $<1$ & 4 & 6 & 20 & 13 & 20 \\
\hline $\mathrm{SiO} 2$ & 278,494 & 313,000 & 296,000 & 257,000 & 277,151 & \\
\hline $\mathrm{TiO} 2$ & 50,557 & 4,800 & 4,100 & 4,200 & 4,231 & \\
\hline $\mathrm{ZnO}$ & 108 & 492 & 880 & 2,256 & 1,569 & 2,256 \\
\hline $\mathrm{ZrO2}$ & 24,935 & 98,800 & 57,800 & 18,100 & 41,245 & \\
\hline Total & 942,806 & 948,441 & 925,965 & 923,512 & 927,158 & 366,862 \\
\hline Portion of bas & se catch assum & o be from volatili & ation (\%) & & & 40 \\
\hline
\end{tabular}

Notes: $\quad$ 1. The slag composition is the most representative slag composition for the N80-IV-Mod waste mixture. (weighted mean composition of last 3 slag molds)

2. The composition of the total APCS solids is from the weighted average composition for the combined fume traps and bag house.

3. Components in the baghouse catch that increased in concentration from the fume trap 1

to the fume trap 2 to the baghouse were assumed to be volatilized.

4. The N80-IV-Mod slag weight was calculated from: total slag(N80_IV+N80-IV-Mod) - N80-IV slag. 
Table K-8. Masses and chemical composition of furnace products from melting test of M60 waste mixture.

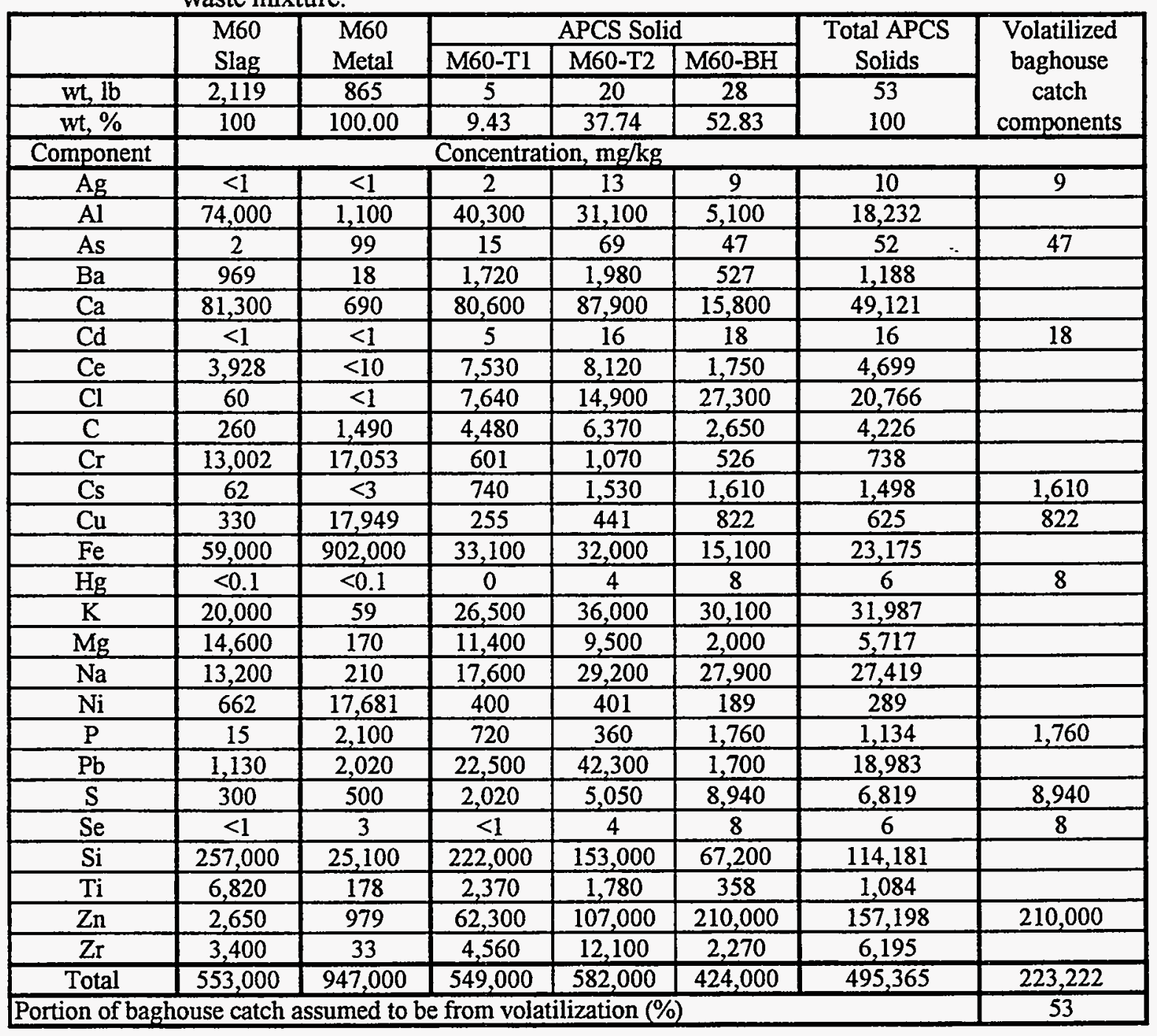

Notes: 1. For ease of use, all analyzed elements are reported as oxides, even though many of the elements such as $\mathrm{C}, \mathrm{Ca}, \mathrm{Cl}, \mathrm{Mg}$, and other metals may be present (especially in the fume traps and baghouse) as carbonates, chlorides, and sulfates.

2. The slag composition is from the M60 rod sample.

3. The composition of the total APCS solids is from the weighted average composition for the combined fume traps and baghouse.

4. Components in the baghouse catch that increased in concentration from the fume trap 1 to the fume trap 2 to the baghouse were assumed to be volatilized.

5. The $\mathrm{M} 60$ slag weight is the weight of the $\mathrm{M} 60$ slag remaining in the furnace before feeding the modified composition [total $\mathrm{M} 60$ mixture fed-volatiles in $\mathrm{M} 60$ feed (including $\mathrm{Cu}, \mathrm{Fe}$, and $\mathrm{Ni}$ ) which partitioned to the metal phase]

6. The M60 metal weight is the M60 remaining in the furnace before feeding the modified composition $[\mathrm{Cu}, \mathrm{Fe}, \mathrm{Ni}$ in feed]. 
Table K-9. Masses and chemical composition of furnace products from melting test of M60-Mod waste mixture.

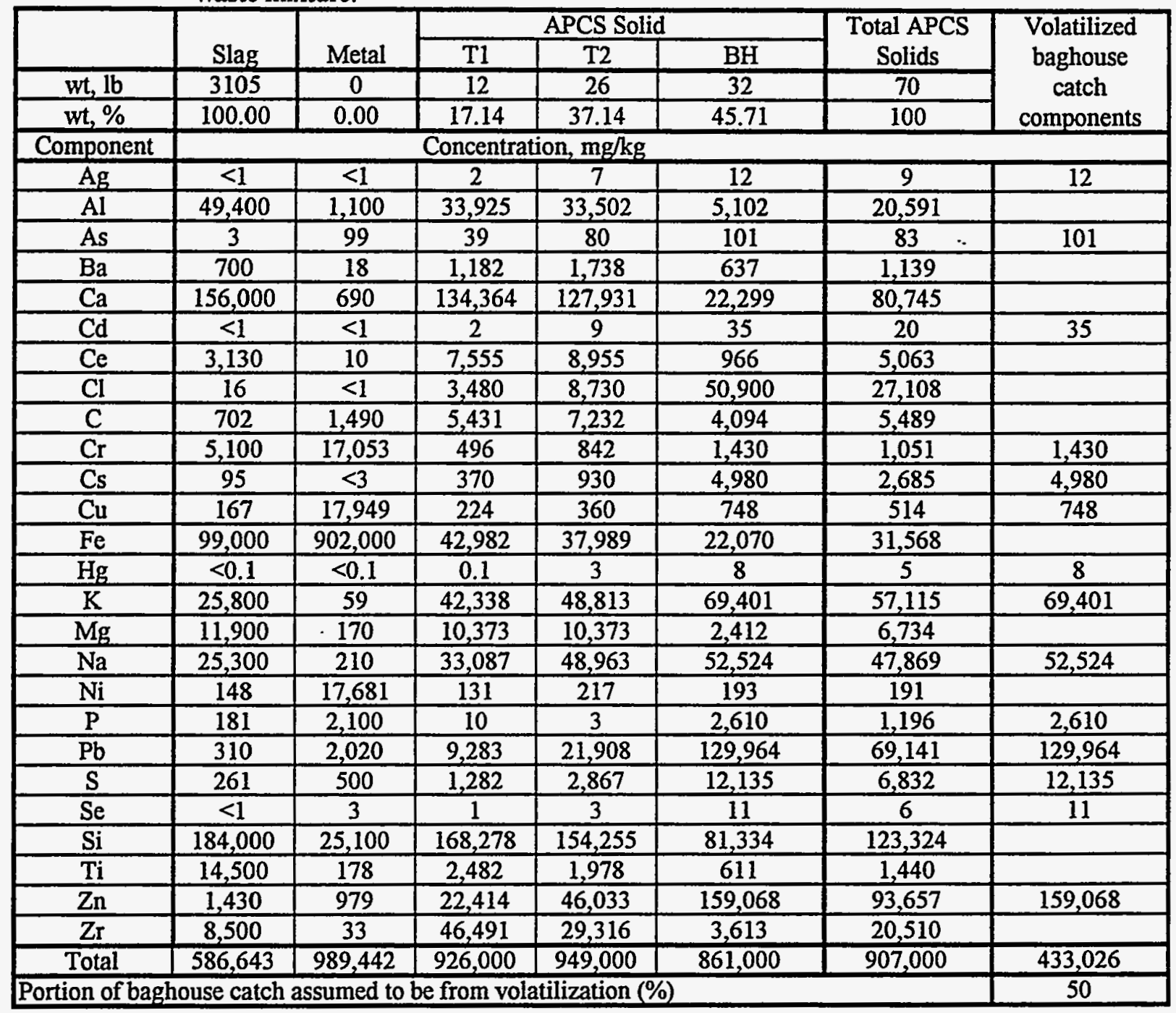


Appendix L

Distribution of Components Among Furnace Products 

- 
Table L-1. Distribution of components among furnace products during the shakedown test of the RWMC soil and mill scale.

\begin{tabular}{|c|c|c|c|c|c|c|c|c|c|c|c|c|}
\hline & \multicolumn{6}{|c|}{ APCS solid } & \multirow{2}{*}{\multicolumn{2}{|c|}{$\begin{array}{l}\text { APCS solid } \\
\text { Subtotal }\end{array}$}} & \multirow{2}{*}{\multicolumn{2}{|c|}{$\begin{array}{c}\text { Slag } \\
\text { Subtotal }\end{array}$}} & \multirow{2}{*}{\multicolumn{2}{|c|}{ Total }} \\
\hline & \multicolumn{2}{|c|}{ SD-Tl } & \multicolumn{2}{|c|}{ SD-T2 } & \multicolumn{2}{|c|}{ SD-BH } & & & & & & \\
\hline wt, pct & & 0.02 & & 0.48 & & 0.57 & & 1.07 & & 98.93 & & 100 \\
\hline Component & wt, $1 \mathrm{~b}$ & wt, pct & $\mathrm{wt}, \mathrm{lb}$ & wt, pct & wt, lb & $\mathrm{wt}, \mathrm{pct}$ & wt, lb & wt, pct & wt, lb & wt, pct & $\mathrm{wt}, \mathrm{lb}$ & $\mathrm{wt}, \mathrm{pct}$ \\
\hline $\mathrm{Al} 2 \mathrm{O} 3$ & 0.08 & 0.01 & 2.51 & 0.47 & 1.36 & 0.25 & 3.95 & 0.74 & 530.66 & 99.26 & 534.61 & 100.00 \\
\hline As203 & 0.000 & 0.05 & 0.007 & 7.63 & 0.02 & 25.02 & 0.03 & 32.70 & 0.06 & 67.30 & 0.09 & 100.00 \\
\hline $\mathrm{BaO}$ & 0.0005 & 0.01 & 0.02 & 0.32 & 0.01 & 0.13 & 0.03 & 0.45 & 5.67 & 99.55 & 5.70 & 100.00 \\
\hline $\mathrm{CeO} 2$ & $\mathrm{NC}$ & $\mathrm{NC}$ & $\mathrm{NC}$ & $\mathrm{NC}$ & $\mathrm{NC}$ & $\mathrm{NC}$ & NC & NC & $\mathrm{NC}$ & $\mathrm{NC}$ & $\mathrm{NC}$ & $\mathrm{NC}$ \\
\hline $\mathrm{Cl}$ & 0.00 & 0.11 & 0.50 & 58.46 & 0.35 & 41.43 & 0.85 & 100.00 & $\mathrm{NC}$ & $\mathrm{NC}$ & 0.85 & 100.00 \\
\hline $\mathrm{CO} 2$ & 0.009 & 0.52 & 0.12 & 6.79 & 0.09 & 5.42 & 0.22 & 12.72 & 1.49 & 87.28 & 1.70 & 100.00 \\
\hline $\mathrm{CrO} 2$ & 0.0004 & 0.01 & 0.02 & 0.23 & 0.01 & 0.18 & 0.03 & 0.42 & 6.75 & 99.58 & 6.78 & 100.00 \\
\hline $\mathrm{Cs} 2 \mathrm{O}$ & 0.00002 & 0.04 & 0.0008 & 1.29 & 0.002 & 3.63 & 0.003 & 4.95 & 0.06 & 95.05 & 0.06 & 100.00 \\
\hline $\mathrm{CuO}$ & 0.0004 & 0.01 & 0.02 & 0.40 & 0.05 & 1.20 & 0.07 & 1.61 & 4.31 & 98.39 & 4.38 & 100.00 \\
\hline $\mathrm{Fe} 3 \mathrm{O} 4$ & 0.09 & 0.01 & 2.26 & 0.16 & 2.52 & 0.18 & 4.88 & 0.35 & 1381.92 & 99.65 & 1386.80 & 100.00 \\
\hline $\mathrm{NiO}$ & 0.0001 & 0.01 & 0.004 & 0.20 & 0.008 & 0.42 & 0.012 & 0.63 & 1.87 & 99.37 & 1.89 & 100.00 \\
\hline $\mathrm{P} 2 \mathrm{O5}$ & 0.005 & 0.08 & 0.40 & 7.15 & 0.89 & 15.99 & 1.29 & 23.23 & 4.27 & 76.77 & 5.56 & 100.00 \\
\hline $\mathrm{PbO}$ & 0.0001 & 0.05 & 0.090 & 34.38 & 0.05 & 18.40 & 0.14 & 52.83 & 0.12 & 47.17 & 0.26 & 100.00 \\
\hline$\overline{\mathrm{SO} 3}$ & 0.001 & 0.21 & 0.14 & 28.95 & 0.24 & 49.97 & 0.39 & 79.14 & 0.10 & 20.86 & 0.49 & 100.00 \\
\hline $\mathrm{SeO} 2$ & 0.000003 & 0.26 & 0.00038 & 32.78 & 0.0008 & 66.96 & 0.0012 & 100.00 & 0.00 & $\mathrm{NC}$ & 0.0012 & 100.00 \\
\hline $\mathrm{SiO} 2$ & 0.64 & 0.02 & 16.47 & 0.59 & 22.79 & 0.81 & 39.90 & 1.42 & 2761.83 & 98.58 & 2801.73 & 100.00 \\
\hline TiO2 & 0.003 & 0.01 & 0.17 & 0.31 & 0.05 & 0.09 & 0.22 & 0.41 & 53.50 & 99.59 & 53.72 & 100.00 \\
\hline $\mathrm{ZnO}$ & 0.0003 & 0.02 & 0.19 & 13.76 & 0.12 & 8.90 & 0.31 & 22.68 & 1.07 & 77.32 & 1.39 & 100.00 \\
\hline $\mathrm{ZrO2}$ & 0.00014 & 0.004 & 0.004 & 0.12 & 0.001 & 0.04 & 0.005 & 0.16 & 3.17 & 99.84 & 3.18 & 100.00 \\
\hline Total & 1 & & 27 & & 32 & & 60 & & 5301 & & 5360 & \\
\hline
\end{tabular}


Table L-2. Distribution of components among furnace products in the melting test of the S60 waste mixture.

\begin{tabular}{|c|c|c|c|c|c|c|c|c|c|c|c|c|}
\hline & \multicolumn{6}{|c|}{ APCS solid } & \multirow{2}{*}{\multicolumn{2}{|c|}{$\begin{array}{l}\text { APCS solid } \\
\text { Subtotal }\end{array}$}} & \multirow{2}{*}{\multicolumn{2}{|c|}{$\begin{array}{c}\text { Slag } \\
\text { Subtotal }\end{array}$}} & \multirow{2}{*}{\multicolumn{2}{|c|}{ Total }} \\
\hline & \multicolumn{2}{|c|}{ S60-T1 } & \multicolumn{2}{|c|}{$\mathrm{S} 60-\mathrm{T} 2$} & \multicolumn{2}{|c|}{ S60-BH } & & & & & & \\
\hline $\mathrm{wt}, \mathrm{lb}$ & & 8 & & 49 & & 84 & & 141 & & 9040 & & 9181 \\
\hline $\mathrm{wt}, \mathrm{pct}$ & & 0.09 & & 0.53 & & 0.91 & & 1.54 & & 98.46 & & 100 \\
\hline Component & $\mathrm{wt}, \mathrm{lb}$ & wt, pct & $\mathrm{wt}, \mathrm{lb}$ & wt, pct & wt, lb & wt, pct & $\mathrm{wt}, \mathrm{lb}$ & wt, pct & $w t, l b$ & wt, pct & $\mathrm{wt}, \mathrm{lb}$ & wt, pct \\
\hline $\mathrm{Ag} 2 \mathrm{O}$ & 0.0001 & 0.18 & 0.0008 & 1.17 & 0.002 & 3.00 & 0.003 & 4.35 & 0.06 & 95.65 & 0.07 & 100.00 \\
\hline $\mathrm{A} 12 \mathrm{O} 3$ & 0.5488 & 0.08 & 2.9792 & 0.44 & 1.092 & 0.16 & 4.62 & 0.68 & 677.64 & 99.32 & 682.26 & 100.00 \\
\hline As2O3 & 0.0002 & 0.47 & 0.0029 & 6.07 & 0.011 & 22.42 & 0.01 & 28.96 & 0.03 & 71.04 & 0.05 & 100.00 \\
\hline $\mathrm{BaO}$ & 0.0110 & 0.17 & 0.0828 & 1.28 & 0.062 & 0.96 & 0.16 & 2.41 & 6.29 & 97.59 & 6.45 & 100.00 \\
\hline $\mathrm{CaO}$ & 0.8080 & 0.11 & 4.8559 & 0.67 & 3.049 & 0.42 & 8.71 & 1.21 & 713.42 & 98.79 & 722.13 & 100.00 \\
\hline $\mathrm{CdO}$ & 0.0000 & 0.80 & 0.0004 & 19.56 & 0.002 & 79.64 & 0.002 & 100.00 & $\mathrm{NC}$ & $\overline{\mathrm{NC}}$ & 0.002 & 100.00 \\
\hline $\mathrm{CeO} 2$ & 0.0304 & 0.12 & 0.3185 & 1.22 & 0.048 & 0.18 & 0.40 & 1.51 & 25.79 & 98.49 & 26.18 & 100.00 \\
\hline $\mathrm{Cl}$ & 0.1672 & 0.44 & 6.2230 & 16.34 & 30.324 & 79.63 & 36.71 & 96.41 & 1.37 & 3.59 & 38.08 & 100.00 \\
\hline $\mathrm{CO} 2$ & 0.1368 & 1.24 & 0.3773 & 3.41 & 0.148 & 1.34 & 0.66 & 5.98 & 10.41 & 94.02 & 11.07 & 100.00 \\
\hline $\mathrm{CrO} 2$ & 0.0035 & 0.04 & 0.0121 & 0.14 & 0.021 & 0.24 & 0.04 & 0.42 & 8.56 & 99.58 & 8.59 & 100.00 \\
\hline $\mathrm{Cs} 2 \mathrm{O}$ & 0.1240 & 0.54 & 1.4112 & 6.12 & 7.316 & 31.71 & 8.85 & 38.36 & 14.22 & 61.64 & 23.08 & 100.00 \\
\hline $\mathrm{CuO}$ & 0.0058 & 0.09 & 0.0593 & 0.94 & 0.343 & 5.45 & 0.41 & 6.48 & 5.88 & 93.52 & 6.29 & 100.00 \\
\hline $\mathrm{Fe} 3 \mathrm{O} 4$ & 0.7736 & 0.05 & 3.8318 & 0.24 & 5.426 & 0.34 & 10.03 & 0.64 & 1566.57 & 99.36 & 1576.60 & 100.00 \\
\hline $\mathrm{HgO}$ & 0.0000 & 0.14 & 0.0001 & 12.71 & 0.001 & 87.15 & 0.001 & 100.00 & $\mathrm{NC}$ & $\mathrm{NC}$ & 0.001 & 100.00 \\
\hline $\mathrm{K} 2 \mathrm{O}$ & 0.3344 & 0.40 & 2.9057 & 3.50 & 11.928 & 14.37 & 15.17 & 18.27 & 67.86 & 81.73 & 83.03 & 100.00 \\
\hline $\mathrm{MgO}$ & 0.2040 & 0.01 & 1.1172 & 0.08 & 0.941 & 0.06 & 2.26 & 0.15 & 1481.81 & 99.85 & 1484.07 & 100.00 \\
\hline $\mathrm{Na} 2 \mathrm{O}$ & 0.3120 & 0.46 & 2.5382 & 3.76 & 10.668 & 15.79 & 13.52 & 20.01 & 54.05 & 79.99 & 67.57 & 100.00 \\
\hline $\mathrm{NiO}$ & 0.0012 & 0.14 & 0.0053 & 0.64 & 0.009 & 1.08 & 0.02 & 1.87 & 0.82 & 98.13 & 0.83 & 100.00 \\
\hline $\mathrm{P2O5}$ & 0.0337 & 0.59 & 0.2141 & 3.73 & 0.723 & 12.61 & 0.97 & 16.93 & 4.76 & 83.07 & 5.73 & 100.00 \\
\hline $\mathrm{PbO}$ & 0.0009 & 0.15 & 0.0264 & 4.22 & 0.124 & 19.87 & 0.15 & 24.24 & 0.47 & 75.76 & 0.63 & 100.00 \\
\hline $\mathrm{SO} 3$ & 0.0686 & 3.18 & 0.4395 & 20.34 & 1.579 & 73.07 & 2.09 & 96.59 & 0.07 & 3.41 & 2.16 & 100.00 \\
\hline $\mathrm{SeO} 2$ & 0.0000 & 0.77 & 0.0002 & 18.77 & 0.001 & 80.46 & 0.0010 & 100.00 & $\overline{\mathrm{NC}}$ & $\overline{\mathrm{NC}}$ & 0.0010 & 100.00 \\
\hline $\mathrm{SiO} 2$ & 3.7520 & 0.09 & 19.3060 & 0.46 & 13.440 & 0.32 & 36.50 & 0.87 & 4177.39 & 99.13 & 4213.89 & 100.00 \\
\hline TiO2 & 0.0630 & 0.04 & 0.2680 & 0.17 & 0.098 & 0.06 & 0.43 & 0.27 & 157.91 & 99.73 & 158.33 & 100.00 \\
\hline $\mathrm{ZnO}$ & 0.0055 & 0.32 & 0.0828 & 4.82 & 0.284 & 16.52 & 0.37 & 21.66 & 1.35 & $\begin{array}{l}78.34 \\
\end{array}$ & 1.72 & 100.00 \\
\hline $\mathrm{ZrO2}$ & 0.0009 & 0.05 & 0.0047 & 0.24 & 0.001 & 0.06 & 0.007 & 0.35 & 1.96 & 99.65 & 1.97 & 100.00 \\
\hline Total & 7 & & 47 & & 88 & & $\overline{142}$ & & 8979 & & $\overline{9121}$ & \\
\hline
\end{tabular}


Table L-3. Distribution of components among furnace products in the melting test of the S60-IV waste mixture.

\begin{tabular}{|c|c|c|c|c|c|c|c|c|c|c|c|c|}
\hline & \multicolumn{6}{|c|}{ APCS solid } & \multirow{2}{*}{\multicolumn{2}{|c|}{$\begin{array}{l}\text { APCS solid } \\
\text { Subtotal }\end{array}$}} & \multirow{2}{*}{\multicolumn{2}{|c|}{$\begin{array}{c}\text { Slag } \\
\text { Subtotal }\end{array}$}} & \multirow{2}{*}{\multicolumn{2}{|c|}{ Total }} \\
\hline & \multicolumn{2}{|c|}{ S60-IV-T1 } & \multicolumn{2}{|c|}{ S60-IV-T2 } & \multicolumn{2}{|c|}{ S60-IV-BH } & & & & & & \\
\hline $\mathrm{wt}, \mathrm{lb}$ & & 11 & & 43 & & 110 & & 164 & & 7019 & & 7183 \\
\hline $\mathrm{wt}, \mathrm{pct}$ & & 0.15 & & 0.60 & & 1.53 & & 2.28 & & 97.72 & & 100 \\
\hline Component & $\mathrm{wt}, \mathrm{lb}$ & wt, pct & $w t, 1 b$ & $\overline{w t}, \mathrm{pct}$ & $\mathrm{wt}, \mathrm{lb}$ & $\mathrm{wt}, \mathrm{pct}$ & $w t, 1 b$ & wt, pct & $\mathrm{wt}, \mathrm{lb}$ & $\mathrm{wt}, \mathrm{pct}$ & $w t, 1 b$ & wt, pct \\
\hline Ag2O & 0.00003 & 1.80 & 0.0003 & 14.09 & 0.002 & 84.11 & 0.002 & 100.00 & NC & NC & 0.002 & 100.00 \\
\hline $\mathrm{Al} 2 \mathrm{O} 3$ & 0.62810 & 0.13 & 2.0296 & 0.40 & 0.913 & 0.18 & 3.571 & 0.71 & 498.13 & 99.29 & 501.70 & 100.00 \\
\hline $\mathrm{As} 203$ & 0.00041 & 1.22 & 0.0027 & 8.12 & 0.007 & 22.10 & 0.010 & 31.44 & 0.02 & 68.56 & 0.03 & 100.00 \\
\hline $\mathrm{BaO}$ & 0.01870 & 0.34 & 0.0783 & 1.40 & 0.074 & 1.33 & 0.171 & 3.06 & 5.41 & 96.94 & 5.58 & 100.00 \\
\hline $\mathrm{CaO}$ & 1.17700 & 0.15 & 4.6440 & 0.60 & 3.916 & 0.51 & 9.737 & 1.27 & 758.35 & 98.73 & 768.08 & 100.00 \\
\hline $\mathrm{CdO}$ & 0.00003 & 1.02 & 0.0003 & 10.63 & 0.003 & 88.35 & 0.003 & 100.00 & NC & NC & 0.003 & 100.00 \\
\hline $\mathrm{CeO} 2$ & 0.07656 & 0.23 & 0.2206 & 0.66 & 0.052 & 0.16 & 0.349 & 1.05 & 32.84 & 98.95 & 33.19 & 100.00 \\
\hline $\mathrm{Cl}$ & 1.03400 & 2.03 & 6.6220 & 13.00 & 42.570 & 83.58 & 50.226 & 98.62 & 0.70 & 1.38 & 50.93 & 100.00 \\
\hline $\mathrm{CO} 2$ & 0.12650 & 0.69 & 0.4300 & 2.34 & 0.194 & 1.05 & 0.751 & 4.08 & 17.63 & 95.92 & 18.38 & 100.00 \\
\hline $\mathrm{CrO} 2$ & 0.00419 & 0.08 & 0.0118 & 0.23 & 0.025 & 0.49 & 0.041 & 0.81 & 5.10 & 99.19 & 5.14 & 100.00 \\
\hline Cs2O & 0.23210 & 0.83 & 1.6598 & 5.93 & 10.681 & 38.18 & 12.573 & 44.94 & 15.40 & 55.06 & 27.98 & 100.00 \\
\hline $\mathrm{CuO}$ & 0.00223 & 0.37 & 0.0129 & 2.16 & 0.139 & 23.16 & 0.154 & 25.69 & 0.44 & 74.31 & 0.60 & 100.00 \\
\hline $\mathrm{Fe} 3 \mathrm{O} 4$ & 1.26500 & 0.10 & 3.9732 & 0.31 & 7.139 & 0.55 & 12.377 & 0.95 & 1289.79 & 99.05 & 1302.17 & 100.00 \\
\hline $\mathrm{HgO}$ & 0.00000 & 0.18 & 0.0000 & 3.43 & 0.001 & 96.40 & 0.001 & 100.00 & NC & $\mathrm{NC}$ & 0.001 & 100.00 \\
\hline $\mathrm{K} 2 \mathrm{O}$ & 0.50160 & 0.56 & 3.0358 & 3.41 & 18.590 & 20.85 & 22.127 & 24.82 & 67.03 & 75.18 & 89.16 & 100.00 \\
\hline $\mathrm{MgO}$ & 0.33770 & 0.14 & 1.0621 & 0.44 & 0.806 & 0.34 & 2.206 & 0.92 & 236.57 & 99.08 & 238.78 & 100.00 \\
\hline $\mathrm{Na} 2 \mathrm{O}$ & 0.45320 & 0.28 & 2.6144 & 1.60 & 18.040 & 11.06 & 21.108 & 12.94 & 141.98 & 87.06 & 163.09 & 100.00 \\
\hline $\mathrm{NiO}$ & 0.00099 & 0.18 & 0.0045 & 0.83 & 0.010 & 1.88 & 0.015 & 2.90 & 0.52 & 97.10 & 0.54 & 100.00 \\
\hline $\mathrm{P} 205$ & 0.04433 & 1.68 & 0.2335 & 8.83 & 1.518 & 57.43 & 1.796 & 67.94 & 0.85 & 32.06 & 2.64 & 100.00 \\
\hline $\mathrm{PbO}$ & 0.00154 & 0.62 & 0.0152 & 6.13 & 0.160 & 64.19 & 0.177 & 70.93 & 0.07 & 29.07 & 0.25 & 100.00 \\
\hline $\mathrm{SO} 3$ & 0.14740 & 3.08 & 0.5676 & 11.87 & 3.267 & 68.30 & 3.982 & 83.25 & 0.80 & 16.75 & 4.78 & 100.00 \\
\hline $\mathrm{SeO} 2$ & 0.00004 & 3.47 & 0.0003 & 27.13 & 0.001 & 69.40 & 0.001 & 100.00 & NC & $\overline{\mathrm{NC}}$ & 0.001 & 100.00 \\
\hline SiO2 & 4.45500 & 0.13 & 14.9210 & 0.43 & 14.960 & 0.44 & 34.336 & 1.00 & 3400.73 & 99.00 & 3435.07 & 100.00 \\
\hline TiO2 & 0.12870 & 0.04 & 0.2498 & 0.08 & 0.125 & 0.04 & 0.504 & 0.16 & 312.90 & 99.84 & 313.41 & 100.00 \\
\hline $\mathrm{ZnO}$ & 0.01057 & 0.78 & 0.0598 & 4.43 & 0.446 & 33.01 & 0.516 & 38.22 & 0.83 & 61.78 & 1.35 & 100.00 \\
\hline $\mathrm{ZrO2}$ & 0.00290 & 0.002 & 0.0068 & 0.004 & 0.013 & 0.01 & 0.023 & 0.01 & 155.90 & 99.99 & 155.92 & 100.00 \\
\hline Total & 11 & & 42 & & 124 & & 177 & & 6942 & & 7119 & \\
\hline
\end{tabular}


Table L-4. Distribution of components among furnace products in the melting test of the N80 waste mixture.

\begin{tabular}{|c|c|c|c|c|c|c|c|c|c|c|c|c|}
\hline & & & $\overline{\mathrm{APCS}}$ & & & & $\overline{\mathrm{APC}}$ & & & & & \\
\hline & $\overline{\mathrm{N} 80}$ & & & & & $\overline{\mathrm{BH}}$ & & & & & & \\
\hline $\mathrm{wt}, \mathrm{lb}$ & & 15 & & 14 & & 80 & & 109 & & 4069 & & 4178 \\
\hline $\mathrm{wt}, \mathrm{pct}$ & & 0.36 & & 0.34 & & 1.91 & & 2.61 & & 97.39 & & 100 \\
\hline Component & $\mathrm{wt}, \mathrm{lb}$ & pct & $\mathrm{wt}, \mathrm{lb}$ & wt, pct & $\mathrm{wt}, \mathrm{lb}$ & $\mathrm{wt}, \mathrm{pct}$ & $w t, 1 b$ & $\mathrm{wt}, \mathrm{pct}$ & $\mathrm{wt}, \mathrm{lb}$ & wt, pct & $\mathrm{wt}, \mathrm{lb}$ & wt, pct \\
\hline $\mathrm{Ag} 2 \mathrm{O}$ & 0.00003 & 0.79 & 0.0002 & 4.07 & 0.004 & 95.14 & 0.004 & 100.00 & $\overline{\mathrm{NC}}$ & $\overline{\mathrm{NC}}$ & 0.004 & 100.00 \\
\hline $\mathrm{Al} 2 \mathrm{O} 3$ & 1.19250 & 0.32 & 0.97 & 0.26 & 0.98 & 0.26 & 3.15 & 0.83 & 374.34 & 99.17 & 377.49 & 100.00 \\
\hline$\overline{\mathrm{As} 2 \mathrm{O} 3}$ & 0.0009 & 3.73 & 0.002 & 7.73 & 0.009 & 37.09 & 0.01 & 48.55 & 0.01 & 51.45 & 0.02 & 100.00 \\
\hline $\mathrm{BaO}$ & 0.02 & 0.44 & 0.02 & 0.58 & 0.06 & 1.54 & 0.10 & 2.55 & 3.79 & 97.45 & 3.89 & 100.00 \\
\hline $\mathrm{CaO}$ & 1.05 & 0.31 & 1.15 & 0.34 & 2.36 & 0.70 & 4.56 & 1.35 & 332.69 & 98.65 & 337.25 & 100.00 \\
\hline $\mathrm{CdO}$ & 0.0001 & 4.61 & 0.0003 & 11.07 & 0.002 & 84.32 & 0.002 & 100.00 & $\mathrm{NC}$ & NC & 0.002 & 100.00 \\
\hline $\mathrm{CeO} 2$ & 0.04 & 0.37 & 0.07 & 0.68 & 0.04 & 0.35 & 0.14 & 1.39 & 9.91 & 98.61 & 10.05 & 100.00 \\
\hline $\mathrm{Cl}$ & 0.13 & 0.42 & 0.80 & 2.58 & 30.00 & 96.67 & 30.93 & 99.67 & 0.10 & 0.33 & 31.03 & 100.00 \\
\hline $\mathrm{CO} 2$ & 0.43 & 5.35 & 0.47 & 5.93 & 0.25 & 3.15 & 1.15 & 14.43 & 6.84 & 85.57 & 8.00 & 100.00 \\
\hline $\mathrm{CrO} 2$ & 0.004 & 0.30 & 0.007 & 0.48 & 0.02 & 1.37 & 0.03 & 2.14 & 1.42 & 97.86 & 1.45 & 100.00 \\
\hline $\mathrm{Cs} 2 \mathrm{O}$ & 0.02 & 0.29 & 0.13 & 1.56 & 6.85 & 80.60 & 7.01 & 82.46 & 1.49 & 17.54 & 8.50 & 100.00 \\
\hline $\mathrm{CuO}$ & 0.0008 & 0.26 & 0.003 & 0.93 & 0.12 & 37.58 & 0.13 & 38.77 & 0.20 & 61.23 & 0.33 & 100.00 \\
\hline $\mathrm{Fe} 3 \mathrm{O} 4$ & 1.09 & 0.18 & 1.05 & 0.17 & 4.96 & 0.82 & 7.10 & 1.18 & 596.98 & 98.82 & 604.08 & 100.00 \\
\hline $\mathrm{HgO}$ & 0.000002 & 0.14 & 0.0001 & 5.10 & 0.001 & 94.76 & 0.001 & 100.00 & $\mathrm{NC}$ & $\mathrm{NC}$ & 0.001 & 100.00 \\
\hline $\mathrm{K} 2 \mathrm{O}$ & 0.87 & 0.34 & 0.99 & 0.38 & 11.60 & 4.45 & 13.47 & 5.17 & 246.96 & 94.83 & 260.43 & 100.00 \\
\hline $\mathrm{MgO}$ & 0.34 & 0.33 & 0.31 & 0.30 & 0.71 & 0.69 & 1.35 & 1.32 & 101.10 & 98.68 & 102.46 & 100.00 \\
\hline $\mathrm{Na2O}$ & 0.93 & 0.29 & 1.01 & 0.32 & 11.76 & 3.66 & 13.70 & 4.27 & 307.17 & 95.73 & 320.88 & 100.00 \\
\hline $\mathrm{NiO}$ & 0.007 & 1.00 & 0.03 & 4.57 & 0.36 & 48.22 & 0.40 & 53.79 & 0.34 & 46.21 & 0.74 & 100.00 \\
\hline$\overline{\mathrm{P} 2 \mathrm{OS}}$ & 0.05 & 1.37 & 0.10 & 2.45 & 1.07 & 27.00 & 1.22 & 30.82 & 2.75 & 69.18 & 3.97 & 100.00 \\
\hline $\mathrm{PbO}$ & 0.002 & 1.29 & 0.01 & 7.83 & 0.11 & 65.92 & 0.13 & 75.04 & 0.04 & 24.96 & 0.17 & 100.00 \\
\hline $\mathrm{SO} 3$ & 0.18 & 3.93 & 0.33 & 7.09 & 2.56 & 54.93 & 3.07 & 65.95 & 1.59 & 34.05 & 4.66 & 100.00 \\
\hline $\mathrm{SeO} 2$ & 0.00002 & 1.96 & 0.0001 & 14.60 & 0.001 & 83.44 & 0.001 & 100.00 & $\mathrm{NC}$ & $\mathrm{NC}$ & 0.001 & 100.00 \\
\hline $\mathrm{SiO2}$ & 7.620 & 0.36 & 5.59 & 0.27 & 11.92 & 0.57 & 25.13 & 1.20 & 2071.22 & 98.80 & 2096.35 & 100.00 \\
\hline TiO2 & 0.086 & 0.14 & 0.07 & 0.11 & 0.10 & 0.15 & 0.25 & 0.40 & 62.72 & 99.60 & 62.97 & 100.00 \\
\hline $\mathrm{ZnO}$ & 0.007 & 0.85 & 0.03 & 3.88 & 0.35 & 40.99 & 0.39 & 45.72 & 0.47 & 54.28 & 0.86 & 100.00 \\
\hline $\mathrm{ZrO2}$ & 0.002 & 0.03 & 0.002 & 0.03 & 0.007 & 0.09 & 0.01 & 0.15 & 6.98 & 99.85 & 7.00 & 100.00 \\
\hline Total & 14 & & 13 & & 86 & & 113 & & 4129 & & 4243 & \\
\hline
\end{tabular}


Table L-5. Distribution of components among furnace products in the melting test of the N80-Mod waste mixture.

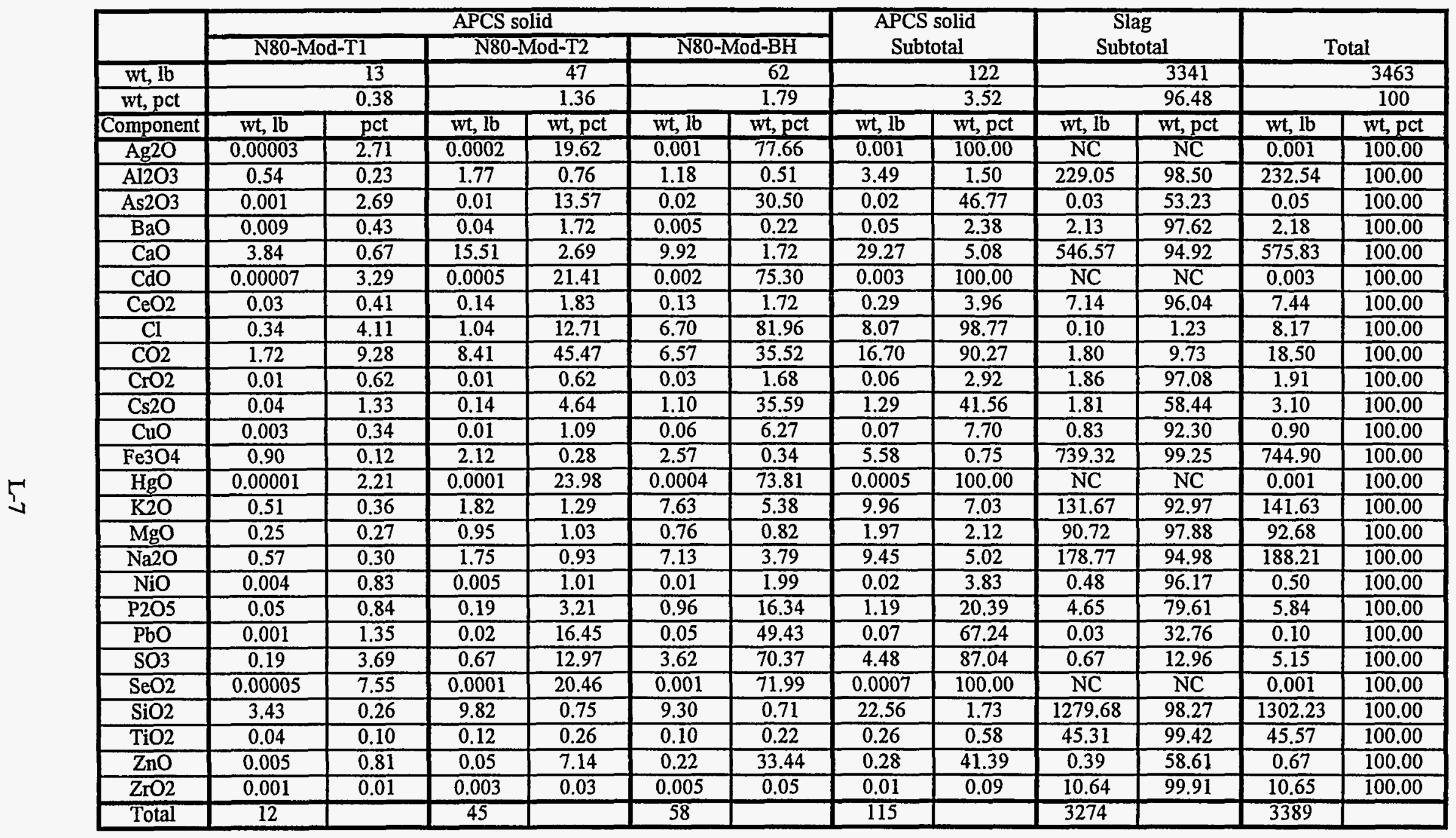


Table L-6. Distribution of components among furnace products in the melting test of the N80-IV waste mixture.

\begin{tabular}{|c|c|c|c|c|c|c|c|c|c|c|c|c|}
\hline & \multicolumn{6}{|c|}{ APCS solid } & \multirow{2}{*}{\multicolumn{2}{|c|}{$\begin{array}{l}\text { APCS solid } \\
\text { Subtotal }\end{array}$}} & \multirow{2}{*}{\multicolumn{2}{|c|}{$\begin{array}{c}\text { Slag } \\
\text { Subtotal }\end{array}$}} & \multirow{2}{*}{\multicolumn{2}{|c|}{ Total }} \\
\hline & \multicolumn{2}{|c|}{ N80-IV-T1 } & \multicolumn{2}{|c|}{ N80-IV-T2 } & \multicolumn{2}{|c|}{ N80-IV-BH } & & & & & & \\
\hline$\overline{w t}, \mathrm{lb}$ & & 26 & & 39 & & 47 & & 112 & & 4613 & & 4725 \\
\hline $\mathrm{wt}, \mathrm{pct}$ & & 0.55 & & 0.83 & & 0.99 & & 2.37 & & 97.63 & & 100 \\
\hline Component & $\mathrm{wt}, \mathrm{lb}$ & $\overline{p c t}$ & $\mathrm{wt}, \mathrm{lb}$ & wt, pct & $\mathrm{wt}, \mathrm{lb}$ & wt, pct & $w t, \mathrm{lb}$ & wt, pct & $w t, l b$ & $\mathrm{wt}, \mathrm{pct}$ & $\mathrm{wt}, \mathrm{lb}$ & $\mathrm{wt}, \mathrm{pct}$ \\
\hline Ag2O & 0.00005 & 2.00 & 0.0004 & 16.53 & 0.002 & 81.47 & 0.003 & 100.00 & $\mathrm{NC}$ & $\mathrm{NC}$ & 0.003 & 100.00 \\
\hline $\mathrm{Al} 2 \mathrm{O} 3$ & 2.06700 & 0.63 & 2.7105 & 0.83 & 0.578 & 0.18 & 5.36 & 1.64 & 320.30 & 98.36 & 325.66 & 100.00 \\
\hline As2O3 & 0.00153 & 5.65 & 0.0051 & 18.81 & 0.005 & 19.04 & 0.01 & 43.50 & 0.02 & 56.50 & 0.03 & 100.00 \\
\hline $\mathrm{BaO}$ & 0.02935 & 0.63 & 0.0626 & 1.35 & 0.035 & 0.76 & 0.13 & 2.74 & 4.52 & 97.26 & 4.64 & 100.00 \\
\hline $\mathrm{CaO}$ & 1.82260 & 0.54 & 3.1941 & 0.95 & 1.387 & 0.41 & 6.40 & 1.90 & 329.78 & 98.10 & 336.18 & 100.00 \\
\hline $\mathrm{CdO}$ & 0.00018 & 9.05 & 0.0007 & 34.89 & 0.001 & 56.06 & 0.002 & 100.00 & $\overline{\mathrm{NC}}$ & $\mathrm{NC}$ & 0.002 & 100.00 \\
\hline $\mathrm{CeO} 2$ & 0.06370 & 0.34 & 0.1892 & 1.00 & 0.020 & 0.11 & 0.27 & 1.45 & 18.61 & 98.55 & 18.88 & 100.00 \\
\hline $\mathrm{Cl}$ & 0.22620 & 1.12 & 2.2308 & 11.09 & 17.625 & 87.60 & 20.08 & 99.81 & 0.04 & 0.19 & 20.12 & 100.00 \\
\hline $\mathrm{CO} 2$ & 0.74100 & 12.75 & 1.3221 & 22.75 & 0.148 & 2.55 & 2.21 & 38.04 & 3.60 & 61.96 & 5.81 & 100.00 \\
\hline $\mathrm{CrO} 2$ & 0.00751 & 0.36 & 0.0193 & 0.93 & 0.012 & 0.56 & 0.04 & 1.85 & 2.04 & 98.15 & 2.08 & 100.00 \\
\hline $\mathrm{Cs} 2 \mathrm{O}$ & 0.04316 & 0.91 & 0.3701 & 7.84 & 4.023 & 85.18 & 4.44 & 93.93 & 0.29 & 6.07 & 4.72 & 100.00 \\
\hline $\mathrm{CuO}$ & 0.00146 & 0.43 & 0.0084 & 2.47 & 0.072 & 21.06 & 0.08 & 23.96 & 0.26 & 76.04 & 0.34 & 100.00 \\
\hline $\mathrm{Fe} 3 \mathrm{O} 4$ & 1.89280 & 0.35 & 2.9250 & 0.54 & 2.914 & 0.54 & 7.73 & 1.43 & 534.81 & 98.57 & 542.54 & 100.00 \\
\hline $\mathrm{HgO}$ & 0.00000 & 0.34 & 0.0002 & 20.27 & 0.001 & 79.39 & 0.001 & 100.00 & $\mathrm{NC}$ & $\overline{\mathrm{NC}}$ & 0.001 & 100.00 \\
\hline $\mathrm{K} 2 \mathrm{O}$ & 1.51580 & 0.52 & 2.7651 & 0.96 & 6.815 & 2.36 & 11.10 & 3.83 & 278.24 & 96.17 & 289.34 & 100.00 \\
\hline $\mathrm{MgO}$ & 0.59280 & 0.53 & 0.8502 & 0.76 & 0.415 & 0.37 & 1.86 & 1.66 & 109.83 & 98.34 & 111.69 & 100.00 \\
\hline $\mathrm{Na} 2 \mathrm{O}$ & 1.61460 & 0.43 & 2.8158 & 0.74 & 6.909 & 1.83 & 11.34 & 3.00 & 366.68 & 97.00 & 378.02 & 100.00 \\
\hline $\mathrm{NiO}$ & 0.01295 & 2.19 & 0.0948 & 16.07 & 0.211 & 35.77 & 0.32 & 54.03 & 0.27 & 45.97 & 0.59 & 100.00 \\
\hline $\mathrm{P} 2 \mathrm{O5}$ & 0.09464 & 9.00 & 0.2707 & 25.75 & 0.630 & 59.91 & 1.00 & 94.66 & 0.06 & 5.34 & 1.05 & 100.00 \\
\hline $\mathrm{PbO}$ & 0.00382 & 1.67 & 0.0373 & 16.32 & 0.066 & 28.97 & 0.11 & 46.96 & 0.12 & 53.04 & 0.23 & 100.00 \\
\hline $\mathrm{SO} 3$ & 0.31720 & 8.34 & 0.9204 & 24.19 & 1.504 & 39.53 & 2.74 & 72.05 & 1.06 & 27.95 & 3.81 & 100.00 \\
\hline $\mathrm{SeO} 2$ & 0.00003 & 3.64 & 0.0003 & 43.70 & 0.000 & 52.66 & 0.001 & 100.00 & $\mathrm{NC}$ & NC & 0.001 & 100.00 \\
\hline SiO2 & 13.20800 & 0.64 & 15.5610 & 0.75 & 7.003 & 0.34 & 35.77 & 1.74 & 2025.31 & 98.26 & 2061.08 & 100.00 \\
\hline $\mathrm{TiO} 2$ & 0.14872 & 0.04 & 0.1903 & 0.05 & 0.056 & 0.02 & 0.40 & 0.11 & 372.20 & 99.89 & 372.60 & 100.00 \\
\hline $\mathrm{ZnO}$ & 0.01269 & 1.54 & 0.0928 & 11.30 & 0.207 & 25.18 & 0.31 & 38.02 & 0.51 & 61.98 & 0.82 & 100.00 \\
\hline$\overline{\mathrm{ZrO} 2}$ & 0.00312 & 0.002 & 0.0059 & 0.004 & 0.004 & 0.003 & 0.01 & 0.01 & 144.70 & 99.99 & 144.71 & 100.00 \\
\hline Total & 24 & & 37 & & 51 & & 112 & & 4513 & & 4625 & \\
\hline
\end{tabular}


Table L-7. Distribution of components among furnace products in the melting test of the N80-IV-Mod waste mixture.

\begin{tabular}{|c|c|c|c|c|c|c|c|c|c|c|c|c|}
\hline & \multicolumn{6}{|c|}{ APCS solid } & \multirow{2}{*}{\multicolumn{2}{|c|}{$\begin{array}{l}\text { APCS solid } \\
\text { Subtotal }\end{array}$}} & \multirow{2}{*}{\multicolumn{2}{|c|}{$\begin{array}{c}\text { Slag } \\
\text { Subtotal }\end{array}$}} & \multirow{2}{*}{\multicolumn{2}{|c|}{ Total }} \\
\hline & \multicolumn{2}{|c|}{ N80-T1 } & \multicolumn{2}{|c|}{ N80-T2 } & \multicolumn{2}{|c|}{ N80-BH } & & & & & & \\
\hline $\mathrm{wt}, \mathrm{lb}$ & & 14 & & 45 & & 67 & & 126 & & 4167 & & 4293 \\
\hline $\mathrm{wt}, \mathrm{pct}$ & & 0.33 & & 1.05 & & 1.56 & & 2.94 & & 97.06 & & 100 \\
\hline Component & $\mathrm{wt}, \mathrm{lb}$ & pct & wt, lb & wt, pct & $\mathrm{wt}, \mathrm{lb}$ & $\mathrm{wt}, \mathrm{pct}$ & $w t, 1 b$ & wt, pct & $\mathrm{wt}, 1 \mathrm{~b}$ & $\mathrm{wt}, \mathrm{pct}$ & $w t, 1 b$ & wt, pct \\
\hline Ag2O & 0.00003 & 3.55 & 0.0002 & 28.52 & 0.001 & 67.93 & 0.001 & 100.00 & $\mathrm{NC}$ & $\mathrm{NC}$ & 0.001 & 100.00 \\
\hline $\mathrm{A} 12 \mathrm{O} 3$ & 0.75320 & 0.30 & 2.5605 & 1.02 & 0.972 & 0.39 & 4.29 & 1.70 & $24 \overline{47.20}$ & 98.30 & 251.49 & 100.00 \\
\hline As203 & 0.00203 & 2.84 & 0.0113 & 15.78 & 0.013 & 18.54 & 0.03 & 37.16 & 0.04 & 62.84 & 0.07 & 100.00 \\
\hline $\mathrm{BaO}$ & 0.01848 & 0.61 & 0.0756 & 2.48 & 0.109 & 3.56 & 0.20 & 6.65 & 2.85 & 93.35 & 3.05 & 100.00 \\
\hline $\mathrm{CaO}$ & 2.74400 & 0.35 & 8.8200 & 1.12 & 5.206 & 0.66 & 16.77 & 2.14 & 767.30 & 97.86 & 784.07 & 100.00 \\
\hline $\mathrm{CdO}$ & 0.00004 & 1.21 & 0.0004 & 10.33 & 0.003 & 88.46 & 0.003 & 100.00 & NC & $\mathrm{NC}$ & 0.003 & 100.00 \\
\hline $\mathrm{CeO} 2$ & 0.13986 & 0.91 & 0.4680 & 3.03 & 0.697 & 4.51 & 1.30 & 8.45 & 14.13 & 91.55 & 15.44 & 100.00 \\
\hline $\mathrm{Cl}$ & 0.04340 & 1.31 & 0.3960 & 11.96 & 2.841 & 85.77 & 3.28 & 99.04 & 0.03 & 0.96 & 3.31 & 100.00 \\
\hline $\mathrm{CO} 2$ & 0.41720 & 3.64 & 2.0475 & 17.87 & 4.100 & 35.79 & 6.57 & 57.31 & 4.89 & 42.69 & 11.46 & 100.00 \\
\hline $\mathrm{CrO} 2$ & 0.00371 & 0.15 & 0.0146 & 0.57 & 0.065 & 2.54 & 0.08 & 3.26 & 2.46 & 96.74 & 2.54 & 100.00 \\
\hline $\mathrm{Cs} 2 \mathrm{O}$ & 0.00461 & 0.80 & 0.0477 & 8.30 & 0.279 & 48.50 & 0.33 & 57.60 & 0.24 & 42.40 & 0.57 & 100.00 \\
\hline $\mathrm{CuO}$ & 0.00455 & 0.34 & 0.0169 & 1.26 & 0.069 & 5.14 & 0.09 & 6.74 & 1.25 & 93.26 & 1.34 & 100.00 \\
\hline $\mathrm{Fe} 3 \mathrm{O} 4$ & 0.82180 & 0.09 & 2.3625 & 0.26 & 4.000 & 0.45 & 7.18 & 0.81 & 885.10 & 99.19 & 892.28 & 100.00 \\
\hline $\mathrm{HgO}$ & 0.00000 & 0.37 & 0.0000 & 11.80 & 0.000 & 87.83 & 0.0004 & 100.00 & $\mathrm{NC}$ & NC & 0.000 & 100.00 \\
\hline $\mathrm{K} 2 \mathrm{O}$ & 1.09900 & 0.53 & 3.6540 & 1.77 & 8.777 & 4.26 & 13.53 & 6.56 & 192.66 & 93.44 & 206.19 & 100.00 \\
\hline $\mathrm{MgO}$ & 0.23380 & 0.31 & 0.8190 & 1.08 & 0.659 & 0.87 & 1.71 & 2.25 & $\overline{74.42}$ & 97.75 & 76.13 & 100.00 \\
\hline $\mathrm{Na2O}$ & 0.98280 & 0.36 & 3.5550 & 1.31 & 11.658 & 4.28 & 16.20 & 5.95 & 255.90 & 94.05 & 272.10 & 100.00 \\
\hline $\mathrm{NiO}$ & 0.00091 & 0.13 & 0.0040 & 0.56 & 0.010 & 1.38 & 0.01 & 2.08 & 0.69 & 97.92 & 0.70 & 100.00 \\
\hline $\mathrm{P} 205$ & 0.00000 & 0.00 & 0.0002 & 0.01 & 0.084 & 2.70 & 0.08 & 2.71 & 3.04 & 97.29 & 3.13 & 100.00 \\
\hline $\mathrm{PbO}$ & 0.00141 & 0.62 & 0.0126 & 5.52 & 0.119 & 51.91 & 0.13 & 58.05 & 0.10 & 41.95 & 0.23 & 100.00 \\
\hline $\mathrm{SO} 3$ & 0.16800 & 3.34 & 0.6570 & 13.05 & 3.350 & 66.53 & 4.18 & 82.92 & 0.86 & 17.08 & 5.03 & 100.00 \\
\hline $\mathrm{SeO} 2$ & 0.00006 & 3.36 & 0.0003 & 16.21 & 0.001 & 80.43 & 0.0017 & 100.00 & $\mathrm{NC}$ & $\mathrm{NC}$ & 0.002 & 100.00 \\
\hline SiO2 & 4.38200 & 0.37 & 13.3200 & 1.11 & 17.219 & 1.44 & 34.92 & 2.92 & 1160.48 & 97.08 & 1195.40 & 100.00 \\
\hline $\mathrm{TiO}_{2}$ & 0.06720 & 0.03 & 0.1845 & 0.09 & 0.281 & 0.13 & 0.53 & 0.25 & 210.67 & 99.75 & 211.21 & 100.00 \\
\hline $\mathrm{ZnO}$ & 0.00689 & 1.07 & 0.0396 & 6.12 & 0.151 & 23.37 & 0.20 & 30.56 & 0.45 & 69.44 & 0.65 & 100.00 \\
\hline $\mathrm{ZrO2}$ & 1.38320 & 1.27 & 2.6010 & 2.38 & 1.213 & 1.11 & 5.20 & $\overline{4.76}$ & 103.90 & 95.24 & 109.10 & 100.00 \\
\hline Total & 13 & & 42 & & 62 & & 117 & & 3929 & & 4045 & \\
\hline
\end{tabular}


Table L-8. Distribution of components among furnace products in the melting test of the M60 waste mixture.

\begin{tabular}{|c|c|c|c|c|c|c|c|c|c|c|c|c|c|c|}
\hline & \multirow{2}{*}{\multicolumn{4}{|c|}{$\frac{\text { APCS solid }}{\text { M60-T2 }}$}} & \multirow{2}{*}{\multicolumn{2}{|c|}{ M60-BH }} & \multirow{2}{*}{\multicolumn{2}{|c|}{$\begin{array}{l}\text { APCS solid } \\
\text { Subtotal }\end{array}$}} & \multirow{2}{*}{\multicolumn{2}{|c|}{$\begin{array}{c}\text { Slag } \\
\text { Subtotal }\end{array}$}} & \multirow{2}{*}{\multicolumn{2}{|c|}{$\begin{array}{c}\text { Metal } \\
\text { Subtotal }\end{array}$}} & \multirow{2}{*}{\multicolumn{2}{|c|}{ Total }} \\
\hline & & & & & & & & & & & & & & \\
\hline$w, 10$ & & 5 & & 20 & & 28 & & 53 & & 2119 & & 865 & & 3037 \\
\hline wt, pct & & 0.16 & & 0.66 & & 0.92 & & 1.75 & & 69.77 & & 28.48 & & 100 \\
\hline Component & $w t, 1 b$ & pet & $\mathrm{wt}, \mathrm{lb}$ & wt, pct & $w t, 1 b$ & wt, pct & $\mathrm{wt}, \mathrm{lb}$ & $\mathrm{wt}, \mathrm{pct}$ & $\mathrm{wt}, \mathrm{lb}$ & wt, pct & $\mathrm{wt}, \mathrm{lb}$ & wt, pct & $\mathrm{wt}, \mathrm{lb}$ & wt, pct \\
\hline $\mathrm{Ag}$ & 0.00001 & 1.92 & 0.0003 & 49.81 & 0.0003 & 48.28 & 0.001 & 100.00 & $\mathrm{NC}$ & $\mathrm{NC}$ & $\mathrm{NC}$ & $\mathrm{NC}$ & 0.001 & 100.00 \\
\hline $\mathrm{Al}$ & 0.20150 & 0.13 & 0.6220 & 0.39 & 0.1428 & 0.09 & 0.97 & 0.61 & 156.81 & 98.79 & 0.95 & 0.60 & 158.72 & 100.00 \\
\hline As & 0.00008 & 0.08 & 0.0014 & 1.49 & 0.0013 & 1.42 & 0.003 & 2.99 & 0.00 & 4.57 & 0.09 & 92.43 & 0.09 & 100.00 \\
\hline $\mathrm{Ba}$ & 0.00860 & 0.40 & 0.0396 & 1.86 & 0.0148 & 0.69 & 0.06 & 2.95 & 2.05 & 96.32 & 0.02 & 0.73 & 2.13 & 100.00 \\
\hline $\mathrm{Ca}$ & 0.40300 & 0.23 & 1.7580 & 1.00 & 0.4424 & 0.25 & 2.60 & 1.48 & 172.27 & 98.18 & 0.60 & 0.34 & 175.47 & 100.00 \\
\hline$\overline{C d}$ & 0.00003 & 2.94 & 0.0003 & 37.69 & 0.0005 & 59.36 & 0.001 & 100.00 & $\mathrm{NC}$ & $\mathrm{NC}$ & NC & $\mathrm{NC}$ & 0.001 & 100.00 \\
\hline $\mathrm{Ce}$ & 0.03765 & 0.44 & 0.1624 & 1.89 & 0.0490 & 0.57 & 0.25 & 2.91 & 8.32 & 97.09 & $\mathrm{NC}$ & $\overline{N C}$ & 8.57 & 100.00 \\
\hline $\mathrm{Cl}$ & 0.03820 & 3.11 & 0.2980 & 24.27 & 0.7644 & 62.26 & 1.10 & 89.64 & 0.13 & 10.36 & $\mathrm{NC}$ & $\mathrm{NC}$ & 1.23 & 100.00 \\
\hline $\mathrm{C}$ & 0.02240 & 1.09 & 0.1274 & 6.17 & 0.0742 & 3.60 & 0.22 & 10.85 & 0.55 & 26.70 & 1.29 & 62.45 & 2.06 & 100.00 \\
\hline $\mathrm{Cr}$ & 0.00301 & 0.01 & 0.0214 & 0.05 & 0.0147 & 0.03 & 0.04 & 0.09 & 27.55 & 65.07 & 14.75 & 34.84 & 42.34 & 100.00 \\
\hline Cs & 0.00370 & 1.76 & 0.0306 & 14.52 & 0.0451 & 21.39 & 0.08 & 37.66 & 0.13 & 62.34 & $\mathrm{NC}$ & $\mathrm{NC}$ & 0.21 & 100.00 \\
\hline $\mathrm{Cu}$ & 0.00128 & 0.01 & 0.0088 & 0.05 & 0.0230 & 0.14 & 0.03 & 0.20 & 0.70 & 4.30 & 15.53 & 95.50 & 16.26 & 100.00 \\
\hline $\mathrm{Fe}$ & 0.16550 & 0.02 & 0.6400 & 0.07 & 0.4228 & 0.05 & 1.23 & 0.14 & 125.02 & 13.79 & 780.23 & 86.07 & 906.48 & 100.00 \\
\hline $\mathrm{Hg}$ & 0.00000 & 0.32 & 0.0001 & 27.90 & 0.0002 & 71.77 & 0.0003 & 100.00 & $\mathrm{NC}$ & $\mathrm{NC}$ & $\mathrm{NC}$ & $\mathrm{NC}$ & 0.0003 & 100.00 \\
\hline $\mathrm{K}$ & 0.13250 & 0.30 & 0.7200 & 1.63 & 0.8428 & 1.91 & 1.70 & 3.84 & 42.38 & 96.04 & 0.05 & 0.12 & 44.13 & 100.00 \\
\hline$\overline{\mathrm{Mg}}$ & 0.05700 & 0.18 & 0.1900 & 0.61 & 0.0560 & 0.18 & 0.30 & 0.97 & 30.94 & 98.57 & 0.15 & 0.47 & 31.39 & 100.00 \\
\hline $\mathrm{Na}$ & 0.08800 & 0.30 & 0.5840 & 1.97 & 0.7812 & 2.64 & 1.45 & 4.91 & 27.97 & 94.48 & 0.18 & 0.61 & 29.61 & 100.00 \\
\hline $\mathrm{Ni}$ & 0.00200 & 0.01 & 0.0080 & 0.05 & 0.0053 & 0.03 & 0.02 & 0.09 & 1.40 & 8.39 & 15.29 & 91.51 & 16.71 & 100.00 \\
\hline $\bar{P}$ & 0.00360 & 0.19 & 0.0072 & 0.38 & 0.0493 & 2.58 & 0.06 & 3.15 & 0.03 & 1.67 & 1.82 & 95.19 & 1.91 & 100.00 \\
\hline$\overline{\mathrm{Pb}}$ & 0.11250 & 2.19 & 0.8460 & 16.43 & 0.0476 & 0.92 & 1.01 & 19.54 & 2.39 & 46.51 & 1.75 & 33.94 & 5.15 & 100.00 \\
\hline $\mathrm{S}$ & 0.01010 & 0.71 & 0.1010 & 7.06 & 0.2503 & 17.51 & 0.36 & 25.28 & 0.64 & 44.47 & 0.43 & 30.25 & 1.43 & 100.00 \\
\hline $\mathrm{Se}$ & $\overline{\mathrm{NC}}$ & $\mathrm{NC}$ & 0.0001 & 2.76 & 0.0002 & 7.73 & 0.0003 & 10.49 & $\mathrm{NC}$ & $\mathrm{NC}$ & 0.003 & 89.51 & 0.0029 & 100.00 \\
\hline $\mathrm{Si}$ & 1.11000 & 0.19 & 3.0600 & 0.53 & 1.8816 & 0.33 & 6.05 & 1.06 & 544.58 & 95.15 & 21.71 & 3.79 & 572.35 & 100.00 \\
\hline Ti & 0.01185 & 0.08 & 0.0356 & 0.24 & 0.0100 & 0.07 & 0.06 & 0.39 & 14.45 & 98.56 & 0.15 & 1.05 & 14.66 & 100.00 \\
\hline $\mathrm{Zn}$ & 0.31150 & 2.11 & 2.1400 & 14.47 & 5.8800 & 39.75 & 8.33 & 56.32 & 5.62 & 37.96 & 0.85 & 5.72 & 14.79 & 100.00 \\
\hline $\mathrm{Zr}$ & 0.02280 & 0.30 & 0.2420 & 3.20 & 0.0636 & 0.84 & 0.33 & 4.34 & 7.20 & 95.28 & 0.03 & 0.38 & 7.56 & 100.00 \\
\hline Total & 3 & & 12 & & 12 & & 26 & & 1171 & & 856 & & 2053 & \\
\hline
\end{tabular}




\section{Appendix M}

\section{Distribution of $\mathrm{Ce}$ and Toxic Metals Among Furnace Products}





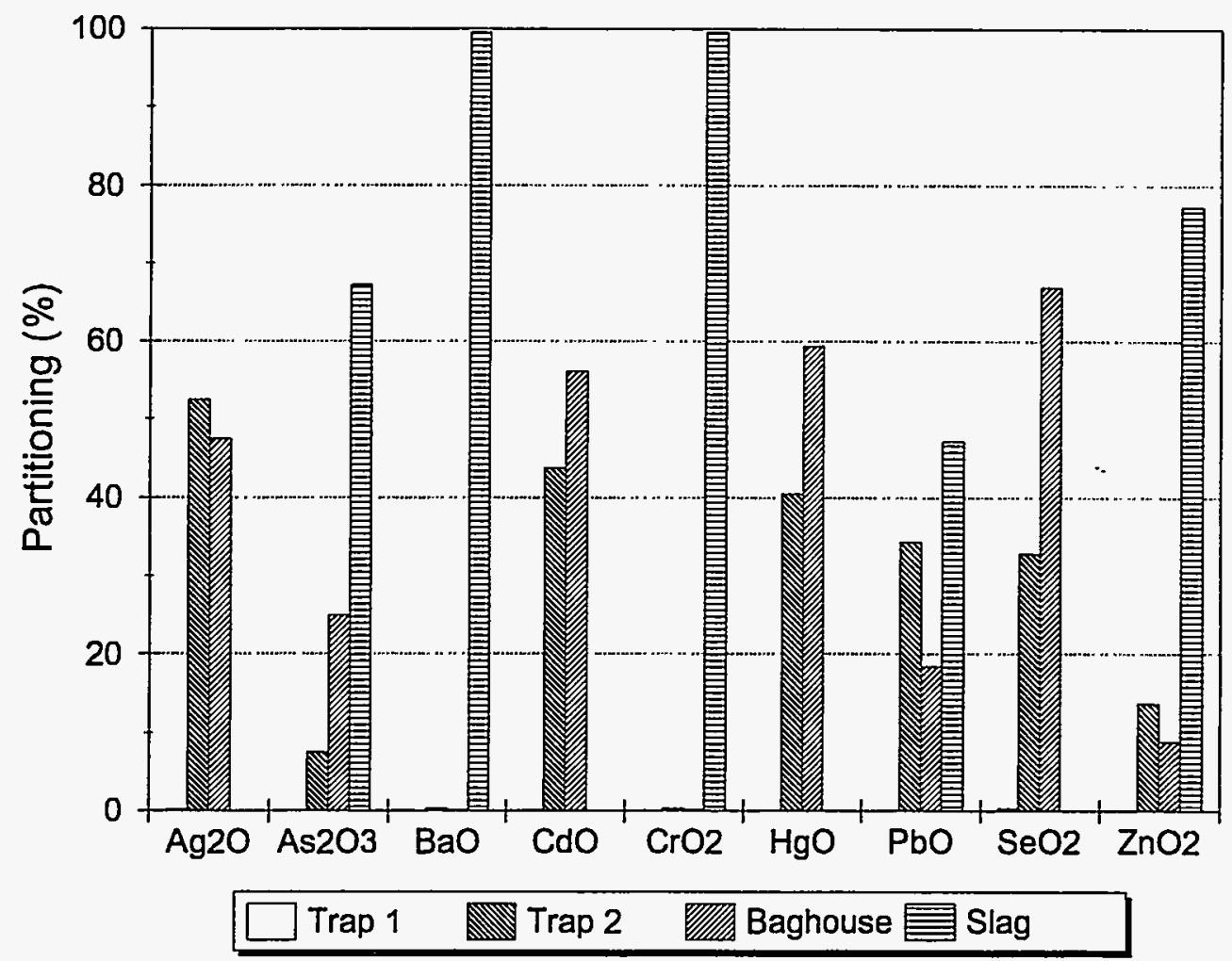

Figure M-1. Toxic metal partitioning for the RWMC soil and mill scale. 


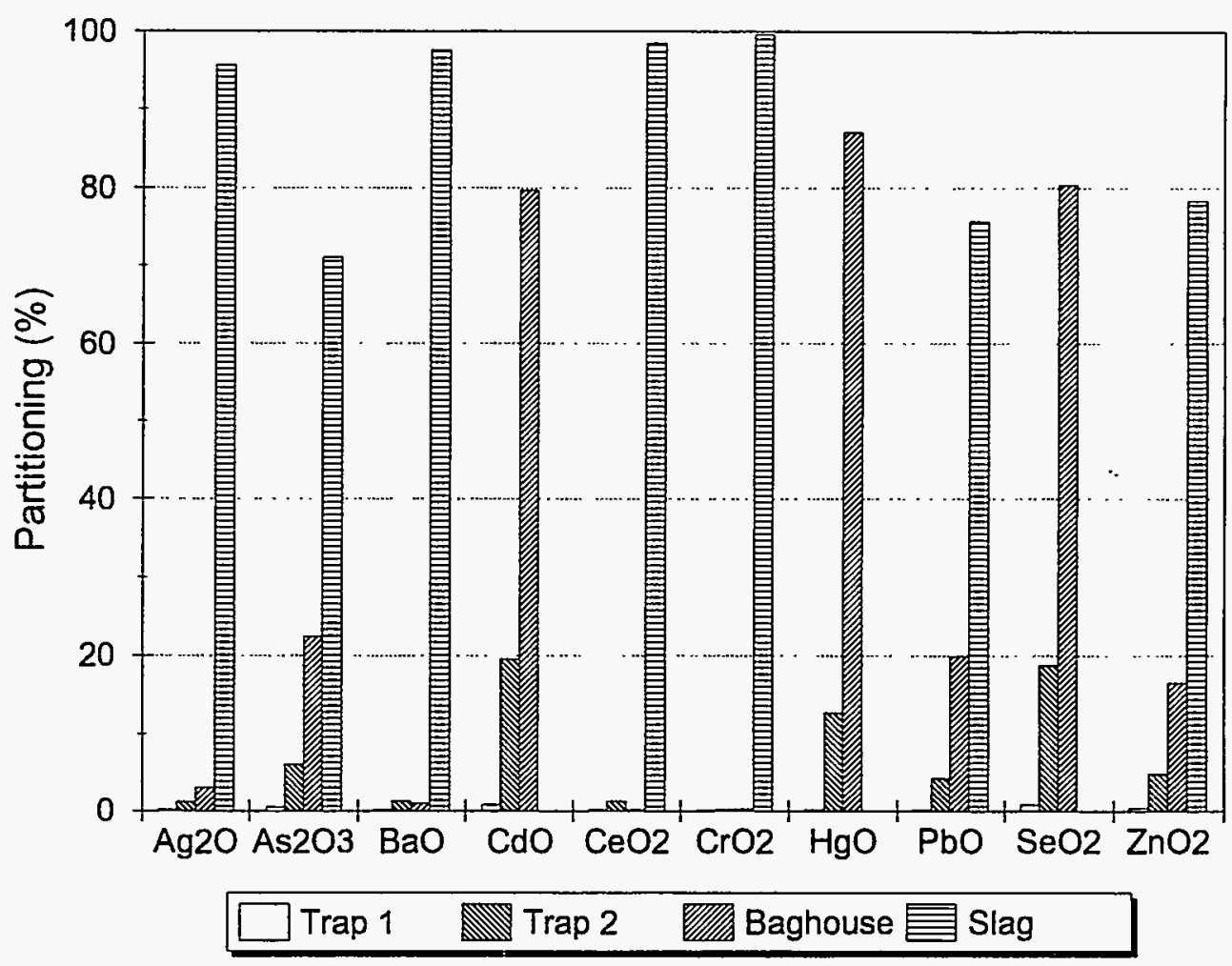

Figure $\mathrm{M}-2$. Cerium and toxic metal partitioning for the $\mathrm{S} 60$ waste mixture.

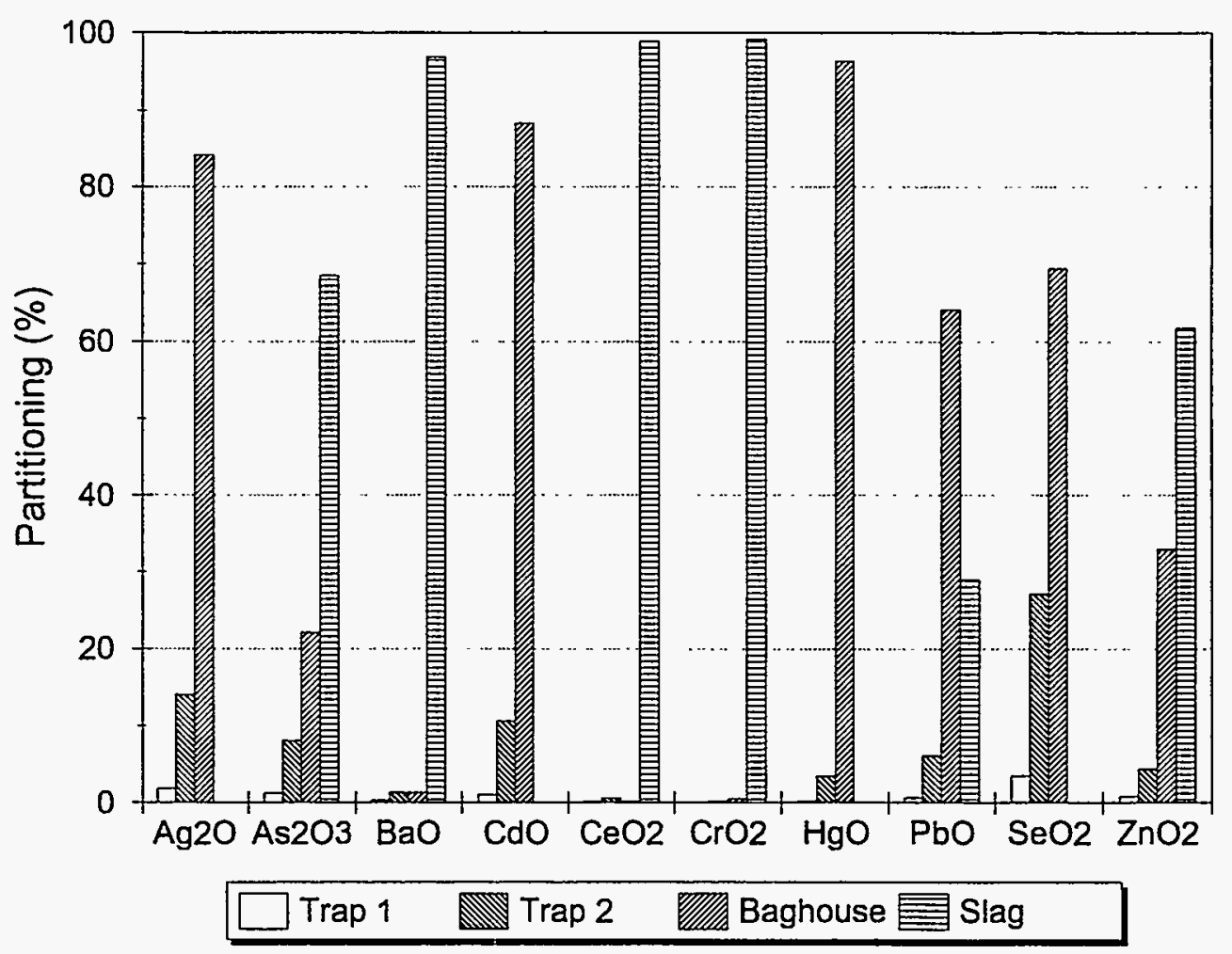

Figure M-3. Cerium and toxic metal partitioning for the S60-IV waste mixture. 


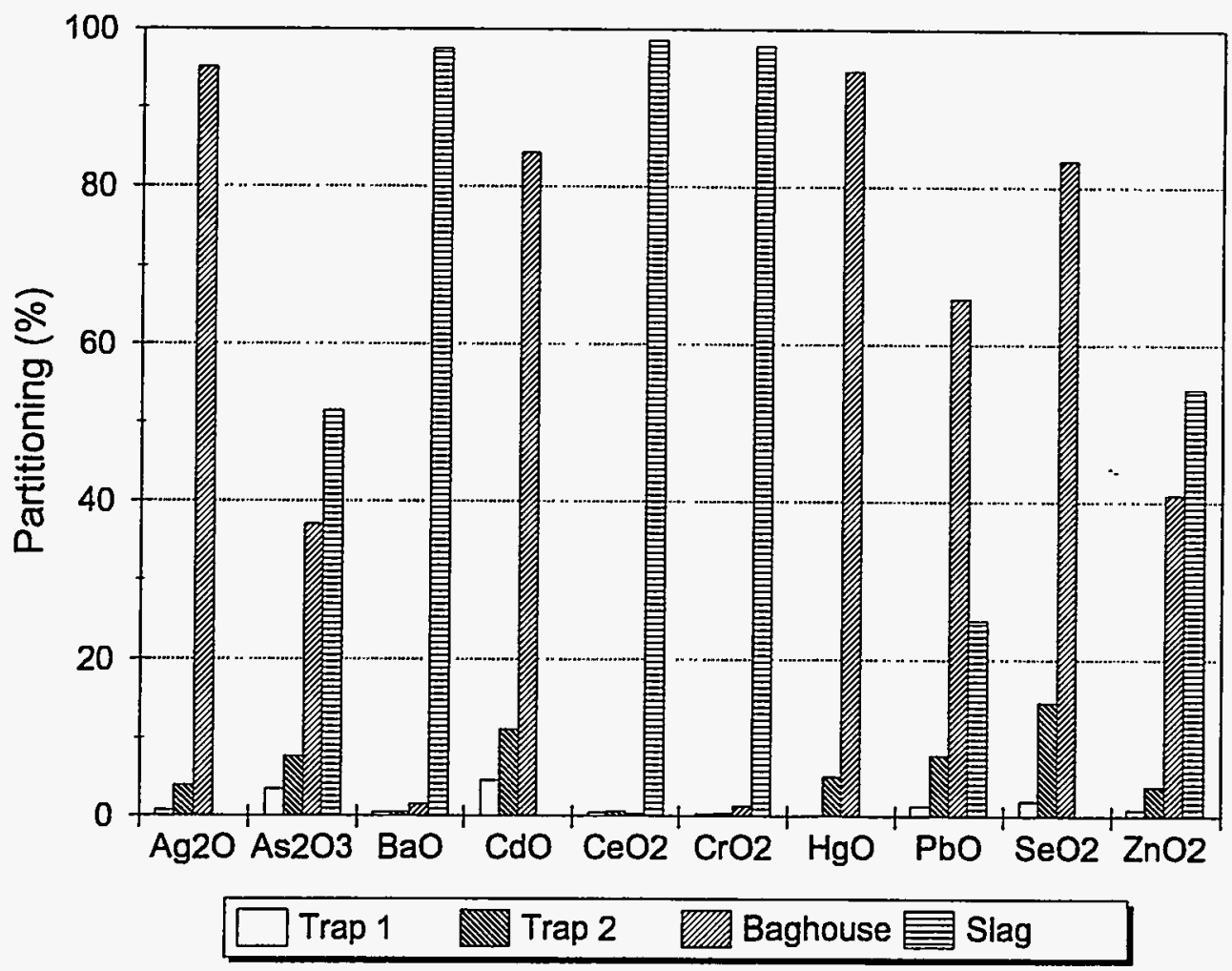

Figure $M-4$. Cerium and toxic metal partitioning for the $N 80$ waste mixture.

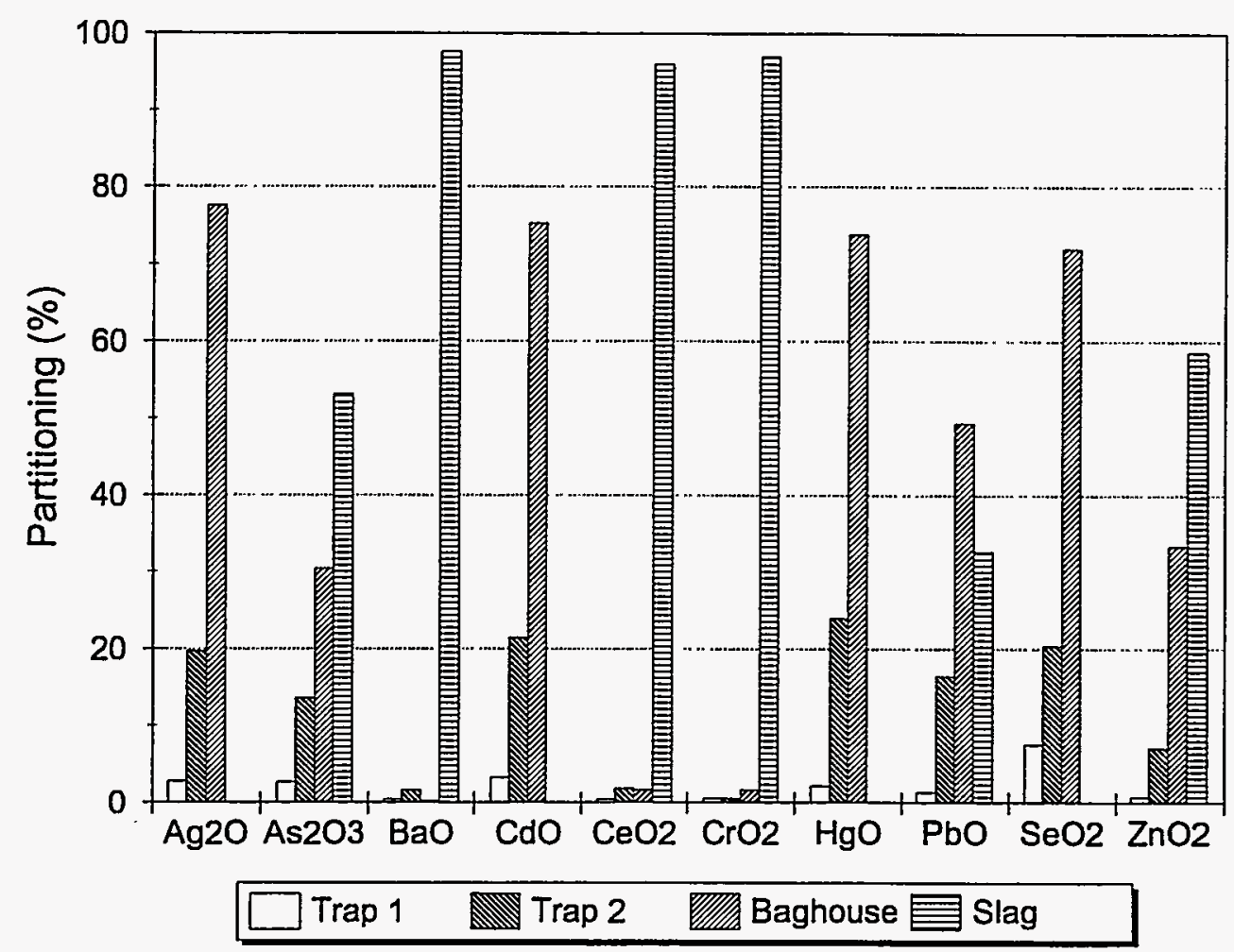

Figure M-5. Cerium and toxic metal partitioning for the N80-Mod waste mixture. 


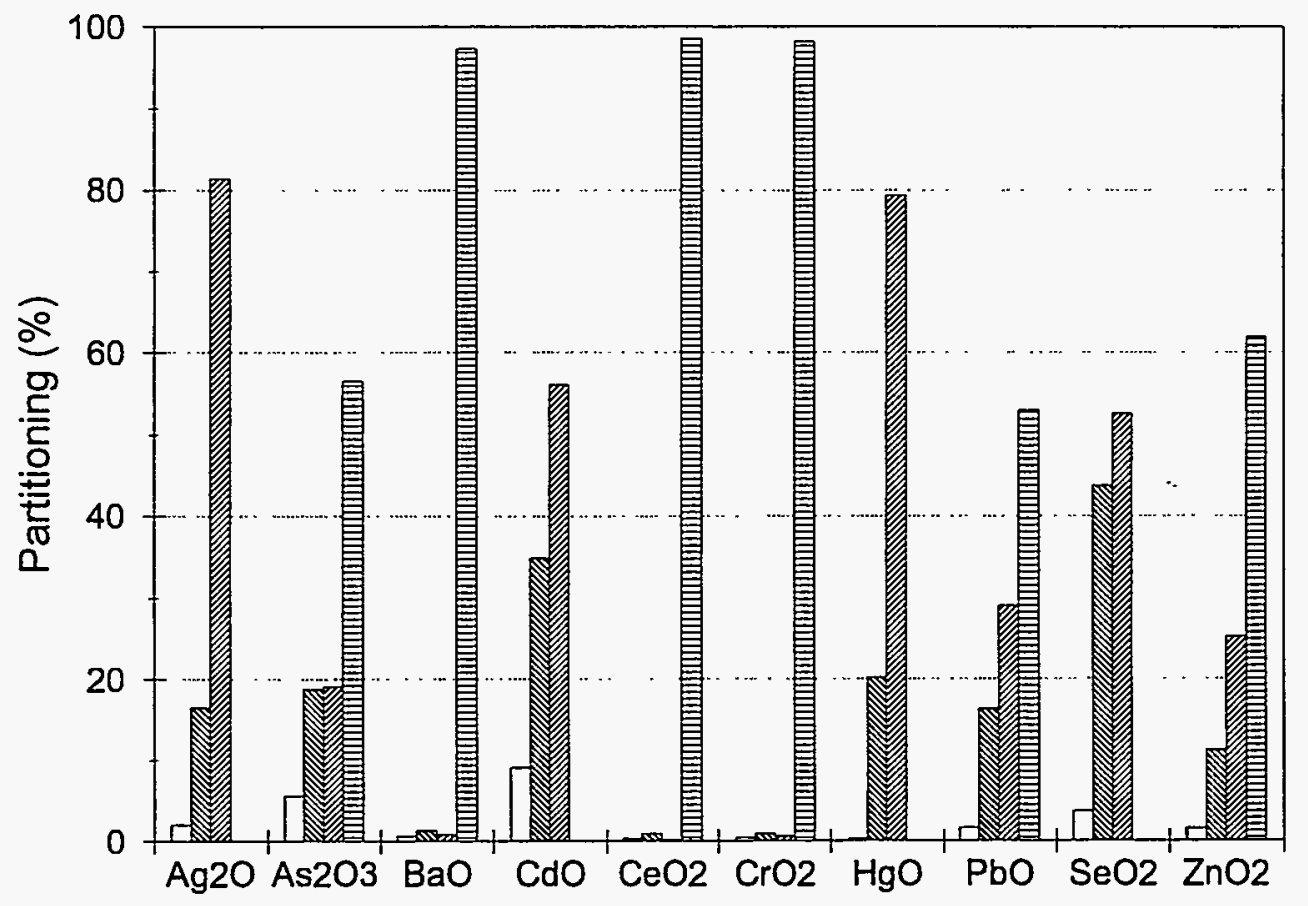

\begin{tabular}{lll}
$\square$ Trap 1 & Trap 2 & OMaghouse \\
\hline
\end{tabular}

Figure M-6. Cerium and toxic metal partitioning for the N80-IV waste mixture.

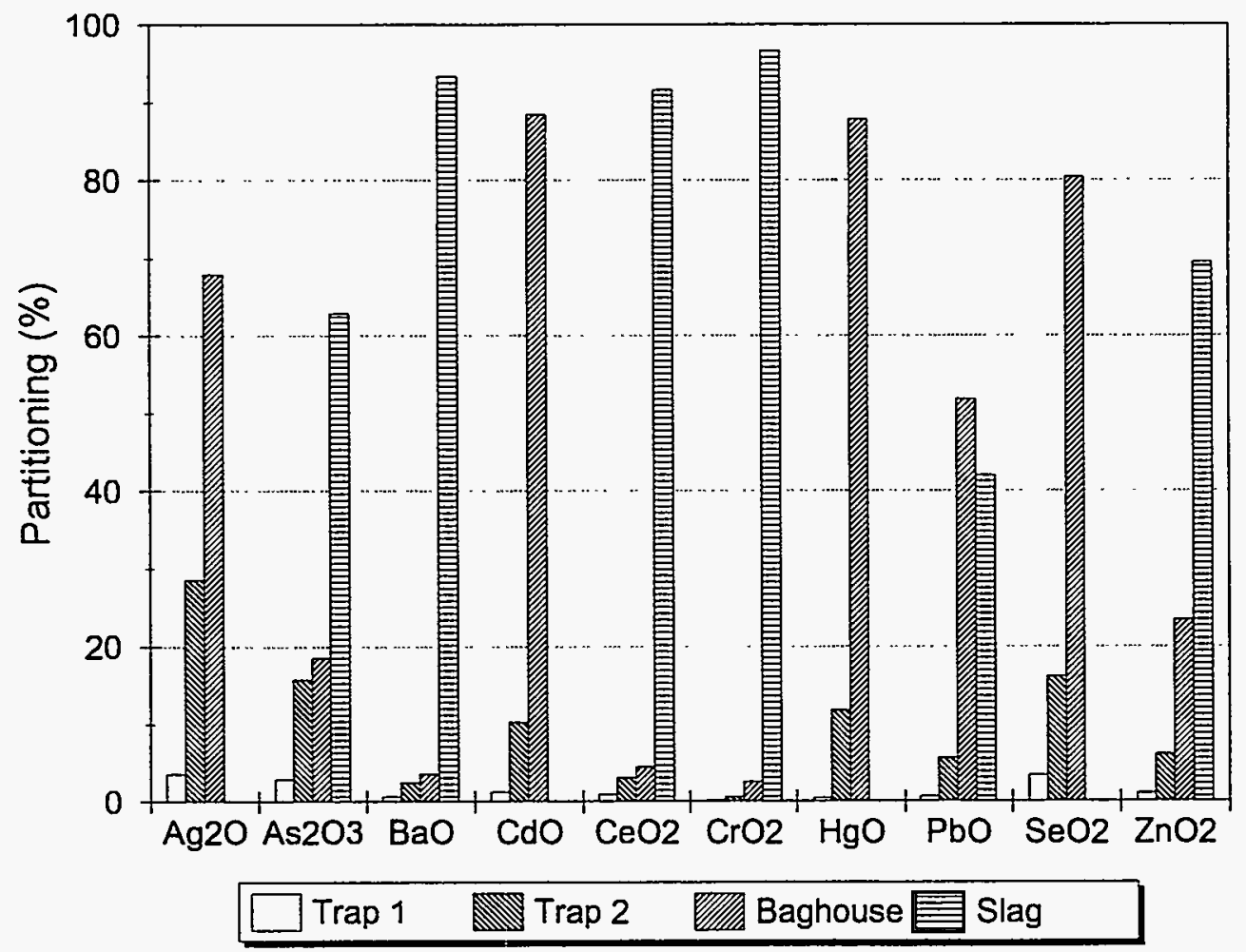

Figure M-7. Cerium and toxic metal partitioning for the N80-IV-Mod waste mixture. 


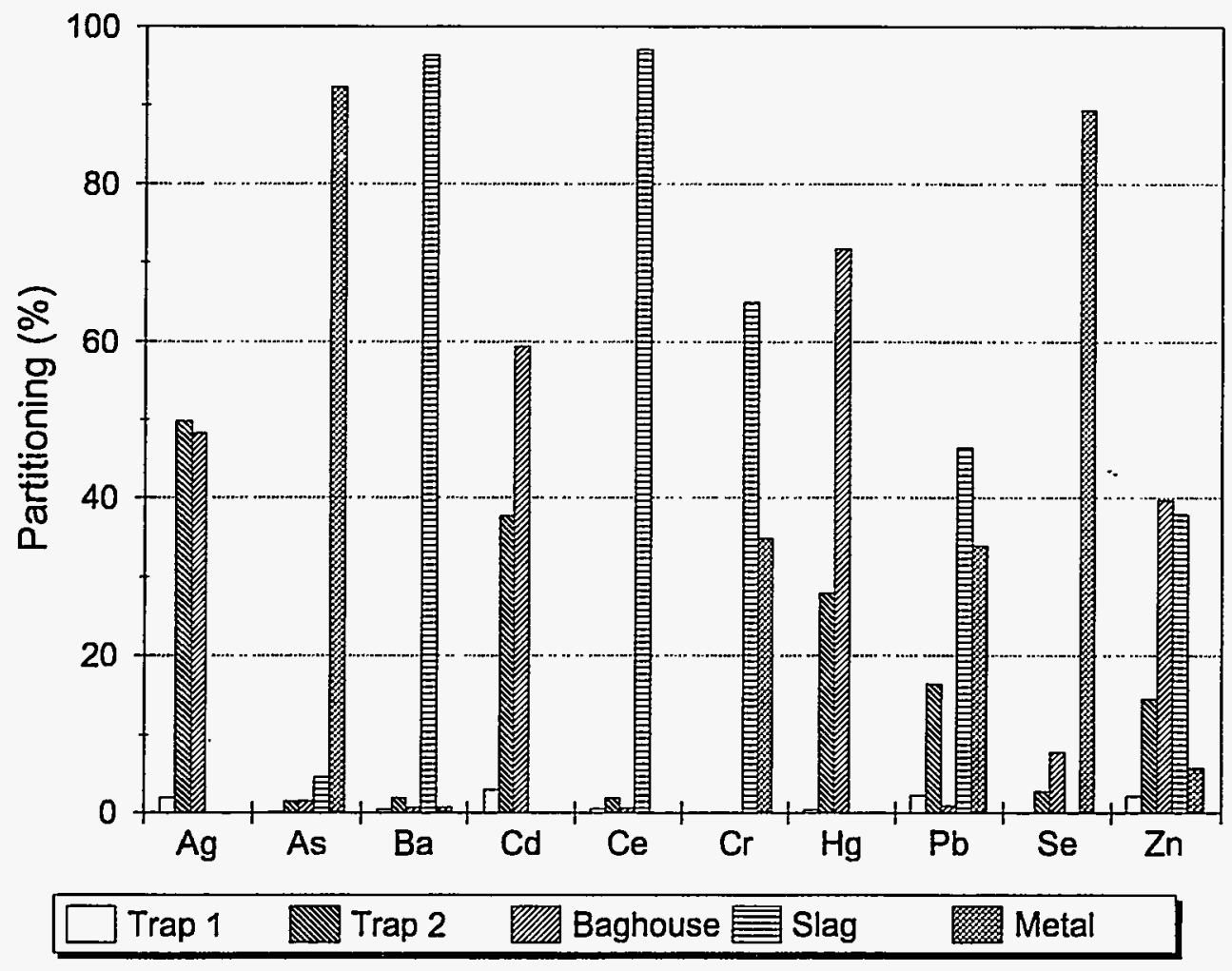

Figure $M-8$. Cerium and toxic metal partitioning for the M60 waste mixture. 


\section{Appendix N}

Toxic Characteristic Leaching Procedure (TCLP) Analysis of Furnace Products 

Table N-1. TCLP test results for slag samples.

\begin{tabular}{|c|c|c|c|c|c|c|c|c|c|c|c|c|c|}
\hline \multirow[b]{3}{*}{ Analyte } & \multicolumn{13}{|c|}{ Analyte Concentration } \\
\hline & \multicolumn{4}{|c|}{ S60-Sl } & \multicolumn{3}{|c|}{ S60-S7 } & \multicolumn{3}{|c|}{ S60-IV-S1 } & \multicolumn{3}{|c|}{ S60-IV-S6 } \\
\hline & $\begin{array}{c}\text { TCLP } \\
\text { Limits }(\mathrm{mg} / \mathrm{L})\end{array}$ & \begin{tabular}{|c|} 
Leachate \\
Conc. (mg/L)
\end{tabular} & $\begin{array}{l}\text { Element Conc. } \\
\text { in slag }(\mathrm{mg} / \mathrm{kg}\end{array}$ & $\begin{array}{l}\text { Percent } \\
\text { Dissolved }\end{array}$ & \begin{tabular}{|c|} 
Leachate \\
Conc. (mg $/$ )
\end{tabular} & $\begin{array}{l}\text { Element Conc. } \\
\text { in slag (mg/kg }\end{array}$ & $\begin{array}{l}\text { Percent } \\
\text { Dissolved }\end{array}$ & $\begin{array}{c}\text { Leachate } \\
\text { Conc. }(\mathrm{mg} / \mathrm{L})\end{array}$ & $\begin{array}{l}\text { Element Conc. } \\
\text { in slag ( } \mathrm{mg} / \mathrm{kg}\end{array}$ & $\begin{array}{l}\text { Percent } \\
\text { Dissolved }\end{array}$ & \begin{tabular}{|c} 
Leachate \\
Conc. (mg/L
\end{tabular} & $\begin{array}{l}\text { Element Conc. } \\
\text { in slag }(m g / k g\end{array}$ & $\begin{array}{l}\text { Percent } \\
\text { Dissolved }\end{array}$ \\
\hline Arsenic & 5.0 & $<0.2$ & 2 & $<100$ & $<0.2$ & 3 & $<100$ & $<0.2$ & 3 & $<100$ & $<0.2$ & 3 & $<100$ \\
\hline Barium & 100.0 & $<0.2$ & 591 & $<6.77$ & $<0.2$ & 587 & $<6.81$ & $<0.2$ & 613 & $<6.53$ & $<0.2$ & 655 & $<6.11$ \\
\hline Cadmium & 1.0 & $<0.1$ & $<1$ & NC & $<0.1$ & $<1$ & $\mathrm{NC}$ & $<0.1$ & $<1$ & NC & $<0.1$ & $<1$ & NC \\
\hline Chromium & 5.0 & 0.2 & 260 & 15.4 & 0.3 & 555 & 10.8 & 0.2 & 313 & 12.8 & $<0.1$ & 324 & $<6.17$ \\
\hline Lead & 5.0 & $<0.1$ & 5 & $<100$ & $<0.1$ & 49 & $<40.8$ & $<0.1$ & 14 & $<100$ & $<0.1$ & 11 & $<100$ \\
\hline \begin{tabular}{|l} 
Mercury \\
\end{tabular} & 0.2 & $<0.1$ & $<0.1$ & NC & $<0.1$ & $<0.1$ & NC & $<0.1$ & $<0.1$ & NC & $<0.1$ & $<0.1$ & NC \\
\hline \begin{tabular}{|l|} 
Sclenium \\
\end{tabular} & 1.0 & $<0.1$ & $<1$ & $\mathrm{NC}$ & $<0.1$ & $<1$ & $\mathrm{NC}$ & $<0.1$ & $<1$ & NC & $<0.1$ & $<1$ & NC \\
\hline Silver & 5.0 & $<0.1$ & $<1$ & $\mathrm{NC}$ & $<0.1$ & 8 & $<100$ & $<0.1$ & $<1$ & NC & $<0.1$ & $<1$ & NC \\
\hline Cerium & - & 0.17 & 2227 & 1.53 & 0.17 & 2264 & 1.50 & 0.06 & 3232 & 0.37 & 0.07 & 3608 & 0.39 \\
\hline Basicity & & & 0.64 & & & 0.82 & & & 0.52 & & & 0.50 & \\
\hline
\end{tabular}

\begin{tabular}{|c|c|c|c|c|c|c|c|c|c|c|c|c|c|}
\hline \multirow[b]{3}{*}{ Analyte } & \multicolumn{13}{|c|}{ Analyte Concentration } \\
\hline & \multicolumn{4}{|c|}{ N80-S3 } & \multicolumn{3}{|c|}{ N80-Mod-S6 } & \multicolumn{3}{|c|}{ N80-Mod-S7 } & \multicolumn{3}{|c|}{ N80-IV-S4 } \\
\hline & $\begin{array}{c}\text { TCLP } \\
\text { Limits }(\mathrm{mg} / \mathrm{L})\end{array}$ & \begin{tabular}{|c|} 
Leachate \\
Conc. (mg/L)
\end{tabular} & $\begin{array}{l}\text { Element Conc. } \\
\text { in slag }(\mathrm{mg} / \mathrm{kg}\end{array}$ & $\begin{array}{l}\text { Percent } \\
\text { Dissolved }\end{array}$ & $\begin{array}{l}\text { Leachate } \\
\text { Conc. }(\mathrm{mg} / \mathrm{L})\end{array}$ & $\begin{array}{l}\text { Element Conc. } \\
\text { in slag }(\mathrm{mg} / \mathrm{kg}\end{array}$ & $\begin{array}{l}\text { Percent } \\
\text { Dissolved }\end{array}$ & $\begin{array}{c}\text { Leachate } \\
\text { Conc. }(\mathrm{mg} / \mathrm{L} \text { ) }\end{array}$ & $\begin{array}{l}\text { Element Conc. } \\
\text { in slag }(\mathrm{mg} / \mathrm{kg}\end{array}$ & $\begin{array}{l}\text { Percent } \\
\text { Dissolved }\end{array}$ & $\begin{array}{c}\text { Leachate } \\
\text { Conc. (mg/L }\end{array}$ & $\begin{array}{l}\text { Element Conc. } \\
\text { in slag }(\mathrm{mg} / \mathrm{kg}\end{array}$ & $\begin{array}{l}\text { Percent } \\
\text { Dissolved }\end{array}$ \\
\hline Arsenic & 5.0 & $<0.2$ & 2 & $<100$ & $<0.2$ & 5 & $<100$ & $<0.2$ & 6 & $<100$ & $<0.2$ & 3 & $<100$ \\
\hline Barium & 100.0 & $<0.2$ & 782 & $<5.12$ & $<0.2$ & 589 & $<6.79$ & $<0.2$ & 592 & $<6.76$ & $<0.2$ & 782 & $<5.12$ \\
\hline Cadmium & 1.0 & $<0.1$ & $<1$ & NC & $<0.1$ & $<1$ & NC & $<0.1$ & $<1$ & NC & $<0.1$ & $<1$ & NC \\
\hline Chromium & 5.0 & $<0.1$ & 202 & $<9.90$ & 0.1 & 245 & 8.16 & 0.1 & 313 & $<6.39$ & 0.1 & 213 & 9.39 \\
\hline Lead & 5.0 & $<0.1$ & 10 & $<100$ & $<0.1$ & 10 & $<100$ & $<0.1$ & 9 & $<100$ & $<0.1$ & 27 & $<74.1$ \\
\hline Mercury & 0.2 & $<0.1$ & $<0.1$ & $\mathrm{NC}$ & $<0.1$ & $<0.1$ & $\mathrm{NC}$ & $<0.1$ & $<0.1$ & $\mathrm{NC}$ & $<0.1$ & $<0.1$ & NC \\
\hline Selenium & 1.0 & $<0.1$ & $<1$ & $\mathrm{NC}$ & $<0.1$ & $<1$ & NC & $<0.1$ & $<1$ & NC & $<0.1$ & $<1$ & NC \\
\hline Silver & 5.0 & $<0.1$ & $<1$ & NC & $<0.1$ & $<1$ & NC & $<0.1$ & $<1$ & $\mathrm{NC}$ & $<0.1$ & $<1$ & NC \\
\hline Cerium & - & 0.35 & 1838 & 3.81 & 0.36 & 1808 & 3.98 & 0.58 & 1760 & 6.59 & 0.13 & 3240 & 0.80 \\
\hline Basicity & & & 0.56 & & & 0.79 & & & 0.90 & & & 0.52 & \\
\hline
\end{tabular}

Notes: 1. Percent dissolved was based on 1 gram of slag put into 0.2 liters of solvent. 2. $\mathrm{NC}=$ Not calculated dut to uncertainty in data. 
Table N-1. TCLP test results for slag samples (continued).

\begin{tabular}{|c|c|c|c|c|c|c|c|c|c|c|c|c|c|}
\hline \multirow[b]{3}{*}{ Analyte } & \multicolumn{13}{|c|}{ Analyte Concentration } \\
\hline & \multicolumn{4}{|c|}{ N80-IV-Mod-S10 } & \multicolumn{3}{|c|}{ M60-RS } & \multicolumn{3}{|c|}{ M60-Mod-S2 } & \multicolumn{3}{|c|}{ M60-Mod-S5 } \\
\hline & $\begin{array}{c}\text { TCLP } \\
\text { Limits }(m g / L)\end{array}$ & \begin{tabular}{|c|} 
Leachate \\
Conc. (mg/L)
\end{tabular} & $\begin{array}{l}\text { Element Conc. } \\
\text { in slag }(\mathrm{mg} / \mathrm{kg}\end{array}$ & $\begin{array}{l}\text { Percent } \\
\text { Dissolved }\end{array}$ & \begin{tabular}{|c} 
Leachate \\
Conc. $(\mathrm{mg} / \mathrm{L})$
\end{tabular} & $\begin{array}{l}\text { Element Conc. } \\
\text { in slag }(\mathrm{mg} / \mathrm{kg}\end{array}$ & $\begin{array}{l}\text { Percent } \\
\text { Dissolved }\end{array}$ & \begin{tabular}{|c|} 
Leachate \\
Conc. $(\mathrm{mg} / \mathrm{L})$
\end{tabular} & $\begin{array}{l}\text { Element Conc. } \\
\text { in slag (mg/kg }\end{array}$ & $\begin{array}{l}\text { Percent } \\
\text { Dissolved }\end{array}$ & \begin{tabular}{|c|} 
Leachate \\
Conc. $(\mathrm{mg} / \mathrm{L})$
\end{tabular} & $\begin{array}{l}\text { Element Conc. } \\
\text { in slag ( } \mathrm{mg} / \mathrm{kg}\end{array}$ & $\begin{array}{l}\text { Percent } \\
\text { Dissolved } \\
\end{array}$ \\
\hline Arsenic & 5.0 & $<0.2$ & 7 & $<100$ & $<0.2$ & 2 & $<100$ & $<0.2$ & 1 & $<100$ & $<0.2$ & $\frac{5}{5}$ & $<100$ \\
\hline Barium & 100.0 & $<0.2$ & 600 & $<6.67$ & $<0.2$ & 969 & $<4.13$ & $<0.2$ & 801 & $<4.99$ & $<0.2$ & 568 & $<7.04$ \\
\hline Cadmium & 1.0 & $<0.1$ & $<1$ & $\mathrm{NC}$ & $<0.1$ & $<1$ & $<100$ & $<0.1$ & $<1$ & NC & $<0.1$ & $<1$ & $\mathrm{NC}$ \\
\hline Chromium & 5.0 & 0.2 & 210 & 19.0 & 0.5 & 13002 & 0.77 & 0.1 & 8219 & 0.24 & $<0.1$ & 1958 & $<1.02$ \\
\hline Lead & 5.0 & $<0.1$ & 21 & $<95.2$ & $<0.1$ & 1130 & $<1.77$ & $<0.1$ & 350 & $<5.71$ & $<0.1$ & 420 & $<4.76$ \\
\hline Mercury & 0.2 & $<0.1$ & $<0.1$ & NC & $<0.1$ & $<0.1$ & $<100$ & $<0.1$ & $<0.1$ & NC & $<0.1$ & $<0.1$ & $\mathrm{NC}$ \\
\hline Selenium & 1.0 & $<0.1$ & $<1$ & $\mathrm{NC}$ & $<0.1$ & $<1$ & $<100$ & 0.3 & $<1$ & NC & 0.2 & $<1$ & $\mathrm{NC}$ \\
\hline Silver & 5.0 & $<0.1$ & $<1$ & NC & $<0.1$ & $<1$ & $<100$ & $<0.1$ & $<1$ & NC & $<0.1$ & $<1$ & $\mathrm{NC}$ \\
\hline Cerium & - & 0.32 & 2545 & 2.51 & 0.18 & 3928 & 0.92 & 0.3 & 3864 & 1.55 & 1.75 & 2739 & 12.8 \\
\hline Basicity & & & NC & & & NC & & & 0.61 & & & 1.08 & \\
\hline
\end{tabular}

Notes: 1. Percent dissolved was based on 1 gram of slag put into 0.2 liters of solvent. 2. $\mathrm{NC}=$ Not calculated dut to uncertainty in data. 
Table N-2. TCLP test results for APCS solids.

\begin{tabular}{|c|c|c|c|c|c|c|c|c|c|c|c|c|c|}
\hline \multirow[b]{3}{*}{ Analyte } & \multicolumn{13}{|c|}{ Analyte Concentration } \\
\hline & \multicolumn{4}{|c|}{560} & \multicolumn{3}{|c|}{ S60-IV } & \multicolumn{3}{|c|}{ N80 } & \multicolumn{3}{|c|}{ N80-Mod } \\
\hline & $\begin{array}{c}\text { TCLP } \\
\text { Limits }(\mathrm{mg} / \mathrm{L})\end{array}$ & $\begin{array}{c}\text { Leachate } \\
\text { Conc. (mg/L }\end{array}$ & $\begin{array}{l}\text { Element Conc. } \\
\text { in slag }(\mathrm{mg} / \mathrm{kg}\end{array}$ & $\begin{array}{l}\text { Percent } \\
\text { Dissolved }\end{array}$ & \begin{tabular}{|c|} 
Leachate \\
Conc. $(\mathrm{m} g / \mathrm{L})$
\end{tabular} & $\begin{array}{l}\text { Element Conc. } \\
\text { in slag }(\mathrm{mg} / \mathrm{kg}\end{array}$ & $\begin{array}{l}\text { Percent } \\
\text { Dissolved }\end{array}$ & \begin{tabular}{|c} 
Leachate \\
Conc. (mg/L
\end{tabular} & $\begin{array}{l}\text { Element Conc. } \\
\text { in slag }(\mathrm{mg} / \mathrm{kg}\end{array}$ & $\begin{array}{l}\text { Percent } \\
\text { Dissolved }\end{array}$ & \begin{tabular}{|c|} 
Leachate \\
Conc. (mg/L)
\end{tabular} & $\begin{array}{l}\text { Element Conc. } \\
\text { in slag }(\mathrm{m} g / \mathrm{kg}\end{array}$ & $\begin{array}{l}\text { Percent } \\
\text { Dissolved }\end{array}$ \\
\hline Arsenic & 5.0 & $<0.2$ & 74 & $<54.1$ & $<0.2$ & 49 & $<81.6$ & $<0.2$ & 80 & $<50$ & $<0.2$ & 146 & $<27.4$ \\
\hline Barium & 100.0 & $<0.2$ & 989 & $<4.04$ & $<0.2$ & 933 & $<4.29$ & $<0.2$ & 810 & $<4.94$ & $<0.2$ & 381 & $<10.5$ \\
\hline Cadmium & 1.0 & 0.7 & 13 & 100 & 0.8 & 17 & 100 & 0.7 & 18 & 100 & $<0.1$ & 16 & $<100$ \\
\hline Chromium & 5.0 & $<0.1$ & 159 & $<12.6$ & $<0.1$ & 156 & $<12.8$ & $<0.1$ & 176 & $<11.4$ & 0.1 & 283 & 7.07 \\
\hline Lead & 5.0 & 12.2 & 994 & 100 & 13.8 & 1001 & 100 & 4.1 & 1094 & 75.0 & 0.2 & 522 & 7.66 \\
\hline Mercury & 0.2 & $<0.1$ & 8 & $<100$ & $<0.1$ & 7 & $<100$ & $<0.1$ & 9 & $<100$ & $<0.1$ & 4 & $<100$ \\
\hline Selenium & 1.0 & 0.2 & 5 & 100 & 0.2 & 6 & 100 & 0.1 & 5 & 100 & 0.4 & 4 & 100 \\
\hline Silver & 5.0 & 0.1 & 19 & 100 & $<0.1$ & 10 & $<100$ & $<0.1$ & 32 & $<62.5$ & $<0.1$ & 8 & $<100$ \\
\hline Cerium & - & 8.44 & 2297 & 73.5 & 7.41 & 1732 & 85.6 & 3.65 & 1025 & 71.2 & 0.03 & 1965 & 3.05 \\
\hline Basicity & & & NC & & & $\mathrm{NC}$ & & & $\mathrm{NC}$ & & & NC & \\
\hline
\end{tabular}

\begin{tabular}{|c|c|c|c|c|c|c|c|c|c|c|c|c|c|}
\hline \multirow[b]{3}{*}{ Analyte } & \multicolumn{13}{|c|}{ Analyte Concentration } \\
\hline & \multicolumn{4}{|c|}{ N80-IV } & \multicolumn{3}{|c|}{ N80-IV-Mod } & \multicolumn{3}{|c|}{ M60 } & \multicolumn{3}{|c|}{ M60-Mod } \\
\hline & $\begin{array}{c}\text { TCLP } \\
\text { Limits }(\mathrm{mg} / \mathrm{L})\end{array}$ & \begin{tabular}{|c} 
Leachate \\
Conc. $(\mathrm{mg} / \mathrm{L})$
\end{tabular} & $\begin{array}{l}\text { Element Conc. } \\
\text { in slag }(\mathrm{mg} / \mathrm{kg}\end{array}$ & $\begin{array}{l}\text { Percent } \\
\text { Dissolved }\end{array}$ & \begin{tabular}{|c|} 
Leachate \\
Conc. (mg/L)
\end{tabular} & $\begin{array}{l}\text { Element Conc. } \\
\text { in slag (mg/kg }\end{array}$ & $\begin{array}{l}\text { Pcrcent } \\
\text { Dissolved }\end{array}$ & \begin{tabular}{|c|} 
Leachate \\
Conc. (mg/L)
\end{tabular} & $\begin{array}{l}\text { Elcment Conc } \\
\text { in slag ( } \mathrm{mg} / \mathrm{kg}\end{array}$ & $\begin{array}{l}\text { Percent } \\
\text { Dissolved }\end{array}$ & \begin{tabular}{|c|} 
Leachate \\
Conc. (mg/L)
\end{tabular} & $\begin{array}{l}\text { Element Conc. } \\
\text { in slag (mg/kg }\end{array}$ & $\begin{array}{l}\text { Percent } \\
\text { Dissolved }\end{array}$ \\
\hline Arsenic & 5.0 & $<0.2$ & 136 & $<29.4$ & $<0.2$ & 160 & $<25$ & $<0.2$ & 52 & $<76.9$ & $<0.2$ & 99 & $<40.4$ \\
\hline Barium & 100.0 & $<0.2$ & 1278 & $<3.13$ & $<0.2$ & 1441 & $<2.78$ & $<0.2$ & 1178 & $<3.40$ & $<0.2$ & 1136 & $<3.52$ \\
\hline Cadmium & 1.0 & $<0.1$ & 17 & $<100$ & $<0.1$ & 24 & $<83.3$ & 0.4 & 16 & 100 & 0.4 & 20 & 100 \\
\hline Chromium & 5.0 & 0.1 & 239 & 8.37 & $<0.1$ & 408 & $<4.90$ & $<0.1$ & 736 & $<2.72$ & $<0.1$ & 1056 & $<1.89$ \\
\hline Lead & 5.0 & $<0.1$ & 769 & $<2.60$ & $<0.1$ & 978 & $<2.04$ & 164 & 18743 & 100 & 3.9 & 69953 & 1.1 \\
\hline Mercury & 0.2 & $<0.1$ & 3 & $<100$ & $<0.1$ & 3 & $<100$ & $<0.1$ & 6 & $<100$ & $<0.1$ & 5 & $<100$ \\
\hline Selenium & 1.0 & 0.5 & 9 & 100 & 0.2 & 11 & 100 & $<0.1$ & 6 & $<100$ & 0.3 & 6 & 100 \\
\hline Silver & 5.0 & $<0.1$ & 6 & $<100$ & $<0.1$ & 6 & $<100$ & $<0.1$ & 10 & $<100$ & $<0.1$ & 8 & $<100$ \\
\hline Ccrium & - & 0.01 & 6364 & 0.03 & $<0.01$ & 8454 & 0.02 & 0.02 & 4653 & 0.09 & 0.02 & 5027 & 0.08 \\
\hline Basicity & & & $\overline{\mathrm{NC}}$ & & & NC & & & $\mathrm{NC}$ & & & NC & \\
\hline
\end{tabular}

Notes: 1. Percent dissolved was based on 1 gram of slag put into 0.2 liters of solvent. 2. $\mathrm{NC}=$ Not calculated dut to uncertainty in data. 


\section{Appendix 0}

\section{Offgas CEMS Reduced Data}

O-1 

• 
Table 0.1 Calculated furnace outlet offrgas compositions for $\mathbf{S 6 0}$.

\begin{tabular}{|c|c|c|c|c|c|c|c|c|c|c|c|c|c|c|c|c|c|c|c|}
\hline \multirow{2}{*}{$\operatorname{TME}(\mathrm{a})$} & \multirow{2}{*}{$\frac{Q_{v}}{N O x(p p m}$} & \multirow{2}{*}{\multicolumn{3}{|c|}{$\begin{array}{l}\text { vench Outet Dhy vol. \%/ppm (a) } \\
\text { m) } 02(\%) \operatorname{CO} 2(\%) \operatorname{Co~(ppm)~}\end{array}$}} & \multirow{2}{*}{ (ppm) } & \multirow{2}{*}{$\begin{array}{l}\text { Wet (b) } \\
\mathrm{H} 2 \mathrm{O}(\%)\end{array}$} & \multirow{2}{*}{$\begin{array}{l}\text { Quench Outlet (c) } \\
\text { Flowrate (dscfn) }\end{array}$} & \multirow{2}{*}{$\begin{array}{l}\text { Quench Ounlet } \\
\text { Flowrate (wscfn) }\end{array}$} & \multirow{2}{*}{$\begin{array}{l}\text { Quench Air (d) } \\
\text { Flowrate (wacfin) }\end{array}$} & \multirow{2}{*}{$\begin{array}{c}\text { Quench Air } \\
\text { Flowrate (wscfm) }\end{array}$} & \multirow{2}{*}{\multicolumn{2}{|c|}{$\begin{array}{l}\text { Temp. Quench Dilution } \\
\text { Air (C) (e) Factor }\end{array}$}} & Dilution & Furnace Ou & et Ofigas & mposition & (wet basis \% & (b) (B) & \\
\hline & & & & & & & & & & & & & Factor (I) & $\overline{\mathrm{NOx} \text { (ppm }}$ & $02(\mathrm{~h})$ & $\mathrm{CO2}$ & $\mathrm{CO}(\mathrm{ppm})$ & $\mathrm{SO} 2(\mathrm{pprn})$ & $\mathrm{H2O}$ \\
\hline $10: 13$ & 17.3 & 19.8 & 2.9 & 3654 & 1038 & 6.05 & 457.00 & 486.43 & 492.36 & 308.00 & 24.70 & 0.21 & 4.77 & 77.5 & 14.39 & 13.00 & 16375.1 & 4651.7 & 28.86 \\
\hline $10: 14$ & 19.5 & 19.8 & 2.93 & 3654 & 1038 & 6.05 & 457.00 & 486.43 & 492.36 & 308.00 & 24.70 & 0.21 & 4.77 & 87.4 & 14.39 & 13.13 & 16375.1 & 4651.7 & 28.86 \\
\hline $10: 15$ & 20.2 & 19.9 & 2.74 & 3654 & 1038 & 6.05 & 457.00 & 486.43 & 492.36 & 308.00 & 24.70 & 0.21 & 4.77 & 90.5 & 14.75 & 12.28 & 16375.1 & 4651.7 & 28.86 \\
\hline $10: 16$ & 22 & 19.9 & 2.71 & 3654 & 1038 & 6.05 & 457.00 & 486.43 & 492.36 & 308.00 & 24.70 & 0.21 & 4.77 & 98.6 & 14.80 & 12.14 & 16375.1 & 4651.7 & 28.86 \\
\hline $10: 17$ & 23.1 & 19.9 & 263 & 3654 & 1038 & 6.05 & 457.00 & 486.43 & 489.32 & 308.00 & 25.30 & 0.21 & 4.77 & 103.5 & 15.02 & 11.79 & 16375.1 & 4651.7 & 28.86 \\
\hline $10: 18$ & 24.5 & 19.9 & 2.63 & 3654 & 1038 & 6.05 & 457.00 & 486.43 & 489.32 & 308.00 & 25.30 & 0.21 & 4.77 & 109.8 & 15.02 & 11.79 & 16375.1 & 4651.7 & 28.86 \\
\hline $10: 19$ & 27.9 & 20 & 2.49 & 3654 & 1038 & 6.05 & 457.00 & 486.43 & 489.32 & 308.00 & 25.30 & 0.21 & 4.77 & 125.0 & 15.25 & 11.16 & 16375.1 & 4651.7 & 28.86 \\
\hline $10: 20$ & 31 & 19.9 & 2.62 & 3924 & 1048 & 6.05 & 457.00 & 486.43 & 489.32 & 308.00 & 25.30 & 0.21 & 4.77 & 138.9 & 14.98 & 11.74 & 17585.1 & 4696.5 & 28.86 \\
\hline $10: 21$ & 35.5 & 19.9 & 2.55 & 3924 & 1048 & 6.05 & 457,00 & 486.43 & $489: 32$ & 308.00 & 25.30 & 0.21 & 4.77 & 159.1 & 14.93 & 11.43 & 17585.1 & 4696.5 & 28.86 \\
\hline $10: 22$ & 30.2 & 19.9 & 2.52 & 3604 & 1048 & 6.05 & 457.00 & 486.43 & 489.32 & 308.00 & 25.30 & 0.21 & 4.77 & 135.3 & 14.98 & 11.29 & 16151.0 & 4696.5 & 28.86 \\
\hline $10: 23$ & 38.7 & 19.8 & 2.82 & 3604 & 1048 & 6.05 & 457.00 & 486.43 & 471.77 & 308.00 & 25.30 & 0.21 & 4.77 & 173.4 & 14.44 & 12.64 & 16151.0 & 4696.5 & 28.86 \\
\hline $10: 24$ & 39.3 & 19.8 & 2.72 & 3542 & 1049 & 6.05 & 457.00 & 486.43 & 471.77 & 308.00 & 25.30 & 0.21 & 4.77 & 176.1 & 14.57 & 12.19 & 15873.2 & 4701.0 & 28.86 \\
\hline $10: 25$ & 39.1 & 19.8 & 2.76 & 3542 & 1049 & 6.05 & 457.00 & 486.43 & 471.77 & 308.00 & 25.30 & 0.21 & 4.77 & 175.2 & 14.53 & 12.37 & 15873.2 & 4701.0 & 28.86 \\
\hline $10: 26$ & 39 & 19.8 & 2.88 & 3467 & 1051 & 6.05 & 457.00 & 486.43 & 471.77 & 308.00 & 25.30 & 0.21 & 4.77 & 174.8 & 14.35 & 12.91 & 15537.1 & 4710,0 & 28.86 \\
\hline $10: 27$ & 35.6 & 19.8 & 2.78 & 3467 & 1051 & 6.05 & 457.00 & 486.43 & 471.77 & 308.00 & 25.30 & 0.21 & 4.77 & 159.5 & 14.53 & 12.46 & 15537.1 & 4710.0 & 28.86 \\
\hline $10: 28$ & 44.8 & 19.7 & 2.97 & 3825 & 1044 & 6.05 & 457.00 & 486.43 & 471.77 & 308.00 & 25.30 & 0.21 & 4.77 & 200.8 & 14.22 & 13.31 & 17141.4 & 4678.6 & 28.86 \\
\hline $10: 29$ & 40.6 & 19.8 & 2.66 & 3825 & 1044 & 6.05 & 457.00 & 486.43 & 498.37 & 308.00 & 26.00 & 0.21 & 4.77 & 181.9 & 14.62 & 11.92 & 17141.4 & 4678.6 & 28.86 \\
\hline $10: 30$ & 37.5 & 19.8 & 2.65 & 4045 & 1047 & 6.05 & 457.00 & 486.43 & 498.37 & 308.00 & 26.00 & 0.21 & 4.77 & 168.1 & 14.62 & 11.88 & 18127.3 & 4692.0 & 28.86 \\
\hline $10: 31$ & 32.5 & 19.9 & 2.46 & 4045 & 1047 & 6.05 & 457.00 & 486.43 & 498.37 & 308.00 & 26.00 & 0.21 & 4.77 & 145.6 & 14.89 & 11.02 & 18127.3 & 4692.0 & 28.86 \\
\hline $10: 32$ & 38.3 & 19.8 & 2.64 & 4665 & 1052 & 6.05 & 457.00 & 486.43 & 498.37 & 308.00 & 26.00 & 0.21 & 4.77 & 171.6 & 14.57 & 11.83 & 20905.8 & 4714.4 & 28.86 \\
\hline $10: 33$ & 49 & 19.1 & 2.64 & 4665 & 1052 & 6.05 & 457.00 & 486.43 & 498.37 & 308.00 & 26.00 & 0.21 & 4.77 & 219.6 & 11.57 & 11.83 & 20905.8 & 4714.4 & 28.86 \\
\hline 10.57 & 34.8 & 20 & 1.94 & 4665 & 1052 & 6.05 & 457.00 & 486.43 & 487.69 & 308.00 & 23.60 & 0.21 & 4.77 & 156.0 & 15.51 & 8.69 & 20905.8 & 4714.4 & 28.86 \\
\hline $10: 58$ & 41.2 & 20 & 2.08 & 4665 & 1052 & 6.05 & 457.00 & 486.43 & 487.69 & 308.00 & 23.60 & 0.21 & 4.77 & 184.6 & 15.29 & 9.32 & 20905.8 & 4714.4 & 28.86 \\
\hline $10: 59$ & 41.2 & 20 & 2.01 & 4665 & 1052 & 6.05 & 457.00 & 486.43 & 461.01 & 308.00 & 23.60 & 0.21 & 4.77 & 184,6 & 15.25 & 9.01 & 20905.8 & 4714.4 & 28.86 \\
\hline $11: 00$ & 37.1 & 20 & 1.92 & 3006 & 1043 & 6.05 & 457.00 & 486.43 & 461.01 & 308.00 & 23.60 & 0.21 & 4.77 & 166.3 & 15.51 & 8.60 & 13471.1 & 4674.1 & 28.86 \\
\hline $11: 01$ & 34.6 & 20 & 1.9 & 3006 & 1043 & 6.05 & 457.00 & 486.43 & 461.01 & 308.00 & 23.60 & 0.21 & 4.77 & 155.1 & 15.51 & 8.51 & 13471.1 & 4674.1 & 28.86 \\
\hline $11: 02$ & 34.8 & 19.9 & 2.1 & 5713 & 1045 & 6.05 & 457.00 & 486.43 & 461.01 & 308.00 & 23.60 & 0.21 & 4.77 & 156.0 & 15.16 & 9.41 & 25602.3 & 4683.1 & 28.86 \\
\hline $11: 03$ & 45.1 & 19.9 & 2.27 & 5713 & 1045 & 6.05 & 457.00 & 486.43 & 461.01 & 308.00 & 23.60 & 0.21 & 4.77 & 202.1 & 14.75 & 10.17 & 25602.3 & 4683.1 & 28.86 \\
\hline $11: 04$ & 34.5 & 20 & 1.93 & 2677 & 1039 & 6.05 & 457.00 & 486.43 & 461.01 & 308.00 & 23.60 & 0.21 & 4.77 & 154.6 & 15.38 & 8.65 & 11996.7 & 4656.2 & 28.86 \\
\hline 11:05 & 32.3 & 20 & 1.91 & 2677 & 1039 & 6.05 & 457.00 & 486.43 & 509.91 & 308.00 & 25.40 & 0.21 & 4.77 & 144.7 & 15.43 & 8.56 & 11996.7 & 4656.2 & 28.86 \\
\hline $11: 06$ & 39 & 19.9 & 2.04 & 3437 & 1045 & 6.05 & 457.00 & 486.43 & 509.91 & 308.00 & 25.40 & 0.21 & 4.77 & 174.8 & 15.16 & 9.14 & 15402.6 & 4683.1 & 28.86 \\
\hline $11: 07$ & 38.8 & 20 & 1.9 & 3437 & 1045 & 6.05 & 457.00 & 486.43 & 509.91 & 308.00 & 25.40 & 0.21 & 4.77 & 173.9 & 15.38 & 8.51 & 15402.6 & 4683.1 & 28.86 \\
\hline $11: 08$ & 38.5 & 20 & 1.93 & 2586 & 1045 & 6.05 & 457.00 & 486.43 & 509.91 & 308.00 & 25.40 & 0.21 & 4.77 & 172.5 & 15.20 & 8.65 & 11588.9 & 4683.1 & 28.86 \\
\hline $11: 09$ & 38.9 & 20 & 1.88 & 2586 & 1045 & 6.05 & 457.00 & 486.43 & 509.91 & 308.00 & 25.40 & 0.21 & 4.77 & 174.3 & 15.29 & 8.43 & 11588.9 & 4683.1 & 28.86 \\
\hline $11: 10$ & 36.4 & 20 & 1.8 & 2371 & 1043 & 6.05 & 457.00 & 486.43 & 509.91 & 308.00 & 25.40 & 0.21 & 4.77 & 163.1 & 15.43 & 8.07 & 10625.4 & 4674.1 & 28.86 \\
\hline $11: 11$ & 34.5 & 20 & 1.7 & 2371 & 1043 & 6.05 & 457.00 & 486.43 & 510.19 & 308.00 & 26.50 & 0.21 & 4.77 & 154.6 & 15.51 & 7.62 & 10625.4 & 4674.1 & 28.86 \\
\hline $11: 12$ & 36.7 & 20 & 186 & 2787 & 1050 & 6.05 & 457.00 & 486.43 & 510.19 & 308.00 & 26.50 & 0.21 & 4.77 & 164.5 & 15.25 & 8.34 & 12489.7 & 4705.5 & 28.86 \\
\hline $11: 13$ & 38.4 & 20 & 1.82 & 2787 & 1050 & 6.05 & 457.00 & 486.43 & 510.19 & 308.00 & 26.50 & 0.21 & 4.77 & 172.1 & 15.29 & 8.16 & 12489.7 & 4705.5 & 28.86 \\
\hline $11: 14$ & 37.9 & 19.9 & 1.93 & 3982 & 1048 & 6.05 & 457.00 & 486.43 & 510.19 & 308.00 & 26.50 & 0.21 & 4.77 & 169.8 & is.11 & 8.65 & 17845.0 & 4696.5 & 28.86 \\
\hline $11: 15$ & 39.9 & 20 & 1.94 & 3982 & 1048 & 6.05 & 457.00 & 486.43 & 510.19 & 308.00 & 26.50 & 0.21 & 4.77 & 178.8 & 15.20 & 8.69 & 17845.0 & 4696.5 & 28.86 \\
\hline $11: 16$ & 37.7 & 20 & 1.87 & 2292 & 1046 & 6.05 & 457.00 & 486.43 & 510.19 & 308.00 & 26.50 & 0.21 & 4.77 & 168.9 & 15.29 & 8.38 & 102714 & 4687.6 & 28.86 \\
\hline $11: 17$ & 36.4 & 20 & 1.74 & 2292 & 1046 & 6.05 & 457.00 & 486.43 & 506.37 & 308.00 & 26.60 & 0.21 & 4.77 & 163.1 & 15.43 & 7.80 & 10271.4 & 4687.6 & 28.86 \\
\hline $11: 18$ & 35.9 & 20 & 176 & 2686 & 1040 & 6.05 & 457,00 & 486.43 & 506.37 & 308,00 & 26.60 & 0.21 & 4.77 & 160.9 & 15.34 & 7.89 & 12037.1 & 4660.7 & 28.86 \\
\hline $11: 19$ & 35.5 & 20 & 1.69 & 2686 & 1040 & 6.05 & 457.00 & 486.43 & 506.37 & 308.00 & 26.60 & 0.21 & 4.77 & 159.1 & 15.51 & 7.57 & 12037.1 & 4660.7 & 28.86 \\
\hline $11: 20$ & 37.6 & 20 & 1.75 & 2694 & 1051 & 6.05 & 457.00 & 486.43 & 506.37 & 308.00 & 26.60 & 0.21 & 4.77 & 168.5 & 15.34 & 7.84 & 12072.9 & 4710.0 & 28.86 \\
\hline $11: 21$ & 42.8 & 20 & 18 & 2694 & 1051 & 6.05 & 457.00 & 486.43 & 506.37 & 308.00 & 26.60 & 0.21 & 4.77 & 191.8 & 15.29 & 8.07 & 12072.9 & 4710.0 & 28.86 \\
\hline $11: 22$ & 33.7 & 20 & 1.65 & 2293 & 1044 & 6.05 & 457.00 & 486.43 & 506.37 & 308.00 & 26.60 & 021 & 4.77 & 151.0 & 1551 & 7.39 & 10275.9 & 4678.6 & 28.86 \\
\hline $11: 23$ & 37.4 & 20 & 1.72 & 2293 & 1044 & 6.05 & 457.00 & 48643 & 463.49 & 308.00 & 26.80 & 0.21 & 4.77 & 167.6 & 15.34 & 7.71 & 10275.9 & 4678.6 & 28.86 \\
\hline $11: 24$ & 364 & 19.9 & 1.86 & 3185 & 1060 & 6.05 & 457.00 & 486.43 & 463.49 & 308.00 & 26.80 & $0.2 !$ & 4.77 & 163.1 & 15.11 & 8.34 & 14273.3 & 4750.3 & 28.86 \\
\hline $11: 25$ & 446 & 19.9 & 186 & 3185 & 1060 & 6.05 & 457.00 & 486.43 & 463.49 & 308.00 & 26.80 & 0.21 & 4.77 & 199.9 & 15.11 & 8.34 & 14273.3 & 4750.3 & 28.86 \\
\hline $11: 26$ & 33.5 & 20 & 163 & 1835 & 1039 & 6.05 & 457.00 & 486.43 & 463.49 & 308.00 & 26.80 & 0.21 & 4.77 & 1501 & 15.56 & 7.30 & 8223.4 & 4656.2 & 28.86 \\
\hline 11.27 & 38.3 & 20 & 169 & 1835 & 1039 & 6.05 & 457.00 & 486.43 & 463.49 & 308.00 & 26.80 & 0.21 & 4.77 & 171.6 & 15.43 & 7.57 & 8223.4 & 4656.2 & 28.86 \\
\hline $11: 28$ & 36.8 & 20.1 & 1.61 & 2865 & 1041 & 6.05 & 457.00 & 486.43 & 463.49 & 308.00 & 26.80 & 0.21 & 4.77 & 164.9 & 15.65 & 7.22 & 12839.3 & 4665.2 & 28.86 \\
\hline $11: 29$ & 39.7 & 20 & 1.83 & 2865 & 1041 & 605 & 457.00 & 48643 & 513.45 & 308.00 & 2680 & 0.21 & 477 & 177.9 & 15.38 & 8.20 & 12839.3 & 4665.2 & 28.86 \\
\hline $11: 30$ & 35.8 & 20 & 1.82 & 2865 & 1041 & 6.05 & 457.00 & 486.43 & 513.45 & 308.00 & 26.80 & 0.21 & 4.77 & 160.4 & 15.34 & 8.16 & 12839.3 & 4665.2 & 28.86 \\
\hline $11: 31$ & 34.7 & 20 & 177 & 2865 & 1041 & 6.05 & 457.00 & 48643 & 513.45 & 308.00 & 2680 & 0.21 & 477 & 155.5 & 15.34 & 7.93 & 12839.3 & 4665.2 & 28.86 \\
\hline 1401 & 35.66 & 19.91 & 217 & 3,36188 & $1,045.36$ & 6.05 & & 48643 & & 308.00 & & 0.21 & 4.77 & & & & & & \\
\hline
\end{tabular}


Table O-1 Calculated fumace outlet offgas compositions for $\$ 60$ (continued)

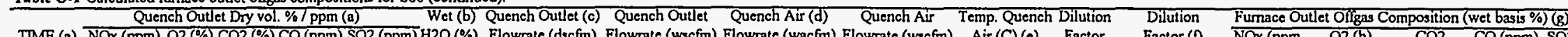

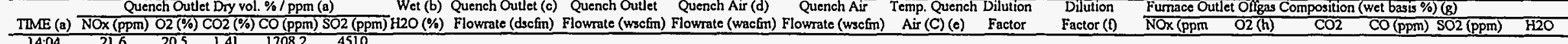

\begin{tabular}{|c|c|c|c|c|c|c|}
\hline 14.05 & 21.1 & 20.5 & 132 & 1401.2 & 4510 & \\
\hline 1406 & 22.3 & 20.5 & 1.38 & 1216.6 & 4510 & 6.45 \\
\hline 1407 & 28.6 & 204 & 166 & 1951.4 & 4510 & 6.45 \\
\hline $14: 08$ & 22.2 & 20.5 & 148 & 2298.4 & 4950 & 645 \\
\hline $14: 09$ & 23.2 & 20.4 & 164 & 2065.3 & 4950 & 6.45 \\
\hline 14.10 & 19.9 & 20.5 & i 58 & 1887.7 & 5370 & 6.45 \\
\hline $14: 11$ & 22.4 & 20.4 & 1.69 & 1831.3 & 5370 & 6.45 \\
\hline $14: 12$ & 19 & 20.5 & 154 & 1683 & 4600 & 6.45 \\
\hline $14: 13$ & 18.2 & 20.5 & 157 & 1524.2 & 4600 & 645 \\
\hline $14: 14$ & 17.7 & 20.5 & 155 & 1641.4 & 4780 & 6.45 \\
\hline $14: 15$ & 22 & 20.4 & 173 & 1709.1 & 4780 & 6.45 \\
\hline $14: 16$ & 19 & 20.4 & is 58 & 1719.7 & 5970 & 6.45 \\
\hline $14: 17$ & 22 & 20.4 & 1.67 & 1738.6 & 5970 & 6.45 \\
\hline $14: 18$ & 20 & 20.4 & 1.61 & 1556.8 & 5340 & 6.45 \\
\hline $\begin{array}{l}14: 19 \\
\end{array}$ & 17.8 & 20.4 & 161 & 1514.3 & 5340 & 6.45 \\
\hline $14: 20$ & 17.8 & 20.5 & 1.55 & 1435.1 & 4240 & 6.45 \\
\hline $14.2 !$ & 15.5 & 20.5 & 1.33 & 1109.1 & 4240 & 6.45 \\
\hline $14: 22$ & 17.1 & 20.4 & 1.55 & 1342.9 & 4830 & 6.45 \\
\hline $14: 23$ & 16.3 & 20.4 & 163 & 14271 & 4830 & 6.45 \\
\hline $14: 24$ & 16.7 & 20.4 & 1.62 & 1825.9 & 4510 & 6.45 \\
\hline 1425 & 169 & 20.4 & 1.73 & 1746.4 & 4510 & 6.45 \\
\hline $14: 26$ & 16.7 & 20.4 & 1.67 & 1765.1 & 4620 & 6.45 \\
\hline 14.27 & 17.2 & 20.4 & 1.59 & 1660.1 & 4620 & 6.45 \\
\hline 14.28 & 16.7 & 20.5 & 1.51 & 1585.2 & 4330 & 6.45 \\
\hline $14: 29$ & 24.6 & 20.4 & 1.7 & 2236.5 & 4330 & 6.45 \\
\hline $14 \cdot 30$ & 196 & 20.4 & 1.59 & 2260.9 & 4940 & 6.45 \\
\hline $14: 31$ & 20.1 & 20.4 & 157 & 16141 & 4940 & 6.45 \\
\hline $14: 32$ & 211 & 20.3 & 1.69 & 1768.8 & 5240 & 6.45 \\
\hline $14: 33$ & 24.8 & 20.4 & 154 & 2043 & 5240 & 6.45 \\
\hline $14: 34$ & 14.6 & 20.4 & 148 & 1252.4 & 4570 & 6.45 \\
\hline $14: 35$ & 16 & 20.3 & 1.6 & 1522.9 & 4570 & 6.45 \\
\hline $14: 36$ & 153 & 20.4 & 1.54 & 14366 & 4450 & 6.45 \\
\hline 14.37 & 136 & 20.4 & 1.41 & 1310.8 & 4450 & 6.45 \\
\hline 14.38 & 13.9 & 20.4 & 1.34 & 1188.5 & 4300 & 6.45 \\
\hline $14: 39$ & 161 & 204 & 148 & 1447.5 & 4300 & 645 \\
\hline $14: 40$ & 143 & 204 & 138 & 1328.5 & 4750 & 6.45 \\
\hline $14: 41$ & 17.9 & 20.4 & 147 & 13233 & 4750 & 6.45 \\
\hline 14.42 & 176 & 204 & 1.48 & 1583.4 & 4950 & 6.45 \\
\hline $14: 43$ & 143 & 204 & 147 & 1320.6 & 4950 & 645 \\
\hline 14.44 & 18 & 203 & 1.61 & 1464.4 & 5520 & 6.45 \\
\hline $14: 45$ & 171 & 203 & 157 & 1282.4 & 5520 & 6.45 \\
\hline $14: 46$ & 163 & 20.3 & 16 & 1435 & 5060 & 645 \\
\hline $14: 47$ & 12.5 & 20.3 & 158 & 987.2 & 5060 & 645 \\
\hline 14.48 & 16.7 & 203 & 1.71 & 1399.3 & 5360 & 6.45 \\
\hline $14: 49$ & 119 & 20.2 & 165 & 12006 & 5360 & 645 \\
\hline 14.50 & 11 & 20.2 & 168 & 1037.7 & 5790 & 645 \\
\hline 14.51 & 8.7 & 20.2 & 163 & 936.2 & 5790 & 6.45 \\
\hline $14: 52$ & 8.1 & 20.3 & 1.4 & 822.5 & 4540 & 6.45 \\
\hline 14.53 & 83 & 204 & 129 & 681 & 4540 & 6.45 \\
\hline 1454 & 86 & 20.4 & 123 & 817.5 & 4820 & 645 \\
\hline $14: 55$ & 77 & 204 & 1.3 & 6792 & 4820 & 645 \\
\hline $14: 56$ & 89 & 203 & 147 & 846.6 & 5330 & 6.45 \\
\hline 14.57 & 83 & 203 & $i_{47}$ & 806.9 & 5330 & 6.45 \\
\hline 14:58 & 9.6 & 20.3 & 157 & 1046.3 & 4880 & 645 \\
\hline 14.59 & 97 & 20.3 & 1.65 & 1033.1 & 4880 & 6.45 \\
\hline $15: 00$ & 15.3 & 202 & 18 & 14251 & 5250 & 645 \\
\hline 1501 & 98 & 20.3 & 167 & 12906 & 5250 & 645 \\
\hline 15.02 & 106 & 202 & 171 & 1116 & 5240 & 645 \\
\hline
\end{tabular}

\begin{tabular}{|c|c|c|c|c|c|c|}
\hline 446 & 476.75 & 521.94 & 308.00 & 31.00 & 0.24 & 416 \\
\hline 446 & 47675 & 521.94 & 308.00 & 31.00 & 0.24 & 4.16 \\
\hline 446 & 476.75 & 521.94 & 308.00 & 31.00 & 0.24 & 4.16 \\
\hline 446 & 476.75 & S21.94 & 308.00 & 31.00 & 0.24 & 4.16 \\
\hline 446 & 476.75 & 521.94 & 308.00 & 31.00 & 0.24 & 4.16 \\
\hline 446 & 476.75 & 521.94 & 308,00 & 29.70 & 0.24 & 4.16 \\
\hline 446 & 476.75 & 521.94 & 308.00 & 29.70 & 0.24 & 416 \\
\hline 446 & 476.75 & 521.94 & 30800 & 29.70 & 0.24 & 4.16 \\
\hline 446 & 476.75 & 521.94 & 30800 & 29.70 & 0.24 & 4.16 \\
\hline 446 & 47675 & 521.94 & 308.00 & 29.70 & 024 & 4.16 \\
\hline 446 & 47675 & 521.94 & 308.00 & 29.70 & 0.24 & 4.16 \\
\hline 446 & 47675 & 500.21 & 308.00 & 30.30 & 0.24 & 4.16 \\
\hline 446 & 476.75 & 500.21 & 308.00 & 30.30 & 0.24 & 4.16 \\
\hline 446 & 476.75 & 500.21 & 308.00 & 30.30 & 0.24 & 4.16 \\
\hline 446 & 476.75 & 500.21 & 308.00 & 30.30 & 0.24 & 4.16 \\
\hline 446 & 476.75 & 50021 & 308.00 & 30.30 & 0.24 & 4.16 \\
\hline 446 & 476.75 & 500.21 & 308.00 & 30.30 & 0.24 & 4.16 \\
\hline 446 & 476.75 & 538.57 & 308.00 & 31.50 & 0.24 & 4.16 \\
\hline 446 & 476.75 & 538.57 & 308.00 & 3150 & 0.24 & 4.16 \\
\hline 446 & 476.75 & 538.57 & 308.00 & 31.50 & 0.24 & 4.16 \\
\hline 446 & 476.75 & 53857 & 308.00 & 31.50 & 0.24 & 4.16 \\
\hline 446 & 476.75 & 538.57 & 308.00 & 31.50 & 0.24 & 4.16 \\
\hline 446 & 476.75 & 538.57 & 308.00 & 31.50 & 0.24 & 4.16 \\
\hline 446 & 476.75 & 465.25 & 30800 & 31.10 & 0.24 & 416 \\
\hline 446 & 476.75 & 465.25 & 308.00 & 31.10 & 0.24 & 4.16 \\
\hline 446 & 476.75 & 465.25 & 308.00 & 31.10 & 0.24 & 4.16 \\
\hline 446 & 476.75 & 465.25 & 308.00 & 31.10 & 0.24 & 416 \\
\hline 446 & 476.75 & 465.25 & 308.00 & 31.10 & 0.24 & 4.16 \\
\hline 446 & 476.75 & 465.25 & 308.00 & 3110 & 0.24 & 4.16 \\
\hline 446 & 476.75 & 533.47 & 308.00 & 31.40 & 0.24 & 4.16 \\
\hline 446 & 476.75 & 533.47 & 308.00 & 31.40 & 0.24 & 4.16 \\
\hline 446 & 47675 & 533.47 & 308.00 & 31.40 & 0.24 & 4.16 \\
\hline 446 & 476.75 & 533.47 & 30800 & 31,40 & 0.24 & 4.16 \\
\hline 446 & 476.75 & 533,47 & 308.00 & 31.40 & 0.24 & 4.16 \\
\hline 446 & 476.75 & 533.47 & 308.00 & 31.40 & 0.24 & 4.16 \\
\hline 446 & 476.75 & 517.69 & 308.00 & 31.10 & 0.24 & 41 \\
\hline 446 & 476.75 & 517,69 & 308.00 & 31.10 & 0.24 & 416 \\
\hline 446 & 476.75 & 517.69 & 308.00 & 3110 & 0.24 & 4.16 \\
\hline 446 & 476.75 & 51769 & 308.00 & 3110 & 024 & 4.16 \\
\hline 446 & 47675 & 517.69 & 30800 & 31.10 & 0.24 & 416 \\
\hline 446 & 476.75 & 517.69 & 308.00 & 31.10 & 0.24 & 4.16 \\
\hline 446 & 47675 & 505.24 & 308.00 & 3110 & 0.24 & 4.16 \\
\hline 446 & 47675 & 505.24 & 308.00 & 31.10 & 0.24 & 416 \\
\hline 446 & 476.75 & 505.24 & 30800 & 31.10 & 0.24 & 4.16 \\
\hline 446 & 476.75 & 505.24 & 308.00 & 31.10 & 0.24 & 41 \\
\hline 446 & 476.75 & 505.24 & 30800 & 31.10 & 0.24 & 4.1 \\
\hline 446 & 476.75 & 505.24 & 308.00 & 31.10 & 0.24 & 41 \\
\hline 446 & 47675 & 50743 & 308.00 & 31.30 & 0.24 & $4 !$ \\
\hline 446 & 476.75 & 50743 & 308.00 & 31.30 & 0.24 & 4. \\
\hline 446 & 47675 & 507,43 & 308.00 & 31.30 & 0.24 & 4 \\
\hline 446 & 476.75 & 507.43 & 308.00 & 31.30 & 0.24 & 4 \\
\hline 446 & 476.75 & 507.43 & 30800 & 3130 & 024 & 4. \\
\hline 446 & 47675 & 507.43 & 308.00 & 31.30 & 024 & 4. \\
\hline 446 & 47675 & 52951 & 30800 & 3120 & 024 & 4 \\
\hline 446 & 47675 & 52951 & 30800 & 3120 & 024 & \\
\hline 446 & 47675 & 52951 & 30800 & 3120 & 024 & \\
\hline 446 & 47675 & 52951 & 30800 & 31 20 & 024 & 41 \\
\hline
\end{tabular}

\begin{tabular}{|c|c|c|c|c|c|}
\hline 86.8 & 17.89 & 5.37 & 4734.6 & 17551.5 & 26.83 \\
\hline 111.3 & 17.58 & 6.46 & 7594.2 & 17551.5 & 26.83 \\
\hline 86.4 & 17.73 & 5.76 & 89446 & 19263.8 & 26.83 \\
\hline 903 & 17.54 & 6.38 & 8037.5 & 192638 & 26.83 \\
\hline 77.4 & 17.65 & 6.15 & 7346.3 & 208983 & 26.83 \\
\hline 872 & 17.50 & 6.58 & 7126.8 & 20898.3 & 26.83 \\
\hline 73.9 & 17.65 & 5.99 & 6549.7 & 17901.7 & 26.83 \\
\hline 70.8 & 17.65 & 6.11 & 5931.7 & 179017 & 26.83 \\
\hline 68.9 & 17.69 & 6.03 & 6387.8 & 186022 & 26.83 \\
\hline 85.6 & 17.42 & 6.73 & 66513 & 186022 & 26.83 \\
\hline 73.9 & 17.58 & 6.15 & 6692.5 & 23233.3 & 26.83 \\
\hline 85.6 & 17.46 & 650 & 67661 & 23233.3 & 26.83 \\
\hline 77.8 & 17.61 & 6.27 & 6058.6 & 207816 & 26.83 \\
\hline 69.3 & 17.58 & 6.27 & 5893.2 & 20781.6 & 26.83 \\
\hline 69.3 & 1765 & 6.03 & 5584.9 & 16500.7 & 26.83 \\
\hline 60.3 & 17.96 & 5.18 & 4316.3 & 16500.7 & 26.83 \\
\hline 66.5 & 17.61 & 6.03 & 5226.1 & 18796.8 & 26.83 \\
\hline 63.4 & 17.54 & 6.34 & 55538 & 18796.8 & 26.83 \\
\hline 65.0 & 17.54 & 6.30 & 7105.8 & 17551.5 & 26.83 \\
\hline 658 & 17.46 & 6.73 & 6796.4 & 17551.5 & 26.83 \\
\hline 65.0 & 17.46 & 6.50 & 6869.2 & 17979.6 & 26.83 \\
\hline 669 & 17.54 & 6.19 & 6460.6 & 17979.6 & 26.83 \\
\hline 65.0 & 17.65 & 5.88 & 6169.1 & 168510 & 26.83 \\
\hline 957 & 17.38 & 6.62 & 8703.7 & 16851.0 & 26.83 \\
\hline 763 & $17.4 \%$ & 6.19 & 8798.7 & 19224.9 & 26.83 \\
\hline 78.2 & 17.38 & 6.11 & 6281.6 & 192249 & 26,83 \\
\hline 82.1 & 17.15 & 6.58 & 6883.6 & 20392.4 & 26.83 \\
\hline 96.5 & 17.38 & 5.99 & 7950.7 & 20392.4 & 26.83 \\
\hline 56.8 & 17.50 & 5.76 & 4873.9 & 17785.0 & 26.83 \\
\hline 623 & 17.19 & 6.23 & 59266 & 17785.0 & 26.83 \\
\hline 59.5 & 17.34 & 5.99 & 5590.8 & 17318.0 & 26.83 \\
\hline 52.9 & 17.46 & 5.49 & 5101.2 & 173180 & 26.83 \\
\hline 541 & 17.54 & 5.21 & 4625.3 & 16734.2 & 26.83 \\
\hline 62.7 & 17.30 & 5.76 & 5633.2 & 167342 & 26.83 \\
\hline 557 & 17.38 & 5.37 & 5170.1 & 18485.5 & 26.83 \\
\hline 69.7 & 17.38 & 5.72 & 5149.9 & 18485.5 & 26.83 \\
\hline 685 & 17.34 & 576 & 6162.1 & 192638 & 26.83 \\
\hline 557 & 1730 & 5.72 & 5139.4 & 192638 & 26.83 \\
\hline 70.1 & 17.19 & 6.27 & 56990 & 21482.1 & 2683 \\
\hline 66.5 & 17.11 & 6.11 & $4990 ?$ & 214821 & 26.83 \\
\hline 634 & 17.03 & 623 & 5584.6 & 19691.9 & 26.83 \\
\hline 486 & 1707 & 6.15 & 38419 & 19691.9 & 26.83 \\
\hline 650 & 16.87 & 6.65 & 5445.6 & 208594 & 26.83 \\
\hline 463 & 16.84 & 642 & 46724 & 208594 & 2683 \\
\hline 428 & 1676 & 654 & 4038.4 & 22532.8 & 26.83 \\
\hline 339 & 16.84 & 634 & 3643.4 & 225328 & 26.83 \\
\hline 31.5 & 17.15 & 5.45 & 32009 & 17668.2 & 2683 \\
\hline 32.3 & 1730 & 502 & 26502 & 176682 & 26.83 \\
\hline 335 & 1738 & 479 & 31814 & 187579 & 26.83 \\
\hline 300 & 1730 & 506 & 26432 & 187579 & 26.83 \\
\hline 346 & 17.15 & 5.72 & 32947 & 207427 & 26.83 \\
\hline 323 & 17.11 & 572 & 31402 & 207427 & 2683 \\
\hline 374 & 1695 & 6.11 & 40719 & 189914 & 26.83 \\
\hline 377 & 16 & 642 & $4020 \mathrm{~S}$ & 189914 & 2683 \\
\hline 595 & 1676 & 701 & 55460 & 204313 & 268 \\
\hline 381 & 1687 & 650 & 50226 & 204313 & 268 \\
\hline & & & & & \\
\hline
\end{tabular}


Table 0-1 Calculated furnace outlet offgas compositions for $S 60$ (continued)

\begin{tabular}{|c|c|c|c|c|c|c|c|c|c|c|c|c|c|c|c|c|c|c|c|}
\hline \multirow{2}{*}{ TIME (a) } & \multirow{2}{*}{$\frac{\text { Que }}{\text { NOx (ppm) }}$} & \multirow{2}{*}{\multicolumn{3}{|c|}{ ench outlet Dry vol. \%/ppm (e) }} & \multirow{2}{*}{$\overline{102(\mathrm{ppm}}$} & \multirow{2}{*}{$\begin{array}{l}\text { Wet (b) } \\
\mathrm{H} 2 \mathrm{O}(\%)\end{array}$} & \multirow{2}{*}{$\begin{array}{l}\text { Quench Outlet (c) } \\
\text { Flowrate (dscfin) }\end{array}$} & \multirow{2}{*}{$\begin{array}{l}\text { Quench Outlet } \\
\text { Flowrate (wsefin) }\end{array}$} & \multirow{2}{*}{$\begin{array}{l}\text { Quench Air (d) } \\
\text { Flowrate (wacfm) }\end{array}$} & \multirow{2}{*}{$\begin{array}{c}\text { Quench Air } \\
\text { Flowrate (wscfn) }\end{array}$} & \multicolumn{2}{|l|}{ Temp. Quen } & \multirow{2}{*}{$\begin{array}{l}\text { Dilution } \\
\text { Factor (f) }\end{array}$} & \multicolumn{6}{|c|}{ Furngce Outlet Ofgas Composition (wet basis \%) (g) } \\
\hline & & & & & & & & & & & $\operatorname{Air}(C)(c)$ & Factor & & NOX (ppm & $02(\mathrm{~h})$ & $\mathrm{CO} 2$ & $\mathrm{CO}(\mathrm{ppm})$ & $\mathrm{SO} 2(\mathrm{ppm})$ & $\mathrm{H2O}$ \\
\hline $15: 03$ & 9.8 & 202 & 175 & 1129.8 & 5240 & 645 & 446 & 476.75 & 529.51 & 308.00 & 31.20 & 0.24 & 4.16 & 38.1 & 16.76 & 681 & 4396.8 & 20392.4 & 26.83 \\
\hline 15:04 & 10.3 & 20.3 & 17 & 1266.9 & 5180 & 6.45 & 446 & 476.75 & 529.51 & 308.00 & 31.20 & 0.24 & 4.16 & 40.1 & 16.87 & 6.62 & 4930.4 & 20158.9 & 26.83 \\
\hline 15:05 & 11.8 & 20.2 & 1.76 & 1340.4 & 5180 & 6.45 & 446 & 476.75 & 555.98 & 308.00 & 32.00 & 0.24 & 4.16 & 45.9 & 16.84 & 6.85 & 5216.4 & 20158.9 & 2683 \\
\hline 15:06 & 14.1 & 20.2 & 1.82 & 1456.2 & 5310 & 6.45 & 446 & 476.75 & 555.98 & 308.00 & 32.00 & 0.24 & 4.16 & 54.9 & 16.80 & 7.08 & 5667.1 & 20664.8 & 26.83 \\
\hline 15:07 & 14.2 & 20.2 & 1.76 & 1528.9 & 5310 & 6.45 & 446 & 476.75 & 555.98 & 308.00 & 32.00 & 0.24 & 4.16 & 55.3 & 16.80 & 6.85 & 5950.0 & 20664.8 & 26.83 \\
\hline 15:08 & 11.7 & 20.3 & 1.65 & 1412.8 & 4900 & 6.45 & 446 & 476.75 & 555.98 & 308.00 & 32.00 & 0.24 & 4.16 & 45.5 & 16.95 & 6.42 & 5498.2 & 19069.2 & 26.83 \\
\hline 15:09 & 12.3 & 20.2 & 1.76 & 1424 & 4900 & 6.45 & 446 & 476.75 & 555.98 & 308.00 & 32.00 & 0.24 & 4.16 & 47.9 & 16.80 & 6.85 & 5541.8 & 19069.2 & 26.83 \\
\hline 15:10 & 9 & 20.2 & 1.64 & 1230.9 & 4430 & 6.45 & 446 & 476.75 & 555.98 & 308.00 & 32.00 & 0.24 & 4.16 & 35.0 & 16.84 & 6.38 & 4790.3 & 17240.1 & 26.83 \\
\hline 15:11 & 9.4 & 20.3 & 1.63 & 1184.3 & 4430 & 6.45 & 446 & 476.75 & 520.1 & 308.00 & 32.90 & 0.24 & 4.16 & 36.6 & 16.95 & 6.34 & 4608.9 & 17240.1 & 26.83 \\
\hline 15:12 & 9.1 & 20.3 & 1.65 & 1155.8 & 4620 & 645 & 446 & 476.75 & $\mathbf{5 2 0 . 1}$ & 308.00 & 32.90 & 0.24 & 4.16 & 35.4 & 16.91 & 6.42 & 4498.0 & 17979.6 & 26.83 \\
\hline $15: 13$ & 13.2 & 20.2 & 1.75 & 1389.5 & 4620 & 6.45 & 446 & 476.75 & 520.1 & 308.00 & 32.90 & 0.24 & 4.16 & 51.4 & 16.76 & 6.81 & 5407.5 & 17979.6 & 26.83 \\
\hline 15:14 & 9.6 & 20.3 & 1.56 & 1111.8 & 4470 & 6.45 & 446 & 476.75 & 520.1 & 308.00 & 32.90 & 0.24 & 4.16 & 37.4 & 17.07 & 6.07 & 4326.8 & 17395.8 & 26.83 \\
\hline 15:15 & 7.8 & 20.3 & 1.63 & 975.8 & 4470 & 6.45 & 446 & 476.75 & 520.1 & 308.00 & 32.90 & 0.24 & 4.16 & 30.4 & 17.03 & 6.34 & 3797.5 & 17395.8 & 26.83 \\
\hline 15:16 & 7.2 & 20.3 & 1.64 & 1060.8 & 4520 & 6.45 & 446 & 476.75 & 520.1 & 308.00 & 32.90 & 0.24 & 4.16 & 28.0 & 16.95 & 6.38 & 4128,3 & 17590.4 & 26.83 \\
\hline 15:17 & 6.4 & 20.3 & 1.61 & 1030.6 & 4520 & 6.45 & 446 & 476.75 & $\mathbf{5 2 0 . 1}$ & 308.00 & 32.90 & 0.24 & 4.16 & 24.9 & 16.87 & 6.27 & 4010.8 & 17590.4 & 26.83 \\
\hline 15:18 & 5.2 & 20.3 & 1.54 & 855.9 & 3820 & 6.45 & 446 & 476.75 & 520.1 & 308.00 & 32.90 & 0.24 & 4.16 & 20.2 & 16.91 & 5.99 & 3330.9 & 14866.2 & 26.83 \\
\hline 15:19 & 5.3 & 20.3 & 1.39 & 848.9 & 3820 & 6.45 & 446 & 476.75 & $\$ 20.1$ & 308.00 & 32.90 & 0.24 & 4.16 & 20.6 & 17.11 & 5.41 & 3303.6 & 14866.2 & 26.83 \\
\hline $15: 20$ & 5.3 & 20.3 & 1.48 & 872 & 4500 & 6.45 & 446 & 476.75 & 520.1 & 308.00 & 32.90 & 0.24 & 4.16 & 20.6 & 17.11 & 5.76 & 3393.5 & 17512.6 & 26.83 \\
\hline 15:21 & 6.6 & 20.3 & 1.43 & 1107.9 & 4500 & 6.45 & 446 & 476.75 & 520.1 & 308.00 & 32.90 & 0.24 & 4.16 & 25.7 & 17.11 & 5.57 & 4311.6 & 17512.6 & 26.83 \\
\hline $15: 22$ & 6.5 & 20.3 & 1.39 & 1098.7 & 3590 & 6.45 & 446 & 476.75 & 520.1 & 308.00 & 32.90 & 0.24 & 4.16 & 25.3 & 17.15 & 5.41 & 4275.8 & 13971.1 & 26.83 \\
\hline & 14.06829 & 19.8 & 1.513 & 1342.9 & 4718.4 & 6.2081 & & & & & & 0.231 & 4.16 & 54.0408 & 16.80203 & 5.97742 & 5205.097 & 18383 & 26.1527 \\
\hline
\end{tabular}

a. Data obtained from Continuous Emissions Monitoring Systems (CEMS) data provided by Entropy personrel.

b. Moisture content, percent by volume, as shown in analysis from particulate/metals sampling period (MMT)

Source gas volumetric flowrate from MMT date.

Quench air lowrate, channel 15 from Data Acquisition System (DAS).

Quench air temperature, channel I from DAS.

f. Calculated from mass and energy balances at the quench section as the quench outlet lowrate divided by the furnace outlet flowrate.

in $\mathrm{g}$. Calculated from the quench outlet composition and the dilution factor, making the necessary conversions from a dry to a wet basis. 
Table 0-2 Calculated furnace outlet offgas compositions for S60-IV.

\begin{tabular}{|c|c|c|c|c|c|c|c|c|c|c|c|c|c|c|c|c|c|c|c|}
\hline & & nch out & et Diy & $\% / \mathrm{ppm}$ & & Wet (b) & Quench Ouldet (c) & Quench Outlet & Quench Air (d) & Quench Air & Temp. Quenc & Dilution & Dilution & Furnace 0 & ullet on & $\mathrm{Igas}_{\mathrm{Ca}}$ & omposition & (wet basis \%) & \\
\hline TDME (a) & NOX (ppm & $02(\%$ & $\mathrm{CO} 2$ & $\mathrm{CO}(\mathrm{ppm})$ & SO2(ppm) & $\mathrm{H} 2 \mathrm{O}(\%)$ & Flowrate (dscfin) & Flowrate (wscfm) & Flowrate (wacfm) & Flowrate (wscfm) & $\operatorname{Air}(C)(e)$ & Factor & Factor $(\Omega)$ & $\overline{\mathrm{NO}}$ (ppm & $\mathrm{O} 2 \mathrm{~h}$ & $\mathrm{CO} 2$ & $\mathrm{CO}(\mathrm{ppm})$ & SO2 (ppm) & $\mathrm{H} 20$ \\
\hline $12: 29$ & 242 & 199 & 21 & 2836.0 & 5470.0 & 8.2 & 450.0 & 490.4 & 300.1 & 280.2 & 41.2 & 0.2 & 4.2 & 928 & 15.3 & 8.2 & 10878.9 & 20982.8 & 344 \\
\hline 12.30 & 243 & 19.9 & 23 & 2546.8 & 54700 & 8.2 & 4500 & 490.4 & 300.1 & 280.2 & 41.2 & 0.2 & 4.2 & 93.2 & 15.1 & 8.8 & 9769.5 & 20982.8 & 34.4 \\
\hline 12.31 & 244 & 19.9 & 23 & 27893 & 5470.0 & 8.2 & 450.0 & 490.4 & 300.1 & 280.2 & 412 & 0.2 & 4.2 & 936 & 15.3 & 8.7 & 106997 & 20982.8 & 344 \\
\hline $12: 32$ & 23.7 & 20.0 & 2.2 & 3130.1 & 5070.0 & 8.2 & 450.0 & 490.4 & 294.3 & 280.4 & 34.9 & 02 & 4.2 & 90.9 & 154 & 8.6 & 12007.0 & 19448.4 & 344 \\
\hline $12: 33$ & 177 & 20.0 & 2.2 & 2927.1 & 50700 & 82 & 450.0 & 490.4 & 294.3 & 280.4 & 34.9 & 02 & 4.2 & 67.9 & 154 & 8.4 & 11228.3 & 19448.4 & 344 \\
\hline $12: 34$ & 13.9 & 199 & 2.3 & 25933 & 50700 & 8.2 & 4500 & 490.4 & 294.3 & 280.4 & 349 & 0.2 & 42 & 53.3 & 15.2 & 8.6 & 99479 & 19448.4 & 34.4 \\
\hline 12.35 & 14.7 & 19.9 & 24 & 2239.8 & 5070.0 & 8.2 & 450.0 & 490.4 & 294.3 & 2804 & 34.9 & 02 & 4.2 & 564 & 151 & 9.1 & 8591.8 & 19448.4 & 34.4 \\
\hline $12: 36$ & 12.0 & 19.9 & 2.3 & 2305.4 & 5640.0 & 82 & 4500 & 490.4 & 294.3 & 280.4 & 34.9 & 0.2 & 4.2 & 46.0 & 15.1 & 9.0 & 8843.5 & 216350 & 344 \\
\hline 12.37 & 29.7 & 19.8 & 28 & 3180.6 & 5640.0 & 8.2 & 450.0 & 490.4 & 294.3 & 280.4 & 34.9 & 02 & 4.2 & 113.9 & 14.7 & 10.7 & 12200.7 & 21635.0 & 344 \\
\hline $12: 38$ & 24.3 & 19.9 & 25 & 4024.8 & 5150.0 & 8.2 & 450.0 & 490.4 & 287.5 & 275.4 & 33.3 & 0.2 & 4.2 & 93.2 & 15.2 & 9.4 & 15439.1 & 19755.3 & 344 \\
\hline 12.44 & 320 & 19.9 & 25 & 4762.6 & 5760.0 & 8.2 & 450.0 & 490.4 & 306.9 & 2938 & 33.5 & 0.2 & 4.2 & 122.8 & 152 & 9.6 & 18269.3 & 22095.3 & 344 \\
\hline 12.45 & 28.1 & 19.7 & 3.0 & 3871.9 & 57600 & 8.2 & 450.0 & 490.4 & 306.9 & 293.8 & 33.5 & 0.2 & 4.2 & 107.8 & 145 & 11.5 & 148526 & 22095.3 & 34.4 \\
\hline $12: 46$ & 47.8 & 19.8 & 2.8 & 4634.8 & 6940.0 & 8.2 & 450.0 & 490.4 & 306.9 & 293.8 & 33.5 & 0.2 & 4.2 & 1834 & 14.7 & 10.9 & 17779.0 & 26621.7 & 34.4 \\
\hline $12: 47$ & 303 & 19.8 & 2.7 & 4406.4 & 6940.0 & 8.2 & 450.0 & 490.4 & 306.9 & 293.8 & 33.5 & 0.2 & 4.2 & 116.2 & 14.8 & 10.4 & 16902.9 & 26621.7 & 34.4 \\
\hline $12: 48$ & 313 & 19.7 & 2.8 & 3818.8 & 64300 & 8.2 & 450.0 & 490.4 & 306.9 & 293.8 & 33.5 & 0.2 & 4.2 & 120.1 & 14.5 & 10.7 & 14648.9 & 24665.4 & 34.4 \\
\hline $12: 49$ & 34.0 & 19.7 & 2.7 & 4100.0 & 6430.0 & 8.2 & 4500 & 490.4 & 306.9 & 293.8 & 33.5 & 0.2 & 4.2 & 130.4 & 14.6 & 10.3 & 15727.5 & 24665.4 & 34.4 \\
\hline $12: 50$ & 378 & 19.6 & 2.9 & 4228.9 & 7600.0 & 8.2 & 450.0 & 490.4 & 324.9 & 310.0 & 34.4 & 0.2 & 4.2 & 145.0 & 14.1 & 11.1 & 16222.0 & 29153.5 & 344 \\
\hline $12: 51$ & 41.2 & 19.6 & 27 & 4859.6 & 7600.0 & 8.2 & 450.0 & 4904 & 324.9 & 310.0 & 34.4 & 0.2 & 4.2 & 158.0 & 14.1 & 10.5 & 18641.4 & 29153.5 & 344 \\
\hline $12: 52$ & 39.4 & 19.6 & 2.7 & 4933.2 & 7420.0 & 8.2 & 450.0 & 490.4 & 324.9 & 310.0 & 34.4 & 0.2 & 4.2 & 151.1 & 14.2 & 10.3 & 18923.7 & 28463.0 & 34.4 \\
\hline $12: 53$ & 33.6 & 19.7 & 2.7 & 4321.5 & 7420.0 & 8.2 & 450.0 & 490.4 & 324.9 & 310.0 & 34.4 & 0.2 & 4.2 & 128.9 & 14.3 & 10.2 & 16577.2 & 28463.0 & 34.4 \\
\hline $12: 54$ & 28.6 & 19.8 & 2.5 & 4046.4 & 6240.0 & 8.2 & 450.0 & 490.4 & 3249 & 310.0 & 34.4 & 0.2 & 4.2 & 109.7 & 14.7 & 9.4 & 15521.9 & 239366 & 34.4 \\
\hline 12:55 & 29.3 & 19.8 & 2.4 & 4437.9 & 6240.0 & 8.2 & 450.0 & 490.4 & 324.9 & 310.0 & 34.4 & 0.2 & 4.2 & 112.4 & 14.8 & 9.2 & 17023.7 & 23936.6 & 34.4 \\
\hline $12: 56$ & 29.0 & 19.7 & 2.6 & 4614.5 & 7660.0 & 8.2 & 450.0 & 490.4 & 301.5 & 288.1 & 34.0 & 0.2 & 4.2 & 111.2 & 14.6 & 9.9 & 17701.2 & 29383.7 & 34.4 \\
\hline 12:57 & 37.2 & 19.7 & 2.7 & 4913.6 & 7660.0 & 8.2 & 450.0 & 490.4 & 301.5 & 288.1 & 34.0 & 0.2 & 4.2 & 142.7 & 146 & 10.3 & 18848.5 & 29383.7 & 34.4 \\
\hline 12:58 & 40.2 & 19.7 & 2.8 & 5411.0 & 7270.0 & 8.2 & 450.0 & 490.4 & 301.5 & 288.1 & 34.0 & 0.2 & 4.2 & 154.2 & 14.4 & 10.8 & 20756.5 & 27887.6 & 34.4 \\
\hline $12: 59$ & 36.0 & 19.7 & 2.8 & 4942.4 & 7270.0 & 8.2 & 450.0 & 490.4 & 301.5 & 288.1 & 34.0 & 0.2 & 4.2 & 138.1 & 14.4 & 10.6 & 18959.0 & 27887.6 & 34.4 \\
\hline $13: 00$ & 29.6 & 19.8 & 26 & 4824.8 & 7060.0 & 8.2 & 450.0 & 490.4 & 301.5 & 288.1 & 34.0 & 0.2 & 4.2 & 113.5 & 14.8 & 10.1 & 18507.9 & 27082.1 & 344 \\
\hline $13: 01$ & 31.0 & 19.7 & 2.7 & 4719.3 & 7060.0 & 8.2 & 450.0 & 490.4 & 301.5 & 288.1 & 34.0 & 0.2 & 4.2 & 118.9 & 14.6 & 10.5 & 18103.2 & 27082.1 & 344 \\
\hline $13: 02$ & 28.2 & 198 & 2.6 & 4952.3 & 5720.0 & 8.2 & 450.0 & 4904 & 309.9 & 294.0 & 36.3 & 02 & 4.2 & 108.2 & 14.8 & 10.0 & 18997.0 & 21941.8 & 34.4 \\
\hline 13.03 & 32.6 & 19.8 & 28 & 4982.0 & 5720.0 & 8.2 & 4500 & 490.4 & 309.9 & 294.0 & 36.3 & 0.2 & 4.2 & 125.1 & 14.6 & 10.6 & 19110.9 & 219418 & 344 \\
\hline 13:04 & 32.8 & 19.8 & 2.6 & 4982.1 & 6360.0 & 8.2 & 450.0 & 4904 & 309,9 & 294.0 & 36.3 & 0.2 & 4.2 & 125.8 & 14.9 & 9.9 & 19111.3 & 24396.9 & 34.4 \\
\hline $13: 05$ & 26.6 & 19.8 & 2.5 & 4671.1 & 6360.0 & 8.2 & 450.0 & 490.4 & 309.9 & 294.0 & 363 & 0.2 & 4.2 & 102.0 & 14.8 & 9.7 & 17918.3 & 24396.9 & 34.4 \\
\hline $13: 06$ & 261 & 19.9 & 2.3 & 5758.0 & 5800.0 & 8.2 & 450.0 & 490.4 & 309.9 & 294.0 & 36.3 & 0.2 & 4.2 & 1001 & 15.3 & 8.9 & 22087.6 & 22248.7 & 34.4 \\
\hline 13:07 & 30.5 & 198 & 2.7 & 5758.0 & 5800.0 & 8.2 & 450.0 & 490.4 & 309.9 & 294.0 & 36.3 & 0.2 & 42 & 117.0 & 15.0 & 10.2 & 22087.6 & 22248.7 & 34,4 \\
\hline $13: 08$ & 29.1 & 19.8 & 2.6 & 5649.0 & 5740.0 & 8.2 & 450.0 & 490.4 & 309.9 & 294.0 & 36.3 & 0.2 & 4.2 & 111.6 & 14.8 & 10.1 & 21669.5 & 22018.6 & 344 \\
\hline 13.09 & 22.7 & 19.8 & 26 & 5649.0 & 5740.0 & 8.2 & 450.0 & 490.4 & 2920 & 277.8 & 35.4 & 0.2 & 4.2 & 87.1 & 14.9 & 9.8 & 21669.5 & 22018.6 & 34.4 \\
\hline 13:10 & 30.5 & 197 & 2.9 & 7590.0 & 6930.0 & 82 & 450.0 & 490.4 & 292.0 & 277.8 & 35.4 & 0.2 & 4.2 & 117.0 & 14.3 & 11.0 & 29115.1 & 26583.4 & 34.4 \\
\hline $13: 11$ & 43.8 & 19.7 & 2.8 & 7590.0 & 6930.0 & 8.2 & 450.0 & 490.4 & 292.0 & 277.8 & 35.4 & 0.2 & 4.2 & 168.0 & 14.5 & 107 & 29115.1 & 26583.4 & 34.4 \\
\hline 13.12 & 26.0 & 19.7 & 2.6 & 5399.0 & 5850.0 & 8.2 & 4500 & 490.4 & 292.0 & 2778 & 35.4 & 0.2 & 4.2 & 99.7 & 14.6 & 10.1 & 20710.5 & 22440.5 & 344 \\
\hline 13.13 & 213 & 19.6 & 2.8 & 53990 & 58500 & 8.2 & 450.0 & 490.4 & 292.0 & 2778 & 35.4 & 0.2 & 4.2 & 81.7 & 14.2 & 10.7 & 20710.5 & 22440.5 & 34.4 \\
\hline $13: 14$ & 35.8 & 19.7 & 2.7 & 7202.0 & 7210.0 & 8.2 & 450.0 & 490.4 & 292.0 & 277.8 & 35.4 & 0.2 & 4.2 & 1373 & 144 & 105 & 27626.8 & 276575 & 344 \\
\hline 13:15 & 32.4 & 197 & 2.7 & 7202.0 & 7210.0 & 82 & 450.0 & 490.4 & 301.2 & 2858 & 36.1 & 0.2 & 4.2 & 124.3 & 144 & 103 & 276268 & 27657.5 & 34.4 \\
\hline 13:16 & 28.6 & 19.7 & 2.6 & 7019.0 & 5860.0 & 8.2 & 450.0 & 490.4 & 301.2 & 285.8 & 361 & 0.2 & 4.2 & 109.7 & 146 & 100 & 26924.8 & 22478.9 & 344 \\
\hline 13:17 & 29.1 & 19.7 & 2.8 & 7019.0 & 5860.0 & 8.2 & 4500 & 490.4 & 301.2 & 285.8 & 36.1 & 02 & 4.2 & 1116 & 144 & 10.6 & 26924.8 & 22478.9 & 344 \\
\hline 13:18 & 30.3 & 19.7 & 2.8 & 7856.0 & 6780.0 & 8.2 & 450.0 & 490,4 & 301.2 & 2858 & 36.1 & 02 & 4.2 & 1162 & 14.3 & 10.7 & 30135.5 & 26008.0 & 344 \\
\hline $13 \cdot 19$ & 370 & 19.6 & 2.9 & 7856.0 & 67800 & 8.2 & 4500 & 490.4 & 301.2 & 2858 & 36.1 & 0.2 & 4.2 & 141.9 & 14.2 & 10.9 & 30135.5 & 26008.0 & 34.4 \\
\hline 13.20 & 32.4 & 19.7 & 27 & 77040 & 6310.0 & 8.2 & 4500 & 490.4 & 3012 & 2858 & 36.1 & 0.2 & 4.2 & 124.3 & 144 & 10.2 & 29552.4 & 24205.1 & 344 \\
\hline $13: 21$ & 44.2 & 19.6 & 3.0 & 77040 & 63100 & 82 & 450.0 & 4904 & 293.7 & 279.0 & 35.9 & 02 & 4.2 & 169.6 & 139 & 11.5 & 295524 & 24205.1 & 344 \\
\hline 1322 & 474 & 19.6 & 3.1 & 9994.0 & 7450.0 & 8.2 & 450.0 & 4904 & 2937 & 2790 & 35.9 & 0.2 & 42 & 1818 & 13.9 & 11.7 & 383368 & 28578.1 & 344 \\
\hline 13.23 & 367 & 19.7 & 2.7 & 99940 & 74500 & 82 & 450.0 & 490.4 & 2937 & 279.0 & 35.9 & 0.2 & 4.2 & 1408 & 142 & 10.3 & 38336.8 & 285781 & 344 \\
\hline $13: 24$ & 31.3 & 19.7 & 26 & 9893.0 & 67100 & 8.2 & 4500 & 490.4 & 293.7 & 279.0 & 35.9 & 0.2 & 4.2 & 120.1 & 143 & 9.9 & 37949.4 & 257395 & 344 \\
\hline 13.25 & 35.8 & 196 & 2.8 & 9893.0 & 67100 & 8.2 & 4500 & 490.4 & 293.7 & 279.0 & 35.9 & 0.2 & 42 & 1373 & 14.0 & 10.9 & 379494 & 257395 & 34.4 \\
\hline 1326 & 263 & 19.6 & 27 & 7559.0 & 4660.0 & 8.2 & 450.0 & 4904 & 2937 & 279.0 & 35.9 & 0.2 & 42 & 100.9 & 141 & 10.4 & 289962 & 17875.7 & 344 \\
\hline 13.27 & 203 & 19.6 & 2.7 & 7559.0 & 4660.0 & 82 & 450.0 & 490,4 & 278.3 & 2688 & 30.8 & 02 & 4.2 & 779 & 142 & 104 & 289962 & 17875.7 & 344 \\
\hline $13: 28$ & 25.1 & 197 & 27 & 12865.0 & 61400 & 8.2 & 4500 & 4904 & 278.3 & 268.8 & 30.8 & 0.2 & 42 & 96.3 & 14.3 & 10.2 & 493500 & 235530 & 344 \\
\hline 13:29 & 426 & 19.6 & 29 & 128650 & 6140.0 & 82 & 4500 & 490.4 & 2783 & 2688 & 30.8 & 0.2 & 4.2 & 1634 & 140 & 112 & 493500 & 23553.0 & 344 \\
\hline $13: 30$ & 32.1 & 196 & 29 & 8031.0 & 6140.0 & 82 & 450.0 & 490.4 & 2783 & 2688 & 308 & 02 & 4.2 & 1231 & 14.0 & 11.0 & 30806.8 & 235530 & 344 \\
\hline 13.31 & 25.0 & 196 & 2.8 & 8031.0 & 6140.0 & 82 & 4500 & 4904 & 278.3 & 2688 & 308 & 02 & 42 & 959 & 142 & 105 & 30806.8 & 235530 & 344 \\
\hline 1332 & 261 & 1 & 26 & 72910 & 45400 & 82 & 450.0 & 4904 & 278.3 & 2688 & 308 & 02 & 4.2 & 1001 & 14.4 & 99 & 27968 & 174154 & 344 \\
\hline
\end{tabular}




\begin{tabular}{|c|c|c|c|c|c|c|c|c|c|c|c|c|c|c|c|c|c|c|c|}
\hline \multirow{2}{*}{$\operatorname{TDME}(\mathrm{a})$} & \multicolumn{5}{|c|}{$\frac{\text { Quench Outlet Dry vol. \%/ppm (a) }}{\mathrm{NOx} \text { (ppm } 02(\%) C O 2(\%) \mathrm{CO}(\mathrm{ppm}) \mathrm{SO2} \text { (ppr }}$} & \multirow{2}{*}{$\begin{array}{l}\text { Wet (b) } \\
\mathrm{H} 2 \mathrm{O}(\%) \\
8.2\end{array}$} & \multirow{2}{*}{$\begin{array}{l}\text { Quench Outlet (c } \\
\text { Flowrate (dsefm) } \\
450.0\end{array}$} & \multirow{2}{*}{$\begin{array}{c}\text { Quench Outlet } \\
\text { Flowrete (wscfin) } \\
490.4\end{array}$} & \multirow{2}{*}{$\begin{array}{l}\text { Quench Air (d) } \\
\text { Flowrate (wacfin) } \\
300.8\end{array}$} & \multirow{2}{*}{$\begin{array}{c}\text { Quench Air } \\
\text { Flowrate (wsefm) } \\
291.9\end{array}$} & \multirow{2}{*}{$\begin{array}{l}\text { Temp. Quenc } \\
\text { Air (C) (e) } \\
29.3\end{array}$} & \multirow{2}{*}{$\begin{array}{c}\text { Dilution } \\
\text { Factor } \\
0.2\end{array}$} & $\begin{array}{c}\text { Dalution } \\
\text { Factor (f) }\end{array}$ & $\frac{\text { Funnace } 0}{\text { NOx (ppm }}$ & petet Oof & $\frac{\mathrm{CO} \mathrm{CO}_{\mathrm{Co}}}{\mathrm{CO}}$ & Composition (ppra) & $\frac{1 \text { (wet basis \%) }}{\mathrm{SO}(\mathrm{ppm})}$ & $\frac{\mathrm{H}}{\mathrm{H} 2 \mathrm{O}}$ \\
\hline & 30.4 & 19.6 & 2.8 & 7291.0 & 45400 & & & & & & & & & 116.6 & 14.1 & 10.8 & 27968.2 & 17415.4 & 34.4 \\
\hline $13: 34$ & 32.4 & 195 & 3.0 & 10841.0 & 73600 & 8.2 & 450.0 & 490.4 & 300.8 & 291.9 & 29.3 & 0.2 & 4.2 & 124.3 & 13.8 & 11.4 & 41585.9 & 28232.9 & 34.4 \\
\hline 13:35 & 49.1 & 19.5 & 3.3 & 10841.0 & 7360.0 & 8.2 & 450.0 & 490.4 & 300.8 & 291.9 & 29.3 & 0.2 & 4.2 & 188.3 & 13.5 & 125 & 41585.9 & 28232.9 & 34.4 \\
\hline $13: 36$ & 63.7 & 19.5 & 3.5 & 10841.0 & 7360.0 & 8.2 & 450.0 & 490.4 & 3008 & 291.9 & 29.3 & 0.2 & 4.2 & 244.4 & 13.5 & 13.2 & 41585.9 & 28232.9 & 34.4 \\
\hline $13: 37$ & 32.0 & 19.6 & 2.8 & 10841.0 & 7360.0 & 82 & 450.0 & 490.4 & 300.8 & 291.9 & 29.3 & 0.2 & 4.2 & 122.8 & 14.0 & 10.7 & 41585.9 & 28232.9 & 34.4 \\
\hline $13: 38$ & 35.9 & 19.6 & 2.9 & 8352.0 & 5970.0 & 8.2 & 450.0 & 490.4 & 300.8 & 291.9 & 29.3 & 0.2 & 4.2 & 137.7 & 13.9 & 11.1 & 32038.2 & 22900.8 & 34.4 \\
\hline $13: 39$ & 30.4 & 19.6 & 28 & 8352.0 & 5970.0 & 8.2 & 450.0 & 490.4 & 274.3 & 266.2 & 29.4 & 0.2 & 4.2 & 116.6 & 14.0 & 10.6 & 32038.2 & 22900.8 & 34.4 \\
\hline $13: 40$ & 388 & 19.5 & 2.9 & 7333.0 & 5570.0 & 8.2 & 450.0 & 490.4 & 274.3 & 266.2 & 29.4 & 0.2 & 4.2 & 148.8 & 13.7 & 11.0 & 28129.3 & 21366.4 & 34.4 \\
\hline $15: 23$ & 14.1 & 20.6 & 1.7 & 2297.4 & 3740.0 & 6.2 & 462.0 & 492.5 & 340.7 & 323.4 & 36.1 & 0.2 & 4.2 & 56.1 & 18.2 & 6.9 & 9138.0 & 14876.0 & 26.2 \\
\hline $15: 24$ & 15.7 & 20.5 & 1.8 & 2522.3 & 3470.0 & 6.2 & 462.0 & 492.5 & 340.7 & 323.4 & 36.1 & 0.2 & 4.2 & 62.4 & 18.0 & 7.2 & 10032.6 & 13802.1 & 26.2 \\
\hline $15: 25$ & 17.3 & 20.6 & 1.7 & 2915.3 & 3470.0 & 6.2 & 462.0 & 492.5 & 340.7 & 323.4 & 36.1 & 0.2 & 4.2 & 68.8 & 18.1 & 6.8 & 11595.7 & 13802.1 & 26.2 \\
\hline $15: 26$ & 16.8 & 20.6 & 17 & 3045.0 & 3290.0 & 6.2 & 462.0 & 492.5 & 340.7 & 323.4 & 36.1 & 0.2 & 4.2 & 66.8 & 18.1 & 6.7 & 12111.6 & 13086.1 & 26.2 \\
\hline $15: 27$ & 15.9 & 20.6 & 1.6 & 2748.8 & 3290.0 & 6.2 & 462.0 & 492.5 & 340.7 & 323.4 & 36.1 & 0.2 & 4.2 & 63.2 & 18.2 & 6.5 & 10933.5 & 13086.1 & 26.2 \\
\hline $15: 28$ & 14.7 & 20.6 & 1.6 & 2494.3 & 3240.0 & 6.2 & 462.0 & 492.5 & 331.4 & $3 ! 4.7$ & 36.0 & 0.2 & 4.2 & 58.5 & 18.1 & 6.4 & 9921.2 & 12887.2 & 26.2 \\
\hline $15: 29$ & 13.2 & 20.6 & 1.6 & 2476.1 & 3078.4 & 6.2 & 462.0 & 492.5 & 331.4 & 314.7 & 36.0 & 0.2 & 4.2 & 52.5 & 18.1 & 6.3 & 9848.8 & 12244.5 & 26.2 \\
\hline $15: 30$ & 12.7 & 20.6 & 1.6 & 2543.7 & 3010.4 & 6.2 & 462.0 & 492.5 & 331.4 & 314.7 & 36.0 & 0.2 & 4.2 & 50.5 & 18.1 & 6.3 & 10117.7 & 11974.0 & 26.2 \\
\hline $15: 31$ & 12.8 & 20.5 & 1.6 & 2816.2 & 3040.7 & 6.2 & 462.0 & 492.5 & 331.4 & 314.7 & 36.0 & 0.2 & 4.2 & 50.9 & 18.0 & 6.4 & 11201.6 & 12094.5 & 26.2 \\
\hline $15: 32$ & 12.0 & 20.6 & 1.6 & 2584.3 & 3009.4 & 6.2 & 462.0 & 492.5 & 331.4 & 314.7 & 36.0 & 0.2 & 4.2 & 47.7 & 18.1 & 6.3 & 10279.2 & 11970.0 & 26.2 \\
\hline $15: 33$ & 11.7 & 20.5 & 1.6 & 2485.3 & 3057.0 & 6.2 & 462.0 & 492.5 & 331.4 & 314.7 & 36.0 & 0.2 & 4.2 & 46.5 & 18.0 & 6.4 & 9885.4 & 12159.4 & 26.2 \\
\hline $15: 34$ & 12.2 & 20.6 & 1.6 & 2501.0 & 3029.2 & 6.2 & 462,0 & 492.5 & 350.5 & 327.6 & 40.9 & 0.2 & 4.2 & 48.5 & 18.1 & 6.5 & 9947.8 & 12048.8 & 26.2 \\
\hline $15: 35$ & 12.3 & 20.5 & 1.7 & 2877.0 & 3124.6 & 6.2 & 462.0 & 492.5 & 350.5 & 327.6 & 40.9 & 0.2 & 4.2 & 48.9 & 18.0 & 6.6 & 11443.4 & 12428.2 & 26.2 \\
\hline $15: 36$ & 11.1 & 20.5 & 1.7 & 2969.4 & 3105.9 & 6.2 & 462.0 & 492.5 & 350.5 & 327.6 & 40.9 & 0.2 & 4.2 & 44.2 & 18.0 & 6.8 & 11810.9 & 12353.9 & 26.2 \\
\hline $15: 37$ & 10.0 & 20.6 & 1.7 & 2989.9 & 2960.8 & 6.2 & 462.0 & 492.5 & 350.5 & 327.6 & 40.9 & 0.2 & 4.2 & 39.8 & 18.1 & 6.7 & 11892.5 & 11776.7 & 26.2 \\
\hline $15: 38$ & 10.1 & 20.5 & 1.8 & 3261.8 & 3079.5 & 6.2 & 462.0 & 492.5 & 350.5 & 327.6 & 40.9 & 0.2 & 4.2 & 40.2 & 17.9 & 7.0 & 12974.0 & 12248.8 & 26.2 \\
\hline $15: 39$ & 9.2 & 20.5 & 1.7 & 2966.9 & 3058.3 & 6.2 & 462.0 & 492.5 & 350.5 & 327.6 & 40.9 & 0.2 & 4.2 & 36.6 & 17.9 & 6.8 & 11801.0 & 12164.5 & 26.2 \\
\hline $15: 40$ & 8.4 & 20.5 & 1.7 & 2700.9 & 3054.1 & 6.2 & 462.0 & 492.5 & 364.3 & 340.9 & 40.6 & 0.2 & 4.2 & 33.4 & 17.9 & 6.9 & 10742.9 & 12147.8 & 26.2 \\
\hline $15: 41$ & 9.3 & 20.5 & 1.7 & 2515.8 & 3054.1 & 6.2 & 462.0 & 492.5 & 364.3 & 340.9 & 40.6 & 0.2 & 4.2 & 37.0 & 17.9 & 6.9 & 10005.7 & 12147.8 & 26.2 \\
\hline $15: 42$ & 10.1 & 20.5 & 1.7 & 2641.3 & 3520.0 & 6.2 & 462.0 & 492.5 & 364.3 & 340.9 & 40.6 & 0.2 & 4.2 & 40.2 & 17.8 & 6.8 & 10505.9 & 14001.0 & 26.2 \\
\hline $15: 43$ & 10.9 & 20.5 & 1.7 & 2576.4 & 3520.0 & 6.2 & 462.0 & 492.5 & 364.3 & 340.9 & 40.6 & 0.2 & 4.2 & 43.4 & 17.9 & 6.6 & 10247.7 & 14001.0 & 26.2 \\
\hline $15: 44$ & 11.0 & 20.5 & 1.7 & 2734,8 & 3450.0 & 6.2 & 462.0 & 492.5 & 364.3 & 340.9 & 40.6 & 0.2 & 4.2 & 43.8 & 17.8 & 6.9 & 10877.8 & 13722.5 & 26.2 \\
\hline $15: 45$ & 9.5 & 20.5 & 1.7 & 2654.0 & 3450.0 & 6.2 & 462.0 & 492.5 & 364.3 & 340.9 & 40.6 & 0.2 & 4.2 & 37.8 & 17.8 & 6.8 & 10556.4 & 13722.5 & 26.2 \\
\hline $15: 46$ & 10.5 & 20.5 & 1.7 & 2952.7 & 3480.0 & 6.2 & 462.0 & 492.5 & 354.7 & 336.6 & 36.2 & 0.2 & 4.2 & 41.8 & 17.8 & 6.8 & 11744.5 & 13841.9 & 26.2 \\
\hline $15: 47$ & 11.8 & 20.5 & 1.8 & 2887.5 & $\mathbf{3 4 8 0 . 0}$ & 6.2 & 462.0 & 492.5 & 354.7 & 336.6 & 36.2 & 0.2 & 4.2 & 46.9 & 17.8 & 7.0 & 11485.2 & 13841.9 & 26.2 \\
\hline $15: 48$ & 10.9 & 20.5 & 1.7 & 2834.4 & 3540.0 & 6.2 & 462.0 & 492.5 & 354.7 & 336.6 & 36.2 & 0.2 & 4.2 & 43.4 & 17.8 & 6.7 & 11274.0 & 14080.5 & 26.2 \\
\hline $15: 49$ & 10.9 & 20.5 & 1.6 & 2913.2 & 3540.0 & 6.2 & 462.0 & 492.5 & 354.7 & 336.6 & 36.2 & 0.2 & 4.2 & 43.4 & 17.8 & 6.5 & 11587.4 & 14080.5 & 26.2 \\
\hline 15:50 & 10.2 & 20.5 & 1.6 & 2749.1 & 3460.0 & 6.2 & 462.0 & 492.5 & 354.7 & 336.6 & 36.2 & 0.2 & 4.2 & 40.6 & 17.9 & 6.3 & 10934.7 & 13762.3 & 26.2 \\
\hline $15: 51$ & 10.1 & 20.5 & 1.6 & 2819.2 & 3460.0 & 6.2 & 462.0 & 492.5 & 354.7 & 336.6 & 36.2 & 0.2 & 4.2 & 40.2 & 17.9 & 6.4 & 11213.5 & 13762.3 & 26.2 \\
\hline $15: 52$ & 11.3 & 20.5 & 1.6 & 2744.3 & 3620.0 & 6.2 & 462.0 & 492.5 & 337.9 & 325.2 & 31.8 & 0.2 & 4.2 & 44.9 & 17.9 & 6.2 & 10915.6 & 14398.7 & 26.2 \\
\hline $15: 53$ & 11.4 & 20.6 & 1.6 & 2869.4 & 3620.0 & 6.2 & 462.0 & 492.5 & 337.9 & 325.2 & 31.8 & 0.2 & 4.2 & 45.3 & 18.1 & 6.4 & 11413.2 & 14398.7 & 26.2 \\
\hline $15: 54$ & 11.1 & 20.6 & 1.6 & 2994.3 & 3390.0 & 6.2 & 462.0 & 492.5 & 337.9 & 325.2 & 31.8 & 0.2 & 4.2 & 44.2 & 18.2 & 6.4 & 11910.0 & 13483.9 & 26.2 \\
\hline $15: 55$ & 11.9 & 20.6 & 1.6 & 3277.6 & 3066.8 & 6.2 & 462.0 & 492.5 & 337.9 & 325.2 & 31.8 & 0.2 & 4.2 & 47.3 & 18.4 & 6.4 & 13036.8 & 12198.3 & 26.2 \\
\hline $15: 56$ & 11.5 & 20.6 & 1.8 & 4361.7 & 3097.9 & 6.2 & 462.0 & 492.5 & 337.9 & 325.2 & 31.8 & 0.2 & 4.2 & 45.7 & 18.2 & 7.0 & 17348.9 & 12322.0 & 26.2 \\
\hline 15:57 & 9.9 & 20.6 & 1.7 & 4254.4 & 2815.4 & 6.2 & 462.0 & 492.5 & 337.9 & 325.2 & 31.8 & 0.2 & 4.2 & 39.4 & 18.3 & 6.8 & 16922.1 & 11198.4 & 26.2 \\
\hline $15: 58$ & 9.2 & 20.6 & 1.7 & 4197.3 & 2758.1 & 6.2 & 462.0 & 492.5 & 342.3 & 329.0 & 32.2 & 0.2 & 4.2 & 36.6 & 18.3 & 6.8 & 16694.9 & 10970.5 & 26.2 \\
\hline $15: 59$ & 10.3 & 20.6 & 1.7 & 4088.9 & 2889.2 & 6.2 & 462.0 & 492.5 & 342.3 & 329.0 & 32.2 & 0.2 & 4.2 & 41.0 & 18.2 & 6.9 & 16263.8 & 11491.9 & 26.2 \\
\hline $16: 00$ & 12.3 & 20.6 & 1.6 & 4090.5 & 3078.7 & 6.2 & 462.0 & 492.5 & 342.3 & 329.0 & 32.2 & 0.2 & 4.2 & 48.9 & 18.3 & 6.3 & 16270.1 & 12245.7 & 26.2 \\
\hline $16: 01$ & 12.9 & 20.6 & 16 & 4227.8 & 3107.4 & 6.2 & 462.0 & 492.5 & 342.3 & 329.0 & 32.2 & 02 & 4.2 & 51.3 & 18.4 & 6.3 & 16816.3 & 12359.8 & 26.2 \\
\hline $16: 02$ & 11.2 & 20.7 & 1.6 & 4103.1 & 2999.4 & 6.2 & 462.0 & 492.5 & 342.3 & 329.0 & 32.2 & 02 & 4.2 & 44.5 & 18.5 & $6.4^{\circ}$ & 16320.3 & 11930.2 & 26.2 \\
\hline $16: 03$ & 9.7 & 20.6 & 1.8 & 3950.1 & 2982.6 & 6.2 & 462.0 & 492.5 & 342.3 & 329.0 & 32.2 & 0.2 & 42 & 38.6 & 18.3 & 7.0 & 15711.7 & 11863.4 & 26.2 \\
\hline 16.04 & 9.6 & 20.6 & 1.7 & 3878.2 & 2860.1 & 6.2 & 462.0 & 4925 & 371.7 & 357.8 & 31.8 & 0.2 & 4.2 & 38.2 & 18.4 & 6.6 & 15425.7 & 11376.2 & 26.2 \\
\hline $16: 05$ & 7.3 & 20.7 & 1.6 & 3558.4 & 2357.2 & 6.2 & 462.0 & 492.5 & 371.7 & 357.8 & 31.8 & 0.2 & 4.2 & 29.0 & 18.6 & 6.4 & 141537 & 9375.9 & 26.2 \\
\hline $16: 06$ & 6.5 & 20.7 & 1.6 & 3015.0 & 2109.8 & 6.2 & 462.0 & 492.5 & 371.7 & 357.8 & 31.8 & 0.2 & 4.2 & 25.9 & 18.7 & 6.3 & 11992.3 & 8391.8 & 26.2 \\
\hline 16.07 & 7.3 & 20.7 & 1.8 & 3518.6 & 2122.7 & 6.2 & 462.0 & 492.5 & 371.7 & 357.8 & 31.8 & 0.2 & 4.2 & 29.0 & 18.5 & 7.2 & 13995.4 & 8443.1 & 26.2 \\
\hline 16.08 & 8.0 & 20.7 & 1.8 & 3716.2 & 2104.2 & 6.2 & 462.0 & 492.5 & 371.7 & 357.8 & 31.8 & 0.2 & 42 & 31.8 & 18.5 & 7.3 & 14781.3 & 8369.5 & 26.2 \\
\hline $\begin{array}{l}16: 09 \\
\text { 1 }\end{array}$ & 8.2 & 20.7 & 1.7 & 3225.4 & 2371.6 & 6.2 & 462.0 & 4925 & 371.7 & 357.8 & 31.8 & 0.2 & 4.2 & 32.6 & 18.6 & 6.8 & 12829.2 & 9433.1 & 26.2 \\
\hline $16: 10$ & 8.8 & 20.7 & 1.8 & 3312.3 & 2608.3 & 6.2 & 462.0 & 492.5 & 3426 & 329.6 & 31.9 & 0.2 & 4.2 & 35.0 & 18.5 & 7.1 & 13174.8 & 10374.6 & 26.2 \\
\hline $16 \cdot 11$ & 7.9 & 20.7 & 17 & 3398.0 & 2386.5 & 62 & 462.0 & 492.5 & 3426 & 329.6 & 31.9 & 0.2 & 42 & 31.4 & 18.5 & 6.8 & 13515.7 & 9492.4 & 262 \\
\hline $16: 12$ & 8.8 & 20.7 & 1.7 & 3051.9 & 2595.7 & 6.2 & 462.0 & 492.5 & 342.6 & 3296 & 31.9 & 0.2 & 4.2 & 35.0 & 18.7 & 6.7 & 121391 & 10324.5 & 26.2 \\
\hline $16: 13$ & 7.9 & 20.7 & 17 & 3404.2 & 2657.1 & 6.2 & 462.0 & 492.5 & 3426 & 329.6 & 31.9 & 0.2 & 4.2 & 314 & 18.5 & 6.8 & 13540.4 & 10568.7 & 262 \\
\hline
\end{tabular}


Table 0.2 Calculated furnace outlet offgas compositions for S60-IV (continued)

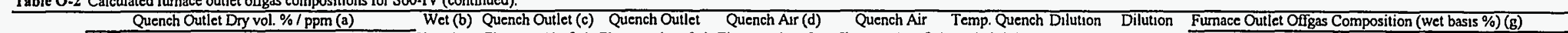

\begin{tabular}{|c|c|c|c|c|c|c|c|c|c|c|c|c|c|c|c|c|c|c|c|}
\hline TIME (a) & NOx(ppm & O2(\%) & $\mathrm{CO2} \%$ & $\operatorname{Co}(\mathrm{ppm}$ & $02(\mathrm{ppm}$ & $20(\%)$ & Flowrate (dscfm) & Flowrate (wscfm) & Flowrate (wacfm) & Flowrate (wscfm) & Air (C) (c) & Factor & Factor (f) & NOX (ppm & $\mathrm{O} 2(\mathrm{~h})$ & $\mathrm{CO} 2$ & $\mathrm{CO}(\mathrm{ppm})$ & $\mathrm{SO} 2(\mathrm{ppm})$ & $\mathrm{H} 2 \mathrm{O}$ \\
\hline $16 \cdot 14$ & 83 & 206 & 18 & 3460.0 & 2616.8 & 6.2 & 462.0 & 492.5 & 342.6 & 329.6 & 31.9 & 0.2 & 4.2 & 33.0 & 18.3 & 7.1 & 13762.3 & 104084 & 26.2 \\
\hline 16.15 & 31.3 & 20.5 & 23 & 4832.4 & 2616.8 & 6.2 & 462.0 & 492.5 & 3426 & 329.6 & 31.9 & 0.2 & 4.2 & 124.5 & 17.7 & 9.1 & 19221.1 & 10408.4 & 26.2 \\
\hline $16 \cdot 16$ & 17.4 & 206 & 18 & 4518.6 & 2616.8 & 6.2 & 462.0 & 492.5 & 3236 & 315.8 & 276 & 0.2 & 4.2 & 69.2 & 18.4 & 7.2 & 17972.9 & 104084 & 26.2 \\
\hline $16 \cdot 17$ & 96 & 20.6 & 1.8 & 4191.8 & 28072 & 6.2 & 462.0 & 492.5 & 323.6 & 315.8 & 27.6 & 0.2 & 42 & 382 & 18.3 & 7.1 & 16673.1 & 111658 & 262 \\
\hline $16: 18$ & 81 & 207 & 13 & 3474.7 & 2358.6 & 6.2 & 462.0 & 492.5 & 323.6 & 315.8 & 27.6 & 0.2 & 42 & 32.2 & 18.6 & 5.0 & 13820.8 & 9381.4 & 26.2 \\
\hline $16 \cdot 19$ & 6.3 & 207 & 15 & 31782 & 2097.7 & 6.2 & 462.0 & 492.5 & 323.6 & 315.8 & 27.6 & 0.2 & 42 & 25.1 & 18.7 & 6.0 & 12641.4 & 8343.7 & 26.2 \\
\hline $16: 20$ & 6.0 & 20.5 & 1.9 & 2853.8 & 2889.0 & 6.2 & 462.0 & 492.5 & 323.6 & 315.8 & 27.6 & 0.2 & 4.2 & 23.9 & 17.9 & 7.5 & 11351.1 & 114911 & 26.2 \\
\hline $16 \cdot 21$ & 5.8 & 20.5 & 1.6 & 1768.9 & 2889.0 & 6.2 & 4620 & 492.5 & 323.6 & 315.8 & 27.6 & 02 & 4.2 & 23.1 & 17.9 & 6.2 & 7035.9 & 11491.1 & 262 \\
\hline $16: 22$ & 59 & 20,6 & 1.6 & 2054.7 & 2889.0 & 6.2 & 462.0 & 492.5 & 330.2 & 3233 & 26.7 & 0.2 & 4.2 & 23.5 & 18.1 & 6.5 & 8172.7 & 114911 & 26.2 \\
\hline $16: 23$ & 6.7 & 20.6 & 16 & 1608.2 & 2889.0 & 6.2 & 462.0 & 492.5 & 330.2 & 323.3 & 26.7 & 0.2 & 4.2 & 26.6 & 18.1 & 6.2 & 6396.7 & 11491.1 & 26.2 \\
\hline $16: 24$ & 8.8 & 20.7 & 14 & 2219.1 & 3810.0 & 62 & 462.0 & 492.5 & 330.2 & 323.3 & 26.7 & 0.2 & 4.2 & 35.0 & 18.7 & 5.7 & 8826.6 & 15154.4 & 26.2 \\
\hline $16: 25$ & 50 & 20.7 & 14 & 1553.6 & 3810.0 & 6.2 & 462.0 & 492.5 & 330.2 & 3233 & 26.7 & 0.2 & 4.2 & 19.9 & 187 & 5.4 & 6179.5 & 15154.4 & 26.2 \\
\hline $16: 26$ & 2.5 & 20.8 & 1.3 & 850.1 & 3052.3 & 6.2 & 4620 & 492.5 & 330.2 & 323.3 & 26.7 & 0.2 & 42 & 9.9 & 19.1 & 5.1 & 3381.3 & 12140.7 & 26.2 \\
\hline $16 \cdot 27$ & 2.5 & 20.8 & 14 & 696.8 & 3098.6 & 6.2 & 462.0 & 492.5 & 330.2 & 323.3 & 26.7 & 0.2 & 4.2 & 9.9 & 19.0 & 5.6 & 2771.6 & 123248 & 26.2 \\
\hline $16: 28$ & 2.2 & 20.8 & 1.4 & 772.0 & 3300.0 & 6.2 & 462.0 & 492.5 & 3166 & 310.8 & 25.8 & 0.2 & 4.2 & 8.8 & 18.9 & 5.7 & 3070.7 & 13125.9 & 26.2 \\
\hline 16.29 & 1.6 & 20.8 & 1.3 & 625.8 & 3300.0 & 62 & 462.0 & 492.5 & 316.6 & 310.8 & 25.8 & 0.2 & 4.2 & 6.4 & 19.1 & 5.3 & 2489.1 & 13125.9 & 26.2 \\
\hline $16: 30$ & 1.5 & 20.8 & 14 & 563.7 & 3460.0 & 6.2 & 462.0 & 492.5 & 316.6 & 310.8 & 25.8 & 0.2 & 4.2 & 6.0 & 19.1 & 5.5 & 2242.1 & 13762.3 & 26.2 \\
\hline $16: 31$ & 1.4 & 20.8 & 14 & 564.4 & 3460.0 & 6.2 & 462.0 & 492.5 & 316.6 & 310.8 & 25.8 & 0.2 & 4.2 & 5.6 & 19.1 & 5.6 & 2244.9 & 13762.3 & 26.2 \\
\hline $16: 32$ & 1.7 & 20.8 & 1.4 & 714.4 & 3260.0 & 6.2 & 462.0 & 492.5 & 316.6 & 310.8 & 25.8 & 0.2 & 4.2 & 6.8 & 190 & 5.7 & 2841.6 & 12966.8 & 26.2 \\
\hline $16: 33$ & 20 & 20.8 & 1.4 & 947.5 & 3000.5 & 6.2 & 462.0 & 492.5 & 316.6 & 310.8 & 25.8 & 0.2 & 4.2 & 8.0 & 19.1 & 5.5 & 3768.7 & 11934.6 & 26.2 \\
\hline $16: 34$ & 1.9 & 20.8 & 15 & 1232.7 & 2841.8 & 6.2 & 462.0 & 492.5 & 342.3 & 331.6 & 29.8 & 0.2 & 4.2 & 7.6 & 19.1 & 6.0 & 4903.1 & 11303.4 & 26.2 \\
\hline $16: 35$ & 1.6 & 20.8 & 1.5 & 1167.2 & 2960.8 & 6.2 & 462.0 & 492.5 & 342.3 & 331.6 & 29.8 & 0.2 & 4.2 & 6.4 & 19.0 & 5.8 & 4642.6 & 11776.7 & 26.2 \\
\hline $16: 36$ & 26 & 208 & 15 & 1273.5 & 2733.6 & 6.2 & 462.0 & 492.5 & 342.3 & 331.6 & 29.8 & 0.2 & 4.2 & 10.3 & 19.2 & 5.9 & 5065.4 & 10873.0 & 26.2 \\
\hline $16: 37$ & 5.1 & 20.8 & 1.7 & 1906.4 & 2932.2 & 6.2 & 462.0 & 492.5 & 342.3 & 331.6 & 29.8 & 0.2 & 4.2 & 20.3 & 19.1 & 6.6 & 7582.8 & 11663.0 & 26.2 \\
\hline $16: 38$ & 5.4 & 20.8 & 1.8 & 2464.2 & 3310.0 & 6.2 & 462.0 & 492.5 & 342.3 & 331.6 & 29.8 & 02 & 4.2 & 21.5 & 19.0 & 7.2 & 9801.5 & 13165.7 & 262 \\
\hline $16: 39$ & 57 & 20.8 & 18 & 2319.3 & 3310.0 & 6.2 & 462.0 & 492.5 & 342.3 & 3316 & 29.8 & 0.2 & 4.2 & 22.7 & 18.9 & 7.2 & 9225.1 & 13165.7 & 262 \\
\hline 16.40 & 6.1 & 20.8 & 17 & 2402.0 & 3280.0 & 6.2 & 4620 & 492.5 & 351.5 & 338.0 & 32.1 & 0.2 & 4.2 & 24.3 & 19.0 & 6.7 & 9554.1 & 13046.3 & 26.2 \\
\hline $16: 41$ & 5.7 & 20.8 & 1.6 & 2209.9 & 32800 & 6.2 & 4620 & 492.5 & 351.5 & 338.0 & 32.1 & 0.2 & 4.2 & 22.7 & 19.2 & 6.5 & 8790.0 & 13046.3 & 26.2 \\
\hline $16: 42$ & 6.3 & 20.8 & 1.6 & 2180.4 & 3120.0 & 6.2 & 462.0 & 492.5 & 351.5 & 338.0 & 32.1 & 0.2 & 4.2 & 25.1 & 19.2 & 62 & 8672.6 & 124099 & 26.2 \\
\hline $16: 43$ & 5.8 & 20.9 & 15 & 2080.4 & 3120.0 & 6.2 & 462.0 & 492.5 & 351.5 & 338.0 & 32.1 & 0.2 & 4.2 & 23.1 & 19.3 & 6.0 & 8274.9 & 12409.9 & 26.2 \\
\hline $16: 44$ & 5.1 & 20.8 & 15 & 1909.4 & 3095.8 & 62 & 462.0 & 492.5 & 351.5 & 338.0 & 32.1 & 0.2 & 4.2 & 20.3 & 19.2 & 5.9 & 7594.7 & 12313.7 & 26.2 \\
\hline $16: 45$ & 5.8 & 20.8 & 1.5 & 1852.5 & 30958 & 6.2 & 4620 & 492.5 & 351.5 & 338.0 & 32.1 . & 02 & 42 & 23.1 & 19.1 & 6.0 & 7368.4 & 12313.7 & 26.2 \\
\hline Avg. $\# 2$ & 9.0 & 20.6 & 1.6 & 2688.7 & 3059.8 & 6.2 & & & & 328.9 & & 0.2 & 4.2 & 35.9 & 18.4 & 6.5 & 10694.2 & 121704 & 26.2 \\
\hline
\end{tabular}

a. Data obtained from Continuous Emissions Monitoring Systems (CEMS) data provided by Entropy personnel.

b Moisture content, percent by volume, as shown in analysis from particulate/metals sampling period (MMT).

c. Source gas volumetric flowrate from MMT data.

d Quench air flowrate, channel 15 from Data Acquisition System (DAS).

c. Quench air temperature, channel 1 from DAS.

f. Calculated from mass and energy balances at the quench section as the quench outlet flowrate divided by the furnace outlet flowrate.

g Calculated from the quench outlet composition and the dilution factor, making the necessary conversions from a dry to a wet basis.

h. Calculated from the quench outlet composition and the dilution factor, taking into account the amount of oxygen added by the quench ar. 
Table 0-3 Calculated furnace outlet offgas compositions for N80 and N80-Mod.

\begin{tabular}{|c|c|c|c|c|c|c|c|c|c|c|c|c|c|c|c|c|c|c|c|}
\hline \multirow{3}{*}{$\frac{\operatorname{TIME}(\mathrm{a})}{10: 50}$} & \multirow{3}{*}{$\frac{\mathrm{NO}(\mathrm{ppm})}{0.2}$} & & \multirow{2}{*}{$\mathrm{SO}(\mathrm{ppm})$} & \multirow{2}{*}{$\begin{array}{l}\text { Wet (b) } \\
\text { H2O (\%) }\end{array}$} & \multirow{2}{*}{\multicolumn{2}{|c|}{$\begin{array}{l}\text { Quench Outtet (c) Quench Outlet } \\
\text { F Fowrate (dscfm) Fourate (wsefin) }\end{array}$}} & \multirow{2}{*}{$\begin{array}{l}\text { Quench Air (d) } \\
\text { Fowrate (waefin }\end{array}$} & & & & & & & . & postbon (wet) & basis \%)(g & \\
\hline & & $02(\%)$ & $\cos (\%)$ & $\mathrm{CO}(\mathrm{ppm})$ & & & & & & Fowrate (wscfin) & $\operatorname{Air}(C)(c)$ & Factor & Factor (n) & NOX (ppm) & $02(\mathrm{~h})$ & $\mathrm{CO} 2$ & CO (ppm) & $\mathrm{SO} 2(\mathrm{ppm})$ & $\mathrm{H} 2 \mathrm{O}$ \\
\hline & & 20.15 & 0.61 & 839.2 & 11.9 & 5.49 & 511.00 & 540.68 & 531.35 & 516.89 & 28.50 & 0.30 & 3.29 & 0.62 & 17.31 & 1.90 & $2,609.39$ & 37.00 & 18.06 \\
\hline & & 20.16 & 0.6 & 783.5 & 10.9 & 5.49 & 511.00 & 540.68 & 531.35 & 516.89 & 28.60 & 0.30 & 3.29 & 0.62 & 17.34 & 1.87 & $2,436.20$ & 33.89 & 18.06 \\
\hline 10:52 & 0.2 & 20.17 & 0.59 & 800.3 & 9.4 & 5.49 & 511.00 & 540.68 & 531.35 & 516.89 & 2860 & 0.30 & 3.29 & 0.62 & 17.37 & 1.83 & $2,488.44$ & 29.23 & 18.06 \\
\hline $10: 53$ & 0.2 & 20.18 & 0.59 & 789.1 & 7.9 & 5.49 & 511.00 & 540.68 & 531.35 & 516.89 & 28.60 & 0.30 & 3.29 & 0.62 & 17.41 & 1.83 & $2,453.61$ & 24.56 & 18.06 \\
\hline $10: 54$ & 0.2 & 20.18 & 0.58 & 807.8 & 81 & 5.49 & 511.00 & 540.68 & 531.35 & 516.89 & 28.60 & 0.30 & 3.29 & 0.62 & 17.41 & 1.80 & $2,511.76$ & 25.19 & 18.06 \\
\hline 10:55 & 0.2 & 20.19 & 0.53 & 764.7 & 7.2 & 5.49 & 511.00 & 540.68 & 531.35 & 516.89 & 28.60 & 0.30 & 3.29 & 0.62 & 17.44 & 1.65 & $2,377.74$ & 22.39 & 18.06 \\
\hline 10:56 & 0.2 & 20.22 & 0.54 & 749 & 8.3 & 5.49 & 511.00 & 540.68 & 509.13 & 493.15 & 29.90 & 0.30 & 3.29 & 0.62 & 17.53 & 1.68 & $2,328.92$ & 25.81 & 18.06 \\
\hline $10: 57$ & 0.3 & 20.2 & 0.56 & 892.1 & 6.5 & 5.49 & 511.00 & 540.68 & 509.13 & 493.15 & 29.90 & 0.30 & 3.29 & 0.93 & 17.47 & 1.74 & $2,773.88$ & 20.21 & 18.06 \\
\hline $10: 58$ & 0.4 & 20.21 & 0.55 & 801 & 4.2 & 5.49 & 511.00 & 540.68 & 509.13 & 493.15 & 29.90 & 0.30 & 3.29 & 1.24 & 17.50 & 1.71 & $2,490.61$ & 13.06 & 18.06 \\
\hline $10: 59$ & 0.4 & 20.21 & 0.56 & 710.5 & 2.5 & 5.49 & 511.00 & 540.68 & 509.13 & 493.15 & 29.90 & 0.30 & 3.29 & 1.24 & 17.50 & 1.74 & $2,209.21$ & 7.77 & 18.06 \\
\hline 11:00 & 0.4 & 20.2 & 0.53 & 7008 & 2.6 & 5.49 & 511.00 & 540.68 & 509.13 & 493.15 & 29.90 & 0.30 & 3.29 & 1.24 & 17.47 & 1.65 & $2,179.05$ & 8.08 & 18.06 \\
\hline 11:01 & 0.5 & 20.22 & 0.49 & 605.6 & 0.6 & 5.49 & 511.00 & 540.68 & 509.13 & 493.15 & 29.90 & 0.30 & 3.29 & 1.55 & 17.53 & 1.52 & $1,883.04$ & 1.87 & 18.06 \\
\hline 11:02 & 0.5 & 20.21 & 0.48 & 600.4 & 0.6 & 5.49 & 511.00 & 540.68 & 488.25 & 471.06 & 31.10 & 0.30 & 3.29 & 1.55 & 17.50 & 1.49 & $1,866.87$ & 1.87 & 18.06 \\
\hline $11: 03$ & 0.5 & 20.22 & 0.51 & 651.6 & 0.9 & 5.49 & 511.00 & 540.68 & 488.25 & 471.06 & 31.10 & 0.30 & 3.29 & 1.55 & 17.53 & 1.59 & $2,026.07$ & 2.80 & 18.06 \\
\hline 11:04 & 0.5 & 20.21 & 0.52 & 715.9 & 1.5 & 5.49 & 511.00 & 540.68 & 488.25 & 471.06 & 31.10 & 0.30 & 3.29 & 1.55 & 17.50 & 1.62 & $2,226.00$ & 4.66 & 18.06 \\
\hline $11: 05$ & 0.5 & 20.21 & 0.52 & 780.1 & 1.6 & 5.49 & 511.00 & 540.68 & 488.25 & 471.06 & 31.10 & 0.30 & 3.29 & 1.55 & 17.50 & 1.62 & $2,425.63$ & 4.98 & 18.06 \\
\hline 11:06 & 0.5 & 20.22 & 0.5 & 747.3 & 1.1 & 5.49 & 511.00 & 540.68 & 488.25 & 471.06 & 31.10 & 0.30 & 3.29 & 1.55 & 17.53 & 1.55 & $2,323.64$ & 3.42 & 18.06 \\
\hline 11:07 & 0.5 & 20.22 & 0.54 & 846.5 & 1.8 & 5.49 & 511.00 & 540.68 & 488.25 & 471.06 & 31.10 & 0.30 & 3.29 & 1.55 & 17.53 & 1.68 & $2,632.09$ & 5.60 & 18.06 \\
\hline 11:08 & 0.5 & 20.21 & 0.51 & 866.7 & 2 & 5.49 & 511.00 & 540.68 & 566.59 & 543.25 & 33.00 & 0.30 & 3.29 & 1.55 & 17.50 & 1.59 & $2,694.90$ & 6.22 & 18.06 \\
\hline 11:09 & 0.6 & 20.21 & 0.56 & 892.4 & 1.2 & 5.49 & 511.00 & 540.68 & 566.59 & 543.25 & 33.00 & 0.30 & 3.29 & 1.87 & 17.50 & 1.74 & $2,774,81$ & 3.73 & 18.06 \\
\hline $11: 10$ & 0.7 & 20.2 & 0.52 & 833.9 & 0.6 & 5.49 & 511.00 & $\$ 40.68$ & 565.59 & 543.25 & 33.00 & 0.30 & 3.29 & 2.18 & 17.47 & 1.62 & $2,592.91$ & 1.87 & 18.06 \\
\hline $11: 11$ & 0.6 & 20.19 & 0.52 & 746.7 & 0.6 & 5.49 & 511.00 & 540.68 & 566.59 & 543.25 & 33.00 & 0.30 & 3.29 & 1.87 & 17.44 & 1.62 & $2,321.77$ & 1.87 & 18.06 \\
\hline $11: 12$ & 0.7 & 20.2 & 0.49 & 730.6 & 0.2 & 5.49 & 511.00 & 540.68 & 566.59 & 543.25 & 33.00 & 0.30 & 3.29 & 2.18 & 17.47 & 1.52 & $2,271.71$ & 0.62 & 18.06 \\
\hline $11: 13$ & 0.7 & 20.21 & 0.48 & 690.3 & 0.2 & 5.49 & 511.00 & 540.68 & 566.59 & 543.25 & 33.00 & 0.30 & 3.29 & 2.18 & 17.50 & 1.49 & $2,146.40$ & 0.62 & 18.06 \\
\hline $11: 14$ & 0.8 & 20.2 & 0.5 & 703.1 & 0.1 & 5.49 & 511.00 & 540.68 & 513.45 & 496.02 & 30.70 & 0.30 & 3.29 & 2.49 & 17.47 & 1.55 & $2,186.20$ & 0.31 & 18.06 \\
\hline $11: 15$ & 0.7 & 20.19 & 0.5 & 744.8 & 0.2 & 5.49 & 511.00 & 540.68 & 513.45 & 496.02 & 30.70 & 0.30 & 3.29 & 2.18 & 17.44 & 1.55 & $2,315.87$ & 0.62 & 18,06 \\
\hline $11: 16$ & 0.7 & 20.19 & 0.5 & 712.9 & 0.2 & 5.49 & 511.00 & 540.68 & 513.45 & 496.02 & 30.70 & 0.30 & 3.29 & 2.18 & 17.44 & 1.55 & $2,216.68$ & 0.62 & 18.06 \\
\hline $11: 17$ & 0.6 & 20.17 & 0.49 & 683.6 & 0.2 & 5.49 & 511.00 & 540.68 & 513.45 & 496.02 & 30.70 & 0.30 & 3.29 & 1.87 & 17.37 & 1.52 & $2,125.57$ & 0.62 & 18.06 \\
\hline $11: 18$ & 0.6 & 20.19 & 0.45 & 644.1 & 0.3 & 5.49 & 511.00 & 540.68 & 513.45 & 496.02 & 30.70 & 0.30 & 3.29 & 1.87 & 17.44 & 1.40 & $2,002.75$ & 0.93 & 18.06 \\
\hline 11:19 & 0.6 & 20.19 & 0.44 & 626.9 & 0.4 & 5.49 & 511,00 & 540.68 & 513.45 & 496.02 & 30.70 & 0.30 & 3.29 & 1.87 & 17.44 & 1.37 & $1,949.27$ & 1.24 & 18.06 \\
\hline 11:20 & 0.6 & 20.19 & 0.46 & 627.2 & 0.2 & 5.49 & 511.00 & 540.68 & 517.27 & 497.42 & 32.10 & 0.30 & 3.29 & 1.87 & 17.44 & 1.43 & $1,950.20$ & 0.62 & 18.06 \\
\hline $11: 21$ & 0.7 & 20.18 & 0.47 & 652 & 0.1 & 5.49 & 511.00 & 540.68 & 517.27 & 497.42 & 32.10 & 0.30 & 3.29 & 2.18 & 17.41 & 1.46 & $2,027.32$ & 031 & 18.06 \\
\hline 11:22 & 0.6 & 20.18 & 0.46 & 628.5 & 0.1 & 5.49 & 511.00 & 540.68 & 517.27 & 497.42 & 32.10 & 0.30 & 3.29 & 1.87 & 17.41 & 1.43 & $1,954.24$ & 0.31 & 18.06 \\
\hline 11:23 & 0.7 & 20.18 & 0.49 & 669.6 & 0.1 & 5.49 & 511.00 & 540.68 & 517.27 & 497.42 & 32.10 & 0.30 & 3.29 & 2.18 & 17.41 & 1.52 & $2,082.04$ & 0.31 & 18.06 \\
\hline $11: 24$ & 0.6 & 20.19 & 0.47 & 646.3 & 0.1 & 5.49 & 511.00 & 540.68 & 517.27 & 497.42 & 32.10 & 0.30 & 3.29 & 1.87 & 17.44 & 1.46 & $2,009.59$ & 0.31 & 18.06 \\
\hline $11: 25$ & 0.6 & 20.17 & 0.53 & 767.7 & 0.8 & 5.49 & 511.00 & 540.68 & 517.27 & 497.42 & 32.10 & 0.30 & 3.29 & 1.87 & 17.37 & 1.65 & $2,387.07$ & 2.49 & 18.06 \\
\hline $11: 26$ & 0.7 & 20.17 & 0.52 & 746.8 & 0.4 & 5.49 & 511.00 & 540.68 & 514.51 & 494.60 & 32.20 & 0.30 & 3.29 & 2.18 & 17.37 & 1.62 & $2,322.08$ & 1.24 & 18.06 \\
\hline $11: 27$ & 0.8 & 20.17 & 0.55 & 806.8 & 0.5 & 5.49 & 511,00 & 540.68 & S14.51 & 494,60 & 32.20 & 0.30 & 3.29 & 2.49 & 17.37 & 1.71 & $2,508.65$ & 1.55 & 18.06 \\
\hline $11: 28$ & 0.8 & 20.17 & 0.55 & 826.5 & 0.3 & 5.49 & 511.00 & 540.68 & 514.51 & 494.60 & 32.20 & 0.30 & 3.29 & 2.49 & 17.37 & 1.71 & $2,569.90$ & 0.93 & 18.06 \\
\hline $11: 29$ & 0.7 & 20.17 & 0.57 & 821.9 & 0.4 & 5.49 & 511.00 & 540,68 & 514.51 & 494.60 & 32.20 & 0.30 & 3.29 & 2.18 & 17.37 & 1.77 & $2,555.60$ & 1.24 & 18.06 \\
\hline $11: 30$ & 0.8 & 20.15 & 0.61 & 978.3 & 1 & 5.49 & 511.00 & 540.68 & 514.51 & 494.60 & 32.20 & 0,30 & 3.29 & 2.49 & 17.31 & 1.90 & $3,041.91$ & 3.11 & 18.06 \\
\hline 11:31 & 0.8 & 20.16 & 0.57 & 937.6 & 0.5 & 5.49 & 511.00 & 540.68 & 514.51 & 494.60 & 32.20 & 0.30 & 3.29 & 2.49 & 17.34 & 1.77 & $2,915.35$ & 1.55 & 18.06 \\
\hline $11: 32$ & 0.8 & 20.15 & 0.6 & 930.2 & 0.7 & 5.49 & 511.00 & 540.68 & 518.26 & 495.45 & 33.90 & 0,30 & 3.29 & 2.49 & 17.31 & 1.87 & $2,892.34$ & 2.18 & 18.06 \\
\hline 11:33 & 0.7 & 20.17 & 0.53 & 851.8 & 1.5 & 5.49 & 511.00 & 540.68 & 518.26 & 495.45 & 33.90 & 0.30 & 3.29 & 2.18 & 17.37 & 1.65 & $2,648.57$ & 4.66 & 18.06 \\
\hline $11: 34$ & 0.8 & 20.16 & 0.53 & 760.8 & 1 & 5.49 & 511.00 & 540.68 & 518.26 & 495.45 & 33.90 & 0.30 & 3.29 & 2.49 & 17.34 & 1.65 & $2,365,62$ & 3.11 & 18.06 \\
\hline $11: 35$ & 0.7 & 20.17 & 0.54 & 902.3 & 4.6 & 5.49 & 511.00 & 540.68 & 518.26 & 495.45 & 33.90 & 0.30 & 3.29 & 2.18 & 17.37 & 1.68 & $2,805.59$ & 14.30 & 18.06 \\
\hline $11: 36$ & 0.6 & 20.15 & 0.59 & $11 \times 2.9$ & 4.4 & 5.49 & 511.00 & 540.68 & 518.26 & 495.45 & 33.90 & 0.30 & 3.29 & 1.87 & 17.31 & 1.83 & $3,553.71$ & 13.68 & 18.06 \\
\hline $11: 37$ & 0.7 & 20.15 & 0.59 & 1212.6 & 3.1 & 5.49 & 511.00 & 540.68 & 518.26 & 495.45 & 33.90 & 0.30 & 3.29 & 2.18 & 17.31 & 1.83 & $3,770.43$ & 9.64 & 18.06 \\
\hline $11: 38$ & 0.8 & 20.15 & 0.58 & 1188.3 & 1.9 & 5.49 & 511.00 & 540.68 & 540.48 & 515.85 & 34.40 & 0.30 & 3.29 & 2.49 & 17.31 & 1.80 & $3,694.88$ & 591 & 18.06 \\
\hline $11: 39$ & 0.7 & 20.16 & 0.58 & 1158.8 & 1.9 & 5.49 & 511.00 & 540.68 & 540.48 & 515.85 & 34.40 & 0.30 & 3.29 & 2.18 & 17.34 & 1.80 & 3,603 is & 5.91 & 18.06 \\
\hline $11: 40$ & 0.8 & 20.15 & 0.61 & 1268.6 & 2.5 & 5.49 & 511.00 & 540.68 & 540.48 & 515.85 & 34.40 & 0.30 & 3.29 & 2.49 & 17.31 & 1.90 & $3,944.56$ & 7.77 & 18.06 \\
\hline $11: 41$ & 0.9 & 20.14 & 0.65 & 1292.8 & 2.8 & 5.49 & 511.00 & 540.68 & 540.48 & 515.85 & 34.40 & 0.30 & 3.29 & 2.80 & 17.28 & 2.02 & $4,019.81$ & 871 & 18.06 \\
\hline $11: 42$ & 0.9 & 20.14 & 0.63 & 1315.3 & 3 & 5.49 & 51100 & 540.68 & 540.48 & 515.85 & 34.40 & 0.30 & 3.29 & 2.80 & 17.28 & 1.96 & $4,089.77$ & 9.33 & 18.06 \\
\hline $11: 43$ & 1 & 20.14 & 0.64 & 1313.4 & 3.2 & 5.49 & $\$ 11.00$ & 540.68 & 540.48 & 515.85 & 34.40 & 0.30 & 3.29 & 3.11 & 17.28 & 1.99 & 4,08386 & 9.95 & 18.06 \\
\hline $11: 44$ & 11 & 20.14 & 0.64 & 1259.5 & 3 & 5.49 & 511.00 & 540.68 & 553.71 & $\$ 20.19$ & 39.30 & 0.30 & 3.29 & 3.42 & 17.28 & 1.99 & $3,916.26$ & 9.33 & 18.06 \\
\hline $11: 45$ & ii & 20.14 & 0.64 & 1286.9 & 2.7 & 5.49 & 511.00 & 540.68 & 553.71 & 520.19 & 39.30 & 0.30 & 3.29 & 3.42 & 17.28 & 1.99 & $4,001.46$ & 8.40 & 18.06 \\
\hline $11: 46$ & i.i & 20.13 & 0.63 & 1290.8 & 2.6 & 5.49 & 511.00 & 540.68 & 553.71 & 520.19 & 39.30 & 0.30 & 3.29 & 3.42 & 17.25 & 1.96 & $4,013.59$ & 808 & 18.06 \\
\hline $11: 47$ & 1.2 & 20.13 & 0.64 & 1251.9 & 2.4 & 5,49 & $\$ 11.00$ & 540.68 & 553.71 & 520.19 & 39.30 & 0.30 & 3.29 & 3.73 & 17.25 & 1.99 & $3,892.63$ & 7.46 & 18.06 \\
\hline 11.48 & 1.2 & 20.11 & 0.68 & 1381 & 3.3 & 5.49 & 511.00 & 540.68 & 553.71 & 520.19 & 39.30 & 0.30 & 329 & 3.73 & 17.19 & 2.11 & $4,294.05$ & 10.26 & 18.06 \\
\hline $11: 49$ & 1.2 & 20.1 & 0.73 & 1595.4 & 4.7 & 5.49 & 511.00 & 540.68 & 553.71 & 520.19 & 39.30 & 0.30 & 3.29 & 3.73 & 17.16 & 2.27 & $4,960.70$ & 14.61 & 18.06 \\
\hline $11: 50$ & 12 & 20.08 & 0.73 & 1552.5 & 4.8 & 5.49 & 511.00 & 540.68 & 530.29 & 504.65 & 35.30 & 0.30 & 3.29 & 3.73 & 17.09 & 2.27 & $4,827.31$ & 14.93 & 18.06 \\
\hline $11: 51$ & 1.2 & 20.09 & 067 & 1462.5 & 3.4 & 5.49 & 511.00 & 540.68 & 530.29 & 504.65 & 35.30 & 0.30 & 3.29 & 3.73 & 17.13 & 2.08 & 4,54747 & 1057 & 18.06 \\
\hline $11: 52$ & 1.2 & 20.06 & 069 & 1440.2 & 3.4 & 5.49 & 511.00 & 540.68 & $\$ 30.29$ & 504.65 & 3530 & 0.30 & 329 & 3.73 & 17.03 & 2.15 & $4,478.13$ & 1057 & 18.06 \\
\hline
\end{tabular}


Table 0.3 Calculated furnace outter offgas compositions for N80 and N80-Mod (continued).

\begin{tabular}{|c|c|c|c|c|c|c|c|c|c|c|c|c|c|c|c|c|c|c|c|}
\hline \multirow[b]{2}{*}{$\operatorname{TIME}(\mathrm{a})$} & \multicolumn{5}{|c|}{ Quench Outlet Dry vol. \% / ppm (a) } & \multirow{2}{*}{ 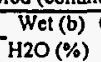 } & \multirow{2}{*}{$\begin{array}{l}\text { Quench Orillet (c) } \\
\text { Fowrate (dscfin) }\end{array}$} & \multirow{2}{*}{$\begin{array}{l}\text { Quench Outlet } \\
\text { Flowrate (wsefm) }\end{array}$} & \multirow{2}{*}{$\begin{array}{l}\text { Quench Aur (d) } \\
\text { Flowrate (wacfm : }\end{array}$} & \multirow{2}{*}{$\begin{array}{l}\text { Quench Air } \\
\text { Flowrate (wscfin) }\end{array}$} & emp Quenc & Daluthon & Disuton & Fumace Outle & det Ongas & as Compo & posstion (wet be & bass \%) (g) & \\
\hline & NOX $(\mathrm{ppm})$ & $02(\%)$ & $\mathrm{CO} 2(\%)$ & $\mathrm{CO}(\mathrm{ppm})$ & SO2 (ppm) & & & & & & $\operatorname{Air}(C)(e)$ & Factor & Factor (n) & NOx (ppm) & $02(\mathrm{~h})$ & $\mathrm{CO} 2$ & $\mathrm{CO}(\mathrm{ppm})$ & $\mathrm{SO} 2(\mathrm{ppm})$ & $\mathrm{H} 2 \mathrm{O}$ \\
\hline $11: 53$ & 1.3 & 20.07 & 0.69 & 1407.8 & 3.2 & 5.49 & & & & & 35.30 & 0.30 & 3.29 & 4.04 & 77.06 & 2.15 & 4,37738 & 9.95 & 18.06 \\
\hline 11:54 & 14 & 2008 & 0.69 & 14286 & 3.9 & 5.49 & 511.00 & 540.68 & 530.29 & 504.65 & 35.30 & 0.30 & 3.29 & 4.35 & 17.09 & 2.15 & $4,442.06$ & 12.13 & 18.06 \\
\hline $11: 55$ & 13 & 20.08 & 0.7 & 1325.8 & 3.2 & 549 & 511.00 & 54068 & 530.29 & 504.65 & 35.30 & 0.30 & 3.29 & 4.04 & 1709 & 218 & $4,122.41$ & 9.95 & 1806 \\
\hline $11: 56$ & 12 & 2007 & 07 & 1370.5 & 2.7 & 5.49 & 511.00 & 540.68 & 51246 & 49280 & 32.10 & 0.30 & 3.29 & 3.73 & 17.06 & 2.18 & $4,261.40$ & 8.40 & 18.06 \\
\hline 11.57 & 13 & 20.06 & 071 & 1325.7 & 2.2 & 5.49 & 511.00 & 54068 & $\$ 12.46$ & 492.80 & 3210 & 0.30 & 3.29 & 4.04 & 17.03 & 2.21 & $4,122.10$ & 6.84 & 18.06 \\
\hline $11: 58$ & 1.4 & 20.06 & 0.73 & 1394.1 & 2.6 & 5.49 & 511.00 & 54068 & 512.46 & 492.80 & 3210 & 0.30 & 3.29 & 4.35 & 17.03 & 2.27 & $4,334.79$ & 808 & 18.06 \\
\hline 11.59 & 1.6 & 2006 & 0.72 & I413.4 & 3 & 549 & 511.00 & 540.68 & 512.46 & 49280 & 32.10 & 0.30 & 3.29 & 4.98 & 17.03 & 2.24 & $4,394.80$ & 9.33 & 18.06 \\
\hline 12.00 & 1.5 & 20.09 & 067 & 1373.1 & 23 & 5.49 & 511.00 & 540.68 & 512.46 & 492.80 & 3210 & 030 & 329 & 4.66 & 17.13 & 2.08 & $4,269.49$ & 7.15 & 18.06 \\
\hline 12:01 & 15 & 20.08 & 0.69 & 1391 & 25 & 5.49 & 51100 & 540.68 & 51246 & 492.80 & 32.10 & 0.30 & 3.29 & 4.66 & 17.09 & 2.15 & $4,325.15$ & 7.77 & 18.06 \\
\hline 12.02 & 1.4 & 20.08 & 0.66 & 1427.1 & 22 & 5.49 & 511.00 & 540.68 & 49660 & 475.83 & 33.20 & 0.30 & 329 & 4.35 & 17.09 & 2.05 & $4,437,39$ & 6.84 & 18.06 \\
\hline 12.03 & 13 & 2006 & 0.68 & 1431.7 & 1.8 & 5.49 & 51100 & 540.68 & 49660 & 47583 & 33.20 & 0.30 & 3.29 & 4.04 & 17.03 & 2.11 & $4,451.70$ & 5.60 & 18.06 \\
\hline 12:04 & 1.3 & 20.07 & 069 & 14679 & 19 & 5.49 & 511.00 & 540.68 & 496.60 & 475.83 & 33.20 & 0.30 & 3.29 & 4.04 & 17.06 & 2.15 & $4,564.26$ & 5.91 & 18.06 \\
\hline 12:05 & 14 & 2008 & 0.71 & 1429.5 & 22 & 5.49 & 511.00 & 540.68 & 496.60 & 475.83 & 33.20 & 0.30 & 3.29 & 4.35 & 17.09 & 2.21 & $4,444,86$ & 6.84 & 18.06 \\
\hline $12: 06$ & 15 & 20.09 & 0.7 & 1450.6 & 2.2 & 549 & 511.00 & 540.68 & 496.60 & 475.83 & 33.20 & 0.30 & 3.29 & 4.66 & 17.13 & 2.18 & $4,510.47$ & 6.84 & 18.06 \\
\hline 12:07 & 15 & 20.1 & 0.68 & 1445 & 2.9 & 5.49 & 511.00 & 540.68 & 49660 & 475.83 & 33.20 & 0.30 & 3.29 & 4.66 & 17.16 & 2.11 & $4,493.05$ & 9.02 & 18.06 \\
\hline 1208 & 1.5 & 20.08 & 0.69 & 1461.6 & 3 & 5.49 & $\$ 11.00$ & 540.68 & 509.48 & 483.90 & 35.90 & 0.30 & 3.29 & 4.66 & 17.09 & 215 & $4,544.67$ & 9.33 & 18.06 \\
\hline $12: 09$ & 0.80 & 19.90 & 0.57 & 999.66 & 2.51 & 5.35 & \#REF! & 527.33 & 509.48 & 488.73 & 31.98 & 0.30 & 3.21 & 256 & 16.64 & 1.82 & $3,191.57$ & 8.02 & \\
\hline 15:20 & 31 & 20.39 & 2.38 & 3884.1 & 9.9 & 4.58 & 474.00 & 496.75 & 491.72 & 476.44 & 29.80 & 0.14 & 7.33 & 21.68 & 16.07 & 16.65 & $27,166.51$ & 69.24 & 33.57 \\
\hline $15: 21$ & 3.2 & 20.26 & 2.69 & 5814.7 & 8.8 & 4.58 & 474.00 & 496.75 & 491.72 & 476.44 & 29.80 & 0.14 & 7.33 & 22.38 & 15.16 & 18.81 & $40,669.67$ & 61.55 & 33.57 \\
\hline $15: 22$ & 31 & 20.33 & 2.34 & 4736.7 & 7.2 & 4.58 & 474.00 & 496.75 & 49172 & 476.44 & 29.80 & 0.14 & 7,33 & 21.68 & 15.65 & 16.37 & $33,129.83$ & 50.36 & 33.57 \\
\hline $15 \cdot 23$ & 3.2 & 20.35 & 2.32 & 4138.1 & 6.7 & 4.58 & 474.00 & 496.75 & 491.72 & 476.44 & 29.80 & 0.14 & 7.33 & 22.38 & 15.79 & 16.23 & $28,943.05$ & 46.86 & 33.57 \\
\hline $15: 24$ & 3.3 & 20.28 & 2.52 & 4514.6 & 7.8 & 4.58 & 474.00 & 496.75 & 500.57 & 484.70 & 3000 & 0.14 & 7.33 & 23.08 & 15,30 & 17.63 & $31,576.40$ & 54.56 & 33.57 \\
\hline $15: 25$ & 32 & 2029 & 2.47 & 4379.5 & 6.4 & 4.58 & 474.00 & 496.75 & 500.57 & 484.70 & 30.00 & 0.14 & 7.33 & 22.38 & 15.37 & 17.28 & $30,631.48$ & 44.76 & 33.57 \\
\hline $15: 26$ & 3.4 & 20.29 & 2.45 & 4236.2 & 6.8 & 4.58 & 474.00 & 496.75 & 500.57 & 484.70 & 30.00 & 0.14 & 7.33 & 23.78 & 15.37 & 17.14 & $29,629.19$ & 47.56 & 33.57 \\
\hline 15.27 & 3 & 20.31 & 2.35 & 3974.2 & 65 & 4.58 & 474.00 & 496.75 & 500.57 & 484.70 & 30.00 & 0.14 & 733 & 20.98 & 1551 & 16.44 & $27,796,69$ & 45.46 & 33.57 \\
\hline $15: 28$ & 2.8 & 20.28 & 2.39 & 4179.9 & 7.7 & 4.58 & 474.00 & 496.75 & 500.57 & 484.70 & 30.00 & 0.14 & 7.33 & 19.58 & 15.30 & 16.72 & $29,235.42$ & $\$ 3.86$ & 33.57 \\
\hline $15: 29$ & 27 & 2033 & 2.22 & 4114 & 6.4 & 4.58 & 474.00 & 496.75 & 500.57 & 484.70 & 30.00 & 0.14 & 7.33 & 18.88 & 15.65 & 15.53 & $28,774.49$ & 44.76 & 33.57 \\
\hline $15: 30$ & 2.9 & 20.3 & 2.24 & 3796.9 & 6.2 & 4.58 & 474,00 & 496.75 & 506.72 & 491.30 & 29.60 & 0.14 & 7.33 & 20.28 & 15.44 & 15,67 & $26,556.60$ & 43.36 & 33.57 \\
\hline $15 ; 31$ & 2.9 & 20.32 & 2.19 & 3659 & 5.5 & 4.58 & 474.00 & 496.75 & 506.72 & 491.30 & 29.60 & 0.14 & 7.33 & 20.28 & 15.58 & 15.32 & $25,592.09$ & 38.47 & 33.57 \\
\hline $15 \cdot 32$ & 2.9 & 20.25 & 2.61 & 3928 & 7.6 & 4.58 & 474.00 & 496.75 & 506.72 & 491.30 & 2960 & 0.14 & 733 & 20.28 & 15.09 & 18.26 & $27,473.56$ & 53.16 & 33.57 \\
\hline $15: 33$ & 33 & 19.96 & 3.36 & 6040.6 & 8.6 & 4.58 & 474.00 & 496.75 & 506.72 & 491.30 & 29.60 & 0.14 & 7.33 & 23.08 & 13.07 & 23.50 & $42,249.68$ & 60.15 & 33.57 \\
\hline $15: 34$ & 6.5 & 19.66 & 4.91 & 6479.3 & 47.2 & 4.58 & 474.00 & 496.75 & 50672 & 491.30 & 29.60 & 0.14 & 7.33 & 45.46 & 10.97 & 34.34 & $45,318.08$ & 330.13 & 33.57 \\
\hline $15: 35$ & 6.8 & 19.87 & 3.85 & 8125.9 & 39.9 & 4.58 & 474.00 & 496.75 & 506.72 & 491.30 & 29.60 & 0.14 & 7.33 & 47.56 & 12.44 & 26.93 & $56,834.87$ & 279.07 & 33.57 \\
\hline $15: 36$ & 38 & 19.94 & 359 & 67742 & 14.4 & 4.58 & 474.00 & 496.75 & 454.22 & 440.54 & 29.50 & 0.14 & 7.33 & 26.58 & 12.93 & 25.11 & $47,380.69$ & 100.72 & 33.57 \\
\hline $15: 37$ & 36 & 20 & 3 & 6882.4 & 11.5 & 4.58 & 474.00 & 496.75 & 454.22 & 440.54 & 29.50 & 0.14 & 7.33 & 25.18 & 13.35 & 20.98 & $48,137,47$ & 80.43 & 33.57 \\
\hline $15 \cdot 38$ & 3.3 & 20.08 & 28 & 4703.8 & 8.3 & 4.58 & 47400 & 496.75 & 454.22 & 440.54 & 29.50 & 0.14 & 7.33 & 23.08 & 13.91 & 1958 & $32,899.72$ & 58.05 & 33.57 \\
\hline $15: 39$ & 2.5 & 20.16 & 2.71 & 4371.1 & 105 & 4.58 & 474.00 & 496.75 & 45422 & 440.54 & 29.50 & 0.14 & 7.33 & 17.49 & 14.47 & 18.95 & $30,572.72$ & 73.44 & 33.57 \\
\hline $15: 40$ & 2.5 & 19.98 & 3.27 & 5213.1 & 11.1 & 4.58 & 474.00 & 496.75 & 454.22 & 440.54 & 29.50 & 0.14 & 7.33 & 17.49 & 13.21 & 22.87 & $36,461.91$ & 77.64 & 33.57 \\
\hline $15: 41$ & 3 & 19.96 & 3.3 & 64234 & 8.7 & 4.58 & 474.00 & 496.75 & 454.22 & 440.54 & 29.50 & 0.14 & 7.33 & 20.98 & 13.07 & 23.08 & $44,927.10$ & 60.85 & 33.57 \\
\hline $15: 42$ & 19 & 20.07 & 296 & 5146.4 & 6.7 & 4.58 & 474.00 & 496.75 & 493.35 & 482.48 & 27.00 & 0.14 & 7.33 & 13.29 & 13.84 & 20.70 & $35,995.39$ & 46.86 & 33.57 \\
\hline 15.43 & 3 & 2008 & 2.89 & 4823.9 & 9 & 4.58 & 474.00 & 49675 & 493.35 & 482,48 & 27.00 & 014 & 7,33 & 20.98 & 13.91 & 20.21 & $33,739.74$ & 62.95 & 33.57 \\
\hline $15: 44$ & 4.3 & 20.06 & 2.93 & $\$ 181.2$ & 7 & 4.58 & 474.00 & 496.75 & 493.35 & 482.48 & 27.00 & 0.14 & 733 & 30.08 & 13.77 & 20.49 & $36,238.79$ & 48.96 & 3357 \\
\hline $15: 45$ & 62 & 2005 & 294 & 51907 & 6 & 4.58 & 474,00 & 496.75 & 493.35 & 482.48 & 27.00 & 0.14 & 7.33 & 43.36 & 13.70 & 20.56 & $36,305.24$ & 41.97 & 33.57 \\
\hline $15: 46$ & 4.2 & 20.09 & 2.92 & 4934.4 & 6.3 & 458 & 47400 & 496.75 & 493.35 & 482.48 & 27.00 & 0.14 & 7.33 & 29.38 & 1398 & 2042 & 34,51260 & 44.06 & 33.57 \\
\hline $\begin{array}{l}15: 47 \\
15: 47\end{array}$ & $\begin{array}{l}5.2 \\
54\end{array}$ & 201 & 287 & 5253.1 & 6.5 & 458 & 474.00 & 496.75 & 493.35 & 482.48 & 27.00 & 014 & 7.33 & 37.77 & 14.05 & 20.07 & $36,741.68$ & 45.46 & 33.57 \\
\hline $15: 48$ & 49 & 2006 & 3.04 & 53229 & 7.4 & 458 & 474.00 & 49675 & 50425 & 48633 & 31.20 & 014 & 733 & 3427 & 13.77 & 21.26 & $37,229.88$ & 51.76 & 33.57 \\
\hline $15: 49$ & 5 & 2003 & 3.07 & 5453.2 & 68 & 458 & 474.00 & 496.75 & 504.25 & 48633 & 31.20 & 014 & 7.33 & 34.97 & 1356 & 2147 & $38,141.24$ & 47.56 & 33.57 \\
\hline $15: 50$ & 46 & 20.03 & 3.02 & 5164.9 & 67 & 4.58 & 474.00 & 496.75 & 504.25 & 486.33 & 31.20 & 0.14 & 7.33 & 32.17 & 13.56 & 21.12 & 36,12479 & 46.86 & 33.57 \\
\hline 15.51 & 61 & 20.06 & 2.92 & 51389 & 69 & 458 & 474.00 & 49675 & 504.25 & 486.33 & 3120 & 014 & 7.33 & 42.67 & 13.77 & 20.42 & $35,942.94$ & 48.26 & 3357 \\
\hline 15.52 & 4.3 & 20.02 & 311 & 5446 & 8 & 4.58 & 474.00 & 496.75 & 50425 & 486.33 & 31.20 & 0.14 & 7.33 & 3008 & 13.49 & 21.75 & $38,090.88$ & 55.95 & 3357 \\
\hline 15.53 & 37 & 2006 & 302 & 56524 & 81 & 4.58 & 47400 & 49675 & 504.25 & 48633 & 31.20 & 0.14 & 733 & 25.88 & 13.77 & 2112 & $39,534.50$ & 56.65 & 3357 \\
\hline 15.54 & 42 & 2003 & 314 & 5932.9 & 99 & 458 & 47400 & 49675 & 539.77 & 518.38 & 3250 & 014 & 733 & 29.38 & 13.56 & 21.96 & $41,496.40$ & 6924 & 33.57 \\
\hline 15:ss & 4 & 20.04 & 3.18 & 5907 & 116 & 458 & 474.00 & 496.75 & 53977 & 518.38 & 32.50 & 014 & 733 & 2798 & 1363 & 2224 & $41,315.25$ & 81.13 & 33.57 \\
\hline 15.56 & 4 & 1996 & 3.36 & 6558 & 178 & 458 & 47400 & 496.75 & 53977 & 518.38 & 32.50 & 014 & 7.33 & 27.98 & 1307 & 23.50 & $45,868.53$ & 12450 & 3357 \\
\hline 15.57 & 35 & 20.05 & 311 & 5838.7 & 109 & 458 & 474,00 & 496.75 & 539.77 & 518.38 & 32.50 & 014 & 7.33 & 24.48 & 13.70 & 2175 & $40,837.54$ & 7624 & 33.57 \\
\hline 1558 & 37 & 19.97 & 334 & 65226 & 113 & 458 & 474.00 & 496.75 & 539.77 & 518.38 & 3250 & 014 & 733 & 25.88 & 1314 & 23.36 & 45,62093 & 79.04 & 3357 \\
\hline 15.59 & 4 & 1993 & 35 & 6571.5 & 112 & 4.58 & 474.00 & 49675 & 539.77 & 51838 & 3250 & 014 & 733 & 27.98 & 1286 & 2448 & $45,962.95$ & 78.34 & 33.57 \\
\hline 16.00 & 45 & 19.97 & 335 & 6277.6 & 11 & 458 & 47400 & 49675 & 49696 & 47462 & 3420 & 014 & 733 & 31.47 & 1314 & 2343 & 43,90733 & 76.94 & 3357 \\
\hline 16.01 & 4.6 & 1994 & 348 & 6252 & 10 & 458 & 47400 & 49675 & 496.96 & 474.62 & 3420 & 014 & 733 & 3217 & 1293 & 24.34 & $43,728.28$ & 6994 & 3357 \\
\hline 16.02 & 47 & 1991 & 3.61 & 62803 & $\pi$ & 458 & 47400 & 49675 & 49696 & 47462 & 3420 & 014 & 733 & 3287 & 1272 & 2525 & 43,92621 & 7694 & 33.57 \\
\hline $16: 03$ & 49 & 19.9 & 362 & 62245 & 116 & 458 & 47400 & 49675 & 49696 & 47462 & 34.20 & 014 & 7.33 & 3427 & 1265 & 2532 & 43,53593 & 8113 & 3357 \\
\hline $16: 04$ & 4.5 & 19.89 & 3.75 & 7072.5 & 12.7 & 458 & 47400 & 49675 & 49696 & 47462 & 3420 & 014 & 7.33 & 3147 & 1258 & 2623 & $49,467.09$ & 8883 & 33.57 \\
\hline 1605 & 51 & 1987 & 38 & 6786 & 108 & 4.58 & 47400 & 49675 & 49696 & 47462 & 34.20 & 014 & 733 & 3567 & 1244 & 2658 & 47,46322 & 7554 & 3357 \\
\hline
\end{tabular}


Table O-3 Calculated funnase outet off gas compositions for N80 and N80-Mod (continued).

\begin{tabular}{|c|c|c|c|c|c|c|c|c|c|c|c|c|c|c|c|c|c|c|c|}
\hline \multirow{2}{*}{\multicolumn{2}{|c|}{ TIME (a) NOX(ppm) }} & \multirow{2}{*}{\multicolumn{3}{|c|}{$\begin{array}{l}\text { Quench Outlet Dry vol \%/ppm (a) } \\
02(\%) \cos (\%) \operatorname{co}(\mathrm{ppm})\end{array}$}} & \multirow{2}{*}{$\mathrm{SO} 2(\mathrm{ppm})$} & \multirow{2}{*}{$\begin{array}{r}\text { Wet (b) } \\
\text { H2O(\%) }\end{array}$} & \multirow{3}{*}{$\begin{array}{l}\text { Quench Oudlet (c) } \\
\text { Flowrate (dscfin) }\end{array}$} & \multirow{2}{*}{$\begin{array}{l}\text { Quench Oullet } \\
\text { Flowrate (wsefn) }\end{array}$} & \multirow{2}{*}{$\begin{array}{l}\text { Quench AIr (d) } \\
\text { Flowrate (wrecfin }\end{array}$} & \multirow{2}{*}{$\begin{array}{c}\text { Quench AIr } \\
\text { Fowrate (wscin) }\end{array}$} & \multirow{2}{*}{\multicolumn{2}{|c|}{$\begin{array}{l}\text { emp. Quene Dilution } \\
\text { Air (C) (e) Factor }\end{array}$}} & \multirow{2}{*}{$\begin{array}{l}\text { Diluton } \\
\text { Factor (f) }\end{array}$} & \multicolumn{6}{|c|}{ Funzec Outlet Offgas Composition (wet basis $\%$ )(R) } \\
\hline & & & & & & & & & & & & & & NOX(pprn) & O2(h) & $\mathrm{CO}$ & $\mathrm{CO}(\mathrm{ppm})$ & SO2 (ppm) & $\mathrm{H} 2 \mathrm{O}$ \\
\hline $16: 06$ & 5 & 19.93 & 3.65 & 6694.9 & 11.6 & 4.58 & & 496.75 & 557.18 & 537.03 & 31.40 & 0.14 & 7.33 & 34.97 & 12.86 & 25.53 & $46,826.05$ & 81.13 & 33.57 \\
\hline 16:07 & 5.2 & 19.98 & 3.57 & 6573.1 & 11.7 & 4.58 & 474.00 & 496.75 & 557.18 & 537.03 & 31.40 & 0.14 & 7.33 & 36.37 & 13.21 & 24.97 & $46,673.57$ & 81.83 & 33.57 \\
\hline 16:08 & 5.2 & 19.95 & 3.66 & 6194 & 12.2 & 4.58 & 474.00 & 496.75 & 557.18 & 537.03 & 31.40 & 0.14 & 7.33 & 36.37 & 13.00 & 25.60 & $43,322.61$ & 85.33 & 33.57 \\
\hline 16.09 & 5.4 & 19.94 & 3.66 & 6569.8 & 12.3 & 4.58 & 474.00 & 496.75 & 557.18 & 537.03 & 31.40 & 0.14 & 7.33 & 37.77 & 12.93 & 25.60 & $45,951.06$ & 85.03 & 33.57 \\
\hline 16:10 & 5 & 19.96 & 3.66 & 6434.1 & 11.8 & 4.58 & 474.00 & 496.75 & 557.18 & 537.03 & 31.40 & 0.14 & 7.33 & 34.97 & 13.07 & 25.60 & $45,001.94$ & 82.53 & 33.57 \\
\hline 16:11 & 5.1 & 19.94 & 3.67 & 6748.8 & 12.7 & 4.58 & 474.00 & 495.75 & 557.18 & 537.03 & 31.40 & 0.14 & 7.33 & 35.67 & 12.93 & 25.67 & $47,203.04$ & 88.83 & 33.57 \\
\hline $16: 12$ & 6.2 & 19.92 & 3.72 & 6548 & 12.9 & 4.58 & 474.00 & 496.75 & 573.95 & 554.84 & 30.50 & 0.14 & 7.33 & 43.36 & 12.79 & 26.02 & $45,798.58$ & 90.23 & 33.57 \\
\hline 16:13 & 5.2 & 19.94 & 3.73 & 6917.5 & 15.9 & 4.58 & 474.00 & 496.75 & 573.95 & 554.84 & 30.50 & 0.14 & 7.33 & 36.37 & 12.93 & 26.09 & $48,382.97$ & 111.21 & 33.57 \\
\hline 16:14 & 5 & 19.92 & 3.76 & 6852.3 & 13 & 4.58 & 474.00 & 496.75 & 573.95 & 554.84 & 30.50 & 0.14 & 7.33 & 34.97 & 12.79 & 26.30 & $47,926.95$ & 90.93 & 33.57 \\
\hline 16:15 & 5.7 & 19.79 & 4.25 & 6499.2 & 10.9 & 4.58 & 474.00 & 496.75 & 573.95 & 554.84 & 30.50 & 0.14 & 7.33 & 39.87 & 11.88 & 29.73 & $45,457.26$ & 76.24 & 33.57 \\
\hline 16:16 & 7.7 & 19.55 & 4.98 & 8630 & 12 & 4.58 & 474.00 & 496.75 & 573.95 & $\$ 54.84$ & 30.50 & 0.14 & 7.33 & 53.86 & 10.20 & 34.83 & $60,360.69$ & 83.93 & 33.57 \\
\hline 16:17 & 8.1 & 20.04 & 3.14 & 5416.2 & 6.6 & 4.58 & 474.00 & 496.75 & 573.95 & 554.84 & 30.50 & 0.14 & 7.33 & 56.65 & 13.63 & 21.96 & $37,882.45$ & 46.16 & 33.57 \\
\hline 16:18 & 5.6 & 20.01 & 3.35 & 5334.1 & 9.2 & 4.58 & 474.00 & 496.75 & 525.26 & 507.27 & 30.80 & 0.14 & 7.33 & 39.17 & 13.42 & 23.43 & $37,308.22$ & 64.35 & 33.57 \\
\hline 16:19 & 7 & 20.02 & 3.34 & 5044.9 & 7.4 & 4.58 & 474.00 & 496.75 & 525.26 & 507.27 & 30.80 & 0.14 & 7.33 & 48.96 & 13.49 & 23.36 & $35,285.47$ & 51.76 & 33.57 \\
\hline $16 \cdot 20$ & 5.2 & 19.93 & 3.6 & 6382.3 & 10.8 & 4.58 & 474.00 & 496.75 & 525.26 & 507.27 & 30.80 & 0.14 & 7.33 & 36.37 & 12.86 & 25.18 & $44,639.63$ & 75.54 & 33.57 \\
\hline $16: 21$ & 4.9 & 19.9 & 3.77 & 6749.1 & 12.9 & 4.58 & 474.00 & 496.75 & 525.26 & 507.27 & 30.8 & 0.14 & 7.33 & 34.27 & 12.65 & 26.37 & $47,205.14$ & 90.23 & 33.57 \\
\hline $16: 22$ & 5.7 & 19.97 & 3.53 & 6668 & 10.2 & 4.58 & 474.00 & 496.75 & 525.26 & 507.27 & 30.8 & 0.14 & 7.33 & 39.87 & 13.14 & 24.69 & $46,637.90$ & 71.34 & 33.57 \\
\hline $16: 23$ & 8.9 & 19.99 & 3.39 & 5775.7 & 8.2 & 4.58 & 474.00 & 496.75 & 525.26 & 507.27 & 30.80 & 0.14 & 7.33 & 62.25 & 13.28 & 23.71 & $40,396.90$ & 57.35 & 33.57 \\
\hline $16: 24$ & 11.5 & 20.02 & 3.26 & 4677.9 & 6.4 & 4.58 & 474.00 & 496.75 & 522.65 & 505.58 & 30.30 & 0.14 & 7.33 & 80.43 & 13.49 & 22.80 & $32,718.57$ & 44.76 & 33.57 \\
\hline $16: 25$ & 6.8 & 19.98 & 3.46 & 4884.1 & 6.7 & 4.58 & 474.00 & 496.75 & 522.65 & 505.58 & 30.30 & 0.14 & 7.33 & 47.56 & 13.21 & 24.20 & $34,160.79$ & 46.86 & 33.57 \\
\hline Avg. $\# 2$ & 4.4808824 & 19.73791 & 3.1182 & 5596.9448 & 10.362687 & 4.4453 & & 482.1408756 & & 482.0865339 & 29.7058824 & 0.132 & .114411765 & 31.34057 & 13.4 & 22.1 & 39146.63 & 72.47959 & 33.07 \\
\hline
\end{tabular}

a. Data obtaned from Continuous Emissions Monitoning Systems (CEMS) data provided by Entropy personnel.

b. Moisture content, percent by volume, as shown in analysis from particulate/metals sampling period (MMT).

c. Source gas volumetric flowrate from MMT data

d. Querch air dowrate, channel 15 from Data Aequisition System (DAS).

-. Quench air temperature, channel 1 from DAS.

Calle quench outlet flowrate divided by the fumsec outet lowrate.

\& Calculated from the quench outlet composition and the dilution factor, making the necessary conversions from a dry to a wet basis. 
Table O-4 Calculated furmace oullet off gas compositions for N80--IV and N80.JV-Mod

\begin{tabular}{|c|c|c|c|c|c|c|c|c|c|c|c|c|c|c|c|c|c|c|c|c|}
\hline $\operatorname{TIME}(\mathrm{a})$ & $\frac{9}{\operatorname{NOx}(100}$ & 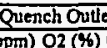 & 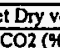 & $\frac{1.9 / \mathrm{ppm}}{\mathrm{co}(\mathrm{pmm}}$ & $\frac{9)}{502(\mathrm{pPm}}$ & $\begin{array}{l}\text { Wet (b) } \\
\text { W }\end{array}$ & Quench Outlet (c) & Quench Outlet & Quench Air (d) & Quench Air & Temp. Quench & Temp, at & Dilution & Dilution & Furnace Outle & ct Offera $\mathrm{Co}$ & ompontion (w & Wet bass \%) (8) & Sosinnt & \\
\hline$\frac{\operatorname{IIME}(\mathrm{a})}{12 \cdot 20}$ & $\frac{N O x(O P}{112}$ & 2min) $02(5.6)$ & $\frac{C O 2(4)}{413}$ & $\frac{C 00(\mathrm{gmm}}{5869.3}$ & $\frac{82 . \mathrm{ppm}}{100}$ & $\frac{120(7)}{65}$ & Hlownglo(acsim) & 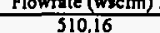 & Flownate (raclim & Howrate (Wzictim & $\frac{A \text { iri }(C)(c)}{39.10}$ & $\begin{array}{l}\text { Furnace outlet } \\
71.40\end{array}$ & $\frac{\text { Factor }}{0.17}$ & $\frac{\text { Factor }(A)}{5.86}$ & $\frac{\text { NOx (ppm) }}{6137}$ & $\frac{02(h)}{11.10}$ & $\frac{\mathrm{CO} 2}{2263}$ & $\frac{\mathrm{CO}(\mathrm{ppm})}{32158.8}$ & $\frac{\mathrm{SO} 2(\mathrm{ppm})}{5479}$ & $\frac{\mathrm{H} 2 \mathrm{O}}{3200}$ \\
\hline 1221 & 115 & $\begin{array}{l}19.4 \\
19.4\end{array}$ & 4.17 & 6655.5 & 94.2 & 6.5 & 477 & 51016 & 4 & 423.53 & 39.10 & 71,40 & 0.17 & 3.86 & $\begin{array}{l}63.01 \\
63.0\end{array}$ & 11.10 & 22.85 & $\begin{array}{l}32,436.98 \\
36,46.15\end{array}$ & $\begin{array}{l}51613 \\
5131\end{array}$ & 38.09 \\
\hline 12.22 & 11.3 & 19.39 & 42 & 6023.4 & 916 & 6.5 & 477 & $\$ 10.16$ & 450.54 & 423.53 & 39.10 & 7140 & 017 & 5.86 & 61.91 & 11.04 & 23.01 & 33,00281 & 50189 & 38.09 \\
\hline $12 \cdot 23$ & 10.1 & 1941 & 4.2 & 59852 & 90 & 65 & 477 & $\$ 10.16$ & 454.43 & 430.64 & 3660 & 71.50 & 0.17 & 5.86 & 55.34 & 11.15 & 2301 & 32.793 .51 & 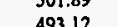 & 38.09 \\
\hline $12: 24$ & 98 & 19.41 & 421 & 6609.5 & 87.7 & 6.5 & 477 & 510.16 & 45443 & 430.64 & 36.60 & 71.50 & 0.17 & 386 & 53.70 & 11.15 & 23.07 & 36,21411 & 495.12 & 3809 \\
\hline 12.25 & 9 & 1943 & 426 & 5953.4 & 858 & 6.5 & 477 & $\$ 10.16$ & 454.43 & 430.64 & 36.60 & 71.50 & 0.17 & 5.86 & 49.31 & 11.26 & 23.34 & 32.619 .27 & 48032 & 3809 \\
\hline $12: 26$ & 81 & 1945 & 414 & 6204.2 & 80.4 & 6.5 & 477 & 510.16 & 438.72 & 418.05 & 34.90 & 70.10 & 0.17 & 5.86 & 4438 & 11.37 & 22.68 & $33,993.43$ & 470.11 & 3809 \\
\hline $12: 27$ & 71 & 1947 & 4.22 & 6388.4 & 80 & 6.5 & 477 & 510.16 & 438.72 & 418.05 & 34.90 & 70.10 & 0.17 & 5.86 & 38.90 & 11.48 & 23,12 & $35,002,68$ & $\begin{array}{l}440.52 \\
40333\end{array}$ & 38.09 \\
\hline 12.28 & 39 & 1947 & 4.26 & 5831.5 & 78.8 & 6.5 & 477 & $\$ 10.16$ & 438.72 & 418.05 & 34.90 & 70.10 & 0.17 & 5.86 & 32.33 & 1148 & 23.34 & 31.95137 & 438.33 & 38.09 \\
\hline $12: 29$ & 5.4 & 19.52 & 3.98 & 5492.7 & 77 & 6.5 & 477 & 510.16 & 443.39 & 423.46 & 34,20 & 6900 & 0.17 & 586 & 2059 & ii 75 & 2181 & 3009505 & 431.75 & 3809 \\
\hline $12: 30$ & 4 & 19.61 & 3.86 & 5472 & 72.5 & 6.5 & 477 & 51016 & 443.39 & 423.46 & 34,20 & 6900 & 0.17 & 586 & 2192 & 1225 & 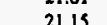 & 200811 & $\begin{array}{r}21.89 \\
307.73\end{array}$ & 38.09 \\
\hline 12.31 & 35 & 1961 & 379 & 51698 & 643 & 69 & 477 & 51016 & 443,39 & 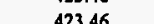 & 30 & 6000 & (1) & 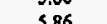 & 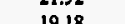 & 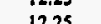 & 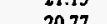 & 20 & 397.23 & 38.09 \\
\hline 1.:30 & & 19.957 & 387 & 年 & 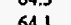 & 6.9 & 477 & 51016 & 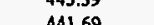 & 0 & $\begin{array}{l}34.20 \\
3370\end{array}$ & 0700 & 0.11 & 2.006 & 19.18 & 1002 & 20.71 & 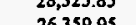 & 352.31 & 38.09 \\
\hline $\begin{array}{l}12.32 \\
-3.33\end{array}$ & 3.3 & $\begin{array}{l}1937 \\
1955\end{array}$ & 387 & 50258 & $\begin{array}{l}04.1 \\
639\end{array}$ & . & 471 & 5016 & 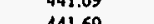 & 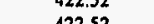 & 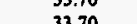 & 67.60 & 1. & 586 & 19.18 & 12.03 & $\begin{array}{l}21.20 \\
\end{array}$ & $\begin{array}{l}26,339.95 \\
\end{array}$ & 351.21 & 38.09 \\
\hline $\begin{array}{l}12: 33 \\
12: 34\end{array}$ & $\begin{array}{l}3.3 \\
3\end{array}$ & $\begin{array}{l}1955 \\
1955\end{array}$ & $\begin{array}{l}397 \\
399\end{array}$ & $\begin{array}{l}5925.8 \\
5751 .\end{array}$ & 604 & 6.3 & 477 & 310.16 & $\begin{array}{l}441.09 \\
44169\end{array}$ & 42352 & $\begin{array}{l}33.70 \\
3370\end{array}$ & 67.60 & 017 & 585 & 18.08 & 11.92 & 21.75 & $32,468.05$ & 350.11 & 38.09 \\
\hline $\begin{array}{l}12: 34 \\
12 \cdot 35\end{array}$ & 3 & $\begin{array}{l}19.55 \\
10.54\end{array}$ & $\begin{array}{l}399 \\
403\end{array}$ & 58844 & 38.8 & $\begin{array}{l}6.5 \\
6.5\end{array}$ & 477 & 510.10 & 309.16 & 481.34 & 33.70 & 67.60 & 0.17 & 586 & 16.44 & 1192 & 21.86 & $31,510.85$ & 330.94 & 3809 \\
\hline $\begin{array}{l}12: 35 \\
12.36\end{array}$ & 33 & $\begin{array}{l}19.54 \\
10.54\end{array}$ & $\begin{array}{l}4.03 \\
4.04\end{array}$ & $\begin{array}{l}8884.4 \\
52595\end{array}$ & $\begin{array}{l}38.8 \\
59.9\end{array}$ & 63 & 477 & $\begin{array}{l}510.16 \\
510.16\end{array}$ & 399.10 & $\begin{array}{l}581.54 \\
38134\end{array}$ & 34.100 & 03.40 & 0.17 & 5.86 & 1808 & 11.86 & 22.08 & $32,241.22$ & 322.17 & 38.09 \\
\hline $\begin{array}{l}12: 36 \\
12.37\end{array}$ & 33 & $\begin{array}{l}19.54 \\
10.57\end{array}$ & $\begin{array}{l}4.04 \\
3.98\end{array}$ & 40835 & $\begin{array}{l}59.9 \\
58\end{array}$ & 63 & (77 & 30.10 & (399.10 & 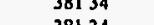 & 34.10 & 03.40 & 0.17 & 586 & 19.18 & 11.86 & 22.14 & $28,817.33$ & 328.20 & 38.09 \\
\hline $\begin{array}{l}12.37 \\
12.38\end{array}$ & 3.1 & 19.57 & 3.98 & 4983.3 & 58 & 0.5 & $4 \pi$ & 310.16 & 399.16 & (381.34 & 34.10 & 63.40 & 0.17 & 5.86 & 16.99 & 12.03 & 21.81 & $27,305.09$ & 317.79 & 38.09 \\
\hline 12:38 & 3.2 & 19.61 & 3.88 & 1135.7 & 56.7 & 6.5 & 477 & 510.16 & 472.4 & 452.05 & 33,60 & 64.20 & 0.17 & 5.86 & 17.53 & 12.25 & 21.26 & $6,222.61$ & 310.66 & 3809 \\
\hline 12:39 & 34 & $19.6 !$ & 3.82 & 5937.7 & 54.3 & 6.5 & 477 & 510.16 & 472.4 & 452.05 & 33.60 & 64.20 & 0.17 & 5.86 & 1863 & 12.25 & 20.93 & 32.533 .25 & 297.52 & 3809 \\
\hline 12:40 & 34 & 19.62 & 3.73 & 5069.5 & 57.7 & 65 & 477 & 510.16 & 472.4 & 45205 & 33.60 & 64.20 & 0.17 & 5.86 & 1863 & 12.30 & 20.44 & $27,776,30$ & 316.14 & 3800 \\
\hline 12:41 & 3.3 & 19.63 & 3.72 & 5560.6 & 58.2 & 6.5 & 477 & 510.16 & 435.04 & 415.62 & 34.10 & 62.70 & 0.17 & 586 & 1808 & 12.36 & 20.38 & 30.467 .08 & 318.88 & 3809 \\
\hline 12:42 & 3.5 & 19.6 & 3.77 & 5610.7 & 62.4 & 6.5 & 477 & 510.16 & 435.04 & 41562 & 34.10 & 62.70 & 017 & 5.86 & 1918 & 1219 & 2066 & 3074159 & 34190 & 3809 \\
\hline 12:43 & 3.8 & 1957 & 3.88 & 5256.2 & 61.8 & 6.5 & 477 & 510.16 & 435.04 & 415.62 & 34.10 & 62.70 & 0.17 & 5.86 & 2082 & 12.03 & 21.26 & 2879925 & 33861 & 380 \\
\hline $12: 44$ & 3.3 & 19,35 & 4.04 & 6056.7 & 63.2 & 65 & 477 & 510.16 & 436.31 & 415.75 & 34.90 & 6180 & 0.17 & 5.86 & 1808 & 1102 & 204 & 3318526 & 34628 & 38.09 \\
\hline 12.45 & 3.1 & 19.52 & 4.18 & 67146 & 66.6 & 6.5 & 477 & 510.16 & 436.31 & 415.75 & 34.90 & 61.80 & 0.17 & 5.86 & 1699 & 1175 & 290 & 3678996 & 36490 & 38.09 \\
\hline 12.46 & 3.1 & 19.57 & 402 & 57978 & 666 & 65 & 477 & 510.16 & 43631 & 415.75 & 34.90 & 6180 & 0.17 & 586 & 1699 & 1203 & 203 & 317673 & 3699 & 3800 \\
\hline $12 \cdot 47$ & 3 & 1955 & 4.02 & 61863 & 658 & 6.5 & 477 & 510.16 & 43136 & 41170 & 34.40 & 6060 & 0,77 & 586 & 1699 & 1192 & 230 & 3385,35 & 30050 & $\begin{array}{l}38.09 \\
3809\end{array}$ \\
\hline 12.88 & 3.1 & 19.58 & 4.1 & 54742 & 772 & 65 & 477 & 510.16 & 43136 & 41170 & 34.40 & 6060 & 0.7 & 586 & 1600 & 1208 & 226 & 209360 & 3996 & 3809 \\
\hline $12: 49$ & $\begin{array}{l}3.1 \\
33\end{array}$ & 19.6 & $\begin{array}{l}4.1 \\
4.05\end{array}$ & 63413 & 74.8 & 65 & 477 & 510.16 & 431.36 & 411.70 & 3440 & 60.60 & 0.17 & 386 & 108 & 1210 & 2010 & 347462 & (4) & 38.09 \\
\hline 12.50 & 35 & 19.59 & $\begin{array}{l}4.00 \\
4.09\end{array}$ & 5908.7 & 74.3 & 6.5 & 477 & $\$ 10.16$ & 440,63 & 416.49 & 37.40 & 60,40 & 0.17 & 5.86 & 19.18 & 12.14 & 224 & 307136 & . & 38.09 \\
\hline 12.51 & $\begin{array}{l}3.5 \\
3.7\end{array}$ & 9.997 & $\begin{array}{l}4.09 \\
4.14\end{array}$ & 5584.7 & 70.3 & 6.5 & 477 & $\$ 10.16$ & 440.63 & 416.49 & 37.40 & 60.40 & 0.17 & 5.86 & 20.27 & 1203 & 226 & 305913 & 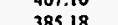 & 38.09 \\
\hline 12.52 & 3.7 & 9.62 & $\begin{array}{l}4.14 \\
3.98\end{array}$ & 5645.5 & 65.6 & 6.5 & 477 & 510.16 & 440.63 & 416.49 & 3740 & 60.40 & 0.17 & 586 & 20.27 & 1230 & 218 & 3092? & 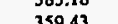 & 38.09 \\
\hline 12.53 & 36 & 19.68 & 389 & 6192 & 67.1 & 6.5 & 477 & 510.16 & 432.49 & 409.06 & 37.20 & 59.60 & 0.17 & $\begin{array}{l}5.00 \\
586\end{array}$ & 1972 & 12.63 & 2131 & 33.926 .59 & 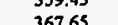 & 8809 \\
\hline 12.54 & 3.7 & 19.66 & 3.84 & 5986.5 & 64.2 & 6.5 & 477 & 510.16 & 432.49 & 409.06 & 37.20 & 59.60 & 0.17 & 5.86 & 20.27 & 12.52 & 2104 & $32,800,63$ & 3576 & T.09 \\
\hline $12: 55$ & 3.1 & 20.24 & $\begin{array}{l}3.04 \\
1.67\end{array}$ & 4102.5 & 44 & 6.5 & 477 & $\$ 10.16$ & 432.49 & 409.06 & 37.20 & 5960 & a.17 & $\begin{array}{l}3.00 \\
586\end{array}$ & 16.99 & 1570 & 0.04 & 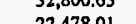 & 年, & $\begin{array}{r}38.09 \\
3800\end{array}$ \\
\hline $12: 56$ & 3 & 20.94 & 0.1 & 62.2 & 21.5 & 6.5 & 477 & 510.16 & 512.03 & 487.11 & 35.40 & 59.10 & 0.17 & $\begin{array}{l}1.80 \\
5.86\end{array}$ & 10.48 & 19.53 & 0.55 & 34080 & $\begin{array}{l}211.08 \\
11780\end{array}$ & $\begin{array}{l}38.09 \\
38.09\end{array}$ \\
\hline $12: 57$ & 6.9 & 20.96 & 0.09 & 3.5 & 22.3 & 6.5 & 477 & $\$ 10.16$ & $\$ 12.03$ & 487.11 & 35.40 & 59.10 & 0.17 & 5.86 & 37.81 & 19.64 & 049 & 19.18 & 122.18 & 3809 \\
\hline 12:58 & 17.3 & 20.88 & 0.12 & 19.7 & 24.3 & 65 & 477 & 510.16 & 512.03 & 487.11 & 35.40 & 39.10 & 0.17 & 5.86 & 94.79 & 19.20 & 0.66 & 107.94 & 133.14 & 38.09 \\
\hline $12: 59$ & 15.7 & 2083 & 0.12 & 60.6 & 23.7 & 6.5 & 477 & 510.16 & 478.84 & 453.48 & 3680 & 58.80 & 0.17 & 3.86 & 86.02 & 18.93 & 0.66 & 332.03 & 129.85 & 38.09 \\
\hline $13: 00$ & 10.4 & 2082 & 0.13 & 44 & 24.9 & 6.5 & 477 & $\$ 10.16$ & 478.84 & 453.48 & 36.80 & 58.80 & 017 & 586 & 56.98 & 18.88 & 0.71 & 24108 & 13643 & 3809 \\
\hline $13: 01$ & 8.2 & 2079 & 0.14 & 43.9 & 26.2 & 6.5 & 477 & 510.16 & 478.84 & 453.48 & 3680 & 5880 & 0.17 & 5.86 & 493 & 1877 & 077 & 240.53 & 14355 & 3809 \\
\hline $13: 02$ & 6.9 & 2078 & 0.16 & 42.4 & 268 & 6.5 & 477 & $\$ 10.16$ & 445.09 & 421.38 & 3690 & 58.40 & 0.17 & 586 & 37.81 & 18.66 & 088 & 2331 & 1684 & 38.09 \\
\hline 13.03 & 6 & 20.78 & 013 & 33.8 & 26.9 & 6.5 & 477 & 310.16 & 445.09 & 42138 & 36.90 & 5840 & 0.17 & 5.86 & 32.87 & 1866 & 0.71 & 18819 & 17439 & 38.09 \\
\hline $13: 04$ & 5.6 & 20.77 & 0.11 & 34 & 26.9 & 6.5 & 477 & 51016 & 445.09 & 421.38 & 36.90 & $\begin{array}{l}58.40 \\
58.40\end{array}$ & 0.17 & $\begin{array}{l}.00 \\
5.86\end{array}$ & 30.68 & $\begin{array}{l}18.00 \\
18.60\end{array}$ & 0.60 & 186.29 & $\begin{array}{l}147.38 \\
147.39\end{array}$ & $\begin{array}{l}38.09 \\
3809\end{array}$ \\
\hline 13.05 & 5.3 & 2076 & 0.11 & 33.3 & 269 & 6.5 & 477 & $\$ 10.16$ & 453.65 & $\begin{array}{l}430.04 \\
430.04\end{array}$ & $\begin{array}{l}30.50 \\
36.50\end{array}$ & $\begin{array}{l}57.40 \\
57.50\end{array}$ & 0.17 & $\begin{array}{l}3.80 \\
586\end{array}$ & 29.04 & $\begin{array}{l}18.00 \\
1859\end{array}$ & 0.60 & $\begin{array}{l}100.29 \\
182.45\end{array}$ & $\begin{array}{l}147,39 \\
147.39\end{array}$ & $\begin{array}{r}38.09 \\
38.09\end{array}$ \\
\hline 13.06 & 5.2 & 20.75 & 011 & 33.5 & 268 & 6.5 & 477 & 510.16 & 453.65 & $\begin{array}{l}430.04 \\
430.04\end{array}$ & $\begin{array}{l}30.50 \\
36.50\end{array}$ & 57.50 & $\begin{array}{l}0.17 \\
0.17\end{array}$ & $\begin{array}{l}3.80 \\
5.86\end{array}$ & $\begin{array}{l}29.04 \\
2849\end{array}$ & 1849 & 0.00 & $\begin{array}{l}882.49 \\
183.55\end{array}$ & $\begin{array}{l}147.39 \\
14684\end{array}$ & $\begin{array}{r}38.09 \\
38.09\end{array}$ \\
\hline 13.07 & 5.2 & 20.73 & 0.11 & 36.9 & 26.9 & 6.5 & 477 & 51016 & 453.65 & 430.04 & 3650 & 57. & 017 & 5.8 & 28.49 & 18.38 & 0.60 & 202.18 & $\begin{array}{l}140.39 \\
147.39\end{array}$ & 38.09 \\
\hline 13.08 & 4.4 & 2053 & 1.45 & 238.9 & 33.6 & 6.5 & 477 & 510.16 & 428 & 407.08 & 35 . & 56 & 0.1 & 5.8 & 24 & 17.29 & 7.94 & 1308.96 & 184,10 & 38.09 \\
\hline $13: 09$ & 23 & 19.61 & 4.08 & 4472.5 & 50.4 & 6.5 & 477 & $\$ 10.16$ & 428 & 407.08 & 35. & 56. & 0.1 & s. & 12.60 & 1225 & 22.35 & $24,505.27$ & 276.15 & 38.09 \\
\hline $\begin{array}{l}13: 10 \\
10\end{array}$ & 24 & 1958 & $\begin{array}{l}4.00 \\
4.23\end{array}$ & 5825 & 49.1 & 6.5 & $\begin{array}{l}477 \\
477\end{array}$ & 510.16 & 428.6 & 407.08 & 3590 & 5660 & 01 & 5.8 & 13.15 & 1208 & 23.18 & $\begin{array}{l}42,030.21 \\
31,915.76\end{array}$ & 269.02 & $\begin{array}{l}38.09 \\
38.09\end{array}$ \\
\hline $13 \cdot 11$ & 3.5 & 19.56 & 4.09 & 54262 & 515 & 6.5 & 477 & 51016 & 41636 & 394.95 & 36.30 & 62.70 & 0.1 & $\begin{array}{l}380 \\
586\end{array}$ & 19.18 & 11.97 & 22.41 & 29,73069 & $\begin{array}{l}287.02 \\
282.17\end{array}$ & 3809 \\
\hline $13: 12$ & 4.2 & 19.65 & 385 & 4619.9 & 50.3 & 6.5 & 477 & 510.16 & 41636 & 394.95 & 3630 & 62.70 & 0.1 & 5.86 & 23.01 & 12.47 & 21.09 & 25,31289 & 275.60 & 3809 \\
\hline $13: 13$ & 53 & 19.66 & 381 & 5277 & 43.4 & 65 & 477 & 510.16 & 416.36 & 39495 & 3630 & 62.70 & 017 & 586 & 29.04 & 12.52 & 20.88 & $28,913.21$ & 237.79 & 38.09 \\
\hline $13: 14$ & 64 & 1959 & 399 & 5181.4 & 484 & 65 & 477 & 510.16 & 419.26 & 39783 & 36.20 & 67.70 & 0.17 & 5.86 & 3507 & 12.14 & 21.85 & 28,38941 & 265.19 & 38.09 \\
\hline 1315 & 7.3 & 19.59 & 3.94 & 5245.2 & 445 & 6.5 & 477 & 51016 & 41926 & 39783 & 3620 & 67.70 & 0.17 & 586 & 40.00 & 12.14 & 21.59 & 28,73898 & 24382 & 3809 \\
\hline $13: 16$ & 8 & 1964 & 3.79 & 4591.9 & 51.9 & 6.5 & 477 & 510.16 & 419.26 & 397.83 & 36.20 & 67.70 & 0.17 & 586 & 4383 & 1241 & 2077 & 25.15948 & 28437 & 3809 \\
\hline $13: 17$ & 8.6 & 1966 & 378 & 4401.3 & 57.8 & 65 & 477 & 51016 & 46483 & 441.07 & 3620 & 70.40 & 0.17 & 586 & 47.12 & 1252 & 2071 & $24,115,16$ & 316,69 & 38.09 \\
\hline 13.18 & 92 & 1968 & 374 & 4871 & 37.7 & 65 & 477 & 51016 & 46483 & 44107 & 3620 & 70.40 & 0.17 & 586 & 50.41 & 1263 & 2040 & $26,688.70$ & 31614 & 3809 \\
\hline 13:19 & 9.7 & 1972 & 368 & 5291.8 & 362 & 63 & 477 & 510.16 & 46483 & $44 ! 07$ & 3620 & 70.40 & 0.17 & 5.86 & 53.15 & 12.85 & 20.16 & 28.994 .30 & 3079 & 3800 \\
\hline 13.20 & 101 & 19.71 & 3.75 & 5229.5 & 55.4 & 65 & 477 & 510.16 & 437.8 & 412.62 & 38.30 & 73.10 & 0.17 & 58 & 55.34 & 12.79 & 20.55 & $28,652.95$ & 30354 & 38.09 \\
\hline 13.21 & 104 & 19.63 & 391 & $\$ 492.9$ & 54.7 & 65 & 477 & 51016 & 437 & 412.62 & 3830 & 73. & 0. & s. & 56.98 & 12 & 2142 & 30,09615 & 299.71 & 38.09 \\
\hline $13: 22$ & 11.2 & 19.71 & 3.61 & 45215 & 46.7 & 6.5 & 477 & 510 & 43 & 412 & 38 & 73 & 0 & 5 & 61. & 12 & 19.78 & 3.75 & 255.87 & 38.09 \\
\hline $13: 23$ & 116 & 1972 & 355 & 44571 & 46.5 & 65 & 47 & SIC & & & 36 & & 0 & 5 & & 12 & 19 & & 25478 & 3809 \\
\hline 13.24 & 12 & 1976 & 348 & 41761 & $\begin{array}{l}48.3 \\
48.3\end{array}$ & 65 & 47 & 310 & & 40 & 36 & 74 & 0 & & & & 19 & & 26464 & 38.09 \\
\hline $13: 25$ & 124 & 19.76 & 3.5 & 4609.3 & 51 & 65 & 47 & 51016 & & 40 & 36 & 74 & 0 & 3 & 67 & 13 & 1918 & & 27943 & 3809 \\
\hline 1326 & 13 & 1977 & 353 & 50273 & 478 & 65 & 477 & $\$ 10.16$ & 510.55 & 48258 & 3740 & 73. & 01 & 58 & 712 & 1312 & 1934 & 27,54503 & 26190 & 3809 \\
\hline 1327 & 135 & 1975 & 363 & 45004 & 536 & 65 & 477 & 51016 & 510.55 & 482.58 & 3740 & 7390 & 017 & $\begin{array}{l}586 \\
586\end{array}$ & 73.97 & 1301 & $\begin{array}{l}1938 \\
1989\end{array}$ & $\begin{array}{l}24,658.14 \\
\end{array}$ & 293.68 & 3809 \\
\hline
\end{tabular}


Table O-1 Calentanted furmace outlet offess comporitions for N8O-IV end N8O-NV-Mod (continned).

\begin{tabular}{|c|c|c|c|c|c|c|c|c|c|c|c|c|c|c|c|c|c|c|c|c|}
\hline ים & & ench Out & et Dry vo & $5 \%$ / ppm & a) & Wet (b) & Quench Outlet (c) & Quench orviet & Quench Air (d) & Quench Air & Temp. Quench & h Temp. at & Dilution & Dilution & Furnece Outl & let Offear $\mathrm{Co}_{0}$ & ampocition (we & et basi & & \\
\hline TMEE (a) & NOx $(\mathrm{gP}$ & $\frac{02(36)}{1096}$ & $\frac{\cos (96}{357}$ & $\mathrm{CO}(\mathrm{ppm})$ & $\frac{\mathrm{SO} 2(\mathrm{ppr}}{510}$ & {$[\mathrm{H} 2 \mathrm{O}(\%)$} & ) Fowrate (decem) & Flowrzte (mectm) & Flownte (mactin & Flowrate (wrefin & $\operatorname{Air}(\bar{C})(c)$ & $\frac{\text { Fumzec outlet }}{70 \%}$ & Factor & Factor (n) & $\mathrm{NOX}(\mathrm{ppm})$ & $02(\mathrm{~h})$ & $\mathrm{CO2}$ & $\mathrm{CO}(\mathrm{pg} \mathrm{pm})$ & $\mathrm{SO2}(\mathrm{ppm})$ & $\mathrm{H} 2 \mathrm{O}$ \\
\hline $\begin{array}{l}13: 28 \\
13: 00\end{array}$ & 14.1 & 19.76 & 3.57 & 30033 & $\begin{array}{l}15.9 \\
5.9\end{array}$ & 6.3 & 477 & 310.16 & 310.35 & 482.58 & 37,40 & 73.90 & 0.17 & 5.86 & 77.26 & 13.07 & 19.56 & $22,042.42$ & 28437 & 38.09 \\
\hline $\begin{array}{l}13: 99 \\
13: 30\end{array}$ & 17.7 & $\begin{array}{l}19.8 \\
19.82\end{array}$ & 3.46 & 39307 & 54.9 & $\begin{array}{l}6.3 \\
65\end{array}$ & 47 & 510.10 & $\begin{array}{l}443.38 \\
45.58\end{array}$ & 418.74 & 39.20 & 72.50 & 0.17 & 5.86 & 86.02 & 13.29 & 18.96 & $21,855.54$ & 298.61 & 38.09 \\
\hline 13.31 & 178 & 10.87 & 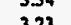 & , & 50 & 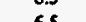 & (11 & . & 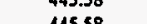 & & 39.20 & 72.50 & 0.16 & 2.80 & 96.98 & 13.40 & 18.30 & $21,586.01$ & 282.72 & 38.09 \\
\hline & & & S.2. & 2000.1 & 26.9 & 0.5 & 47 & 310.10 & 445.38 & 41874 & 39.20 & 72.50 & 0.17 & 5.86 & 98.08 & 13.67 & 17.70 & $19,615.73$ & 289.84 & 38.09 \\
\hline $13: 32$ & 18.1 & 19.88 & 3.26 & 3784.3 & 55.8 & 6.5 & 477 & 510.16 & 425,41 & 400,42 & 38.70 & 71.00 & 0.17 & 5.86 & 99.17 & 13.73 & 17.86 & $20,734.56$ & 311.21 & 38.09 \\
\hline 13:33 & 19.1 & 19.86 & 3.41 & 3743.6 & 57.7 & 6.5 & 477 & 510.16 & 425.41 & 400.42 & 38.70 & 71.00 & 0.17 & 5.86 & 104.65 & 1362 & 18.68 & $20,511.56$ & 316.14 & 3809 \\
\hline 13:34 & 22.1 & 19.89 & 3.09 & 2860.9 & 36.8 & 6.5 & 477 & 510.16 & 425.41 & 400,42 & 38.70 & 71.00 & 0.17 & 5.86 & 121.09 & 13.78 & 16.93 & $15,675.16$ & 201.63 & 38.09 \\
\hline $16: 31$ & 0.6 & 19.83 & 3.15 & 4904.3 & 36.8 & 5.74 & 447 & 474.22 & 374.96 & 356.83 & 35.30 & 83.20 & 0.28 & 3.59 & 2.03 & 15.96 & 10.66 & $16,595.83$ & 124.53 & 20,61 \\
\hline $16: 32$ & 0.7 & 19.87 & 3.12 & 4390.1 & 36.6 & 5.74 & 447 & 474.22 & 394.28 & 373.52 & 36.70 & 81.40 & 0.28 & 3.59 & 237 & 16.09 & 10.56 & 1485581 & 123.85 & 20.61 \\
\hline $16: 33$ & 0.8 & 19.87 & 3.14 & 4127 & 37 & 5.74 & 447 & 474.22 & 394.28 & 373.52 & 36.70 & 81.40 & 0.28 & 3.59 & 2.71 & 16.09 & 1063 & $13,965.50$ & 125.21 & 20.61 \\
\hline $16: 34$ & 0.9 & 19.86 & 3.14 & 1093.1 & 366 & 5.74 & 447 & 474.22 & 394.28 & 373.52 & 36.70 & 81.40 & 0.28 & 3.59 & 3.05 & 16.06 & 10.63 & $13,850.78$ & 123.85 & 20.61 \\
\hline $16: 35$ & 1 & 19.87 & 3.12 & 4521.4 & 35.1 & 5.74 & 447 & 474.22 & 359.11 & 342.41 & 34.70 & 79.30 & 0.28 & 3.59 & 3.38 & 16.09 & 10.56 & $15,300.12$ & 118.78 & 20.61 \\
\hline $16: 36$ & 1.1 & 19.86 & 3.14 & 4082.4 & 34 & 5.74 & 447 & 474.22 & 359.11 & 342.41 & 34.70 & 79.30 & 0.28 & 3.59 & 3.72 & 16.06 & 10.63 & $13,814,57$ & 115.05 & 20.61 \\
\hline $16: 37$ & 1.2 & 19.86 & 3.11 & 3915.3 & 33.2 & 5.74 & 447 & 474.22 & 359.11 & 342.41 & 34.70 & 79.30 & 0.28 & 3.59 & 4.06 & 16.06 & 10.52 & $13,249.12$ & 112.35 & 20.61 \\
\hline $16: 38$ & 1.3 & 19.87 & 3.09 & 3767.4 & 32.6 & 5.74 & 447 & 474.22 & 346.93 & 329.41 & 36.00 & 78.50 & 0.28 & 3.59 & 4.40 & 16.09 & 10.46 & $12,748.63$ & 110.32 & 20.61 \\
\hline $16: 39$ & i.s & 19.87 & 3.11 & 3806.2 & 32.5 & 5.74 & 447 & 474.22 & 346.93 & 329.41 & 36.00 & 78.50 & 0.28 & 3.59 & 5.08 & 1609 & 1052 & 2879.93 & 10998 & 2061 \\
\hline $16: 40$ & 2 & 19.85 & 3.14 & 4049 & 33 & 5.74 & 447 & 474.22 & 346.93 & 329.41 & 36.00 & 78.50 & 0.28 & 3.59 & 6.77 & 16.03 & 10.63 & $13,701.55$ & 111.67 & 20.61 \\
\hline $16: 41$ & 2 & 19.9 & 3.05 & 4000.2 & 32.1 & 5.74 & 447 & 474.22 & 360.17 & 341.43 & 36.50 & 77.70 & 0.28 & 3.59 & 6.77 & 16.19 & 10.32 & $13,536.41$ & 108.62 & 20.61 \\
\hline $16: 42$ & 2.2 & 19.88 & 3.09 & 4197 & 32.5 & 5.74 & 447 & 474.22 & 360.17 & 341.43 & 36.50 & 77.70 & 0.28 & 3.59 & 7.44 & 16.13 & 10.46 & $14,202.37$ & 109.98 & $\begin{array}{l}20.61 \\
20.61\end{array}$ \\
\hline $16: 43$ & 2.6 & 19.88 & 3.06 & 3820.8 & 33.6 & 5.74 & 447 & 474.22 & 360.17 & 341.43 & 36.50 & 77.70 & 0.28 & 3.59 & 8.80 & 16.13 & 10.35 & $12,929.34$ & 113.70 & 20.61 \\
\hline $16: 44$ & 2.4 & 19.9 & 2.97 & 3839.2 & 32.1 & 5.74 & 447 & 474.22 & 359.6 & 345.46 & 32.40 & 77.00 & 0.28 & 3.59 & 8.12 & 16.19 & 10.05 & $12,991.60$ & 10862 & 20.61 \\
\hline $16: 45$ & 2.4 & 19.95 & 2.87 & 3766.3 & 32.2 & 5.74 & 447 & 474.22 & 359.6 & 345.46 & 32.40 & 77.00 & 0.28 & 3.59 & 8.12 & 16.36 & 9.71 & $12,744.91$ & 108.96 & 20.61 \\
\hline $16: 46$ & 1.5 & 19.97 & 2.81 & 3558.8 & 33 & 3.74 & 447 & 474.22 & 359.6 & 345.46 & 32.40 & 77.00 & 0.28 & 3.59 & 5.08 & 16.43 & 9.51 & $12,042.74$ & 111.67 & 20.61 \\
\hline $16: 47$ & 1.6 & 19.99 & 2.71 & 3862.2 & 33.2 & 5.74 & 447 & 474.22 & 337.95 & 325.41 & 31.70 & 76.90 & 0.28 & 3.59 & 5.41 & 1650 & 9.17 & $13,059.43$ & 112.35 & 20.61 \\
\hline $16: 48$ & 1.3 & 20.01 & 2.59 & 4127.6 & 35.8 & 5.74 & 447 & 474.22 & 337.95 & 325.41 & 31.70 & 76.90 & 0.28 & 3.59 & 4.40 & 16.57 & 8.76 & $13,967.53$ & 121.14 & 20.61 \\
\hline $16: 49$ & 0.9 & 20.03 & 2.51 & 4031.7 & 44.3 & 5.74 & 447 & 474.22 & 337.95 & 325.41 & 31.70 & 76.90 & 0.28 & 3.59 & 3.05 & 16.63 & 8.49 & $13,643.01$ & 149.91 & 20.61 \\
\hline $16: 50$ & 1.3 & 20 & 2.56 & 3854.9 & 48.7 & 5.74 & 447 & 474.22 & 396.84 & 344.28 & 31.10 & 77.90 & 0.28 & 3.59 & 4.40 & 16.53 & 8.66 & $13,044.73$ & 164.80 & 20.61 \\
\hline $16: 51$ & 1.7 & 19.96 & 2.73 & 4059.5 & 51.8 & 5.74 & 447 & 474.22 & 356.84 & 344.28 & 31.10 & 77.90 & 0.28 & 3.59 & 5.75 & 16.40 & 9.24 & $13,737.08$ & 175.29 & 20.61 \\
\hline $16: 52$ & 1.8 & 19.88 & 3.05 & 5100.6 & 44.7 & 5.74 & 447 & 474.22 & 356.84 & 344.28 & 31.10 & 77.90 & 0.28 & 3.59 & 6.09 & 16.13 & 10.32 & $17,260.09$ & 151.26 & 20.61 \\
\hline $16: 53$ & 1.6 & 19.86 & 3.22 & 4771.5 & 40 & 5.74 & 447 & 474.22 & 338.94 & 326.47 & 31.60 & 76.70 & 0.28 & 3.59 & 5.41 & 16.06 & 10.90 & $16,146.44$ & 135.36 & 2061 \\
\hline $16: 54$ & 1.8 & 19.85 & 3.27 & 5156 & 40.1 & 5.74 & 447 & 474.22 & 338.94 & 326.47 & 31.60 & 76.70 & 0.28 & 3.59 & 6.09 & 16.03 & 11.07 & $17,447.56$ & 135.70 & 20.61 \\
\hline $16: 55$ & 2.1 & 19.83 & 3.39 & 5885.5 & 40 & 5.74 & 447 & 474.22 & 338.94 & 326.47 & 31.60 & 76.70 & 0.28 & 3.59 & 7.11 & 15.96 & 11.47 & $\begin{array}{l}19,941.00 \\
19,916.14\end{array}$ & 135,36 & 20.61 \\
\hline Avg. H2 & 1.532 & 19.9 & 3.0056 & 4227.52 & 36.86 & 5.74 & & 474.2202419 & & 341.6781723 & 33.896 & & 0.27855 & 3.59 & 5.184187 & 16.194339 & 10.170752 & 14305.649 & 124.73181 & 20.6066 \\
\hline $\begin{array}{l}\text { a. Data ob } \\
\text { b. Moistur } \\
\text { c. Source } \\
\text { d. Quench } \\
\text { e. Quench } \\
\text { f. Calculat } \\
\text { g. Caleulat } \\
\text { h. Caleulat }\end{array}$ & $\begin{array}{l}\text { ga volum } \\
\text { air hown } \\
\text { air tempe } \\
\text { ted from } \\
\text { ted from } t \\
\text { ted from }\end{array}$ & $\begin{array}{l}\text { thre, ches } \\
\text { ws end en } \\
\text { o quench } \\
\text { e quench }\end{array}$ & 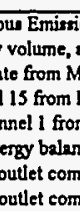 & $\begin{array}{l}\text { ions Moni } \\
\text { as thown } \\
\text { uMT data } \\
\text { Data Acq } \\
\text { on DAS. } \\
\text { nces at the } \\
\text { mporition } \\
\text { mporition }\end{array}$ & $\begin{array}{l}\text { Uench sec } \\
\text { the dilut } \\
\text { the dilut }\end{array}$ & $\begin{array}{l}\text { CEMS) } \\
\text { particul } \\
\text { (DAS). } \\
\text { as tho o } \\
\text { factor, } \\
\text { factor, }\end{array}$ & $\begin{array}{l}\text { data provided by } \\
\text { ate/metalo samp }\end{array}$ & $\begin{array}{l}\text { Entropy perzonsel. } \\
\text { is period (MMT) } \\
\text { rate divided by the fu } \\
\text { un conversions from } \\
\text { the amount of oxyge }\end{array}$ & $\begin{array}{l}\text { asce outlet } \\
\text { dry to a wet } \\
\text { added by th }\end{array}$ & ch air. & & & & & & & & & & \\
\hline
\end{tabular}


Table O.5 Calculated furmace outlet offgas conpositons for M60 and N80.1V.Mod.2.

\begin{tabular}{|c|c|c|c|c|c|c|c|c|c|c|c|c|c|c|c|c|c|c|c|}
\hline TIME (2) & $\frac{1}{N O x(00)}$ & Quench Out & 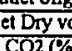 & $\frac{1 \mathrm{ppm}}{\cos }$ & 502 & Wet (b) & Quench Oudet (c & Quench outet & Quench Air (d) & & Temp. Quenc & Dilution & Dilution & Fumbec Or & untet Offgas & $\frac{a \mathrm{Compo}}{\mathrm{COP}^{2}}$ & osition (wet b & basis \%)(g) & $4 \overline{20}$ \\
\hline$\frac{11 \mathrm{MLE}(2)}{1005}$ & NOxpp & pm) $02(\%)$ & $\frac{c 02 \%}{154}$ & $\frac{\mathrm{CO}(\mathrm{ppm}}{3060.8}$ & $\frac{\mathrm{OO} 2(\mathrm{ppm})}{3.3}$ & $\frac{\mathrm{H} 2 \mathrm{O}(\%)}{464}$ & Flownatc (dscefm) & & $\frac{\text { Fowrate (wacfin) }}{42527}$ & $\begin{array}{l}\text { Flowrate (wscfin) } \\
423.38\end{array}$ & & Factor & $\frac{\text { Factor }(A)}{555}$ & & $\frac{02(\mathrm{~h})}{1707}$ & $\mathrm{CO} 2$ & $\frac{\mathrm{CO}(\mathrm{ppm})}{1610922}$ & $\mathrm{SO2}(\mathrm{ppm}$ & $\frac{\mathrm{H} 20}{25.75}$ \\
\hline 10.06 & 27.6 & 2024 & 1.7 & 3699.7 & 2.9 & 464 & 513.00 & $\$ 37.96$ & 400.72 & 398.40 & 22.10 & 0.18 & 5.55 & 146.07 & 1622 & 9.00 & $19,580.59$ & 15.35 & 25.75 \\
\hline 10.07 & 281 & 2023 & 172 & 3659.3 & 2.9 & 4.64 & 513.00 & 537.96 & 40072 & 398.40 & 22.10 & 018 & 5.55 & 148.72 & 16.17 & 9.10 & $19,366.77$ & 15.35 & 25.75 \\
\hline 10.08 & 28.7 & 2022 & 1.75 & 36849 & 2.9 & 4.64 & 513.00 & 537.96 & 400.72 & 398.40 & 22.10 & 018 & 5.55 & 15189 & 16.11 & 9.26 & $19,502.26$ & 15.35 & 25.75 \\
\hline 1009 & 28 & 20.22 & 174 & 3993.2 & 3.1 & 464 & 513.00 & 537.96 & 419.26 & 41683 & 22.10 & 0.18 & 5.55 & 148.19 & 16.11 & 921 & $21,133.93$ & 16.41 & 25.75 \\
\hline 1010 & 24.1 & 20.27 & 164 & 4021.2 & 3.4 & 4.64 & 513.00 & 537.96 & 41926 & 416.83 & 22.10 & 0.18 & 5.55 & 127.55 & 1638 & 868 & $21,282.12$ & 17.99 & 25.75 \\
\hline 10.11 & 22.7 & 20.27 & 1.62 & 4770.9 & 4 & 464 & 513,00 & 537.96 & 419.26 & 416.83 & 22.10 & 018 & 5.55 & 120.14 & 16.38 & 8.57 & $25,249.89$ & 21.17 & 25.75 \\
\hline $10: 12$ & 246 & 20.25 & 1.67 & 4820.9 & 3.9 & 4.64 & 513.00 & 537.96 & 385.5 & 383.14 & 22.20 & 0.18 & 5.55 & 130.20 & 16.27 & 884 & $25,514.52$ & 20.64 & 25.75 \\
\hline $10: 13$ & 271 & 20.23 & 1.73 & 44656 & 3.6 & 4.64 & 513,00 & 537.96 & 385.5 & 383.14 & 22.20 & 0.18 & 5.55 & 14343 & 16.17 & 9.16 & $23,634.10$ & 1905 & 25.75 \\
\hline $10: 14$ & 28.2 & 20.22 & 1.75 & 3627.8 & 3.1 & 464 & $\$ 13.00$ & 537,96 & 385.5 & 383.14 & 22.20 & 0.18 & 5.55 & 149.25 & 16.11 & 9.26 & $19,200.06$ & 1641 & 25.75 \\
\hline 1015 & 30.5 & 20.15 & 1.81 & 3028.7 & 2.7 & 4.64 & 51300 & 537.96 & 397.6 & 395.03 & 22.30 & 0.18 & 5.55 & 161.42 & 15.74 & 9.58 & $16,029.33$ & 14.29 & 25.75 \\
\hline 10.16 & 30 & 20.16 & 1.77 & 23933 & 2 & 464 & 513.00 & 537.96 & 397.6 & 395.03 & 22.30 & 0.18 & 5.55 & 158.77 & 15.80 & 9.37 & $12,666.49$ & 10.58 & 25.75 \\
\hline $10 \cdot 17$ & 27.9 & 2029 & 1.58 & 2222.7 & 1.9 & 4.64 & 513.00 & 537.96 & 397.6 & 395.03 & 22.30 & 0.18 & 5.55 & 147.66 & 16.48 & 8.36 & $11,763.60$ & 10.06 & 25.75 \\
\hline 10.18 & 35.1 & 2015 & 1.9 & 1692.3 & 1.8 & 4.64 & 513.00 & 537.96 & 451,88 & 449.11 & 22.20 & 0.18 & 555 & 185.77 & 15.74 & 10.06 & $8,956.46$ & 9.53 & 25.75 \\
\hline 10.19 & 38.8 & 20.05 & 2.03 & 1661.5 & 2 & 4.64 & 513.00 & 537.96 & 451.88 & 449.11 & 22.20 & 0.18 & 5. & 205.35 & 15.21 & 1074 & $8,793.46$ & 10.58 & 25.75 \\
\hline $10 \cdot 20$ & 39.4 & 20.02 & 2.07 & 1483.8 & 1.6 & 4.64 & 513.00 & 537.96 & 451.88 & 449.11 & 22.20 & 0.18 & s. & 208.52 & 15.06 & 10.96 & $7,852.98$ & 8.47 & 25.75 \\
\hline $10: 21$ & 362 & 20.08 & 191 & 1390 & 1.5 & 464 & 513.00 & 537.96 & 501.56 & 497,65 & 22.70 & 0.18 & 5.55 & 191.59 & 15.37 & 10.11 & $7,356.55$ & $\begin{array}{l}0.94 \\
7.94\end{array}$ & 25.75 \\
\hline $10: 22$ & 35.6 & 20.09 & 1.97 & 1110.1 & 1.4 & 464 & 513.00 & 537.96 & 501.56 & 497.65 & 22.70 & 0.18 & 5.55 & 188.41 & 15.43 & 10.43 & $5,875.18$ & 7.41 & 25.75 \\
\hline $10: 23$ & 47.7 & 20.01 & 23 & 1966.9 & 3.2 & 464 & 513.00 & 537.96 & 501.56 & 497.65 & 22.70 & 0.18 & 5.55 & 252.45 & 15.00 & 12.17 & $10,409.78$ & 16.94 & 25.75 \\
\hline 10.24 & 76.7 & 19.55 & 2.63 & 4026.3 & 6.9 & 4.64 & 513.00 & 537.96 & 460.02 & 456.74 & 22.50 & 0.18 & 5.55 & 405.93 & 12.57 & 13.92 & $21,309.11$ & 36.52 & 25.75 \\
\hline $10: 25$ & 50.1 & 19.86 & 2.24 & $\begin{array}{l}1617.7 \\
\text { a }\end{array}$ & 2.6 & 4.64 & 513.00 & 537.96 & 460.02 & 456.74 & 22.50 & 0.18 & 5.55 & 265.15 & 14.21 & 11.86 & $8,561.64$ & 13.76 & 25.75 \\
\hline 10.26 & 46.3 & 19.87 & 2.22 & 1116.7 & 1.9 & 464 & 513.00 & 537.96 & 460.02 & 456.74 & 22.50 & 0.18 & 5. & 245.04 & 14.26 & 11.75 & $5,910.11$ & 10.06 & 25.75 \\
\hline 10:27 & 43.4 & 19.91 & 2.16 & 1099.3 & 1.8 & 4.64 & 513.00 & $\$ 37.96$ & 405.6 & 402.30 & 22.80 & 0.1 & 5. & 229.69 & 1447 & 11.43 & $5,818.02$ & 9.53 & 25.75 \\
\hline 10:28 & 41.6 & 19.88 & 2.2 & 1070.5 & 1.7 & 4.64 & 513.00 & 537.8 & 405.6 & 402.30 & 22.80 & 0.18 & s. & 220.17 & 14.31 & 11.64 & $5,665.60$ & 9.00 & 25.75 \\
\hline $10: 29$ & 42.1 & 19.83 & 2.29 & 1148.6 & 1.4 & 4.64 & 513.00 & 537,96 & 405.6 & 402.30 & 22.80 & 0.18 & 5.55 & 222.81 & 14.05 & 12.12 & $6,078.94$ & 7.41 & 25.75 \\
\hline $10: 30$ & 53.7 & 19.73 & 2.41 & 1289 & 1.6 & 4.64 & 513.00 & 53796 & 48132 & 47708 & 23.00 & 0.18 & 5.55 & 284.21 & 13.52 & 12.75 & $6,822.01$ & 8.47 & 25.75 \\
\hline $10: 31$ & 56.2 & 19.67 & 2.53 & 1317.4 & 1.8 & 4.64 & 513.00 & 537.96 & 481.32 & 477.08 & 23.00 & 0.18 & 5.55 & 297.44 & 13.20 & 13.39 & $6,972.31$ & 9.53 & 25.75 \\
\hline 10:32 & 62.5 & 19.58 & 2.65 & 1363.3 & 2 & 4.64 & 513.00 & 537.96 & 481.32 & 477.08 & 23.00 & 0.18 & 5.55 & 330.78 & 12.73 & 14.03 & $7,215.24$ & 10.58 & 25.75 \\
\hline 10.33 & 38.5 & 19.66 & 2.53 & 1527.2 & 1.8 & 4.64 & 513.00 & 537.96 & 444.45 & 440.39 & 23.10 & 018 & 5.55 & 30961 & 13.15 & 13.39 & $8,082.68$ & 9.53 & 2575 \\
\hline 10.34 & 50.9 & 19.74 & 2.4 & 1237.8 & 1.6 & 464 & 51300 & 537.96 & 444.45 & 440.39 & 23.10 & 0.18 & s. & 269.39 & 1357 & 12.70 & $6,551.03$ & 847 & 25.75 \\
\hline $10: 35$ & 45.1 & 19,79 & 2.27 & 1100.4 & 1.5 & 4.64 & 513.00 & 537.96 & 444,45 & 440.39 & 23.10 & 0.18 & 5. & 238.69 & 1384 & 12.01 & $5,823,84$ & 7.94 & 25.75 \\
\hline $10: 36$ & 38 & 19.86 & 2.07 & 1711.8 & 2 & 4.64 & 513.00 & 537.96 & 426.55 & 421.94 & 23.60 & 0.18 & 5.55 & 201.11 & 14.21 & 10.96 & 9,05967 & 10.58 & 25.75 \\
\hline $10: 37$ & 31.8 & 20.21 & 1.69 & 1497.4 & 1.6 & 4.64 & 513.00 & 537.96 & 426.55 & 421.94 & 23.60 & 0.18 & 555 & 168.30 & 16.06 & 8.94 & $7,924.96$ & 8.47 & 25.75 \\
\hline $10: 38$ & 40.3 & 19.97 & 2.07 & 1679.1 & 1.6 & 4.64 & 513.00 & 537.96 & 426.55 & 421.94 & 23.60 & 0.18 & 5.55 & 213.29 & 14.79 & 10.96 & $8,886.60$ & 8.47 & 25.75 \\
\hline $10: 39$ & 43.7 & 19.88 & 2.14 & 1601.2 & 1.5 & 4.64 & 513.00 & 537.96 & 453.58 & 448.83 & 23.50 & 0.18 & 5.55 & 231.28 & 14.31 & 11.33 & $8,474.32$ & 7.94 & 25.75 \\
\hline $10: 40$ & 45 & 19.85 & 2.15 & 18798 & 1.5 & 4.64 & 513.00 & 537.96 & 453.58 & 448.83 & 23.50 & 018 & 5.5 & 238.16 & 1416 & 11.38 & $9,948.80$ & 7.94 & 25.75 \\
\hline $10: 41$ & 46.6 & 19.86 & 2.16 & 1937.5 & 1.6 & 4.64 & 513.00 & 53796 & 453.58 & 448.83 & 23.50 & 0.18 & 5.55 & 246.63 & 1421 & 11.43 & 10,25418 & 8.47 & 25.75 \\
\hline $\begin{array}{l}10: 42 \\
1042\end{array}$ & 40.2 & 19.91 & 2.02 & 1822.2 & 1.6 & 4.64 & 513.00 & 537.96 & 456.13 & 451.81 & 23.20 & 0.18 & 5.5 & 212.76 & 14.47 & 10.69 & $9,643.96$ & $\begin{array}{l}8.47 \\
8.47\end{array}$ & 25.75 \\
\hline $10: 43$ & 60.3 & 1975 & 234 & 2232.4 & 3.5 & 464 & 513.00 & 537.96 & 456.13 & 451.81 & 23.20 & 0.18 & 5. & 319.14 & 13.63 & 12.38 & $11,814.93$ & 18.52 & 25.75 \\
\hline $10: 44$ & 45.3 & 19.92 & 2.04 & 2257.8 & 2.3 & 464 & 513 & 537.9 & 456.1 & 451.81 & 23. & 0.1 & $\therefore$ & 239.75 & 14.53 & 10.80 & & 12. & 25.75 \\
\hline 10.45 & 39.8 & 19.91 & 2.07 & 1.451.1 & 1.6 & 4.64 & 513 & 537 & 471 . & 466.44 & 23. & 0 & s. & 21064 & 14.47 & 10.96 & 7,6 & 8 & 25.75 \\
\hline $10: 46$ & 47.5 & 19.81 & 221 & 16722 & 1.6 & 4.64 & 513.0 & 537.9 & 471.0 & 466.44 & 23. & 01 & SS & 25139 & 13.94 & 11.70 & $8,850.09$ & 8.47 & 2575 \\
\hline $10: 47$ & 60.8 & 19.64 & 2.38 & 21038 & 1.9 & 4.64 & 513.0 & 537. & 471.0 & 466.44 & 23.30 & 0.18 & 5 & 321.78 & 13.04 & 12.60 & $11,134.32$ & 10.06 & 25.75 \\
\hline 10.48 & 47.9 & 19.8 & 2.22 & 1386.7 & 1.4 & 464 & 513 & 5 & 460. & 456.95 & 22.50 & 0.18 & 5. & 253.51 & 13.89 & 11.75 & 7,33908 & 7.41 & 25.75 \\
\hline $10: 49$ & $\$ 2.4$ & 1976 & 23 & 1148.4 & 1.4 & 464 & 513.00 & 537.96 & 460.23 & 456.95 & 22.50 & 0.18 & 5. & 277.33 & 13.68 & 12.17 & $6,077.88$ & 7.41 & 25.75 \\
\hline $\begin{array}{l}10: 50 \\
10: 50\end{array}$ & 54.2 & 19.71 & 2.33 & 1072.4 & 1.4 & 464 & 51300 & 537.96 & 460.23 & 456.95 & 22.50 & 0.18 & 5 & 286.85 & 13.42 & 1233 & $5,675.66$ & 7.41 & 25.75 \\
\hline $10: 51$ & 49.9 & 19.7 & 2.31 & 1249.8 & 1.3 & 4.64 & 513.00 & 53796 & 434.54 & 431.59 & 22.40 & 0.1 & 5. & 264.09 & 13.36 & 12.23 & $6,614.54$ & 688 & 25.75 \\
\hline 10.52 & 575 & 1964 & 2.44 & 12582 & 1.5 & 4.64 & 513 & 897 & 434 & 431.59 & 22. & 0 & $s$ & 30432 & 13.04 & 12.91 & 6,65 & 7.94 & 25.75 \\
\hline 1053 & 56.4 & 19.67 & 238 & 1360 & 1.5 & 464 & si & 537 & 43 & 431 & 22. & 0. & 5 & 298 & 13.20 & 12.60 & & 7.94 & 2575 \\
\hline 10.54 & $\begin{array}{l}0.4 \\
50\end{array}$ & 1977 & 2.23 & 11417 & 14 & 464 & 51 & & 458 & 455 & 22. & 0. & 5. & 264.62 & 1373 & 1180 & 6,0 & $\begin{array}{l}7.94 \\
741\end{array}$ & 25.75 \\
\hline 1055 & 41.1 & 20 & 1.93 & 928 & 1.8 & 464 & 513 & & & 455 & 22. & 0 & 5. & 217.52 & 14.95 & 1021 & $4,916.18$ & 9.53 & 25.75 \\
\hline $10: 56$ & 57.1 & 19.74 & 2.29 & 10438 & 2.1 & 464 & 51300 & 537. & 458.39 & 455 & 22.50 & 0.18 & 5 . & 302.20 & 13.57 & 1212 & $.5,524,29$ & 11.11 & 2575 \\
\hline $\begin{array}{l}10: 57 \\
\text {. }\end{array}$ & 53.2 & 19.77 & 2.29 & 1085.5 & 1.7 & 464 & $\$ 1300$ & 537.96 & 465.89 & 463.19 & 22.10 & 0 is & 5 & 281.56 & 13.73 & 1212 & $5,744.99$ & 900 & 2575 \\
\hline $10: 58$ & 566 & 1975 & 2.34 & 1365.3 & 1.8 & 464 & 513 & 537 & 465.89 & 463.19 & 22. & 0. & s. & 299.55 & 13.63 & 12.38 & 7,22582 & 953 & 2575 \\
\hline 1059 & 606 & 19.68 & 2.4 & 1458 & is & 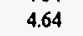 & 513 & רח & $\mathrm{Nes}$ & 463. & 22. & & & 72 & 1326 & 1307 & & & 25.75 \\
\hline 11.0 & 598 & 197 & 24 & iI. & 18 & 4 & & & & & 22 & 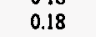 & & & 13.36 & 12 & & & 2575 \\
\hline 11.01 & 50.6 & 1987 & 2.25 & 100 & 2.2 & 4 & 51 . & & 43 & 43 & 22 & 0 & 5 & 26780 & 1426 & 11.91 & $5,333.76$ & 1164 & 25.75 \\
\hline $11: 02$ & 34 & 1983 & 2 & 2925.2 & 4 & 464 & 513 & & 437 & 434.31 & 22.8 & 0.18 & 5.5 & 17994 & 1405 & 10.58 & $15,481.56$ & 21.17 & 25.75 \\
\hline 11.03 & 32.4 & 20.14 & 1.72 & 35108 & 2.3 & 4.64 & 51300 & 537.96 & 46823 & 46442 & 2280 & 0.18 & 5 & 171.48 & 1569 & 910 & $18,580.84$ & 12.17 & 2575 \\
\hline 11.04 & 37.4 & 20.15 & 171 & 2029.8 & 2.3 & 464 & 51300 & 537.96 & 46823 & 46442 & 22.80 & $\begin{array}{l}018 \\
0.80\end{array}$ & 5. & 19794 & 1574 & 905 & $10,742.68$ & 1217 & 2575 \\
\hline 11.05 & 34.7 & 20.13 & 1.74 & & & 46 & & & N & & & 0 & 5 & 18365 & 15.64 & 9.21 & $15,274,10$ & 1535 & 2575 \\
\hline $11: 0$ & 688 & 19.5 & $\ddot{2}$ & 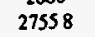 & J & 4 & & & & 45 & & & & & an & 12.86 & & 17 & 2575 \\
\hline 11:07 & 38.4 & 20.14 & $\begin{array}{l}179 \\
179\end{array}$ & 26593 & 33 & 464 & 51300 & 537.96 & $\begin{array}{l}455.49 \\
\end{array}$ & 452.24 & 22.50 & 018 & 55 & 20323 & 15.69 & 9.47 & $\begin{array}{l}4,07429 \\
\end{array}$ & 17,47 & 2575 \\
\hline 11.08 & 382 & 20.13 & 172 & 2140.8 & 2.6 & 464 & 51300 & 53796 & 45549 & 452.24 & 22.50 & 018 & 555 & 20217 & 1564 & 910 & 11,33014 & 1376 & 2575 \\
\hline & & & & 20062 & & & & & & & & & & & & & & & \\
\hline
\end{tabular}


Table Q.5 Caleulated furnace oullet offgas compositions for M60 and N80-IV-Mod-2 (continued).

\begin{tabular}{|c|c|c|c|c|c|c|c|c|c|c|c|c|c|c|c|c|c|c|c|}
\hline TME (a) & & 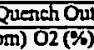 & $\frac{d e t \text { Dry vo }}{\cos (\%)}$ & 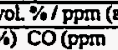 & $\overline{\mathrm{SO} 2(\mathrm{ppm})}$ & $\begin{array}{l}\text { Wet(b) } \\
\text { H2O (\%) }\end{array}$ & $\begin{array}{l}\text { Quench Outblet(c) } \\
\text { Flownte (dscfin) }\end{array}$ & $\begin{array}{l}\text { Quench Outlet } \\
\text { Flowrate (wsefm) }\end{array}$ & $\begin{array}{l}\text { Quench Air (d) } \\
\text { Flowrate (wacfin) }\end{array}$ & $\begin{array}{l}\text { Quench Air } \\
\text { Flowrate (wsefin) }\end{array}$ & $\begin{array}{l}\text { Temp. Quenc } \\
\text { Air (C) (e) }\end{array}$ & $\begin{array}{l}\text { Difution } \\
\text { Factor }\end{array}$ & $\begin{array}{l}\text { Dylution } \\
\text { Fastor (f) }\end{array}$ & $\frac{\text { Fumace Out }}{\text { NOx(ppm) }}$ & $\frac{\text { Uet Ollgas }}{\text { O2(h) }}$ & $\frac{\operatorname{comp}}{\mathrm{CO2}}$ & $\frac{\cos (\text { pet } b \text { ) }}{\operatorname{cosm}}$ & $\frac{2935)(\mathrm{g})}{\mathrm{SO2}(\mathrm{ppm}}$ & $\overline{\mathrm{H} 2 \mathrm{O}}$ \\
\hline $11: 10$ & $\frac{4.7}{42.3}$ & 2001 & 1.93 & 865.4 & 2.1 & 4.64 & 513.00 & 537.96 & 44579 & 442.46 & $\frac{201(1)}{22.60}$ & 0.18 & 5.55 & 22387 & $\frac{251019}{15.00}$ & $\frac{0.2}{10.21}$ & $\frac{c 0(\mathrm{ppomi})}{4,580.11}$ & $\frac{302 \mathrm{ppm}}{11.11}$ & $\frac{\mathrm{H} 2 \mathrm{O}}{25.75}$ \\
\hline $11: 11$ & 43.5 & 19.99 & 1.99 & 598.6 & 1.7 & 4.64 & $\$ 13.00$ & 537.96 & 445.79 & 442.46 & 22.60 & 0.18 & 5.55 & 230.22 & 1490 & 10.53 & 3,16808 & 900 & 25.75 \\
\hline $11: 12$ & 43.8 & 19.99 & 1.99 & 516.1 & 17 & 4.64 & 513.00 & 537.96 & 432.28 & 429.05 & 22.60 & 0.18 & s.s5 & 231.81 & 14.90 & 10.53 & $2,731.45$ & 9.00 & 25.75 \\
\hline 11:13 & 40.8 & 20.06 & 1.94 & 482.4 & 1.5 & 464 & $\$ 13.00$ & 537.96 & 432.28 & 429.05 & 22.60 & 0.18 & 5.55 & 215.93 & 15.27 & 10.27 & $2,553.09$ & 7.94 & 25.75 \\
\hline 11:14 & 42.1 & 20.03 & 201 & 547.1 & 1.5 & 4.64 & 513.00 & 537.96 & 432.28 & 429.05 & 22.60 & 0.18 & 5.55 & 222.81 & 15.11 & 1064 & 2895.52 & 7.94 & 25.75 \\
\hline $11: 15$ & 43 & 19.97 & 2.04 & 509.1 & 1.9 & 4.64 & 513.00 & $\$ 37.96$ & 433.76 & 430.08 & 22.90 & 0.18 & 5.55 & 227.58 & 14.79 & 10.80 & $2,694,40$ & 10.06 & 25.75 \\
\hline $11: 16$ & 42.1 & 19.88 & 2.12 & 476.9 & 2.3 & 4.64 & 513.00 & 537.96 & 433.76 & 430.08 & 22.90 & 018 & 5.55 & 222.81 & 14.31 & 11.22 & 2523.98 & 12.17 & 25.75 \\
\hline i1:17 & 44.3 & 19.96 & 2.05 & 664.9 & 8.8 & 4.64 & 513.00 & 537.96 & 433.76 & 430.08 & 22.90 & 0.18 & 5.55 & 234.46 & 14.74 & 10.85 & $3,518.97$ & 45.57 & 25.75 \\
\hline $11: 18$ & 43.4 & 19.88 & 2.1 & 693.9 & 16.9 & 4.64 & 513.00 & 537.96 & 442.04 & 438.29 & 22.90 & 0.18 & s.s5 & 229.69 & 14.31 & 11.11 & $3,672.45$ & 89.44 & 25.75 \\
\hline $11: 19$ & 47.9 & 19.86 & 2.21 & 671.1 & 11.5 & 4.64 & 513.00 & 537.96 & 442,04 & 438.29 & 22.90 & 0.18 & 5.55 & 253.51 & 14.21 & 11.70 & $3,551.78$ & 60.85 & 25.75 \\
\hline $11: 20$ & 49.2 & 19.76 & 2.3 & 559.2 & 7.5 & 4.64 & 513.00 & 537.96 & 442.04 & 438.29 & 22.90 & 0.18 & 5.55 & 260.39 & 13.68 & 12.17 & $2,959.55$ & 39.69 & 25.75 \\
\hline $11: 21$ & 48.5 & 19.77 & 2.3 & 475.6 & 6.4 & 4.64 & 513.00 & 537.96 & 454,64 & 450.63 & 23.00 & 0.18 & 5.55 & 256.69 & 13.73 & 12.17 & $2,517.10$ & 3387 & 25.75 \\
\hline 11:22 & 44 & 19.85 & 2.18 & 399.4 & 3.7 & 4.64 & 513.00 & 537.96 & 454.64 & 450.63 & 23.00 & 0.18 & 5.55 & 232.87 & 14.16 & 11.54 & $2,113.82$ & 19.58 & 25.75 \\
\hline $11: 23$ & 45.3 & 19.71 & 2.37 & 437.5 & 2.4 & 4.64 & 513.00 & 537.96 & 45464 & 450.63 & 23.00 & 0.18 & 5.55 & 239.75 & 13.42 & 12.54 & $2,35.46$ & 12.70 & 25.75 \\
\hline 11:24 & 46.5 & 19.82 & 2.16 & 630.6 & 2.3 & 4.64 & 513.00 & 537.96 & 459.85 & 464.93 & 23.50 & 0.18 & 5.55 & 246.10 & 14.00 & 11.43 & $3,337.44$ & & 25.75 \\
\hline $11: 25$ & 46.8 & 19.79 & 2.21 & 442.5 & 2.2 & 4.64 & 513,00 & 537.96 & 459.85 & 464.93 & 23.50 & 0.18 & 5.55 & 247.69 & 13.84 & 11.70 & $2,341.92$ & 11.64 & 25.75 \\
\hline 14:12 & 3.3 & 20.46 & 1.73 & 2085.6 & 2.2 & 3.92 & 530 & 551.62 & $\$ 13.31$ & 487.86 & 35.70 & 0.18 & 5.49 & 17.41 & 17.54 & 9.13 & $11,001.11$ & 11.60 & 21.52 \\
\hline $14: 13$ & 2.2 & 20.5 & 1.97 & 2363 & 6.4 & 3.92 & 530 & 551.62 & 513.31 & 487.86 & 35.70 & 0.18 & 5.49 & 11.60 & 17.76 & 10.39 & $12,464,33$ & 33.76 & 21.52 \\
\hline $14: 14$ & 7.2 & 20.27 & 2.59 & 4501.5 & 6.9 & 3.92 & 530 & 551.62 & $S 13.31$ & 487.86 & 35.70 & 0.18 & 5.49 & 37.98 & 16.54 & 13.66 & $23,744.48$ & 36.40 & 21.52 \\
\hline $14: 15$ & 16.5 & 20.18 & 2.68 & 3340.3 & 2.2 & 3.92 & $\$ 30$ & 551.62 & 608.2 & 575.25 & 37.20 & 0.18 & 5.49 & 87.03 & 16.07 & 14.14 & $17,619.39$ & 11.60 & 21.52 \\
\hline $14: 16$ & 17.6 & 20.2 & 2.54 & 1815.7 & 0.1 & 3.92 & $\$ 30$ & 551.62 & 608.2 & 575.25 & 37.20 & 0.18 & 5.49 & 9284 & 16.17 & 1340 & 957744 & 0.53 & $\begin{array}{l}11.32 \\
21.52\end{array}$ \\
\hline 14:17 & 18.9 & 20.17 & 2.5 & 1229.6 & 0.8 & 3.92 & 530 & 551.62 & 608.2 & 575.25 & 37.20 & 0.18 & 5.49 & 99.69 & 16.01 & 13.19 & $6,485.88$ & 4.22 & 21.52 \\
\hline $14: 18$ & 21.5 & 20.19 & 2.41 & 1158.1 & 1.4 & 3.92 & 530 & 551.62 & 538.22 & 510.54 & 36.30 & 0.18 & 5.49 & 113,41 & 16.12 & 12.71 & $6,108.74$ & 7.38 & 21.52 \\
\hline $14: 19$ & 26.1 & 20.31 & 1.93 & 712.2 & 2.6 & 3.92 & $\$ 30$ & 551.62 & 538.22 & 510.54 & 36.30 & 0.18 & 5.49 & $\begin{array}{l}137.67 \\
\end{array}$ & 16.75 & 10.18 & $3,756.71$ & 13.71 & 21.52 \\
\hline $14: 20$ & 16.3 & 20.37 & 1.62 & $\$ 24.1$ & 3.4 & 3.92 & 530 & 551.62 & $\$ 38.22$ & s10.54 & 36.30 & $\begin{array}{l}018 \\
018\end{array}$ & 5.49 & 85.98 & 17.07 & 8.55 & $2,764.52$ & 17.93 & 21.52 \\
\hline $14: 21$ & 7.9 & 20.36 & 1.56 & 808.4 & 3.7 & 3.92 & 530 & 551.62 & 496.6 & 471.52 & 36.00 & 0.18 & 5.49 & $\begin{array}{l}41.67 \\
41.67\end{array}$ & 17.02 & 8.23 & $4,264.14$ & 19.52 & 21.52 \\
\hline $14: 22$ & 7.2 & 20.26 & 1.93 & 1297.9 & 3.3 & 3.92 & 530 & 551.62 & 496.6 & 471.52 & 36.00 & 0.18 & 5.49 & 37.98 & 16.49 & $\begin{array}{l}10.18 \\
10.6\end{array}$ & $6,846.15$ & 17.41 & 21.52 \\
\hline $14: 23$ & 8.9 & 20.16 & 2.26 & 2102.6 & 2.5 & 3.92 & 530 & 551.62 & 496.6 & 471.52 & 36.00 & 0.18 & 5.49 & 46.95 & 15.96 & 11.92 & $11,090.78$ & 13.19 & 21.52 \\
\hline $14: 24$ & 5.2 & 20.15 & 2.57 & 2815.6 & 0.8 & 3.92 & 530 & 551.62 & 496.89 & 472.25 & 35.70 & 0.18 & 5.49 & 27.43 & 15.91 & 13.56 & 14,85170 & 422 & 21.52 \\
\hline $14: 25$ & 6.9 & 20.1 & 2.88 & 37445 & 0.4 & 3.92 & 530 & 551.62 & 496.89 & 472.25 & 35.70 & 0.18 & 5.49 & 36.40 & 15.65 & 15.19 & $19,751.46$ & 2.11 & 21.52 \\
\hline $14: 26$ & 8.6 & 20.1 & 2.91 & & 1.3 & 3.92 & 530 & S51.62 & 49689 & 472.25 & 35.70 & 0.18 & 5.49 & 45.36 & 15.65 & 15.35 & $17,896.31$ & 6.86 & 21.52 \\
\hline $14: 27$ & 9.7 & 20.08 & 3.03 & 3532.8 & 1.1 & 3.92 & 530 & 551.62 & 536.8 & 510.02 & 35.80 & 0.18 & 5.49 & 51.17 & 15.54 & 15.98 & $18,634.79$ & 5.80 & 21.52 \\
\hline $14: 28$ & 10.7 & 20.03 & 3.14 & 3272.9 & 1.3 & 3.92 & 530 & 551.62 & 536.8 & 510.02 & 35.80 & 0.18 & 5.49 & 56.44 & 15.28 & 16.56 & $17,263.87$ & 6.86 & 21.52 \\
\hline $14: 29$ & 12.2 & 20.03 & 3.07 & 3003.8 & 1.4 & 3.92 & 530 & 551.62 & 536.8 & $\$ 10.02$ & 35.80 & 0.18 & 5.49 & 64.35 & 15.28 & 16.19 & $15,844.42$ & 7.38 & 21.52 \\
\hline $14: 30$ & 8.9 & 20.06 & 3.02 & 2651.8 & 2 & 3.92 & 530 & 551.62 & $\$ 43.66$ & 513.54 & 37.60 & 0.18 & 5.49 & 45.95 & 15.43 & 15.93 & $13,987.69$ & 10.55 & 21.52 \\
\hline $14: 31$ & 15.7 & 20.1 & 2.73 & 1240.9 & 3.2 & 3.92 & 530 & 551.62 & $\$ 43.66$ & 513.54 & 37.60 & 0.18 & 5.49 & 82.81 & 15.65 & 14.40 & 6.545 .49 & 16.88 & $\begin{array}{l}21.32 \\
21.52\end{array}$ \\
\hline $14: 32$ & 10.9 & 20.26 & 2.44 & 227.9 & 4.4 & 3.92 & 530 & SSt.62 & 543.66 & 51354 & 37.60 & 0.18 & 5.49 & 57.50 & 16.49 & 12.87 & $1,202.13$ & $\begin{array}{l}23.00 \\
23.21\end{array}$ & $\begin{array}{l}21.52 \\
21.52\end{array}$ \\
\hline $14: 33$ & 15.9 & 20.14 & 2.69 & 299.3 & 4.5 & 3.92 & 530 & 551.62 & 503.89 & 474.29 & 38.70 & 0.18 & 5.49 & 83.87 & 15.86 & 14.19 & $1,578.75$ & 23.74 & 21.52 \\
\hline $14: 34$ & 15.6 & 20.07 & 2.88 & sis & 4.6 & 3.92 & 530 & 551.62 & 503.89 & 474.29 & 38.70 & 0.18 & 5.49 & 82.29 & $\begin{array}{l}15.49 \\
\end{array}$ & 15.19 & $2,716.52$ & 24.26 & 21.52 \\
\hline $14: 35$ & 13.2 & 20.07 & 3.02 & 1247.5 & 4.9 & 3.92 & 530 & 551.62 & 503.89 & $\$ 74.29$ & 38.70 & 0.18 & 5.49 & 69.63 & 15.49 & 15.93 & $6,580.30$ & 25.85 & 21.52 \\
\hline $14: 36$ & 20.3 & 20.02 & 3.08 & 1527.1 & 4.4 & 3.92 & $\$ 30$ & 551.62 & 498.87 & $\$ 70.63$ & 38.00 & 0.18 & 5.49 & 107.08 & 15.22 & 16.25 & $8,055.13$ & 23.21 & 21.52 \\
\hline 14:37 & 17.5 & 20.02 & 3.01 & 1531.1 & 4.5 & 3.92 & 530 & 551.62 & 498.87 & 470.63 & 38.00 & 0.18 & 5.49 & 92.31 & 15.22 & 15.88 & $8,076.23$ & 23.74 & 21.52 \\
\hline $14: 38$ & 12.5 & 20.1 & 2.8 & 1748.3 & 4.3 & 3.92 & 530 & 551.62 & 498.87 & 470.63 & 38.00 & 0.18 & 5.49 & 65.93 & 15.65 & 14.77 & $9,221.92$ & 22.68 & 21.52 \\
\hline $14: 39$ & 21.5 & 20.11 & 2.85 & 785.1 & 5 & 3.92 & 530 & 551.62 & 500.85 & 469.92 & 39.70 & 0.18 & 5.4 & 113.41 & 15.70 & 15.03 & $4,141.24$ & $\begin{array}{l}22.08 \\
26.37\end{array}$ & $\begin{array}{l}21.32 \\
21.52\end{array}$ \\
\hline $14: 40$ & 22.4 & 20.04 & 3.05 & 1203.2 & 4.7 & 3.92 & 530 & 551.62 & 500.85 & 469.92 & 39.70 & 0.18 & 5.49 & 118.16 & 15.33 & 16.09 & $6,346.63$ & 24.79 & 21.52 \\
\hline 14:41 & 12.8 & 20.02 & 3.01 & 1697.3 & 4.7 & 3.92 & 530 & 351.62 & 500.85 & 469.92 & 39.70 & 0.18 & 5.49 & 67.52 & 15.22 & 15.88 & $8,952.90$ & 24.79 & $\begin{array}{l}21.52 \\
21.52\end{array}$ \\
\hline $14: 42$ & 18.5 & 20.01 & 3.07 & 1523.2 & 5 & 3.92 & 530 & 351.62 & 581.24 & 545.87 & 39.40 & 0.18 & 5.49 & 97.58 & $\begin{array}{l}15.17 \\
\end{array}$ & 16.19 & $8,034.56$ & 26.37 & 21.52 \\
\hline $14: 43$ & 22.1 & 20.03 & 3.05 & 1170.9 & 4.9 & 3.92 & 530 & 551.62 & 581.24 & 545.87 & 39.40 & 0.18 & 5.49 & 116.57 & 15.28 & 16.09 & $6,176.25$ & 25.85 & 21.52 \\
\hline $14: 44$ & 18.7 & 20.04 & 3.04 & 1272.9 & 5.2 & 3.92 & 530 & 551.62 & 581.24 & 545.87 & 39.40 & 0.18 & 5.4 & 98.64 & 15.33 & 16.04 & $6,714.28$ & 27.43 & 21.52 \\
\hline 14:45 & 19.6 & 20.06 & 2.95 & 1080.3 & 5 & 3.92 & 530 & 551.62 & 506.09 & 475.45 & 39.30 & 018 & 5.4 & 103.39 & 15.43 & 15.56 & $5,698.36$ & 26.37 & 21.52 \\
\hline $14: 45$ & 19.3 & 20.09 & 2.88 & 1178 & 4.6 & 3.92 & 530 & 551.62 & 506.09 & 475.45 & 39.30 & 0.18 & 5.4 & 101.80 & $\begin{array}{l}10.43 \\
15.59\end{array}$ & $\begin{array}{l}15.50 \\
15.19\end{array}$ & $\begin{array}{l}\text {, } \\
6,213.730\end{array}$ & $\begin{array}{l}20.31 \\
24.26\end{array}$ & $\begin{array}{l}21.32 \\
21.52\end{array}$ \\
\hline $14: 47$ & 266 & 19.99 & 2.99 & 1028.2 & 4.9 & 3.92 & 530 & 55162 & 506.09 & 475.45 & 39.30 & 0.18 & 5.4 & 140.31 & 15.06 & 15.77 & $3,423.54$ & 25.85 & 21.52 \\
\hline I4.48 & 31.5 & 20.02 & 2.97 & 612.1 & 5 & 3.92 & 530 & 551.62 & 444.31 & 420.10 & 37.30 & 0.1 & s. & 166.16 & 15.22 & 15.67 & $3,228.70$ & 26.37 & $\begin{array}{l}21.52 \\
21.58\end{array}$ \\
\hline 14:49 & 28.1 & 20.04 & 2.93 & 523.2 & 5.3 & 3.92 & $\$ 30$ & sst.62 & 444.31 & 420.10 & 37.30 & 0.18 & 5.4 & 148.22 & 15.33 & 15.46 & $2,759.77$ & 27.96 & 21.52 \\
\hline $14: 50$ & 25.5 & 20.05 & 2.91 & 574 & 5.3 & 3.92 & $\$ 30$ & S51.62 & 444.31 & $\$ 20.10$ & 37.30 & 0.18 & 5.4 & 134.51 & 15.38 & 15.35 & $3,027.73$ & 27.96 & 21.52 \\
\hline $14: 51$ & 22 & 2005 & 2.85 & 710.2 & 5.5 & 3.92 & 530 & 551.62 & 565.46 & 538.99 & 34.80 & 0.18 & 5.4 & 116.05 & 15.38 & 15.03 & $3,746.16$ & 29.01 & $\begin{array}{l}21.52 \\
21.52\end{array}$ \\
\hline 14:52 & 10.2 & 20.27 & 2.22 & 716.7 & 4.4 & 3.92 & 530 & 551.62 & 565.46 & 538.99 & 34.80 & 0.18 & 5.4 & 53.80 & 16.54 & 11.71 & $3,780.44$ & 23.21 & 21.52 \\
\hline 14:53 & 1.1 & 20.42 & 2.07 & 2492.7 & 1.3 & 3.92 & 530 & 551.62 & 565.46 & 538.99 & 34.80 & 0.18 & 5.4 & 5.8 & 17.33 & 10.92 & & 6.86 & 21.52 \\
\hline 14:5 & 0.3 & 20.36 & 2.46 & 3972.9 & 1.6 & 39 & 330 & ssi. & 527 & 503 & 34 & 0. & s. & 1. & 17.02 & 12.98 & 20.956 .22 & $\begin{array}{l}8.44 \\
8.44\end{array}$ & 21.52 \\
\hline $14: 55$ & 3.6 & 20.1 & 304 & 53146 & 0.1 & 3.9 & 530 & 551.62 & 527 & 503 & 34.50 & 0.18 & 5.4 & 18.99 & 15.65 & 16.04 & $28,033.41$ & 0.53 & 21.52 \\
\hline 14:56 & 11.9 & 20.06 & 2.84 & 3238.4 & 2.4 & 3.92 & 530 & 551.62 & S27.95 & 503.73 & 34.50 & 0.18 & 5.49 & 62.77 & 1543 & 14.98 & 17,08189 & 12.66 & 21.52 \\
\hline 14:57 & 10.3 & 20.06 & 2.89 & 2492.6 & 3 & 3.92 & 530 & 551.62 & 546.64 & $\$ 21.73$ & 34.40 & 0.18 & 5.4 & 54.33 & 15.43 & 15.24 & $13,147,95$ & $\begin{array}{l}1582 \\
1582\end{array}$ & $\begin{array}{l}21.52 \\
21.52\end{array}$ \\
\hline 14:58 & 7.9 & 2008 & 2.87 & 2394.1 & 3.5 & 3.92 & 530 & 551.62 & 546.64 & 521.73 & 34.40 & 0.18 & 5.4 & 41.67 & 15.54 & 15.14 & $12,628.38$ & 18.46 & 21.52 \\
\hline 14.59 & 13.9 & 20.06 & 2.92 & 19983 & 3.9 & 3.92 & 530 & 551.62 & 546.64 & $\$ 21.73$ & 34.40 & 018 & 549 & 73.32 & 15.43 & 15.40 & 10,54062 & 20.57 & 21.52 \\
\hline 15:00 & 126 & 20.08 & 2.88 & 2035.4 & 3.7 & 3.92 & 530 & 551.62 & 521.94 & 495.74 & 35.90 & 018 & 549 & 66.46 & 1554 & $\begin{array}{l}15.19 \\
1.40\end{array}$ & 10,73631 & 19.52 & 2152 \\
\hline
\end{tabular}




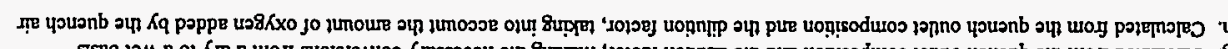

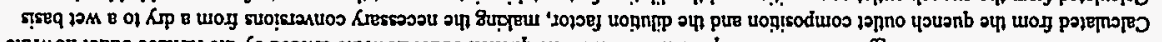

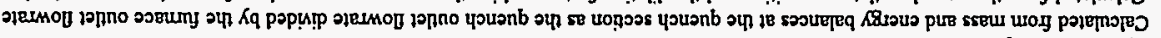

\begin{tabular}{|c|c|c|c|c|c|c|c|c|c|}
\hline $2 z z^{\circ} 1 z$ & $z \angle 96^{\prime} \triangleright 1$ & E60'b0IEI & $\varepsilon s^{\prime} \not 1$ & $D S S I$ & E6sz6.8S & 68S6EE'S & $\angle 40^{\circ}$ & V068S66 ऽE & $p 11056^{\circ} 18 p$ \\
\hline & & & $86 . \varsigma I$ & 08 'SI & SL't & $60 \% 5$ & $81^{\circ} 0$ & OI'sE & $89^{\circ} 9 \angle \mathrm{V}$ \\
\hline$\tau S^{\prime} I \tau$ & se'p & $6 S^{\prime} S 96^{\prime} \nabla z$ & $98 \cdot 9 l$ & VS'SI & ⿷匚' & 6P'S & $81^{\circ} 0$ & ol $8 \varepsilon$ & $89.9 \angle V$ \\
\hline $2 s^{\prime} i z$ & ⿷匚' & $08^{\prime} 691^{\prime} \angle 2$ & $50<21$ & EP'SI & $8 \varepsilon^{\prime} L$ & $6 t^{\prime} S$ & $81{ }^{\circ} 0$ & or It & L0625 \\
\hline $2 s: 12$ & $t+8$ & $\varepsilon و^{\prime} s \forall 8^{\prime} \iota z$ & E691 & OS'SI & $D \nabla 8$ & $60 \% 5$ & $81^{\prime} 0$ & ob It & $\angle 0.625$ \\
\hline$z s^{\prime} 1 z$ & SLD & $6 I^{\prime} 66 S^{\prime} 92$ & 9691 & OL'SI & દะ 9 & $60 \%$ & $81^{\prime} 0$ & OP 10 & $\angle 0^{\circ} 625$ \\
\hline 25.12 & $8 \varepsilon L$ & $69^{\circ} \mathrm{Ez} \sigma^{\prime} \mathrm{LZ}$ & $\angle 991$ & $\forall S ' s I$ & $16 \%$ & $60 \%$ & $81^{\circ} 0$ & $0<9 \varepsilon$ & $016 \angle 4$ \\
\hline$z s^{\prime} \mathrm{iz}$ & 268 & †S'E81' 92 & E8.91 & $8 E^{\prime} S i$ & $\angle 68$ & $60 ' 5$ & $81^{\circ} 0$ & $0<9 \varepsilon$ & $016 \angle \mathrm{V}$ \\
\hline$z s i z$ & 85.1 & $008 \angle T^{\circ} 92$ & 6091 & OL'Si & 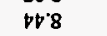 & $60 \%$ & $81^{\circ} 0$ & $O L ' Q \varepsilon$ & Ol $6 \angle P$ \\
\hline 25.12 & $9 l^{\prime} \mathcal{E}$ & Ez'EVI'6z & $\varepsilon \sigma^{\prime} \mathrm{sl}$ & 08 'si & દE' & 605 & $810^{\circ}$ & $O Z \angle \varepsilon$ & ع0.988 \\
\hline $2 s^{\prime} \mathrm{Iz}$ & ES'O & 16.ZLE' & 50.91 & $S L S I$ & L2'S & 675 & 810 & $0 z\llcorner\varepsilon$ & E0.98 \\
\hline $2 s: t z$ & ES 0 & $8 L^{\prime} O \varepsilon \sigma^{\prime} D Z$ & IS SI & 08'sI & $\angle Z ' S$ & $60^{\prime} \mathrm{s}$ & $81^{\circ} 0$ & $0 Z \angle \varepsilon$ & E098p \\
\hline 25.12 & $\$ 9^{\prime} z$ & LI'196'zz & $96 \cdot s i$ & $S L S I$ & $2 z^{\prime} b$ & $60 \%$ & $81^{\circ} 0$ & $00<\varepsilon$ & $\$ 8.260$ \\
\hline is iz & $\| z$ & SI' $161^{\prime} \varepsilon z$ & $I S s \mid$ & sisi & sit & $60 \%$ & $811^{\circ}$ & $00^{\circ}<\mathcal{E}$ & $\nabla 8.260$ \\
\hline $25 i 2$ & SL' & $0 L^{\prime} \$ \nabla L^{\prime} O Z$ & $95 \mathrm{SI}$ & $98 \mathrm{Si}$ & $20 \% 01$ & $60 \mathrm{~s}$ & $81{ }^{\circ} 0$ & $00 \angle \varepsilon$ & $\$ 826 p$ \\
\hline$z s \mathrm{iz}$ & $80^{\prime} 11$ & $0 L^{\prime} \$ 60^{\prime} 81$ & $D I ' S I$ & $98 \mathrm{SI}$ & 6681 & 605 & $81^{\circ} 0$ & of 'se & 80060 \\
\hline $2 s^{\prime} 1 z$ & 28.51 & ES'ZSB'Ol & £o'st & $\forall 5 S i$ & $61 \div 19$ & $6 \mathrm{~S}$ & $81^{\circ} 0$ & OI $S E$ & $80.06 t$ \\
\hline $25^{\prime} 12$ & 6681 & $6 Z^{\prime} 8 \angle 9^{\prime} 0 \mathrm{OI}$ & $28 \mathrm{sI}$ & $90 \circ \mathrm{SI}$ & $z \forall \bullet 6$ & $60 \%$ & $81^{\circ} 0$ & ol s£ & $8006 p$ \\
\hline$z s i z$ & $88^{\prime} 91$ & $\tau \varepsilon^{\prime} \angle \nabla|' z|$ & $L L ' S I$ & EE'S! & $21.6 L$ & $6 P S$ & 810 & $089 \varepsilon$ & $\varepsilon I^{\prime} S \angle \downarrow$ \\
\hline$z s^{\prime} i z$ & 6681 & $80^{\circ} 910^{\circ} \mathrm{El}$ & \$0'91 & $8 Z$ 'SI & 1828 & $60 \mathrm{~s}$ & $81{ }^{\circ} 0$ & $089 \varepsilon$ & $\varepsilon \mid s \angle b$ \\
\hline $2 s i z$ & $18: 21$ & OSOLI'El & E6.S1 & $8 Z^{\prime} \mathrm{SI}$ & 0169 & 605 & $81 \%$ & $089 \varepsilon$ & 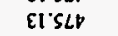 \\
\hline $2 s^{\prime} 12$ & 2561 & бЕ'00ع' $\varepsilon 1$ & $\angle 9 ' S I$ & 2151 & $2<19$ & 605 & $81 \%$ & $06^{\prime} \mathrm{se}$ & $\nabla L ' S 6 b$ \\
\hline 2512 & $18<1$ & $25 \angle 8\left[I^{\prime} \forall\right)$ & $\angle L S I$ & $8 Z^{\prime} \mathrm{SI}$ & $80^{\prime} 65$ & $6 v^{\prime} S$ & $81^{\circ} 0$ & $06 \Omega$ & $P L S S G$ \\
\hline $\mathrm{OZH}$ & udd) zOS & (udd) 0.5 & 200 & (4) 20 & undd) $\times 0$ & 1) 10158 & I0100 & (D) (D) IV & \\
\hline
\end{tabular}

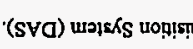
me (IWW) pourd sumdures sहlow

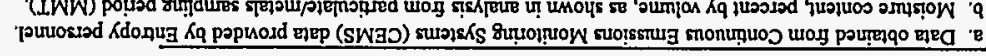

\begin{tabular}{|c|c|}
\hline & E0L9015'9ES \\
\hline St'sos & Z9. ISS \\
\hline So'sos & 29155 \\
\hline 56995 & 29.155 \\
\hline 56.995 & 29 IsS \\
\hline 56.995 & 29 iss \\
\hline EL'SOS & zg.iss \\
\hline EL'SOS & zo'tss \\
\hline EL'SOS & 29155 \\
\hline L8'EIS & zQ'Iss \\
\hline$\angle 8^{\circ} E 1 S$ & Z9. ISS \\
\hline L8'EIS & 29 Iss \\
\hline VLozs & z9.15s \\
\hline vLozs & za:15s \\
\hline TLOZS & 29.155 \\
\hline 59.015 & Z9:15s \\
\hline 59015 & zo'iss \\
\hline $59^{\circ} \mathrm{bls}$ & zg*Iss \\
\hline L'Los & $29^{\circ}$ iss \\
\hline$\angle 105$ & 29.155 \\
\hline L'tos & $29^{\circ}$ iss \\
\hline 76125 & Z9.15s \\
\hline
\end{tabular}

\begin{tabular}{|c|c|c|c|c|c|c|c|}
\hline & & 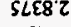 & & 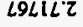 & & & \\
\hline O\&S & $26^{\prime} \varepsilon$ & ⿷'0 & Z'IS8P & $\varepsilon 0^{\prime} \varepsilon$ & El०oz & 60 & $z z: s 1$ \\
\hline OES & $26 \varepsilon$ & $6^{\prime} 0$ & $\varepsilon \varepsilon<\downarrow$ & Zा'E & $80^{\circ} 0 z$ & $\tau l$ & $\{Z: S\rceil$ \\
\hline oEs & $26^{\circ} \mathrm{E}$ & $2 \cdot I$ & 80515 & $\mathfrak{E}^{\prime} \varepsilon$ & $90.0 z$ & $\nabla !$ & $0 Z .51$ \\
\hline OES & $2 \sigma^{\prime} \varepsilon$ & 91 & $6 L z S$ & $i z^{\prime} \varepsilon$ & $60^{\circ} 02$ & $9 !$ & $61: 51$ \\
\hline OES & $26^{\prime} \varepsilon$ & 60 & $\angle$ LZOS & zI' & 1102 & $i i$ & 81 :SI \\
\hline OES & $26^{\circ} \mathrm{E}$ & 1 & $8^{\prime} \varepsilon 6 Z \varsigma$ & 9I' & $80^{\circ} 02$ & s. & LI:SI \\
\hline O\&S & $26^{\circ} \mathcal{E}$ & $\because \dot{I}$ & 6 'E96b & 6I' & $50^{\circ} 0 \mathrm{z}$ & $\iota^{\prime \prime}$ & 9l:si \\
\hline OES & $26^{\circ} \varepsilon$ & \&0 & 86105 & SO' $\varepsilon$ & $110 z$ & آ I' & SI:SI \\
\hline OES & $26^{\circ} \mathcal{E}$ & 90 & szss & $20 \mathcal{\varepsilon}$ & $\varepsilon I^{\prime} 0 z$ & $\tau !$ & plisl \\
\hline OES & $26^{\prime} \varepsilon$ & I'0 & $8.666 \mathrm{~b}$ & ○OE & zा०0 & 1 & દl:Sl \\
\hline oEs & $26^{\prime} \varepsilon$ & I'0 & $\nabla 9 z L b$ & 1062 & Et $0 z$ & I & Zl.st \\
\hline OES & $26^{\prime} \varepsilon$ & 50 & ESEP & E6? & $210 z$ & 80 & II:SI \\
\hline O\&S & $26^{\circ} \varepsilon$ & $\nabla 0$ & $9^{\prime} 96 \varepsilon b$ & 162 & $\tau 10 \tau$ & 60 & 0l:sl \\
\hline OES & $\tau \sigma^{\prime} \varepsilon$ & 60 & $8^{\prime} z \varepsilon \sigma \varepsilon$ & 562 & $\nabla l^{\prime} 0 z$ & 61 & 60.51 \\
\hline OES & $26^{\prime} \mathcal{E}$ & $1 z$ & 9 OEDE & $\angle 8 Z$ & Dioz & $9 \mathcal{\varepsilon}$ & $80: 51$ \\
\hline OES & $26^{\prime} \varepsilon$ & $\varepsilon$ & 9 โ861 & $58^{\circ} \mathrm{z}$ & $80^{\circ} 0 z$ & $9 \cdot 11$ & LO:SI \\
\hline OES & $2 \sigma^{\prime} \varepsilon$ & $g^{\prime} \varepsilon$ & $\nabla \nabla z 0 z$ & $\varepsilon$ & 66.61 & $6 . \mathrm{LI}$ & $90: 5 \mathrm{sI}$ \\
\hline OES & $26^{\prime} \varepsilon$ & $\tau \cdot \mathcal{\varepsilon}$ & 6'ZOEZ & $66 \mathrm{z}$ & po:0z & Si & 50.51 \\
\hline OES & $26^{\circ} \varepsilon$ & $g^{\prime} \mathcal{\varepsilon}$ & $9 \cdot \angle 9 p Z$ & $\nabla 0^{\circ} \mathcal{\varepsilon}$ & ⿷匚, $0 \tau$ & 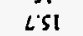 & PO.SI \\
\hline OES & $26^{\circ} \varepsilon$ & $\mathcal{E} \mathfrak{E}$ & $5 \$ 8 \mathrm{tz}$ & $20^{\circ} \varepsilon$ & हo'0z & โદા & EO:SI \\
\hline OES & $26^{\prime} \varepsilon$ & $\llcorner\cdot \mathcal{E}$ & s'IZsz & $\angle \sigma^{\prime} \tau$ & $0 z$ & $\angle I I$ & 20.51 \\
\hline OES & $\tau \sigma^{\prime} \varepsilon$ & $\varepsilon \varepsilon$ & 17899 & 662 & E0.0Z & 211 & $10: 51$ \\
\hline
\end{tabular}




\section{Appendix P}

\section{Particulate/Metals Reduced Data}




\section{Appendix P-1}

\section{MMT Analysis for the S60 Feed Mixture}


Table P-1-1. MMT analysis for the 560 feed mixture.

\begin{tabular}{|c|c|c|c|}
\hline FIELD DATA & RUNI & RUN2 & \\
\hline Enter Pathway & $d: \backslash 11885 \backslash$ & $d: \backslash 11885 \backslash$ & \\
\hline Enter File Name & $m t-s 60-1$ & $m t-560-2$ & \\
\hline Complete Path Is & $\mathrm{d}: \backslash 11885 \backslash \mathrm{mt}-\mathrm{s} 60$ & $\mathrm{~d}: \backslash 11885 \backslash \mathrm{mt}-\mathrm{s} 60-2$ & \\
\hline Enter Number of Runs & 2 & & \\
\hline $\begin{array}{l}\text { Plant Name, City, state } \\
\text { Test Location }\end{array}$ & $\begin{array}{l}\text { U.S. Bureau of } M \\
\text { Arc Melter Exhau }\end{array}$ & $\begin{array}{l}\text { Iines, Albany, Oregon } \\
\text { ist }\end{array}$ & \\
\hline Enter Operator Name (s) & Miguel Chavez & Miguel Chavez & Chavez \\
\hline Press <Alt> C To Combine & The Data From The & Laptop Files & \\
\hline Run Number & $M M T-560-1$ & $\mathrm{MMT}-\mathrm{S} 60-2$ & \\
\hline Date & $7 / 19 / 93$ & $7 / 19 / 93$ & \\
\hline start & 1156 & 1406 & \\
\hline Stop & 1321 & 1522 & \\
\hline Points & 12 & 12 & \\
\hline Theta & 60 & 60 & \\
\hline Dia & 0.259 & 0.215 & \\
\hline $\mathrm{Cp}$ & 0.99 & 0.99 & \\
\hline$Y$ & 1.006 & 1.006 & \\
\hline Pbar & 29.88 & 29.88 & \\
\hline Delta-H & 2.383333333 & 1.698333333 & \\
\hline $\mathrm{Vm}$ & 46.871 & 39.843 & \\
\hline $\operatorname{tm}$ & 67.58333333 & 77 & \\
\hline VIc & 64.8 & 57.9 & \\
\hline $\mathrm{CO} 2$ & 1.9 & 1.8 & \\
\hline $\mathrm{O} 2$ & 20 & 20 & \\
\hline $\mathrm{Pg}$ & -1.6 & -1.6 & \\
\hline ts & 154 & 172 & \\
\hline Delta-p & 0.634060963 & 0.626678522 & \\
\hline Area & 23.75829444 & 23.75829444 & \\
\hline \multicolumn{4}{|l|}{ F-Factor } \\
\hline Tstd & 68 & 68 & \\
\hline Pstd & 29.92 & 29.92 & \\
\hline
\end{tabular}

< Indicates the value is below the detection limit. 
LABORATORY DATA

RUN1

RUN2

Compound

Fwt Unit

FH

$\mathrm{BH}$

FH

BH

$\begin{array}{lr}\text { Arsenic } & 74.92 \\ \text { Aluminum } & 26.98 \\ \text { Barium } & 137.33 \\ \text { Boron } & 10.81 \\ \text { Cadmium } & 112.41 \\ \text { Calcium } & 40.08 \\ \text { Cerium } & 140.12 \\ \text { Cesium } & 132.91 \\ \text { Chromium } & 52 \\ \text { Copper } & 63.55 \\ \text { Iron } & 55.85 \\ \text { Lead } & 207.19 \\ \text { Magnesium } & 24.31 \\ \text { Manganese } & 54.94 \\ \text { Mercury } & 200.59 \\ \text { Nickel } & 58.71 \\ \text { Phosphorus } & 30.97 \\ \text { Potassium } & 39.1 \\ \text { Selenium } & 78.96 \\ \text { Silicon } & 28.09 \\ \text { Silver } & 107.87 \\ \text { Sodium } & 22.99 \\ \text { Strontium } & 87.62 \\ \text { Titanium } & 47.9 \\ \text { Vanadium } & 50.94 \\ \text { Zinc } & 65.38 \\ \text { Zirconium } & 91.22 \\ \text { Particulate (Filter) } & \\ \text { Particulate } & \text { (Nitricid) } \\ \text { Particulate (Acetone) } & \\ & \end{array}$

\begin{tabular}{|c|c|c|}
\hline$m g<$ & 3.82 & \\
\hline $\mathrm{mg}$ & 346.42 & \\
\hline $\mathrm{mg}$ & 20.20 & $<$ \\
\hline 9 & - & \\
\hline $\mathrm{mg}$ & 0.19 & $<$ \\
\hline $\mathrm{mg}$ & 820.86 & \\
\hline 19 & 64.66 & $<$ \\
\hline$g$ & & \\
\hline $\mathrm{mg}$ & 2.50 & $<$ \\
\hline $\mathrm{mg}$ & 11.97 & $<$ \\
\hline $\mathrm{mg}$ & 880.57 & $<$ \\
\hline $\mathrm{mg}$ & 7.56 & $<$ \\
\hline $\mathrm{mg}$ & 177.99 & $<$ \\
\hline mg & 8.38 & $<$ \\
\hline $\mathrm{mg}<$ & 3.82 & $<$ \\
\hline $\mathrm{mg}$ & 1.09 & $<$ \\
\hline $\mathrm{mg}$ & 71.24 & $<$ \\
\hline $\mathrm{mg}$ & 1340.31 & $<$ \\
\hline $\mathrm{mg}<$ & 3.82 & $<$ \\
\hline $\mathrm{mg}$ & 2118.97 & $<$ \\
\hline$m g<$ & 0.38 & $<$ \\
\hline mg & 1295.78 & \\
\hline $\mathrm{mg}$ & 7.04 & $<$ \\
\hline $\mathrm{mg}$ & 41.42 & $<$ \\
\hline mg & 4.54 & $<$ \\
\hline mg & 33.60 & $<$ \\
\hline mg & 0.90 & $<$ \\
\hline 9 & 16.334 & \\
\hline$g$ & 1.074 & \\
\hline . & 1.682 & \\
\hline
\end{tabular}

$0.15<2.40<0.10$

$0.45 \quad 181.50 \quad 0.43$

$0.03 \quad 11.64<0.03$

$0.23-0.38$

$0.00 \quad 0.13<0.00$

$\begin{array}{lll}1.55 & 368.70 & 3.57\end{array}$

$0.0517 .25<0.05$

Cerium

Cesium

Copper

$0.012 .91<0.01$

$0.0548 .77<0.05$

$0.25 \quad 545.63<0.26$

$0.05 \quad 12.82<0.05$

$0.2596 .74<0.26$

$0.017 .06<0.01$

$0.10<2.40<0.10$

$0.03 \quad 0.84<0.03$

$0.10 \quad 164.25 \quad 0.10$

$\begin{array}{rrr}0.10 & 164.25 & 0.10 \\ 0.25 & 1093.25 & 0.33\end{array}$

$0.10<2.40<0.10$

$0.101258 .49<0.10$

$0.03 \quad 0.24<0.03$

$\begin{array}{lll}2.50 & 1052.17 & 5.36\end{array}$

$0.014 .02<0.01$

$0.03 \quad 18.30<0.03$

$0.013 .20<0.01$

$0.2530 .35<0.26$

$0.030 .52<0.03$

8.783

0.941

2. 261

< Indicates the value is below the detection limit. 


\section{LAABORATORY DATA}

Particulate Total ( $g$ )
Sample Volume (ml)
Compound
Arsenic
Aluminum
Barium
Boron
Cadmium
Calcium
Cerium
Cesium
Chromium
Copper
Iron
Lead
Magnesium
Manganese
Mercury
Nickel
Phosphorus
Potassium
Selenium
Silicon
Silver
Sodium
Strontium
Titanium
Vanadium
Zinc
Zirconium

\begin{tabular}{|c|c|c|c|c|c|c|c|}
\hline \multicolumn{3}{|c|}{19.09} & \multicolumn{5}{|c|}{11.986} \\
\hline & & & 500 & & & & 510 \\
\hline & $\begin{array}{r}F F \\
(\mathrm{mg} / \mathrm{kg})\end{array}$ & & $\begin{array}{r}\mathrm{BH} \\
(\mathrm{ug} / \mathrm{L})\end{array}$ & & $\begin{array}{l}\mathrm{FH} \\
(\mathrm{mg} / \mathrm{kg})\end{array}$ & & ${ }^{H}(u g / L)$ \\
\hline$<$ & 200 & & 300 & $<$ & 200 & $<$ & 200 \\
\hline & 18147 & & 900 & & 15143 & & 850 \\
\hline & 1058 & $<$ & 50 & & 971 & $<$ & 50 \\
\hline & - & & 450 & & $\cdot \quad-$ & & 750 \\
\hline & 10 & $<$ & 1 & & 11 & $<$ & 1 \\
\hline & 43000 & & 3100 & & 30762 & & 7000 \\
\hline & 3387 & $<$ & 100 & & 1439 & $<$ & 100 \\
\hline & 131 & $<$ & 20 & & 243 & $<$ & 20 \\
\hline & 627 & $<$ & 100 & & 4069 & $<$ & 100 \\
\hline & 46128 & $<$ & 500 & & 45524 & $<$ & 500 \\
\hline & 396 & $<$ & 100 & & 1070 & $<$ & 100 \\
\hline & 9324 & $<$ & 500 & & 8071 & $<$ & 500 \\
\hline & 439 & $<$ & 20 & & 589 & $<$ & 20 \\
\hline$<$ & 200 & $<$ & 200 & $<$ & 200 & $<$ & 200 \\
\hline & 57 & $<$ & 50 & & 70 & $<$ & 50 \\
\hline & 3732 & $<$ & 200 & & 13704 & & 200 \\
\hline & 70211 & $<$ & 500 & & 91214 & & 650 \\
\hline$<$ & 200 & $<$ & 200 & $<$ & 200 & $<$ & 200 \\
\hline & 111000 & $<$ & 200 & & 105000 & $<$ & 200 \\
\hline$<$ & 20 & $<$ & 50 & & 20 & $<$ & 50 \\
\hline & 67878 & & 5000 & & 87786 & & 10500 \\
\hline & 369 & $<$ & 20 & & 335 & $<$ & 20 \\
\hline & 2170 & $<$ & 50 & & 1527 & $<$ & 50 \\
\hline & 238 & $<$ & 20 & & 267 & $<$ & 20 \\
\hline & 1760 & $<$ & 500 & & 2532 & $<$ & 500 \\
\hline & 47 & $<$ & 50 & & 43 & $<$ & 50 \\
\hline
\end{tabular}

< Indicates the value is below the detection limit. 
Plant: U.S. Bureau of Mines, Albany; Oregon

Test Location: Arc Melter Exhaust

\author{
Run Number \\ MMT-S60-1 \\ MMT-S60-2 \\ Run Date \\ $7 / 19 / 93$ \\ $7 / 19 / 93$
}

Run start Time

Run stop Time

Net Sampling/Traversing Points

Net Run Time, Minutes

Dia

Cp

$Y$

Pbar

Delta-H

$\mathrm{Vm}$

Vmm

tm

Vmstd

Vmstdm

VIc

Vwstd

$\% \mathrm{H} 2 \mathrm{O}$

응 2 sat

Mfd

\% $\mathrm{CO} 2$

은

Md

Ms

Pg

Ps

ts

Delta-p

vs

A

Qsd

Qmsd

Qaw

Qmaw

\% I

?EA

Fo
Operator

Miguel Chavez

Miguel Chavez
MMT-S60-1

1156

1321

12

60

0.259

0.99

1.0060

29.88

2.383

46.871

1.33

68

47.403

1.342

64.8

3.050

6.05

28.0

0.940

1.9

20.0

29.10

28.43

$-1.60$

29.76

154

0.6341

57.41

24

457

13

568

16

78.0

3234

0.474
MMT-S60-2

1406

1522

12

60

0.215

0.99

1.0060

29.88

1.698

39.843

1.13

77

39.522

1.119

57.9

2. 725

6.45

42.8

0.935

1.8

20.0

29.09

28.37

$-1.60$

29.76

172

0.6267

57.96

24

446

13

574

16

96.6

3102

0.500

Note:

All standard volumes and flow rates based on 68 Degrees $F(20$ Degrees C) -- 29.92 Inches of Mercury $(\mathrm{Hg})$

The lesser of $\% \mathrm{H} 2 \mathrm{O}$ and $\% \mathrm{H} 2 \mathrm{O}$ sat was used for calculation purposes. 
FWt

$\mathrm{mg}$

ug/DSCM

ng/DSCM

lb/hr

FWt

mg

ug/DSCM

$\mathrm{ng} / \mathrm{DSCM}$

lb/hr

FWt

$\mathrm{mg}$

ug/DSCM

$\mathrm{ng} / \mathrm{DSCM}$

1b/hr

FWt

$\mathrm{mg}$

ug/DSCM

$\mathrm{ng} / \mathrm{DSCM}$

Ib/hr

EWt

$\mathrm{mg}$

ug/DSCM

$\mathrm{ng} / \mathrm{DSCM}$

Ib/hr

FWt

mg

ug/DSCM

$\mathrm{ng} / \mathrm{DSCM}$

Ib/hr
Arsenic

Formula Weight, Ib/Lb-Mole

Catch Weight, Milligrams

Concentration, Micrograms per DSCM

Concentration, Nanograms per DSCM

Emission Rate, Pounds per Hour

Aluminum

Formula Weight, Ib/Lb-Mole

Catch Weight, Milligrams

Concentration, Micrograms per DSCM

Concentration, Nanograms per DSCM

Emission Rate, Pounds per Hour

Barium

Formula Weight, Lb/Lb-Mole

Catch Weight, Milligrams

Concentration, Micrograms per DSCM

Concentration, Nanograms per DSCM

Emission Rate, Pounds per Hour

Boron

Formula Weight, Lb/Lb-Mole

Catch Weight, Milligrams

Concentration, Micrograms per DSCM

Concentration, Nanograms per DSCM

Emission Rate, Pounds per Hour

Cadmium

Formula Weight, Lb/Lb-Mole

Catch Weight, Milligrams

Concentration, Micrograms per DSCM

Concentration, Nanograms per DSCM

Emission Rate, Pounds per Hour

Calcium

Formula Weight, Lb/Lb-Mole

Catch Weight, Milligrams

Concentration, Micrograms per DSCM

Concentration, Nanograms per DSCM

Emission Rate, Pounds per Hour
MMT-S6 0-1

MMT-S60-2

$\begin{array}{rrrr} & 74.92 & & 74.92 \\ < & 4.0< & 2.5 \\ < & 2.956< & 2.233 \\ < & 2.96 \mathrm{E}+06< & <.23 \mathrm{E}+06 \\ < & 5.06 \mathrm{E}-03< & <.73 \mathrm{E}-03\end{array}$

$\begin{array}{rr}26.98 & 26.98 \\ 346.9 & 181.9 \\ 258,416 & 162.563 \\ 2.58 E+08 & 1.63 E+08 \\ 4.42 E-01 & 2.72 E-01\end{array}$

$\begin{array}{rrrr} & 137.33 & & 137.33 \\ < & 20.2< & 11.7 \\ < & 15.065< & 10.422 \\ < & 1.51 E+07< & 1.04 E+07 \\ < & 2.58 E-02< & 1.74 E-02\end{array}$

$$
\begin{array}{r}
10.81 \\
0.2 \\
168
\end{array}
$$

1. $68 \mathrm{E}+05$

2. 87E-04

3. $42 \mathrm{E}+05$

5. $71 \mathrm{E}-04$

$\begin{array}{rr} & 112.41 \\ < & 0.2< \\ < & 143< \\ < & 1.43 \mathrm{E}+05<\end{array}$

112.41

0.1

118

1. $18 \mathrm{E}+05$

1. $98 \mathrm{E}-04$
40.08

372.3

612

$6.135+08$

1. $05 \mathrm{E}+00$
332,638

3. $33 E+08$

5. 56E-01

< Indicates the value is below the detection limit. 


\section{FWt \\ $\mathrm{mg}$ \\ ug/DSCM \\ $\mathrm{ng} / \mathrm{DSCM}$ \\ Ib/hr}

FWt

$\mathrm{mg}$

ug/DSCM

$\mathrm{ng} / \mathrm{DSCM}$

1b/hr

FWt

mg

ug/DSCM

$\mathrm{ng} / \mathrm{DSCM}$

Ib/hr

FWt

$\mathrm{mg}$

ug/DSCM

$\mathrm{ng} / \mathrm{DSCM}$

$\mathrm{Ib} / \mathrm{hr}$

Fwt

$\mathrm{mg}$

ug/DSCM

$\mathrm{ng} / \mathrm{DSCM}$

$\mathrm{lb} / \mathrm{hr}$

FWt

mg

ug/DSCM

$\mathrm{ng} / \mathrm{DSCM}$

Ib/hr
Cerium

Formula Weight, Lb/Lb-Mole

Catch Weight, Milligrams

Concentration, Micrograms per DSCM

Concentration, Nanograms per DSCM

Emission Rate, Pounds per Hour

\begin{tabular}{rrr} 
& \multicolumn{2}{c}{ MMT-S60-1 MMT-S60-2 } \\
& 140.12 & \\
$<$ & $64.7<$ & 140.12 \\
$<$ & $48,206<$ & 17.3 \\
$<$ & $4.82 \mathrm{E}+07<$ & $1.55 \mathrm{E}+07$ \\
$<$ & $8.25 \mathrm{E}-02<$ & $<$
\end{tabular}

$\begin{array}{rr}132.91 & 132.91 \\ 0.0 & 0.0 \\ 0 & 0 \\ 0.00 E+00 & 0.00 E+00 \\ 0.00 E+00 & 0.00 E+00\end{array}$

Chromium

Formula Weight, Lb/Ib-Mole

Catch Weight, Milligrams

Concentration, Micrograms per DSCM

Concentration, Nanograms per DSCM

Emission Rate, Pounds per Hour

Copper

Formula Weight, Lb/Ib-Mole

Catch Weight, Milligrams

Concentration, Micrograms per DSCM

Concentration, Nanograms per DSCM

Emission Rate, Pounds per Hour

Iron

Formula Weight, Lb/Lb-Mole

Catch Weight, Milligrams

Concentration, Micrograms per DSCM

Concentration, Nanograms per DSCM

Emission Rate, Pounds per Hour

Lead

Formula Weight, Ib/Lb-Mole

Catch Weight, Milligrams

Concentration, Micrograms per DSCM

Concentration, Nanograms per DSCM

Emission Rate, Pounds per Hour

$\begin{array}{rr} & 63.55 \\ < & 12.0< \\ < & 8.954< \\ < & 8.95 \mathrm{E}+06< \\ < & 1.53 \mathrm{E}-02<\end{array}$

63.55

48.8

43,623

4. $36 \mathrm{E}+07$

7. 29E-02

$\begin{array}{rrrr} & 55.85 & & 55.85 \\ < & 880.8< & 545.9 \\ < & 656,203< & 487,771 \\ < & 6.56 \mathrm{E}+08< & 4.88 \mathrm{E}+08 \\ & 1.12 \mathrm{E}+00< & 8.15 \mathrm{E}-01 \\ & & & \\ & & & \\ < & 207.19 & & 207.19 \\ < & 7.6 & < & 12.9 \\ < & 5.669 & < & 11,505 \\ < & 9.70 \mathrm{E}+06 & < & 1.15 \mathrm{E}+07 \\ & 9.03 & < & 1.92 \mathrm{E}-02\end{array}$

< Indicates the value is below the detection limit. 


\section{Magnesium}

FWt Formula Weight, Ib/Lb-Mole

mg Catch Weight, Milligrams

ug/DSCM Concentration, Micrograms per DSCM

$\mathrm{ng} / \mathrm{DSCM}$

$1 \mathrm{~b} / \mathrm{hr}$

FWt

mg

ug/DSCM

$\mathrm{ng} / \mathrm{DSCM}$

lb/hr

FWt

mg

ug/DSCM

$\mathrm{ng} / \mathrm{DSCM}$

Ib/hr

FWt

$\mathrm{mg}$

ug/DSCM

$\mathrm{ng} / \mathrm{DSCM}$

lb/hr

FWt

mg

ug/DSCM

$\mathrm{ng} / \mathrm{DSCM}$

1b/hr

FWt

mg

ug/DSCM

$\mathrm{ng} / \mathrm{DSCM}$

$1 \mathrm{~b} / \mathrm{hr}$
Concentration, Nanograms per DSCM

Emission Rate, Pounds per Hour

\section{Manganese}

Formula Weight, Lb/Lb-Mole

Catch Weight, Milligrams

Concentration, Micrograms per DSCM

Concentration, Nanograms per DSCM

Emission Rate, Pounds per Hour

Mercury

Formula Weight, Lb/Lb-Mole

Catch Weight, Milligrams

Concentration, Micrograms per DSCM

Concentration, Nanograms per DSCM

Emission Rate, Pounds per Hour

Nickel

Formula Weight, Ib/Lb-Mole

Catch Weight, Milligrams

Concentration, Micrograms per DSCM

Concentration, Nanograms per DSCM

Emission Rate, Pounds per Hour

\section{Phosphorus}

Formula Weight, Ib/Lb-Mole

Catch Weight, Milligrams

Concentration, Micrograms per DSCM

Concentration, Nanograms per DSCM

Emission Rate, Pounds per Hour

\section{Potassium}

Formula Weight, Ib/Ib-Mole

Catch Weight, Milligrams

Concentration, Micrograms per DSCM

Concentration, Nanograms per DSCM

Emission Rate, Pounds per Hour

$\begin{array}{rrrr} & 24.31 & & 24.31 \\ < & 178.2< & 97.0 \\ < & 132,789< & 86,665 \\ < & 1.33 \mathrm{E}+08< & 8.67 \mathrm{E}+07 \\ < & 2.27 \mathrm{E}-01< & < & 1.45 \mathrm{E}-01\end{array}$

$\begin{array}{rrrr} & 54.94 & & 54.94 \\ < & 8.4< & 7.1 \\ < & 6.251< & 6.317 \\ < & 6.25 \mathrm{E}+06< & < & 6.32 \mathrm{E}+06 \\ < & 1.07 \mathrm{E}-02 & < & 1.06 \mathrm{E}-02\end{array}$

$\begin{array}{rrrr} & 200.59 & 200.59 \\ < & 3.9< & 2.5 \\ < & 2.919< & 2.233 \\ < & 2.92 \mathrm{E}+06< & 2.23 \mathrm{E}+06 \\ < & 4.99 \mathrm{E}-03< & 3.73 \mathrm{E}-03\end{array}$

$\begin{array}{rrr} & 58.71 & 58.71 \\ < & 1.1< & 0.9 \\ < & 829< & 772 \\ < & 8.29 E+05< & 7.72 E+05 \\ < & 1.42 E-03< & 1.29 E-03\end{array}$

$\begin{array}{rrrr} & 30.97 & 30.97 \\ < & 71.3< & 164.4 \\ < & 53,150< & 146,855 \\ < & 5.31 E+07< & 1.47 E+08 \\ < & 9.09 E-02< & 2.45 E-01\end{array}$

$\begin{array}{rrr} & 39.10 & 39.10 \\ < & 1340.6 & 1093.6 \\ < & 998.703 & 977.160 \\ < & 9.99 \mathrm{E}+08 & 9.77 \mathrm{E}+08 \\ & 1.71 \mathrm{E}+00 & 1.63 \mathrm{E}+00\end{array}$

< Indicates the value is below the detection limit. 
FWt

$\mathrm{mg}$

ug/DSCM

$\mathrm{ng} / \mathrm{DSCM}$

$\mathrm{lb} / \mathrm{hr}$

FWt

mg

ug/DSCM

$\mathrm{ng} / \mathrm{DSCM}$

$\mathrm{Ib} / \mathrm{hr}$

FWt

$\mathrm{mg}$

ug/DSCM

$\mathrm{ng} / \mathrm{DSCM}$

$\mathrm{lb} / \mathrm{hr}$

FWt

mg

ug/DSCM

$\mathrm{ng} / \mathrm{DSCM}$

$\mathrm{lb} / \mathrm{hr}$

FWt

$\mathrm{mg}$

ug/DSCM

$\mathrm{ng} / \mathrm{DSCM}$

$\mathrm{Ib} / \mathrm{hr}$

FWt

$\mathrm{mg}$

ug/DSCM

$\mathrm{ng} / \mathrm{DSCM}$

$1 \mathrm{~b} / \mathrm{hr}$

\section{Selenium}

Formula Weight, Lb/Ib-Mole

Catch Weight, Milligrams

Concentration, Micrograms per DSCM

Concentration, Nanograms per DSCM

Emission Rate, Pounds per Hour

\section{Silicon}

Formula Weight, Lb/Lb-Mole

Catch Weight, Milligrams

Concentration, Micrograms per DSCM

Concentration, Nanograms per DSCM

Emission Rate, Pounds per Hour

Silver

Formula Weight, Lb/Ib-Mole

Catch Weight, Milligrams

Concentration, Micrograms per DSCM

Concentration, Nanograms per DSCM

Emission Rate, Pounds per Hour

\section{Sodium}

Formula Weight, Lb/Lb-Mole

Catch Weight, Milligrams

Concentration, Micrograms per DSCM

Concentration, Nanograms per DSCM

Emission Rate, Pounds per Hour

Strontium

Formula Weight, Lb/Lb-Mole

Catch Weight, Milligrams

Concentration, Micrograms per DSCM

Concentration, Nanograms per DSCM

Emission Rate, Pounds per Hour

Titanium

Formula Weight, Lb/Lb-Mole

Catch Weight, Milligrams

Concentration, Micrograms per DSCM

Concentration, Nanograms per DSCM

Emission Rate, Pounds per Hour

$\begin{array}{rrrr} & 78.96 & 78.96 \\ < & 3.9< & 2.5 \\ < & 2.919< & 2.233 \\ < & 2.92 \mathrm{E}+06< & 2.23 \mathrm{E}+06 \\ < & 4.99 \mathrm{E}-03< & 3.73 \mathrm{E}-03\end{array}$

$\begin{array}{rrrr} & 28.09 & 28.09 \\ < & 2119.1< & 1258.6 \\ <\quad 1.578 .679 & < & 1,124.598 \\ <\quad 1.58 \mathrm{E}+09 & < & 1.12 \mathrm{E}+09 \\ & 2.70 \mathrm{E}+00< & < & 1.88 \mathrm{E}+00\end{array}$

$\begin{array}{rrrr} & 107.87 & 107.87 \\ < & 0.4< & 0.3 \\ < & 303< & 237 \\ < & 3.03 E+05< & 2.37 E+05 \\ < & 5.18 E-04< & 3.96 E-04\end{array}$

22.99

1057.5

944,936

9. $45 \mathrm{E}+08$

1. $58 \mathrm{E}+00$
1298.3

7.201

$1.65 \mathrm{E}+00$

$\begin{array}{lr} & 87.62 \\ < & 7.1 \\ < & 5.255 \\ < & 8.26 \mathrm{E}+06 \\ & 89 \mathrm{E}-03\end{array}$

87.62

4.0

3,597

3. $60 \mathrm{E}+06$

6. $01 \mathrm{E}-03$

< Indicates the value is below the detection limit. 
MMT-S60-1 MMT-S60-2

$\begin{array}{llrr}\text { FWt } & \text { Vanadium } & & 50.94 \\ \text { mg } & \text { Formula Weight, Lb/Lb-Mole } & < & 50.94 \\ \text { ug/DSCM } & \text { Catch Weight, Milligrams } & < & 3.6 \\ \text { ng/DSCM } & \text { Concentration, Micrograms per DSCM } & <92< & <.869 \\ \text { lb/hr } & \text { Concentration, Nanograms per DSCM } & 3.39 E+06< & 2.87 \mathrm{E}+06 \\ & \text { Emission Rate, Pounds per Hour } & 5.80 \mathrm{E}-03< & 4.79 \mathrm{E}-03\end{array}$

FWt Formula Weight, Ib/Lb-Mole

mg Catch Weight, Milligrams

ug/DSCM Concentration, Micrograms per DSCM

$\mathrm{ng} / \mathrm{DSCM}$

$1 \mathrm{~b} / \mathrm{hr}$

Concentration, Nanograms per DSCM

Emission Rate, Pounds per Hour

$\begin{array}{rrr} & 65.38 & 65.38 \\ < & 33.8< & 30.6 \\ < & 25.216< & 27.345 \\ < & 2.52 \mathrm{E}+07< & 2.73 \mathrm{E}+07 \\ < & 4.31 \mathrm{E}-02< & <.57 \mathrm{E}-02\end{array}$

FWt

Zirconium

\section{mg}

ug/DSCM

$\mathrm{ng} / \mathrm{DSCM}$

$1 \mathrm{~b} / \mathrm{hr}$

Formula Weight, Lb/Lb-Mole

Catch Weight, Milligrams

Concentration, Micrograms per DSCM

Concentration, Nanograms per DSCM

Emission Rate, Pounds per Hour

$\begin{array}{rrrr} & 91.22 & 91.22 \\ < & 0.9< & 0.5 \\ < & 687< & 483 \\ < & 6.87 E+05< & 4.83 E+05 \\ < & 1.18 E-03< & 8.08 E-04\end{array}$

$\mathrm{g}$
$\frac{8}{8}$
$\mathrm{~g}$
$\frac{9}{8}$
$\mathrm{~g}$
$\frac{9}{0}$
$\mathrm{~g}$
$\mathrm{~g} / \mathrm{DSCM}$
$\mathrm{gr} / \mathrm{DSCF}$
$1 \mathrm{~b} / \mathrm{hr}$

Particulate

Catch Weight, Grams (Filter)

Percent of Particulate in Filter

Catch Weight, Grams (HNO3)

Percent of particulate in HNO3 Rinse

Catch Weight, Grams (Acetone)

Percent of Particulate in Acetone Rinse

Catch Weight, Grams (Total)

Concentration, Total Milligrams per DSCM

Concentration, Total Grains per DSCF

Emission Rate, Total pounds per Hour

$\begin{array}{rr}16.3338 & 8.7834 \\ 85.6 & 73.3 \\ 1.0743 & 0.941 \\ 5.6 & 7.9 \\ 1.6817 & 2.2612 \\ 8.8 & 18.9 \\ 19.0898 & 11.9856 \\ 14.222 & 10.710 \\ 6.215 & 4.680 \\ 24.330 & 17.894\end{array}$

< Indicates the value is below the detection Iimit. 


\section{Appendix P-2}

\section{MMT Analysis for the S60-IV Feed Mixture}




\section{,}


Table $\mathrm{P}-2-1$. MMT analysis for the s60-IV feed mixture.

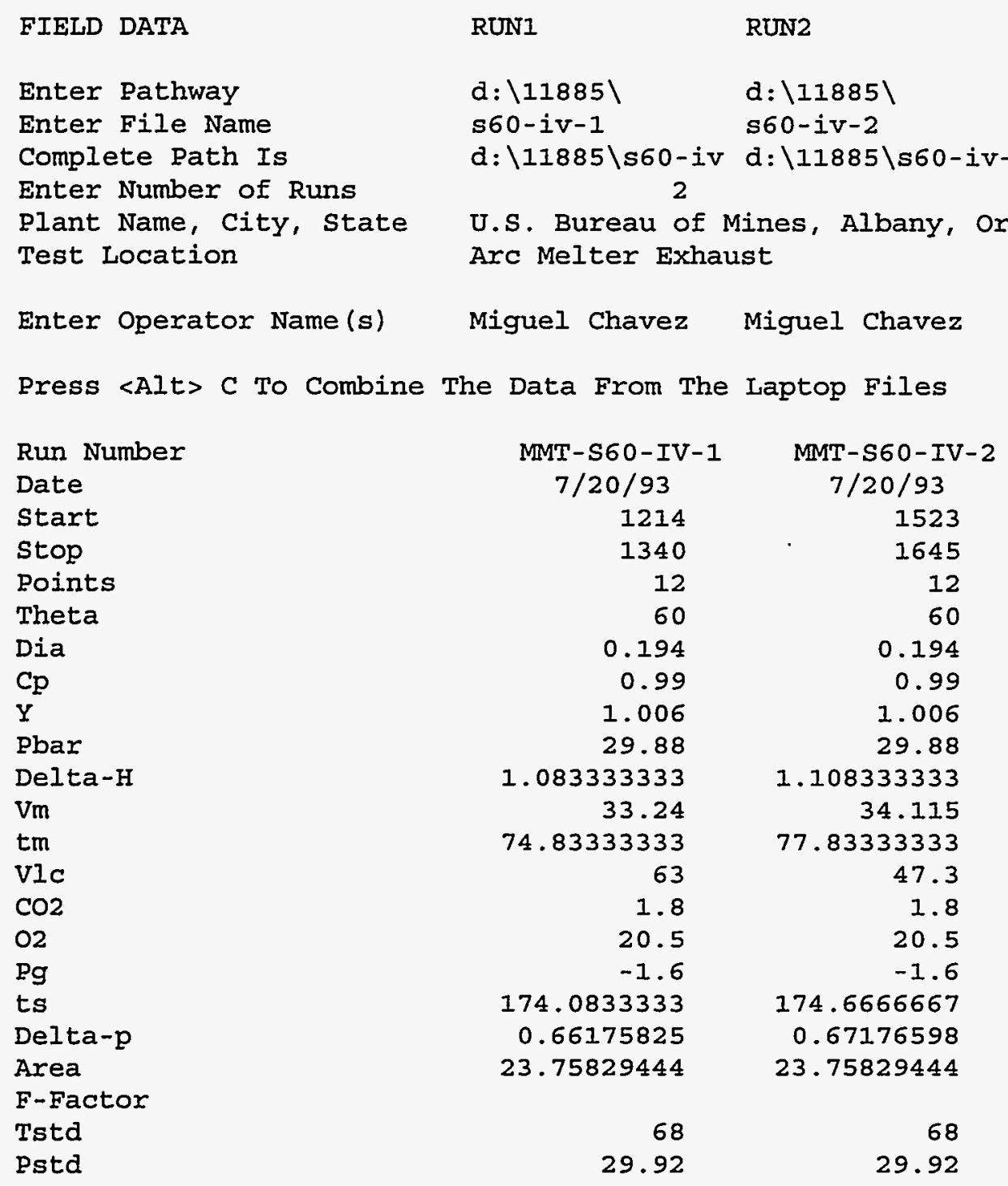

< Indicates the value is below the detection Iimit. 
RUN1

RUN2

\section{Compound}

Arsenic

Aluminum

Barium

Boron

Cadmium

Calcium

Cerium

Cesium

Chromium

Copper

Iron

Lead

Magnesium

Manganese

Mercury

Nickel

Phosphorus

Potassium

Selenium

silicon

silver

Sodium

strontium

Titanium

Vanadium

Zinc

Zirconium

Particulate (Filter)

Particulate (Nitric Acid)

particulate (Acetone)

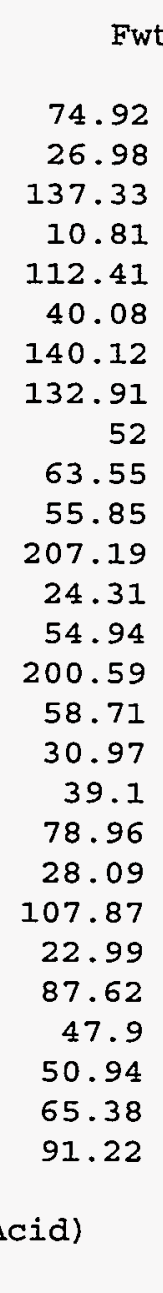

Fwt Unit

FH

BH

FH

BH

$<$

0.73

$$
\text { mg }
$$

$$
\mathrm{mg}
$$

$$
\text { mg }
$$

$$
\mathrm{mg}
$$$$
\text { mg }
$$

$$
\text { mg }
$$

$$
\text { mg }
$$$$
\text { m }
$$

$$
\text { mg }
$$$$
\mathrm{mg}
$$$$
\mathrm{mg}
$$$$
\text { mg < }
$$$$
\text { mg }
$$$$
\mathrm{mg}
$$

mg$$
\begin{aligned}
& \mathrm{mg} \quad 1283.31<0.10 \\
& \mathrm{mg}<\quad 0.28<0.03
\end{aligned}
$$$$
\mathrm{mg} \quad 1124.99 \quad 5.68
$$

\section{mg}

$\mathrm{mg}$

$\mathrm{mg}$

$\mathrm{mg}$

mg

$2.77<0.10$
181.84
$17.30<0.73$
$-\infty .17<0.28$
$0.17<0.00$
578.25
$47.21<0.28$

$1.90 \quad 0.03$

$4.44<0.05$

$660.95 \quad 0.25$

$7.42<0.05$

$103.82<0.25$

$7.51<0.01$

$2.77<$

$0.64<$

$48.28<$

0.10

0.03

0.10

0.42

0.4

63.19

2.77

5.52

$33.13<$

$3.47<$

$25.06<$

$1.33<$

12.53

0.78

0.52
0.01

0.03

0.01

0.25

0.03
$1.92<$

0.43

$5.75<0.02$

- 0.17

$0.12<0.00$
2278.94

$24.66<0.02$

$1.53<0.01$

$3.73<0.05$

$242.56<0.24$

$2.44<0.05$

$90.01<0.24$

$2.88<0.01$

$1.92<0.10$

$0.46<0.02$

$33.66<0.05$

$643.35<0.24$

$1.92<0.10$

$722.44<0.10$

$0.19<0.02$

$437.10 \quad 4.18$

$3.38<0.01$

$11.42<0.02$

$1.56<0.01$

$9.38<0.24$

$0.50<0.02$

7.15

1.08

1. 38

< Indicates the value is below the detection limit. 


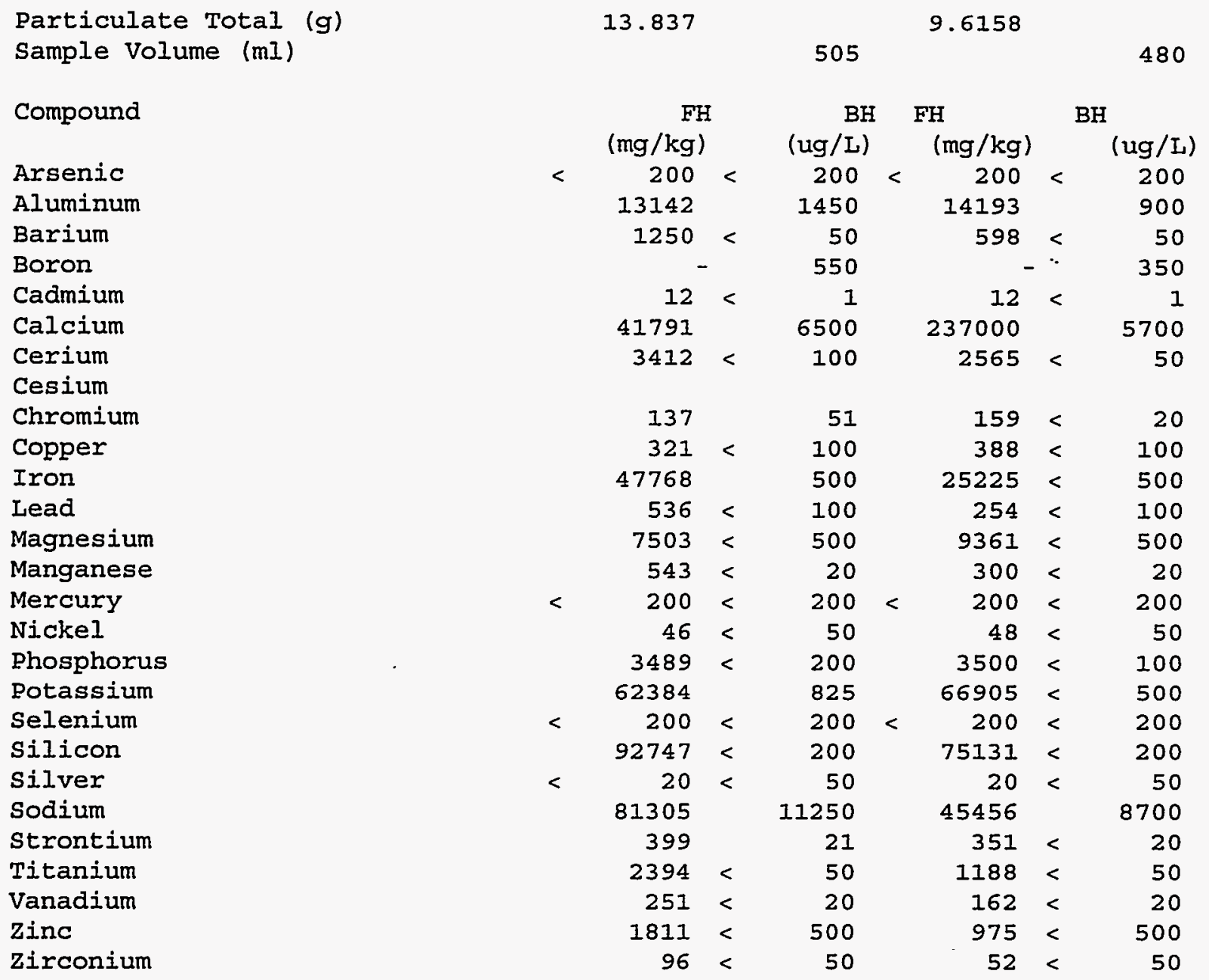

< Indicates the value is below the detection limit. 
Plant: U.S. Bureau of Mines, Albany, Oregon

Test Location: Arc Melter Exhaust

$\begin{array}{ll}\text { Run Number } & \text { Run Date } \\ \text { MMT-S60-IV-1 } & 7 / 20 / 93 \\ \text { MMT-S60-IV-2 } & 7 / 20 / 93\end{array}$

Run start Time

Run stop Time

Net Sampling/Traversing Points

Net Run Time, Minutes

Dia Nozzle Diameter, Inches

Cp Pitot Tube Coefficient

Y Dry Gas Meter Calibration Coefficient

Pbar Barometric Pressure, Inches $\mathrm{Hg}$

Delta-H Orifice Average Pressure Differential, Inch

Vm

Vmm

tm

Vmstd

Vmstdm

Vlc

Vwstd

․ㅏ2O

영2Osat

MEd

$\frac{\mathrm{CO} 2}{2}$

$\% \mathrm{O} 2$

Md

Ms

Pg

Ps

ts

Delta-p

vs

A

Qsd

Qmsd

Qaw

Qmaw

\%I

:EA

Fo
Sampled Volume of Source Gas, Dry ACF

Sampled Volume of Source Gas, Dry ACM

Dry Gas Meter Temperature, Degrees F

Sampled Volume of Source Gas, Dry SCF

Sampled Volume of Source Gas, Dry SCM

Volume of Condensed Liquid, $\mathrm{mL}$

Volume of Water Vapor, SCF

Moisture Content, Percent by Volume

Saturated Moisture Content, Percent by Volu

Source Gas Dry Mole Fraction

Source Gas $\mathrm{CO} 2$ Content, Percent by Dry Volu

Source Gas 02 Content, Percent by Dry Volum

Source Gas Dry Molecular Weight, Lb/Lb-Mole

Source Gas Wet Molecular Weight, Lb/Lb-Mole

Source Gas static Pressure, Inches H2O

Source Gas Absolute Pressure, Inches Hg

Source Gas Temperature, Degrees F

Source Gas Average Velocity Head, Inches H2

Source Gas Velocity, Feet/Second

Source Cross Sectional Area, square Inches

Source Gas Volumetric Flow Rate, Dry SCFM

Source Gas Volumetric Flow Rate, Dry SCMM

Source Gas Volumetric Flow Rate, Wet ACFM

Source Gas Volumetric Flow Rate, wet ACMM

Average Isokinetic Sampling Rate, Percent

Excess Air, Percent

Fuel Factor

$\begin{array}{rr}\text { MMT-S60-IV-1 } & \text { MMT-S60-IV-2 } \\ 1214 & 1523 \\ 1340 & 1645 \\ 12 & 12 \\ 60 & 60 \\ 0.194 & 0.194 \\ 0.99 & 0.99 \\ 1.0060 & 1.0060 \\ 29.88 & 29.88 \\ 1.083 & 1.108 \\ 33.240 & 34.115 \\ 0.94 & 0.97 \\ 75 & 78 \\ 33.056 & 33.739 \\ 0.936 & 0.955 \\ 63.0 & 47.3 \\ 2.965 & 2.226 \\ 8.23 & 6.19 \\ 44.9 & 45.5 \\ 0.918 & 0.938 \\ 1.8 & 1.8 \\ 20.5 & 20.5 \\ 29.11 & 29.11 \\ 28.19 & 28.42 \\ -1.60 & -1.60 \\ 29.76 & 29.76 \\ 174 & 175 \\ 0.6618 & 0.6718 \\ 59.85 & 60.09 \\ 24 & 24 \\ 450 & 462 \\ 13 & 13 \\ 592 & 595 \\ 17 & 17 \\ 98.3 & 97.9 \\ 160156 & 0.222 \\ 0.222 & \\ & \end{array}$

Operator

Miguel Chavez

Miguel Chavez 
Fwt

$\mathrm{mg}$

ug/DSCM

ng/DSCM

Ib/hr

FWt

mg

ug/DSCM

$\mathrm{ng} / \mathrm{DSCM}$

$\mathrm{Ib} / \mathrm{hr}$

FWt

mg

$\mathrm{ug} / \mathrm{DSCM}$

$\mathrm{ng} / \mathrm{DSCM}$

lb/hr

FWt

mg

ug/DSCM

$\mathrm{ng} / \mathrm{DSCM}$

lb/hr

Fwt

mg

ug/DSCM

$\mathrm{ng} / \mathrm{DSCM}$

$\mathrm{Ib} / \mathrm{hr}$

FWt

$\mathrm{mg}$

ug/DSCM

$\mathrm{ng} / \mathrm{DSCM}$

$\mathrm{Ib} / \mathrm{hr}$
Arsenic

Formula Weight, Lb/Lb-Mole

Catch Weight, Milligrams

Concentration, Micrograms per DSCM

Concentration, Nanograms per DSCM

Emission Rate, Pounds per Hour

Aluminum

Formula Weight, Ib/Lb-Mole

Catch Weight, Milligrams

Concentration, Micrograms per DSCM

Concentration, Nanograms per DSCM

Emission Rate, Pounds per Hour

Barium

Formula Weight, Lb/Lb-Mole

Catch Weight, Milligrams

Concentration, Micrograms per DSCM

Concentration, Nanograms per DSCM

Emission Rate, Pounds per Hour

Boron

Formula Weight, Lb/Lb-Mole

Catch Weight, Milligrams

Concentration, Micrograms per DSCM

Concentration, Nanograms per DSCM

Emission Rate, Pounds per Hour

\section{Cadmium}

Formula Weight, Ib/Lb-Mole

Catch Weight, Milligrams

Concentration, Micrograms per DSCM

Concentration, Nanograms per DSCM

Emission Rate, Pounds per Hour

\section{Calcium}

Formula Weight, Lb/Lb-Mole

Catch Weight, Milligrams

Concentration, Micrograms per DSCM

Concentration, Nanograms per DSCM

Emission Rate, Pounds per Hour
MMT-S60-IV-1 MMT-S60-IV-2

$\begin{array}{rrrr} & 74.92 & 74.92 \\ < & 2.9< & 2.0 \\ < & 3.064< & 2.113 \\ < & 3.06 \mathrm{E}+06< & 2.11 \mathrm{E}+06 \\ < & 5.17 \mathrm{E}-03< & 3.66 \mathrm{E}-03\end{array}$

$\begin{array}{rrrr} & 137.33 & 137.33 \\ < & 17.3< & 5.8 \\ < & 18.505< & 6.044 \\ < & 1.85 E+07< & 6.04 E+06 \\ < & 3.12 E-02< & 1.05 E-02\end{array}$

26.98

26.98

136.9

195,048

143,302

1. $95 \mathrm{E}+08$

$1.43 \mathrm{E}+08$

3. 29E- 01

2. $48 \mathrm{E}-01$

$$
\begin{array}{rr}
10.81 & 10.81 \\
0.3 & 0.2 \\
297 & 176
\end{array}
$$

2. $97 \mathrm{E}+05$

1. $76 \mathrm{E}+05$

5. 01E-04

3. $04 E-04$

$\begin{array}{rrrr} & 112.41 & 112.41 \\ < & 0.2< & 0.1 \\ < & 178< & 121 \\ < & 1.78 E+05< & 1.21 E+05 \\ < & 3.00 E-04< & 2.10 E-04\end{array}$

40.08

40.08

581.5

2281.7

621,265

$2,388,230$

$6.21 \mathrm{E}+08$

2. $39 \mathrm{E}+09$

1. $05 \mathrm{E}+00$

$4.13 E+00$

< Indicates the value is below the detection limit. 


Fwt
mg
ug/DSCM
$\mathrm{ng} / \mathrm{DSCM}$
$\mathrm{lb} / \mathrm{hr}$

FWt

$\mathrm{mg}$

ug/DSCM

$\mathrm{ng} / \mathrm{DSCM}$

$\mathrm{Ib} / \mathrm{hr}$
Cerium

Formula Weight, Lb/Lb-Mole

Catch Weight, Milligrams

Concentration, Micrograms per DSCM

Concentration, Nanograms per DSCM

Emission Rate, Pounds per Hour

Cesium

Formula Weight, Lb/Lb-Mole

Catch Weight, Milligrams

Concentration, Micrograms per DSCM

Concentration, Nanograms per DSCM

Emission Rate, Pounds per Hour

Chromium

FWt

$\mathrm{mg}$

ug/DSCM

$\mathrm{ng} / \mathrm{DSCM}$

lb/hr

FWt

mg

ug/DSCM

$\mathrm{ng} / \mathrm{DSCM}$

1b/hr

Fwt

mg

ug/DSCM

$\mathrm{ng} / \mathrm{DSCM}$

1b/hr
Formula Weight, Lb/Lb-Mole

Catch Weight, Milligrams

Concentration, Micrograms per DSCM

Concentration, Nanograms per DSCM

Emission Rate, Pounds per Hour
Copper

Formula Weight, Iub/Lb-Mole

Catch Weight, Milligrams

Concentration, Micrograms per DSCM

Concentration, Nanograms per DSCM

Emission Rate, Pounds per Hour
Iron

Formula Weight, Lb/Lb-Mole

Catch Weight, Milligrams

Concentration, Micrograms per DSCM

Concentration, Nanograms per DSCM

Emission Rate, Pounds per Hour
MMT-S60-IV-1 MMT-S60-IV-2

$\begin{array}{rrrr} & 140.12 & & 140.12 \\ < & 47.3< & 24.7 \\ < & 50,490< & 25,841 \\ < & 5.05 \mathrm{E}+07< & 2.58 \mathrm{E}+07 \\ < & 8.52 \mathrm{E}-02< & <\end{array}$

$\begin{array}{rrr}52.00 & 52.00 \\ 1.9 & 1.5 \\ 2.053< & 1.610 \\ 2.05 E+06< & 1.61 E+06 \\ 3.46 E-03< & 2.79 E-03\end{array}$

63.55

$4.5<$

63.55

3.8

3,955

$4.80 \mathrm{E}+06<3.96 \mathrm{E}+06$

$8.10 \mathrm{E}-03<6.84 \mathrm{E}-03$

Lead

Formula Weight, Lb/Lb-Mole

Catch Weight, Milligrams

Concentration, Micrograms per DSCM

Concentration, Nanograms per DSCM

Emission Rate, Pounds per Hour

\begin{tabular}{|c|c|c|}
\hline 55.85 & & 55.85 \\
\hline 661.2 & $<$ & 242 . \\
\hline 706,380 & $<$ & 254,13 \\
\hline $7.06 \mathrm{E}+08$ & $<$ & $2.54 E+0$ \\
\hline 1. $19 \mathrm{E}+00$ & $<$ & 4.40 \\
\hline
\end{tabular}

$\begin{array}{rrr} & 207.19 & 207.19 \\ < & 7.5< & 2.5 \\ < & 7.977< & 2.607 \\ < & 7.98 E+06< & 2.61 E+06 \\ < & 1.35 E-02< & 4.51 E-03\end{array}$

< Indicates the value is below the detection limit. 


\section{ug/DSCM \\ $\mathrm{ng} / \mathrm{DSCM}$ \\ lb/hr}

FWt

FWt

$\mathrm{mg}$

ug/DSCM

$\mathrm{ng} / \mathrm{DSCM}$

1b/hr

FWt

$\mathrm{mg}$

ug/DSCM

ng/DSCM

1b/hr

FWt

$\mathrm{mg}$

ug/DSCM

$\mathrm{ng} / \mathrm{DSCM}$

lb/hr

FWt

$\mathrm{mg}$

$u g / D S C M$

$\mathrm{ng} / \mathrm{DSCM}$

$\mathrm{Ib} / \mathrm{hr}$

Fwt

mg

ug/DSCM

$\mathrm{ng} / \mathrm{DSCM}$

Ib/hr

\section{Magnesium}

Formula Weight, Lb/Lb-Mole

Catch Weight, Milligrams

Concentration, Micrograms per DSCM

Concentration, Nanograms per DSCM

Emission Rate, Pounds per Hour

$\begin{array}{rrrr} & 24.31 & & 24.31 \\ < & 104.1 & < & 90.3 \\ < & 111,180< & 94,468 \\ < & 1.11 \mathrm{E}+08< & 9.45 \mathrm{E}+07 \\ < & 1.88 \mathrm{E}-01< & 1.63 \mathrm{E}-01\end{array}$

\section{Manganese}

Formula Weight, Lb/Lb-Mole

Catch Weight, Milligrams

Concentration, Micrograms per DSCM

Concentration, Nanograms per DSCM

Emission Rate, Pounds per Hour

Mercury

Formula Weight, Lb/Lb-Mole

Catch Weight, Milligrams

Concentration, Micrograms per DSCM

Concentration, Nanograms per DSCM

Emission Rate, Pounds per Hour

Nickel

Formula Weight, Ib/Lb-Mole

Catch Weight, Milligrams

Concentration, Micrograms per DSCM

Concentration, Nanograms per DSCM

Emission Rate, Pounds per Hour

Phosphorus

Formula Weight, Lb/Lb-Mole

Catch Weight, Milligrams

Concentration, Micrograms per DSCM

Concentration, Nanograms per DSCM

Emission Rate, Pounds per Hour

Potassium

Formula Weight, Lb/Lb-Mole

Catch Weight, Milligrams

Concentration, Micrograms per DSCM

Concentration, Nanograms per DSCM

Emission Rate, Pounds per Hour

$\begin{array}{rrrr} & 200.59 & & 200.59 \\ < & 2.9< & 2.0 \\ < & 3,064< & 2,113 \\ < & 3.06 \mathrm{E}+06< & 2.11 \mathrm{E}+06 \\ < & 5.17 \mathrm{E}-03< & 3.66 \mathrm{E}-03\end{array}$

$\begin{array}{rrrr} & 58.71 & 58.71 \\ < & 0.7< & 0.5 \\ < & 707< & 508 \\ < & 7.07 E+05< & 5.08 E+05 \\ < & 1.19 E-03< & 8.79 E-04\end{array}$

$\begin{array}{rrrr} & 30.97 & & 30.97 \\ < & 48.4 & < & 33.7 \\ < & 51.683 & < & 35.277 \\ < & 5.17 \mathrm{E}+07< & 3.53 \mathrm{E}+07 \\ < & 8.72 \mathrm{E}-02 & < & 6.10 \mathrm{E}-02\end{array}$

$\begin{array}{rr}39.10 & 39.10 \\ 863.6 & < \\ 922.610< & 643.6 \\ 9.23 \mathrm{E}+08< & 6.74 \mathrm{E}+08 \\ 1.56 \mathrm{E}+00< & <.17 \mathrm{E}+00\end{array}$

< Indicates the value is below the detection limit. 


FWt
$\mathrm{mg}$
$\mathrm{ug} / \mathrm{DSCM}$
$\mathrm{ng} / \mathrm{DSCM}$
$\mathrm{lb} / \mathrm{hr}$

FWt

$\mathrm{mg}$

ug/DSCM

$\mathrm{ng} / \mathrm{DSCM}$

$\mathrm{lb} / \mathrm{hr}$

FWt

mg

ug/DSCM

$\mathrm{ng} / \mathrm{DSCM}$

$\mathrm{lb} / \mathrm{hr}$

FWt

$\mathrm{mg}$

ug/DSCM

$\mathrm{ng} / \mathrm{DSCM}$

$1 \mathrm{~b} / \mathrm{hr}$

FWt

mg

$u g / D S C M$

$\mathrm{ng} / \mathrm{DSCM}$

$1 \mathrm{~b} / \mathrm{hr}$

\section{FWt}

$\mathrm{mg}$

ug/DSCM

$\mathrm{ng} / \mathrm{DSCM}$

$\mathrm{lb} / \mathrm{hr}$
Selenium

Formula Weight, Lb/Lb-Mole

Catch Weight, Milligrams

Concentration, Micrograms per DSCM

Concentration, Nanograms per DSCM

Emission Rate, Pounds per Hour

silicon

Formula Weight, Lb/Lb-Mole

Catch Weight, Milligrams

Concentration, Micrograms per DSCM

Concentration, Nanograms per DSCM

Emission Rate, Pounds per Hour

Silver

Catch Weight, Milligrams

Concentration, Micrograms per DSCM

Concentration, Nanograms per DSCM

Emission Rate, Pounds per Hour

Sodium

Formula Weight, Ib/Lb-Mole

Catch Weight, Milligrams

Concentration, Micrograms per DSCM

Concentration, Nanograms per DSCM

Emission Rate, Pounds per Hour

Strontium

Formula Weight, Lb/Lb-Mole

Catch Weight, Milligrams

Concentration, Micrograms per DSCM

Concentration, Nanograms per DSCM

Emission Rate, Pounds per Hour

Titanium

Formula Weight, Lb/Lb-Mole

Catch Weight, Milligrams

Concentration, Micrograms per DSCM

Concentration, Nanograms per DSCM

Emission Rate, Pounds per Hour
Formula Weight, Ib/Lb-Mole

$\begin{array}{rrrr} & 78.96 & 78.96 \\ < & 2.9< & 2.0 \\ < & 3.064< & 2.113 \\ < & 3.06 \mathrm{E}+06< & 2.11 \mathrm{E}+06 \\ < & 5.17 \mathrm{E}-03< & 3.66 \mathrm{E}-03\end{array}$

$\begin{array}{rrrr} & 28.09 & & 28.09 \\ < & 1283.4< & 722.5 \\ <\quad 1.371 .102< & 756,282 \\ <\quad 1.37 \mathrm{E}+09< & 7.56 \mathrm{E}+08 \\ <\quad 2.31 \mathrm{E}+00< & <1.31 \mathrm{E}+00\end{array}$

$\begin{array}{rrrr} & 107.87 & 107.87 \\ < & 0.3< & 0.2 \\ < & 323< & 226 \\ < & 3.23 \mathrm{E}+05< & 2.26 \mathrm{E}+05 \\ < & 5.44 \mathrm{E}-04< & 3.92 \mathrm{E}-04\end{array}$

22.99

22.99

441.3

1130.7

$1,207,927$

461,878

$1.21 \mathrm{E}+09 \quad 4.62 \mathrm{E}+08$

$2.04 \mathrm{E}+00 \quad 7.99 \mathrm{E}-01$

$\begin{array}{rrr}87.62 & 87.62 \\ 5.5 & 3.4 \\ 5.909< & 3.543 \\ 5.91 \mathrm{E}+06< & 3.54 \mathrm{E}+06 \\ 9.97 \mathrm{E}-03< & 6.13 \mathrm{E}-03\end{array}$

< Indicates the value is below the detection limit.

$\begin{array}{rrr} & 47.90 & 47.90 \\ < & 33.2< & 11.4 \\ < & 35.415< & 11.982 \\ < & 3.54 \mathrm{E}+07< & 1.20 \mathrm{E}+07 \\ < & 5.97 \mathrm{E}-02< & <.07 \mathrm{E}-02\end{array}$


MMT-S60-IV-1 MMT-S60-IV-2

Vanadium

FWt Formula Weight, Lb/Ib-Mole

mg Catch Weight, Milligrams

$\mathrm{ug} / \mathrm{DSCM}$

$\mathrm{ng} / \mathrm{DSCM}$

$1 \mathrm{~b} / \mathrm{hr}$

Concentration, Micrograms per DSCM

Concentration, Nanograms per DSCM

Emission Rate, Pounds per Hour

$\begin{array}{rrrr} & 50.94 & & 50.94 \\ < & 3.5< & 1.6 \\ < & 3.721< & 1.641 \\ < & 3.72 \mathrm{E}+06< & 1.64 \mathrm{E}+06 \\ < & 6.28 \mathrm{E}-03< & 2.84 \mathrm{E}-03\end{array}$

FWt

Zinc

mg

ug/DSCM

$\mathrm{ng} / \mathrm{DSCM}$

Ib/hr

Formula Weight, Lb/Lb-Mole

Catch Weight, Milligrams

Concentration, Micrograms per DSCM

Concentration, Nanograms per DSCM

Emission Rate, Pounds per Hour

65.38

65.38

$25.3<$

9.6

$<$

$<$

$27,040<$

10,064

$2.70 \mathrm{E}+07<$

1. $01 E+07$

$<4.56 \mathrm{E}-02<1.74 \mathrm{E}-02$

FWt

$\mathrm{mg}$

ug/DSCM

$\mathrm{ng} / \mathrm{DSCM}$

1b/hr

\section{Zirconium}

Formula Weight, Lb/Ib-Mole

Catch Weight, Milligrams

Concentration, Micrograms per DSCM

Concentration, Nanograms per DSCM

Emission Rate, Pounds per Hour

$\begin{array}{rrrr} & 91.22 & 91.22 \\ < & 1.4< & 0.5 \\ < & 1,446< & 548 \\ < & 1.45 \mathrm{E}+06< & 5.48 \mathrm{E}+05 \\ < & 2.44 \mathrm{E}-03< & 9.49 \mathrm{E}-04\end{array}$

\section{Particulate}

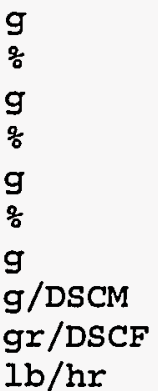

Catch Weight, Grams (Filter)

Percent of Particulate in Filter

Catch Weight, Grams (HNO3)

Percent of Particulate in HNO3 Rinse

Catch Weight, Grams (Acetone)

Percent of Particulate in Acetone Rinse
12.5337
90.6
0.7809
5.6
0.5221
3.8
14.782
6.460
24.936

Catch Weight, Grams (Total)

Concentration, Total Milligrams per DSCM

Concentration, Total Grains per DSCF

Emission Rate, Total Pounds per Hour

7.1526

74.4

1.08

11.2

1. 3832

14.4

9.6158

10.065

4.398

17.409

< Indicates the value is below the detection limit. 


\section{Appendix P-3}

\section{MMT Analysis for the N80 and N80-Mod Feed Mixtures}




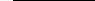


Table P-3-1. MMT analysis for the N80 and N80-Mod feed mixtures.

FIELD DATA

Enter Pathway

Enter File Name

Complete Path Is

Enter Number of Runs

Plant Name, City, state

Test Location

Enter Operator Name(s)
RUNI

$$
d: \backslash 11885 \backslash \quad \mathrm{d}: \backslash 11885 \backslash
$$

$\mathrm{mt}-\mathrm{n} 80-1$ mt-n80-2

$d: \backslash 11885 \backslash m t-n 80 \quad d: \backslash 11885 \backslash m t-n 80-2$

2

U.S. Bureau of Mines, Albany, Oregon

Arc Melter Exhaust

Miguel Chavez Miguel Chavez Miguel Chavez

Press <Alt> C To Combine The Data From The Laptop Files

Run Number

Date

Start

Stop

Points

Theta

Dia

$\mathrm{Cp}$

$Y$

Pbar

Delta-H

Vm

tm

VIC

$\mathrm{CO} 2$

$\mathrm{O} 2$

$\mathrm{Pg}$

ts

Delta-p

Area

F-Factor

Tstd

Pstd

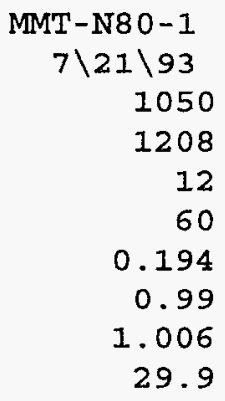

1.433333333

37.352

73.41666667

46

20.2

3

$-1.8$

186

0.888518155

23.75829444

68

29.92
MMT-N80-2

$7 \backslash 21 \backslash 93$

1520

1625

12

60

0.194

0.99

1.006

29.8

1. 208333333

35.692

74.75

36.1

20.2

3

$-1.8$

201.6666667

0.773897621

23. 75829444

68

29.92 
LABORATORY DATA

Compound

1 Arsenic

Aluminum

Barium

Boron

Cadmium

Calcium

Cerium

Cesium

Chromium

Copper

Iron

Lead

Magnesium

Manganese

Mercury

Nickel

phosphorus

Potassium

selenium

silicon

silver

Sodium

Strontium

Titanium

Vanadium

zinc

zirconium

Fwt Unit
$74.92 \quad \mathrm{mg}$

26.98

137.33

10.81

112.41

40.08

140.12

132.91

52

63.55

55.85

207.19

24.31

54.94

200.59

58.71

30.97

39.1

78.96

28.09

107.87

22.99

87.62

47.9

50.94

65.38

91.22

28 Particulate (Filter)

29 Particulate (Nitric Acid)

30 Particulate (Acetone)

$\mathrm{m}$

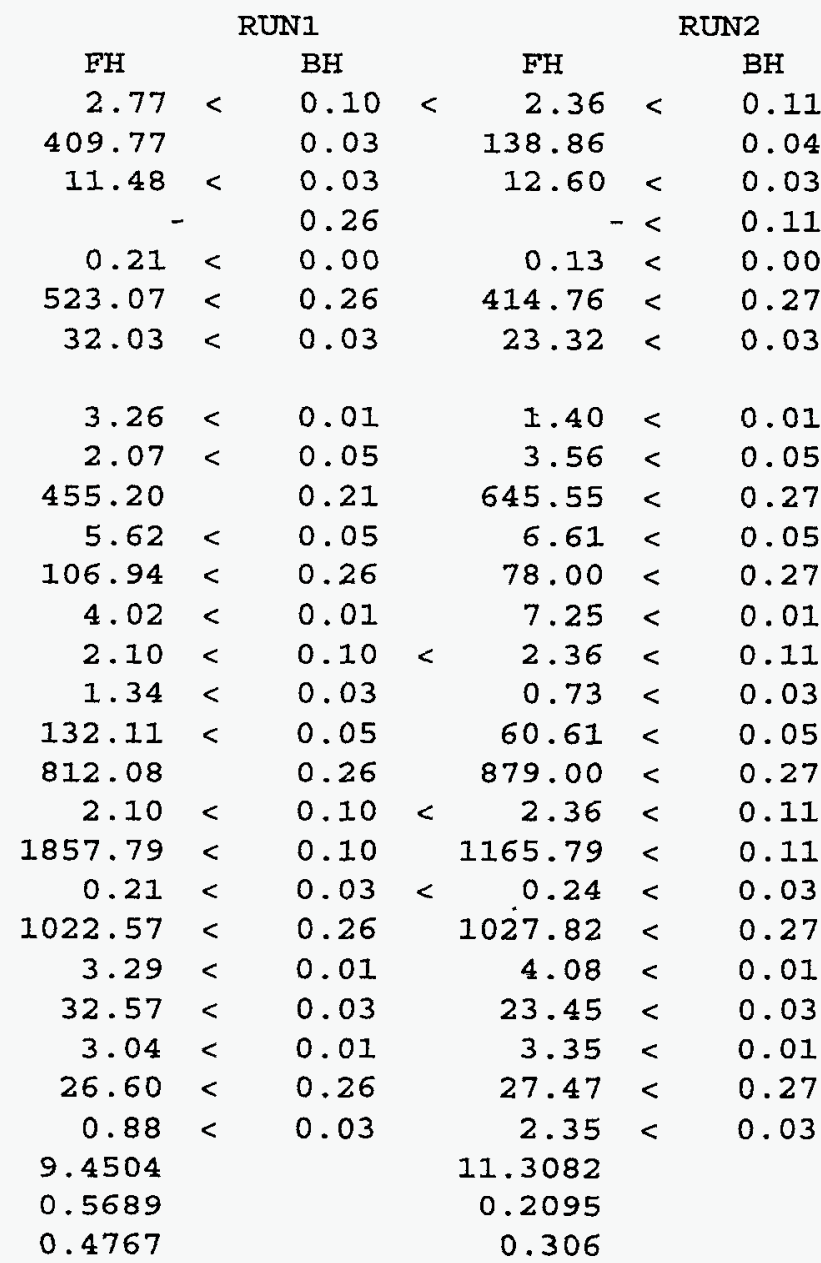

$>$ Indicates the value is below the detection limit. 


\section{LABORATORY DATA}

Particulate Total (g)

Sample Volume (ml)

Compound

Arsenic

Aluminum

Barium

Boron

Cadmium

Calcium

Cerium

Cesium

Chromium

Copper

Iron

Lead

Magnesium

Manganese

Mercury

Nickel

Phosphorus

potassium

Selenium

silicon

Silver

Sodium

strontium

Titanium

Vanadium

zinc

Zirconium
10.496

520

11.8237

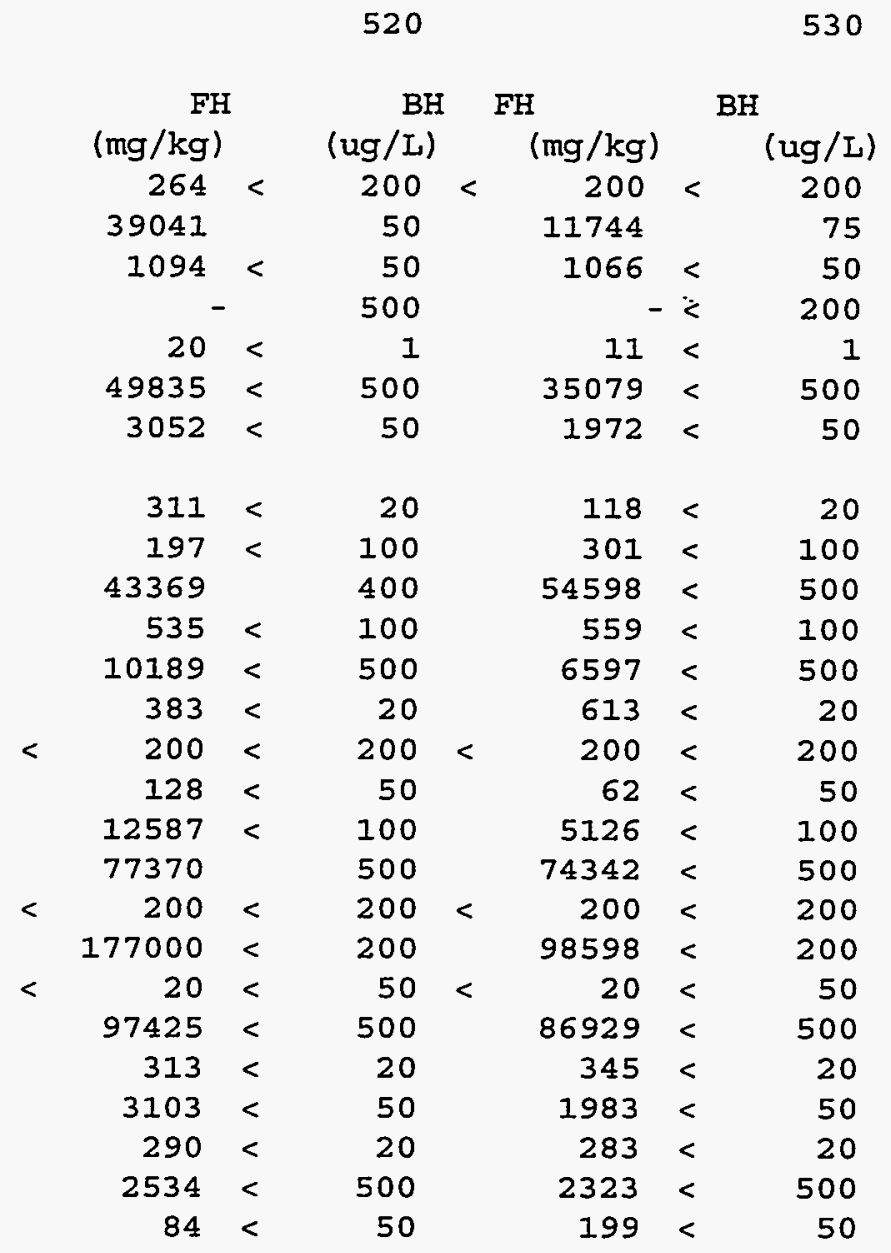

< Indicates the value is below the detection limit. 
Plant: U.S. Bureau of Mines, Albany, Oregon

Test Location: Arc Melter Exhaust

Run Number

MMT-N80-1

MMT-N80-2

Run start Time

Run stop Time

Net Sampling/Traversing Points
Run Date

$7 \backslash 21 \backslash 93$

$7 \backslash 21 \backslash 93$
Operator

Miguel Chavez

Miguel Chavez

MMT-N80-1

1050

1208

MMT-N80-2

1520

1625

12

60

Net Run Time, Minutes

12

0.194

0.194

0.99

Pitot Tube Coefficient

Dry Gas Meter Calibration Coefficient

0.99

1.0060

1.0060

29.90

1.433

Orifice Average Pressure Differential, Inch

37.352

1.06

Sampled Volume of source Gas, Dry ACM

73

29.80

1.208

35.692

1.01

75

37.301

Source Gas Absolute Pressure, Inches Hg

Source Gas Temperature, Degrees F

Source Gas Average Velocity Head, Inches H2

Source Gas Velocity, Feet/Second

0.8885

Source Gas Volumetric Flow Rate, Dry SCFM

Source Gas Volumetric Flow Rate, Dry SCMM

Source Gas Volumetric Flow Rate, wet ACFM

Source Gas Volumetric Flow Rate, wet ACMM

Average Isokinetic Sampling Rate, Percent

Excess Air, Percent

Fuel Factor
1.056

46.0

2.165

5.49

58.5

0.945

20.2

3.0

31.35

30.62

$-1.80$

29.77

186

67.16

24

511

35.416

1.003

36.1

1.699

4.58

81.8

0.954

20.2

3.0

31.35

30.74

$-1.80$

29.67

202

0.7739

63.42

24

474

13

628

18

100.1

17

97.8

17

0.886

0.886

Note:

All standard volumes and flow rates based on 68 Degrees F (20 Degrees C) -- 29.92 Inches of Mercury (Hg)

The lesser of $\% \mathrm{H} 2 \mathrm{O}$ and $\% \mathrm{H} 2 \mathrm{O}$ sat was used for calculation purposes. 


\section{FWt \\ $\mathrm{mg}$ \\ ug/DSCM $\mathrm{ng} / \mathrm{DSCM}$ $\mathrm{Ib} / \mathrm{hr}$}

FWt

$\mathrm{mg}$

ug/DSCM $\mathrm{ng} / \mathrm{DSCM}$ $\mathrm{lb} / \mathrm{hr}$

FWt

mg

ug/DSCM $\mathrm{ng} / \mathrm{DSCM}$ $\mathrm{lb} / \mathrm{hr}$

FWt

mg

ug/DSCM ng/DSCM $\mathrm{lb} / \mathrm{hr}$

FWt

mg

ug/DSCM

$\mathrm{ng} / \mathrm{DSCM}$

lb/hr

FWt

mg

ug/DSCM

ng/DSCM

$\mathrm{lb} / \mathrm{hr}$
Arsenic

Formula Weight, Lb/Lb-Mole

Catch Weight, Milligrams

Concentration, Micrograms per DSCM

Concentration, Nanograms per DSCM

Emission Rate, Pounds per Hour
MMT-N80-1

MMT-N80-2

$\begin{array}{rrr} & 74.92 & \\ < & 2.9< & 74.92 \\ < & 2.722< & 2.5 \\ < & 2.72 \mathrm{E}+06< & 2.464 \\ < & 5.21 \mathrm{E}-03< & <.46 \mathrm{E}+06 \\ & & 4.37 \mathrm{E}-03\end{array}$

\section{Aluminum}

Formula Weight, Lb/Lb-Mole Catch Weight, Milligrams

Concentration, Micrograms per DSCM Concentration, Nanograms per DSCM

Emission Rate, Pounds per Hour

Barium

Formula Weight, Lb/Lb-Mole

Catch Weight, Milligrams

Concentration, Micrograms per DSCM

Concentration, Nanograms per DSCM

Emission Rate, Pounds per Hour

Boron

Formula Weight, Lb/Lb-Mole

Catch Weight, Milligrams

Concentration, Micrograms per DSCM

Concentration, Nanograms per DSCM

Emission Rate, Pounds per Hour

Cadmium

Formula Weight, Lb/Lb-Mole

Catch Weight, Milligrams

Concentration, Micrograms per DSCM

Concentration, Nanograms per DSCM

Emission Rate, Pounds per Hour

\section{Calcium}

Formula Weight, Lb/Lb-Mole

Catch Weight, Milligrams

Concentration, Micrograms per DSCM

Concentration, Nanograms per DSCM

Emission Rate, Pounds per Hour

$\begin{array}{rr}26.98 & 26.98 \\ 409.8 & 138.9 \\ 387,979 & 138,499 \\ 3.88 \mathrm{E}+08 & 1.38 \mathrm{E}+08 \\ 7.43 \mathrm{E}-01 & 2.46 \mathrm{E}-01\end{array}$

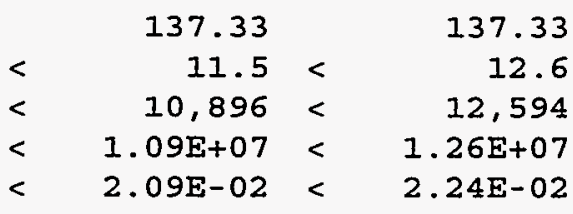

$>$ Indicates the value is below the detection limit. 
FWt

mg

ug/DSCM

$\mathrm{ng} / \mathrm{DSCM}$

lb/hr

Fwt

mg

ug/DSCM

ng/DSCM

$\mathrm{lb} / \mathrm{hr}$

FWt

$\mathrm{mg}$

$u g / D S C M$

ng/DSCM

$\mathrm{Ib} / \mathrm{hr}$

FWt

mg

ug/DSCM

ng/DSCM

lb/hr

EWt

mg

ug/DSCM

$\mathrm{ng} / \mathrm{DSCM}$

Ib/hr

FWt

mg

ug/DSCM

ng/DSCM

Ib/hr
Cerium

Formula Weight, Lb/Lb-Mole

Catch Weight, Milligrams

Concentration, Micrograms per DSCM

Concentration, Nanograms per DSCM

Emission Rate, Pounds per Hour

\section{Cesium}

Formula Weight, Lb/Lb-Mole

Catch Weight, Milligrams

Concentration, Micrograms per DSCM

Concentration, Nanograms per DSCM

Emission Rate, Pounds per Hour

Chromium

Formula Weight, Lb/Lb-Mole

Catch Weight, Milligrams

Concentration, Micrograms per DSCM

Concentration, Nanograms per DSCM

Emission Rate, Pounds per Hour

Copper

Formula Weight, Lb/Lb-Mole

Catch Weight, Milligrams

Concentration, Micrograms per DSCM

Concentration, Nanograms per DSCM

Emission Rate, Pounds per Hour

Iron

Formula Weight, Lb/Lb-Mole

Catch Weight, Milligrams

Concentration, Micrograms per DSCM

Concentration, Nanograms per DSCM

Emission Rate, Pounds per Hour

Lead

Formula Weight, Ib/Ib-Mole

Catch Weight, Milligrams

Concentration, Micrograms per DSCM

Concentration, Nanograms per DSCM

Emission Rate, Pounds per Hour
MMT-N80-1

MMT-N80-2

$\begin{array}{rrr} & 140.12 & 140.12 \\ < & 32.1< & 23.3 \\ < & 30.353< & 23.276 \\ < & 3.04 E+07< & 2.33 E+07 \\ < & 5.81 E-02< & 4.13 E-02\end{array}$

$\begin{array}{rr}132.91 & 132.91 \\ 0.0 & 0.0 \\ 0 & 0 \\ 0.00 E+00 & 0.00 E+00 \\ 0.00 E+00 & 0.00 E+00\end{array}$

52.00

52.00

$<\quad 3.3<$

1.4

1,402

$3,100<$

3. $10 E+06$

1. $40 \mathrm{OE}+06$

$5.93 \mathrm{E}-03<2.49 \mathrm{E}-03$

$\begin{array}{rrr}63.55 & 63.55 \\ 2.1< & 3.6 \\ 2,007< & 3.602 \\ 2.01 \mathrm{E}+06< & 3.60 \mathrm{E}+06 \\ 3.84 \mathrm{E}-03< & 6.39 \mathrm{E}-03\end{array}$

> Indicates the value is below the detection limit. 
EWt

$\mathrm{mg}$

ug/DSCM

ng/DSCM

Ib/hr

FWt

$\mathrm{mg}$

ug/DSCM

$\mathrm{ng} / \mathrm{DSCM}$

$\mathrm{lb} / \mathrm{hr}$

Fwt

$\mathrm{mg}$

ug/DSCM

$\mathrm{ng} / \mathrm{DSCM}$

Ib/hr

FWt

mg

ug/DSCM

$\mathrm{ng} / \mathrm{DSCM}$

$1 \mathrm{~b} / \mathrm{hr}$

FWt

mg

ug/DSCM

$\mathrm{ng} / \mathrm{DSCM}$

Ib/hr

FWt

mg

ug/DSCM

$\mathrm{ng} / \mathrm{DSCM}$

$\mathrm{lb} / \mathrm{hr}$
Magnesium

Formula Weight, Lb/Lb-Mole

Catch Weight, Milligrams

Concentration, Micrograms per DSCM

Concentration, Nanograms per DSCM

Emission Rate, Pounds per Hour

\begin{tabular}{|c|c|c|c|}
\hline & 24.31 & & 24.31 \\
\hline$<$ & 107.2 & $<$ & 78.3 \\
\hline$<$ & 101,495 & $<$ & 78,042 \\
\hline & $1.01 E+08$ & $<$ & $7.80 E+07$ \\
\hline & $1.94 \mathrm{E}-01$ & $<$ & $1.39 \mathrm{E}-0$ \\
\hline
\end{tabular}

\section{Manganese}

Formula Weight, Lb/Lb-Mole

Catch Weight, Milligrams

Concentration, Micrograms per DSCM

Concentration, Nanograms per DSCM

Emission Rate, Pounds per Hour

Mercury

Formula Weight, Lb/Lb-Mole

Catch Weight, Milligrams

Concentration, Micrograms per DSCM

Concentration, Nanograms per DSCM

Emission Rate, Pounds per Hour

Nickel

Formula Weight, Ib/Lb-Mole

Catch Weight, Milligrams

Concentration, Micrograms per DSCM

Concentration, Nanograms per DSCM

Emission Rate, Pounds per Hour

Phosphorus

Formula Weight, Lb/Lb-Mole

Catch Weight, Milligrams

Concentration, Micrograms per DSCM

Concentration, Nanograms per DSCM

Emission Rate, Pounds per Hour

$\begin{array}{rrrr} & 30.97 & & 30.97 \\ < & 132.2< & 60.7 \\ < & 125.128< & 60.487 \\ < & 1.25 \mathrm{E}+08< & 6.05 \mathrm{E}+07 \\ < & 2.39 \mathrm{E}-01< & 1.07 \mathrm{E}-01\end{array}$

Potassium

Formula Weight, Lb/Lb-Mole

Catch Weight, Milligrams

Concentration, Micrograms per DSCM

Concentration, Nanograms per DSCM

Emission Rate, Pounds per Hour

$\begin{array}{rrrr} & 200.59 & 200.59 \\ < & 2.2< & 2.5 \\ < & 2.086< & 2.464 \\ < & 2.09 \mathrm{E}+06< & 2.46 \mathrm{E}+06 \\ < & 3.99 \mathrm{E}-03< & 4.37 \mathrm{E}-03\end{array}$

$\begin{array}{rrr} & 58.71 & 58.71 \\ < & 1.4< & 0.8 \\ < & 1.297< & 757 \\ < & 1.30 \mathrm{E}+06< & 7.57 \mathrm{E}+05 \\ < & 2.48 \mathrm{E}-03< & 1.34 \mathrm{E}-03\end{array}$

$3.82 \mathrm{E}+06<7.24 \mathrm{E}+06$

$7.30 \mathrm{E}-03<1.29 \mathrm{E}-02$

$\begin{array}{rr}39.10 & \\ 812.3< & 39.10 \\ 769.080 & <79.3 \\ 7.69 E+08< & 876.742 \\ 1.47 E+00< & 8.77 E+08 \\ & 1.56 E+00\end{array}$

$>$ Indicates the value is below the detection limit. 
Fwt

$\mathrm{mg}$

$u g / D S C M$

$\mathrm{ng} / \mathrm{DSCM}$

$\mathrm{lb} / \mathrm{hr}$

Fwt

$\mathrm{mg}$

ug/DSCM

$\mathrm{ng} / \mathrm{DSCM}$

$\mathrm{lb} / \mathrm{hr}$

FWt

$\mathrm{mg}$

ug/DSCM

$\mathrm{ng} / \mathrm{DSCM}$

1b/hr

FWt

$\mathrm{mg}$

ug/DSCM

$\mathrm{ng} / \mathrm{DSCM}$

Ib/hr

FWt

$\mathrm{mg}$

ug/DSCM

$\mathrm{ng} / \mathrm{DSCM}$

$\mathrm{Ib} / \mathrm{hr}$

FWt

$\mathrm{mg}$

ug/DSCM

$\mathrm{ng} / \mathrm{DSCM}$

Ib/hr
Selenium

Formula Weight, Ib/Lb-Mole

Catch Weight, Milligrams

Concentration, Micrograms per DSCM

Concentration, Nanograms per DSCM

Emission Rate, Pounds per Hour

\section{Silicon}

Formula Weight, Lb/Lb-Mole

Catch Weight, Milligrams

Concentration, Micrograms per DSCM

Concentration, Nanograms per DSCM

Emission Rate, Pounds per Hour

\section{Silver}

Formula Weight, Lb/Lb-Mole

Catch Weight, Milligrams

Concentration, Micrograms per DSCM

Concentration, Nanograms per DSCM

Emission Rate, Pounds per Hour

\section{Sodium}

Formula Weight, Lb/Lb-Mole

Catch Weight, Milligrams

Concentration, Micrograms per DSCM Concentration, Nanograms per DSCM

Emission Rate, Pounds per Hour

\section{Strontium}

Formula Weight, Lb/Lb-Mole

Catch Weight, Milligrams

Concentration, Micrograms per DSCM

Concentration, Nanograms per DSCM

Emission Rate, Pounds per Hour

Titanium

Formula Weight, Lb/Lb-Mole

Catch Weight, Milligrams

Concentration, Micrograms per DSCM

Concentration, Nanograms per DSCM

Emission Rate, Pounds per Hour

$\begin{array}{rr} & 78.96 \\ < & 2.2< \\ < & 2.086< \\ < & 2.09 E+06< \\ < & 3.99 E-03<\end{array}$

78.96

2.5

2,464

$2.46 \mathrm{E}+06$

$4.37 \mathrm{E}-03$

$\begin{array}{rrrr} & 28.09 & & 28.09 \\ < & 1857.9 & < & 1165.9 \\ <\quad 1.758,965< & 1,162,557 \\ <\quad 1.76 E+09< & 1.16 E+09 \\ <\quad 3.37 E+00< & 2.06 E+00\end{array}$

$\begin{array}{rrr} & 107.87 & 107.87 \\ < & 0.2< & 0.3 \\ < & 223< & 262 \\ < & 2.23 E+05< & 2.62 E+05 \\ < & 4.28 \mathrm{E}-04< & 4.66 \mathrm{E}-04\end{array}$

$\begin{array}{rrrr} & 22.99 & & 22.99 \\ < & 1022.8< & 1028.1 \\ < & 968,368< & 1,025,140 \\ <\quad 9.68 \mathrm{E}+08< & 1.03 \mathrm{E}+09 \\ <\quad 1.85 \mathrm{E}+00< & < & 1.82 \mathrm{E}+00\end{array}$

$\begin{array}{rrr} & 87.62 & 87.62 \\ < & 3.3< & 4.1 \\ < & 3.120< & 4.078 \\ < & 3.12 \mathrm{E}+06< & 4.08 \mathrm{E}+06 \\ < & 5.97 \mathrm{E}-03< & 7.24 \mathrm{E}-03\end{array}$

$>$ Indicates the value is below the detection limit.

$\begin{array}{rrr} & 47.90 & \\ < & 32.6< & 47.90 \\ < & 30.859< & 23.5 \\ < & 3.09 E+07< & 23.406 \\ < & 5.91 E-02< & 4.34 E+07\end{array}$


Vanadium

FWt Formula Weight, Ib/Lb-Mole

mg Catch Weight, Milligrams

$\mathrm{ug} / \mathrm{DSCM}$

Concentration, Micrograms per DSCM

$\mathrm{ng} / \mathrm{DSCM}$

Concentration, Nanograms per DSCM

$1 \mathrm{~b} / \mathrm{hr}$

Emission Rate, Pounds per Hour

$\begin{array}{rrrr} & 50.94 & & 50.94 \\ < & 3.1< & 3.4 \\ < & 2.892< & 3.347 \\ < & 2.89 E+06< & 3.35 E+06 \\ < & 5.53 E-03< & 5.94 E-03\end{array}$

FWt

Zine

mg

Formula Weight, Ib/Lb-Mole

$\mathrm{ug} / \mathrm{DSCM}$

$\mathrm{ng} / \mathrm{DSCM}$

$\mathrm{lb} / \mathrm{hr}$

Catch Weight, Milligrams

Concentration, Micrograms per DSCM

Concentration, Nanograms per DSCM

Emission Rate, Pounds per Hour

65.38

65.38

$26.9<$

27.7

$<$

25,427

27,652

$2.54 \mathrm{E}+07<$

2. $77 \mathrm{E}+07$

$<4.87 E-02<4.91 E-02$

FWt

Zirconium

$\mathrm{mg}$

ug/DSCM

$\mathrm{ng} / \mathrm{DSCM}$

1b/hr

Formula Weight, Lb/Lb-Mole

Catch Weight, Milligrams

Concentration, Micrograms per DSCM

Concentration, Nanograms per DSCM

Emission Rate, Pounds per Hour

$\begin{array}{rrrr} & 91.22 & 91.22 \\ < & 0.9< & 2.4 \\ < & 859< & 2.373 \\ < & 8.59 \mathrm{E}+05< & 2.37 \mathrm{E}+06 \\ < & 1.64 \mathrm{E}-03< & 4.21 \mathrm{E}-03\end{array}$

\section{particulate}

$\mathrm{g}$
$\frac{9}{9}$
$\mathrm{~g}$
$\frac{9}{0}$
9
$\frac{9}{8}$
$\mathrm{~g}$
$\mathrm{~g} / \mathrm{DSCM}$
$\mathrm{gr} / \mathrm{DSCF}$
$\mathrm{lb} / \mathrm{hr}$

Catch Weight, Grams (Filter)

Percent of Particulate in Filter

Catch Weight, Grams (HNO3)

Percent of Particulate in HNO3 Rinse

Catch Weight, Grams (Acetone)

Percent of Particulate in Acetone Rinse

Catch Weight, Grams (Total)

Concentration, Total Milligrams per DSCM
9.4504
90.0
0.5689
5.4
0.4767
4.5
10.496
9.937
4.342
19.020

Concentration, Total Grains per DSCF

Emission Rate, Total Pounds per Hour

11.3082

95.6

0.2095

1.8

0.306

2.6

11.8237

11.790

5.152

20.932

$>$ Indicates the value is below the detection limit. 
Appendix P-4

MMT Analysis for the N80-IV and N80-IV-Mod Feed Mixtures 

Table P-4-1. MMT analysis for the N80-IV and N80-IV-Mod feed mixtures.

FIELD DATA

Enter Pathway

Enter File Name

Complete Path Is

Enter Number of Runs

plant Name, City, state

Test Location

Enter Operator Name (s)

Press <Alt> C To Combine The

Run Number

Date

start

stop

Points

Theta

Dia

$\mathrm{Cp}$

$Y$

Pbar

Delta-H

$\mathrm{Vm}$

tm

Vlc

$\mathrm{CO} 2$

$\mathrm{O} 2$

$\mathrm{Pg}$

ts

Delta-p

Area

F-Factor

Tstd

pstd
RUN1

$d: \backslash 11885 \backslash \quad d: \backslash 11885 \backslash$

n80-iv-2

n80-iv-3

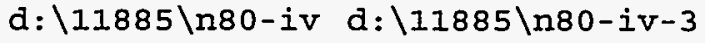

2

U.S. Bureau of Mines, Albany, Oregon

Arc Melter Exhaust

Miguel Chavez Miguel Chavez Miguel Chavez 
LABORATORY DATA

RUN1

RUN2

Compound

\begin{tabular}{|c|c|c|c|c|c|c|c|}
\hline \multicolumn{2}{|c|}{ Fwt Unit } & \multicolumn{2}{|l|}{$\mathrm{FH}$} & \multirow{2}{*}{$\begin{array}{l}\mathrm{BH} \\
0.10\end{array}$} & \multicolumn{2}{|l|}{$\mathrm{FH}$} & \multirow{2}{*}{$\begin{array}{l}\mathrm{BH} \\
0.09\end{array}$} \\
\hline 74.92 & $\mathrm{mg}<$ & 2.77 & $<$ & & 2.20 & $<$ & \\
\hline 26.98 & $\mathrm{mg}$ & 319.07 & & 0.05 & 207.58 & & 0.07 \\
\hline 137.33 & $\mathrm{mg}$ & 20.73 & $<$ & 0.02 & 18.78 & $<$ & 0.02 \\
\hline 10.81 & $\mathrm{mg}$ & & $<$ & 0.10 & - & $<$ & 0.09 \\
\hline 112.41 & $\mathrm{mg}$ & 0.14 & $<$ & 0.00 & 0.17 & $<$ & 0.00 \\
\hline 40.08 & $\mathrm{mg}$ & 453.40 & $<$ & 0.25 & 1213.40 & $<$ & 0.24 \\
\hline 140.12 & $\mathrm{mg}$ & 105.09 & $<$ & 0.02 & 85.75 & $<$ & 0.02 \\
\hline 132.91 & $\mathrm{mg}$ & & & & & & \\
\hline 52 & $\mathrm{mg}$ & 4.44 & $<$ & 0.01 & 3.17 & $<$ & 0.01 \\
\hline 63.55 & $\mathrm{mg}$ & 1.77 & $<$ & 0.05 & 5.93 & $<$ & 0.05 \\
\hline 55.85 & $\mathrm{mg}$ & 379.39 & $<$ & 0.25 & 381.55 & & 1.27 \\
\hline 207.19 & $\mathrm{mg}$ & 6.42 & $<$ & 0.05 & 5.67 & $<$ & 0.05 \\
\hline 24.31 & $\mathrm{mg}$ & 95.95 & $<$ & 0.25 & 74.15 & $<$ & 0.24 \\
\hline 54.94 & $\mathrm{mg}$ & 5.24 & $<$ & 0.01 & 4.15 & $<$ & 0.01 \\
\hline 200.59 & $\mathrm{mg}<$ & 2.77 & $<$ & 0.10 & 1.85 & $<$ & 0.09 \\
\hline 58.71 & $\mathrm{mg}$ & 0.65 & $<$ & 0.02 & 0.76 & $<$ & 0.02 \\
\hline 30.97 & $\mathrm{mg}$ & 114.24 & $<$ & 0.05 & 44.05 & $<$ & 0.05 \\
\hline 39.1 & $\mathrm{mg}$ & 1182.39 & $<$ & 0.25 & 741.71 & $<$ & 0.24 \\
\hline 78.96 & $\mathrm{mg}<$ & 2.77 & $<$ & 0.10 & 1.85 & $<$ & 0.09 \\
\hline 28.09 & $\mathrm{mg}$ & 2005.51 & $<$ & 0.10 & 1213.40 & $<$ & 0.09 \\
\hline 107.87 & $\mathrm{mg}$ & 3.91 & $<$ & 0.02 & 1.99 & $<$ & 0.02 \\
\hline 22.99 & $\mathrm{mg}$ & 1311.73 & $<$ & 0.25 & 659.77 & $<$ & 0.24 \\
\hline 87.62 & $\mathrm{mg}$ & 5.68 & $<$ & 0.01 & 6.09 & $<$ & 0.01 \\
\hline 47.9 & $\mathrm{mg}$ & 47.72 & $<$ & 0.02 & 28.33 & $<$ & 0.02 \\
\hline 50.94 & $\mathrm{mg}$ & 5.02 & $<$ & 0.01 & 2.12 & $<$ & 0.01 \\
\hline 65.38 & $\mathrm{mg}$ & 14.88 & $<$ & 0.25 & 7.28 & $<$ & 0.24 \\
\hline 91.22 & $\mathrm{mg}$ & 648.72 & $<$ & 0.02 & 343.14 & $<$ & 0.02 \\
\hline & $\mathrm{g}$ & 11.204 & & & 6.646 & & \\
\hline ic & g & 1.044 & & & 0.304 & & \\
\hline & $g$ & 1.583 & & & 2.313 & & \\
\hline
\end{tabular}

< Indicates the value is below the detection Iimit. 
LABORATORY DATA

Particulate Total (g)

13.8311

9.2626

Sample Volume (ml)

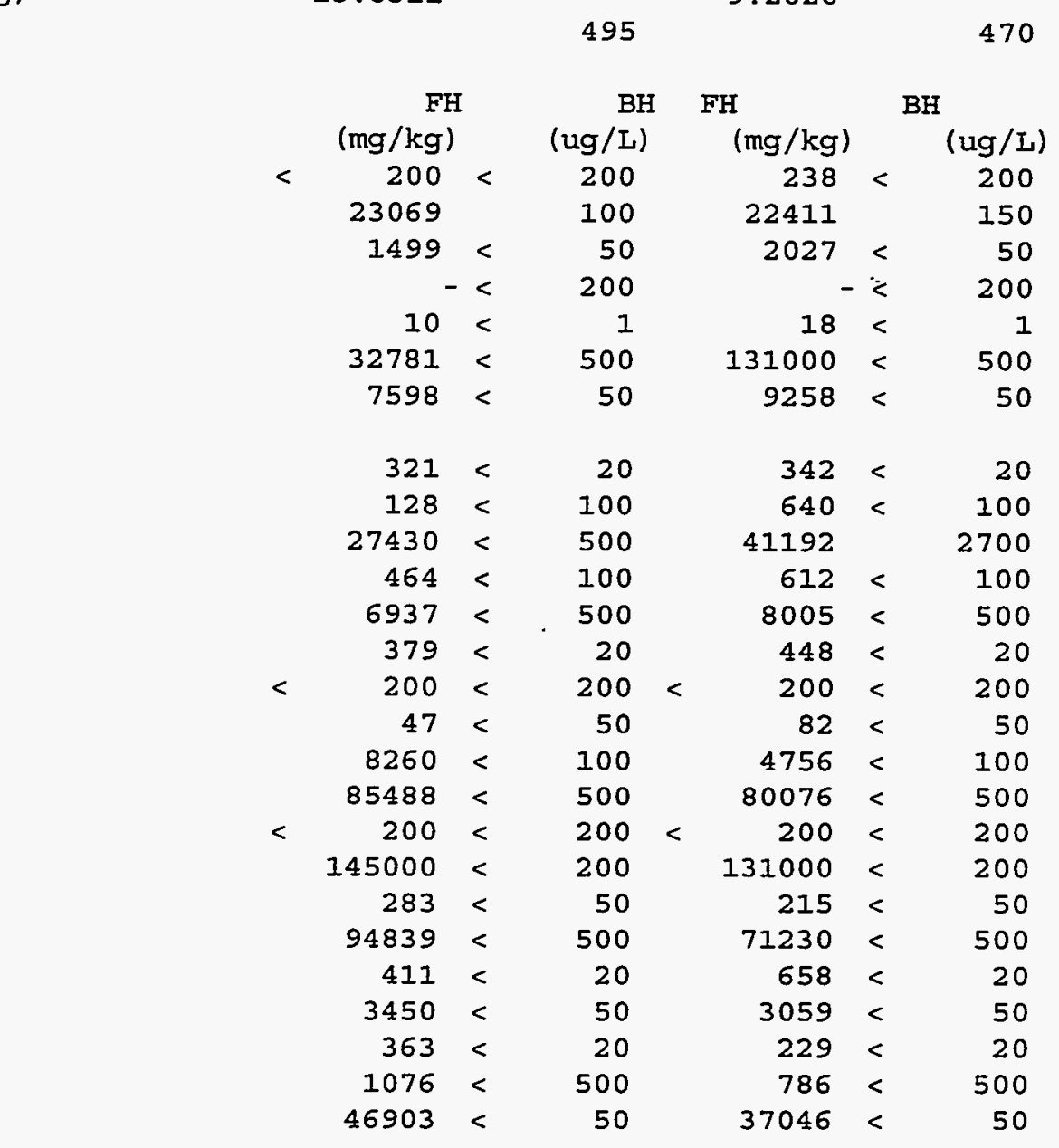

Compound

Arsenic

Aluminum

Barium

Boron

Cadmium

Calcium

Cerium

Cesium

Chromium

Copper

Iron

Lead

Magnesium

Manganese

Mercury

Nickel

Phosphorus

Potassium

Selenium

silicon

Silver

Sodium

strontium

Titanium

Vanadium

Zinc

zirconium

< Indicates the value is below the detection limit. 
Plant: U.S. Bureau of Mines, Albany, Oregon Test Location: Arc Melter Exhaust

Run Number
MMT-N80-IV-2
MMT-N80-IV-3

Run start Time

Run stop Time

Net Sampling/Traversing Points

Net Run Time, Minutes

Dia Nozzle Diameter, Inches

$\mathrm{Cp}$

$Y$

Pbar

Delta-H

$\mathrm{Vm}$

Vmm

tm

Vmstd

Vmstdm

$\mathrm{Vlc}$

Vwstd

\&H2O

\&H2Osat

Mfd

$\because \mathrm{CO} 2$

s02

Md

Ms

$\mathrm{Pg}$

Ps

ts

Delta-p

vs

A

Qsd

Qmsd

Qaw

Qmaw

\&I

$\% E A$

Fo
Pitot Tube Coefficient

Dry Gas Meter Calibration Coefficient

Barometric Pressure, Inches $\mathrm{Hg}$

Orifice Average Pressure Differential, Inch

Sampled Volume of Source Gas, Dry ACF

Sampled Volume of Source Gas, Dry ACM

Dry Gas Meter Temperature, Degrees F

Sampled Volume of Source Gas, Dry SCF

Sampled Volume of Source Gas, Dry SCM

Volume of Condensed Liquid, $\mathrm{mL}$

Volume of water Vapor, SCF

Moisture Content, Percent by Volume

Saturated Moisture Content, Percent by Volu Source Gas Dry Mole Fraction

Source Gas CO2 Content, Percent by Dry Volu Source Gas 02 Content, Percent by Dry Volum Source Gas Dry Molecular Weight, Lb/Lb-Mole Source Gas Wet Molecular Weight, Lb/Lb-Mole Source Gas Static Pressure, Inches H2O

Source Gas Absolute Pressure, Inches Hg Source Gas Temperature, Degrees F

Source Gas Average Velocity Head, Inches H2 Source Gas Velocity, Feet/Second

Source Cross Sectional Area, Square Inches

Source Gas Volumetric Flow Rate, Dry SCFM

Source Gas Volumetric Flow Rate, Dry SCMM

Source Gas Volumetric Flow Rate, wet ACFM

Source Gas Volumetric Flow Rate, Wet ACMM

Average Isokinetic Sampling Rate, Percent

Excess Air, Percent

Fuel Factor

$\begin{array}{rr}\text { MMT-N80-IV-2 } & \text { MMT-N80-IV-3 } \\ 1220 & 1545 \\ 1334 & 1655 \\ 12 & 12 \\ 60 & 60 \\ 0.194 & 0.194 \\ 0.99 & 0.99 \\ 1.0060 & 1.0060 \\ 29.80 & 29.80 \\ 1.175 & 1.575 \\ 34.748 & 40.490 \\ 0.98 & 1.15 \\ 73 & 74 \\ 34.617 & 40.270 \\ 0.980 & 1.140 \\ 51.1 & 52.1 \\ 2.405 & 2.452 \\ 6.50 & 5.74 \\ 100.0 & 100.0 \\ 0.935 & 0.943 \\ 3.8 & 3.1 \\ 19.6 & 20.0 \\ 29.40 & 29.30 \\ 28.65 & 28.66 \\ -1.90 & -1.90 \\ 29.66 & 29.66 \\ 216 & 229 \\ 0.7775 & 0.6860 \\ 66.55 & 63.11 \\ 24 & 24 \\ 477 & 447 \\ 14 & 13 \\ 659 & 625 \\ 19 & 18 \\ 97.2 & 120.6 \\ 3176 & 8333 \\ 0.340 & 0.274\end{array}$

Operator

Miguel Chavez

Miguel Chavez 
FWt

$\mathrm{mg}$

ug/DSCM

$\mathrm{ng} / \mathrm{DSCM}$

$1 \mathrm{~b} / \mathrm{hr}$

FWt

mg

$\mathrm{ug} / \mathrm{DSCM}$

$\mathrm{ng} / \mathrm{DSCM}$

$\mathrm{Ib} / \mathrm{hr}$

FWt

mg

ug/DSCM

$\mathrm{ng} / \mathrm{DSCM}$

$\mathrm{Ib} / \mathrm{hr}$

FWt

$\mathrm{mg}$

ug/DSCM

$\mathrm{ng} / \mathrm{DSCM}$

1b/hr

FWt

mg

ug/DSCM

$\mathrm{ng} / \mathrm{DSCM}$

$1 \mathrm{~b} / \mathrm{hr}$

FWt

$\mathrm{mg}$

ug/DSCM

$\mathrm{ng} / \mathrm{DSCM}$

$\mathrm{Ib} / \mathrm{hr}$
Arsenic

Formula Weight, Lb/Lb-Mole

Catch Weight, Milligrams

Concentration, Micrograms per DSCM

Concentration, Nanograms per DSCM

Emission Rate, Pounds per Hour
MMT-N80-IV-2 MMT-N80-IV-3

$\begin{array}{rrrr} & 74.92 & 74.92 \\ < & 2.9< & 2.3 \\ < & 2.923< & 2,016 \\ < & 2.92 \mathrm{E}+06< & 2.02 \mathrm{E}+06 \\ & 5.22 \mathrm{E}-03< & 3.38 \mathrm{E}-03\end{array}$

\section{Aluminum}

Formula Weight, Lb/Lb-Mole

Catch Weight, Milligrams

Concentration, Micrograms per DSCM

Concentration, Nanograms per DSCM

Emission Rate, Pounds per Hour

\section{Barium}

Formula Weight, Lb/Lb-Mole

Catch Weight, Milligrams

Concentration, Micrograms per DSCM

Concentration, Nanograms per DSCM

Emission Rate, Pounds per Hour

Boron

Formula Weight, Lb/Lb-Mole

Catch Weight, Milligrams

Concentration, Micrograms per DSCM

Concentration, Nanograms per DSCM

Emission Rate, Pounds per Hour

\section{Cadmium}

Formula Weight, Lb/Lb-Mole

Catch Weight, Milligrams

Concentration, Micrograms per DSCM

Concentration, Nanograms per DSCM

Emission Rate, Pounds per Hour

Calcium

Formula Weight, Lb/Lb-Mole

Catch Weight, Milligrams

Concentration, Micrograms per DSCM

Concentration, Nanograms per DSCM

Emission Rate, Pounds per Hour

$\begin{array}{rr}26.98 & 26.98 \\ 319.1 & 207.7 \\ 325,551 & 182,103 \\ 3.26 \mathrm{E}+08 & 1.82 \mathrm{E}+08 \\ 5.82 \mathrm{E}-01 & 3.05 \mathrm{E}-01\end{array}$

\begin{tabular}{|c|c|c|c|}
\hline & 137.33 & & 137.33 \\
\hline$<$ & 20.8 & $<$ & 18.8 \\
\hline & 21,176 & $<$ & 16,486 \\
\hline & $2.12 \mathrm{E}+07$ & $<$ & $1.65 \mathrm{E}+0^{\circ}$ \\
\hline & $3.78 E-02$ & $<$ & $2.76 \mathrm{E}-0$ \\
\hline
\end{tabular}

$\begin{array}{rrrr} & 10.81 & 10.81 \\ < & 0.1< & 0.1 \\ < & 101< & 82 \\ < & 1.01 \mathrm{E}+05< & 8.24 \mathrm{E}+04 \\ < & 1.80 \mathrm{E}-04< & 1.38 \mathrm{E}-04\end{array}$

$\begin{array}{rrrr} & 112.41 & 112.41 \\ < & 0.1< & 0.2 \\ < & 142< & 147 \\ < & 1.42 \mathrm{E}+05< & 1.47 \mathrm{E}+05 \\ < & 2.53 \mathrm{E}-04< & 2.46 \mathrm{E}-04\end{array}$

$\begin{array}{rrrr} & 40.08 & & 40.08 \\ < & 453.6 & < & 1213.6 \\ < & 462.789< & 1,064,299 \\ < & 4.63 \mathrm{E}+08< & 1.06 \mathrm{E}+09 \\ < & 8.27 \mathrm{E}-01< & 1.78 \mathrm{E}+00\end{array}$

< Indicates the value is below the detection limit. 


FWt
$\mathrm{mg}$
$\mathrm{ug} / \mathrm{DSCM}$
$\mathrm{ng} / \mathrm{DSCM}$
$\mathrm{lb} / \mathrm{hr}$

FWt

mg

ug/DSCM

$\mathrm{ng} / \mathrm{DSCM}$

$\mathrm{lb} / \mathrm{hr}$

FWt

mg

ug/DSCM

$\mathrm{ng} / \mathrm{DSCM}$

$\mathrm{lb} / \mathrm{hr}$

FWt

$\mathrm{mg}$

ug/DSCM

$\mathrm{ng} / \mathrm{DSCM}$

$\mathrm{lb} / \mathrm{hr}$

FWt

$\mathrm{mg}$

$\mathrm{ng} / \mathrm{DSCM}$

$\mathrm{lb} / \mathrm{hr}$

FWt

mg

ug/DSCM

$\mathrm{ng} / \mathrm{DSCM}$

$\mathrm{lb} / \mathrm{hr}$
ug/DSCM
Cerium

Formula Weight, Lb/Lb-Mole

Catch Weight, Milligrams

Concentration, Micrograms per DSCM

Concentration, Nanograms per DSCM

Emission Rate, Pounds per Hour

\section{Cesium}

Formula Weight, Lb/Lb-Mole

Catch Weight, Milligrams

Concentration, Micrograms per DSCM

Concentration, Nanograms per DSCM

Emission Rate, Pounds per Hour

\section{Chromium}

Formula Weight, Lb/Lb-Mole

Catch Weight, Milligrams

Concentration, Micrograms per DSCM

Concentration, Nanograms per DSCM

Emission Rate, Pounds per Hour

\section{Copper}

Formula Weight, Lb/Lb-Mole

Catch Weight, Milligrams

Concentration, Micrograms per DSCM

Concentration, Nanograms per DSCM

Emission Rate, Pounds per Hour

Iron

Formula Weight, Lb/Lb-Mole

Catch Weight, Milligrams

Concentration, Micrograms per DSCM

Concentration, Nanograms per DSCM

Emission Rate, Pounds per Hour

Lead

Formula Weight, Lb/Lb-Mole

Catch Weight, Milligrams

Concentration, Micrograms per DSCM

Concentration, Nanograms per DSCM

Emission Rate, Pounds per Hour
MMT-N80-IV-2 MMT-N80-IV-3

\begin{tabular}{|c|c|c|c|}
\hline & 140.12 & & 140.12 \\
\hline & 105.1 & $<$ & 85.8 \\
\hline & 107,232 & $<$ & 75,222 \\
\hline & $1.07 E+08$ & $<$ & $7.52 \mathrm{E}+07$ \\
\hline & $1.92 \mathrm{E}-$ & $<$ & $1.26 \mathrm{E}-01$ \\
\hline
\end{tabular}

$\begin{array}{rr}132.91 & 132.91 \\ 0.0 & 0.0 \\ 0 & 0 \\ 0.00 E+00 & 0.00 E+00 \\ 0.00 E+00 & 0.00 E+00\end{array}$

$\begin{array}{rrrr} & 52.00 & & 52.00 \\ < & 4.4< & 3.2 \\ < & 4.539< & 2.786 \\ < & 4.54 \mathrm{E}+06< & 2.79 \mathrm{E}+06 \\ < & 8.11 \mathrm{E}-03< & 4.67 \mathrm{E}-03\end{array}$

$\begin{array}{rrrr} & 63.55 & & 63.55 \\ < & 1.8< & 6.0 \\ < & 1.857< & 5.240 \\ < & 1.86 \mathrm{E}+06< & 5.24 \mathrm{E}+06 \\ < & 3.32 \mathrm{E}-03< & 8.78 \mathrm{E}-03\end{array}$

$\begin{array}{rrr} & 55.85 & 55.85 \\ < & 379.6 & 382.8 \\ < & 387,287 & 335,709 \\ < & 3.87 \mathrm{E}+08 & 3.36 \mathrm{E}+08 \\ < & 6.92 \mathrm{E}-01 & 5.63 \mathrm{E}-01\end{array}$

< Indicates the value is below the detection limit.

$\begin{array}{rrrr} & 207.19 & & 207.19 \\ < & 6.5< & 5.7 \\ < & 6.597< & 5,012 \\ < & 6.60 \mathrm{E}+06 & < & 5.01 \mathrm{E}+06 \\ < & 1.18 \mathrm{E}-02< & 8.40 \mathrm{E}-03\end{array}$


FWt Formula Weight, Lb/Lb-Mole

mg Catch Weight, Milligrams

$\mathrm{ug} / \mathrm{DSCM}$

$\mathrm{Ib} / \mathrm{hr}$

FWt

mg

$\mathrm{ug} / \mathrm{DSCM}$

$\mathrm{ng} / \mathrm{DSCM}$

$1 \mathrm{~b} / \mathrm{hr}$

FWt

mg

ug/DSCM

$\mathrm{ng} / \mathrm{DSCM}$

Ib/hr

FWt

$\mathrm{mg}$

ug/DSCM

$\mathrm{ng} / \mathrm{DSCM}$

Ib/hr

FWt

mg

ug/DSCM

$\mathrm{ng} / \mathrm{DSCM}$

$1 \mathrm{~b} / \mathrm{hr}$

FWt

mg

ug/DSCM

$\mathrm{ng} / \mathrm{DSCM}$

$\mathrm{lb} / \mathrm{hr}$

\section{Manganese}

Formula Weight, Lb/Lb-Mole

Catch Weight, Milligrams

Mercury

Formula Weight, Lb/Lb-Mole

Catch Weight, Milligrams

Nickel

Formula Weight, Lb/Lb-Mole

Catch Weight, Milligrams

Phosphorus

Formula Weight, Lb/Lb-Mole

Catch Weight, Milligrams

Potassium

Formula Weight, Lb/Lb-Mole

Catch Weight, Milligrams $\mathrm{ng} / \mathrm{DSCM}$
Concentration, Micrograms per DSCM

Concentration, Nanograms per DSCM

Emission Rate, Pounds per Hour

$\begin{array}{rrrr} & 24.31 & & 24.31 \\ < & 96.2< & 74.4 \\ < & 98.133< & 65.229 \\ < & 9.81 E+07< & 6.52 E+07 \\ < & 1.75 E-01< & 1.09 E-01\end{array}$

Concentration, Micrograms per DSCM

Concentration, Nanograms per DSCM

Emission Rate, Pounds per Hour

Concentration, Micrograms per DSCM

Concentration, Nanograms per DSCM

Emission Rate, Pounds per Hour

Concentration, Micrograms per DSCM

Concentration, Nanograms per DSCM

Emission Rate, Pounds per Hour

Concentration, Micrograms per DSCM

Concentration, Nanograms per DSCM

Emission Rate, Pounds per Hour

Concentration, Micrograms per DSCM

Concentration, Nanograms per DSCM

Emission Rate, Pounds per Hour

$\begin{array}{rrrr} & 54.94 & & 54.94 \\ < & 5.3< & 4.2 \\ < & 5,358< & 3.647 \\ < & 5.36 \mathrm{E}+06< & 3.65 \mathrm{E}+06 \\ < & 9.57 \mathrm{E}-03< & 6.11 \mathrm{E}-03\end{array}$

$\begin{array}{rrrr} & 200.59 & & 200.59 \\ < & 2.9 & < & 1.9 \\ < & 2.923< & 1.707 \\ < & 2.92 \mathrm{E}+06< & 1.71 \mathrm{E}+06 \\ < & 5.22 \mathrm{E}-03< & 2.86 \mathrm{E}-03\end{array}$

$\begin{array}{rr} & 58.71 \\ < & 0.7< \\ < & 688< \\ < & 6.88 \mathrm{E}+05< \\ < & 1.23 \mathrm{E}-03<\end{array}$

58.71

0.8

687

$6.87 \mathrm{E}+05$

1. $15 \mathrm{E}-03$

\begin{tabular}{|c|c|c|c|}
\hline & 30.97 & & 30.97 \\
\hline$<$ & 114.3 & $<$ & 44.1 \\
\hline$<$ & 116,598 & $<$ & 38,673 \\
\hline & 1. $17 \mathrm{E}+08$ & $<$ & $3.87 \mathrm{E}+07$ \\
\hline & $2.08 E-01$ & $<$ & $6.48 E-0$ \\
\hline
\end{tabular}

$\begin{array}{rrrr} & 39.10 & & 39.10 \\ < & 1182.6 & < & 741.9 \\ < & 1.206 .478< & 650.651 \\ < & 1.21 E+09< & 6.51 E+08 \\ <\quad 2.16 E+00< & < & 1.09 E+00\end{array}$

< Indicates the value is below the detection limit. 
MMT-N80-IV-2 MMT-N80-IV-3

mg

ug/DSCM

ng/DSCM

$\mathrm{Ib} / \mathrm{hr}$

FWt

mg

ug/DSCM

$\mathrm{ng} / \mathrm{DSCM}$

$\mathrm{lb} / \mathrm{hr}$

FWt

$\mathrm{mg}$

$\mathrm{ug} / \mathrm{DSCM}$

$\mathrm{ng} / \mathrm{DSCM}$

$\mathrm{lb} / \mathrm{hr}$

FWt

mg

ug/DSCM

$\mathrm{ng} / \mathrm{DSCM}$

$\mathrm{Ib} / \mathrm{hr}$

FWt

$\mathrm{mg}$

ug/DSCM

$\mathrm{ng} / \mathrm{DSCM}$

$\mathrm{Ib} / \mathrm{hr}$
Formula weight, Lb/Lb-Mole

Catch Weight, Milligrams

Concentration, Micrograms per DSCM

Concentration, Nanograms per DSCM

Emission Rate, Pounds per Hour

$\begin{array}{rrrr} & 78.96 & 78.96 \\ < & 2.9< & 1.9 \\ < & 2.923< & 1.707 \\ < & 2.92 \mathrm{E}+06< & 1.71 \mathrm{E}+06 \\ < & 5.22 \mathrm{E}-03< & 2.86 \mathrm{E}-03\end{array}$

silicon

Formula Weight, Lb/Lb-Mole

Catch Weight, Mililigrams

Concentration, Micrograms per DSCM

Concentration, Nanograms per DSCM

Emission Rate, Pounds per Hour

Silver

Formula Weight, Ib/Lb-Mole

Catch Weight, Milligrams

Concentration, Micrograms per DSCM

Concentration, Nanograms per DSCM

Emission Rate, Pounds per Hour

Sodium

Formula Weight, Lb/Lb-Mole

Catch Weight, Milligrams

Concentration, Micrograms per DSCM

Concentration, Nanograms per DSCM

Emission Rate, Pounds per Hour

Strontium

Formula Weight, Lb/Lb-Mole

Catch Weight, Milligrams

Concentration, Micrograms per DSCM

Concentration, Nanograms per DSCM

Emission Rate, Pounds per Hour

Titanium

Formula Weight, Lb/Lb-Mole

Catch Weight, Milligrams

Concentration, Micrograms per DSCM

Concentration, Nanograms per DSCM

Emission Rate, Pounds per Hour

$\begin{array}{rrr} & 28.09 & 28.09 \\ <\quad 2005.6 & < & 1213.5 \\ <\quad 2,046.034 & < & 1,064,175 \\ <\quad 2.05 E+09< & 1.06 E+09 \\ <\quad 3.66 E+00< & 1.78 E+00\end{array}$

$\begin{array}{rrrr} & 107.87 & & 107.87 \\ < & 3.9 & < & 2.0 \\ < & 4.018< & 1.767 \\ < & 4.02 \mathrm{E}+06 & < & 1.77 \mathrm{E}+06 \\ < & 7.18 \mathrm{E}-03< & 2.96 \mathrm{E}-03\end{array}$

$\begin{array}{rrrr} & 22.99 & & 22.99 \\ < & 1312.0< & 660.0 \\ <\quad 1.338 .420 & < & 578,796 \\ <\quad 1.34 \mathrm{E}+09 & < & 5.79 \mathrm{E}+08 \\ & 2.39 \mathrm{E}+00< & < & 9.70 \mathrm{E}-01\end{array}$

$\begin{array}{rrr} & 87.62 & 87.62 \\ < & 5.7< & 6.1 \\ < & 5.809< & 5.353 \\ < & 5.81 E+06< & 5.35 \mathrm{E}+06 \\ < & 1.04 \mathrm{E}-02< & 8.97 \mathrm{E}-03\end{array}$

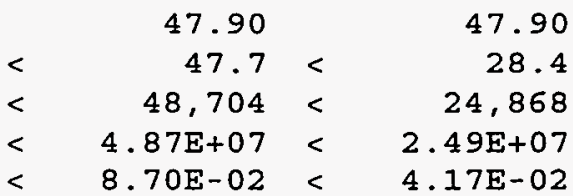

< Indicates the value is below the detection limit. 
MMT-N80-IV-2 MMT-N80-IV-3

FWt
$\mathrm{mg}$
$\mathrm{ug} / \mathrm{DSCM}$
$\mathrm{ng} / \mathrm{DSCM}$
$\mathrm{lb} / \mathrm{hr}$

FWt

mg

$\mathrm{ug} / \mathrm{DSCM}$

$\mathrm{ng} / \mathrm{DSCM}$

$\mathrm{lb} / \mathrm{hr}$

FWt

$\mathrm{mg}$

ug/DSCM

$\mathrm{ng} / \mathrm{DSCM}$

$\mathrm{lb} / \mathrm{hr}$
Vanadium

Formula Weight, Lib/Lb-Mole

Catch Weight, Milligrams

Concentration, Micrograms per DSCM

Concentration, Nanograms per DSCM

Emission Rate, Pounds per Hour

zinc

Formula Weight, Lb/Lb-Mole

Catch Weight, Milligrams

Concentration, Micrograms per DSCM

Concentration, Nanograms per DSCM

Emission Rate, Pounds per Hour

Zirconium

Formula Weight, Lb/Lb-Mole

Catch Weight, Milligrams

Concentration, Micrograms per DSCM

Concentration, Nanograms per DSCM

Emission Rate, Pounds per Hour

\section{Particulate}

Catch Weight, Grams (Filter)

Percent of Particulate in Filter

Catch Weight, Grams (HNO3)

Percent of Particulate in HNO3 Rinse

Catch Weight, Grams (Acetone)

Percent of Particulate in Acetone Rinse

Catch Weight, Grams (Total)

Concentration, Total Milligrams per DSCM

Concentration, Total Grains per DSCF

Emission Rate, Total Pounds per Hour

$\begin{array}{rrrr} & 50.94 & & 50.94 \\ < & 5.0< & 2.1 \\ < & 5.132< & 1,868 \\ < & 5.13 \mathrm{E}+06< & 1.87 \mathrm{E}+06 \\ < & 9.17 \mathrm{E}-03< & 3.13 \mathrm{E}-03\end{array}$

$\begin{array}{rrr} & 65.38 & \\ < & 15.1< & 65.38 \\ < & 15.435< & 7.5 \\ < & 1.54 \mathrm{E}+07< & 6.591 \\ < & 2.76 \mathrm{E}-02< & <.59 \mathrm{E}+06 \\ & & 1.10 \mathrm{E}-02\end{array}$

$\begin{array}{rrr} & 91.22 & \\ < & 648.7< & 91.22 \\ < & 661.821< & 343.2 \\ < & 6.62 \mathrm{E}+08< & 300.939 \\ < & 3.01 \mathrm{E}+08 \\ & 1.18 \mathrm{E}+00< & 5.04 \mathrm{E}-01\end{array}$

g/DSCM

gr/DSCF

$\mathrm{lb} / \mathrm{hr}$

< Indicates the value is below the detection limit.

$\begin{array}{rr}11.2042 & 6.6459 \\ 81.0 & 71.7 \\ 1.0435 & 0.3039 \\ 7.5 & 3.3 \\ 1.5834 & 2.3128 \\ 11.4 & 25.0 \\ 13.8311 & 9.2626 \\ 14.110 & 8.123 \\ 6.166 & 3.550 \\ 25.211 & 13.614\end{array}$




\section{Appendix P-5}

MMT Analysis for the M60 and M60-Mod Feed Mixtures 


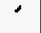


Table P-5-1. MMT analysis for the M60 and N80-IV-Mod 2 feed mixtures.

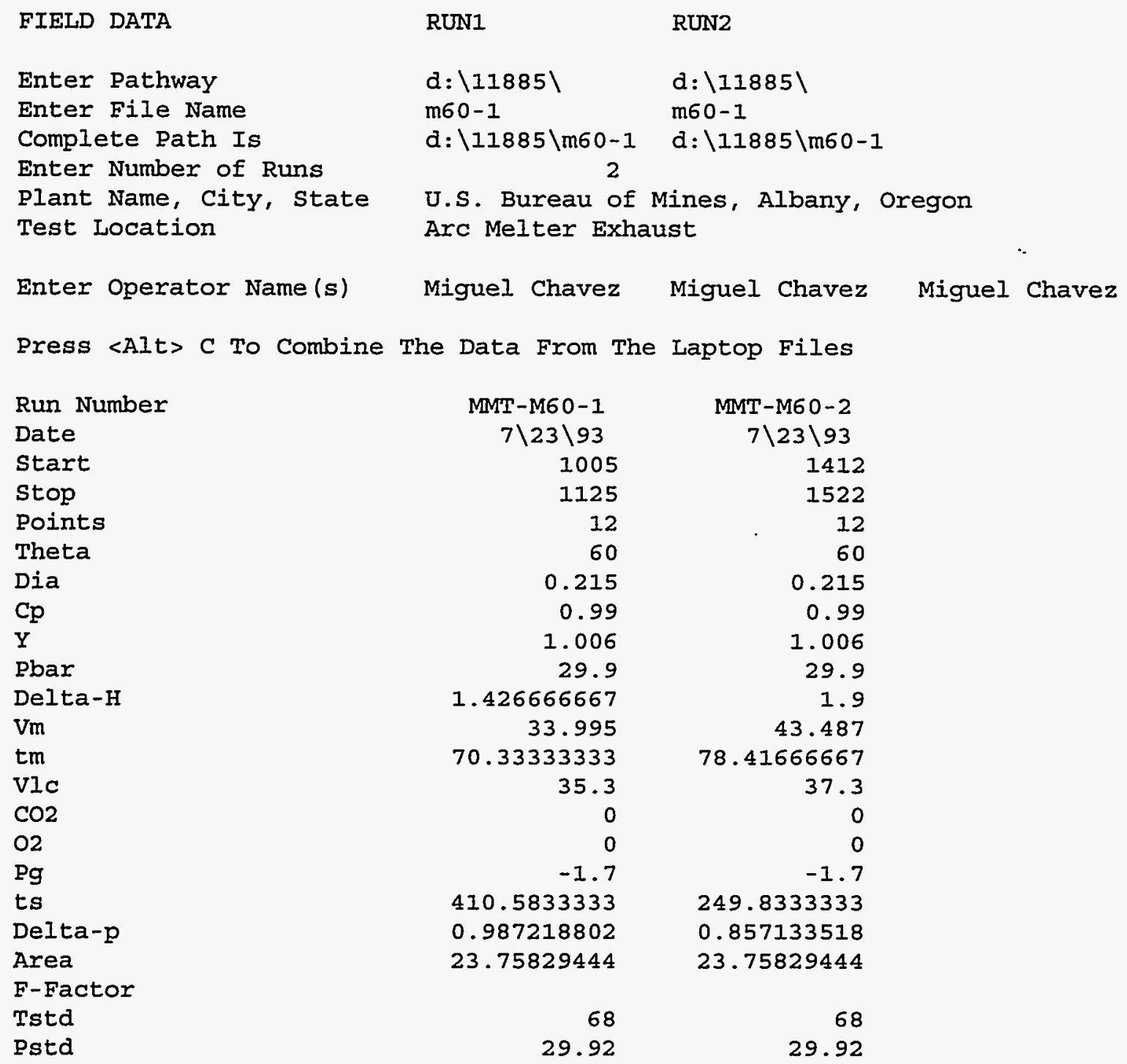




\begin{tabular}{|c|c|c|c|c|c|c|c|c|c|c|c|}
\hline \multirow[b]{3}{*}{1} & \multirow{2}{*}{\multicolumn{2}{|c|}{$\begin{array}{l}\text { LABORATORY DATA } \\
\text { Compound }\end{array}$}} & & & \multicolumn{5}{|c|}{ RUN1 } & \multicolumn{2}{|c|}{ RUN2 } \\
\hline & & & \multicolumn{2}{|c|}{ Fwt Unit } & \multirow{2}{*}{$\begin{array}{l}\mathrm{FH} \\
2.37\end{array}$} & \multicolumn{2}{|r|}{$\mathrm{BH}$} & \multicolumn{2}{|r|}{ FH } & \multirow{2}{*}{\multicolumn{2}{|c|}{$\begin{array}{l}\text { BH } \\
0.10\end{array}$}} \\
\hline & Arsenic & & 74.92 & $\mathrm{mg}<$ & & $<$ & 0.11 & $<$ & 2.68 & & \\
\hline 2 & Aluminum & & 26.98 & mg & 183.74 & & 0.08 & & 313.99 & & 0.03 \\
\hline 3 & Barium & & 137.33 & mg & 15.77 & $<$ & 0.03 & & 20.41 & $<$ & 0.03 \\
\hline 4 & Boron & & 10.81 & $\mathrm{mg}$ & - & $<$ & 0.11 & & - & $<$ & 0.10 \\
\hline 5 & Cadmium & & 112.41 & mg & 0.15 & $<$ & 0.00 & & 0.17 & $<$ & 0.00 \\
\hline 6 & Calcium & & 40.08 & mg & 355.09 & $<$ & 0.27 & & 1368.91 & $<$ & 0.25 \\
\hline 7 & Cerium & & 140.12 & $\mathrm{mg}$ & 20.12 & $<$ & 0.03 & & 90.98 & $<$ & 0.03 \\
\hline 8 & Cesium & & 132.91 & $\mathrm{mg}$ & & & & & & & \\
\hline 9 & Chromium & & 52 & $\mathrm{mg}$ & 5.48 & $<$ & 0.01 & & 25.19 & $<$ & 0.01 \\
\hline 10 & Copper & & 63.55 & mg & 4.97 & $<$ & 0.05 & & 10.52 & $<$ & 0.05 \\
\hline 11 & Iron & & 55.85 & $\mathrm{mg}$ & 153.07 & $<$ & 0.27 & & 571.13 & $<$ & 0.25 \\
\hline 12 & Lead & & 207.19 & $\mathrm{mg}$ & 1703.16 & $<$ & 0.05 & & 73.17 & $<$ & 0.05 \\
\hline 13 & Magnesium & & 24.31 & mg & 51.83 & $<$ & 0.27 & & 102.05 & $<$ & 0.25 \\
\hline 14 & Manganese & & 54.94 & $\mathrm{mg}$ & 4.75 & $<$ & 0.01 & & 6.67 & $<$ & 0.01 \\
\hline 15 & Mercury & & 200.59 & $\mathrm{mg}<$ & 2.37 & $<$ & 0.11 & $<$ & 2.68 & $<$ & 0.10 \\
\hline 16 & Nickel & & 58.71 & $\mathrm{mg}$ & 1.45 & $<$ & 0.03 & & 2.16 & $<$ & 0.03 \\
\hline 17 & Phosphorus & & 30.97 & $\mathrm{mg}$ & 18.24 & $<$ & 0.05 & & 69.28 & $<$ & 0.05 \\
\hline 18 & Potassium & & 39.1 & $\mathrm{mg}$ & 195.75 & $<$ & 0.27 & & 1083.36 & $<$ & 0.25 \\
\hline 19 & Selenium & & 78.96 & $\mathrm{mg}<$ & 2.37 & $<$ & 0.11 & $<$ & 2.68 & $<$ & 0.10 \\
\hline 20 & Silicon & & 28.09 & $\mathrm{mg}$ & 1395.65 & $<$ & 0.11 & & 1691.01 & $<$ & 0.10 \\
\hline 21 & Silver & & 107.87 & $\mathrm{mg}$ & 0.64 & $<$ & 0.03 & & 2.97 & $<$ & 0.03 \\
\hline 22 & Sodium & & 22.99 & $\mathrm{mg}$ & 122.91 & $<$ & 0.27 & & 972.50 & $<$ & 0.25 \\
\hline 23 & strontium & & 87.62 & $\mathrm{mg}$ & 4.22 & $<$ & 0.01 & & 7.65 & $<$ & 0.01 \\
\hline 24 & Titanium & & 47.9 & $\mathrm{mg}$ & 10.89 & $<$ & 0.03 & & 37.69 & $<$ & 0.03 \\
\hline 25 & Vanadium & & 50.94 & mg & 0.33 & $<$ & 0.01 & & 2.52 & $<$ & 0.01 \\
\hline 26 & Zinc & & 65.38 & mg & 2602.05 & $<$ & 0.27 & & 188.10 & $<$ & 0.25 \\
\hline 27 & Zirconium & & 91.22 & $\mathrm{mg}$ & 6.40 & $<$ & 0.03 & & 511.33 & $<$ & 0.03 \\
\hline 28 & Particulate & (Filter) & & $\mathrm{g}$ & 9.834 & & & & 11.145 & & \\
\hline 29 & Particulate & (Nitric I & (cid) & $\mathrm{g}$ & 0.247 & & & & 0.363 & & \\
\hline 30 & Particulate & (Acetone) & & $\mathrm{g}$ & 1.746 & & & & 1.913 & & \\
\hline
\end{tabular}

< Indicates the value is below the detection limit. 
LABORATORY DATA

Particulate Total ( $g$ )

Sample Volume (ml)

Compound

Arsenic

Aluminum

Barium

Boron

Cadmium

Calcium

Cerium

Cesium

Chromium

Copper

Iron

Lead

Magnesium

Manganese

Mercury

Nickel

Phosphorus

Potassium

Selenium

silicon

Silver

Sodium

Strontium

Titanium

Vanadium

zinc

zirconium

$$
11.8275
$$

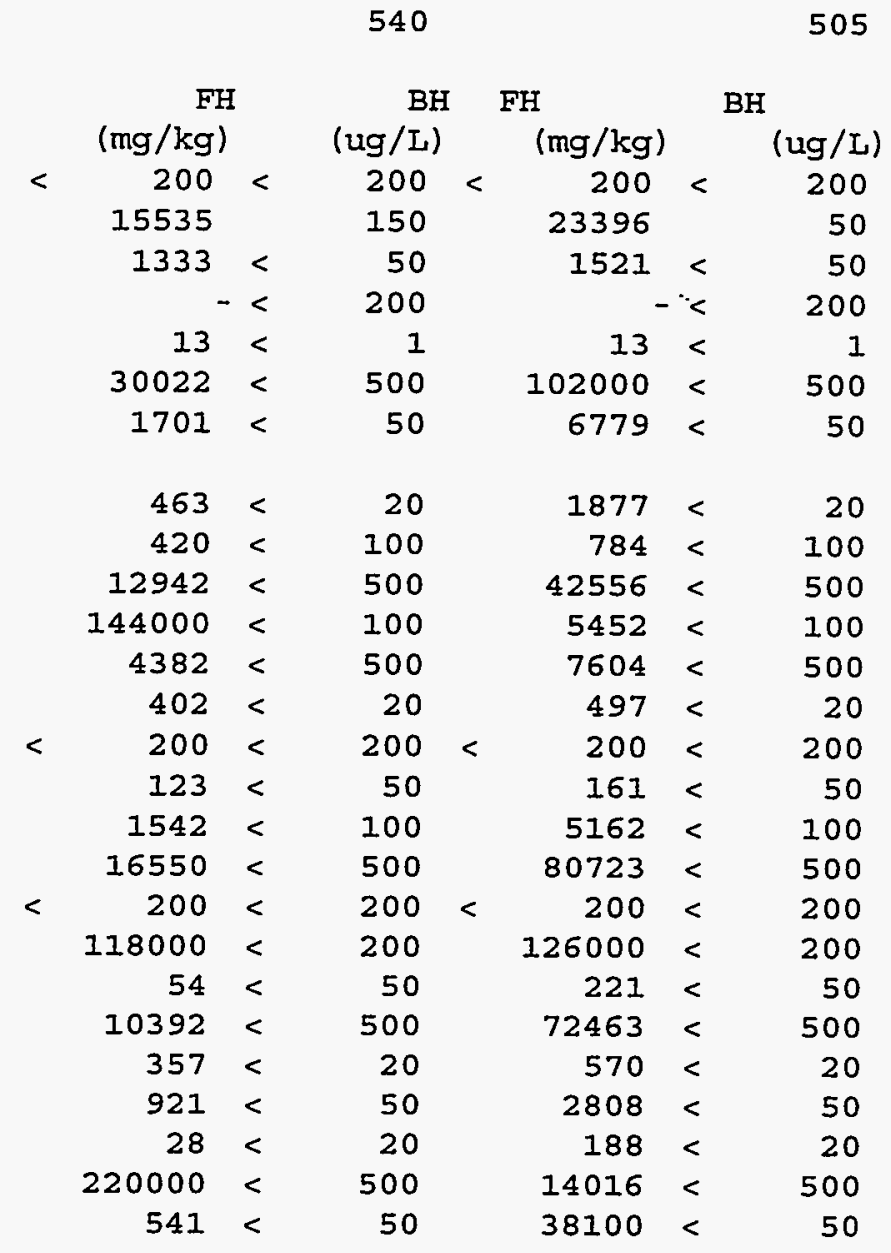


Plant: U.S. Bureau of Mines, Albany, Oregon

Test Location: Arc Melter Exhaust

$\begin{array}{ll}\text { Run Number } & \text { Run Date } \\ \text { MMT-M60-1 } & 7 \backslash 23 \backslash 93 \\ \text { MMT-M60-2 } & 7 \backslash 23 \backslash 93\end{array}$

Run Start Time

Run stop Time

Net Sampling/Traversing points

Net Run Time, Minutes

Dia Nozzle Diameter, Inches

$\mathrm{Cp} \quad$ Pitot Tube Coefficient

Y

Pbar

Delta-H

Vm

Vmm

tm

Vmstd

Vmstdm

VIc

Vwstd

ơ $2 \mathrm{O}$

s.t2Osat

Mfd

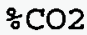

$\therefore \mathrm{O} 2$

Md

Ms

Pg

Ps

ts

Delta-p

vs

A

Qsd

Qmsd

Qaw

Qmaw

\% I

\&EA

Fo
Dry Gas Meter Calibration Coefficient

Barometric Pressure, Inches $\mathrm{Hg}$

Orifice Average Pressure Differential, Inch

Sampled Volume of Source Gas, Dry ACF

Sampled Volume of Source Gas, Dry ACM

Dry Gas Meter Temperature, Degrees F

Sampled Volume of Source Gas, Dry SCF

Sampled Volume of Source Gas, Dry SCM

Volume of Condensed Liquid, $\mathrm{mL}$

Volume of Water Vapor, SCF

Moisture Content, Percent by Volume

Saturated Moisture Content, Percent by Volu

Source Gas Dry Mole Fraction

Source Gas $\mathrm{CO} 2$ Content, Percent by Dry Volu

Source Gas 02 Content, Percent by Dry Volum

Source Gas Dry Molecular Weight, Lb/Lb-Mole

Source Gas Wet Molecular Weight, Lb/Lb-Mole

Source Gas static Pressure, Inches H2O

Source Gas Temperature, Degrees F

Source Gas Average Velocity Head, Inches H2

Source Gas Velocity, Feet/Second

Source Cross Sectional Area, Square Inches

Source Gas Volumetric Flow Rate, Dry SCFM

Source Gas Volumetric Flow Rate, Dry SCMM

Source Gas Volumetric Flow Rate, wet ACFM

Source Gas Volumetric Flow Rate, Wet ACMM

Average Isokinetic Sampling Rate, Percent

Excess Air, Percent

Fuel Factor
Source Gas Absolute Pressure, Inches Hg

\begin{tabular}{|c|c|}
\hline MMT-M60-1 & MMT-M60-2 \\
\hline 1005 & 1412 \\
\hline 1125 & 1522 \\
\hline 12 & 12 \\
\hline 60 & 6 \\
\hline 0.215 & 0.215 \\
\hline 0.99 & 0.99 \\
\hline 1.0060 & 1.0060 \\
\hline 29.90 & 29.90 \\
\hline 1.427 & 1.900 \\
\hline 33.995 & 43.487 \\
\hline 0.96 & 1.23 \\
\hline 70 & 78 \\
\hline 34.145 & 43.073 \\
\hline 0.967 & 1.220 \\
\hline 35.3 & 37.3 \\
\hline 1.662 & 1.756 \\
\hline 4.64 & 3.92 \\
\hline 100.0 & 100.0 \\
\hline 0.954 & 0.961 \\
\hline 0.0 & 0.0 \\
\hline 0.0 & 0.0 \\
\hline 28.00 & 28.00 \\
\hline 27.54 & 27.61 \\
\hline-1.70 & -1.70 \\
\hline 29.78 & 29.78 \\
\hline 411 & 250 \\
\hline 0.9872 & 0.8571 \\
\hline 86.65 & 72.81 \\
\hline 24 & 24 \\
\hline 494 & 513 \\
\hline 14 & 15 \\
\hline 858 & 721 \\
\hline 24 & 20 \\
\hline 75.4 & 91.6 \\
\hline 0 & \\
\hline \#DIV/0! & \#DIV/0! \\
\hline
\end{tabular}

.487

.23

78

.220

37.3

.756

3.92

961

0.0

0.0

28.00

7.61

.70

250

8571

24

513

15

721

20

0

\#DIV/0
Operator

Miguel Chavez

Miguel Chavez

Note:

All standard volumes and flow rates based on 68 Degrees $F(20$ Degrees C) - 29.92 Inches of Mercury $(\mathrm{Hg})$ The lesser of $\% \mathrm{H} 2 \mathrm{O}$ and $\% \mathrm{H} 2 \mathrm{O}$ sat was used for calculation purposes 


\section{FWt \\ mg \\ ug/DSCM \\ ng/DSCM \\ $\mathrm{lb} / \mathrm{hr}$}

FWt

$\mathrm{mg}$

ug/DSCM

$\mathrm{ng} / \mathrm{DSCM}$

$\mathrm{lb} / \mathrm{hr}$

FWt

$\mathrm{mg}$

ug/DSCM

$\mathrm{ng} / \mathrm{DSCM}$

$\mathrm{lb} / \mathrm{hr}$

FWt

$\mathrm{mg}$

ug/DSCM

ng/DSCM

$\mathrm{lb} / \mathrm{hr}$

FWt

$\mathrm{mg}$

ug/DSCM

ng/DSCM

$\mathrm{Ib} / \mathrm{hr}$

FWt

mg

ug/DSCM

ng/DSCM

$\mathrm{Ib} / \mathrm{hr}$
Arsenic

Formula Weight, Lb/Lb-Mole

Catch Weight, Milligrams

Concentration, Micrograms per DSCM

Emission Rate, Pounds per Hour
Concentration, Nanograms per DSCM

MMT-M60-1

MMT-M60-2

$\begin{array}{rrr} & 74.92 & \\ < & 2.5< & 74.92 \\ < & 2.558< & 2.8 \\ < & 2.56 \mathrm{E}+06< & 2.283 \\ < & 4.73 \mathrm{E}-03< & <.28 \mathrm{E}+06 \\ & & 4.38 \mathrm{E}-03\end{array}$

Aluminum

Formula Weight, Lb/Lb-Mole Catch Weight, Milligrams

Concentration, Micrograms per DSCM

Concentration, Nanograms per DSCM

Emission Rate, Pounds per Hour

Barium

Formula Weight, Lb/Lb-Mole

Catch Weight, Milligrams

Concentration, Micrograms per DSCM

Concentration, Nanograms per DSCM

Emission Rate, Pounds per Hour

Boron

Formula Weight, Lb/Lb-Mole

Catch Weight, Milligrams

Concentration, Micrograms per DSCM

Concentration, Nanograms per DSCM

Emission Rate, Pounds per Hour

Cadmium

Formula Weight, Lb/Lb-Mole

Catch Weight, Milligrams

Concentration, Micrograms per DSCM

Concentration, Nanograms per DSCM

Emission Rate, Pounds per Hour

Calcium

Formula Weight, Lb/Ib-Mole

Catch Weight, Milligrams

Concentration, Micrograms per DSCM

Concentration, Nanograms per DSCM

Emission Rate, Pounds per Hour

$\begin{array}{rr}26.98 & 26.98 \\ 183.8 & 314.0 \\ 190,116 & 257,453 \\ 1.90 \mathrm{E}+08 & 2.57 \mathrm{E}+08 \\ 3.52 \mathrm{E}-01 & 4.94 \mathrm{E}-01\end{array}$

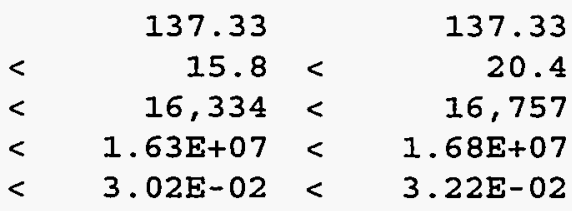

$\begin{array}{rrr} & 10.81 & 10.81 \\ < & 0.1< & 0.1 \\ < & 112< & 83 \\ < & 1.12 \mathrm{E}+05< & 8.28 \mathrm{E}+04 \\ < & 2.07 \mathrm{E}-04< & 1.59 \mathrm{E}-04\end{array}$

$\begin{array}{rrr} & 112.41 & \\ < & 0.2< & 112.41 \\ < & 160< & 0.2 \\ < & 1.60 \mathrm{E}+05< & 143 \\ < & 2.95 \mathrm{E}-04< & 1.43 \mathrm{E}+05 \\ & & 2.75 \mathrm{E}-04\end{array}$

$\begin{array}{rrr} & 40.08 & \\ < & 355.4< & 40.08 \\ < & 367.525< & 1369.2 \\ < & 3.68 \mathrm{E}+08< & <22.539 \\ < & 6.80 \mathrm{E}-01< & <12 \mathrm{E}+09\end{array}$

< Indicates the value is below the detection limit. 


Fwt
mg
ug/DSCM
$\mathrm{ng} / \mathrm{DSCM}$
$\mathrm{lb} / \mathrm{hr}$

FWt

mg

ug/DSCM

$\mathrm{ng} / \mathrm{DSCM}$

Ib/hr

FWt

mg

ug/DSCM

$\mathrm{ng} / \mathrm{DSCM}$

$\mathrm{lb} / \mathrm{hr}$

FWt

$\mathrm{mg}$

ug/DSCM

$\mathrm{ng} / \mathrm{DSCM}$

$\mathrm{Ib} / \mathrm{hr}$

Fwt

mg

ug/DSCM

$\mathrm{ng} / \mathrm{DSCM}$

$1 \mathrm{~b} / \mathrm{hr}$

FWt

$\mathrm{mg}$

ug/DSCM

$\mathrm{ng} / \mathrm{DSCM}$

Ib/hr
Cerium

Formula Weight, Lb/Lb-Mole

Catch Weight, Milligrams

Concentration, Micrograms per DSCM

Concentration, Nanograms per DSCM

Emission Rate, Pounds per Hour

\section{Cesium}

Formula Weight, Lb/Lb-Mole

Catch Weight, Milligrams

Concentration, Micrograms per DSCM

Concentration, Nanograms per DSCM

Emission Rate, Pounds per Hour

\section{Chromium}

Formula Weight, Lb/Lb-Mole

Catch Weight, Milligrams

Concentration, Micrograms per DSCM

Concentration, Nanograms per DSCM

Emission Rate, Pounds per Hour

\section{Copper}

Formula Weight, Lb/Lb-Mole

Catch Weight, Milligrams

Concentration, Micrograms per DSCM

Concentration, Nanograms per DSCM

Emission Rate, Pounds per Hour

Iron

Formula Weight, Lb/Lb-Mole

Catch Weight, Milligrams

Concentration, Micrograms per DSCM

Concentration, Nanograms per DSCM

Emission Rate, Pounds per Hour

\begin{tabular}{|c|c|c|}
\hline MMT-M60-1 & & IT-M6O-2 \\
\hline 140.12 & & 140.12 \\
\hline 20.1 & $<$ & 91. \\
\hline 20,835 & $<$ & 74,612 \\
\hline $2.08 \mathrm{E}+07$ & $<$ & $7.46 \mathrm{E}+07$ \\
\hline $3.85 E-02$ & $<$ & $1.43 \mathrm{E}-0$ \\
\hline
\end{tabular}

$\begin{array}{rr}132.9 I & 132.91 \\ 0.0 & 0.0 \\ 0 & 0 \\ 0.00 E+00 & 0.00 E+00 \\ 0.00 E+00 & 0.00 E+00\end{array}$

$\begin{array}{rrr} & 52.00 & \\ < & 5.5< & 25.2 \\ < & 5.675< & 20.661 \\ < & 5.67 \mathrm{E}+06< & 2.07 \mathrm{E}+07 \\ < & 1.05 \mathrm{E}-02< & 3.97 \mathrm{E}-02\end{array}$

$\begin{array}{rrrr} & 63.55 & 63.55 \\ < & 5.0< & 10.6 \\ < & 5.194< & 8.668 \\ < & 5.19 E+06< & 8.67 E+06 \\ < & 9.60 E-03< & 1.66 E-02\end{array}$

< Indicates the value is below the detection limit. 
FWt

mg

ug/DSCM

$\mathrm{ng} / \mathrm{DSCM}$

1b/hr

FWt

mg

ug/DSCM

$\mathrm{ng} / \mathrm{DSCM}$

1b/hr

FWt

mg

ug/DSCM

$\mathrm{ng} / \mathrm{DSCM}$

1b/hr

FWt

$\mathrm{mg}$

ug/DSCM

$\mathrm{ng} / \mathrm{DSCM}$

Ib/hr

FWt

mg

ug/DSCM

$\mathrm{ng} / \mathrm{DSCM}$

$\mathrm{Ib} / \mathrm{hr}$

FWt

mg

ug/DSCM

$\mathrm{ng} / \mathrm{DSCM}$

Ib/hr
Magnesium

Formula Weight, Lb/Lb-Mole

Catch Weight, Milligrams

Concentration, Micrograms per DSCM

Concentration, Nanograms per DSCM

Emission Rate, Pounds per Hour

Manganese

Formula Weight, Lb/Lb-Mole

Catch Weight, Milligrams

Concentration, Micrograms per DSCM

Concentration, Nanograms per DSCM

Emission Rate, Pounds per Hour

\section{Mercury}

Formula Weight, Ib/Ib-Mole

Catch Weight, Milligrams

Concentration, Micrograms per DSCM

Concentration, Nanograms per DSCM

Emission Rate, Pounds per Hour

\section{Nickel}

Formula Weight, Ib/Lb-Mole

Catch Weight, Milligrams

Concentration, Micrograms per DSCM

Concentration, Nanograms per DSCM

Emission Rate, Pounds per Hour

Phosphorus

Formula Weight, Lb/Lb-Mole

Catch Weight, Milligrams

Concentration, Micrograms per DSCM

Concentration, Nanograms per DSCM

Emission Rate, Pounds per Hour

Potassium

Formula Weight, Lb/Lb-Mole

Catch Weight, Milligrams

Concentration, Micrograms per DSCM

Concentration, Nanograms per DSCM

Emission Rate, Pounds per Hour

$\begin{array}{rrrr} & 24.31 & & 24.31 \\ < & 52.1 & < & 102.3 \\ < & 53.882 & < & 83,876 \\ < & 5.39 E+07< & < & 8.39 E+07 \\ < & 9.96 E-02 & < & 1.61 E-01\end{array}$

$\begin{array}{rrrr} & 54.94 & & 54.94 \\ < & 4.8< & 6.7 \\ < & 4.929< & 5.477 \\ < & 4.93 \mathrm{E}+06< & 5.48 \mathrm{E}+06 \\ < & 9.11 \mathrm{E}-03< & 1.05 \mathrm{E}-02\end{array}$

$\begin{array}{rrrr} & 200.59 & & 200.59 \\ < & 2.5 & 2.8 \\ < & 2.558< & 2,283 \\ < & 2.56 \mathrm{E}+06< & 2.28 \mathrm{E}+06 \\ < & 4.73 \mathrm{E}-03< & <.38 \mathrm{E}-03\end{array}$

58.71

2.2

1,792

1. $79 \mathrm{E}+06$

3. $44 \mathrm{E}-03$

< Indicates the value is below the detection Iimit. 
FWt

$\mathrm{mg}$

ug/DSCM

$\mathrm{ng} / \mathrm{DSCM}$

$\mathrm{lb} / \mathrm{hr}$

FWt

mg

ug/DSCM

$\mathrm{ng} / \mathrm{DSCM}$

$I b / h r$

FWt

mg

ug/DSCM

$\mathrm{ng} / \mathrm{DSCM}$

$\mathrm{Ib} / \mathrm{hr}$

FWt

$\mathrm{mg}$

ug/DSCM

$\mathrm{ng} / \mathrm{DSCM}$

Ib/hr

Fwt

$\mathrm{mg}$

ug/DSCM

$\mathrm{ng} / \mathrm{DSCM}$

$\mathrm{Ib} / \mathrm{hr}$

FWt

mg

ug/DSCM

$\mathrm{ng} / \mathrm{DSCM}$

$\mathrm{lb} / \mathrm{hr}$
Selenium

Formula Weight, Lb/Lb-Mole

Catch Weight, Milligrams

Concentration, Micrograms per DSCM

Concentration, Nanograms per DSCM

Emission Rate, Pounds per Hour

$\begin{array}{rrrr} & 78.96 & 78.96 \\ < & 2.5< & 2.8 \\ < & 2.558< & 2.283 \\ < & 2.56 E+06< & 2.28 E+06 \\ < & 4.73 E-03< & 4.38 E-03\end{array}$

Silicon

Formula Weight, Lb/Lb-Mole

Catch Weight, Milligrams

Concentration, Micrograms per DSCM

Concentration, Nanograms per DSCM

Emission Rate, Pounds per Hour

Silver

Formula Weight, Lb/Lb-Mole

Catch Weight, Milligrams

Concentration, Micrograms per DSCM

Concentration, Nanograms per DSCM

Emission Rate, Pounds per Hour

Sodium

Formula Weight, Lb/Lb-Mole

Catch Weight, Milligrams

Concentration, Micrograms per DSCM

Concentration, Nanograms per DSCM

Emission Rate, Pounds per Hour

Strontium

Formula Weight, Lb/Lb-Mole

Catch Weight, Milligrams

Concentration, Micrograms per DSCM

Concentration, Nanograms per DSCM

Emission Rate, Pounds per Hour

$\begin{array}{rrrr} & 107.87 & & 107.87 \\ < & 0.7< & 3.0 \\ < & 688< & 2.452 \\ < & 6.88 \mathrm{E}+05< & 2.45 \mathrm{E}+06 \\ < & 1.27 \mathrm{E}-03< & 4.71 \mathrm{E}-03\end{array}$

$28.09 \quad 28.09$

$<\quad 1395.8<1691.1$

$<1,443,553<1,386,492$

$<\quad 1.44 \mathrm{E}+09<1.39 \mathrm{E}+09$

$<2.67 \mathrm{E}+00<2.66 \mathrm{E}+00$

$<\quad 1.27 \mathrm{E}-03<4.71 \mathrm{E}-03$

\begin{tabular}{|c|c|c|}
\hline 22.99 & & 22.99 \\
\hline 123.2 & $<$ & 972.8 \\
\hline 127,400 & $<$ & 797,536 \\
\hline $1.27 E+08$ & $<$ & $7.98 \mathrm{E}+08$ \\
\hline $2.36 E-01$ & $<$ & $1.53 \mathrm{E}+00$ \\
\hline
\end{tabular}

$\begin{array}{rrrr} & 87.62 & 87.62 \\ < & 4.2< & 7.7 \\ < & 4.378< & 6.280 \\ < & 4.38 \mathrm{E}+06< & 6.28 \mathrm{E}+06 \\ < & 8.10 \mathrm{E}-03< & 1.21 \mathrm{E}-02\end{array}$

Titanium

Formula Weight, Lb/Lb-Mole

Catch Weight, Milligrams

Concentration, Micrograms per DSCM

Concentration, Nanograms per DSCM

Emission Rate, Pounds per Hour

$\begin{array}{rrrr} & 47.90 & & 47.90 \\ < & 10.9 & < & 37.7 \\ < & 11.294 & < & 30,918 \\ < & 1.13 \mathrm{E}+07< & 3.09 E+07 \\ < & 2.09 \mathrm{E}-02 & < & 5.94 \mathrm{E}-02\end{array}$

< Indicates the value is below the detection limit. 


$$
\text { MMT-M60-1 MMT-M60-2 }
$$

FWt
mg
ug/DSCM
$\mathrm{ng} / \mathrm{DSCM}$
$\mathrm{lb} / \mathrm{hr}$

FWt

mg ug/DSCM $\mathrm{ng} / \mathrm{DSCM}$ lb/hr

FWt

mg

ug/DSCM $\mathrm{ng} / \mathrm{DSCM}$ $\mathrm{Ib} / \mathrm{hr}$

$g$
$q$
$g$
$\frac{g}{0}$
$g$
$\frac{9}{6}$
$g$
$g / D S C M$
$g r / D S C F$
Ib/hr

Vanadium Formula Weight, Lb/Lb-Mole Catch Weight, Milligrams Concentration, Micrograms per DSCM Concentration, Nanograms per DSCM Emission Rate, Pounds per Hour

zinc

Formula Weight, Lb/Lb-Mole Catch Weight, Milligrams Concentration, Micrograms per DSCM Concentration, Nanograms per DSCM Emission Rate, Pounds per Houx

Zirconium

Formula Weight, Ib/Lb-Mole Catch Weight, Milligrams Concentration, Micrograms per DSCM Concentration, Nanograms per DSCM Emission Rate, Pounds per Hour

\section{Particulate} Catch Weight, Grams (Filter) Percent of Particulate in Filter Catch Weight, Grams (HNO3) Percent of Particulate in HNO3 Rinse Catch Weight, Grams (Acetone) Percent of Particulate in Acetone Rinse Catch Weight, Grams (Total) Concentration, Total Milligrams per DSCM Concentration, Total Grains per DSCF Emission Rate, Total Pounds per Hour

$\begin{array}{rrrr} & 50.94 & & 50.94 \\ < & 0.3< & 2.5 \\ < & 354< & 2.077 \\ < & 3.54 \mathrm{E}+05< & 2.08 \mathrm{E}+06 \\ < & 6.54 \mathrm{E}-04< & 3.99 \mathrm{E}-03\end{array}$

$\begin{array}{rrr}65.38 & & 65.38 \\ <\quad 2602.3< & 188.4 \\ <\quad 2,691,441< & 154,429 \\ <\quad 2.69 \mathrm{E}+09< & 1.54 \mathrm{E}+08 \\ <\quad 4.98 \mathrm{E}+00< & 2.97 \mathrm{E}-01\end{array}$

$\begin{array}{rrrr} & 91.22 & & 91.22 \\ < & 6.4 & 5 & 511.4 \\ < & 6.646 & < & 419.245 \\ < & 6.65 \mathrm{E}+06 & < & 4.19 \mathrm{E}+08 \\ < & 1.23 \mathrm{E}-02 & < & 8.05 \mathrm{E}-01\end{array}$

< Indicates the value is below the detection limit. 
Appendix P-6

Partitioning of Feed Material, Toxic, and Structural Metals 

Table P-6-1. Feed material partitioning.

\begin{tabular}{lcccccc}
\hline & & & & N80-IV & & Average \\
& S60 & S60-IV & N80 runs & runs & M60 runs & of runs \\
\hline From MMT & 2.01 & 1.65 & 2.29 & 1.53 & 1.70 & 1.84 \\
APCS solids & 1.32 & 1.97 & 2.76 & 2.27 & 1.82 & 2.02 \\
Entrained feed & 1.01 & 1.40 & 2.10 & 1.84 & 1.36 & 1.42 \\
Condensed volatiles & 0.30 & 0.57 & 0.66 & 0.43 & 0.45 & 0.61 \\
\hline
\end{tabular}

Table P-6-2. Partitioning of toxic metals into the slag.

\begin{tabular}{lcccccc}
\hline & & & \multicolumn{2}{c}{ Total } \\
Element & S60 & S60-IV & $\begin{array}{l}\text { Total } \\
\text { N80 runs }\end{array}$ & $\begin{array}{l}\text { N80-IV } \\
\text { runs }\end{array}$ & M60 & M60 runs \\
\hline Arsenic & 71.0 & 68.6 & 52.7 & 61.1 & 4.6 & 12.6 \\
Barium & 97.6 & 96.9 & 97.5 & 95.7 & 96.3 & 96.4 \\
Cadmium & $<81.9$ & $<68.4$ & $<62.1$ & $<61.5$ & $<55.2$ & $<62.8$ \\
Cerium & 98.5 & 98.9 & 97.5 & 95.4 & 97.0 & 96.7 \\
Chromium & 99.6 & 99.2 & 97.4 & 97.4 & 65.1 & 74.5 \\
Copper & 93.5 & 74.3 & 84.0 & 89.8 & 4.3 & 7.2 \\
Lead & 75.8 & 29.1 & 27.9 & 47.5 & 46.5 & 30.7 \\
Nickel & 98.1 & 97.1 & 66.3 & 74.2 & 8.4 & 10.8 \\
Phosphorus & 83.1 & 32.1 & 75.4 & 74.2 & 1.7 & 23.2 \\
Silver & 95.7 & $<79.3$ & $<60.7$ & $<72.2$ & $<60.3$ & $<72.3$ \\
Zinc & 78.3 & 61.8 & 56.2 & 65.3 & 37.9 & 39.0 \\
Toxic metals & 96.0 & 94.9 & 90.4 & 92.7 & 44.5 & 53.5 \\
\hline
\end{tabular}

$<$ Value below detection limit 
Table P-6-3. Partitioning of metals in the M60 and M60-Mod feed mixtures.

\begin{tabular}{|c|c|c|c|c|c|c|c|c|}
\hline & \multicolumn{4}{|c|}{ M60 (\%) } & \multicolumn{4}{|c|}{ M60 and M60-Mod (\%) } \\
\hline & Metal & Slag & Fume traps & Baghouse & Metal & Slag & Fume traps & Baghouse \\
\hline Aluminum & 0.60 & 98.8 & 0.52 & 0.09 & 0.30 & 98.9 & 0.67 & 0.10 \\
\hline Arsenic & 92.9 & 4.60 & 1.32 & 1.20 & 79.8 & 12.6 & 3.52 & 4.03 \\
\hline Barium & 0.73 & 96.3 & 2.26 & 0.69 & 0.36 & 96.4 & 2.45 & 0.80 \\
\hline Calcium & 0.34 & 98.2 & 1.23 & 0.25 & 0.09 & 98.7 & 1.07 & 0.17 \\
\hline Carbon & 62.4 & 26.7 & 7.27 & 3.60 & 27.8 & 59.0 & 8.71 & 4.44 \\
\hline Chromium & 34.8 & 65.1 & 0.06 & 0.03 & 25.3 & 74.5 & 0.09 & 0.10 \\
\hline Copper & 95.5 & 4.30 & 0.06 & 0.14 & 92.3 & 7.24 & 0.13 & 0.28 \\
\hline Iron & 86.1 & 13.8 & 0.09 & 0.05 & 64.2 & 35.6 & 0.19 & 0.09 \\
\hline Lead & 33.9 & 46.5 & 18.6 & 0.92 & 16.0 & 30.7 & 15.0 & 38.4 \\
\hline Magnesium & 0.47 & 98.6 & 0.79 & 0.18 & 0.21 & 98.7 & 0.93 & 0.19 \\
\hline Nickel & 91.5 & 8.39 & 0.06 & 0.03 & 89.0 & 10.8 & 0.10 & 0.07 \\
\hline Phosphorus & 95.2 & 1.67 & 0.57 & 2.58 & 71.1 & 23.2 & 0.43 & 5.20 \\
\hline Potassium & 0.12 & 96.0 & 1.93 & 1.91 & 0.04 & 95.5 & 2.05 & 2.39 \\
\hline Silicon & 3.79 & 95.1 & 0.73 & 0.33 & 1.88 & 96.8 & 0.89 & 0.39 \\
\hline Sodium & 0.61 & 94.5 & 2.27 & 2.64 & 0.16 & 95.5 & 2.10 & 2.21 \\
\hline Sulfur & 33.7 & 49.5 & 5.20 & 11.7 & 16.8 & 56.2 & 6.09 & 20.9 \\
\hline Titanium & 1.05 & 98.6 & 0.32 & 0.07 & 0.26 & 99.5 & 0.22 & 0.05 \\
\hline Zinc & 5.72 & 37.9 & 16.5 & 39.8 & 3.28 & 39.0 & 15.2 & 42.6 \\
\hline Zirconium & 0.38 & 95.3 & 3.51 & 0.84 & 0.08 & 94.9 & 4.48 & 0.51 \\
\hline
\end{tabular}


Table P-6-4. Partitioning of toxic metals to the fume traps and the baghouse.

\begin{tabular}{lcccccc}
\hline & S60 & S60-IV & N80 runs & runs & M60 & M60 runs \\
\hline Arsenic to baghouse & 22.4 & 22.1 & 32.6 & 18.7 & 1.20 & 4.03 \\
Arsenic to fume traps & 6.55 & 9.34 & 14.6 & 20.2 & 1.32 & 3.52 \\
Barium to baghouse & 0.96 & 1.33 & 1.06 & 1.87 & 0.69 & 0.80 \\
Barium to fume traps & 1.45 & 1.74 & 1.41 & 2.42 & 2.26 & 2.45 \\
Cadmium to baghouse & $>14.45$ & $>27.9$ & $>30.3$ & $>29.5$ & $>13.4$ & $>19.7$ \\
Cadmium to fume traps & $>3.69$ & $>3.68$ & $>7.59$ & $>9.01$ & $>8.89$ & $>7.10$ \\
Cerium to baghouse & 0.18 & 0.16 & 0.93 & 2.09 & 0.57 & 0.43 \\
Cerium to fume traps & 1.33 & 0.90 & 1.54 & 2.51 & 2.33 & 2.81 \\
Chromium to baghouse & 0.24 & 0.49 & 1.54 & 1.65 & 0.03 & 0.10 \\
Chromium to fume traps & 0.18 & 0.31 & 1.03 & 0.98 & 0.06 & 0.09 \\
Copper to baghouse & 5.45 & 23.2 & 14.6 & 8.37 & 0.14 & 0.28 \\
Copper to fume traps & 1.03 & 2.53 & 1.35 & 1.86 & 0.06 & 0.13 \\
Lead to baghouse & 19.9 & 64.2 & 59.9 & 40.4 & 0.92 & 38.4 \\
Lead to fume traps & 4.37 & 6.75 & 12.2 & 12.1 & 18.6 & 15.0 \\
Mercury to baghouse & $>48.9$ & $>61.8$ & $>60.8$ & $>46.6$ & $>37.3$ & $>39.2$ \\
Mercury to fume traps & $>7.2$ & $>2.3$ & $>8.6$ & $>10.1$ & $>15.0$ & $>13.1$ \\
Nickel to baghouse & 1.08 & 1.88 & 29.7 & 17.1 & 0.03 & 0.07 \\
Nickel to fume traps & 0.79 & 1.02 & 3.98 & 8.72 & 0.06 & 0.10 \\
Phosphorus to baghouse & 12.6 & 57.4 & 20.7 & 17.1 & 2.58 & 5.20 \\
Phosphorus to fume traps & 4.32 & 10.5 & 3.92 & 8.75 & 0.57 & 0.43 \\
Selenium to baghouse & $>8.33$ & $>10.6$ & $>12.8$ & $>15.4$ & $>4.36$ & $>6.56$ \\
Selenium to fume traps & $>2.02$ & $>4.68$ & $>3.57$ & $>5.95$ & $>1.77$ & $>2.01$ \\
Silver to baghouse & 3.00 & $>17.4$ & $>36.0$ & $>21.8$ & $>7.42$ & $>8.97$ \\
Silver to fume traps & 1.35 & $>3.29$ & $>3.34$ & $>6.03$ & $>7.68$ & $>6.73$ \\
Zinc to baghouse & 16.5 & 33.0 & 37.7 & 24.4 & 39.8 & 42.6 \\
Zinc to fume traps & 5.14 & 5.21 & 6.07 & 10.4 & 16.5 & 15.2 \\
\hline & & & & & & \\
\end{tabular}




\section{Appendix Q}

\section{Overview of the Integrated Melting Facility}





\section{Q. INTEGRATED MELTING FACILITY}

The integrated facility is composed of three primary components: (a) a feed system, (b) a 3-phase electric arc melting furnace, and (c) an air pollution control system (APCS). Many elements of the arc melting furnace and APCS are unique, and the facility as a whole constitutes a state-of-the-art melting facility. ${ }^{1}$ A process schematic of the facility is shown in Figure Q-1.

\section{Q.1 Feed System}

Feed waste mixtures, received in 55 gal barrels, were either transferred directly by barrel-lift into the $60 \mathrm{ft}^{3}$ receiving bin of the feed system or mixed with additives in a 2-barrel capacity hopper, which then was transferred by overhead crane to the receiving bin. Twin tapered, counter-rotating, 12 in. diameter screws in the base of the bin discharged to a bucket elevator, and lifted the material $17 \mathrm{ft}$ to a $10 \mathrm{ft}^{3}$ residue metering bin. The height of material in the metering bin was controlled by a sonic level indicator with high and low set points.

Two calibrated counter-rotating 6 in. diameter screws discharged the feed material from the metering bin to a 6 in. diameter splitter screw, which delivered feed material to two 6 in. diameter delivery screws. Each delivery screw discharged into the furnace through a pneumatically-activated diverter gate that divided and routed the feed to two separate ports in the furnace roof. Feed was thereby uniformly admitted into the furnace through four ports in the roof (two ports for each delivery screw).

Feed materials entered the furnace roof through four water-cooled tubes that extended through the roof to within 18 in. of the molten pool. These double-walled carbon steel tubes are $48 \mathrm{in.} \mathrm{long} \mathrm{with} \mathrm{an} 8.625$ in. outside diameter (OD) and $5.5 \mathrm{in}$. inside diameter (ID). The annular water jacket in each tube is divided length wise by spacers to form 6 water passages. Cooling water for each passage is supplied by nominal $1 / 4$ in. copper tubes that extend down the length of the passage to within $1 / 2$ in. of the bottom of the passage.

The height of unmelted material (cold top) in the furnace was determined manually by lowering a weight suspended on a 1/16 in. diameter stranded stainless steel cable in the manner of a plumb bob through one of the feed tubes. The feed system, rated to deliver up to $2,000 \mathrm{lb} / \mathrm{h}$ of minus $1 / 2 \mathrm{in}$. screened and dried material with a bulk density of approximately $80 \mathrm{lb} / \mathrm{ft}^{3}$, could be operated manually or controlled automatically by a programmable controller. A detailed description of the feed system is provided in the operations manual. ${ }^{2}$ The receiving bin and charge hopper are shown in Figure Q-2.

Fugitive dust generated during dumping of barrels and operation of the feed system was vented to a baghouse through a system of ducts connected to the receiving bin, bucket elevator, and residue metering bin. The baghouse was emptied after each test, and the weight of fugitive dust was subtracted from the weight of feed material placed in the receiving bin. 


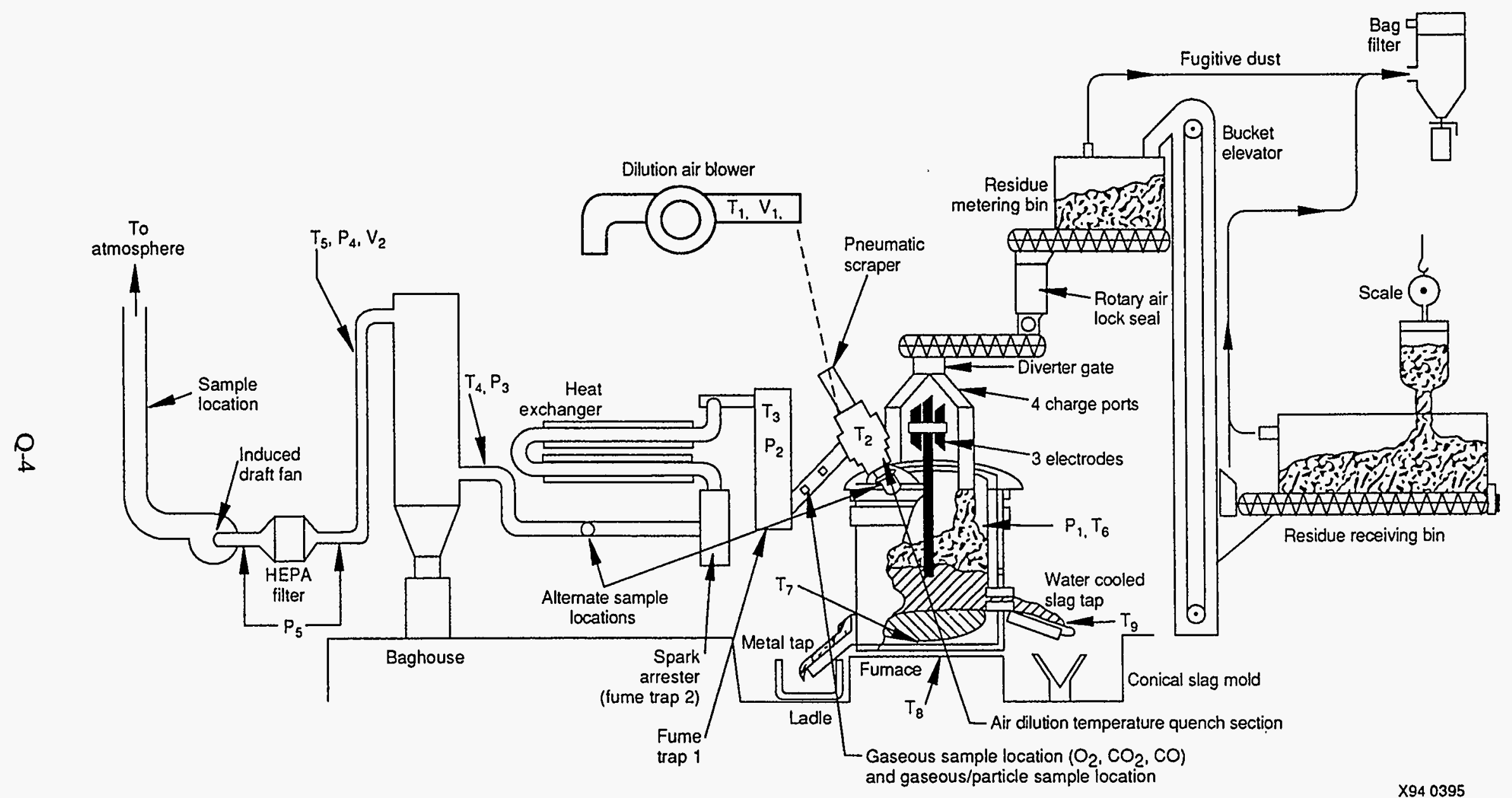

Figure Q-1. Schematic diagram of the Arc Furnace Integrated Waste Processing Test Facility. 


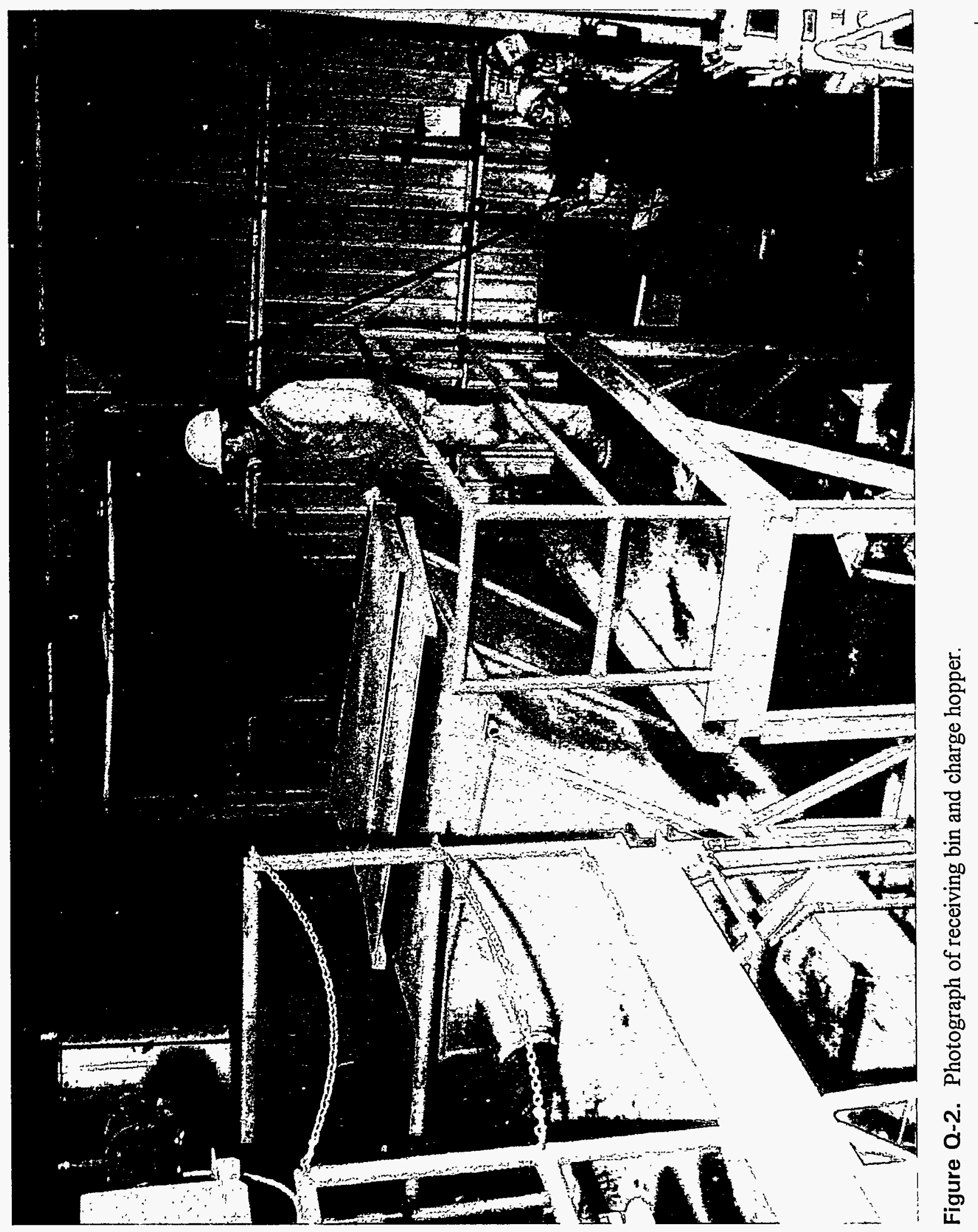





\section{Q.2 Electric Arc Melting Furnace and Power Supply}

\section{Q.2.1 Furnace Description and Design}

The furnace has a refractory-lined steel shell with water-cooled sidewalls, partially water-cooled roof, and air-cooled bottom. The capacity of the hearth is about $5 \mathrm{ft}^{3}$. Figure Q-3 shows a vertical section of the furnace shell and roof showing the upper and lower water trough placement, the air plenum for bottom cooling, tap hole locations, launder, and placement of the furnace with respect to floor level. The carbon steel shell is $65 \mathrm{in}$. high and tapers from $60 \mathrm{in}$. ID at the bottom to $56 \mathrm{in}$. ID at the top. Three carbon steel straps ( 2 in. wide by $0.060 \mathrm{in}$. thick) were welded to the inside bottom of the shell in a triangular array prior to placing the refractory lining in the shell. These straps were worked between the bricks and through the refractory ramming mix during construction of the hearth to provide an electrical circuit to ground between each pair of electrodes. The furnace shell was then securely grounded on the outside. A concrete pedestal supports the furnace between two rectangular pits, each $3 \mathrm{ft} 6$ in. deep by $5 \mathrm{ft}$ 10 in. wide by $7 \mathrm{ft}$ long.

The conceptual design and engineering drawings for the modified furnace, including refractory selection and placement, cooling-water needs, voltage/power requirements, water-cooled tapping fixture, and general furnace operating procedures, were provided by Lectromelt Corp. ${ }^{3}$

Figure Q-4 shows the domed carbon steel roof and identifies numerous ports and water passages in the roof. The roof contains a tubular water passage near the outer edge to protect the roof-to-shell seal, which consists of two annular channels in the shell and two knife edges in the roof. The inner channel contains fine sand, and the outer channel contains a silicone elastomer. Water jackets cover about $70 \%$ of the exterior surface of the roof encompassing the electrode, charge, and exhaust gas ports.

The three central ports in the roof accommodate 4 in. diameter graphite electrodes. The water-cooled feed tubes, each 8.625 in. OD, extend through the four charging ports in the roof. Exhaust gases exit the furnace through the circular exhaust port in the roof. The square inspection port in the roof was fitted with a door that opens to provide access to the furnace. Figure Q-5 shows the furnace roof and the equipment above the furnace roof. The electrodes and electrode seals, water-cooled feed tubes with their extensive plumbing, and feed delivery screws with transfer tubes are visible.

\section{Q.2.2 Furnace Refractories}

Refractory placement within the shell and roof is indicated in Figure Q-6. The bottom of the shell was lined with 5 in. ( 2 courses) of straight Ruby ${ }^{1}$ firebrick. Five courses of Ruby key bricks shape the hearth and form the sidewall up to the steel shelf 28 in. above the bottom, which is approximately $7 \mathrm{in}$. above the slag tap hole. One inch of dry phosphate-bonded silicon carbide

1. Reference to specific trade names or manufacturers does not imply endorsement by the Bureau of Mines or INEL. 


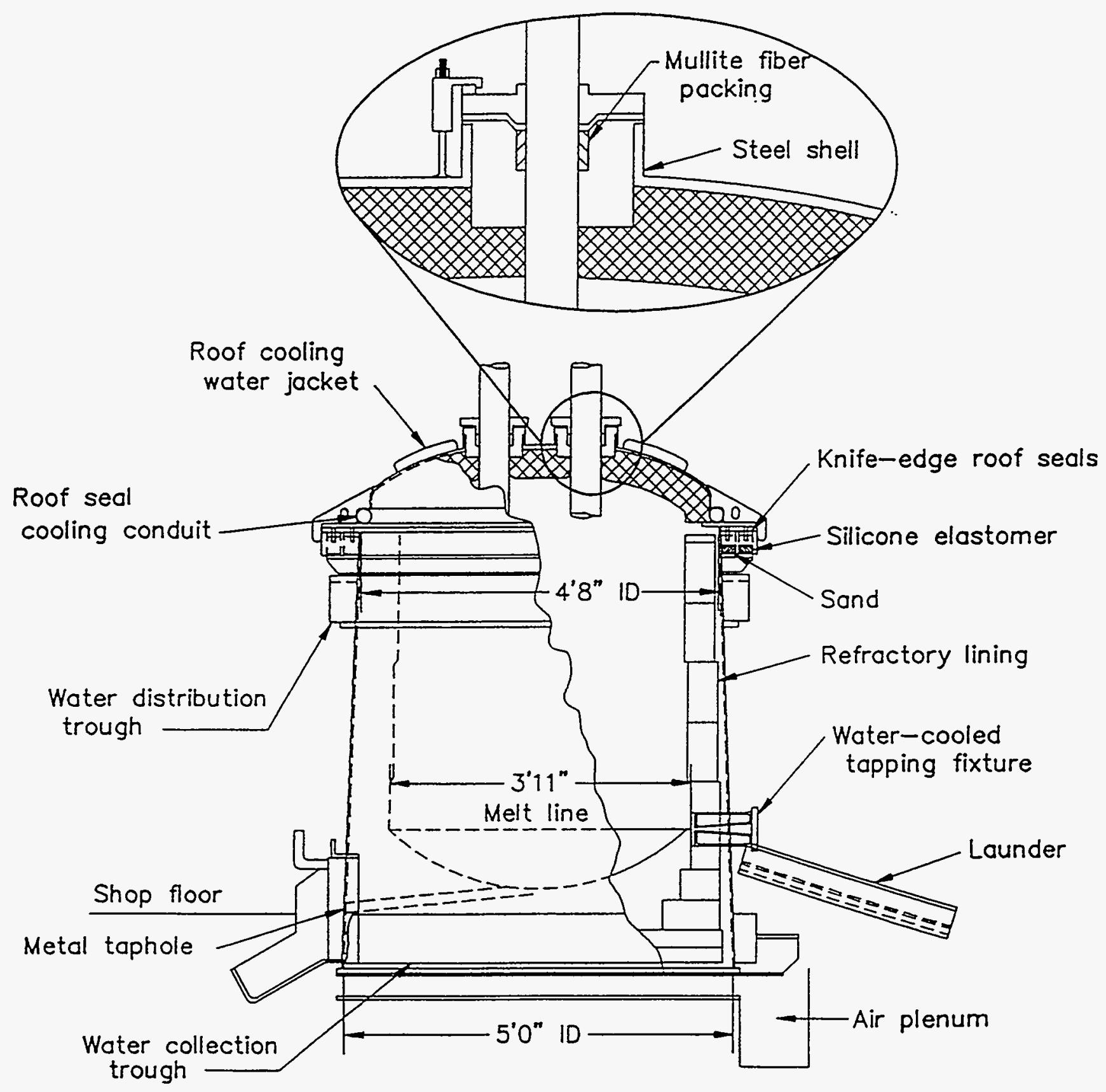

Figure Q-3. Vertical section of electric arc melting furnace. 


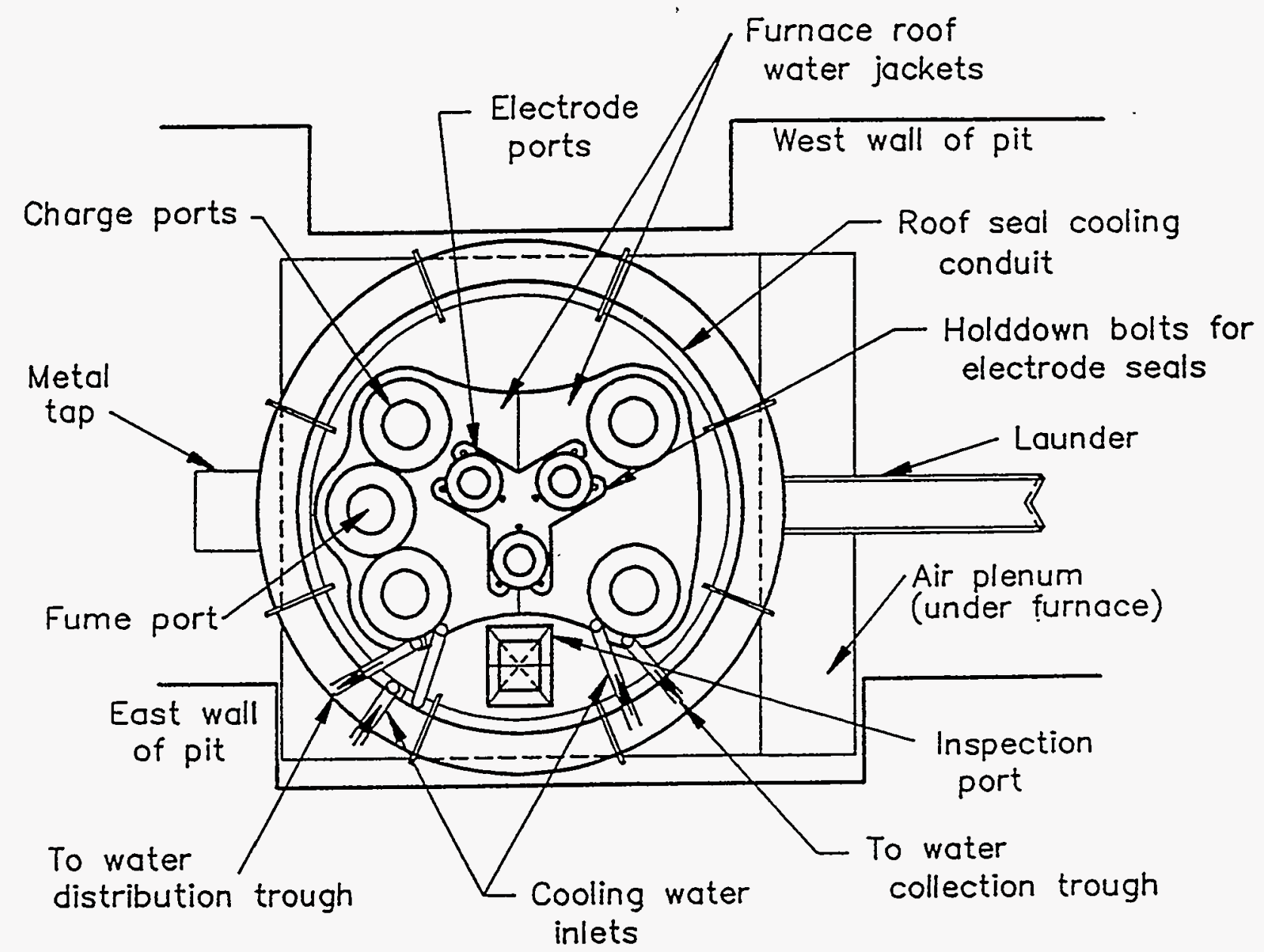

Figure Q-4. Top view of furnace and roof. 
, 


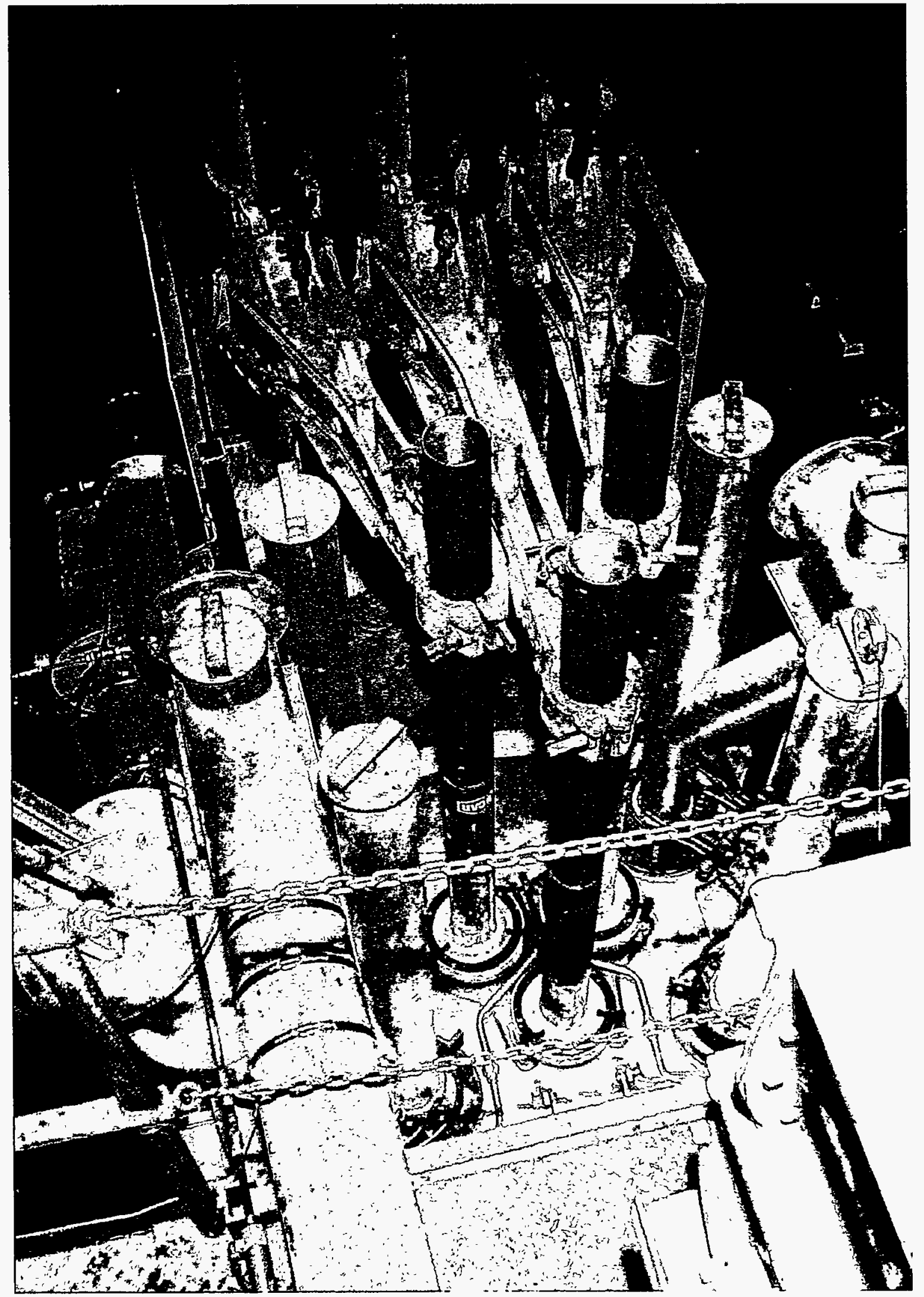

Figure Q-5. Photograph of furnace roof. 


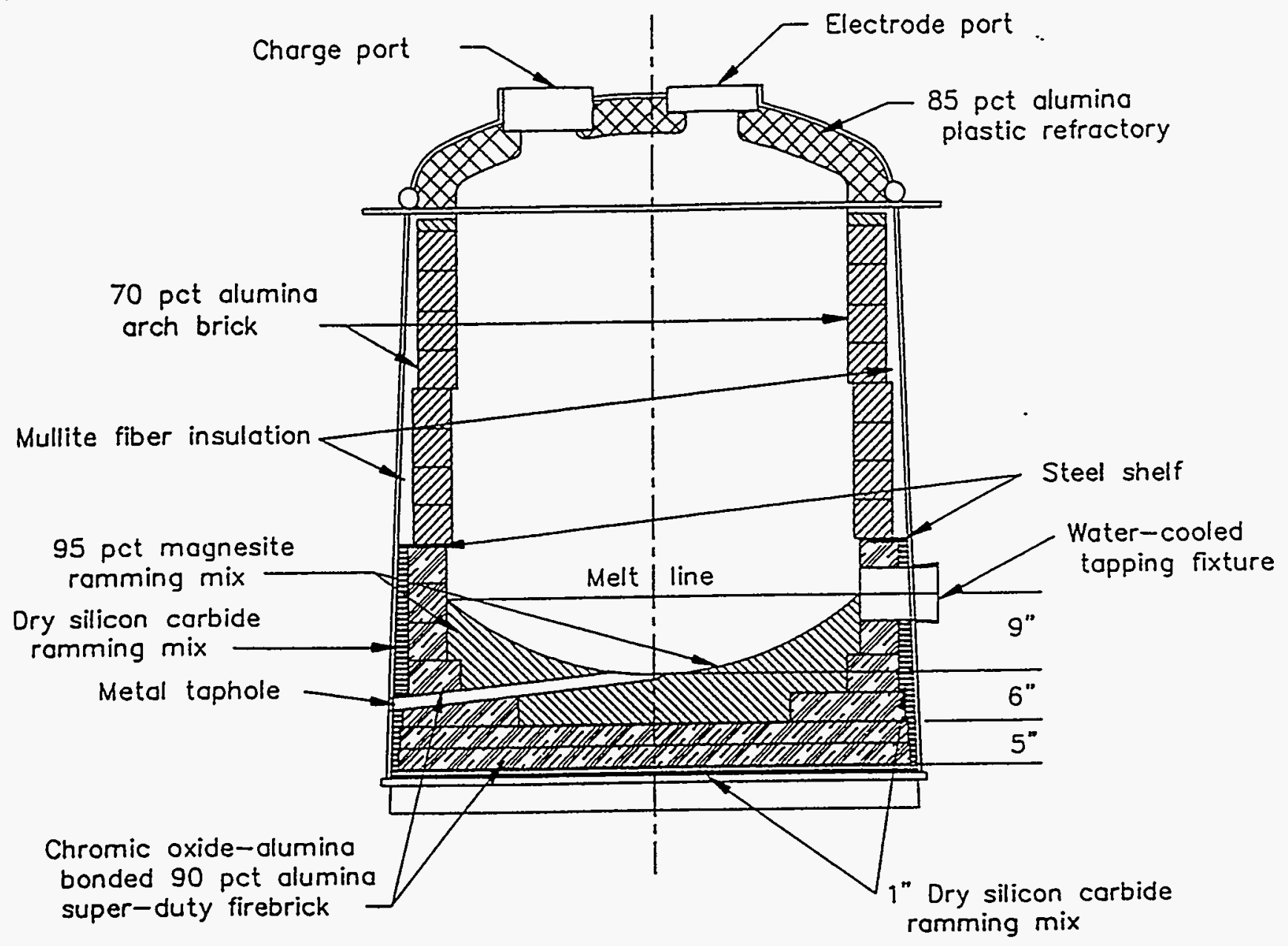

Figure Q-6. Refractory placement in furnace shell and roof. 
(SiC) ramming mix was placed between the steel bottom and the first course of Ruby straights to improve heat transfer to the bottom. This ramming mix, about 1 in. thick, also was placed between the Ruby keys and the sidewall for the same reason. The upper sidewall was lined with 4.5 in. GM $70 \mathrm{DE}$ (70\% alumina) insulating arch fire brick. One inch of Fiberfrax (mullite batting) was placed between the sidewall and the arch brick for additional insulation. At midheight, the finished ID of the furnace is about $46 \mathrm{in}$. The hearth was rammed to a depth of 6 in. at the center with Permanente $165 \mathrm{AF}$ ramming mix $(98 \% \mathrm{MgO})$. The volume of the hearth, when finished to 48 in. diameter by 9 in. deep at the center, is approximately $5 \mathrm{ft}^{3}$.

The roof was lined with 4 in. of NARPHOS 85 P plastic refractory ( $85 \%$ alumina). This material was selected for ease of placement considering the complexity of the roof, and for the ability to withstand the potentially corrosive condensable fumes within the furnace and the high temperatures anticipated during open arc operation. The roof refractory was extended into the inspection port to provide a 6 in. square opening. The roof refractory fit closely to the outside of each feed tube, and the annular space between each feed tube and roof port was packed with Fiberfrax to minimize gas leakage.

Two-part ceramic seals prepared from Cast-O-Last G Ad-Tech were fitted into the annular space between electrode and roof port to minimize gas leakage around the electrodes. A completed electrode seal consists of a ceramic fiber gasket between a shelf on the bottom seal and the top of the roof port, and ceramic fiber packing within the annular space between the bottom and top parts of the seal. The upper part of the seal was clamped to the roof to compress the ceramic packing around the electrode.

Tapping metal and draining the furnace was done through the 1.5 in. diameter hole in the bottom center of the hearth that was built into the furnace lining during construction. The water-cooled tapping fixture was grouted in place with the $\mathrm{MgO}$ ramming mix. This tapping fixture is a welded, double-walled, copper structure 6 in. diameter by $10 \mathrm{in}$. long with a 1 in. diameter central hole designed to permit continuous tapping of slag at rates up to $2,000 \mathrm{lb} / \mathrm{h}$.

\section{Q.2.3 Furnace and Transformer Cooling}

The base of the furnace is cooled by about $1,300 \mathrm{cfm}$ of air flowing through a plenum formed by six $4 \mathrm{in.} \mathrm{high} \mathrm{I-beams} \mathrm{upon} \mathrm{which} \mathrm{the} \mathrm{furnace} \mathrm{rests.} \mathrm{The} \mathrm{furnace} \mathrm{shell,} \mathrm{roof,} \mathrm{slag}$ tapping fixture, launder, metal taphole collar, transformer, feed tubes, emissions control duct, and electrode arms, cables, and clamps are water cooled. Cooling water is pumped to the furnace from a 1,500 gal cool water sump by a $15 \mathrm{hp}$ centrifugal pump. The furnace shell is cooled by a curtain of water ( $50 \mathrm{gpm})$ that cascades down the outer shell wall from the annular distribution trough near the top of the shell. All cooling water is collected at the base of the furnace in a trough and is returned by gravity to a 1,500 gal warm water sump through a 6 -in. PVC pipe. Water is pumped from the warm water sump to a cooling tower of cross flow, induced draft design. ${ }^{4}$ The cooling tower supplies water at a rate of $150 \mathrm{gpm}$ and a temperature of $70^{\circ} \mathrm{F}$ (when the return water temperature is $142^{\circ} \mathrm{F}$ and the ambient air wet bulb temperature is $70^{\circ} \mathrm{F}$ ). Figure Q-7 shows a circuit diagram for cooling water indicating maximum anticipated flowrates. 


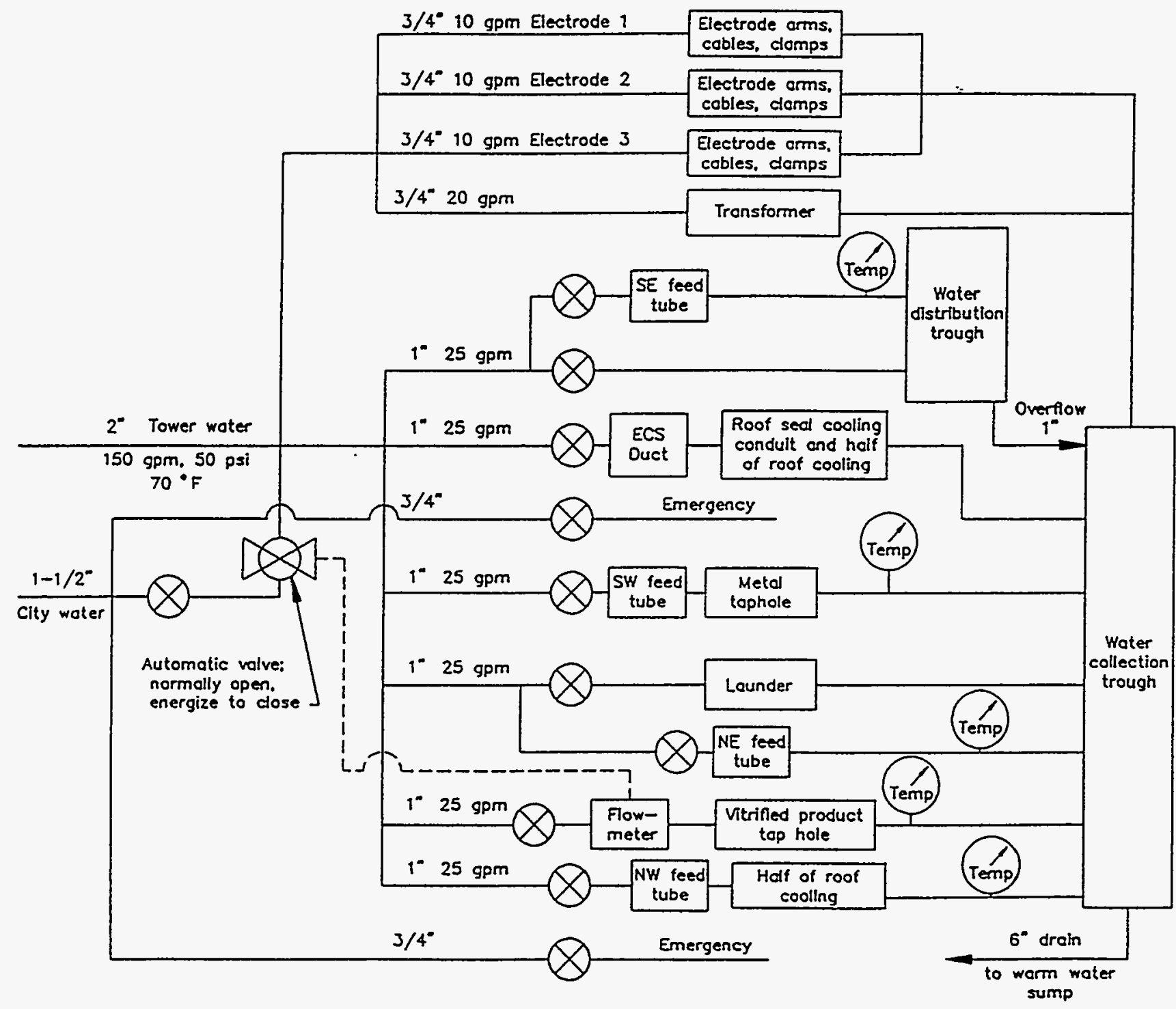

Figure Q-7. Cooling water circuit diagram. 
Municipal water is available for emergency cooling in case of general power failure or malfunction of the circulating pumps. The most critical water-cooled components are the slag tapping fixture, which is in direct contact with the molten contents of the furnace and the feed tubes. All other water-cooled components are less susceptible to damage during a short-term stoppage of water if furnace power also is stopped. A flowmeter in the water circuit to the tapping fixture de-energizes and opens the automatic valve in the city water line if power fails or if the flowrate from the cooling tower decreases below $20 \mathrm{gpm}$ in the circuit to the slag tapping fixture. Municipal water then is delivered to the entire cooling water circuit.

\section{Q.2.4 Power Supply and Furnace Operation}

The power supply is composed of a 3-phase $800 \mathrm{kVA}$ transformer and 3 single-phase, $250 \mathrm{kVA}$ transformers. The primary circuit of each $250 \mathrm{kVA}$ transformer is configured in parallel with the appropriate phase of the $800 \mathrm{kVA}$ transformer. The secondary circuit of each $250 \mathrm{kVA}$ transformer is configured in series with the appropriate phase of the secondary circuit of the $800 \mathrm{kVA}$ transformer. Figure Q-8 shows an electrical line drawing of the power supply beginning $\mathrm{kV}$ line from the substation and continuing to the electric furnace. The vector sum of the $250 \mathrm{kVA}$ and $800 \mathrm{kVA}$ secondary voltages provided the average open-circuit voltages shown in Table Q-1.

The power supply is a constant voltage supply providing regulation within $3 \%$ of the mean from open circuit to full load. The maximum current output of the power supply is 2,080 A. Power can be increased for a given transformer tap position by increasing the rheostats. The rheostat for each phase, working through the electrode positioning circuit for that phase, adjusts the electrode position to decrease the arc length, or even submerge the electrode in the melt, thereby providing increased current. The maximum power attainable is a function of the voltage (transformer tap), current (rheostat setting), and the resistivity of the slag. A rheostat controls each electrode, providing a means to balance the power between electrodes.

\section{Q.3 Air Pollution Control System}

The air pollution control system (APCS) was designed to control emissions of fume and entrained particulate in the offgas and minimize fouling from particulate and condensable fume deposits in the ductwork of the APCS. The primary components were (a) a water-cooled,

Table Q-1. Power supply characteristics.

\begin{tabular}{ccc}
$\begin{array}{c}\text { Transformer } \\
\text { tap }\end{array}$ & $\begin{array}{c}\text { Phase-to-phase } \\
\text { voltage } \\
\text { (V) }\end{array}$ & $\begin{array}{c}\text { Phase-to-ground } \\
\text { voltage } \\
\text { (V) }\end{array}$ \\
\hline A & 352 & 192 \\
B & 304 & 168 \\
C & 256 & 145 \\
D & 239 & 134 \\
\hline
\end{tabular}




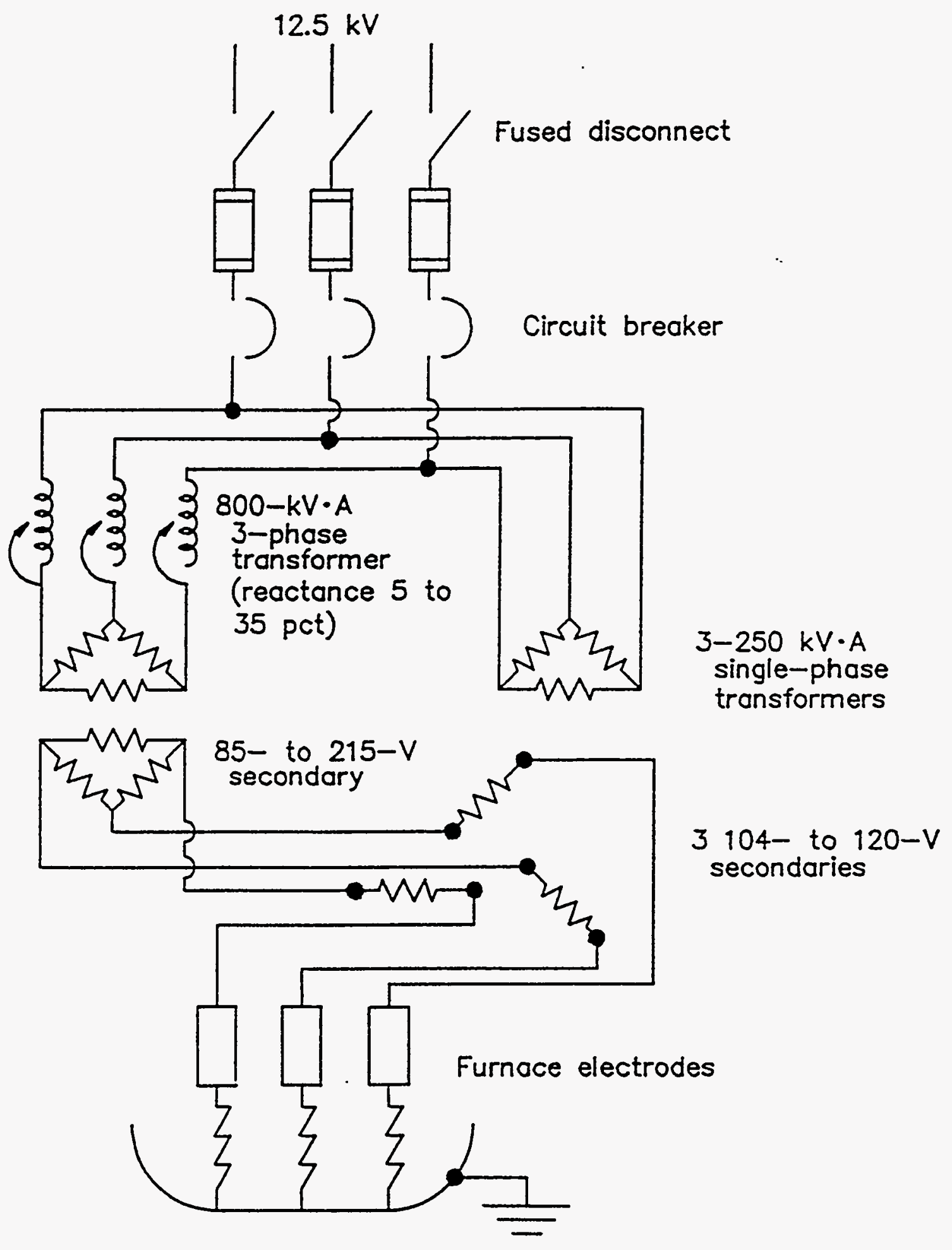

Figure Q-8. Line drawing for electric arc melting furnace power supply. 
with the 12.5 mechanically-scraped duct at the furnace outlet, (b) an air-dilution temperaturequench system, (c) two fume traps for collecting entrained particulate and condensed fume, (d) a heat exchanger, (e) a pulse-jet baghouse, (f) a High Efficiency Particulate-Air (HEPA) filter unit, and (g) an induced draft (ID) fan.

Exhaust gases exited the furnace roof through a 13 in. length of 8 in. ID, double walled water-cooled duct connected to a short ( 2.5 in. long) uncooled section of duct containing 3/4 in. nominal diameter sampling and instrumentation ports. A pneumatically-driven scraper was used to periodically remove fume deposits in this section. This section connected to the temperature quench jacketed section into which air was injected to dilute and cool the furnace exhaust gas.

Dilution air was provided by a 5 hp blower that withdrew air from two hoods, one on either side of the furnace. These hoods also served to collect any fugitive emissions and fume from the slag tap and metals tap areas, thereby positively influencing air quality within the building. The design dilution air to offgas ratio was 5:1.

Cooled gases and condensed fume solids exited the quench section into a $9 \mathrm{ft}$ long by 6 in. ID duct containing four 3 in. (nominal) diameter by 4 in. long pipe nipples, which provide access for exhaust gas analysis. That duct then entered tangentially into a quasi-cyclone settling chamber 13.5 in. ID by 90 in. long (fume trap 1), which allowed large particles to disengage from the gas flow. Accumulated particles were collected within a removable pot on the bottom of the cylinder. Figure Q-9 shows the furnace and the APCS within the building, including the water-cooled section, analysis duct, and fume trap 1 . The quench section, pneumatic cylinder, scraper shaft, and dilution air blower and duct are also shown.

The remaining fumes and gases that exited fume trap 1 entered a water-jacketed double-pipe heat exchanger that either heated the cool gas during startup of the furnace or cooled the hot gas during continuous operation to deliver a $250^{\circ}$ to $400^{\circ} \mathrm{F}$ gas to the baghouse. Hot or cold water for the heat exchanger was provided by a SuperTrol temperature control unit. ${ }^{9}$ The SuperTrol, which is rated at $36 \mathrm{~kW}$, provided $120 \mathrm{gpm}$ of water at $180^{\circ}$ to $250^{\circ} \mathrm{F}$ to the heat exchanger for heating or cooling. The heat exchanger exited to a spark arrestor to prevent any hot particles from entering the baghouse. Fume trap 2 was located at the bottom of the spark arrestor.

The offgas was ducted from the spark arrestor through 6 in. (nominal) ducting to the baghouse. A number of additional sample ports were located in this section for offgas measurements. The baghouse contained 47 Gortex-membrane Teflon-coated fiberglass bags, $4.5 \mathrm{in}$. diameter by $10 \mathrm{ft}$ long. These bags are rated to remove $99.98 \%$ of particulate greater than $0.3 \mu \mathrm{m}$. Bags were cleaned with a back pulse-jet of air at 100 psig. Additional particulate filtration was provided downstream of the baghouse by a HEPA filter unit, also rated to remove 99.98\% of particulate greater than $0.3 \mu \mathrm{m}$. A 10 -hp variable-speed induced draft fan, located after the HEPA filter, discharged the clean gases through a stack into the atmosphere.

The offgas flowrate was established by first setting the dilution air flowrate at 500 acfm by adjusting a damper in the dilution air duct at the outlet of the fan and then adjusting the speed of the fan. The ID fan then was adjusted to provide a negative pressure in the furnace ranging from -0.1 to -0.5 in. water gage. The combined gas flowrate measured at the baghouse inlet ranged from 650 to $900 \mathrm{acfm}$. 


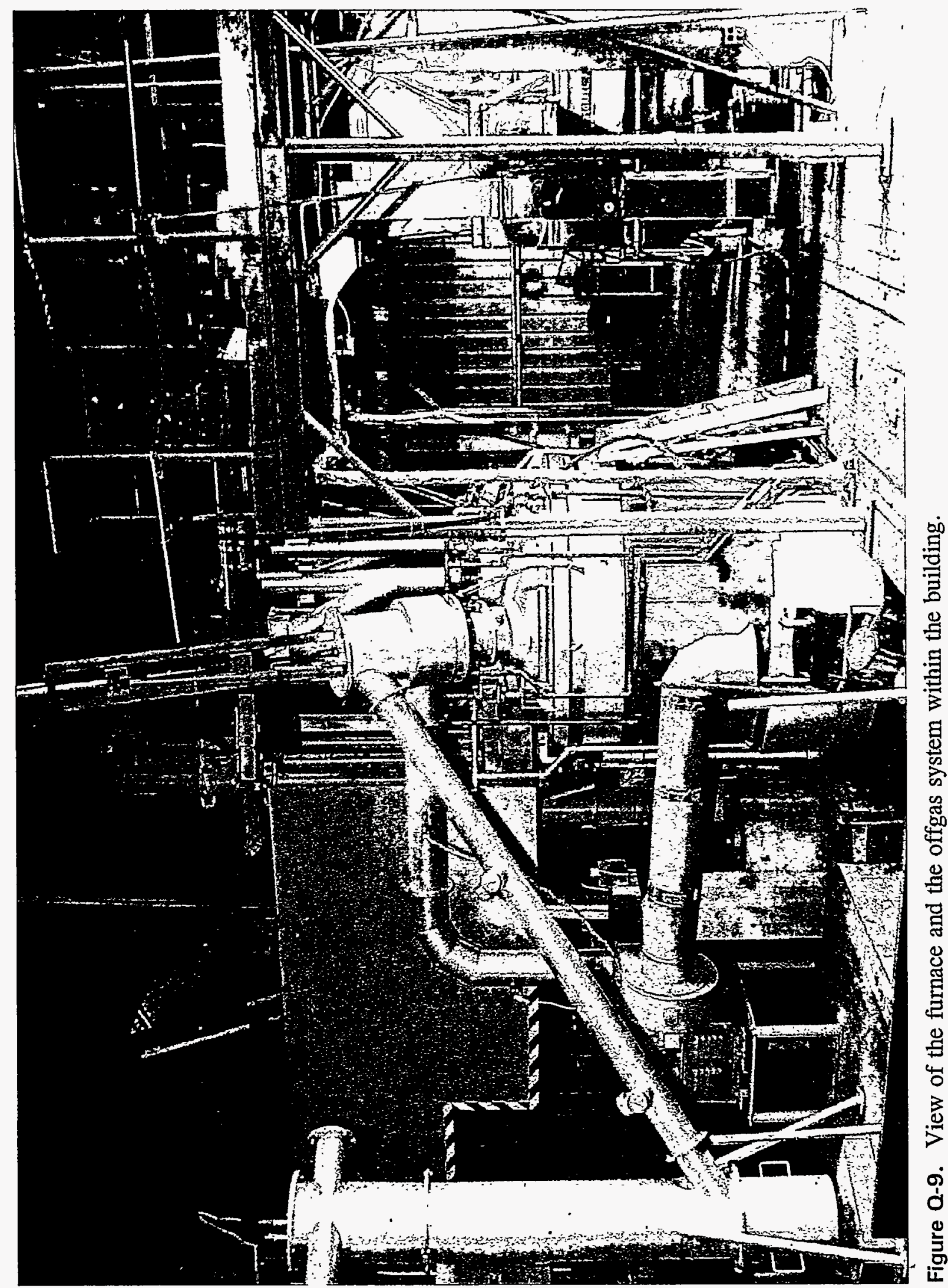





\section{REFERENCES}

1. Hartman, A. D., L. L. Oden, and J. C. White, "Facility for Melting Residues from Municipal Waste Combustion: Design Criteria and Description of Equipment," U.S. Department of Interior, Bureau of Mines Report on Investigations 9476, 1993.

2. Miles, T. R. (Consulting Design Engineers, 5475 SW Arrowwood Lane, Portland, OR 972251323), Feed System Operations Manual 1991-1992; available upon request from L. L. Oden, Bureau of Mines, 1450 Queen Ave., SW, Albany, OR 97321-2198.

3. Davis, H. F., Jr. (Consulting Metallurgical Engineer, 327 Sandalwood Court, Carnegie, PA 15106-1544). Private communication, 1992, available upon request from L. L. Oden, Bureau of Mines, 1450 Queen Ave., SW, Albany, OR 97321-2198.

4. Marley Cooling Tower Co. (P.O. Box 2912, Mission, KS 66201), Marley Manual, Series NC and NC Modular Steel Double-Flow Cooling Towers, Publication OM-NC1-A, August 1991. 


\section{Appendix R}

\section{Molar Basicity and Slag Viscosity}





\section{MOLAR BASICITY AND SLAG VISCOSITY}

The basicity ratio is the molar ratio of total basic oxides to total acidic oxides in the slag. The basicity ratio is a useful indicator of slag viscosity, melting temperature, and refractory compatibility. A slag with basicity ratio less than one is considered acidic, greater than one is basic, and a basicity of one is considered neutral. With high proportions of soil in the surrogate waste mixtures, the resultant slags had high silica $\left(\mathrm{SiO}_{2}\right)$ levels. Silica is a network or polymer former and largely determines the viscosity of the slag. Metals with a valence greater than or equal to three form acidic oxides $\left(\mathrm{P}_{2} \mathrm{O}_{5}, \mathrm{Al}_{2} \mathrm{O}_{3}, \mathrm{Cr}_{2} \mathrm{O}_{3}, \mathrm{TiO}_{2}\right.$, and $\left.\mathrm{ZrO}_{2}\right)$, which tend to extend or incorporate into the silicate network. The alkali metal oxides $\left(\mathrm{Na}_{2} \mathrm{O}, \mathrm{K}_{2} \mathrm{O}, \mathrm{Cs}_{2} \mathrm{O}\right)$ and the alkaline earth metal oxides $(\mathrm{MgO}, \mathrm{CaO}, \mathrm{SrO}, \mathrm{BaO})$ are basic oxides that terminate the Si-O-bonds and tend to break up the silicate network. The divalent oxides of the transition metals ( $\mathrm{FeO}, \mathrm{MnO}, \mathrm{NiO}$ ) are also basic. $\mathrm{Fe}_{2} \mathrm{O}_{3}$ is considered to be half basic and half acidic. Sulfur and chlorine in silicate slags are considered basic because they tend to break up the silicate network, in contrast to their acidic nature in aqueous systems.

The slag viscosity had to be sufficiently low to enable tapping through the slag tap hole. Slag viscosity depended on the slag temperature and the slag composition. Higher slag temperatures were required for continuous tapping when the slag basicity ratio deviated significantly from unity.

The following rules of thumb have been suggested for estimating the melting temperature, viscosity, and refractory compatibility of silicate slags in a rotary kiln slagging incinerator $\left(\right.$ Queneau ${ }^{5}$. These rules may also be applicable to silicate slags in an arc melting furnace:

1. Basic slags should be contained in basic refractories, and acidic slags in acidic refractories.

2. Basicity in excess of neutral tends to increase slag melting temperature but decrease liquid-phase viscosity. Viscosity in the range 25 poise is optimum, with viscosity less than 10 poise leading to refractory brick attack, and viscosity greater than 200 poise leading to slag buildup within the kiln.

3. Slag viscosity should be acceptable if the basicity ratio is between 0.9 and 1.3 .

4. Slags with silica concentration greater than $45 \%$ usually have high viscosities.

5. Slags with high alumina content ( $>10 \%)$ and high silica tend to be especially viscous.

6. Chemical interaction among $\mathrm{Al}_{2} \mathrm{O}_{3}, \mathrm{MgO}, \mathrm{FeO}$, and $\mathrm{Cr}_{2} \mathrm{O}_{3}$ can lead to the formation of insoluble spinel-type precipitates and result in high slag viscosity.

7. Acidic slags tend to resist weathering better (and are less leachable) than basic slags. Similarly, oxidized slags tend to resist weathering better than reduced slags. Basalt, which contains 45 to $55 \%$ silica, is a good example of a naturally occurring weather-resistant slag.

8. The retention of volatile metals, metal oxides, chlorine, and sulfur in slags is inversely related to the melting temperature. 
In light of the above rules and experience with weathering-resistant natural minerals, the ideal slag in the present investigation would be acidic, contain 45 to $50 \% \mathrm{SiO}_{2}$, and be highly oxidized with low melting temperature and low viscosity. That combination of properties likely cannot be obtained, and if compromise is called for, resistance to weathering and long-term stability will be emphasized at the expense of viscosity and melting temperature. Table R-1 lists the calculated molar basicity for slags produced by melting the waste mixtures and the modified furnace feed compositions.

The viscosity of two natural mineral slags and product slags derived from the furnace feed mixtures were calculated by the method of R.W. Shaw ${ }^{6}$. By the standards of Queneau ${ }^{1}$, the viscosity of soil slag should be about 25 poise at $1800^{\circ} \mathrm{C}$ and hence should tap from the furnace at that temperature. Slags derived from the waste mixtures and modified furnace feeds should tap at much lower temperatures.

Table R-1. Molar Basicity of Product Slags.

\begin{tabular}{lccc}
\hline $\begin{array}{c}\text { Furnace Feed } \\
\text { Mixture }\end{array}$ & $\begin{array}{c}\text { Basicity } \\
\text { Ratio }\end{array}$ & $\begin{array}{c}\text { Temperature } \\
\text { Tapping was } \\
\text { Achieved (C) }\end{array}$ & $\begin{array}{c}\text { Calculated Slag } \\
\text { Viscosity at Tapping } \\
\text { Temperature (Poise) }\end{array}$ \\
\hline $\begin{array}{l}\text { RWMC soil } \\
\text { 100 lb soil:10 }\end{array}$ & 0.26 & & \\
lb mill scale & 0.31 & $>1600$ & $<11$ \\
$\begin{array}{l}\text { 100 lb soil:20 } \\
\text { lb mill scale }\end{array}$ & 0.37 & $1450-1700$ & $1-7$ \\
$\begin{array}{l}\text { Calcium } \\
\text { silicate }\end{array}$ & 1.00 & $1550-1600$ & $2-3$ \\
S60 & 0.52 & $1550-1650$ & $5-9$ \\
S60-IV & 0.51 & $1650-1800$ & $1-3$ \\
N80 & 0.48 & $1450-1550$ & $1-2$ \\
N80-Mod & 1.00 & $1650-1750$ & 1 \\
N80-IV & 0.44 & $1550-1590$ & $0.36-0.42$ \\
N80-IV-Mod & 1.00 & No Tap & \\
$\begin{array}{l}\text { M60 (non- } \\
\text { metal } \\
\text { components) }\end{array}$ & 0.28 & & \\
\hline
\end{tabular}


One objective of the melting tests was to determine the relationship between the composition of furnace feed materials and the leaching characteristics of product slags including the influence of additives designed to improve melting and tapping conditions. Unadulterated soil produced a very acidic slag (molar basicity ratio 0.26 ) that proved to be very viscous at desired tapping temperatures $\left(1,550^{\circ} \mathrm{C}\right)$. Other waste mixtures also produced very acidic and viscous slags owing to high silica content (67\%) of the RWMC soil; therefore, additional materials including limestone $\left(\mathrm{CaCO}_{3}\right)$, pebble lime $(\mathrm{CaO})$, and magnetite $\left(\mathrm{Fe}_{3} \mathrm{O}_{4}\right)$ as mill scale from a local steel mill were obtained prior to the melting test to fluidize the melts if needed. 


\section{REFERENCES}

1. Queneau, P. B., D. E. Cregar, and L. J. Karwaski, Slag Control in Rotary Kiln, Pollution Engineering, Jan 15, 1992, pp 26-32.

2. Shaw, R. W. Amer. J. Sci. 272:8780-893. 


\section{Appendix S}

Comparison of Offgas Flowrates, Temperatures, and Dilution Factors 


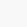


Table S-1. Comparison of offgas flowrates, temperatures, and dilution factors.

\begin{tabular}{|c|c|c|c|c|c|c|c|c|c|c|c|}
\hline \multirow{3}{*}{$\begin{array}{l}\text { Feed } \\
\text { type }\end{array}$} & \multirow{3}{*}{$\begin{array}{c}\text { Barometric } \\
\text { pressure } \\
\text { (in. } \mathrm{Hg} \text { ) }\end{array}$} & \multirow{3}{*}{$\begin{array}{c}\text { Stack } \\
\text { static } \\
\text { pressure } \\
\text { (in } \mathrm{H} 2 \mathrm{O} \text { ) } \\
\end{array}$} & \multicolumn{2}{|c|}{ Quench outlet } & \multicolumn{2}{|c|}{ Quench air } & \multicolumn{3}{|c|}{ Furnace outlet temperature } & \multirow{3}{*}{$\begin{array}{c}\text { Mass } \\
\text { balance } \\
\text { Dilution } \\
\text { factor }\end{array}$} & \multirow{3}{*}{$\begin{array}{c}\text { Energy } \\
\text { balance } \\
\text { Dilution } \\
\text { factor }\end{array}$} \\
\hline & & & \multirow{2}{*}{$\begin{array}{l}\text { Flowrate } \\
\text { (wscfm) }\end{array}$} & \multirow{2}{*}{$\begin{array}{l}\text { Temp. } \\
\text { (C) }\end{array}$} & \multirow{2}{*}{$\begin{array}{l}\text { Flowrate } \\
\text { (wscfm) }\end{array}$} & \multirow{2}{*}{$\begin{array}{l}\text { Temp. } \\
\text { (C) }\end{array}$} & \multirow{2}{*}{$\begin{array}{l}\text { Data Logger } \\
\text { (C) }\end{array}$} & \multicolumn{2}{|c|}{ Manual measurements } & & \\
\hline & & & & & & & & (C) & Clock time & & \\
\hline 560 & 29.88 & -1.6 & 486 & 67.8 & 308 & 25 & 110 & 229 & NM & 2.73 & 4.77 \\
\hline$S 60$ & 29.88 & -1.6 & 477 & 77.8 & 308 & 30 & 62 & 229 & NM & 2.82 & 4.16 \\
\hline S60-IV & 29.88 & -1.6 & 490 & 78.9 & 286 & 35 & 69 & 218 & 1120 & 2.40 & 4.18 \\
\hline \multirow[t]{3}{*}{ S60-IV } & 29.88 & -1.6 & 493 & 79.4 & 329 & 30 & 60 & 239 & Avg. & 3.01 & 4.24 \\
\hline & & & & & & & & 202 & 1515 & & \\
\hline & & & & & & & & 277 & 1655 & & \\
\hline \multirow[t]{3}{*}{ N80 } & 29.9 & -1.8 & 541 & 85.6 & 501 & 33 & 63 & 206 & Avg. & 13.53 & 3.29 \\
\hline & & & & & & & & 500 & 1115 & & \\
\hline & & & & & & & & 429 & 1200 & & \\
\hline \multirow[t]{4}{*}{ N80-Mod } & 29.8 & -1.8 & 497 & 94.4 & 497 & 31 & 60 & 496 & Avg. & - & 7.33 \\
\hline & & & & & & & & 485 & 1535 & & \\
\hline & & & & & & & & 499 & 1547 & & \\
\hline & & & & & & & & 504 & 1635 & & \\
\hline \multirow[t]{3}{*}{ N80-IV } & 29.8 & -1.9 & 510 & 102 & 423 & 36 & 65 & 506 & Avg. & 5.86 & 7.10 \\
\hline & & & & & & & & 504 & 1025 & & \\
\hline & & & & & & & & 507 & 1342 & & \\
\hline \multirow[t]{5}{*}{ N80-IV-Mod } & 29.8 & -1.9 & 474 & 109 & 342 & 34 & 81 & 622 & Avg. & 3.59 & 7.79 \\
\hline & & & & & & & & 623 & 1600 & & \\
\hline & & & & & & & & 616 & 1730 & & \\
\hline & & & & & & & & 643 & 1740 & & \\
\hline & & & & & & & & 604 & 1750 & & \\
\hline M60 & 29.9 & -1.7 & 538 & 211 & 441 & 23 & 120 & & NM & 5.55 & - \\
\hline N80-IV-Mod-2 & 29.9 & -1.7 & 552 & 121 & 496 & 37 & 68 & 499 & 1520 & 9.86 & 5.49 \\
\hline
\end{tabular}

1. $\mathrm{NM}=$ Not Measured.

2. The bolded numbers in the dilution factor columns are the values which have been chosen as most representative and subsequently used in making other calculations.

3. For the $\$ 60$ feed type, the measured quench air flowrates were unreasonably high and the manually measured furnace outlet temperatures were not measured. Average values of these parameters from the

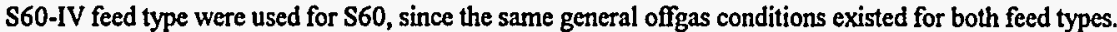

4. Dilution factors were calculated as the Quench outlet flowrate/Fumace outlet flowrate.

5. The Data Logger furnace outlet temperature measurement was made using a Type-K SS-sheathed TC installed through a port to the duct wall, but not penetrating into the offgas flow in order to prevent interference with the mechanical furnace outlet duct scraper.

6. Occasional manual furnace outlet offgas measurements were made using a Type-K SS-sheathed TC inserted through a port in the furnace outlet duct to the duct centerline, to minimize effects of the watercooled outlet duct on the temperature measurements. 


\section{Appendix T}

\section{In-Furnace Velocity and Particle Size Entrainment Calculations}


, 


\section{IN-FURNACE VELOCITY AND PARTICLE SIZE ENTRAINMENT CALCULATIONS}

The furnace gas temperatures, flow rates and compositions were not directly measured during the baseline tests, but were estimated using mass and energy balances from offgas measurements made in the APCS. These estimates of furnace gas conditions may be used to get a semi-quantitative perspective of conditions in the furnace plenum and feed material entrainment from the furnace. From data in Table 6-1, the average furnace gas temperature was $511^{\circ} \mathrm{C}$, and the average furnace offgas flow rate was $110 \mathrm{wscfm}$. The average gas velocity in the furnace just below the feed tubes may be estimated from the cross-section area of this section. For this estimate, an approximate furnace "equivalent inside diameter" of 3.5 feet $(5$ inches less than the nominal diameter of $3 \mathrm{ft} 11 \mathrm{in}$. to account for the diameters of the electrodes and minimal skull on the refractory walls) was used. From the gas temperature, gas flowrate and inside diameter, an average gas velocity of $0.51 \mathrm{ft} / \mathrm{sec}$ was calculated. The actual gas velocity gradient (variation in local velocities) likely varied widely in this zone, with somewhat higher gas velocities near the feed tubes and the electrodes from feed tube air influx and from gas evolution from the melt, while gas recirculation (downward or negative velocities) was likely near the sidewalls. However, using the average gas velocity as the stagnation velocity (also known as terminal velocity, when the force of gravity on a particle equals the drag and buoyancy forces from the gas), the particle radius can be estimated for spherical particles using Stokes's Law: ${ }^{1}$

$$
\mu=2 R^{2}\left(\rho_{s}-\rho\right) g / 9 v_{t}
$$

where $\mu$ is the fluid viscosity, $R$ is the radius of the sphere, $\rho_{s}$ is the density of the sphere, $\rho$ is the density of fluid, and $v_{t}$ is the terminal velocity. Solving for $R$ we get

$$
R=\left[\frac{9 v_{t} \mu}{2 g\left(\rho_{s}-\rho\right)}\right]^{\frac{1}{2}}
$$

This result is valid only when the Reynolds number, $D v_{t} \rho / \mu$, is less than about 0.1 .

To solve for the radius of a sphere that will remain stagnate in the air flow of the furnace is as follows:

\section{Assumed or estimated values:}

Temperature $=511^{\circ} \mathrm{C}$

$\mu=3.55 \mathrm{E}-5\left(\mathrm{~N}^{*} \mathrm{~s}\right) / \mathrm{m}^{2}$

$\rho=0.457 \mathrm{~kg} / \mathrm{m}^{3}$

$\rho_{\mathrm{s}}=2340 \mathrm{~kg} / \mathrm{m}^{3}$
(From White, Fluid Mechanics Second ed.; McGraw-Hill 1986

Table A.2.)

(White, Fluid Mechanics Second ed.; McGraw-Hill 1986 Table A.2.)

Standard density used for particle sizing measurements from thermal processes.

1. From Bird, Stewart, Lightfoot; Transport Phenomena. Wiley 1960. 


$$
\mathrm{g}=9.81 \mathrm{~m} / \mathrm{s}^{2}
$$

\section{Calculations:}

Flow rate $=(110 \mathrm{wscfm})^{*}(784 \mathrm{~K} / 293 \mathrm{~K})=294.3 \mathrm{acfm}$

Furnace Area $=\pi \mathrm{D}^{2} / 4=9.6 \mathrm{ft}^{2}$

$\mathrm{v}_{\mathrm{t}}=0.51 \mathrm{f} / \mathrm{s}=0.155 \mathrm{~m} / \mathrm{s}$

$$
\mathrm{R}=\left[\frac{(9)(0.15 \mathrm{~m} / \mathrm{s})\left(3.55 \mathrm{E}-5 \mathrm{~N} * \mathrm{~s} / \mathrm{m}^{2}\right)}{(2)\left(9.81 \mathrm{~m} / \mathrm{s}^{2}\right)\left(2,340 \mathrm{~kg} / \mathrm{m}^{3}-0.457 \mathrm{~kg} / \mathrm{m}^{3}\right)}\right]^{1 / 2}
$$

Radius $=3.3 \mathrm{E}-5 \mathrm{~m}=33 \mu$.

Diameter $=2 \mathrm{R}=66 \mu=0.066 \mathrm{~mm}$.

Check to verify solution is valid by showing $D v_{t} \rho / \mu$ is less than 0.1 :

$$
\operatorname{Re}=(6.6 \mathrm{E}-5 \mathrm{~m})(0.155 \mathrm{~m} / \mathrm{s})\left(0.457 \mathrm{~kg} / \mathrm{m}^{3}\right) / 3.55 \mathrm{E}-5 \mathrm{~N}^{*} \mathrm{~s} / \mathrm{m}^{2}=0.13 \text {, which is close. }
$$

\section{Results:}

From the calculations any particle less than $66 \mu \mathrm{m}$ in diameter should be entrained by the air flow of the furnace. 
Appendix U

Mass Balances of Individual Elements 
, 
Table U-1. Mass balance closure for selected metals for the S60 feed mixture.

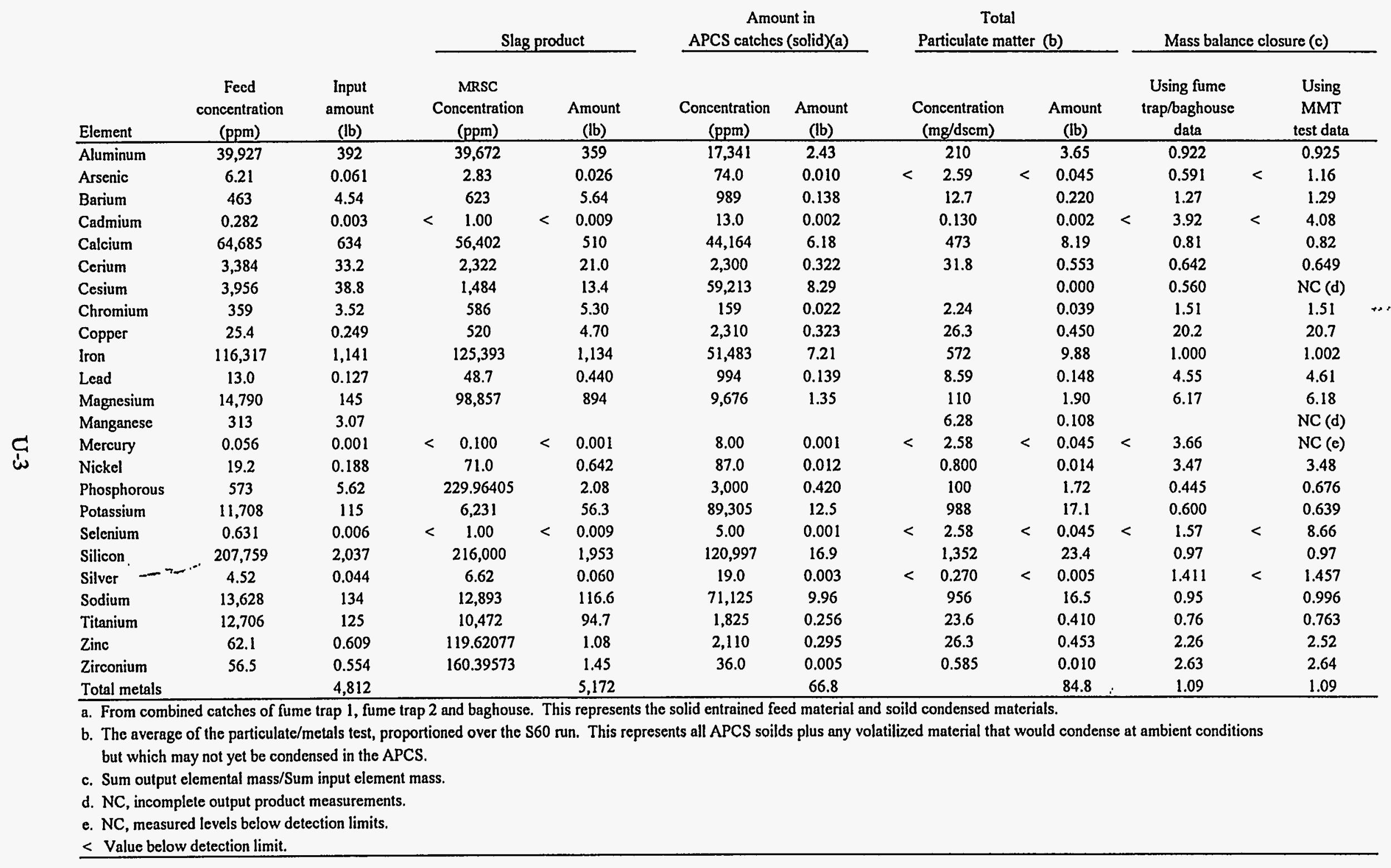


Table U-2. Mass balance closure for selected metals for the S60-IV feed mixture.

Amount in

Slag product

\begin{tabular}{|c|c|c|c|c|c|c|}
\hline \multirow[b]{2}{*}{ Element } & \multirow[b]{2}{*}{$\begin{array}{c}\text { Feed } \\
\text { concentration } \\
(p p m)\end{array}$} & \multirow[b]{2}{*}{$\begin{array}{l}\text { Input } \\
\text { amount } \\
\text { (lb) }\end{array}$} & \multicolumn{4}{|c|}{ Slag product } \\
\hline & & & & $\begin{array}{c}\text { MRSC } \\
\text { Concentration } \\
(\mathrm{ppm})\end{array}$ & & $\begin{array}{c}\text { Amount } \\
\text { (lb) }\end{array}$ \\
\hline Aluminum & 35,819 & 296 & & 37,560 & & 264 \\
\hline Arsenic & 5.46 & 0.045 & & 2.47 & & 0.017 \\
\hline Barium & 467 & 3.87 & & 690 & & 4.84 \\
\hline Cadmium & 0.248 & 0.002 & $<$ & 1.00 & $<$ & 0.007 \\
\hline Calcium & 62,164 & 514 & & 77,217 & & 542 \\
\hline Cerium & 3,384 & 28.0 & & 3,809 & & 26.7 \\
\hline Cesium & 4,063 & 33.6 & & 2,070 & & 14.5 \\
\hline Chromium & 382 & 3.16 & & 450 & & 3.16 \\
\hline Copper & 22.4 & 0.185 & & 50.6 & & 0.355 \\
\hline Iron & 116,628 & 965 & & 132,965 & & 933 \\
\hline Lead & 11.4 & 0.095 & & 9.6 & & 0.067 \\
\hline Magnesium & 14,082 & 117 & & 20,327 & & 143 \\
\hline Mangancse & 755 & 6.24 & & & & 0.000 \\
\hline Mercury & 0.050 & 0.000 & $<$ & 0.100 & $<$ & 0.001 \\
\hline Nickel & 16.9 & 0.140 & & 58.4 & & 0.410 \\
\hline Phosphorous & 528 & 4.36 & & 53 & & 0.370 \\
\hline Potassium & 10,299 & 85.2 & & 7,928 & & 55.6 \\
\hline Selenium & 0.555 & 0.005 & $<$ & 1.00 & $<$ & 0.007 \\
\hline Silicon & 185,066 & 1,531 & & 226,472 & & 1,590 \\
\hline Silver & 3.97 & 0.033 & $<$ & 1.00 & $<$ & 0.007 \\
\hline Sodium & 13,213 & 109 & & 15,006 & & 105 \\
\hline Titanium & 30,368 & 251 & & 26,725 & & 188 \\
\hline Zinc & 54.6 & 0.452 & & 95 & & 0.670 \\
\hline Zirconium & 7,034 & 58.2 & & 16,443 & & 115 \\
\hline Total metals & & 4,007 & & & & 3,986 \\
\hline
\end{tabular}

APCS catches (solid) (a)

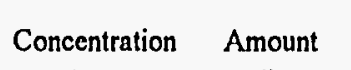

\begin{tabular}{cc} 
(ppm) & $(\mathrm{lb})$ \\
\hline 11,523 & 1.89 \\
49.0 & 0.008 \\
933 & 0.153 \\
17.0 & 0.003 \\
42,433 & 6.96 \\
1,730 & 0.284 \\
72,311 & 11.9 \\
156 & 0.026 \\
752 & 0.123 \\
54,611 & 8.96 \\
1,000 & 0.164 \\
8,113 & 1.33 \\
& \\
7.00 & 0.001 \\
75.0 & 0.012 \\
4,780 & 0.784 \\
112,008 & 18.4 \\
6.00 & 0.001 \\
97,866 & 16.1 \\
10.0 & 0.002 \\
95,481 & 15.7 \\
1,842 & 0.302 \\
2,520 & 0.413 \\
104 & 0.017 \\
& 83.4
\end{tabular}

Total

Particulate matter (b) Mass balance closure (c)

$\frac{\text { Mass balance closure (c) }}{\text { Using }}$

Using fume MMT

Concentration Amount trap/baghouse test

( $\mathrm{mg} / \mathrm{dscm}) \quad(\mathrm{lb}) \quad$ data $\quad$ data

$\begin{array}{ccccc}169 & 2.33 & 0.896 & 0.898 \\ 2.59 & 0.036 & 0.561 & 1.17\end{array}$

$12.3 \quad 0.168$

$0.150 \quad 0.002$

$1,505 \quad 20.9$

$38.2 \quad 0.524$

0.524

0.000

0.025
0.060

6.58

0.072

1.42

0.076

$<\quad 0.036$

0.008

0.598

11.0

$1.29 \quad 1.30$
$4.77<\quad 4.46$

$1.07<-1.09$

$\begin{array}{ll}1.07 & 1.09 \\ 0.965 & 0.974\end{array}$

$\begin{array}{ll}0.965 & 0.974 \\ 0.785 & \text { NC }\end{array}$

$1.006-206$

$\begin{array}{ll}1.006 & 1.006 \\ 2.59 & 2.25\end{array}$

0.977

$\begin{array}{cc}0.977 & 0.974 \\ 2.44 & 1.48\end{array}$

$1.24=1.24$

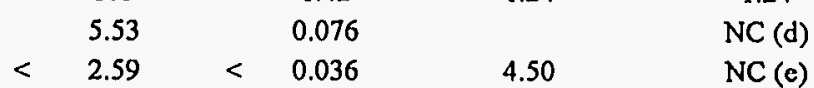

$3.02 \quad 2.99$

$\begin{array}{llll}43.5 & 0.598 & 0.264 & 0.222\end{array}$

$\begin{array}{llll}798 & 11.0 & 0.869 & 0.782\end{array}$

$<2.59<0.036 \quad 1.74<9.28$

$\begin{array}{lll}1,064 & 14.6 & 1.05<\end{array}$

$<0.270<0.004 \quad 0.263<0.327$

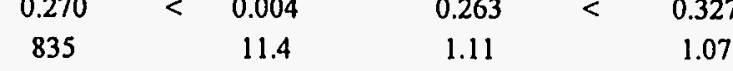

$\begin{array}{llll}23.7 & 0.324 & 0.748 & 0.748\end{array}$

$\begin{array}{llll}18.6 & 0.254 & 2.40 & 2.04\end{array}$

$\begin{array}{llll}1.00 & 0.014 & 1.98 & 1.98\end{array}$

$70.5: \quad 1.02 \quad 1.01$

a. From combined catches of fume trap 1 , fume trap 2 and baghouse. This represents the solid entrained feed material and soild condensed materials.

b. The average of the particulate/metals test, proportioned over the S60-IV run. This represents all APCS solids plus any volatilized material that would condense at ambient conditions but which may not yet be condensed in the APCS.

c. Sum output elemental mass/Sum input element mass.

d. NC, incomplete output product measurements.

c. NC, measured levels below detection limits.

$<$ Value below detection limit. 
Amount in

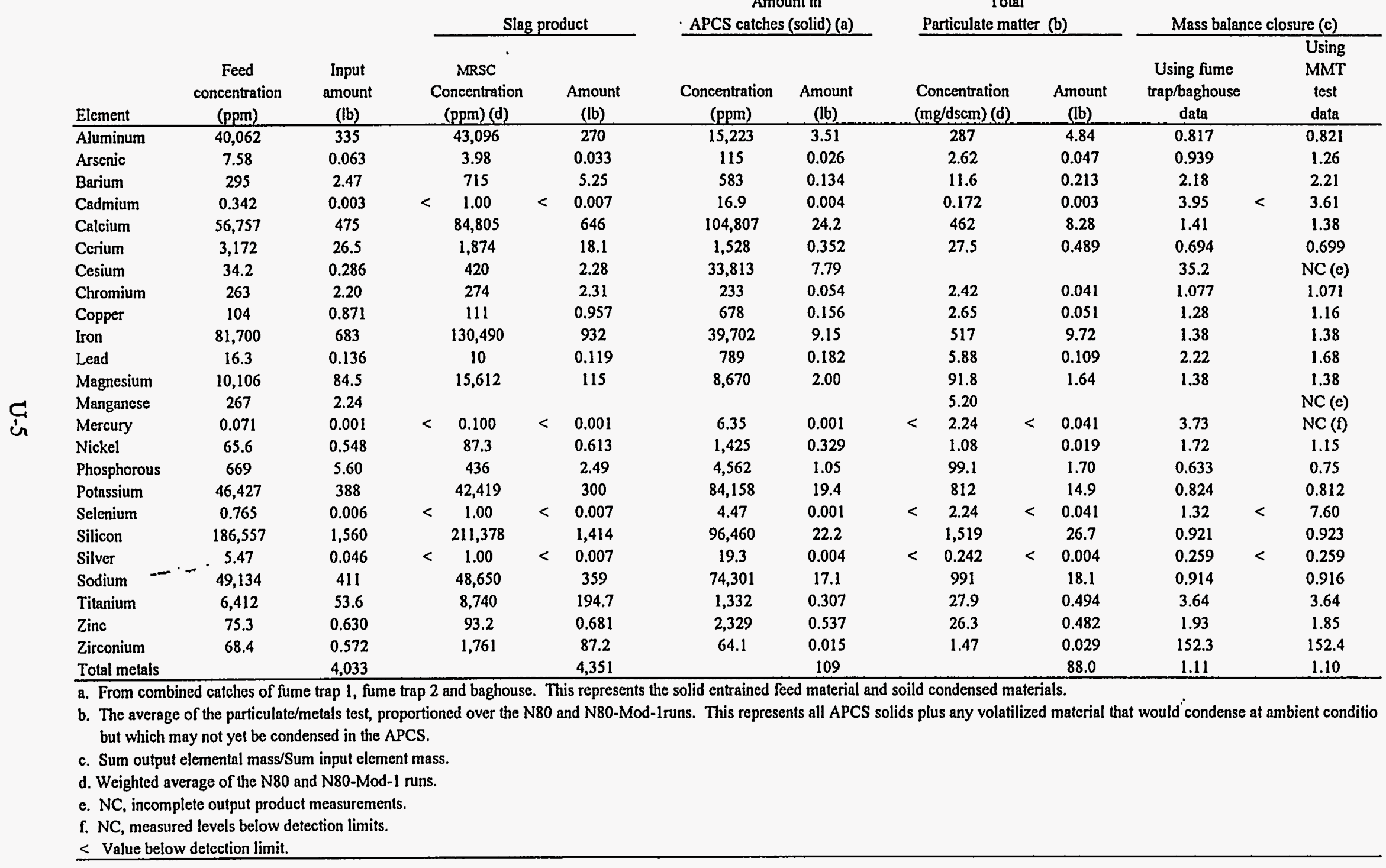


Table U-4. Mass balance closure for sclected metals for the N80-IV and N80-IV-Mod-1 feed mixtures.

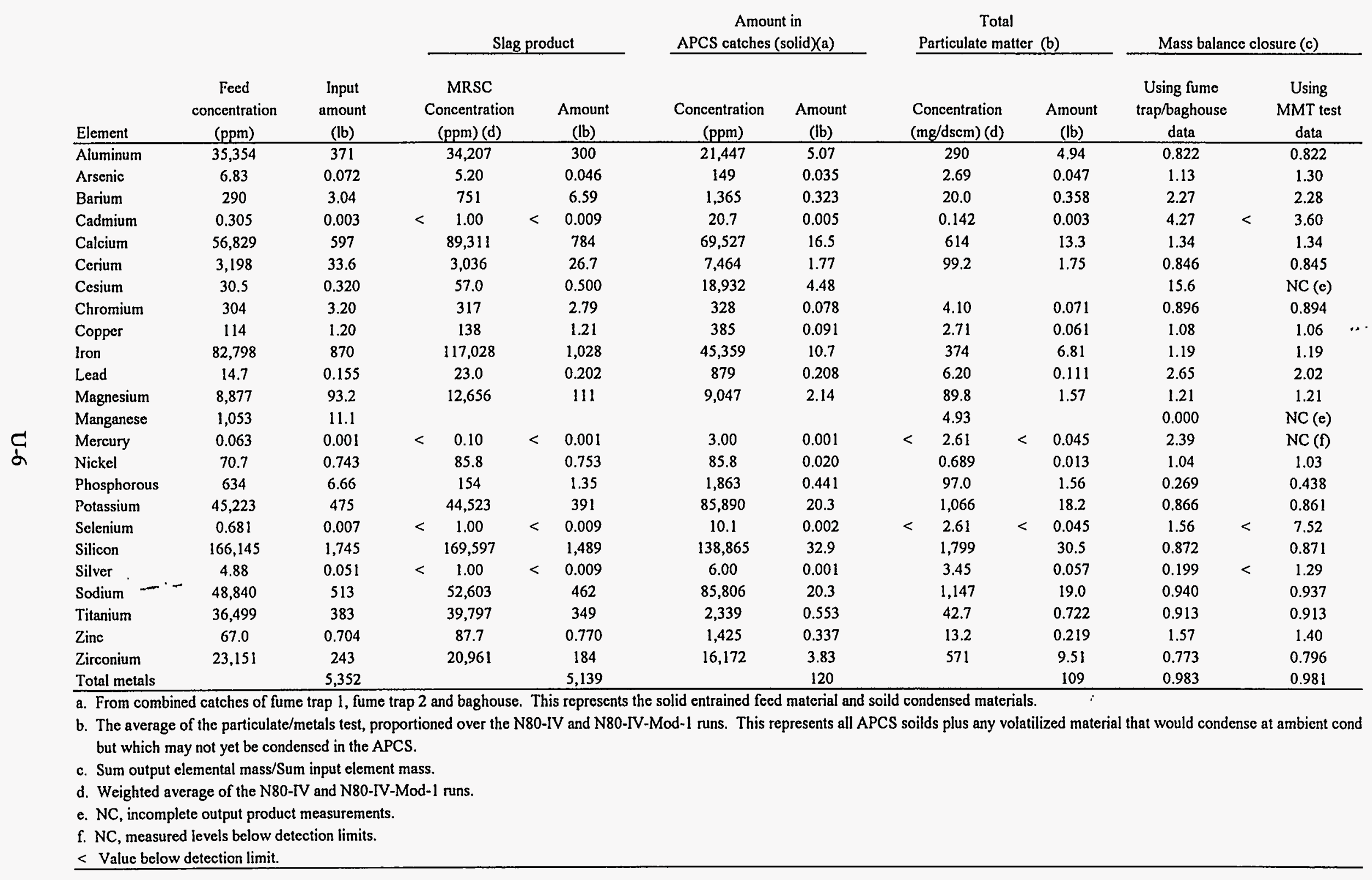


Table U-5. Mass balance closure for selected metals for the M60 and N80-IV-Mod-2 feed mixtures.

Amount in

Total

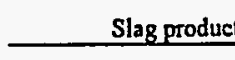

Metal heel

APCS catches (solid) (a)

Particulate matter (b)

Mass balance closure (c)

\section{MRSC}

Amount

Concentration

Amount Concentration Amount

(lb)

(pprm)

(ppm) (d)

(lb)

387

1,100

1.36

18,232

1.36
0.122

18,232

(lb)

Aluminum

44,817
6.64

0.044

2.00

3.66

99.0
18.0

0.022

78.7
1,156

0.010

Banim

0.297

0.002

$<\quad 1.00$

$<\quad 0.005$

$<\quad 1.00$

81,300

Cerium

69,878
3,348

24.8

3,928

425

690

$<\quad 0.001$

1,156
18.3

0.140
0.002

0.852

49,121
4,868

0.002

$<\quad 10.0$

$<\quad 0.012$

2.60

13,002

0.324

10.00
17.053

0.004

4,868
1,498

0.590

$\begin{array}{lll}\text { Chromium } & 8,589 & 57.3\end{array}$

$\begin{array}{lll}\text { Copper } & 3,725 & 24.8\end{array}$

Copper

3,725

330

0.872

17,949

902,000

59,000

$\begin{array}{lll}\text { Lead } & 3,620 & 24.1 \\ \text { Magnesium } & 8,384 & 55.9\end{array}$

Manganese $\quad 620 \quad 4.13$

$\begin{array}{lll}\text { Mercury } & 0.060 & 0.000\end{array}$

0.000
31.7

Nickel

4,761

1,130

308

14,600

1.62
76.3

2,020

$<0.100<0.001$

170

21.1
22.2

920

0.112

$\begin{array}{lll}22.2 & 565 & 0.069\end{array}$

1,114

23,175

1.23
5.81
0.303

$<0.100$

0.210

47,912
5,717

5.81
0.303

$$
\begin{gathered}
662 \\
15
\end{gathered}
$$

0.773

20,000

0.100

$<0.000$

5.43

0.001

2,100

$<\quad 1.00<0.005$

$257,000 \quad 1,343$

59.0
$<\quad 3.00$

3.00
25,100

$\begin{array}{lll}\text { Selenium } & 0.667 & 0.004\end{array}$

Silicon

Silver
Sodium

163,314

1,089

$<\quad 100$

1,343
$<\quad 0.005$

$13,200 \quad 69.0$
6,820

$6,820 \quad 35.6$

Titanium $\quad 17,459$

Zinc . _. $\quad 7,248$

Zirconium

7,248
10,584

168
116

48.3

2,650

3,885

$\begin{array}{ll}2,650 & 7.47 \\ 3,400 & 17.8\end{array}$

17.8
2,824

$233 \quad 0.028$

$1,181 \quad 0.143$

$31,987 \quad 1.70$

0.004

$\begin{array}{ll}6.00 & 0.001\end{array}$

1.00

31.0

0.001

210
178

178
979

114,181

8.86

$\begin{array}{ll}1,419 & 1.45 \\ 1,084 & 0.057\end{array}$

$121,921 \quad 14.8$

$6,195 \quad 0.328$

a. From combined catches of fume trap 1 , fume trap 2 and baghouse. This represents the solid entrained feed material and soild condensed materials.

b. The average of the particulate/metals test, proportioned over the M-60 and N80-IV-Mod-2 runs. This represents all APCS solids plus any volatilized material that would condense at ambient conditions

but which may not yet be condensed in the APCS.

c. Sum output elemental mass'Sum input element mass.

d. Weighted average of the M60 and N80-IV-Mod-2 runs.

e. NC, incomplete output product measurements.

f. NC, measured levels below detection limits.

$\leq$ Value below detection limil. 